\title{
Ion Exchange Modeling for Removal of Cesium from Hanford Waste Using Resorcinol-Formaldehyde Resin
}

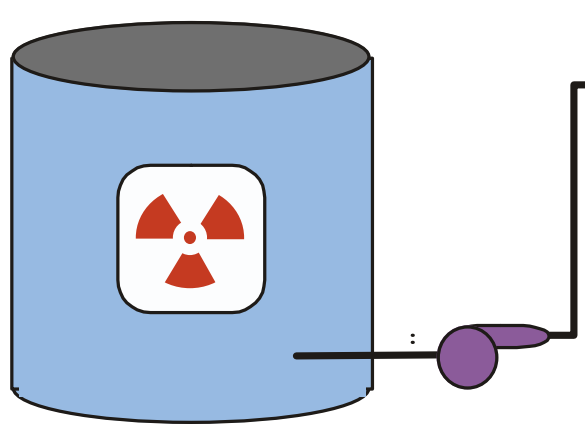

Hanford Radioactive Waste

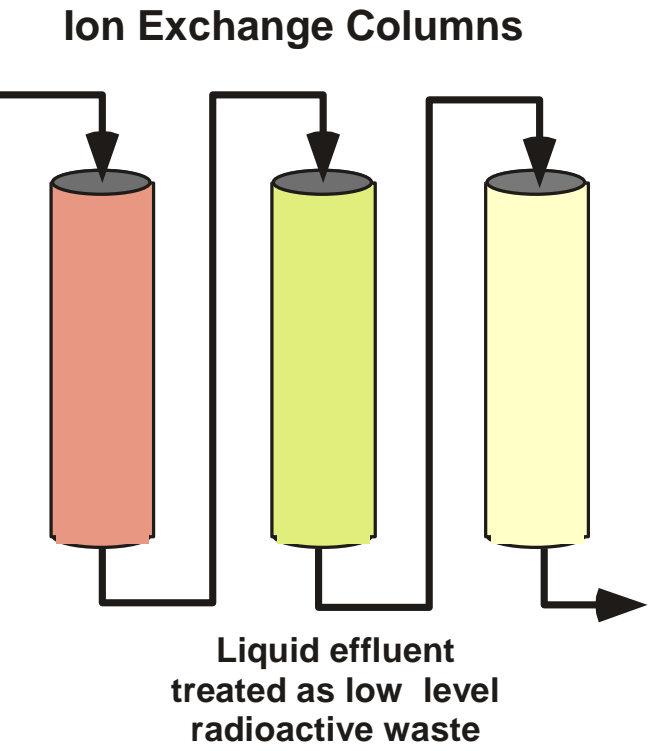

Westinghouse Savannah River Company

Savannah River Site

Aiken, SC 29808

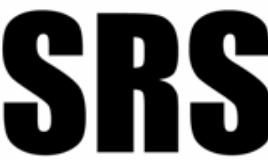


This document was prepared in conjunction with work accomplished under Contract No. DE-AC09-96SR18500 with the U. S. Department of Energy.

\section{DISCLAIMER}

This report was prepared as an account of work sponsored by an agency of the United States Government. Neither the United States Government nor any agency thereof, nor any of their employees, makes any warranty, express or implied, or assumes any legal liability or responsibility for the accuracy, completeness, or usefulness of any information, apparatus, product or process disclosed, or represents that its use would not infringe privately owned rights. Reference herein to any specific commercial product, process or service by trade name, trademark, manufacturer, or otherwise does not necessarily constitute or imply its endorsement, recommendation, or favoring by the United States Government or any agency thereof. The views and opinions of authors expressed herein do not necessarily state or reflect those of the United States Government or any agency thereof.

This report has been reproduced directly from the best available copy.

Available for sale to the public, in paper, from: U.S. Department of Commerce, National Technical Information Service, 5285 Port Royal Road, Springfield, VA 22161, phone: (800) 553-6847, fax: (703) 605-6900

email: orders@ntis.fedworld.gov

online ordering: http://www.ntis.gov/help/index.asp

Available electronically at http://www.osti.gov/bridge

Available for a processing fee to U.S. Department of Energy and its contractors, in paper, from: U.S. Department of Energy, Office of Scientific and Technical Information, P.O. Box 62, Oak Ridge, TN 37831-0062,

phone: (865)576-8401,

fax: (865)576-5728

email: $\underline{\text { reports@ adonis.osti.gov }}$ 
KEYWORDS:

Hanford River Protection Project Ion Exchange Technology

Resorcinol-Formaldehyde Resins

Cesium

VERSE-LC Code

Column Modeling

RETENTION - Permanent

\section{Ion Exchange Modeling for Removal of Cesium from Hanford Waste Using Resorcinol-Formaldehyde Resin}

SAVANNAH RIVER TECHNOLOGY CENTER

Bruce J. Hardy

Sebastian E. Aleman

L. Larry Hamm

Publication Date: June 2004

Westinghouse Savannah River Company

Savannah River Site

Aiken, SC 29808

Prepared for the U.S. Department of Energy under Contract No. DE-AC09-96SR18500

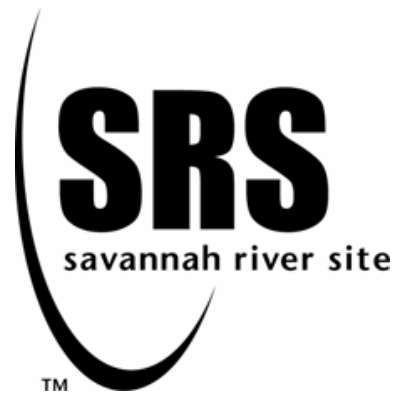


This page was intentionally left blank 


\section{TABLE OF CONTENTS}

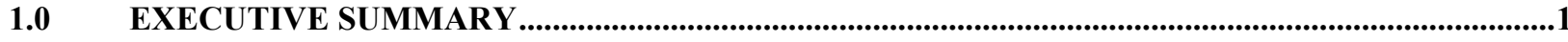

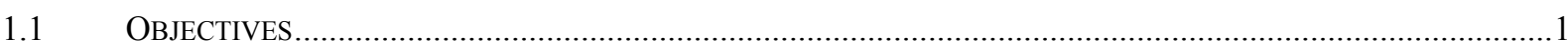

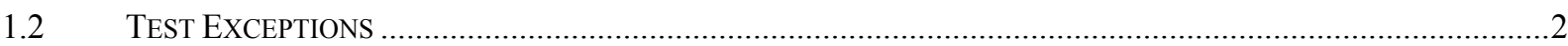

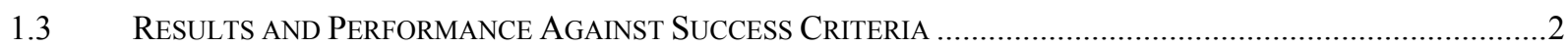

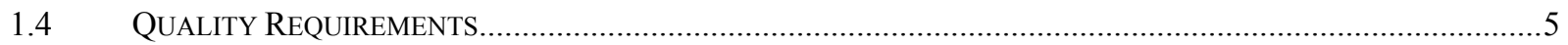

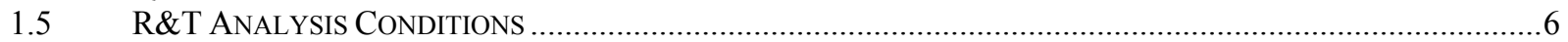

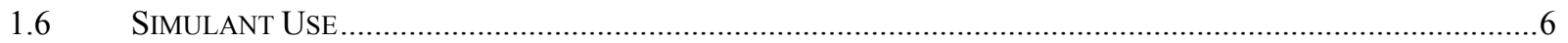

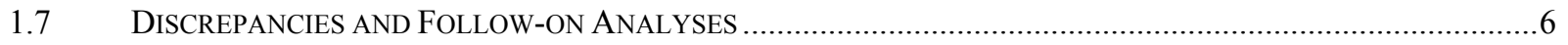

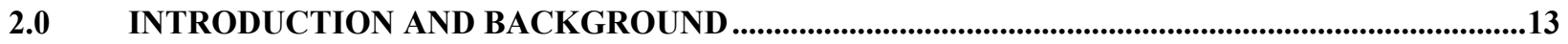

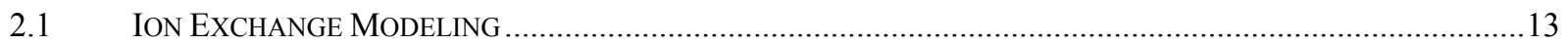

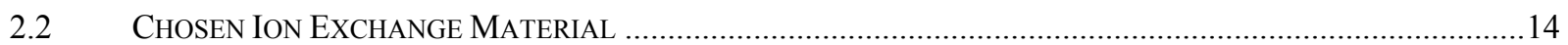

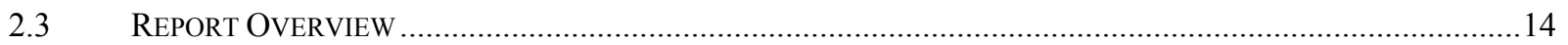

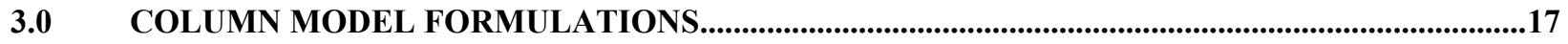

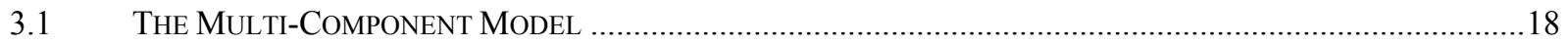

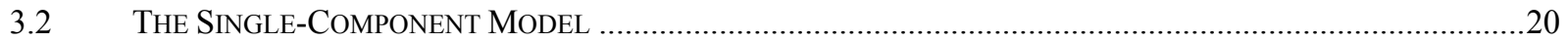

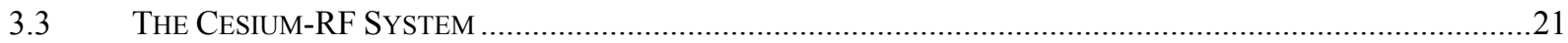

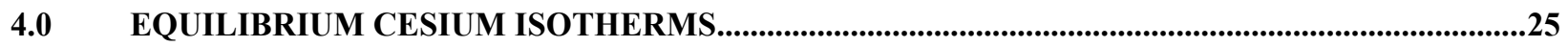

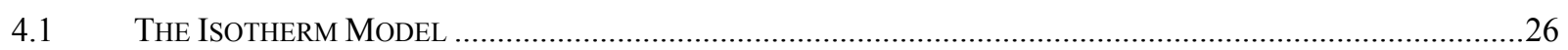

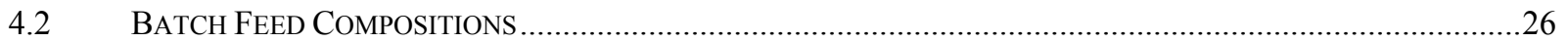

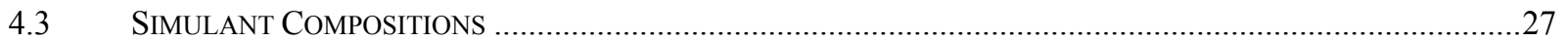

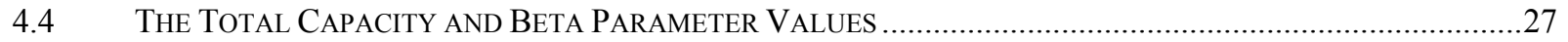

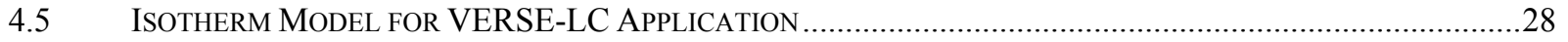

5.0 COLUMN PROPERTIES ......................................................................................................................39

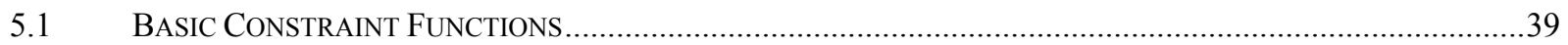

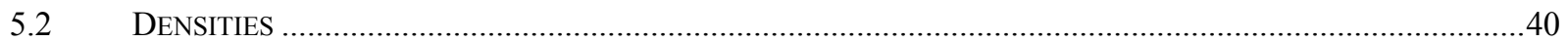

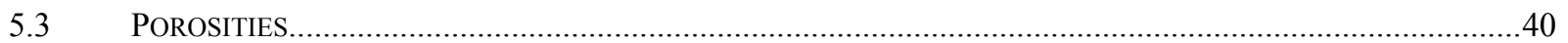

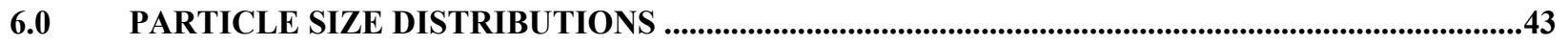

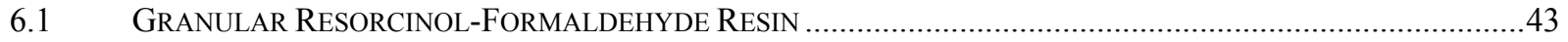

6.2 SPHERICAL RESORCINOL-FORMALDEHYDE RESIN..................................................................................4

6.3 Calculation of Average-Spherically Equivalent Particle Diameters ....................................................44

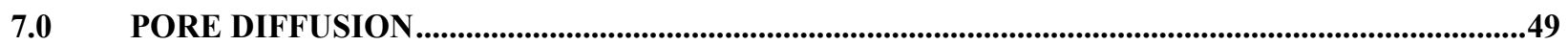

7.1 BULK DIFFUSIVITY OF $\mathrm{CS}^{+}$IN SIMULANTS AND LAW IX FEEDS..........................................................49

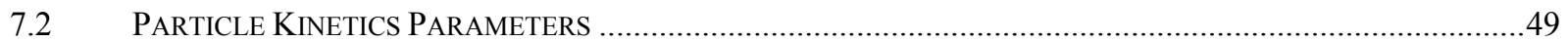

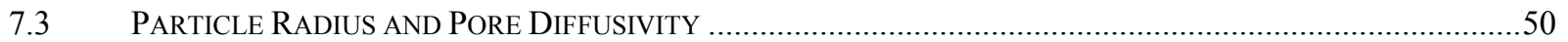

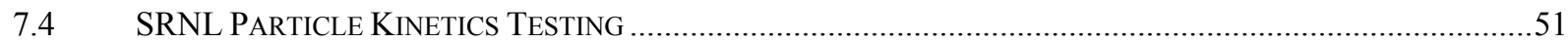

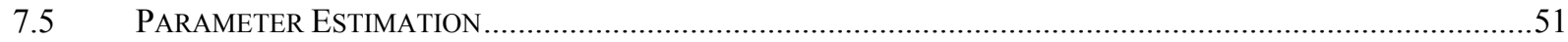

7.6 SRNL PARTICLE KINETICS RIG ASSESSMENT …………...............................................................

8.0 AXIAL DISPERSION AND FILM DIFFUSION

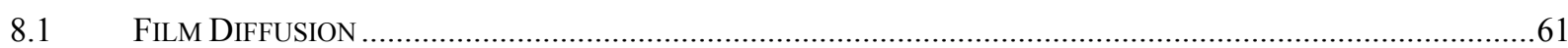

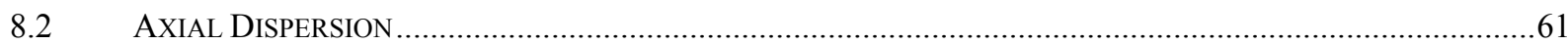

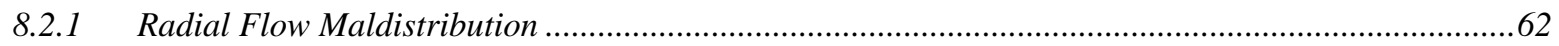

8.2.2 Headspace and Short Column Impacts............................................................................................63

9.0 LABORATORY-SCALE COLUMN ASSESSMENTS .............................................................................65 


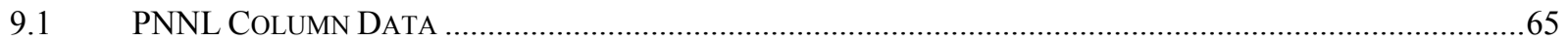

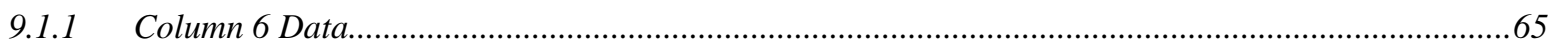

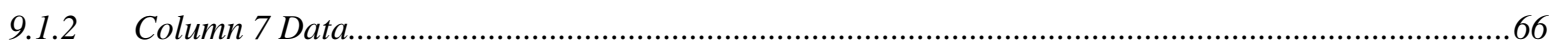

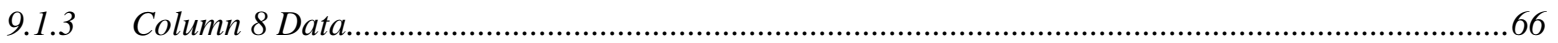

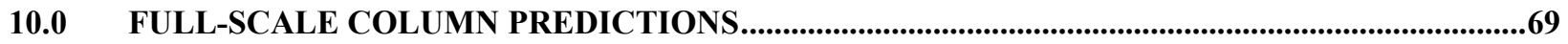

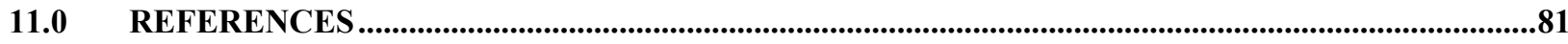

APPENDIX A (PARTICLE KINETICS AND COLUMN ASSESSMENT INPUT AND OUTPUT FILES)...87

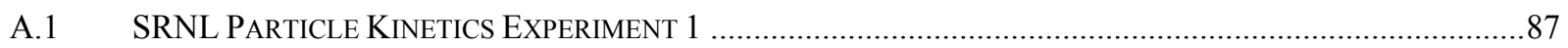

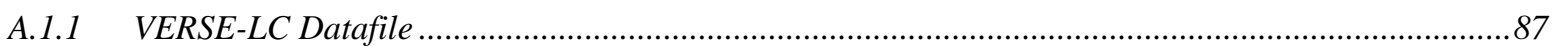

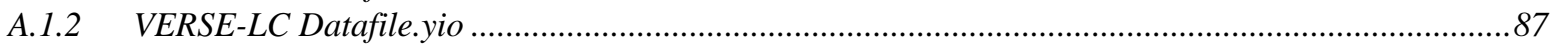

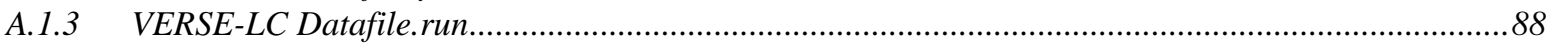

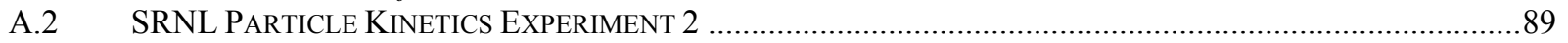

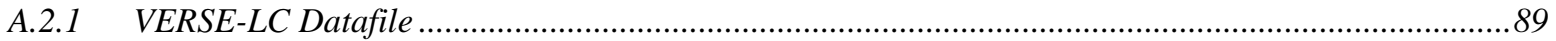

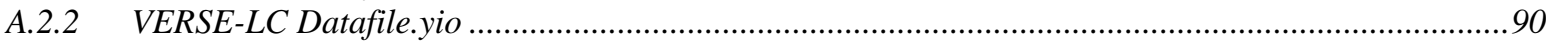

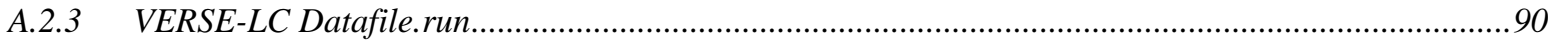

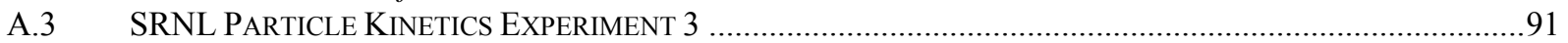

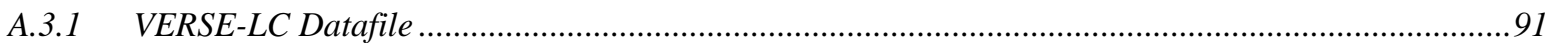

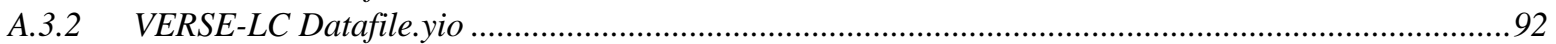

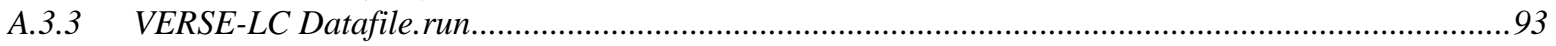

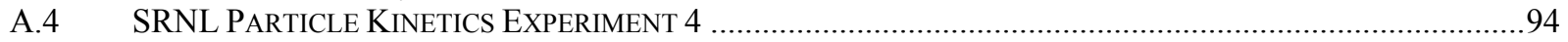

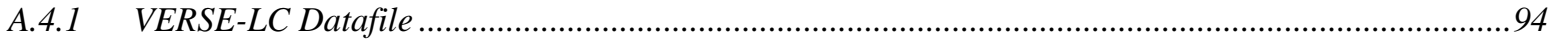

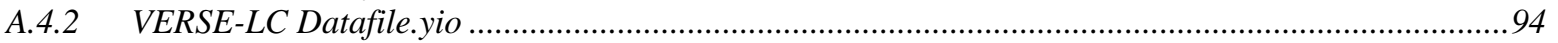

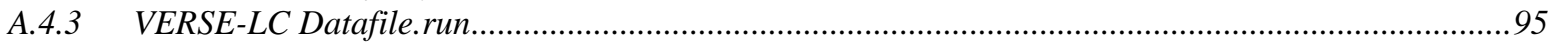

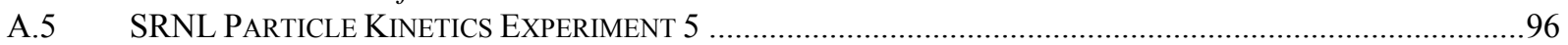

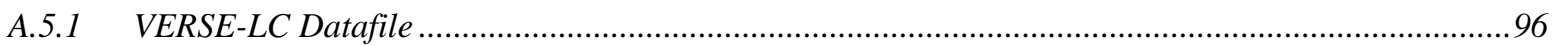

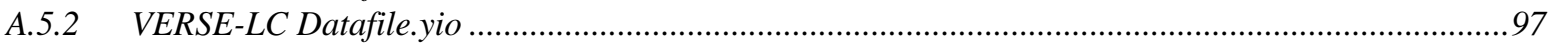

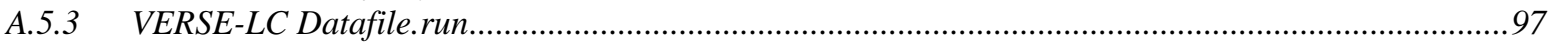

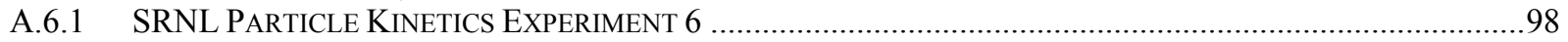

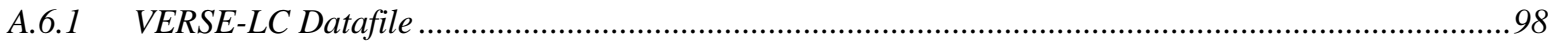

A.6.2 VERSE-LC Datafile.yio ........................................................................................................

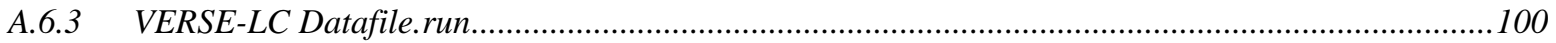

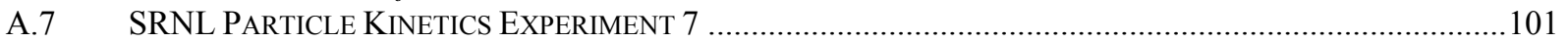

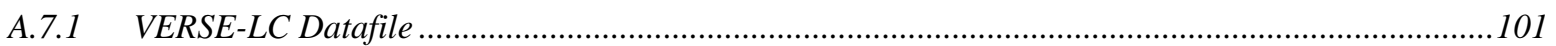

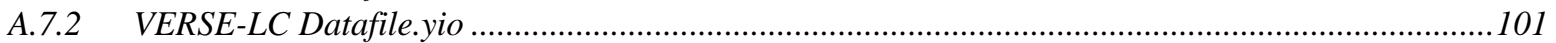

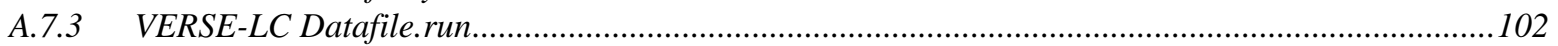

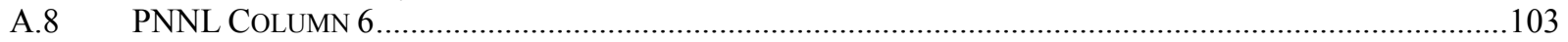

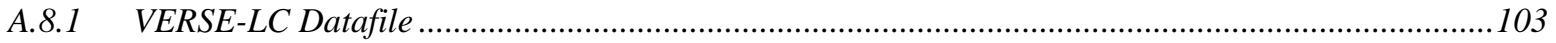

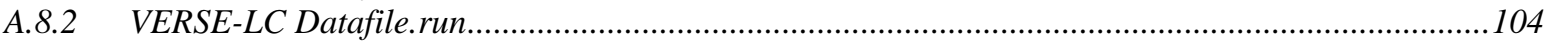

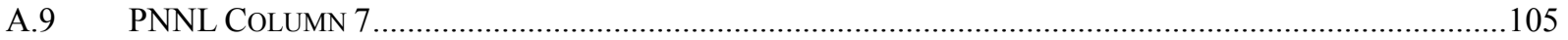

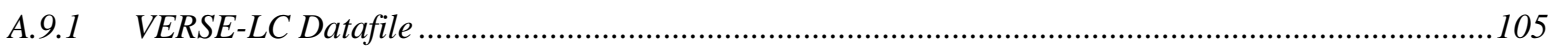

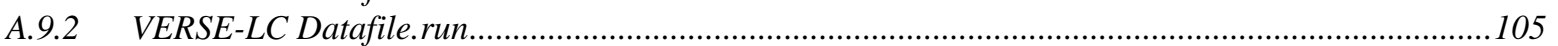

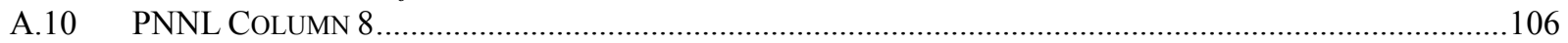

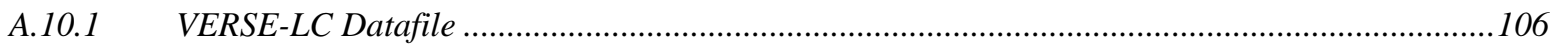

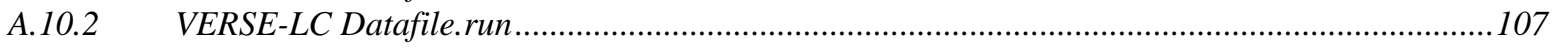

APPENDIX B (FULL-SCALE FACILITY INPUT AND OUTPUT FILES) .....................................................109

B.1 HOT COMMISSIONING OPERATIONS (NOMINAL ISOTHERM) ……......................................................109

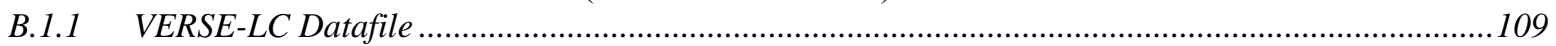

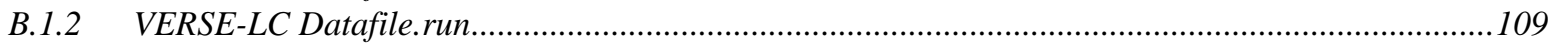

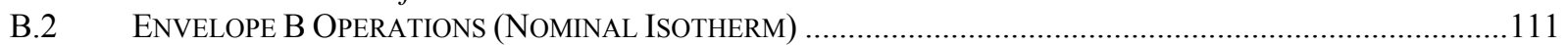

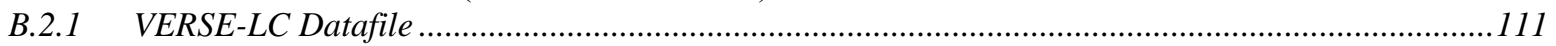

B.2.2 VERSE-LC Datafile.run....................................................................................................112 


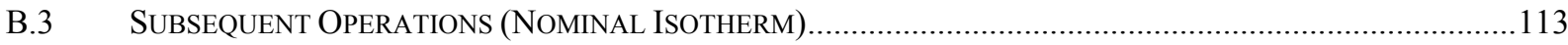

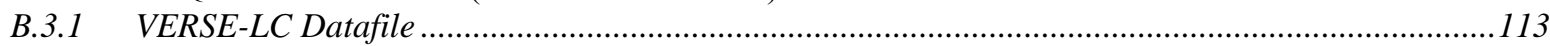

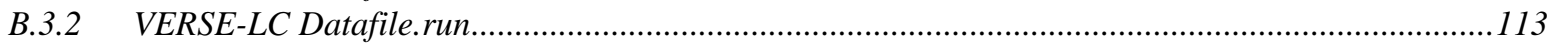

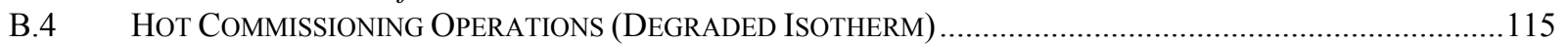

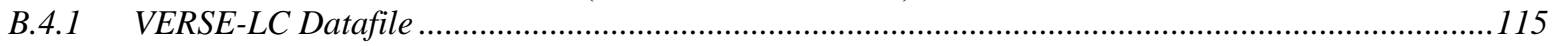

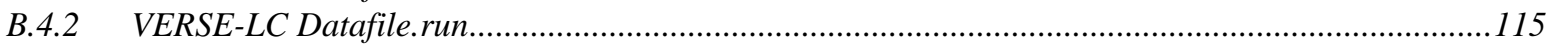

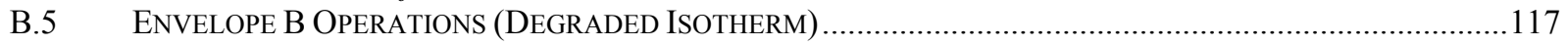

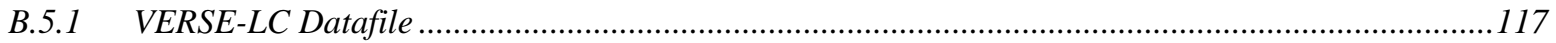

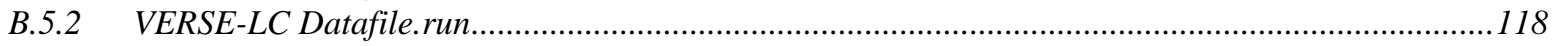

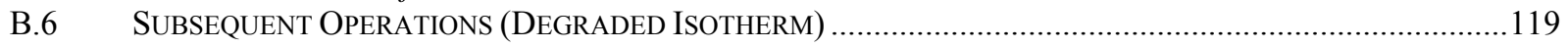

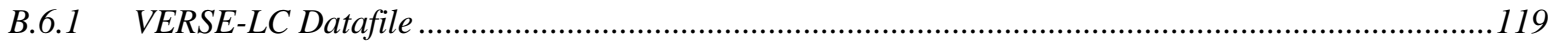

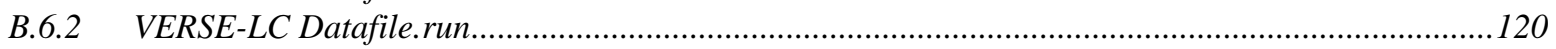

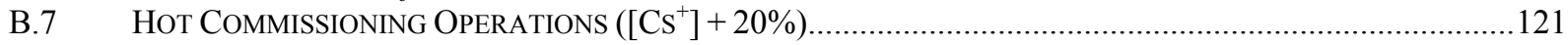

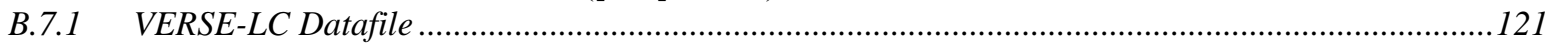

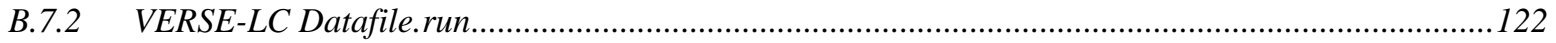

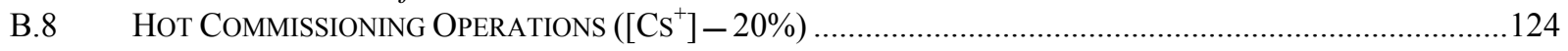

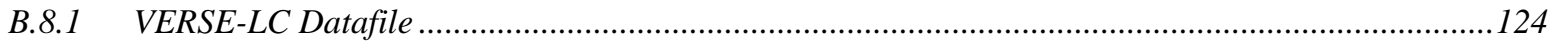

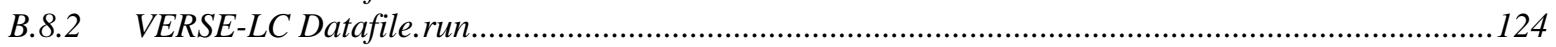

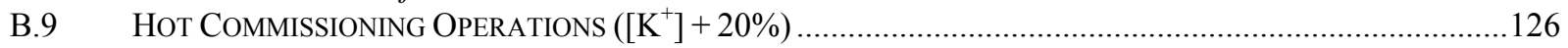

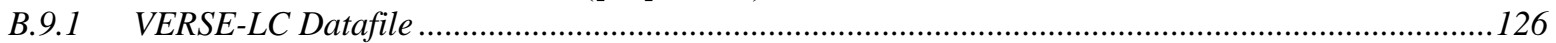

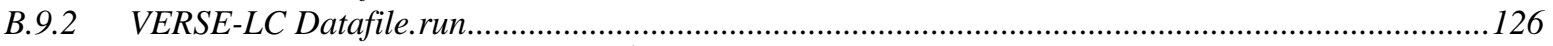

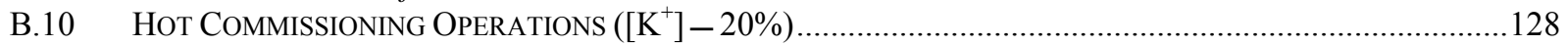

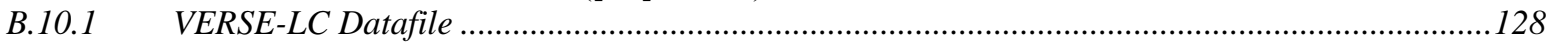

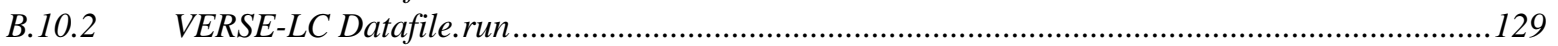

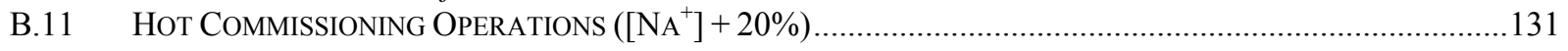

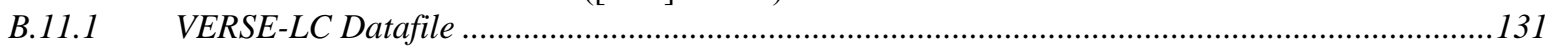

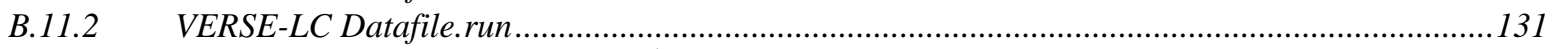

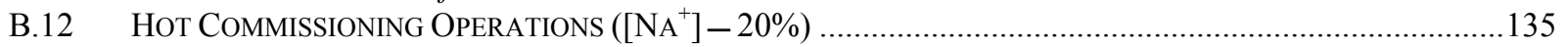

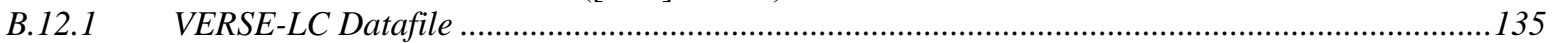

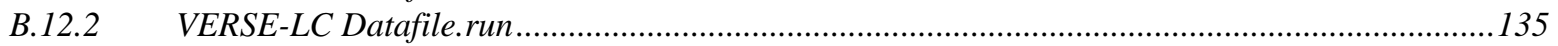

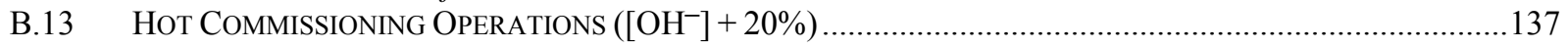

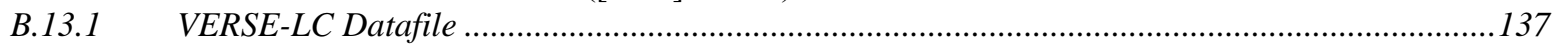

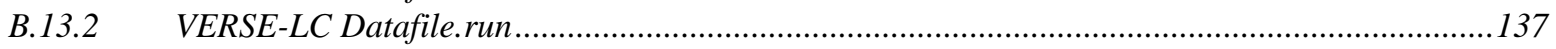

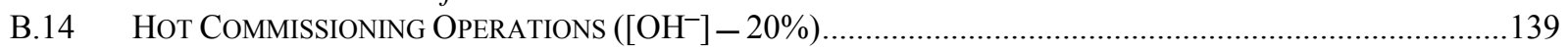

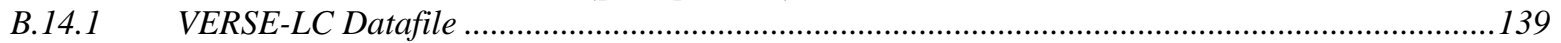

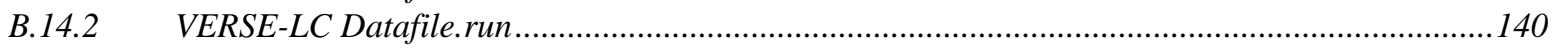

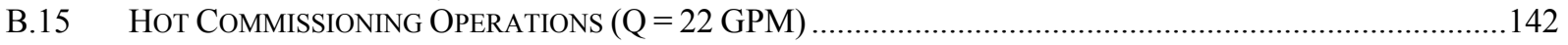

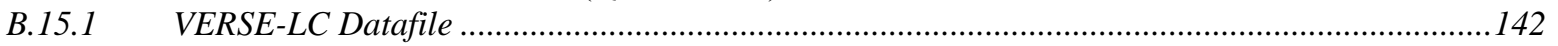

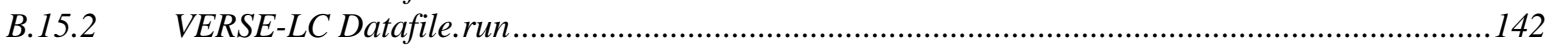

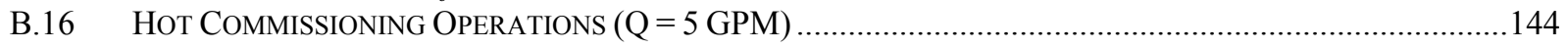

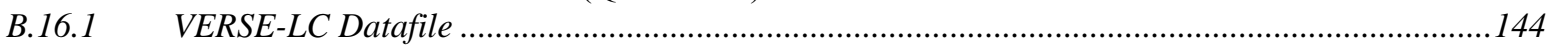

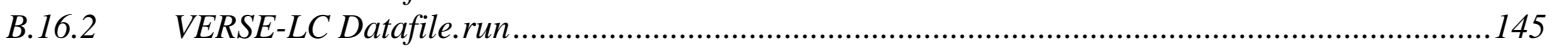

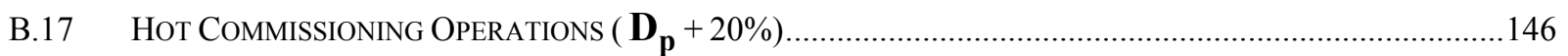

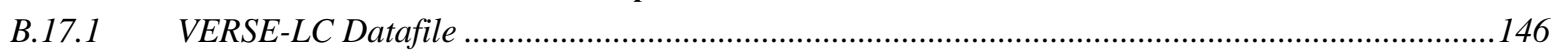

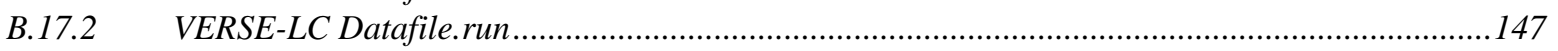

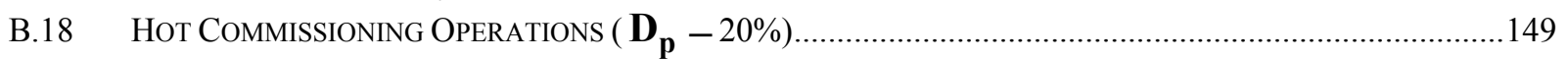

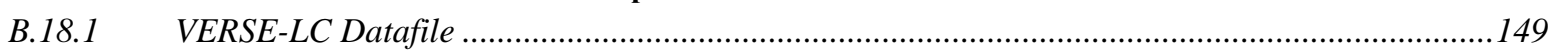

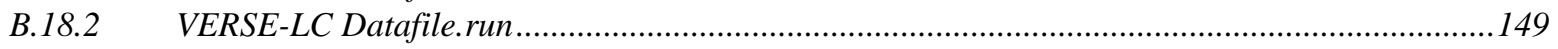

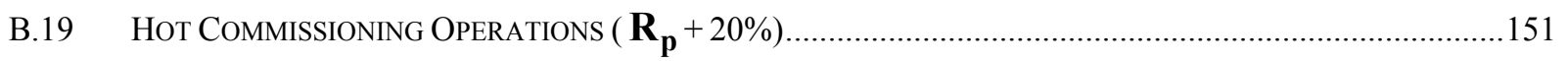

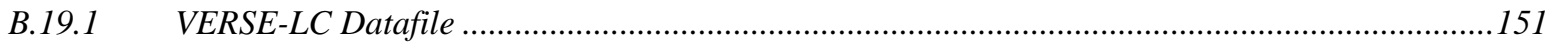

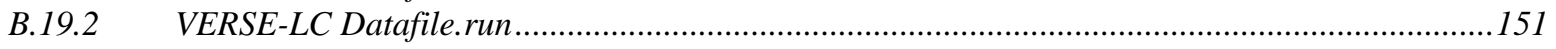

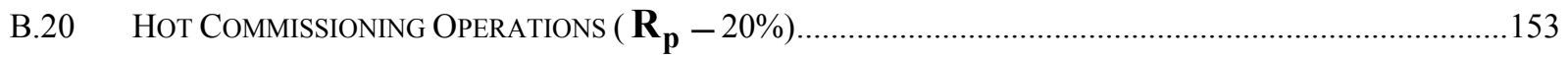


WSRC-TR-2004-00100, REVISION 0

SRT-RPP-2004-00019, REVISION 0

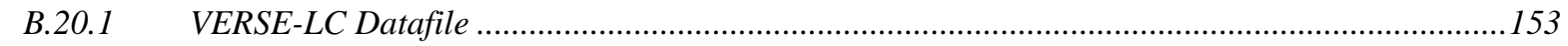

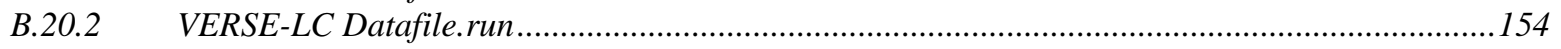

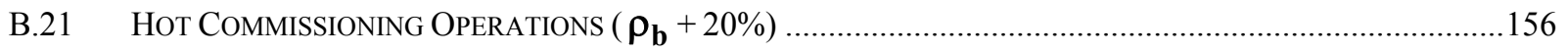

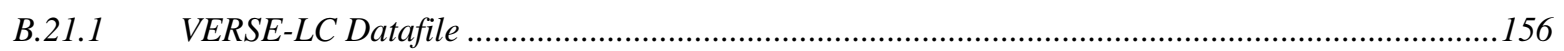

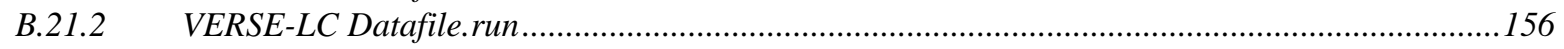

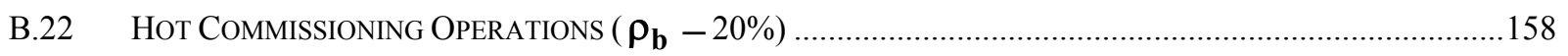

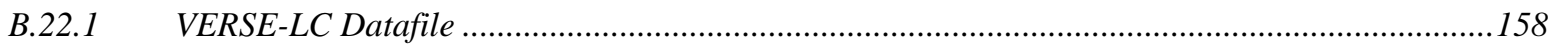

B.22.2 VERSE-LC Datafile.run .................................................................................................158 


\section{LIST OF TABLES}

Table 1-1 Number of bed volumes required to reach lag column Cs breakthrough during three-column carousel operation for Hot Commissioning Operations, Envelope B Operations, and Subsequent Operations feeds. Assumes a $0 \%$ chemical degradation factor for all results listed (i.e., fresh resin). Results listed are for RF Resin BVs followed by (SuperLig ${ }^{\circledR} 644$ resin)...

Table 1-2 Number of bed volumes required to reach lag column Cs breakthrough during three-column carousel operation for Hot Commissioning Operations, Envelope B Operations, and Subsequent Operations feeds. Assumes a 20\% chemical degradation factor for all results listed (resin with an approximated 10 cycle exposure). Results listed are for RF Resin BVs followed by (SuperLig $^{\circledR} 644$ resin)...

Table 4-1. Waste compositions used to represent ion exchange performance during selected operating time periods (nominal values and charge balanced).

Table 4-2. Hot Commissioning Operation waste composition with variation about nominal value in potassium concentration.

Table 4-3. Hot Commissioning Operation waste composition with variation about nominal value in sodium concentration.

Table 4-4. Hot Commissioning Operation waste composition with variation about nominal value in hydroxide concentration.

Table 4-5. Hot Commissioning Operation waste composition with variation about nominal feed value in cesium concentration.

Table 4-6. Waste compositions used to represent AN-105 and AZ-102 simulants at $5 \mathrm{M} \mathrm{Na}^{+}$.

Table 4-7. Two-parameter fit of algebraic isotherm parameters for Resorcinol-Formaldehyde at $25^{\circ} \mathrm{C}$ (Na-

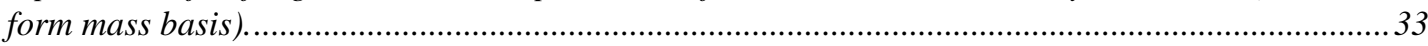

Table 5-1. Particle densities of used spherical Resorcinol-Formaldehyde resin.......................................................41

Table 6-1. Wet sieve particle size analysis data for granular Resorcinol-Formaldehyde sample............................. 44

Table 6-2. Microtrac ${ }^{\circledR}$ particle size analysis data for granular RF sample (volume-based data)............................45

Table 6-3. Rosin-Rammler cumulative and probability distribution functions. ..........................................................45

Table 6-4. Rosin-Rammler parameters for granular RF samples........................................................................46

Table 6-5. Microtrac ${ }^{\circledR}$ particle size analysis data for spherical RF sample (volume-based data).............................46

Table 6-6. Log-normal cumulative and probability distribution functions...............................................................46

Table 6-7. Definitions of various average or mean particle diameters....................................................................46

Table 6-8. Spherically-equivalent particle diameters for granular $R F$................................................................4

Table 6-9. Average particle diameters for spherical RF sample..........................................................................4

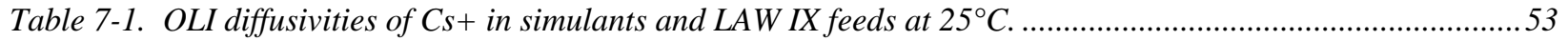

Table 10-1. Number of bed volumes required to reach lag column Cs breakthrough during three-column carousel operation for Nominal Hot Commissioning Operations. Both degraded and fresh resin bed results are provided.

Table 10-2. Number of bed volumes required to reach lag column Cs breakthrough during three-column carousel operation for Nominal Envelope B Operations. Both degraded and fresh resin bed results are provided.

Table 10-3. Number of bed volumes required to reach lag column Cs breakthrough during three-column carousel operation for Nominal Subsequent Operations. Both degraded and fresh resin bed results are provided.

Table 10-4. Number of bed volumes required to reach lag column Cs breakthrough during three-column carousel operation for Nominal Hot Commissioning Operations 20\% degradation factor applied. Parameter sensitivity results provided for isotherm competitors.

Table 10-5 Number of bed volumes required to reach lag column Cs breakthrough during three-column carousel operation for Nominal Hot Commissioning Operations 20\% degradation factor applied. Parameter sensitivity results provided for VERSE input variables.

Table 10-6. Bed volumes required to reach ${ }^{137}$ Cs loading limits (Prior to Cycling). 


\section{LIST OF FIGURES}

Figure 1-1. RF resin cesium isotherm curves for the three feed compositions considered for column performance assessment (i.e., Hot Commissioning Operations, Envelope B Operations, and Subsequent Operations). A 20\% degradation factor was assumed for all three isotherms shown and the solid circles indicate the cesium concentration value for each feed (concentrations in $M$ units provided).

Figure 1-2. VERSE-LC RF resin cesium removal predictions for a full-scale 3 column carousel under Hot Commissioning Operations feed. The figure shows lead, lag, and guard breakthrough behavior. The calculations assume $20 \%$ degradation.

Figure 1-3. VERSE-LC RF resin cesium removal predictions for a full-scale 3 column carousel under Envelope B Operations feed. The figure shows lead, lag, and guard breakthrough behavior. The calculations assume a $20 \%$ degradation factor.

Figure 1-4. VERSE-LC RF resin cesium removal predictions for a full-scale 3 column carousel under Subsequent Operations feed. The figure shows lead, lag, and guard breakthrough behavior. The calculations assume $20 \%$ degradation.

Figure 1-5. VERSE-LC SuperLig ${ }^{\circledR} 644$ resin cesium removal predictions for a full-scale 3 column carousel under Hot Commissioning Operations feed. The figure shows lead, lag, and guard breakthrough behavior. The calculations assume $20 \%$ degradation.

Figure 1-6. VERSE-LC SuperLig ${ }^{\circledR} 644$ resin cesium removal predictions for a full-scale 3 column carousel under Envelope B Operations feed. The figure shows lead, lag, and guard breakthrough behavior. The calculations assume a $20 \%$ degradation factor.

Figure 1-7. VERSE-LC SuperLig ${ }^{\otimes} 644$ resin cesium removal predictions for a full-scale 3 column carousel under Subsequent Operations feed. The figure shows lead, lag, and guard breakthrough behavior. The calculations assume $20 \%$ degradation.

Figure 3-1. The basic building blocks of a porous particle ion exchange column model.

Figure 3-2. Graphical representation of the various mass transport mechanisms considered important for Cesium-SuperLig ${ }^{\circledR} 644$ system ion exchange column modeling.....

Figure 3-3. Estimated cesium, potassium, and sodium exit breakthrough curves for one column experiment based on the porous particle multi-component ion exchange column model (data from King et al., 2000).

Figure 4-1. Hot Commissioning, Envelope B and Subsequent Operation $\mathrm{Cs}^{+}$isotherms for degraded Resorcinol-Formaldehyde resin (Na-form mass basis).

Figure 4-2. Hot Commissioning Operation degraded $\mathrm{Cs}^{+}$isotherms with variation in potassium concentration (Na-form mass basis).

Figure 4-3. Hot Commissioning Operation degraded $\mathrm{Cs}^{+}$isotherms with variation in sodium concentration (Na-form mass basis).

Figure 4-4. $\quad$ Hot Commissioning Operation degraded $\mathrm{Cs}^{+}$isotherms with variation in hydroxide concentration (Na-form mass basis).

Figure 4-5. Hot Commissioning Operation $\mathrm{Cs}^{+}$isotherms for SuperLig ${ }^{\circledR} 644$ and Resorcinol-Formaldehyde

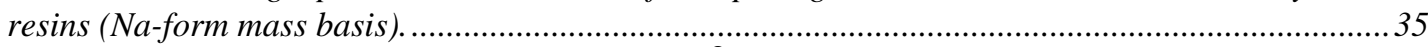

Figure 4-6. $\quad$ Envelope B Operation $\mathrm{Cs}^{+}$isotherms for SuperLig ${ }^{\circledR} 644$ and Resorcinol-Formaldehyde resins (Na-form mass basis).

Figure 4-7. $\quad$ Subsequent Operation $\mathrm{Cs}^{+}$isotherms for SuperLig ${ }^{\circledR} 644$ and Resorcinol-Formaldehyde resins (Na-form mass basis).

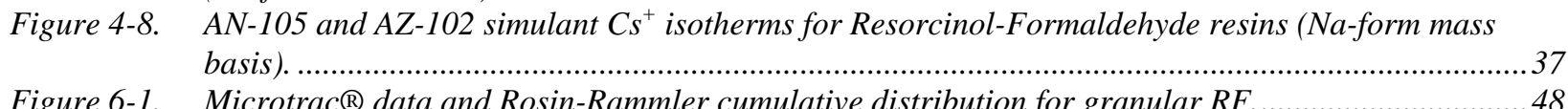

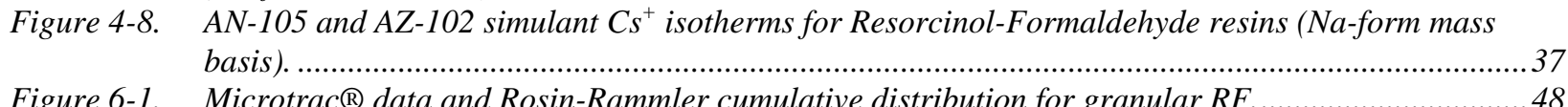

$\begin{array}{ll}\text { Figure 6-1. } & \text { Microtrac }{ }^{\circledR} \text { data and Rosin-Rammler cumulative distribution for granular RF........................... } 48 \\ \text { Figure 6-2. } & \text { Microtrac }{ }^{\circledR} \text { data, Log-Normal and Rosin-Rammler cumulative distributions for spherical RF ........48 }\end{array}$

Figure 7-1. Transient aqueous cesium concentration during SRNL Experiment 2 with used spherical Resorcinol-Formaldehyde resin in $\mathrm{AN}-105$ simulant at $25^{\circ} \mathrm{C}$. Tortuosity factor varied from 1 to 3. Bed flowrate set to $30 \mathrm{ml} / \mathrm{min}$. 
Figure 7-2. $\quad$ Transient cesium solid loading during SRNL Experiment 2 with used spherical ResorcinolFormaldehyde resin in $\mathrm{AN}-105$ simulant at $25^{\circ} \mathrm{C}$. Tortuosity factor set to 1.5. Bed flowrate set to $30 \mathrm{ml} / \mathrm{min}$.

Figure 7-3. Transient aqueous cesium concentration during SRNL Experiment 1 with used spherical Resorcinol-Formaldehyde resin in $\mathrm{AN}-105$ simulant at $25^{\circ} \mathrm{C}$. Bed flowrate set to $90 \mathrm{ml} / \mathrm{min}$...........55

Figure 7-4. Transient cesium solid loading during SRNL Experiment 2 with used spherical ResorcinolFormaldehyde resin in $\mathrm{AN}-105$ simulant at $25^{\circ} \mathrm{C}$. Bed flowrate set to $90 \mathrm{ml} / \mathrm{min}$. 55

Figure 7-5. Transient aqueous cesium concentration during SRNL Experiment 3 with used spherical Resorcinol-Formaldehyde resin in $\mathrm{AN}-105$ simulant at $25^{\circ} \mathrm{C}$. Bed flowrate set to $0.5 \mathrm{ml} / \mathrm{min}$. ..........56

Figure 7-6. Transient cesium solid loading during SRNL Experiment 3 with used spherical ResorcinolFormaldehyde resin in $\mathrm{AN}-105$ simulant at $25^{\circ} \mathrm{C}$. Bed flowrate set to $0.5 \mathrm{ml} / \mathrm{min}$.............................56

Figure 7-7. Transient aqueous cesium concentration during SRNL Experiment 4 with used spherical Resorcinol-Formaldehyde resin in $\mathrm{AN}-105$ simulant at $25^{\circ} \mathrm{C}$. Bed flowrate set to $30 \mathrm{ml} / \mathrm{min}$............57

Figure 7-8. Transient cesium solid loading during SRNL Experiment 4 with used spherical ResorcinolFormaldehyde resin in $\mathrm{AN}-105$ simulant at $25^{\circ} \mathrm{C}$. Bed flowrate set to $30 \mathrm{ml} / \mathrm{min}$. 57

Figure 7-9. Transient aqueous cesium concentration during SRNL Experiment 5 with unused spherical Resorcinol-Formaldehyde resin in $\mathrm{AN}-105$ simulant at $25^{\circ} \mathrm{C}$. Bed flowrate set to $30 \mathrm{ml} / \mathrm{min}$. ..........58

Figure 7-10. Transient cesium solid loading during SRNL Experiment 5 with unused spherical ResorcinolFormaldehyde resin in $\mathrm{AN}-105$ simulant at $25^{\circ} \mathrm{C}$. Bed flowrate set to $30 \mathrm{ml} / \mathrm{min}$. 58

Figure 7-11. Transient aqueous cesium concentration during SRNL Experiment 6 with granular ResorcinolFormaldehyde resin in $\mathrm{AN}-105$ simulant at $25^{\circ} \mathrm{C}$. Bed flowrate set to $30 \mathrm{ml} / \mathrm{min}$.

Figure 7-12. Transient cesium solid loading during SRNL Experiment 6 with granular ResorcinolFormaldehyde resin in $\mathrm{AN}-105$ simulant at $25^{\circ} \mathrm{C}$. Bed flowrate set to $30 \mathrm{ml} / \mathrm{min}$.

Figure 7-13. Transient aqueous cesium concentration during SRNL Experiment 7 with used spherical Resorcinol-Formaldehyde resin in $\mathrm{AN}-105$ simulant at $45^{\circ} \mathrm{C}$. Bed flowrate set to $30 \mathrm{ml} / \mathrm{min}$.

Figure 7-14. Transient cesium solid loading during SRNL Experiment 7 with used spherical ResorcinolFormaldehyde resin in $\mathrm{AN}-105$ simulant at $44^{\circ} \mathrm{C}$. Bed flowrate set to $30 \mathrm{ml} / \mathrm{min}$.

Figure 8-1. Estimated impact of column-to-particle diameter ratios on radial velocity profile based on the limited data by Schwartz and Smith (1953).....

Figure 8-2. Estimation of the impact from end effects and short columns on axial dispersion based on the limited data by Liles and Geankoplis (1960).

Figure 9-1. Comparison of VERSE-LC cesium breakthrough with data from the PNNL Column 6, Cycle 1 test. A sample of granular Resorcinol-Formaldehyde (Resin \#1) was tested with AZ-102 simulant.

Figure 9-2. Comparison of VERSE-LC cesium breakthrough with data from the PNNL Column 7 Cycle 1 test. A sample of spherical Resorcinol-Formaldehyde (Resin \#3) was tested with AZ-102 simulant.

Figure 9-3. Comparison of VERSE-LC cesium breakthrough with data from the PNNL Column 8, Cycle 1 test. A sample of spherical Resorcinol-Formaldehyde (Resin \#6) was tested with AZ-102 simulant.

Figure 10-1. VERSE-LC cesium breakthrough predictions for a full-scale 3 column carousel under Hot Commissioning Operations feed. The calculations assume fresh Resorcinol-Formaldehyde resin.... 73

Figure 10-2. VERSE-LC cesium breakthrough predictions for a full-scale 3 column carousel under Hot Commissioning Operations feed. The calculations assume chemically degraded ResorcinolFormaldehyde resin.

Figure 10-3. VERSE-LC cesium breakthrough predictions for a full-scale 3 column carousel under Envelope

$B$ Operations feed. The calculations assume fresh Resorcinol-Formaldehyde resin.....

Figure 10-4. VERSE-LC cesium breakthrough predictions for a full-scale 3 column carousel under Envelope $B$ Operations feed. The calculations assume chemically degraded Resorcinol-Formaldehyde resin.

Figure 10-5. VERSE-LC cesium breakthrough predictions for a full-scale 3 column carousel under Subsequent Operations feed. The calculations assume fresh Resorcinol-Formaldehyde resin. 75

Figure 10-6. VERSE-LC cesium breakthrough predictions for a full-scale 3 column carousel under Subsequent Operations feed. The calculations assume chemically degraded ResorcinolFormaldehyde resin. 
Figure 10-7. VERSE-LC cesium breakthrough prediction for the lead column under Hot Commissioning Operations feed. The impact on breakthrough with variation in potassium concentration is shown for the first cycle.

Figure 10-8. VERSE-LC cesium breakthrough prediction for the lead column under Hot Commissioning Operations feed. The impact on breakthrough with variation in sodium concentration is shown for the first cycle.

Figure 10-9. VERSE-LC cesium breakthrough prediction for the lead column under Hot Commissioning Operations feed. The impact on breakthrough with variation in hydroxide concentration is shown for the first cycle.

Figure 10-10. VERSE-LC cesium breakthrough prediction for the lead column under Hot Commissioning Operations feed. The impact on breakthrough with variation in cesium concentration is shown for the first cycle.

Figure 10-11. VERSE-LC cesium breakthrough prediction for the lead column under Hot Commissioning Operations feed. The impact on breakthrough with variation in liquid flowrate is shown for the first cycle.

Figure 10-12. VERSE-LC cesium breakthrough prediction for the lead column under Hot Commissioning Operations feed. The impact on breakthrough with variation in pore diffusivity is shown for the first cycle.

Figure 10-13. VERSE-LC cesium breakthrough prediction for the lead column under Hot Commissioning Operations feed. The impact on breakthrough with variation in particle radius is shown for the first cycle.

Figure 10-14. VERSE-LC cesium breakthrough prediction for the lead column under Hot Commissioning Operations feed. The impact on breakthrough with variation in bed density is shown for the first cycle. 


\subsection{Executive Summary}

The expected performance of an alternative ion exchange resin (i.e., Resorcinol-Formaldehyde $[R F])$ for the removal of cesium from Hanford high level radioactive alkaline waste is discussed. The SuperLig ${ }^{\circledR} 644$ resin is the current primary resin of choice. A consistent performance comparison between RF and SuperLig ${ }^{\circledR} 644$ resins is also provided. This report represents an initial report on our ability and knowledge with regard to modeling the RF resin ion exchange system (i.e., RF in its spherical bead structure). Only the loading phase of the cycle process is addressed within this report. Pertinent bench-scale column tests and batch equilibrium experiments are addressed. The methodology employed and sensitivity analyses are also discussed (i.e., the existing methodology employed for SuperLig ${ }^{\circledR} 644$ resin analyses is also employed for the RF resin analyses). Pilot-scale testing is not assessed since no pilot-scale testing was available or planned at the time of this report (i.e., only Stage 1 activities are covered). Column performance predictions are made considering three selected feed compositions under nominal operating conditions. The sensitivity analyses provided help to identify key parameters that aid in resin procurement acceptance criteria. The methodology and application presented within this report reflect the expected behavior of RF resin manufactured at the small-scale (i.e., approximately $250 \mathrm{ml}$ batch size level by Sintef). No analysis associated with the original ground RF resin is presented within this report. WTP decided that the baseline $\mathrm{RF}$ resin should be changed to the spherical bead form.

\section{$1.1 \quad$ Objectives}

The details associated with this task are identified within the technical and quality assurance plan for computer modeling of ion exchange with RF resin (Hardy et al., 2003), performed in support of the River Protection Program Waste Treatment Plant ion exchange process. The original scope of this task is provided in the Test Specification 24590-PTF-TSP-RT-03-008, Rev 0 (Thorson, 2003). The primary objective of this work was, through modeling and verification based on experimental assessments, to predict the cesium removal performance of RF resin for application in the RPP pretreatment facility and to compare its performance to that of SuperLig ${ }^{\mathbb{R}}$ 644 resin on a consistent basis.

Based on necessary scope reductions that occurred during the life of this task plan, only the loading phase performance of RF resin is being addressed within this document. Also, the planned 16 LAW feeds were not addressed individually, but were addressed by looking at just three limiting/composite feed compositions (i.e., referred to as Hot Commissioning Operation, Envelope B Operation, and Subsequent Operation). These alterations in task plan objectives were the result of WTP guidance as discussed in Toth (2003), where feed compositions and product purity criteria were established.

The column performance predictions presented within this report reflect expected performance behavior for RF resin manufactured at the small-scale (i.e., the $250 \mathrm{ml}$ batch size manufactured by Syntef and in its spherical bead form). Data taken for earlier RF resin (e.g., ground material) were not incorporated into the final modeling assessment phase presented within this report (i.e., 
only the spherical resin was employed in establishing model parameter settings). The isotherm database focused on the $250 \mathrm{ml}$ Syntef material.

The specific objectives pertinent to this report, as outlined in the test specification of this activity, are:

\begin{tabular}{|l|l|l|}
\hline \multicolumn{1}{|c|}{ Test Objective } & $\begin{array}{l}\text { Objective } \\
\text { Met (Y/N) }\end{array}$ & \multicolumn{1}{|c|}{ Discussion } \\
\hline $\begin{array}{l}\text { The primary objective is to create or } \\
\text { upgrade a computer model that allows } \\
\text { prediction of cesium sorption along with } \\
\text { sorption of other analytes under a wide } \\
\text { variety of conditions, accounting for } \\
\text { competitors (e.g., potassium on the } \\
\text { cesium resin), pH, ionic strength, PSD, } \\
\text { and temperature in the WTP column and } \\
\text { in test columns and apply that program to } \\
\text { various column arrangements and } \\
\text { carousel plans. Both an isotherm and } \\
\text { column transport model will be } \\
\text { developed. }\end{array}$ & $\begin{array}{l}\text { Met objective } \\
\text { partially }\end{array}$ & $\begin{array}{l}\text { Experimental equilibrium distribution, } \\
\text { particle loading kinetics, and material } \\
\text { property measurements were employed } \\
\text { in the model development phase of this } \\
\text { effort. Only the appropriate/available } \\
\text { data for the spherical bead form was } \\
\text { chosen (i.e., no ground resin data was } \\
\text { used). Only the 3-column configuration } \\
\text { of the carousel was consider to compare } \\
\text { with consistent analyses performed for } \\
\text { the SuperLig }{ }^{\mathbb{B}} \text { 644 resin. Only limited } \\
\text { algebraic isotherm models for the } \\
\text { specific feed compositions are being } \\
\text { provided since only limited isotherm data } \\
\text { and feed stream definitions were } \\
\text { provided. A more developed isotherm } \\
\text { model, and given the 16 specific LAW } \\
\text { feed streams, analyses could potentially } \\
\text { improve the processing strategy chosen. }\end{array}$ \\
\hline $\begin{array}{l}\text { The secondary objective is to create or } \\
\text { upgrade a computer model that allows } \\
\text { prediction of ion exchange column } \\
\text { elution performance, to the extent } \\
\text { practical, accounting for resin loading } \\
\text { and elution volume, using baseline acid } \\
\text { strength. }\end{array}$ & Objective not \\
met & $\begin{array}{l}\text { Due to scope reductions, no RF elution } \\
\text { analyses are provided within this report. } \\
\text { Having an elution model would have } \\
\text { provided operations with the ability to } \\
\text { assess and perhaps achieve a more } \\
\text { optimal operating strategy. }\end{array}$ \\
\hline
\end{tabular}

\section{$1.2 \quad$ Test Exceptions}

No official written test exceptions were imposed on this activity. Various alterations in modeling objectives were made based upon WTP requests to eliminate and alter scope based on overall project needs and available databases required.

\subsection{Results and Performance Against Success Criteria}

The success criteria for this task, for Stage 1 activities, are listed in the following table: 


\begin{tabular}{|c|c|}
\hline Success Criteria & Discussion \\
\hline $\begin{array}{l}\text { Creation and application of an isotherm model to } \\
\text { support the prediction of resin loading } \\
\text { performance under a wide variety of conditions, } \\
\text { accounting for competitors (e.g., potassium on } \\
\text { the cesium resin), ionic strength, and temperature } \\
\text { where appropriate data exist. }\end{array}$ & $\begin{array}{l}\text { Only limited algebraic isotherm models for three } \\
\text { specific feed compositions are being provided } \\
\text { since only limited isotherm data and feed stream } \\
\text { definitions were provided. Insufficient isotherm } \\
\text { database exists to adequately establish parameter } \\
\text { settings with reasonable confidence. }\end{array}$ \\
\hline $\begin{array}{l}\text { Creation and application of an isotherm model to } \\
\text { support the prediction of resin elution } \\
\text { performance as a function of volume, target } \\
\text { effluent concentrations (C/Co), temperature, and } \\
\text { acid concentrations where appropriate data exist. }\end{array}$ & $\begin{array}{l}\text { Due to scope reductions and database } \\
\text { availability, no elution isotherms were } \\
\text { developed. }\end{array}$ \\
\hline $\begin{array}{l}\text { Creation and application of a column-transport } \\
\text { model to support the prediction of IX column } \\
\text { loading for RF resins under a wide variety of } \\
\text { conditions, accounting for competitors (e.g., } \\
\text { potassium on the cesium resin), pH, ionic } \\
\text { strength, and temperature where appropriate data } \\
\text { and understanding exist. }\end{array}$ & $\begin{array}{l}\text { VERSE-LC model assessments are provided } \\
\text { within this report. Small-scale column } \\
\text { assessments were made to all pertinent tests } \\
\text { available. Pilot-scale testing was not performed } \\
\text { since no assessment data were planned for Stage } \\
1 \text { activities. }\end{array}$ \\
\hline $\begin{array}{l}\text { A preliminary attempt at modeling elution will be } \\
\text { made in Stage } 1 \text { to determine the ability of } \\
\text { VERSE-LC to perform calculations for this phase } \\
\text { of column operation. The analysis will be of a } \\
\text { basic nature and will attempt to address the } \\
\text { fundamental aspects of column elution. Included } \\
\text { will be a curve or equation that correlates } \\
\text { residual cesium in the resin versus elution } \\
\text { volume, C/Co and temperature, all at } 0.5 \mathrm{M} \text { acid } \\
\text { strength and at one other acid strength. }\end{array}$ & $\begin{array}{l}\text { Due to scope reductions and database } \\
\text { availability, no elution column performance } \\
\text { analyses are presented within this report. }\end{array}$ \\
\hline
\end{tabular}

Below, additional comments are listed to provide more insight into the specific modeling efforts and results observed during the course of this activity. The methodology employed was completely consistent between the RF analyses presented and the earlier SuperLig ${ }^{\circledR} 644$ analyses performed (e.g., see Hamm et al., 2003b). The major accomplishments and conclusions are:

- A detailed thermodynamic isotherm model was employed to correlate available batch contact data. An approach to correlating the batch equilibrium data was used based on a simple algebraic isotherm model derived assuming average values for the various selectivity coefficients. A four-component (i.e., cesium, potassium, sodium, and hydrogen) cation exchange isotherm model was created, very consistent with the basic formulation used to describe SuperLig ${ }^{\circledR} 644$ resin (see Appendix A of Hamm et al. [2003b] for a detailed discussion of the thermodynamic isotherm model). The adequacy of this approach is tested by comparison to the available database and through their use in column simulations/assessments. 
- To achieve adequate batch contact " $\mathrm{K}_{\mathrm{d}}$ " test data, sufficient contact time and agitation (i.e., mixing) is paramount. A limited set of batch contact tests and particle kinetics tests was performed in a manner consistent with the protocols employed for SuperLig ${ }^{\circledR} 644$ resin testing. This limited database was used to establish key modeling parameter (i.e., isotherm and pore diffusivity) values where focus was made on the most recent small-scale $250 \mathrm{ml}$ batch of RF resin in its spherical bead form. Very consistent data was achieved based primarily on the use of well defined protocols that were initially verified. Prior significant variability observed in batch equilibrium " $\mathrm{K}_{\mathrm{d}}$ " test data was not present.

- Only "effective" single-component (cesium specific) column transport simulations were performed. Prior efforts have shown that for the cesium loading-phase only, the simpler "effective" single-component column model is adequate for design purposes.

- For the majority of modeling parameters required to perform an ion-exchange transport simulation, an existing methodology was employed that was updated as appropriate test data became available. Basically, the same methodology employed for predicting SuperLig ${ }^{\circledR} 644$ resin performance was used for predicting Resorcinol-Formaldehyde resin performance. Only the key parameter values unique to each resin type were altered.

- In the order of estimated affinity, the four major cations competing for surface sites on RF resin considered are: hydronium, cesium, potassium, and sodium. For the above cations RF resin is most selective for $\mathrm{H}^{+}$, then $\mathrm{Cs}^{+}$, followed by $\mathrm{K}^{+}$, and then $\mathrm{Na}^{+}$. Based on prior work with RF resin, Cs capacity varies significantly with $\mathrm{pH}$. Based on the more recent batch contact testing of spherical RF (King et al., 2003), an observed OH dependence can be seen in batch equilibrium " $\mathrm{K}_{\mathrm{d}}$ " test data for liquid solutions with varying $\mathrm{pH}$ values (see Appendix A in Hamm et al., 2003b). The rational selectivity coefficients for RF resin are consistently lower than the corresponding values for SuperLig ${ }^{\circledR} 644$ resin. Basically, RF resin is less selective for Cs than SuperLig ${ }^{\circledR} 644$ resin. Specifically, SuperLig ${ }^{\circledR} 644$ resin affinity for Cs versus $\mathrm{K}$ is $\sim 1.8$ times (Cs versus $\mathrm{Na}$ is $\sim 3.8$ times) greater than the spherical RF resin.

- A total cesium ion-exchange capacity for $\mathrm{RF}$ resin (250 $\mathrm{ml}$ batches) is $\mathrm{pH}$ dependent with a value of approximately $0.48 \mathrm{mmole} / \mathrm{g}$ at high $\mathrm{OH}$ concentration levels (i.e., a plateau value that drops off significantly for $\mathrm{OH}$ concentrations below $0.5 \mathrm{M}$ ). This plateau value of 0.48 $\mathrm{mmole} / \mathrm{g}$ for RF resin is approximately $11 \%$ lower than the $0.54 \mathrm{mmole} / \mathrm{g}$ value for SuperLig ${ }^{\circledR} 644$ resin (i.e., based on fresh resin versus fresh resin).

- Model simulations were run for several experimental column tests to assess the predictability of the methodology. In the majority of cases, reasonable predictions were achieved for the cesium exit breakthrough curves. Both actual and simulant feed solutions have been assessed.

- Based on this methodology full-scale facility "best estimate" (i.e., nominal) simulations were run for three feed streams assuming a three-column carousel configuration. The exit cesium product criterion value (imposed at the exit of the lag column) varied for each feed stream considered. The calculations performed evaluated both fresh resin, as well as resin estimated to be chemically degraded after approximately 10 operating cycles (i.e., a $20 \%$ degradation 
factor was assumed). For all three feed streams considered cesium removal performance exceeded minimum design specifications for "fresh" resin. Under $20 \%$ degradation conditions the Hot Commissioning Operation feed slightly underpredicted design performance (i.e., $\sim 90 \mathrm{BV}$ versus the $100 \mathrm{BV}$ design value).

- When a ${ }^{137} \mathrm{Cs}$ inventory limit is also imposed on the RF resin column loading, we find that the number of BVs to process the "Envelope B Operations" feed stream becomes limited. An inventory limit of 75,000 $\mathrm{Ci}$ was assumed. Given this inventory limit VERSE predictions indicate that this limit is reached in $\sim 43 \mathrm{BVs}$ for the Envelope B Operations feed stream.

Tables 1-1 and 1-2 (i.e., fresh and degraded resin performance) provide a brief summary of the number of bed volumes that can be processed for the first 5 cycles for each of the three feed compositions considered. Results for both RF and SuperLig ${ }^{\circledR} 644$ resin are provided (i.e., SuperLig ${ }^{\circledR} 644$ values shown in parenthesis). Both the number of BVs processed based on a cesium exit product criterion and a total cesium inventory limit were computed The current design and operational strategy appear sufficient to achieve the desired decontamination factors for both resin types (i.e., significant bed volumes of feed can be processed per operation cycle for all three feeds considered). The lead column $75 \mathrm{k}$ curie limit for ${ }^{137} \mathrm{Cs}$ inventory is reached for Envelope B Operations at $43 \mathrm{BVs}$ for both resin types (i.e., design requirement is currently $25 \mathrm{BVs})$. This curie limit is also reached for Subsequent Operations at $338 \mathrm{BVs}$ for the SuperLig ${ }^{\circledR} 644$ resin (i.e., design requirement is currently $100 \mathrm{BVs}$ ).

The estimated RF resin cesium isotherms for each of the three feed compositions considered are shown in Figure 1-1. Figures 1-2 through 1-4 illustrate the cesium breakthrough performance for each feed stream considered for columns packed with RF resin. Figures 1-5 through 1-7 illustrate the cesium breakthrough performance for each feed stream considered for columns packed with SuperLig ${ }^{\circledR} 644$ resin. The results shown are for a resin bed estimated to be chemically degraded due to approximately 10 operating cycles (i.e., a $20 \%$ degradation factor was assumed for both resin types). Very sharp mass transfer zones exist for each resin type when processing the Envelope B Operations feed. This is a direct result of the significantly higher cesium feed concentration along with the reduced feed flowrate.

\subsection{Quality Requirements}

The Liquid Chromatography code VERSE-LC (Whitley and Wang, 1998) was chosen to perform these column performance assessments. Version 7.80 of VERSE-LC was used for verification purposes where several test cases (i.e., see certification package for VERSE-LC Version 7.80 by Hamm et al., 2000a) were checked to ensure its implementation on the stated PC platform. Further benchmarking was made by assessment to several key particle kinetics and column tests. Column test benchmarking is considered to be the ultimate check of the accuracy of the methodology employed. Column test benchmarking results are provided in Chapter 9 where the cases considered demonstrated reasonably good predictive capability.

This work was conducted in accordance with the RPP-WTP QA requirements specified for work conducted by SRNL as identified in DOE IWO MOSRLE60. SRNL has provided matrices to WTP demonstrating compliance of the SRNL QA program with the requirements specified by 
WTP. Specific information regarding the compliance of the SRNL QA program with RW0333P, Revision 10, NQA-1 1989, Part 1, Basic and Supplementary Requirements and NQA-2a 1990, Subpart 2.7 is contained in these matrices. This Task was conducted under the Task Plan for the ion exchange computer model upgrades (Hardy et al., 2003).

\subsection{R\&T Analysis Conditions}

Original effort was to address full-scale facility performance for the 16 Phase 1 LAW feeds in their planned processing sequence. However, by the time required to perform the analyses presented within this report, no such feed stream definitions were available. WTP provided three unique feed stream compositions to be considered instead. The RF resin analyses presented within this report are based on a very limited database consistent with the programmatic needs associated with Stage 1 activities. RF resin behavior at the small-scale (e.g., 250-ml batch size) was used and was created using well-defined protocols. More complete databases are planned during Stage 2 and Stage 3 after resin form down-select has occurred.

\subsection{Simulant Use}

Under this particular task plan no experiments were performed.

\subsection{Discrepancies and Follow-on Analyses}

In the process of performing this work no significant discrepancies (i.e., full-scale facility performance not being able to meet or exceed design objectives) were observed. However, two issues are worthy of mentioning:

- For Hot Commissioning Operation the predicted breakthrough values are very close to the current design specification (i.e., slightly higher for fresh resin and slightly lower for $20 \%$ degraded resin). These are best estimate predictions and any accounting for uncertainties would reduce these estimates.

- A major negative impact is predicted in breakthrough performance when the sodium feed concentration is increased. For example, upon a $20 \%$ increase in sodium from $4.75 \mathrm{M}$ to $5.48 \mathrm{M}$, initial breakthrough of the lead column went from $\sim 55 \mathrm{BV}$ to $\sim 7 \mathrm{BV}$. The premature breakthrough at high sodium concentration is due to highly reduced cesium pore diffusivity. This impact has not been quantified experimentally and it is highly recommend that such testing be performed.

Only Stage 1 analyses have been presented within this report and follow-on analyses are planned during Stage 2 and Stage 3 activities. 
Table 1-1 Number of bed volumes required to reach lag column Cs breakthrough during threecolumn carousel operation for Hot Commissioning Operations, Envelope B Operations, and Subsequent Operations feeds. Assumes a 0\% chemical degradation factor for all results listed (i.e., fresh resin). Results listed are for RF Resin BVs followed by (SuperLig ${ }^{\circledR} 644$ resin).

\begin{tabular}{|c|c|c|c|}
\hline $\begin{array}{c}\text { Cycle } \\
\text { Number }\end{array}$ & $\begin{array}{c}\text { Hot Commissioning } \\
\text { Operation Feed } \\
(\mathbf{B V})\end{array}$ & $\begin{array}{c}\text { Envelope B Operations } \\
\text { Feed } \\
(\mathbf{B V})\end{array}$ & $\begin{array}{c}\text { Subsequent Operations } \\
\text { Feed } \\
\text { (BV) }\end{array}$ \\
\hline 1 & $171(371)$ & $395(693)[43]^{\mathrm{a}}$ & $270(337)$ \\
\hline 2 & $108(240)$ & $210(359)$ & $170(468)$ \\
\hline 3 & $111(249)$ & $210(359)$ & $175(482)$ \\
\hline 4 & $114(255)$ & $210(359)$ & $179(491)$ \\
\hline 5 & $115(259)$ & $210(360)$ & $181(496)$ \\
\hline
\end{tabular}

${ }^{\mathrm{a}}$ Number of bed volumes to reach ${ }^{137} \mathrm{Cs}$ inventory limit of $75 \mathrm{k} \mathrm{Ci}$.

Table 1-2 Number of bed volumes required to reach lag column Cs breakthrough during threecolumn carousel operation for Hot Commissioning Operations, Envelope B Operations, and Subsequent Operations feeds. Assumes a 20\% chemical degradation factor for all results listed (resin with an approximated 10 cycle exposure). Results listed are for RF Resin BVs followed by (SuperLig ${ }^{\circledR} 644$ resin).

\begin{tabular}{|c|c|c|c|}
\hline $\begin{array}{c}\text { Cycle } \\
\text { Number }\end{array}$ & $\begin{array}{c}\text { Hot Commissioning } \\
\text { Operation Feed } \\
\text { (BV) }\end{array}$ & $\begin{array}{c}\text { Envelope B Operations } \\
\text { Feed } \\
\text { (BV) }\end{array}$ & $\begin{array}{c}\text { Subsequent Operations } \\
\text { Feed } \\
\text { (BV) }\end{array}$ \\
\hline 1 & $138(298)$ & $317(556)[43]^{\mathrm{a}}$ & $216(584)$ \\
\hline 2 & $87(192)$ & $168(287)$ & $136(374)$ \\
\hline 3 & $89(200)$ & $168(288)$ & $141(386)$ \\
\hline 4 & $91(204)$ & $168(288)$ & $143(393)$ \\
\hline 5 & $92(207)$ & $168(287)$ & $145(397)$ \\
\hline \multicolumn{3}{|c|}{${ }^{a}$ Number of bed volumes to reach ${ }^{137}$ Cs inventory limit of $75 \mathrm{k} \mathrm{Ci.}$}
\end{tabular}




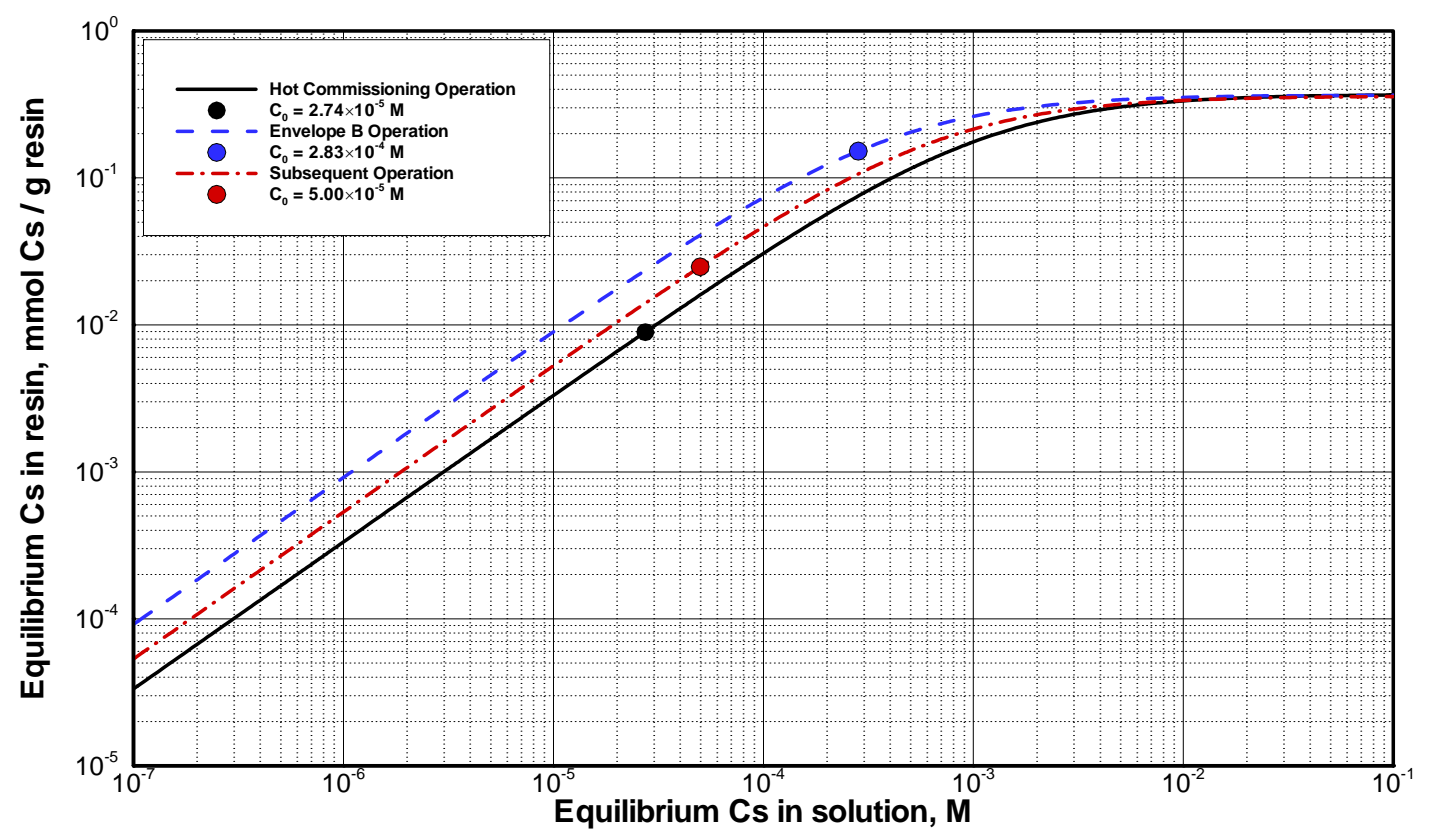

Figure 1-1. RF resin cesium isotherm curves for the three feed compositions considered for column performance assessment (i.e., Hot Commissioning Operations, Envelope B Operations, and Subsequent Operations). A 20\% degradation factor was assumed for all three isotherms shown and the solid circles indicate the cesium concentration value for each feed (concentrations in M units provided). 


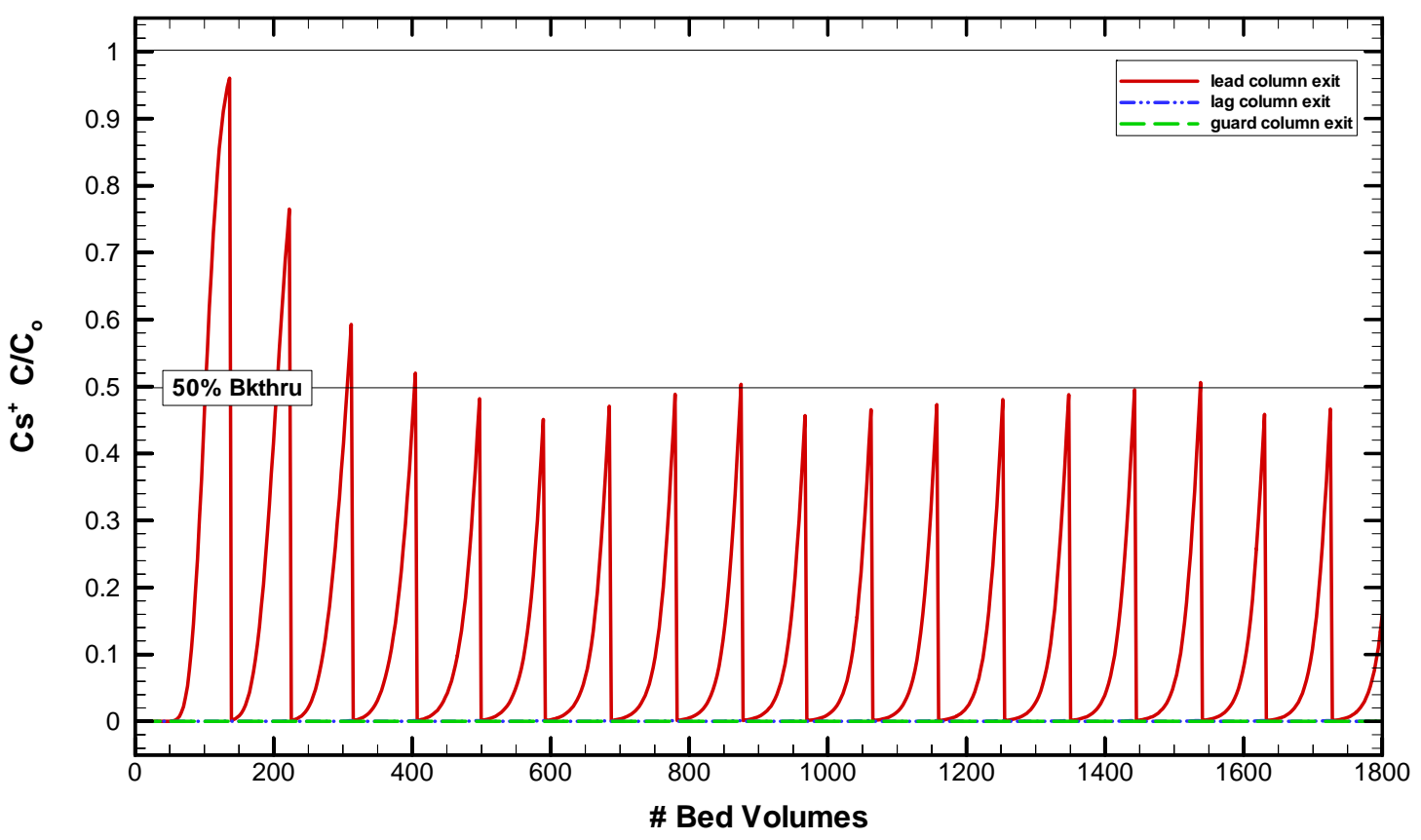

Figure 1-2. VERSE-LC RF resin cesium removal predictions for a full-scale 3 column carousel under Hot Commissioning Operations feed. The figure shows lead, lag, and guard breakthrough behavior. The calculations assume $20 \%$ degradation.

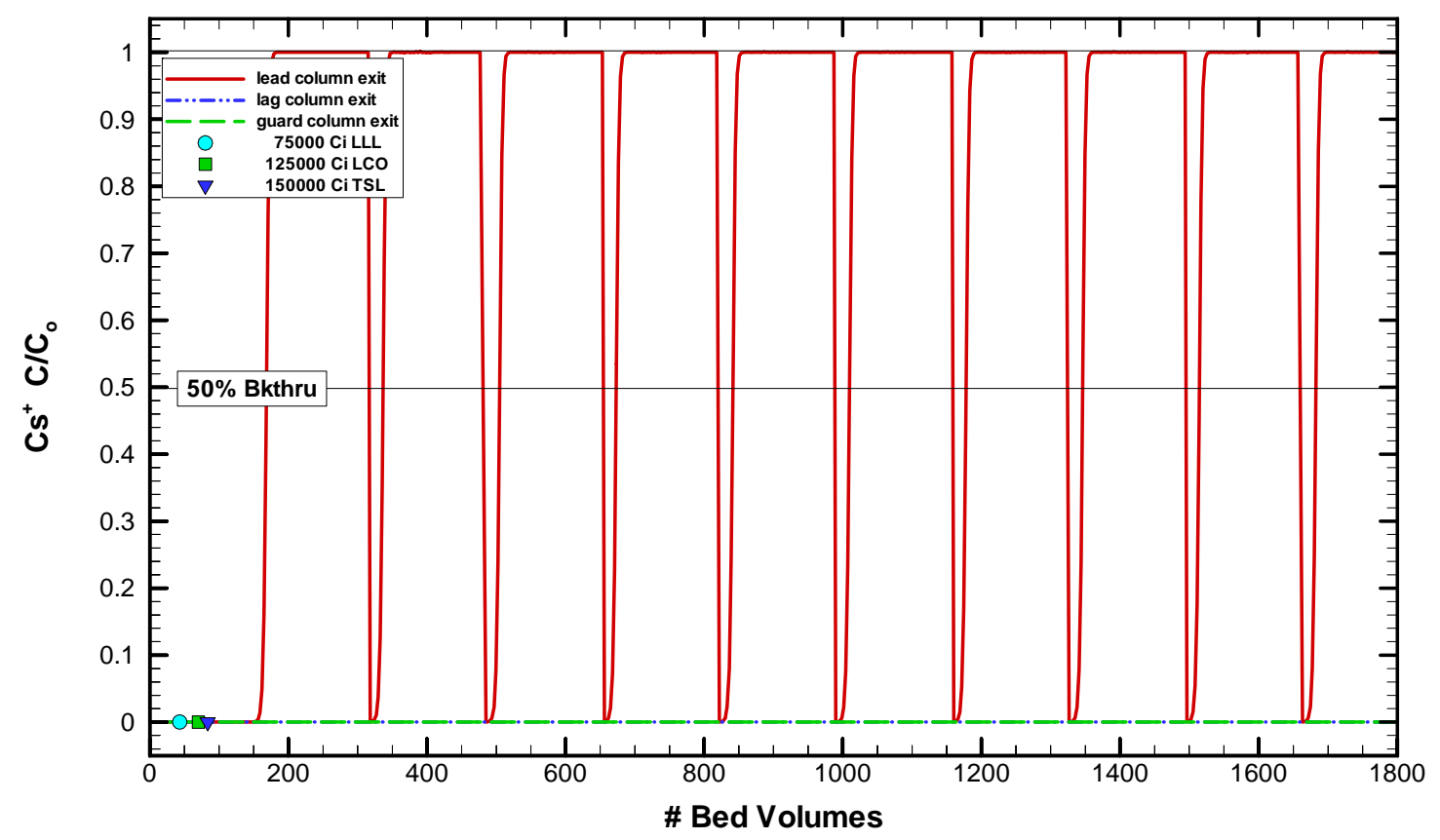

Figure 1-3. VERSE-LC RF resin cesium removal predictions for a full-scale 3 column carousel under Envelope B Operations feed. The figure shows lead, lag, and guard breakthrough behavior. The calculations assume a $20 \%$ degradation factor. 


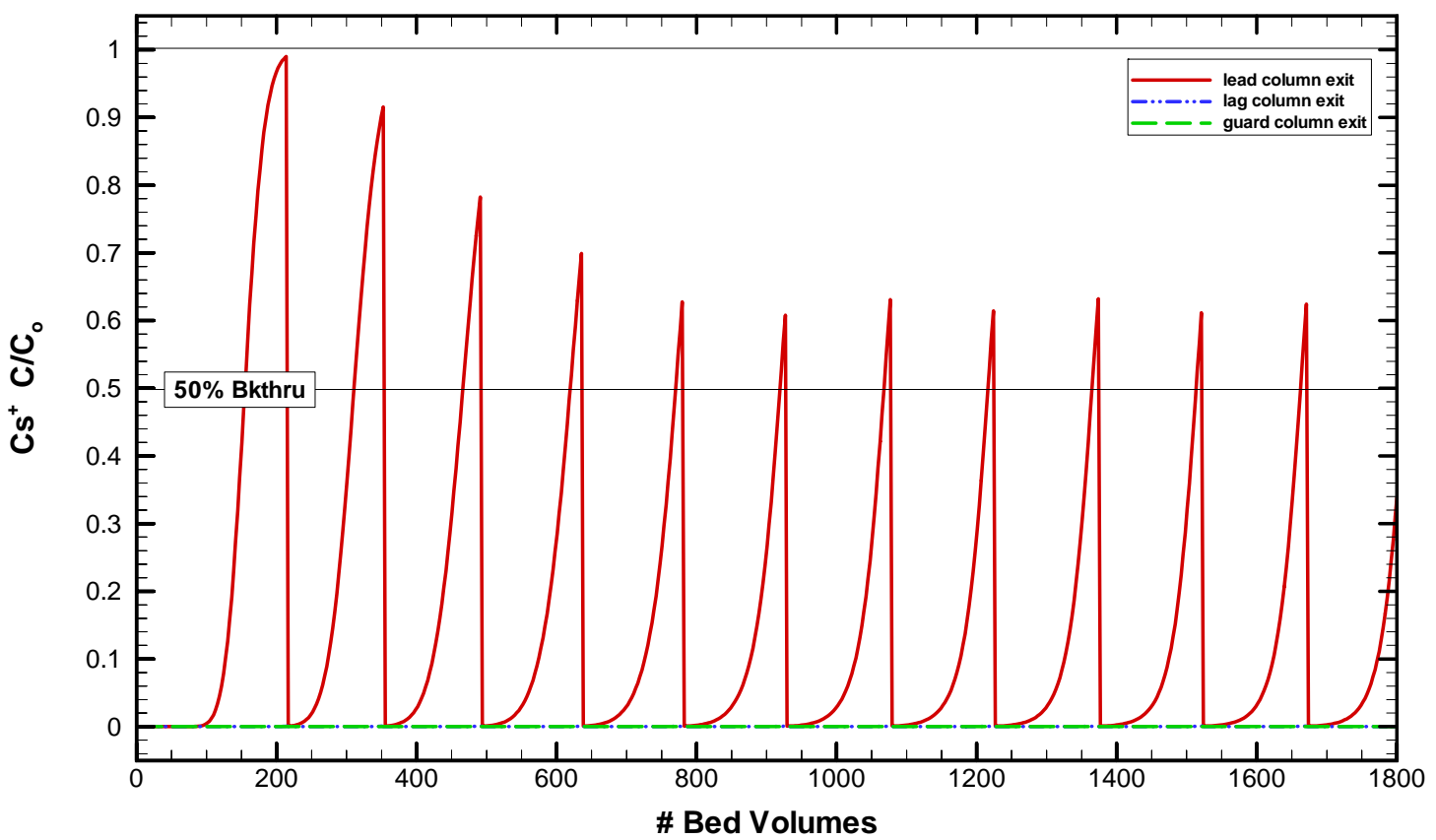

Figure 1-4. VERSE-LC RF resin cesium removal predictions for a full-scale 3 column carousel under Subsequent Operations feed. The figure shows lead, lag, and guard breakthrough behavior. The calculations assume $20 \%$ degradation.

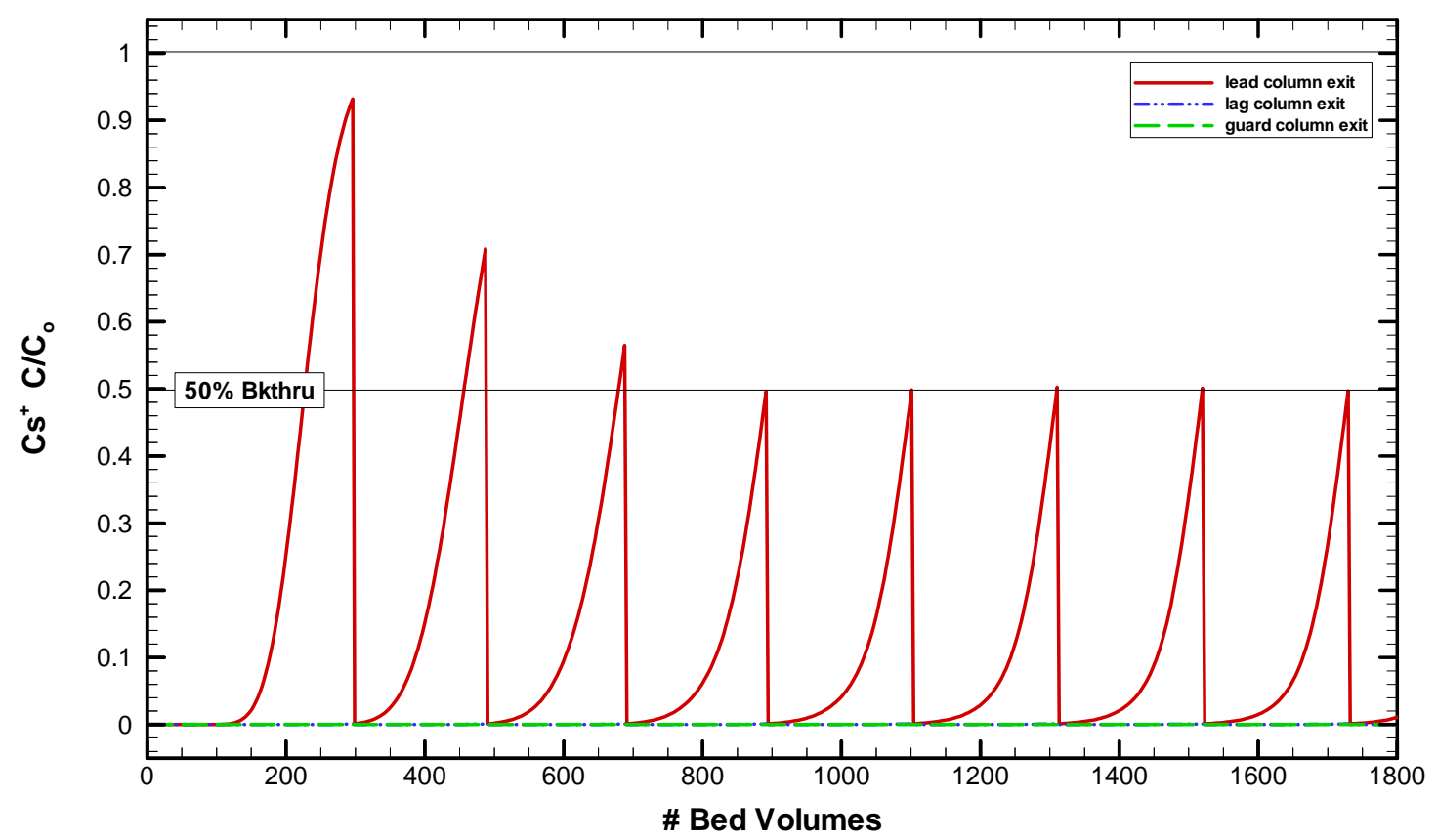

Figure 1-5. VERSE-LC SuperLig ${ }^{\circledR} 644$ resin cesium removal predictions for a full-scale 3 column carousel under Hot Commissioning Operations feed. The figure shows lead, lag, and guard breakthrough behavior. The calculations assume 20\% degradation. 


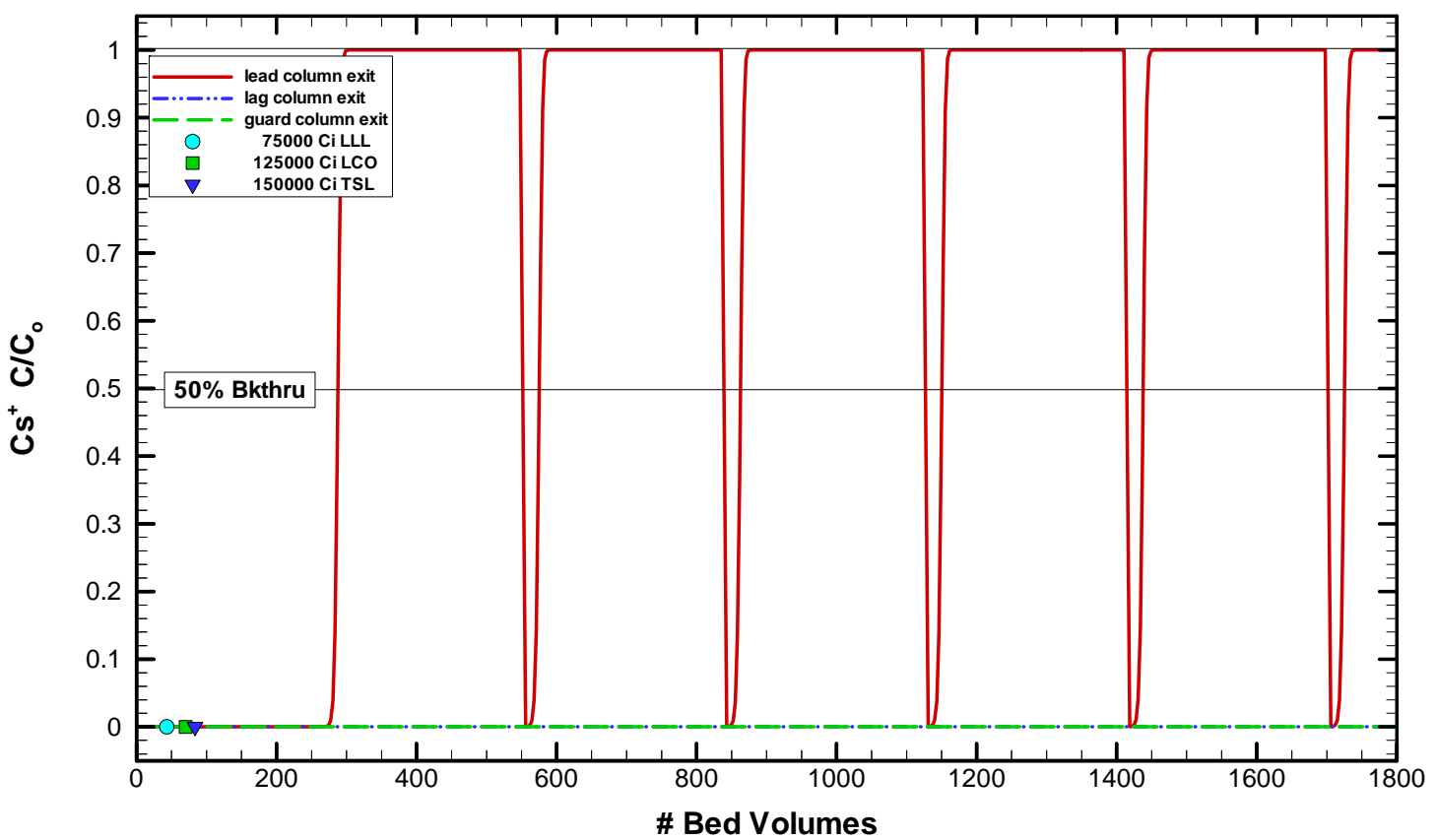

Figure 1-6. VERSE-LC SuperLig ${ }^{\circledR} 644$ resin cesium removal predictions for a full-scale 3 column carousel under Envelope B Operations feed. The figure shows lead, lag, and guard breakthrough behavior. The calculations assume a 20\% degradation factor.

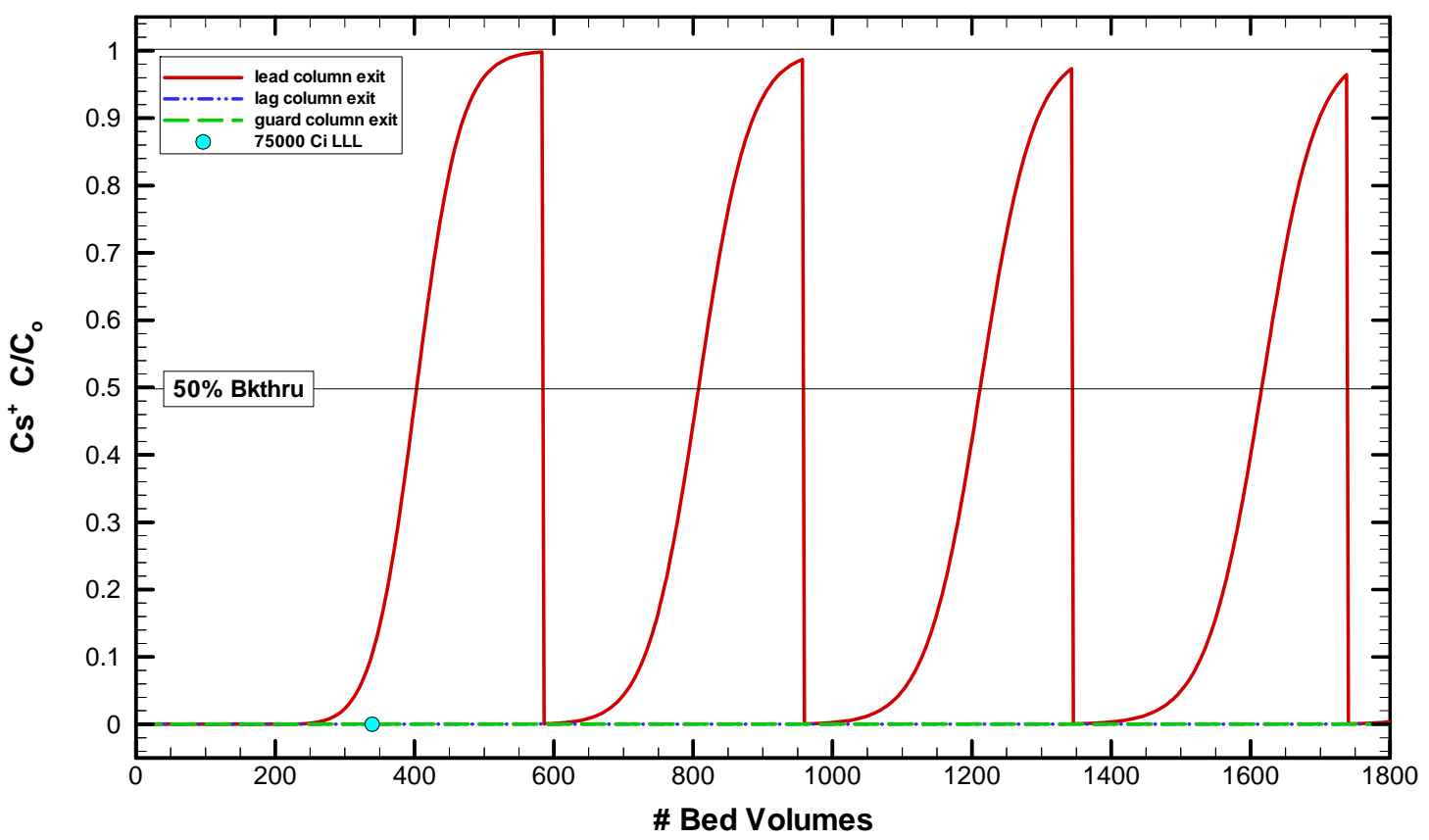

Figure 1-7. VERSE-LC SuperLig ${ }^{\circledR} 644$ resin cesium removal predictions for a full-scale 3 column carousel under Subsequent Operations feed. The figure shows lead, lag, and guard breakthrough behavior. The calculations assume $20 \%$ degradation. 
WSRC-TR-2004-00100, REVISION 0

SRT-RPP-2004-00019, REVISION 0

(This page intentionally left blank.) 


\subsection{Introduction and Background}

A proposed facility is being designed for the immobilization of Hanford high level radioactive waste. One unit process in the facility is designed to remove radioactive cesium by ionexchange from the strongly alkaline aqueous phase. Ion-exchange is to be used to separate cesium from ultrafiltered supernate, originating in underground storage tanks at the Hanford site. Upon elution in acidic conditions, the separated cesium will be sent to the High-Level Waste (HLW) glass melter for vitrification. A resin specifically designed with high selectivity of cesium under alkaline conditions is being investigated. The proposed design of the facility consists of four packed columns, with three columns used in series during loading (i.e., a lead column followed by a lag column then a guard column configuration). Each of the columns will be geometrically identical with only slight variations in bed sizes due to potential resin swelling/shrinkage effects. During operation, upon reaching a specified cesium concentration criterion at the exit of the guard column, the cesium-loaded lead column is processed (i.e., washed and eluted). The fourth standby column is switched to the guard position. The previous lag column is then placed in the lead position (without eluting), the previous guard column is then placed in the lag position, and the system is ready for use in the next cycle. The column train is to use a selective ion exchange resin to remove cesium (for which there is some isotopic fraction of ${ }^{137} \mathrm{Cs}$ ) from the solution. RF resins are under consideration as ion exchangers and will be investigated through the analyses performed in this study. For a well designed process, it is hoped that the loading step will exceed the process time required to elute and place one column back into operation. Note that the original carousel design for the cesium ion exchange system used only two columns in series (i.e., a lead lag configuration) and was then revised to include a single third column located after the lead and lag columns. The third column provides additional assurance that the target cesium concentration in the treated waste solution is not exceeded prior to meeting design objectives.

\subsection{Ion Exchange Modeling}

This ion-exchange system is one of many unit operations within a larger process flowsheet. Experimental efforts were performed to characterize the resin and the ion-exchange process in support of the overall design. Modeling the ion-exchange process in detail provides supporting key information needed in establishing the overall flowsheet. For example, cycle (time) average decontamination factors are required at the overall flowsheet level. Separate (off-line) detailed transient column modeling provides these average decontamination factors where the detail of the analysis is not restricted due to constraints imposed by the flowsheet runtime and storage requirements.

In addition, modeling:

- Reduces the overall number of experiments required;

- Provides guidance on experimental efforts and focuses attention on the critical parameters;

- Evaluates the adequacy and consistency of multiple data sets; 
- Consolidates available information on a particular ion exchange system; and

- Establishes then confirms full-scale facility design and operational requirements.

\subsection{Chosen Ion Exchange Material}

Resorcinol-Formaldehyde cation-exchange resin was developed for the selective removal of cesium (for which there is some isotopic fraction of ${ }^{137} \mathrm{Cs}$ ) from highly alkaline supernates. The resin is prepared by caustic condensation polymerization of resorcinol $\left(\mathrm{C}_{6} \mathrm{H}_{6} \mathrm{O}_{2}\right)$ and formaldehyde ( $\mathrm{HCHO})$. The high selectivity has been attributed to the two weakly acidic hydroxyl groups on resorcinol, which ionize and become functional at high $\mathrm{pH}$. Due to its weak acid nature, the resin has strong preference for $\mathrm{H}^{+}$and can be eluted using acid to remove $\mathrm{Cs}^{+}$ and its competitors. Our current estimate for the relative affinities of RF resin for ion-exchange are $\mathrm{H}^{+}>>\mathrm{Cs}^{+}>>\mathrm{K}^{+}>\mathrm{Na}^{+}$. Resorcinol-formaldehyde has been manufactured in crushed or granular form, similar to SuperLig ${ }^{\circledR} 644$, and in the spherical form.

One granular and two spherical samples of RF were received for testing at SRNL from PNNL in 2003 (King et al., 2003). The majority of the spherical RF resin received had been used in compressibility testing at PNNL. The used, spherical RF resin was used to perform batch contact, particle kinetics, drainable column void and particle (skeletal) density testing. The small sample of unused spherical RF was used to perform batch contact testing.

Hydraulic and chemical testing of ground gel RF resins and spherical RF resins were performed at PNNL.

\subsection{Report Overview}

This report focuses on the cesium-loading phase of a complete cycle. An analysis methodology is developed where as much of the available and pertinent data on the spherical form of Resorcinol-Formaldehyde is incorporated. The methodology can easily be updated as new information becomes available (e.g., measured bed and particle porosities).

This document represents a final report on our current knowledge and capability to model the ion-exchange process for the cesium-spherical RF system under Hanford feed conditions. The methodology, its justification, assessment, and application to the proposed facility are discussed in the following sections. Supporting information has also been provided in several appendices.

Section 3 briefly discusses the transport model chosen for modeling column behavior. The governing equations and an appropriate simplification are presented. For the modeling efforts presented in this report the VERSE-LC code was chosen (Berninger et al., 1991) based on its availability and widespread (and accepted) use in this field and our earlier use of it during preliminary analysis efforts. Local equilibrium between the pore fluid and its neighboring surface sites is assumed where an equilibrium adsorption isotherm must be specified. The algebraic isotherm model used and the database employed in its creation are discussed in Section 4. A detailed thermodynamically based equilibrium model was developed and is documented in Appendix A of Hamm et al. (2003b). Key column properties are addressed in Section 5 where 
the constraint between the porosities is highlighted. Particle size distributions of granular and spherical RF resins in sodium form are addressed in Section 6. The relationship between bulk and pore diffusion are discussed in Section 7 where an assessment to batch kinetics data is provided in Section 9. In Section 8 the constitutive models for axial dispersion and film diffusion are presented. Headspace and short column impacts are also discussed where a correction factor is developed from limited literature data. Section 9 contains our laboratoryscale column assessments. Appendix A contains the VERSE-LC code input and output files for each laboratory-scale simulation. Based on the current design specifications for the full-scale facility, Section 10 presents full-scale column predictions for three proposed inlet feed stream compositions, along with a series of sensitivity analyses. The VERSE-LC code input and output files for the full-scale facility simulations are contained in Appendix B. 
WSRC-TR-2004-00100, REVISION 0

SRT-RPP-2004-00019, REVISION 0

(This Page Intentionally Left Blank)

$-16-$ 


\subsection{Column Model Formulations}

The modeling of ion exchange columns is typically broken up into two basic categories:

- An equilibrium model generally highly empirical in nature, and

- A column model based on one-dimensional solute transport.

In this section the equations for the multi-component and the simpler single-component ion exchange column models are addressed. Section 4 of this report addresses the equilibrium models considered. For details on VERSE-LC ${ }^{\circledR}$ and its application to modeling the Cesium-RF ion exchange system see Hamm et al. (2000a, VERSE-LC ${ }^{\circledR}$ verification report), Hamm et al. (2000b, preliminary Cs removal performance using SuperLig ${ }^{\circledR} 644$ report), Hamm et al. (2000c, preliminary Tc removal performance using SuperLig ${ }^{\circledR} 639$ report), and Hamm et al. (2002b, Cs removal performance using CST report).

To take into account the various mechanisms for ion transport and adsorption as it travels down an ion exchange column, a porous particle solute transport formulation has experienced widespread use and acceptability. For this class of column models five basic aspects of the ion exchange column are addressed as highlighted in Figure 3-1. In order of their importance with respect to predicting exit breakthrough curves for the Cesium-RF system, they are:

- Bed Definition (high impact) - column size, geometry and resin mass have a very direct impact on overall column performance, with particle geometry having a slightly less important impact (Shifts entire breakthrough curve with respect to number of column volumes required to reach a specified concentration level); The Bed Volume (Column Volume) is normally defined as the volume occupied by the resin bed during the regeneration cycle (normally $0.25 \mathrm{M} \mathrm{NaOH}$ solution), although the resin shrinks slightly in a $5 \mathrm{M}\left[\mathrm{Na}^{+}\right]$ salt solution. However, in this report bed volume (or column volume) refers to the conditions associated with the feed conditions during the loading cycle (generally $\sim 5 \mathrm{M}$ $\left.\left[\mathrm{Na}^{+}\right]\right)$.

- Adsorption Isotherms (high impact) - resin affinities for the various competing ions of interest have a very direct impact on overall column performance (Shifts entire breakthrough curve with respect to number of column volumes required to reach a specified concentration level and for non-linear isotherms alters breakthrough curve shape as well as its sensitivity with respect to inlet feed conditions);

- Pore Diffusion (moderate impact) - intra-particle mass transport by pore diffusion to available surface sites has a moderate impact on overall column performance, with particle geometry having a slightly less important impact (Alters the shape of exit breakthrough curves typically by a rotation about the $\sim 50 \%$ relative concentration level with slight shifting);

- Film Diffusion (low impact) - liquid mass transport by film diffusion across the particle-tobed boundary has a low impact on overall column performance (Alters the shape of exit 
breakthrough curves typically by a rotation about the $\sim 50 \%$ relative concentration level with slight shifting);

- Axial Dispersion (low impact) - mass transport along the column by axial dispersion has a low impact on overall column performance (Alters the shape of exit breakthrough curves typically by a rotation about the $\sim 50 \%$ relative concentration level with slight shifting);

The above stated levels of impact are based on sensitivity studies and are relative values. Mechanisms such as surface migration or adsorption kinetics are not included in our column model since their impacts were considered to be negligible or already indirectly incorporated into the other features during our parameter estimation process. A simple graphical representation of the various transport mechanisms listed above and considered to be important for the Cesium-RF system is shown in Figure 3-2.

\subsection{The Multi-Component Model}

For the Cesium-RF resin system a porous particle multi-component ion exchange column model was considered. In this model we assume that the kinetics associated with local ion exchange at an active resin site are very fast (faster than the various liquid mass transfer mechanisms that transport ions to that site). Assuming radial effects to be negligible within the active region of the packed bed (i.e., a large column-to-particle diameter ratio), a one-dimensional species (ion) transport equation for the mobile phase (within the bed) becomes

$\varepsilon_{\mathrm{b}} \frac{\partial \mathrm{c}_{\mathrm{bi}}}{\partial \mathrm{t}}+\varepsilon_{\mathrm{b}} \mathrm{u} \frac{\partial \mathrm{c}_{\mathrm{bi}}}{\partial \mathrm{z}}=\varepsilon_{\mathrm{b}} \mathrm{E}_{\mathrm{bi}} \frac{\partial^{2} \mathrm{c}_{\mathrm{bi}}}{\partial \mathrm{z}^{2}}-\left(\frac{3}{<\mathrm{R}_{\mathrm{p}}>}\right)\left(1-\varepsilon_{\mathrm{b}}\right) \mathrm{k}_{\mathrm{f}}\left(\mathrm{c}_{\mathrm{bi}}-\left.\mathrm{c}_{\mathrm{pi}}\right|_{\mathrm{r}=\mathrm{R}_{\mathrm{p}}}\right)$,

storage advection

axial dispersion liquid film diffusion

(mass transfer)

with boundary and initial conditions

$$
\begin{array}{ll}
\mathrm{z}=0, & E_{b} \frac{\partial c_{b i}}{\partial \mathrm{z}}=u\left[c_{b i}-c_{b i}^{\text {feed }}(t)\right], \\
\mathrm{z}=1, & \varepsilon_{\mathrm{b}} \mathrm{E}_{\mathrm{b}} \frac{\partial \mathrm{c}_{\mathrm{bi}}}{\partial \mathrm{z}}=0, \\
\mathrm{t}=0, & \mathrm{c}_{\mathrm{bi}}=\mathrm{c}_{\mathrm{bi}}(0, \mathrm{z}) .
\end{array}
$$

where

$\begin{array}{ll}\varepsilon_{\mathrm{b}} & \text { Bed porosity } \\ \varepsilon_{\mathrm{p}} & \text { Particle porosity } \\ \mathrm{u} & \text { Linear interstitial velocity, } \mathrm{cm} / \mathrm{min} \\ \mathrm{c}_{\mathrm{bi}} & \text { Species i conc. in bed fluid, } \mathrm{M} \\ \mathrm{z} & \text { Axial coordinate, } \mathrm{cm}\end{array}$




$\begin{array}{ll}\mathrm{E}_{\mathrm{bi}} & \text { Species i axial dispersivity, } \mathrm{cm}^{2} / \mathrm{min} \\ <\mathrm{R}_{\mathrm{p}}> & \text { Average particle radius, } \mu \mathrm{m} \\ \mathrm{k}_{\mathrm{f}} & \text { Liquid film mass transfer coefficient, } \mathrm{cm} / \mathrm{min} \\ \mathrm{c}_{\mathrm{pi}} & \text { Species i conc. in pore fluid, } \mathrm{M} \\ \mathrm{r} & \text { Radial coordinate within avg. size particle, } \mathrm{cm} \\ \mathrm{t} & \text { Time }\end{array}$

Assuming uniformly sized spherical particles with a homogeneous distribution of pores, a onedimensional species transport equation for the pore phase (within an average sized particle of resin) becomes

$$
\varepsilon_{\mathrm{p}} \frac{\partial \mathrm{c}_{\mathrm{pi}}}{\partial \mathrm{t}}+\left(1-\varepsilon_{\mathrm{p}}\right) \overline{\mathrm{C}}_{\mathrm{T}} \sum_{\mathrm{j}=1}^{\mathrm{N}_{\mathrm{s}}}\left[\left(\frac{\partial \mathrm{q}_{\mathrm{i}}}{\partial \mathrm{c}_{\mathrm{pj}}}\right) \frac{\partial \mathrm{c}_{\mathrm{pj}}}{\partial \mathrm{t}}\right]=\varepsilon_{\mathrm{p}} \mathrm{D}_{\mathrm{pi}} \frac{1}{\mathrm{r}^{2}} \frac{\partial}{\partial \mathrm{r}}\left[\mathrm{r}^{2} \frac{\partial \mathrm{c}_{\mathrm{pi}}}{\partial \mathrm{r}}\right],
$$

storage surface adsorption

\section{Fickian pore diffusion}

with boundary and initial conditions

$$
\begin{array}{ll}
\mathrm{r}=0, & \frac{\partial c_{p i}}{\partial r}=0, \\
\mathrm{r}=<\mathrm{R}_{\mathrm{p}}>, & \varepsilon_{p} D_{p} \frac{\partial c_{p i}}{\partial r}=k_{f}\left(c_{b i}-c_{p i}\right), \\
\mathrm{t}=0, & \mathrm{c}_{\mathrm{pi}}=\mathrm{c}_{\mathrm{pi}}(0, \mathrm{r}) .
\end{array}
$$

where

$\begin{array}{ll}\overline{\mathrm{C}}_{\mathrm{T}} & \text { Total ion-exchange capacity of resin, } \mathrm{mmole} / \mathrm{g}_{\text {resin }} . \\ \mathrm{q}_{\mathrm{i}} & \text { Species i fractional surface site loading. } \\ \mathrm{D}_{\mathrm{pi}} & \text { Species i pore diffusion coefficient, } \mathrm{cm}^{2} / \mathrm{min} .\end{array}$

In Eq. (3-2) it is assumed that the pore diameters are large relative to the size of migrating ions of interest. Therefore, Fickian diffusion is acceptable and surface migration is considered to be small when compared to pore diffusion. Details of the above equations are given in Ma et al. (1996). 
Assuming local equilibrium between the pore fluid and its neighboring surface sites, an equilibrium isotherm model for the ion exchange between the pore and solid phases can be generically expressed as:

$$
\begin{aligned}
\mathrm{q}_{\mathrm{i}}= & \mathrm{F}_{\mathrm{i}}\left(\overline{\mathrm{C}}_{\mathrm{T}}, \mathrm{c}_{\mathrm{p} 1}, \mathrm{c}_{\mathrm{p} 2}, \cdots, \mathrm{c}_{\mathrm{pN}_{\mathrm{s}}}\right), \quad \mathrm{i}=1, \mathrm{~N}_{\mathrm{s}}, \\
& \text { multi-component isotherm }
\end{aligned}
$$

where it has been assumed that surface loadings for the $\mathrm{i}^{\text {th }}$ species can be explicitly related to the liquid concentrations locally. The number of species required to model the behavior of the $i^{\text {th }}$ species depends upon its dependence on other species through the functional form (i.e., $F_{i}$ ) of the isotherm model [Eq. (3-3)]. Specific application of Eq. (3-3) to the cesium-RF resin system is discussed in Section 4. Initial and boundary conditions for Eqs. (3-1) and (3-2) must also be specified. For further details on these equations and their solution in VERSE-LC see Berninger et al. (1991) and Ma et al. (1996). Helfferich and Carr (1993) provide an excellent review paper describing the behavior of non-linear waves in chromatography and also a brief listing of available algorithms (see their Table I.4). Their paper provides very clear insight into how the above equation set behaves for non-linear isotherms consistent with the system of interest discussed in this report.

For the modeling efforts presented in this report the VERSE-LC code was chosen (Berninger et al., 1991) based on its availability and widespread (and accepted) use in this field. Prior to applying VERSE-LC to the ion exchange modeling presented in this report a verification process was completed and the results of that effort are reported in Hamm et al. (2000a). The verification process provided us quality assurance that the installed PC Window $95^{\mathrm{TM}}$ version of VERSE-LC (i.e., version 7.80) was capable of adequately solving the above mentioned equations and also helped us to better understand how to accurately use the VERSE-LC code (e.g., mesh refinement requirements and input/output options). For all column results presented in this report numerical errors associated with the results of VERSE-LC should be very small when compared to the uncertainties associated with various model input parameters (bed density, particle radius, pore diffusion, etc.).

\subsection{The Single-Component Model}

Under certain situations the porous particle multi-component transport equations discussed in Section 3.1 can be adequately decoupled to a series of single-component transport equations. The reduction to single-component equations is:

- valid when the total ionic strength, $\mathrm{C}_{\mathrm{T}}$, is the same between the column's native and feed solutions; or

- a reasonable approximation when one ion absorbs significantly more onto the resin than others.

Making the same basic assumptions as in Section 3.1 the single-component equations can be derived. For each species a one-dimensional species (ion) transport equation for the mobile phase (within the bed) becomes 


$$
\underset{\text { storage }}{\varepsilon_{\mathrm{b}} \frac{\partial \mathrm{c}_{\mathrm{b}}}{\partial \mathrm{t}}+\varepsilon_{\mathrm{b}} \mathrm{u} \frac{\partial \mathrm{c}_{\mathrm{b}}}{\partial \mathrm{z}}}=\underset{\substack{\text { advection } \\ \text { axial }}}{\varepsilon_{\mathrm{b}} \mathrm{E}_{\mathrm{b}} \frac{\partial^{2} \mathrm{c}_{\mathrm{b}}}{\partial \mathrm{z}^{2}}}-\left(\frac{3}{\left\langle\mathrm{R}_{\mathrm{p}}>\right.}\right) \underset{\text { dispersion }}{\text { axiol }}\left(1-\varepsilon_{\mathrm{b}}\right) \mathrm{k}_{\mathrm{f}}\left(\mathrm{c}_{\mathrm{b}}-\left.\mathrm{c}_{\mathrm{p}}\right|_{\mathrm{r}=\mathrm{R}_{\mathrm{p}}}\right),
$$

where initial and boundary conditions are consistent with Eqs. (3-1b,c,d). A one-dimensional species transport equation for the pore phase (within a particle of resin) becomes

$$
\begin{aligned}
& \varepsilon_{\mathrm{p}} \frac{\partial \mathrm{c}_{\mathrm{p}}}{\partial \mathrm{t}}+\left(1-\varepsilon_{\mathrm{p}}\right) \overline{\mathrm{C}}_{\mathrm{T}}\left(\frac{\partial \mathrm{q}}{\partial \mathrm{c}_{\mathrm{p}}}\right) \frac{\partial \mathrm{c}_{\mathrm{p}}}{\partial \mathrm{t}}=\varepsilon_{\mathrm{p}} \mathrm{D}_{\mathrm{p}} \frac{1}{\mathrm{r}^{2}} \frac{\partial}{\partial \mathrm{r}}\left[\mathrm{r}^{2} \frac{\partial \mathrm{c}_{\mathrm{p}}}{\partial \mathrm{r}}\right], \\
& \text { storage surface } \\
& \text { adsorption diffusion }
\end{aligned}
$$

where initial and boundary conditions are consistent with Eqs. (3-2b,c,d).

The equilibrium isotherm model for species i for the ion exchange between the pore fluid and solid phases becomes:

$$
q=\frac{c_{p}}{\beta+c_{p}},
$$

\section{single-component isotherm}

where Eq. (3-6) is of the Langmuir form and $\beta$ is a function of the feed conditions.

\subsection{The Cesium-RF System}

Based on our current understanding, for the Cesium-RF resin system the competition for cation exchange loading at the resin sites is primarily between cesium, potassium, and sodium. Prior to the loading phase the initial sodium and potassium levels in the resin pretreatment solution are approximately $0.25 \mathrm{M}$ and $0 \mathrm{M}$, respectively. During the loading phase these concentration levels increase to approximately $5.0 \mathrm{M}$ sodium and 0.0 -to- $1.0 \mathrm{M}$ potassium. Therefore, a total ionic concentration wave will pass through the column. Based on available batch equilibrium studies estimates for the relative affinities for adsorption have been computed as discussed in Section 4 (i.e., the resin affinities are $\mathrm{Cs}^{+}>>\mathrm{K}^{+}>\mathrm{Na}^{+}$).

Given the above information, early column performance (say the first 5 to 10 column volumes or so) probably will require the use of the multi-component formulations of Section 3.1. Long-term performance should be adequately handled using the simpler single-component formulations of Section 3.2. To check the validity of these statements, cesium exit breakthrough curves from several column simulations were compared where both the multi-component and singlecomponent formulations were used. Very similar results were obtained. To illustrate the differences in timing for the three ionic species, the exit breakthrough curves for each species is plotted in Figure 3-3 for a multi-component simulation of one of the experimental column tests (WK Exp. 2, King et al., 2000). As expected sodium breakthrough is the fastest, quickly followed by potassium, and then an order of magnitude later by cesium. When the single- 
component formulations are used (e.g., compare the cesium breakthrough curve in Figure 3-3 to the single-component result provided in Figure 9-4), the cesium breakthrough curve is only slightly altered. For example, 50\% cesium breakthrough is estimated to be $\sim 142$ column volumes based on the multi-component simulation, while the estimate is $\sim 135$ column volumes for the single-component simulation (i.e., a 5\% difference and well within overall uncertainties).

Since significant CPU savings are achieved when the single-component model is used and the differences are well within our current predictive capabilities, the majority of column analyses presented in this report were performed using the single-component model.

\section{Axial Dispersion}

residence time tests

(end-effects \& short column impacts)

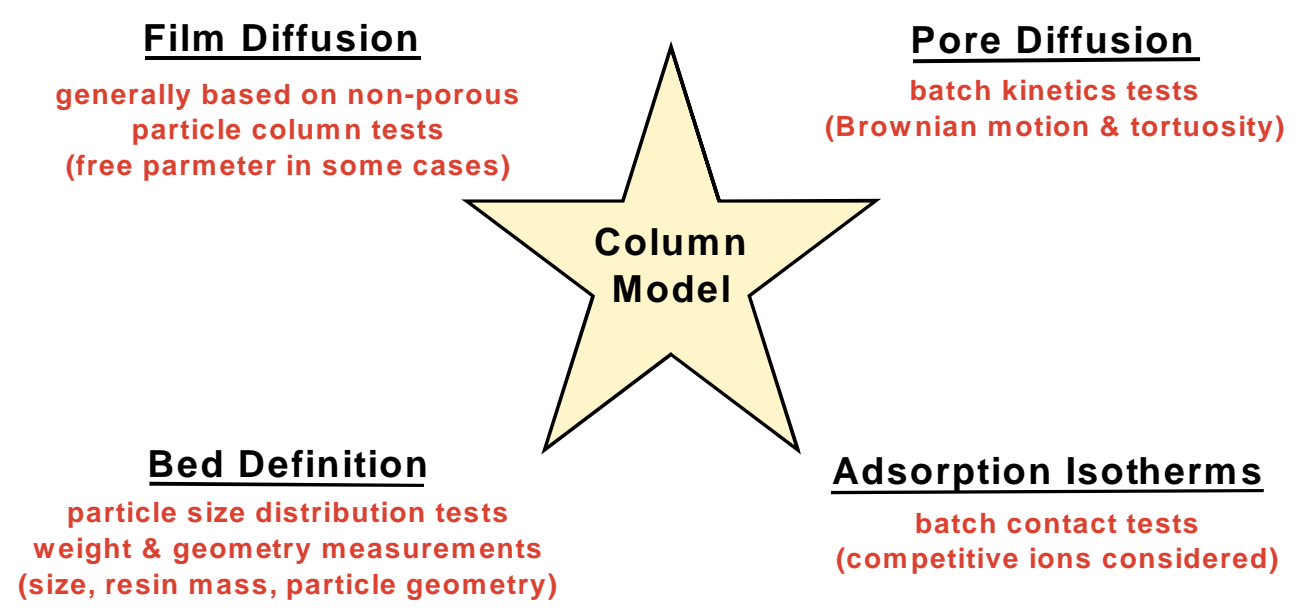

Figure 3-1. The basic building blocks of a porous particle ion exchange column model. 


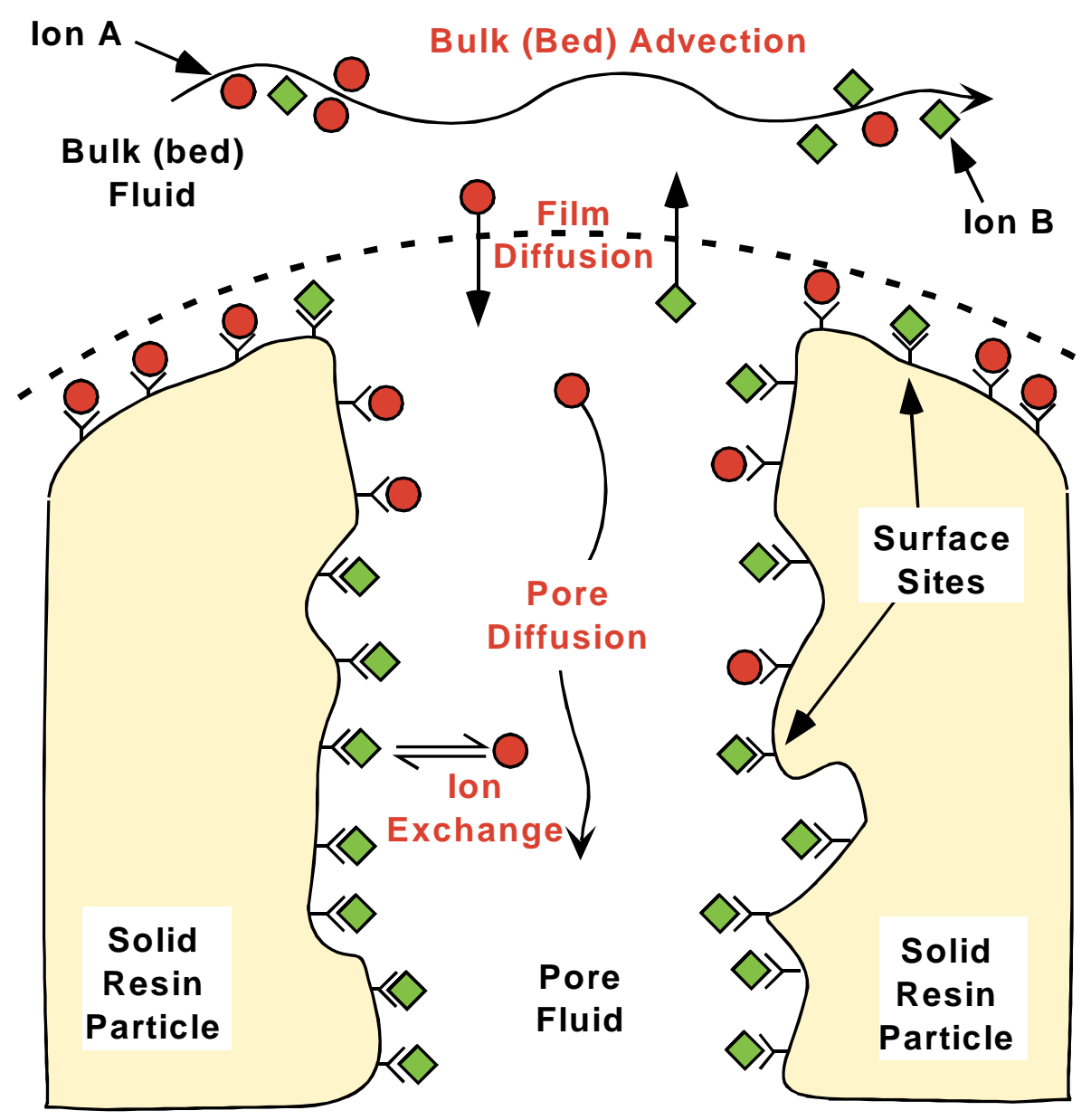

Figure 3-2. Graphical representation of the various mass transport mechanisms considered important for Cesium-SuperLig ${ }^{\circledR} 644$ system ion exchange column modeling. 


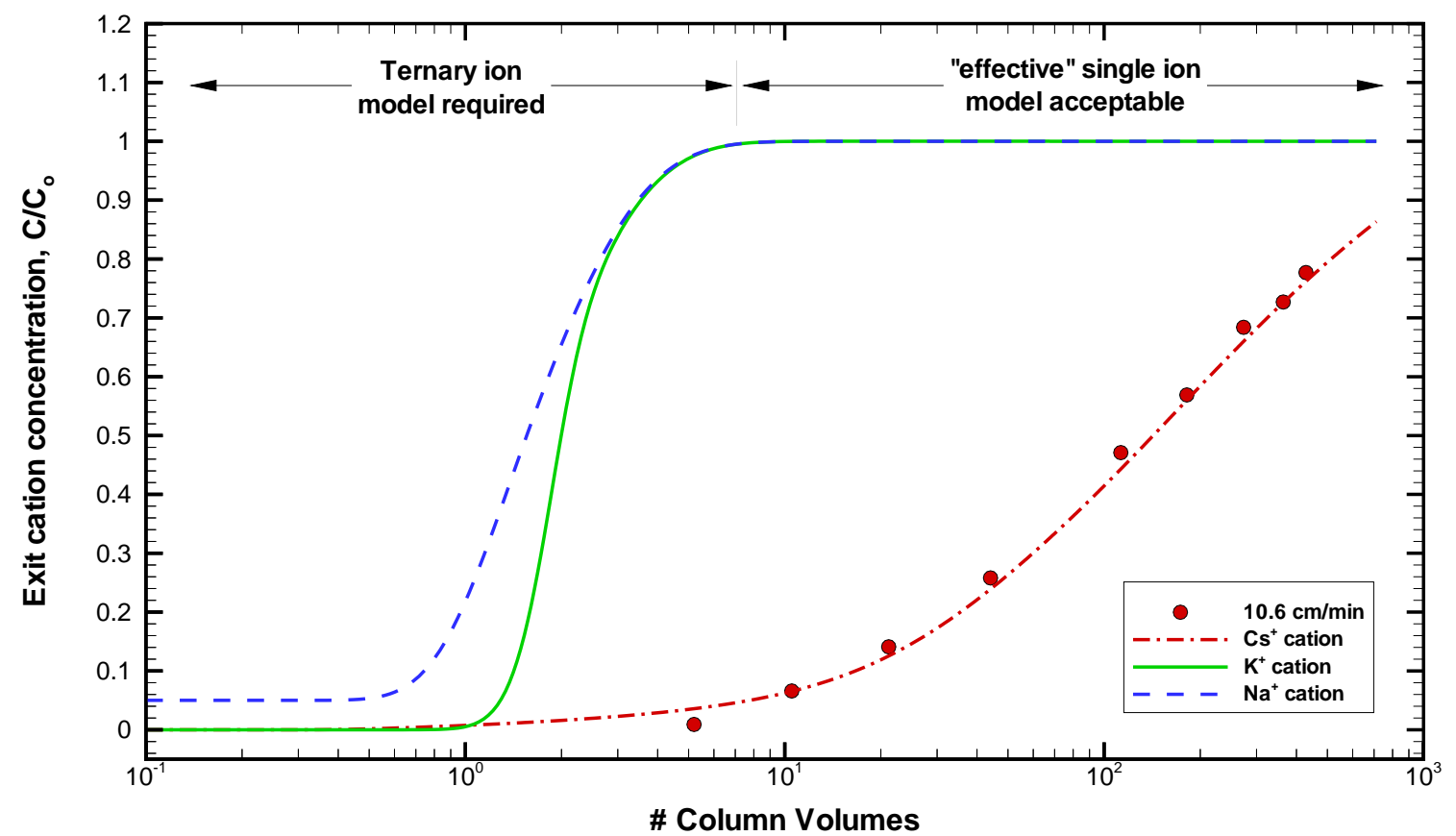

Figure 3-3. Estimated cesium, potassium, and sodium exit breakthrough curves for one column experiment based on the porous particle multi-component ion exchange column model (data from King et al., 2000). 


\subsection{Equilibrium Cesium Isotherms}

In our column modeling efforts we assume that the rate of ion exchange (i.e., exchange of ions at a surface site) is very fast when compared to the rates of diffusion within the pore fluid and mass transfer across the liquid film at the outer boundaries of the particles. In other words, we assume that local equilibrium exists between the pore fluid and its neighboring surface sites. With this assumption an algebraic expression relating ionic (or species) concentrations between the pore fluid and the solid Resorcinol-Formaldehyde resin (i.e., surface sites) can be established. No explicit attempt is made in this report to verify this assumption. In an indirect manner this assumption is either verified or incorporated into some of the model parameters. In addition, we assume that the cesium total ionic capacity (i.e., active sites for cesium per gram of ResorcinolFormaldehyde resin) is independent of total ionic strength or solution composition for each particular feed stream (i.e., unique values are estimated for each unique feed stream). The total cation exchange capacity of the Resorcinol-Formaldehyde resin is hydroxide dependent.

In column sizing one of two possible design strategies are typically considered: (1) bounding analysis where "worst case" feed compositions are used or (2) global optimization where best estimate feed compositions for each individual batch are used. Each approach has its own advantages and disadvantages. For example, the bounding approach requires less analysis overall but it may be difficult to establish a reasonable bound that is not too excessive. Since the amount of waste to be processed, flowrate, and key feed compositions depend significantly on which envelope is being considered, the global optimization strategy is generally preferred. However, to use a global optimization strategy, "best estimate" cesium isotherms for each of the 16 batch feeds must be available. At the time of performing this work, no such set of 16 Phase 1 LAW feed streams was available. Instead, only three operating feed streams were provided (i.e., referred to as Hot Commissioning Operation, Envelope B Operation, and Subsequent Operation). Details describing these three feed streams are provided by Toth (2003). Isotherms for each of three feed streams were generated for both fresh resin and chemically degraded resin (i.e., approximated assuming 10 cycles of exposure). For our nominal feed stream (i.e., Hot Commissioning Operation) isotherms were also generated to assist in column performance sensitivity analyses.

In deriving these isotherms for use with each batch feed, a detailed thermodynamic model was used to generate isotherm data. The simulated isotherm data was then fit to the appropriate algebraic isotherm model consistent with VERSE-LC input needs. Based on these considerations a binary homovalent isotherm model was developed and is presented in this section. Overall the algebraic isotherm model meets all of our objectives for this effort. See Appendix A of Hamm et al., (2004) for further discussion of the detailed thermodynamic isotherm model that was used in support of the creation of the algebraic isotherms used. These isotherms are for the loading phase applications only. The isotherm model development discussed below follows very closely to the development efforts presented by Hamm et al. (2000) for the Cesium-SuperLig ${ }^{\circledR} 644$ ion-exchange system. 
In the next subsection the "effective" cesium isotherm model is discussed based on an ionexchange process and in the following subsection its specific application to the ResorcinolFormaldehyde ion-exchange system is discussed.

\subsection{The Isotherm Model}

As demonstrated by Hamm et al. (2000a, Figure 3-3), for ion exchange competitors with affinities significantly less than the value for cesium, a single-component transport modeling approach is adequate for the cesium loading phase. To perform single-component transport simulations, an "effective" binary isotherm model in an algebraic form must be available for use in the VERSE-LC code. Based on our previous experience using VERSE-LC for modeling SuperLig $^{\circledR} 644$ and SuperLig ${ }^{\circledR} 639$ resins (Hamm et al., 2000a and 2000b), the VERSE-LC Freundlich/Langmuir Hybrid isotherm model was chosen. As described by Hamm et al. (2000a, see Chapter 4), the cations cesium, potassium, sodium, and hydrogen form a 4-component homovalent system where the surface loading for cesium on the RF material can be expressed as:

$$
\mathrm{Q}_{\mathrm{Cs}}=\frac{\eta_{\mathrm{df}} \overline{\mathrm{C}}_{\mathrm{T}} \mathrm{c}_{\mathrm{Cs}}}{\mathrm{c}_{\mathrm{Cs}}+\left[\widetilde{\mathrm{K}}_{21} \mathrm{c}_{\mathrm{K}}+\widetilde{\mathrm{K}}_{31} \mathrm{c}_{\mathrm{Na}}+\widetilde{\mathrm{K}}_{41} \mathrm{c}_{\mathrm{H}}+\cdots\right]} \Rightarrow \frac{\eta_{\mathrm{df}} \overline{\mathrm{C}}_{\mathrm{T}} \mathrm{c}_{\mathrm{Cs}}}{\mathrm{c}_{\mathrm{Cs}}+\beta},
$$

where

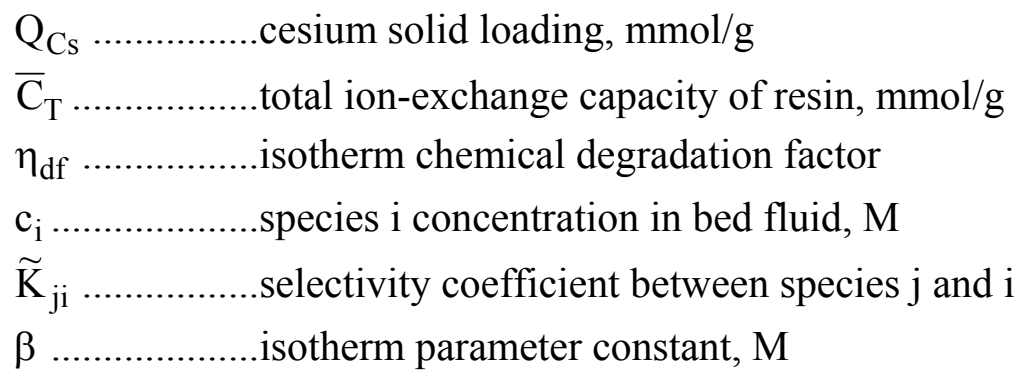

The beta parameter for cesium becomes dependent upon the other ionic competitors for Resorcinol-Formaldehyde adsorption (i.e., $\mathrm{K}^{+}, \mathrm{Na}^{+}$, and $\mathrm{H}^{+}$). The beta parameter contains the selectivity coefficients making it dependent upon temperature and liquid composition of all of the ionic species in solution. The larger the beta parameter the less favorable (and lower loadings) an isotherm will exhibit at lower cesium concentrations. The degradation factor $\left(\eta_{\mathrm{df}}\right)$ is unity when considering a fresh resin and becomes less than unity during chemical exposure (i.e., cycling). Given a degradation factor, Eq. (4-1) contains two free parameters (i.e., a total cesium capacity and a beta value) that need to be specified. For each particular feed stream, these two parameters are estimated by fitting Eq. (4-1) to data simulated using the detailed thermodynamic model as described in Appendix A of Hamm et al. (2004).

\subsection{Batch Feed Compositions}

In order to generate the cesium loading isotherm databases using the detailed thermodynamic isotherm model, the feed compositions for the three candidate batch feeds had to be slightly altered to enforce a charge balance. The original feed compositions for each feed stream were supplied by Toth (2003). For each feed stream overall charge balancing was achieved by 
adjusting the anion concentrations for nitrite and nitrate (i.e., also maintaining the nitrite to nitrate ratio constant). The nominal feed compositions for each feed stream are provided in Table 4-1 after achieving a charge balance.

Additional feed streams under off-nominal settings were also generated for sensitivity studies to determine competitor impacts on column performance. On an individual basis each competitor (i.e., potassium, sodium, and hydrogen [through varying hydroxide]) was varied by plus and minus $20 \%$ about their nominal value. Only sensitivity studies associated with the Hot Commissioning Operation feed stream were considered. The feed compositions for these three competitors are provided in Tables 4-2 to 4-4 for potassium, sodium, and hydrogen, respectively. The off-nominal feed compositions were achieved by varying each competitor along with the anions nitrite and nitrate to maintain charge balance (i.e., keeping the nitrite to nitrate ratio constant).

To address the impact of initial feed cesium concentration on column performance, the cesium feed concentration was also varied by plus and minus $20 \%$ about its nominal value for the Hot Commissioning Operation feed stream. These feed compositions are provided in Table 4-5. The off-nominal feed compositions were achieved by varying cesium along with the anions nitrite and nitrate to maintain charge balance (i.e., keeping the nitrite to nitrate ratio constant).

\subsection{Simulant Compositions}

AN-105 simulant was used by SRNL personnel (King et al., 2004) to conduct batch contact and particle kinetics and testing. AZ-102 simulant was prepared by PNNL personnel to perform batch contact and column testing. Table 4-6 provides the compositions for a Base AN-105 and AZ-102 simulant at $5 \mathrm{M}$ sodium. Trace ions that are not supported by the detailed thermodynamic isotherm model are excluded.

\subsection{The Total Capacity and Beta Parameter Values}

For each of the various feed compositions discussed above and presented in Tables 4-1 through 4-4, an isotherm database was generated using the detailed thermodynamic isotherm model. The detailed isotherm model was established and benchmarked using available batch contact experimental data. King et al. (2004) discusses and provides the results from the batch contact experiments performed. For each unique feed (i.e., a total of nine), a nonlinear regression analyses was used to determine the total cesium exchange capacity and beta value, as defined in Eq. (4-1). The parameter estimation results of these regression analyses are provided in Table 47

As shown in Table 4-7, the cesium exchange capacity varies based on each feeds hydroxide concentration. The chemically degraded isotherms for the three nominal feed streams are shown in Figure 4-1. The chemical degradation factor, as defined in Eq. (4-1), was set to 0.8 to approximate 10 cycles of column bed operation. The Hot Commissioning Operation isotherm is the least favorable isotherm for cesium ion-exchange. The isotherm impact of competitor variations on the nominal Hot Commissioning Operation feed stream $\mathrm{Cs}^{+}$isotherm is shown in Figures 4-2 through 4-4 for potassium, sodium, and hydroxide, respectively. A comparison 
between SuperLig ${ }^{\circledR} 644$ and Resorcinol-Formaldehyde $\mathrm{Cs}^{+}$isotherms is shown in Figures 4-5 through 4-7 for Hot Commissioning, Envelope B and Subsequent Operation, respectively. Overall, SuperLig ${ }^{\circledR} 644$ shows a higher affinity for cesium ion-exchange and higher cesium loading capacity than Resorcinol-Formaldehyde. Figure 4-8 shows the AN-105 and AZ-102 simulant cesium isotherms.

\subsection{Isotherm Model for VERSE-LC Application}

In order to perform column transport simulations, the algebraic model given by Eq. (4-1) above must be converted into one of the available VERSE-LC isotherm modeling options. Based on our previous experience using VERSE-LC for modeling SuperLig ${ }^{\circledR} 644$ and SuperLig ${ }^{\circledR} 639$ resins (Hamm et al., 2000a and 2000b, respectively), the VERSE-LC Freundlich/Langmuir Hybrid isotherm model was chosen. See Hamm et al. (2000a, see Chapter 4) for further descriptions of the multi-component homovalent isotherm approach.

For a 4-component homovalent isotherm, the VERSE-LC Freundlich/Langmuir Hybrid model is expressed as:

$$
\overline{\mathrm{C}}_{\mathrm{pi}}=\frac{\mathrm{a}_{\mathrm{i}} \mathrm{c}_{\mathrm{pi}}^{\mathrm{M}_{\mathrm{ai}}}}{\beta_{\mathrm{i}}+\mathrm{b}_{1} \mathrm{c}_{\mathrm{p} 1}^{\mathrm{M}_{\mathrm{b} 1}}+\mathrm{b}_{2} \mathrm{c}_{\mathrm{p} 2}^{\mathrm{M}_{\mathrm{b} 2}}+\mathrm{b}_{3} \mathrm{c}_{\mathrm{p} 3}^{\mathrm{M}_{\mathrm{b} 3}}+\mathrm{b}_{4} \mathrm{c}_{\mathrm{p} 4}^{\mathrm{M}_{\mathrm{b}}}} \quad \text { for } \mathrm{i}=1,4,
$$

where

$$
\overline{\mathrm{C}}_{\mathrm{pi}}
$$
species i solid surface concentration based on column volume, gmole/LCV or M $\mathrm{c}_{\mathrm{pi}}$ …...............species i concentration in pore fluid, $\mathrm{M}$ $\beta_{\mathrm{i}}, \mathrm{a}_{\mathrm{i}}, \mathrm{b}_{\mathrm{i}} \ldots \ldots \ldots . .$. ..Fruendlich/Langmuir Hybrid model coefficients for species $\mathrm{i}$ $\mathrm{M}_{\mathrm{ai}}, \mathrm{M}_{\mathrm{bi}} \ldots \ldots . .$. Freundlich/Langmuir Hybrid model exponents for species $\mathrm{i}$

The model parameters $\left(a_{i}, b_{i}, M_{a i}, M_{b i}\right.$, and $\beta_{i}$ for $\left.i=1,4\right)$ can be determined from the parameter values associated with the 4-component homovalent model.

The Freundlich/Langmuir Hybrid model can also be used for an "effective" single-component case as well. Here the potassium, sodium, and hydrogen (actually hydroxide) concentrations throughout the column are assumed to be at their feed concentration levels. For an "effective" single-component total cesium isotherm, Eq. (4-2) under these conditions reduces to:

$$
\overline{\mathrm{C}}_{\mathrm{p} 1}=\frac{\mathrm{a}_{1} \mathrm{c}_{\mathrm{pl}}^{\mathrm{M}_{\mathrm{ai}}}}{\left[\beta_{\mathrm{i}}+\mathrm{b}_{2} \mathrm{c}_{\mathrm{p} 2}^{\mathrm{M}_{\mathrm{b} 2}}+\mathrm{b}_{3} \mathrm{c}_{\mathrm{p} 3}^{\mathrm{M}_{\mathrm{b}}}+\mathrm{b}_{4} \mathrm{c}_{\mathrm{p} 4}^{\mathrm{M}_{\mathrm{b} 4}}\right]+\mathrm{b}_{1} \mathrm{c}_{\mathrm{p} 1}^{\mathrm{M}_{\mathrm{b} 1}}} \Rightarrow \frac{\mathrm{a}_{1} \mathrm{c}_{\mathrm{pl}}^{\mathrm{M}_{\mathrm{a}}}}{\hat{\beta}_{\mathrm{i}}+\mathrm{b}_{1} \mathrm{c}_{\mathrm{pl}}^{\mathrm{M}_{\mathrm{b} 1}}},
$$


where

$\hat{\beta}_{\mathrm{i}}$..................Langmuir "effective" single isotherm model constant

The beta parameter for cesium becomes dependent upon the potassium, sodium, and hydrogen feed concentrations. The relationship between the two models expressed by Eqs. (4-2) and (4-3) (i.e., 4-component homovalent and "effective" single-component isotherm models, respectively) can be shown by the following relationships:

or as

$$
\begin{gathered}
\mathrm{Q}_{\mathrm{Cs}^{+}}=\frac{\eta_{\mathrm{df}} \overline{\mathrm{C}}_{\mathrm{T}} \mathrm{c}_{\mathrm{pCs}^{+}}}{\mathrm{c}_{\mathrm{pCs}}{ }^{+}+\widetilde{\mathrm{K}}_{21} \mathrm{c}_{\mathrm{pK}^{+}}+\widetilde{\mathrm{K}}_{31} \mathrm{c}_{\mathrm{pNa}^{+}}+\widetilde{\mathrm{K}}_{41} \mathrm{c}_{\mathrm{pH}^{+}}}, \\
\mathrm{Q}_{\mathrm{Cs}^{+}}=\frac{\eta_{\mathrm{df}} \overline{\mathrm{C}}_{\mathrm{T}} \mathrm{c}_{\mathrm{pCs}}}{\mathrm{c}_{\mathrm{pCs}}+\beta},
\end{gathered}
$$

where

$$
\beta=\widetilde{\mathrm{K}}_{21} \mathrm{c}_{\mathrm{pK}^{+}}+\widetilde{\mathrm{K}}_{31} \mathrm{c}_{\mathrm{pNa}^{+}}+\widetilde{\mathrm{K}}_{41} \mathrm{c}_{\mathrm{pH}^{+}}
$$

It has been assumed that the binary selectivity coefficients are not composition dependent, but are true constants (i.e., note that the selectivity coefficients actually contain the true equilibrium constants and liquid/solid phase activity coefficients; see Appendix A for details). This assumption appears to be somewhat adequate when considering different feeds within the same envelope (i.e., generally only small variations are observed in selectivity coefficients within a given envelope), but should not be used between envelopes. The composite impact on cesium loading from the other cation competitors is summed up in the beta parameter as shown above in Eq. (4-4). The chemical degradation factor, $\eta_{\mathrm{df}}$, is set to unity for fresh resin behavior and less than unity to account for chemical degradation effects.

The modeling parameter values for a cesium single-component isotherm are listed in Table 4-7 for two simulants and nine ion-exchange feed streams. The VERSE-LC a parameter of Eq. (4-3) is computed by:

$$
a_{1}=\rho_{b} \eta_{d f} \bar{C}_{T}
$$

where

$\rho_{\mathrm{b}} \ldots \ldots \ldots \ldots \ldots \ldots . . . . . . .6 e d$ density of active column, $\mathrm{g} / \mathrm{ml}$ 
WSRC-TR-2004-00100, REVISION 0 SRT-RPP-2004-00019, REVISION 0

Table 4-1. Waste compositions used to represent ion exchange performance during selected operating time periods (nominal values and charge balanced).

\begin{tabular}{|c|c|c|c|c|}
\hline $\begin{array}{c}\text { Ion } \\
\text { Category }\end{array}$ & Species & $\begin{array}{c}\text { Hot Commissioning } \\
\text { Operation Projection } \\
\text { (M) }\end{array}$ & $\begin{array}{c}\text { Envelope B } \\
\text { Operation Projection } \\
\text { (M) }\end{array}$ & $\begin{array}{c}\text { Subsequent Operation } \\
\text { Projection } \\
\text { (M) }\end{array}$ \\
\hline \multirow[t]{5}{*}{ Cations* } & $\mathbf{N a}^{+}$ & 4.57 & 4.13 & 4.6 \\
\hline & $\mathbf{K}^{+}$ & 0.48 & 0.091 & 0.15 \\
\hline & Total $\mathrm{Cs}^{+}$ & $2.74 \mathrm{E}-05$ & $2.83 \mathrm{E}-04$ & $5.0 \mathrm{E}-05$ \\
\hline & ${ }^{137} \mathrm{Cs}^{+}(\mathrm{Ci} / \mathrm{L})$ & 0.072 & 1.18 & 0.14 \\
\hline & $\mathrm{g}^{137} \mathrm{Cs}^{+} / \mathrm{g}$ Total $\mathrm{Cs}^{+}$ & 0.22 & 0.35 & 0.24 \\
\hline \multirow[t]{5}{*}{ Anions } & $\mathrm{SO}_{4}{ }^{2-}$ & 0.032 & 0.129 & 0.03 \\
\hline & $\mathrm{OH}^{-}$(free) & 1.85 & 1.28 & 0.80 \\
\hline & $\mathrm{NO}_{2}^{-}$ & 0.523 & 0.921 & 0.750 \\
\hline & $\mathrm{NO}_{3}^{-}$ & 1.393 & 0.882 & 2.340 \\
\hline & $\mathrm{CO}_{3}{ }^{2-}$ & 0.61 & 0.44 & 0.40 \\
\hline
\end{tabular}

Table 4-2. Hot Commissioning Operation waste composition with variation about nominal value in potassium concentration.

\begin{tabular}{|c|c|c|c|c|}
\hline $\begin{array}{c}\text { Ion } \\
\text { Category }\end{array}$ & Species & $\begin{array}{l}\text { Hot Commissioning } \\
\text { Low K } \\
\text { (M) }\end{array}$ & $\begin{array}{l}\text { Hot Commissioning } \\
\text { Nominal } \\
\text { (M) }\end{array}$ & $\begin{array}{l}\text { Hot Commissioning } \\
\text { High K } \\
\text { (M) }\end{array}$ \\
\hline \multirow[t]{5}{*}{ Cations* } & $\mathbf{N a}^{+}$ & 4.57 & 4.57 & 4.57 \\
\hline & $\mathbf{K}^{+}$ & 0.384 & 0.48 & 0.576 \\
\hline & Total $\mathrm{Cs}^{+}$ & $2.74 \mathrm{E}-05$ & $2.74 \mathrm{E}-05$ & $2.74 \mathrm{E}-05$ \\
\hline & ${ }^{137} \mathrm{Cs}^{+}(\mathrm{Ci} / \mathrm{L})$ & 0.072 & 0.072 & 0.072 \\
\hline & $\mathrm{g}^{137} \mathrm{Cs}^{+} / \mathrm{g}$ Total $\mathrm{Cs}^{+}$ & 0.22 & 0.22 & 0.22 \\
\hline \multirow[t]{5}{*}{ Anions } & $\mathrm{SO}_{4}{ }^{2-}$ & 0.032 & 0.032 & 0.032 \\
\hline & $\mathrm{OH}^{-}$(free) & 1.85 & 1.85 & 1.85 \\
\hline & $\mathrm{NO}_{2}^{-}$ & 0.496 & 0.523 & 0.549 \\
\hline & $\mathrm{NO}_{3}^{-}$ & 1.324 & 1.393 & 1.463 \\
\hline & $\mathrm{CO}_{3}{ }^{2-}$ & 0.61 & 0.61 & 0.61 \\
\hline
\end{tabular}


WSRC-TR-2004-00100, REVISION 0 SRT-RPP-2004-00019, REVISION 0

Table 4-3. Hot Commissioning Operation waste composition with variation about nominal value in sodium concentration.

\begin{tabular}{|c|c|c|c|c|}
\hline $\begin{array}{c}\text { Ion } \\
\text { Category }\end{array}$ & Species & $\begin{array}{l}\text { Hot Commissioning } \\
\text { Low Na} \\
\text { (M) }\end{array}$ & $\begin{array}{c}\text { Hot Commissioning } \\
\text { Nominal } \\
\text { (M) }\end{array}$ & $\begin{array}{l}\text { Hot Commissioning } \\
\text { High Na }^{+} \\
\text {(M) }\end{array}$ \\
\hline \multirow[t]{5}{*}{ Cations* } & $\mathbf{N a}^{+}$ & 3.656 & 4.57 & 5.484 \\
\hline & $\mathbf{K}^{+}$ & 0.48 & 0.48 & 0.48 \\
\hline & Total $\mathrm{Cs}^{+}$ & $2.74 \mathrm{E}-05$ & $2.74 \mathrm{E}-05$ & $2.74 \mathrm{E}-05$ \\
\hline & ${ }^{137} \mathrm{Cs}^{+}(\mathrm{Ci} / \mathrm{L})$ & 0.072 & 0.072 & 0.072 \\
\hline & $\mathrm{g}^{137} \mathrm{Cs}^{+} / \mathrm{g}$ Total $\mathrm{Cs}^{+}$ & 0.22 & 0.22 & 0.22 \\
\hline \multirow[t]{5}{*}{ Anions } & $\mathrm{SO}_{4}{ }^{2-}$ & 0.032 & 0.032 & 0.032 \\
\hline & $\mathrm{OH}^{-}$(free) & 1.85 & 1.85 & 1.85 \\
\hline & $\mathrm{NO}_{2}^{-}$ & 0.273 & 0.523 & 0.772 \\
\hline & $\mathrm{NO}_{3}^{-}$ & 0.729 & 1.393 & 2.058 \\
\hline & $\mathrm{CO}_{3}{ }^{2-}$ & 0.61 & 0.61 & 0.61 \\
\hline
\end{tabular}

Table 4-4. Hot Commissioning Operation waste composition with variation about nominal value in hydroxide concentration.

\begin{tabular}{|c|c|c|c|c|}
\hline $\begin{array}{c}\text { Ion } \\
\text { Category }\end{array}$ & Species & $\begin{array}{l}\text { Hot Commissioning } \\
\text { Low } \mathrm{OH}^{-} \\
\text {(M) }\end{array}$ & $\begin{array}{l}\text { Hot Commissioning } \\
\text { Nominal } \\
\text { (M) }\end{array}$ & $\begin{array}{l}\text { Hot Commissioning } \\
\text { High } \mathrm{OH}^{-} \\
\text {(M) }\end{array}$ \\
\hline \multirow[t]{5}{*}{ Cations* } & $\mathrm{Na}^{+}$ & 4.57 & 4.57 & 4.57 \\
\hline & $\mathbf{K}^{+}$ & 0.48 & 0.48 & 0.48 \\
\hline & Total $\mathrm{Cs}^{+}$ & $2.74 \mathrm{E}-05$ & $2.74 \mathrm{E}-05$ & $2.74 \mathrm{E}-05$ \\
\hline & ${ }^{137} \mathrm{Cs}^{+}(\mathrm{Ci} / \mathrm{L})$ & 0.072 & 0.072 & 0.072 \\
\hline & $\mathrm{g}^{137} \mathrm{Cs}^{+} / \mathrm{g}$ Total $\mathrm{Cs}^{+}$ & 0.22 & 0.22 & 0.22 \\
\hline \multirow[t]{5}{*}{ Anions } & $\mathrm{SO}_{4}{ }^{2-}$ & 0.032 & 0.032 & 0.032 \\
\hline & $\mathrm{OH}^{-}$(free) & 1.48 & 1.85 & 2.22 \\
\hline & $\mathrm{NO}_{2}^{-}$ & 0.623 & 0.523 & 0.422 \\
\hline & $\mathrm{NO}_{3}^{-}$ & 1.663 & 1.393 & 1.124 \\
\hline & $\mathrm{CO}_{3}{ }^{2-}$ & 0.61 & 0.61 & 0.61 \\
\hline
\end{tabular}


WSRC-TR-2004-00100, REVISION 0 SRT-RPP-2004-00019, REVISION 0

Table 4-5. Hot Commissioning Operation waste composition with variation about nominal feed value in cesium concentration.

\begin{tabular}{|c|c|c|c|c|}
\hline $\begin{array}{c}\text { Ion } \\
\text { Category }\end{array}$ & Species & $\begin{array}{l}\text { Hot Commissioning } \\
\text { Low Cs } \\
\text { (M) }\end{array}$ & $\begin{array}{l}\text { Hot Commissioning } \\
\text { Nominal } \\
\text { (M) }\end{array}$ & $\begin{array}{c}\text { Hot Commissioning } \\
\text { High } \mathrm{Cs}^{+} \\
\text {(M) }\end{array}$ \\
\hline \multirow[t]{5}{*}{ Cations* } & $\mathbf{N a}^{+}$ & 4.57 & 4.57 & 4.57 \\
\hline & $\mathbf{K}^{+}$ & 0.48 & 0.48 & 0.48 \\
\hline & Total $\mathrm{Cs}^{+}$ & $2.192 \mathrm{E}-05$ & $2.74 \mathrm{E}-05$ & $3.288 \mathrm{E}-05$ \\
\hline & ${ }^{137} \mathrm{Cs}^{+}(\mathrm{Ci} / \mathrm{L})$ & 0.0576 & 0.072 & 0.0864 \\
\hline & $\mathrm{g}^{137} \mathrm{Cs}^{+} / \mathrm{g}$ Total $\mathrm{Cs}^{+}$ & 0.22 & 0.22 & 0.22 \\
\hline \multirow[t]{5}{*}{ Anions } & $\mathrm{SO}_{4}{ }^{2-}$ & 0.032 & 0.032 & 0.032 \\
\hline & $\mathrm{OH}^{-}$(free) & 1.85 & 1.85 & 1.85 \\
\hline & $\mathrm{NO}_{2}^{-}$ & 0.523 & 0.523 & 0.523 \\
\hline & $\mathrm{NO}_{3}^{-}$ & 1.393 & 1.393 & 1.393 \\
\hline & $\mathrm{CO}_{3}{ }^{2-}$ & 0.61 & 0.61 & 0.61 \\
\hline
\end{tabular}

Table 4-6. Waste compositions used to represent AN-105 and AZ-102 simulants at $5 \mathrm{M} \mathrm{Na}^{+}$.

\begin{tabular}{|c|c|c|c|}
\hline $\begin{array}{c}\text { Ion } \\
\text { Category }\end{array}$ & Species & $\begin{array}{l}\text { AN-105 Simulant } \\
\text { (M) }\end{array}$ & $\begin{array}{l}\text { AZ-102 Simulant } \\
\text { (M) }\end{array}$ \\
\hline \multirow[t]{3}{*}{ Cations* } & $\mathrm{Na}^{+}$ & 5.000 & 5.000 \\
\hline & $\mathbf{K}^{+}$ & 0.089 & 0.146 \\
\hline & $\mathrm{Cs}^{+}$ & variable & variable \\
\hline \multirow[t]{12}{*}{ Anions } & $\mathrm{Al}(\mathrm{OH})_{4}^{-}$ & 0.502 & 0.050 \\
\hline & $\mathrm{C}_{2} \mathrm{O}_{4}{ }^{2-}$ & 0.003 & 0.058 \\
\hline & $\mathrm{C}_{2} \mathrm{H}_{3} \mathrm{O}_{2}^{-}$ & 0.022 & 0.020 \\
\hline & $\mathrm{Cl}^{-}$ & 0.120 & 0.000 \\
\hline & $\mathrm{CHO}_{2}^{-}$ & 0.030 & 0.184 \\
\hline & $\mathrm{CO}_{3}{ }^{2-}$ & 0.098 & 0.876 \\
\hline & $\mathbf{F}^{-}$ & 0.000 & 0.096 \\
\hline & $\mathrm{NO}_{2}^{-}$ & 1.127 & 1.190 \\
\hline & $\mathrm{NO}_{3}^{-}$ & 1.290 & 0.753 \\
\hline & $\mathrm{OH}^{-}$(free) & 1.789 & 0.334 \\
\hline & $\mathrm{PO}_{4}{ }^{2-}$ & 0.000 & 0.010 \\
\hline & $\mathrm{SO}_{4}{ }^{2-}$ & 0.004 & 0.310 \\
\hline
\end{tabular}


Table 4-7. Two-parameter fit of algebraic isotherm parameters for Resorcinol-Formaldehyde at $25^{\circ} \mathrm{C}$ (Na-form mass basis).

\begin{tabular}{|c|c|c|c|}
\hline $\begin{array}{c}\text { LAW IX Operating } \\
\text { Time Period }\end{array}$ & $\begin{array}{c}\text { Composition } \\
\text { Variability }\end{array}$ & $\begin{array}{c}\mathbf{C}_{\mathbf{T}} \\
\left(\mathbf{m m o l} / \mathbf{g}_{\text {resin }}\right.\end{array}$ & $\begin{array}{c}\boldsymbol{\beta} \\
\mathbf{( M )}\end{array}$ \\
\hline \hline AN-105 Simulant & $5 \mathrm{M} \mathrm{Na}^{+}$ & 0.4636 & $4.6919 \mathrm{E}-4$ \\
\hline AZ-102 Simulant & $5 \mathrm{M} \mathrm{Na}^{+}$ & 0.4174 & $6.3132 \mathrm{E}-4$ \\
\hline Hot Commissioning Operation & Nominal & 0.4640 & $1.1117 \mathrm{E}-3$ \\
\hline Envelope B Operation & Nominal & 0.4590 & $4.0009 \mathrm{E}-4$ \\
\hline Subsequent Operation & Nominal & 0.4495 & $6.7392 \mathrm{E}-4$ \\
\hline Hot Commissioning Operation & {$[\mathrm{K}+]+20 \%$} & 0.4640 & $1.2765 \mathrm{E}-3$ \\
\hline Hot Commissioning Operation & {$[\mathrm{K}+]-20 \%$} & 0.4640 & $9.4800 \mathrm{E}-4$ \\
\hline Hot Commissioning Operation & {$[\mathrm{Na}+]+20 \%$} & 0.4640 & $1.2732 \mathrm{E}-3$ \\
\hline Hot Commissioning Operation & {$[\mathrm{Na}+]-20 \%$} & 0.4640 & $9.9764 \mathrm{E}-4$ \\
\hline Hot Commissioning Operation & {$[\mathrm{OH}-]+20 \%$} & 0.4659 & $1.0664 \mathrm{E}-3$ \\
\hline Hot Commissioning Operation & {$[\mathrm{OH}-]-20 \%$} & 0.4612 & $1.1618 \mathrm{E}-3$ \\
\hline
\end{tabular}

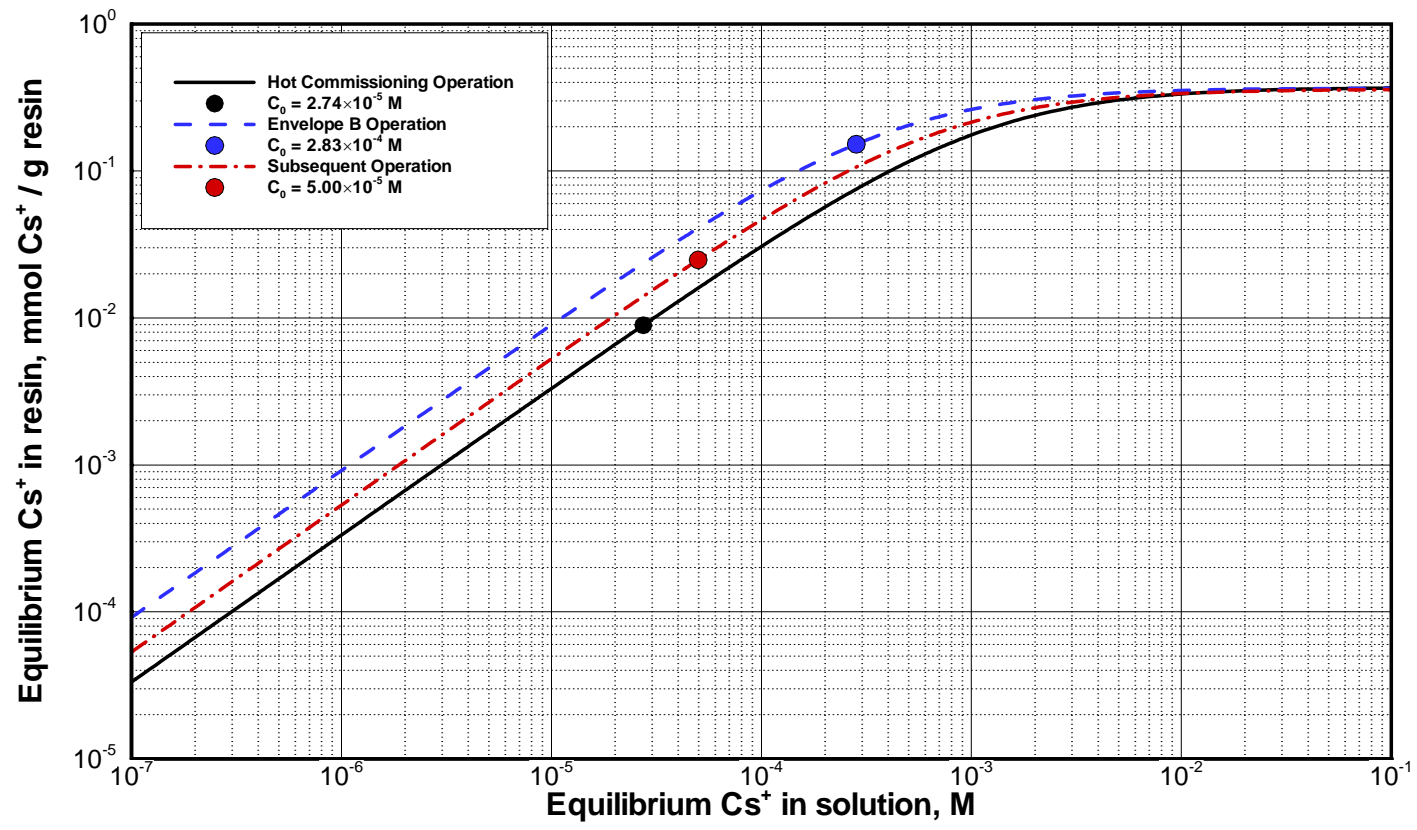

Figure 4-1. Hot Commissioning, Envelope B and Subsequent Operation $\mathrm{Cs}^{+}$isotherms for degraded Resorcinol-Formaldehyde resin (Na-form mass basis). 
WSRC-TR-2004-00100, REVISION 0

SRT-RPP-2004-00019, REVISION 0

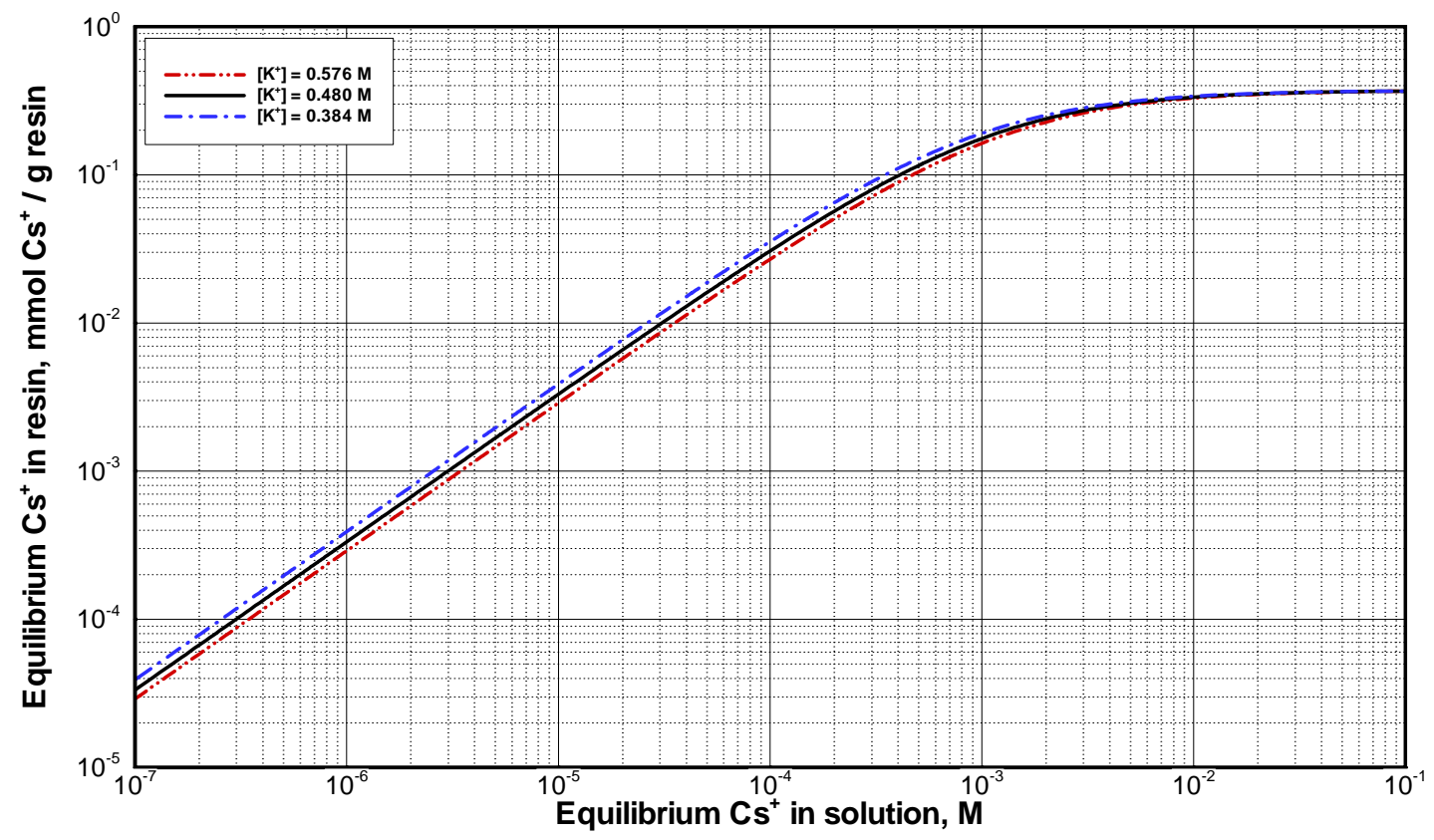

Figure 4-2. Hot Commissioning Operation degraded $\mathrm{Cs}^{+}$isotherms with variation in potassium concentration ( $\mathrm{Na}$-form mass basis).

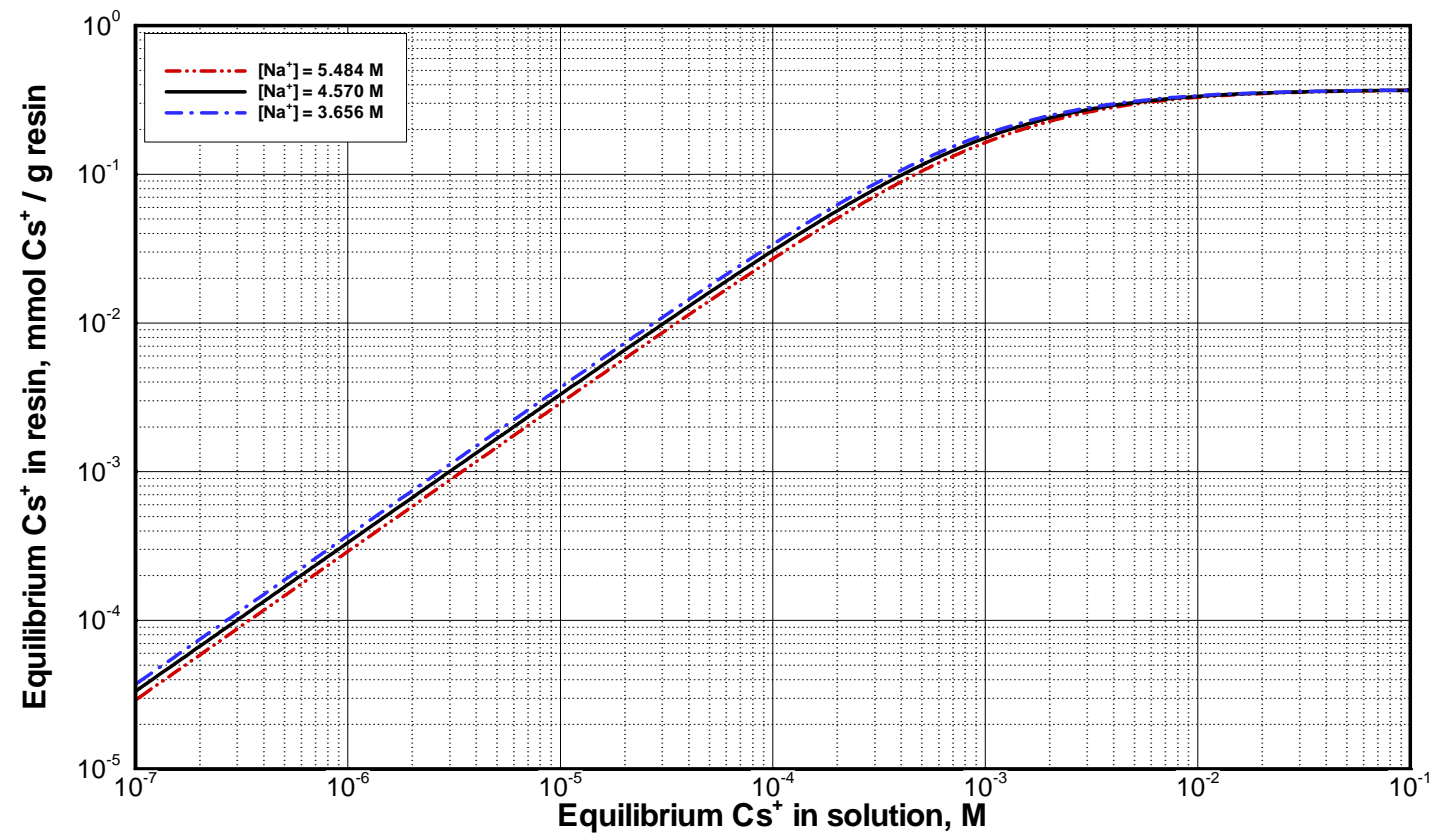

Figure 4-3. Hot Commissioning Operation degraded $\mathrm{Cs}^{+}$isotherms with variation in sodium concentration ( $\mathrm{Na}$-form mass basis). 
WSRC-TR-2004-00100, REVISION 0

SRT-RPP-2004-00019, REVISION 0

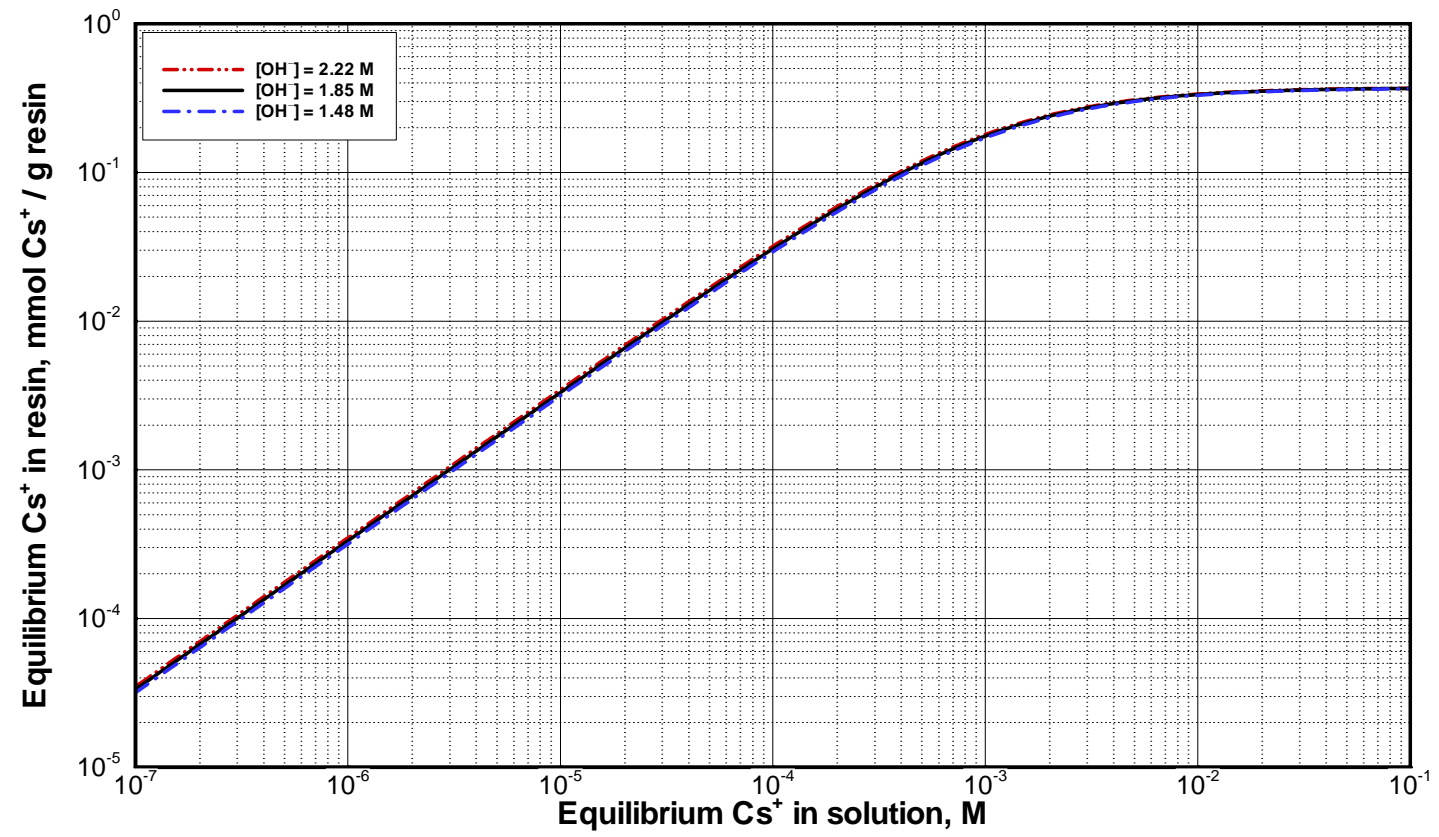

Figure 4-4. Hot Commissioning Operation degraded $\mathrm{Cs}^{+}$isotherms with variation in hydroxide concentration (Na-form mass basis).

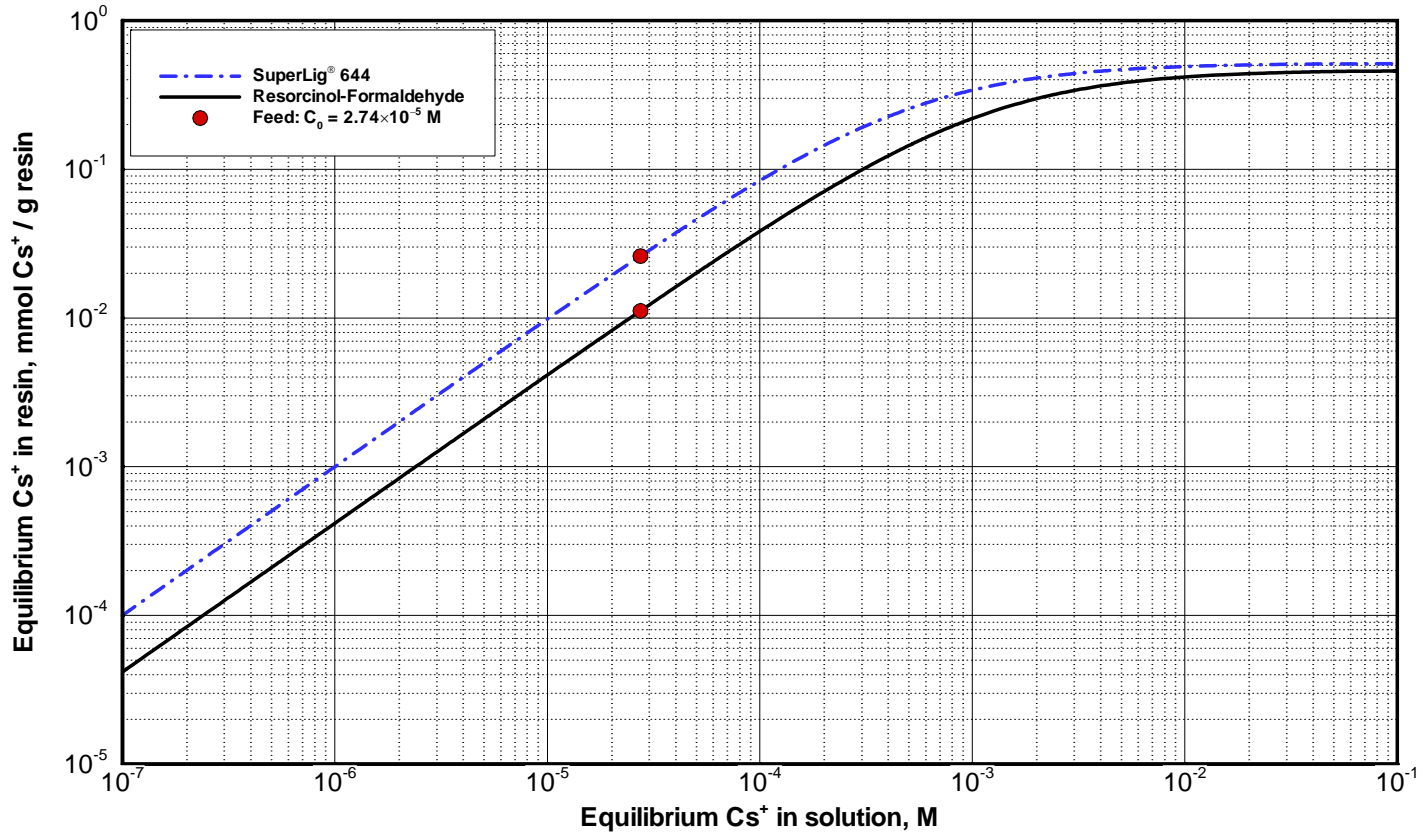

Figure 4-5. Hot Commissioning Operation $\mathrm{Cs}^{+}$isotherms for SuperLig ${ }^{\circledR} 644$ and ResorcinolFormaldehyde resins (Na-form mass basis). 
WSRC-TR-2004-00100, REVISION 0

SRT-RPP-2004-00019, REVISION 0

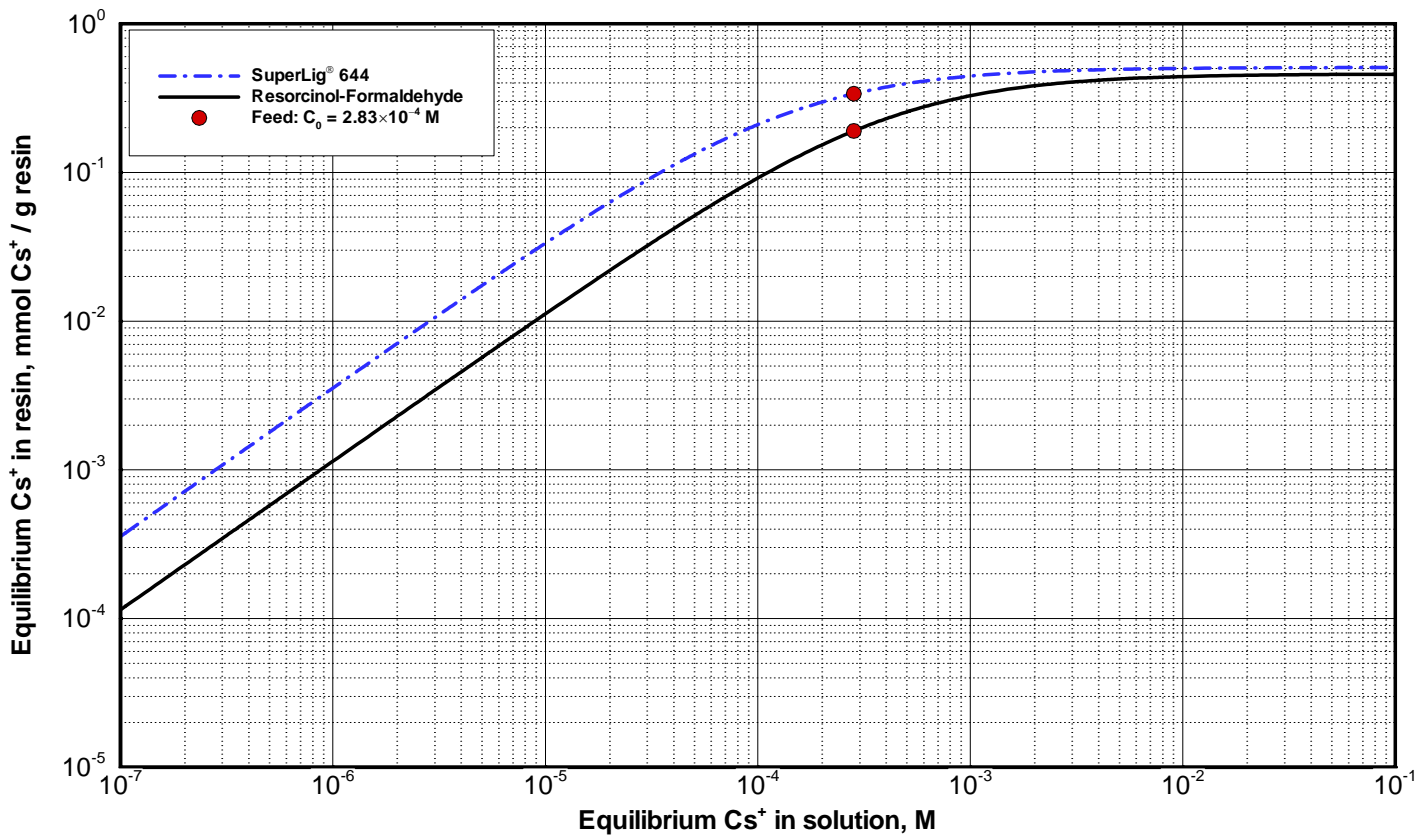

Figure 4-6. Envelope B Operation $\mathrm{Cs}^{+}$isotherms for SuperLig ${ }^{\circledR} 644$ and ResorcinolFormaldehyde resins (Na-form mass basis).

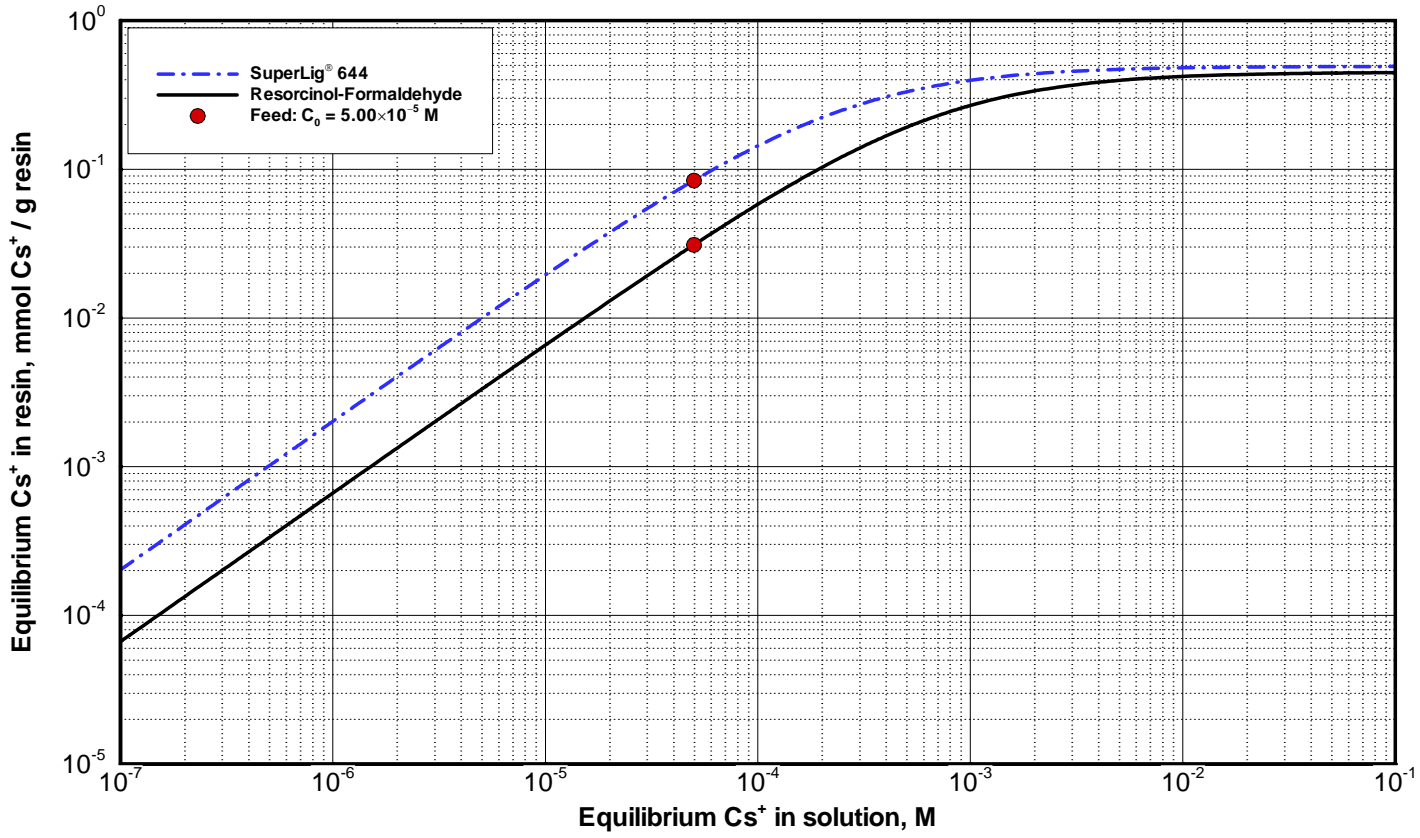

Figure 4-7. Subsequent Operation $\mathrm{Cs}^{+}$isotherms for SuperLig ${ }^{\circledR} 644$ and ResorcinolFormaldehyde resins (Na-form mass basis). 
WSRC-TR-2004-00100, REVISION 0

SRT-RPP-2004-00019, REVISION 0

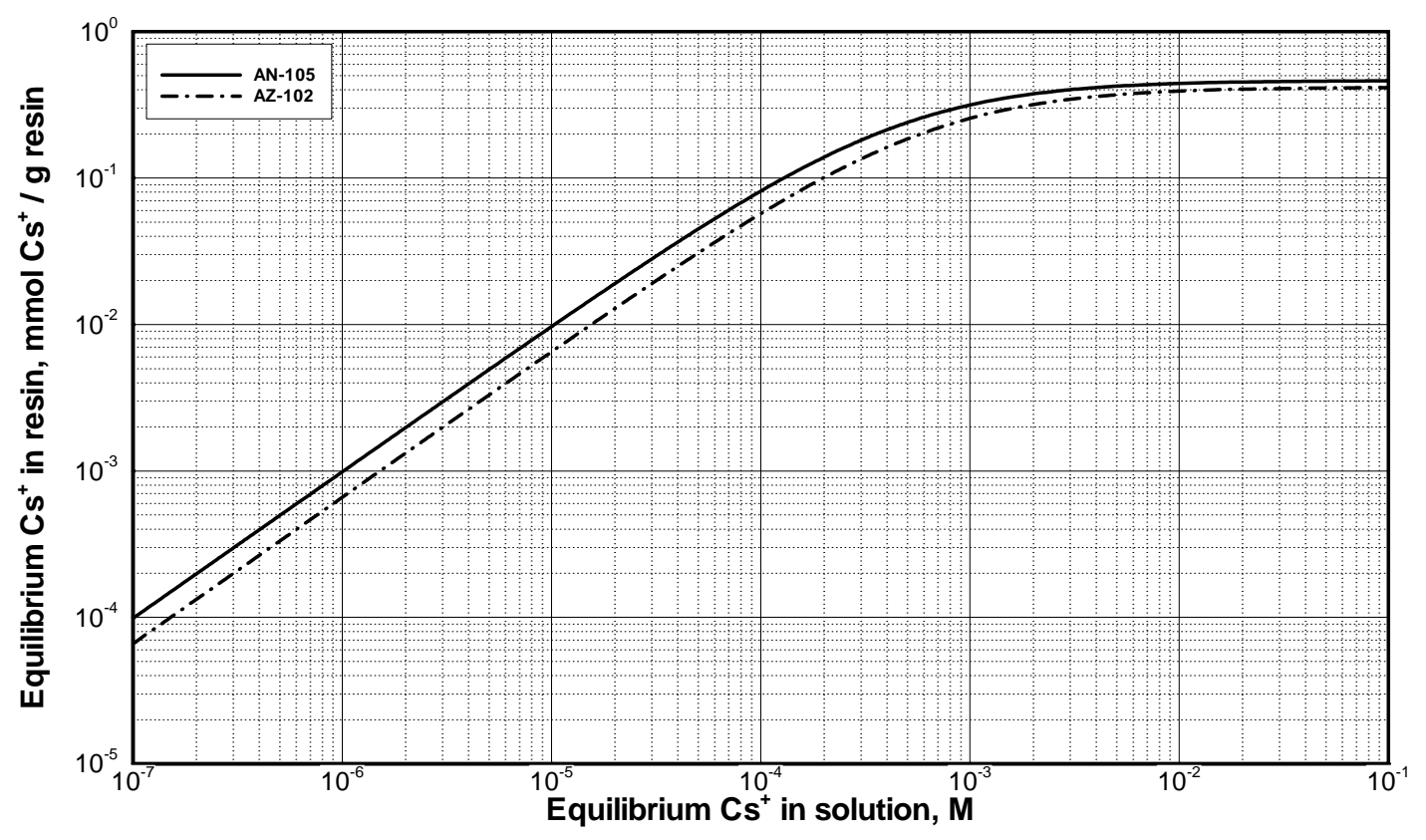

Figure 4-8. AN-105 and AZ-102 simulant $\mathrm{Cs}^{+}$isotherms for Resorcinol-Formaldehyde resins (Na-form mass basis). 
WSRC-TR-2004-00100, REVISION 0

SRT-RPP-2004-00019, REVISION 0

(This page intentionally left blank.) 


\subsection{Column Properties}

Certain material properties (such as, resin density and total ionic capacity) are unique to the ionexchange material and vary only between batches. On the other hand, composite properties associated with an ion-exchange column (such as, bed density and porosities) are inherently column specific. Even when different columns are made from the same batch of resin, column properties can vary. During operational cycles where a significant variation in total ionic strength of the feed occurs, the active bed size of a column can change as much as $100 \%$ (see King et al., 2000). The discussion that follows focuses on the column properties required to perform column transport simulations during the loading phase of a column cycle.

For additional details on column properties required to perform a VERSE-LC column performance analysis see Hamm et al. (2000b, preliminary Cs removal performance using SuperLig $^{\circledR} 644$ report), Hamm et al. (2000c, preliminary Tc removal performance using SuperLig ${ }^{\circledR} 639$ report), and Hamm et al. (2002b, Cs removal performance using CST report)

\subsection{Basic Constraint Functions}

Based on geometrical considerations not all densities and porosities are independent. The following two expressions place constraints on the densities and porosities:

$$
\varepsilon_{\mathrm{t}}=\varepsilon_{\mathrm{b}}+\left(1-\varepsilon_{\mathrm{b}}\right) \varepsilon_{\mathrm{p}}
$$

and

$$
\rho_{\mathrm{b}}=\rho_{\mathrm{s}}\left(1-\varepsilon_{\mathrm{t}}\right)=\rho_{\mathrm{s}}\left(1-\varepsilon_{\mathrm{b}}\right)\left(1-\varepsilon_{\mathrm{p}}\right)
$$

where

$$
\begin{aligned}
& \varepsilon_{\mathrm{t}} \text {..................total porosity of active column, [-] } \\
& \varepsilon_{\mathrm{b}} \text {....................bed porosity of active column, [-] } \\
& \varepsilon_{\mathrm{p}} \text {...................pore porosity of resin particles, [-] } \\
& \rho_{\mathrm{b}} \ldots \ldots \ldots \ldots \ldots . . . . . . . . .6 e d \text { density of active column, } \mathrm{g} / \mathrm{ml} \\
& \rho_{\mathrm{s}} \text {..................solid (particle) density of resin, } \mathrm{g} / \mathrm{ml}
\end{aligned}
$$

For the five variables listed above only three are independent. The various porosities used in Eq. (5-1) are defined as:

$$
\varepsilon_{\mathrm{b}}=\frac{\mathrm{V}_{\text {void }}-\mathrm{V}_{\text {pore }}}{\mathrm{V}_{\text {bed }}} ; \quad \varepsilon_{\mathrm{p}}=\frac{\mathrm{V}_{\text {pore }}}{\mathrm{V}_{\text {part }}} ; \quad \varepsilon_{\mathrm{t}}=\frac{\mathrm{V}_{\text {void }}}{\mathrm{V}_{\text {bed }}}=\frac{\mathrm{V}_{\text {bed }}-\mathrm{V}_{\text {sld }}}{\mathrm{V}_{\text {bed }}}
$$


where

$$
\begin{aligned}
& \mathrm{V}_{\text {bed }} \text {...............total volume of active (bed) column, } \mathrm{ml} \\
& \mathrm{V}_{\text {void }} \text {..............total volume of voids within active column, } \mathrm{ml} \\
& \mathrm{V}_{\text {pore }} \text {..............total volume of pores within particles, } \mathrm{ml} \\
& \mathrm{V}_{\text {part }} \text {...............total volume of particles within active column, ml } \\
& \mathrm{V}_{\text {sld }} \text {................total volume of solid resin within active column, } \mathrm{ml}
\end{aligned}
$$

\subsection{Densities}

The particle ("skeletal") density of the resin in sodium and hydrogen form has been measured based on pycnometer studies (King et al., 2003). A summary of their results is given in Table 5-1. For the column modeling presented in this report the average particle density of $1.582 \mathrm{~g} / \mathrm{ml}$ listed in Table 5-1 for Na-form RF in AN-105 simulant was employed.

The actual amount of resin present within a column is a parameter of prime importance with respect to column performance (i.e., exit breakthrough curves). For the column studies assessed within this report an estimate of column bed density was derived from the drainable void study by King et al., 2003. The dry resin mass of RF in Na-form and bed volume were measured. The column bed density was computed as

$$
\rho_{\mathrm{b}}=\frac{\mathrm{m}_{\text {resin }}}{\mathrm{V}_{\text {bed }}}=\frac{9.02 \mathrm{~g}}{29.20 \mathrm{ml}}=0.3089 \mathrm{~g} / \mathrm{ml}
$$

The bed density computed by Eq. (5-4) represents our nominal value. For application to specific column tests sometimes adjustments were made if column volume changes occurred and were reported.

\subsection{Porosities}

The drainable void volume of a spherical RF resin bed packed in a prototypical manner was determined by a liquid drainage technique (King et al., 2003). The drainable void fraction for a thirty-milliliter nominal sample of RF resin was found to be

$$
\varepsilon_{\mathrm{b}}=\frac{\mathrm{V}_{\text {void }}-\mathrm{V}_{\text {pore }}}{\mathrm{V}_{\text {bed }}}=\frac{10.5 \mathrm{ml}}{29.2 \mathrm{ml}}=0.361 \pm 1 \%
$$

The bed porosity computed by Eq. (5-5) represents our nominal value. The average measured porosity for dense packing of mono-sized hard spheres is 0.363 as reported by German (1989). Greater packing fractions (or smaller bed porosities) can be achieved when multi-sized spheres are employed. The particle size distribution for the spherical RF material was quite narrow with the bulk of the distribution in the range 400 to 600 microns. 
Based on Eq. (5-2) the pore porosity of the resin particles is known once the particle density, bed density and bed porosity are specified. Using the values presented in the above subsection the pore porosity of the resin particles becomes:

$$
\varepsilon_{\mathrm{p}}=1-\rho_{\mathrm{b}} / \rho_{\mathrm{s}}\left(1-\varepsilon_{\mathrm{b}}\right)=1-0.3089 / 1.582(1-0.361)=0.6944
$$

The pore porosity computed by Eq. (5-6) represents our nominal value.

Table 5-1. Particle densities of used spherical Resorcinol-Formaldehyde resin.

\begin{tabular}{|c|c|c|}
\hline Liquid & Resin Form & $\begin{array}{c}\text { Particle Density } \\
(\mathbf{g} / \mathbf{m l})\end{array}$ \\
\hline \hline $\mathrm{DI} \mathrm{H} \mathrm{H}_{2} \mathrm{O}$ & $\mathrm{Na}^{+}$ & 1.630 \\
\hline $\mathrm{AN}-105$ simulant & $\mathrm{Na}^{+}$ & 1.582 \\
\hline $\mathrm{DI} \mathrm{H}_{2} \mathrm{O}$ & $\mathrm{H}^{+}$ & 1.490 \\
\hline $0.5 \mathrm{M} \mathrm{HNO}_{3}$ & $\mathrm{H}^{+}$ & 1.471 \\
\hline
\end{tabular}


WSRC-TR-2004-00100, REVISION 0

SRT-RPP-2004-00019, REVISION 0

(This page intentionally left blank.) 


\subsection{Particle Size Distributions}

The particle size distribution of granular and spherical resorcinol-formaldehyde was characterized in sodium form. Wet sieve and Microtrac ${ }^{\circledR}$ analysis was used to characterize the particle size distribution of the granular resorcinol-formaldehyde resin in King et al. (2004). Only the Microtrac ${ }^{\circledR}$ analysis is presented in King et al. (2004). The particle size distribution of granular RF is presented for comparison to the spherical RF. The particle size distribution of spherical RF (Sintef Batch 1) resin was analyzed using Microtrac ${ }^{\circledR}$ in King et al. (2004).

For details on particle size distribution properties required to perform a VERSE-LC column performance analysis see Hamm et al. (2000b, preliminary Cs removal performance using SuperLig ${ }^{\circledR} 644$ report), Hamm et al. (2000c, preliminary Tc removal performance using SuperLig ${ }^{\circledR} 639$ report), and Hamm et al. (2002b, Cs removal performance using CST report).

\subsection{Granular Resorcinol-Formaldehyde Resin}

Granular Resorcinol-Formaldehyde resin samples were wet sieved with mesh sizes 18, 20, 30, $40,50,70$, and 100 to provide a more resolved size distribution for each sample. After sieving was concluded, the sieve trays were placed on the bench top for air drying. Table 6-1 shows the results of the wet sieve analysis for granular Resorcinol-Formaldehyde. Microtrac ${ }^{\circledR}$ analysis (volume-based data) results for the granular form of RF is provided in Table 6-2.

The Rosin-Rammler equation (Latham et al., 2002) is one of the most commonly used theoretical equations used to fit the observed cumulative distribution of particle sizes for crushed minerals and blastpiles. The Rosin-Rammler cumulative distribution function was applied to the wet sieve and Microtrac ${ }^{\circledR}$ particle size analysis data for granular RF. Table 6-3 summarizes the Rosin-Rammler cumulative and probability distribution functions.

A non-linear least square optimization of the cost function computed from normalized residuals of the wet sieve or Microtrac ${ }^{\circledR}$ data and the Rosin-Rammler equation was performed. The RosinRammler characteristic size and the uniformity coefficient for each analysis method are shown in Table 6-4. Figure 6-1 shows a plot of the wet sieve data, Microtrac ${ }^{\mathbb{B}}$ data and the RosinRammler fit to each dataset. The two Rosin-Rammler fits cross at about the $50 \%$ weight passing with the wet sieve data skewed to the coarse side and the Microtrac ${ }^{\circledR}$ data skewed to the fine side. One hypothesis is that the current wet sieving protocol is time limited and does not allow for sufficient time for finer particles to percolate from the coarser to finer mesh trays. There is a holdup of fines in the upper trays of the wet sieve column.

\subsection{Spherical Resorcinol-Formaldehyde Resin}

Microtrac ${ }^{\circledR}$ particle size analysis data (volume-based) for used spherical RF was measured by King et al. (2004) and is presented in Table 6-5. The bulk of the particle size distribution is in the 400 to 600 micron range. 
The Rosin-Rammler and log-normal cumulative distribution functions were applied to the Microtrac $^{\circledR}$ particle size analysis (volume-based) for spherical RF. The log-normal cumulative distribution function has been used extensively to represent particle size distributions of aerosols. Table 6-6 summarizes the log-normal cumulative and probability distribution functions.

A non-linear least square optimization of the cost function computed from normalized residuals of the Microtrac ${ }^{\circledR}$ data and the log-normal cumulative distribution was performed. The lognormal geometric mass mean diameter was estimated as $\bar{x}_{\mathrm{g}}=479$ and the geometric standard deviation as $\sigma_{\mathrm{g}}=1.15$. Figure 6-2 shows a plot of the Microtrac ${ }^{\circledR}$ particle size analysis data, Rosin-Rammler and log-normal cumulative distributions. The log-normal cumulative distribution adequately represents the particle size distribution of the spherical RF sample.

\subsection{Calculation of Average-Spherically Equivalent Particle Diameters}

Once we have established the cumulative distribution function, we can compute the pdf of the particle size distribution on a weight or number basis. The Powder Technology Handbook (Gotoh, 1997) provides nine distinct definitions of mean or average particle diameters. Table 67 provides the definition and corresponding integral representation of the diameters in terms of the number basis pdf. The range of integration is over the particle size or sieve size interval of interest.

Spherically-equivalent particle diameters were computed for granular RF using the definitions in Table 6-7. Table 6-8 presents the particle diameter calculations in microns. There is good agreement between the Microtrac ${ }^{\circledR}$ Rosin-Rammler fit and the values computed by the proprietary Microtrac ${ }^{\circledR}$ software for the surface and volume mean diameters.

Particle diameters were computed for spherical RF using the definitions in Table 6-7. Table 6-9 presents the particle diameter calculations in microns. There is good agreement between the Microtrac ${ }^{\circledR}$ Log-normal fit and the values computed by the proprietary Microtrac ${ }^{\circledR}$ software for the number, surface and volume mean diameters. The Microtrac ${ }^{\circledR}$ Rosin-Rammler fit predicts lower values for these diameters.

Table 6-1. Wet sieve particle size analysis data for granular Resorcinol-Formaldehyde sample.

\begin{tabular}{|c|c|c|}
\hline ASTM Sieve Size & Sieve Opening (microns) & Weight Percent Passing Sieve \\
\hline \hline 100 & 150 & 0.00 \\
\hline 70 & 212 & 0.19 \\
\hline 50 & 300 & 0.60 \\
\hline 40 & 425 & 9.93 \\
\hline 30 & 600 & 44.37 \\
\hline 20 & 850 & 99.68 \\
\hline 18 & 1000 & 99.98 \\
\hline
\end{tabular}


Table 6-2. Microtrac ${ }^{\circledR}$ particle size analysis data for granular RF sample (volume-based data).

\begin{tabular}{|c|c|c|}
\hline $\begin{array}{c}\text { Channel Size } \\
\text { (microns) }\end{array}$ & \% PASS & \% CHAN \\
\hline 104.7 & 0.00 & 0.00 \\
\hline 124.5 & 0.30 & 0.19 \\
\hline 148.0 & 0.69 & 0.60 \\
\hline 176.0 & 1.16 & 9.93 \\
\hline 209.3 & 1.71 & 0.55 \\
\hline 248.9 & 2.43 & 0.72 \\
\hline 296.0 & 3.66 & 1.23 \\
\hline 352.0 & 6.35 & 2.69 \\
\hline 418.6 & 12.77 & 6.42 \\
\hline 497.8 & 25.98 & 13.21 \\
\hline 592.0 & 46.23 & 20.25 \\
\hline 704.0 & 69.27 & 23.04 \\
\hline 837.2 & 87.35 & 18.08 \\
\hline 995.6 & 96.27 & 8.92 \\
\hline 1184.0 & 98.72 & 2.45 \\
\hline 1408.0 & 100.00 & 1.28 \\
\hline
\end{tabular}

Table 6-3. Rosin-Rammler cumulative and probability distribution functions.

\begin{tabular}{|c|c|c|}
\hline Function & Basis & Equation \\
\hline \hline $\mathrm{cdf}$ & weight & $\mathrm{W}(\mathrm{x})=1-\exp \left\{-\left(\mathrm{x} / \mathrm{x}_{\mathrm{c}}\right)^{\mathrm{m}_{\mathrm{rr}}}\right\}$ \\
\hline $\mathrm{pdf}$ & weight & $\mathrm{w}(\mathrm{x})=\frac{\mathrm{dW}(\mathrm{x})}{\mathrm{dx}}=\left(\frac{\mathrm{m}_{\mathrm{rr}}}{\mathrm{x}_{\mathrm{c}}}\right)\left(\frac{\mathrm{x}}{\mathrm{x}_{\mathrm{c}}}\right)^{\mathrm{m}_{\mathrm{rr}}-1} \exp \left\{-\left(\mathrm{x} / \mathrm{x}_{\mathrm{c}}\right)^{\left.\mathrm{m}_{\mathrm{rr}}\right\}}\right.$ \\
\hline $\mathrm{pdf}$ & number & $\mathrm{n}(\mathrm{x})=\mathrm{w}(\mathrm{x}) / \mathrm{f}(\mathrm{x}) \sigma(\mathrm{x}) \sigma^{3}$ \\
\hline
\end{tabular}

where

cdf .................cumulative distribution function

pdf ...............probability distribution function

$\mathrm{W}(\mathrm{x})$.............fraction by weight finer than a given sieve size or particle diameter $\mathrm{x}$...................sieve size or particle diameter

$\mathrm{x}_{\mathrm{c}}$ …...............Rosin-Rammler characteristic size, taken to be $63.2 \%$ passing size

$\mathrm{m}_{\mathrm{rr}}$ ….............Rosin-Rammler uniformity coefficient

$\mathrm{f}(\mathrm{x})$..............particle volume shape factor $(\pi / 6$ for a sphere $)$

$\sigma(\mathrm{x})$..............particle density (assumed constant) 
Table 6-4. Rosin-Rammler parameters for granular RF samples.

\begin{tabular}{|c|c|c|}
\hline PSD Analysis & $\mathbf{x}_{\mathbf{c}}$ & $\mathbf{m}_{\mathbf{r r}}$ \\
\hline \hline Wet sieve & 658.7 & 5.51 \\
\hline Microtrac $^{\circledR}$ & 679.8 & 3.81 \\
\hline
\end{tabular}

Table 6-5. Microtrac ${ }^{\circledR}$ particle size analysis data for spherical RF sample (volume-based data).

\begin{tabular}{|c|c|c|}
\hline $\begin{array}{c}\text { Channel Size } \\
\text { (microns) }\end{array}$ & \% PASS & \% CHAN \\
\hline 296.0 & 0.00 & 0.00 \\
\hline 352.0 & 0.70 & 0.70 \\
\hline 418.6 & 15.41 & 14.71 \\
\hline 497.8 & 62.18 & 46.77 \\
\hline 592.0 & 92.38 & 30.20 \\
\hline 704.0 & 99.19 & 6.81 \\
\hline 837.2 & 100.00 & 0.81 \\
\hline
\end{tabular}

Table 6-6. Log-normal cumulative and probability distribution functions.

\begin{tabular}{|c|c|c|}
\hline Function & Basis & Equation \\
\hline \hline cdf & weight & $\mathrm{W}(\mathrm{x})=\frac{1}{2}\left\{1+\operatorname{erf}\left(\frac{\ln \left(\mathrm{x} / \overline{\mathrm{x}}_{\mathrm{g}}\right)}{\sqrt{2} \ln \sigma_{\mathrm{g}}}\right)\right\}$ \\
\hline $\mathrm{pdf}$ & weight & $\mathrm{W}(\mathrm{x})=\frac{\mathrm{dW}(\mathrm{x})}{\mathrm{dx}}=\frac{1}{\mathrm{x} \sqrt{2 \pi} \ln \sigma_{\mathrm{g}}} \exp \left[-\left(\frac{\ln \left(\mathrm{x} / \overline{\mathrm{x}}_{\mathrm{g}}\right)}{\sqrt{2} \ln \sigma_{\mathrm{g}}}\right)^{2}\right]$ \\
\hline $\mathrm{pdf}$ & number & $\mathrm{n}(\mathrm{x})=\mathrm{w}(\mathrm{x}) / \mathrm{f}(\mathrm{x}) \sigma(\mathrm{x}) \mathrm{x}^{3}$ \\
\hline
\end{tabular}

where

$$
\begin{aligned}
& \overline{\mathrm{x}}_{\mathrm{g}} \ldots \ldots \ldots \ldots \ldots . . . . . . . \mathrm{geometric} \text { mass mean diameter, } \mathrm{x}_{50} \\
& \sigma_{\mathrm{g}} \text {.................... geometric standard deviation, } \mathrm{x}_{84} / \mathrm{x}_{50}=\mathrm{x}_{50} / \mathrm{x}_{16}=\sqrt{\mathrm{x}_{84} / \mathrm{x}_{16}}
\end{aligned}
$$

Table 6-7. Definitions of various average or mean particle diameters.

\begin{tabular}{|l|l|}
\hline Definition of Diameter & Equation \\
\hline \hline Number mean diameter, $D_{1}$ & $\int n(x) x d x / \int n(x) d x$ \\
\hline Length mean diameter, $D_{2}$ & $\int n(x) x^{2} d x / \int n(x) x d x$ \\
\hline Surface mean, Sauter mean or mean volume-surface diameter, $D_{3}$ & $\int n(x) x^{3} d x / \int n(x) x^{2} d x$ \\
\hline Volume or mass mean diameter, $D_{4}$ & $\int n(x) x^{4} d x / \int n(x) x^{3} d x$ \\
\hline Diameter of average surface, $D_{s}$ & $\left(\int n(x) x^{2} d x / \int n(x) d x\right)^{1 / 2}$ \\
\hline
\end{tabular}




\begin{tabular}{|l|l|}
\hline Definition of Diameter & Equation \\
\hline Diameter of average volume, $\mathrm{D}_{\mathrm{v}}$ & $\left(\int \mathrm{n}(\mathrm{x}) \mathrm{x}^{3} \mathrm{dx} / \int \mathrm{n}(\mathrm{x}) \mathrm{dx}\right)^{1 / 3}$ \\
\hline Harmonic mean diameter, $\mathrm{D}_{\mathrm{h}}$ & $\int \mathrm{n}(\mathrm{x}) \mathrm{dx} / \int \mathrm{n}(\mathrm{x}) / \mathrm{x} d \mathrm{x}$ \\
\hline Number median diameter or geometric mean diameter, NMD & $\exp \left(\int \mathrm{n}(\mathrm{x}) \ln \mathrm{xdx} / \int \mathrm{n}(\mathrm{x}) \mathrm{dx}\right)$ \\
\hline Volume or mass median diameter, MMD & $\exp \left(\int \mathrm{n}(\mathrm{x}) \mathrm{x}^{3} \ln \mathrm{xdx} / \int \mathrm{n}(\mathrm{x}) \mathrm{x}^{3} \mathrm{dx}\right)$ \\
\hline
\end{tabular}

Table 6-8. Spherically-equivalent particle diameters for granular RF.

\begin{tabular}{|c|c|c|c|}
\hline $\begin{array}{c}\text { Diameter } \\
\text { Definition }\end{array}$ & $\begin{array}{c}\text { Wet Sieve } \\
\text { Rosin-Rammler }\end{array}$ & $\begin{array}{c}\text { Microtrac }^{\circledR} \\
\text { Rosin-Rammler }^{(}\end{array}$ & $\begin{array}{c}\text { Microtrac }^{\circledR} \\
\text { Software }\end{array}$ \\
\hline \hline $\mathrm{D}_{1}$ & 488 & 373 & 323 \\
\hline $\mathrm{D}_{2}$ & 537 & 469 & - \\
\hline $\mathrm{D}_{3}$ & 576 & 550 & 549 \\
\hline $\mathrm{D}_{4}$ & 608 & 615 & 623 \\
\hline $\mathrm{D}_{\mathrm{s}}$ & 512 & 418 & - \\
\hline $\mathrm{D}_{\mathrm{v}}$ & 533 & 458 & - \\
\hline $\mathrm{D}_{\mathrm{h}}$ & 430 & 281 & - \\
\hline $\mathrm{NMD}$ & 461 & 326 & - \\
\hline $\mathrm{MMD}$ & 594 & 585 & \\
\hline
\end{tabular}

Table 6-9. Average particle diameters for spherical RF sample.

\begin{tabular}{|c|c|c|c|}
\hline $\begin{array}{c}\text { Diameter } \\
\text { Definition }\end{array}$ & $\begin{array}{c}\text { Microtrac }^{\circledR} \\
\text { Rosin-Rammler }^{\circledR}\end{array}$ & $\begin{array}{c}\text { Microtrac }^{\circledR} \\
\text { Log-Normal }^{(}\end{array}$ & $\begin{array}{c}\text { Microtrac }^{\circledR} \\
\text { Software }^{(12}\end{array}$ \\
\hline \hline $\mathrm{D}_{1}$ & 454 & 457 & 458 \\
\hline $\mathrm{D}_{2}$ & 462 & 466 & - \\
\hline $\mathrm{D}_{3}$ & 470 & 475 & 476 \\
\hline $\mathrm{D}_{4}$ & 477 & 483 & 486 \\
\hline $\mathrm{D}_{\mathrm{s}}$ & 458 & 462 & - \\
\hline $\mathrm{D}_{\mathrm{v}}$ & 462 & 466 & - \\
\hline $\mathrm{D}_{\mathrm{h}}$ & 445 & 449 & - \\
\hline $\mathrm{NMD}$ & 449 & 453 & - \\
\hline $\mathrm{MMD}$ & 474 & 479 & \\
\hline & & & \\
\hline
\end{tabular}




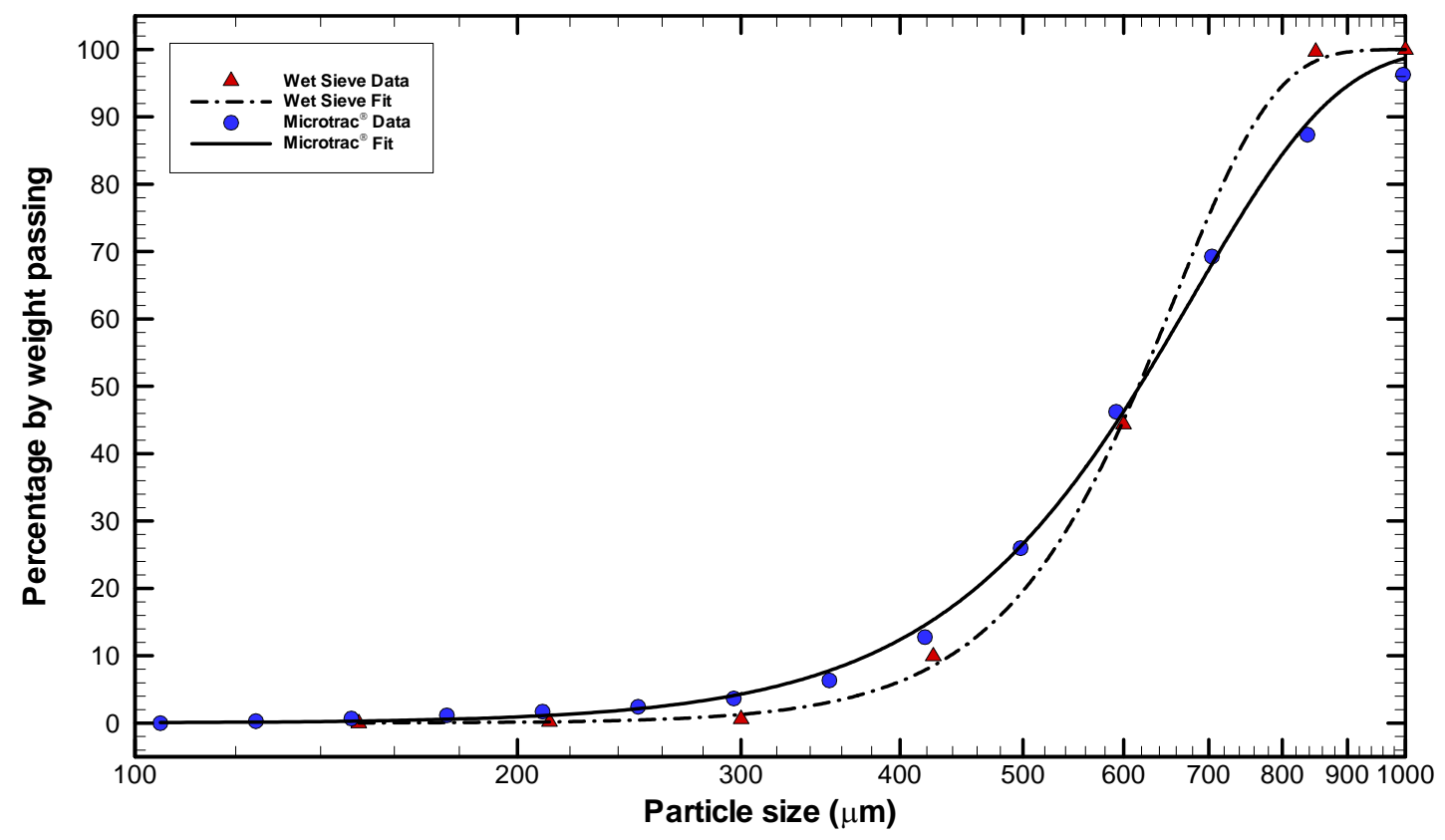

Figure 6-1. Microtrac ${ }^{\circledR}$ data and Rosin-Rammler cumulative distribution for granular RF.

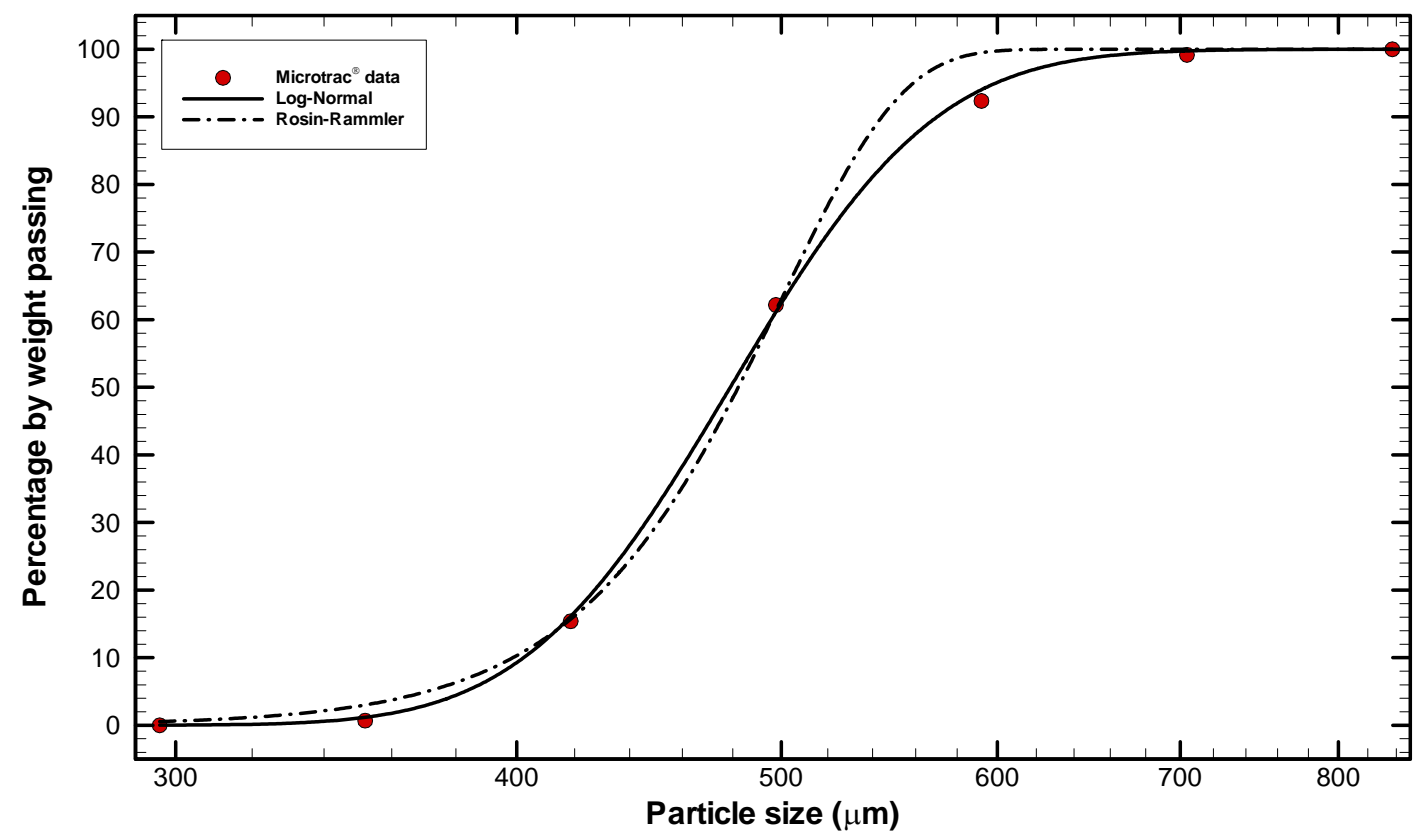

Figure 6-2. Microtrac ${ }^{\circledR}$ data, Log-Normal and Rosin-Rammler cumulative distributions for spherical RF. 


\subsection{Pore Diffusion}

A series of VERSE-LC simulations were performed to identify the values of the pore diffusivity and average particle radius from experimental data. Once the values for these parameters were established, the consistency of the model was tested by comparing its predictions with data from other experiments. All tests discussed in this section were performed using the SRNL kinetics rig and are discussed in King et al. (2004). Sample VERSE-LC input and output files are listed in Appendix C.

\subsection{Bulk Diffusivity of $\mathrm{Cs}^{+}$in Simulants and LAW IX Feeds}

The bulk or free-stream diffusivity of $\mathrm{Cs}^{+}$in various simulants and LAW IX feeds typical of Envelope A, B and C operation were computed using OLI Systems, Inc. Stream Analyzer Version 1.3 (Build 1.3.0.23). The OLI Stream Analyzer contains a comprehensive model for calculating self-diffusion coefficients in multicomponent aqueous electrolyte systems. The model combines contributions of long-range (Coulombic) and short-range interactions. The long-range interaction contribution is obtained from the dielectric continuum-based meanspherical approximation (MSA) theory for the unrestricted primitive model. The short-range interactions are represented using the hard-sphere model. In the combined model, aqueous species are characterized by effective radii, which depend on the ionic environment. For multicomponent systems, a mixing rule has been developed. The effects of complexation are taken into account by combining the diffusivity model with thermodynamic speciation calculations. The model accurately reproduces self-diffusivities of ions and neutral species in aqueous solutions ranging from infinitely dilute to concentrated (up to ca. $30 \mathrm{~mol} / \mathrm{kg} \mathrm{H} \mathrm{H}_{2} \mathrm{O}$ ). Also, the model makes it possible to predict diffusivities in multicomponent solutions using data for single-solute systems. The OLI Stream Analyzer results are shown in Table 7-1. The ratio column in the table refers to the ratio of the diffusivity calculated from the Hot Commissioning sensitivity study in the "Composition Variability" column to the nominal value. The Hot Commissioning Operation feed with sodium variation shows the greatest impact on the diffusivity from the nominal case. The Hot Commissioning Operation feed with sodium concentration increased by $20 \%$ has a diffusivity which is a factor of 20 smaller than the value for the nominal case. This observation warrants further investigation theoretically and experimentally (particle kinetics testing at $6 \mathrm{M} \mathrm{Na}^{+}$simulants).

\subsection{Particle Kinetics Parameters}

The rate of cesium uptake controls the transient behavior of the column. As the rate of cesium uptake by the resin is increased, the breakthrough curve becomes sharper (steeper) and utilization of the resin is increased. Thus, a proper evaluation of the parameters that control the rate of cesium uptake is essential for modeling column performance. For ResorcinolFormaldehyde resin, we assume that the rate of chemical adsorption (i.e. exchange of ions at a surface site) is very fast when compared to the rates of diffusion within the pore fluid and mass transfer across the liquid film at the outer boundary of the particles. Hence, within the resin particles, the rate of cesium uptake is dominated by intra-particle diffusion. Diffusion within the particles is governed by the pore diffusivity, particle porosity, and size of the particles. 
Externally, the rate of cesium transport from the inter-particle fluid to the particle surface depends upon the film mass transfer coefficient. Due to their influence on the rate of cesium uptake and, thus, the transient behavior of the column, the particle porosity, pore diffusivity, particle radius and the film mass transfer coefficient are referred to as kinetics parameters.

\subsection{Particle Radius and Pore Diffusivity}

In VERSE-LC the film mass transfer coefficient is calculated from a correlation developed by Wilson and Geankoplis (1966). The particle porosity is available from data in Section 5. Therefore, of the kinetics parameters, the pore diffusivity and diffusion length remain to be determined. Within VERSE-LC, the model for intra-particle diffusion assumes that the particles are spheres of uniform radius. The spherical Resorcinol-Formaldehyde particles have a narrow distribution of particle sizes as shown in Section 6. To apply the VERSE-LC model to the spherical Resorcinol-Formaldehyde resin it is therefore necessary to determine an average radius for the particle size distribution and an effective pore diffusivity. In this approach, the particle radius or pore diffusion length is expressed as

$$
<\mathrm{r}_{\mathrm{p}}>=\frac{<\mathrm{d}_{\mathrm{p}}>}{2}
$$

where

$$
\begin{aligned}
& <\mathrm{r}_{\mathrm{p}}>\ldots \ldots \ldots \ldots \text {.......erage particle radius or pore diffusion length, } \mu \mathrm{m} \\
& <\mathrm{d}_{\mathrm{p}}>\ldots \ldots \ldots \ldots \text {.....average particle diameter, } \mu \mathrm{m}
\end{aligned}
$$

According to Table 6-9, the average particle diameters for the spherical RF sample range from 449 to 483 microns. In this study, we chose to look at the number median diameter $(453 \mu \mathrm{m})$ and the volume mean diameter $(483 \mu \mathrm{m})$ as candidates for the average particle diameter. The choice is somewhat arbitrary for which average particle diameter metric to use for this narrow particle size distribution.

Specific information on the actual pore sizes are not available, however, IBC vendor information suggests that the pore sizes are large relative to the size of the migrating ions of interest and that pore diffusion coefficients should not be significantly lower than their bulk or free stream values. However, some level of reduction is expected resulting from bends along the pore paths that are generally accounted for by a particle tortuosity factor defined as

$$
\mathrm{D}_{\mathrm{p}}=\frac{\mathrm{D}_{\infty}}{\tau}
$$

where

$\mathrm{D}_{\mathrm{p}}$.................pore diffusivity of $\mathrm{Cs}^{+}$in the particle pore, $\mathrm{cm}^{2} / \mathrm{min}$

$\mathrm{D}_{\infty}$ …..............bulk diffusivity of $\mathrm{Cs}^{+}$in the free stream, $\mathrm{cm}^{2} / \mathrm{min}$

$\tau$....................particle tortuosity factor 


\subsection{SRNL Particle Kinetics Testing}

The SRNL particle kinetics rig is a closed loop differential column with temperature control. The recirculation device contained $120 \mathrm{ml}$ of simulant and produced bed flowrates of $0.5,30$ and $90 \mathrm{ml} / \mathrm{min}$. At these flowrates, film mass transfer resistance is negligible relative to that for diffusion in the pores of the particle (Biot numbers range from 13 to 73). In this way, the effect of the film mass transfer coefficient was eliminated and the data showed only the effect of $\left\langle r_{p}\right\rangle$ and $\tau$.

Seven experiments were conducted using fresh/used spherical RF and granular RF contacted with the base AN-105 simulant (King et al., 2004). Flowrate dependent kinetics testing was conducted with used spherical RF at flowrates of 90, 30 and $0.5 \mathrm{ml} / \mathrm{min}$ (Experiments 1,2 and 3, respectively). Particle type dependent kinetics testing was conducted with used spherical, unused spherical and granular RF (Experiments 4, 5 and 6, respectively). Temperature dependent kinetics testing was conducted with user spherical RF at temperatures of 25 and $45^{\circ} \mathrm{C}$ (Experiments 4 and 7, respectively).

\subsection{Parameter Estimation}

The average particle radius and tortuosity factor for spherical RF were estimated using trial-anderror by comparison of VERSE-LC models for Experiment 2 to data derived from the SRNL particle kinetics rig in Table 4-6 (King et al., 2004). A series of VERSE-LC calculations were executed using tortuosity factors of 1.0, 1.5, 2.0, 2.5 and 3.0 and a volume mean diameter $\left(\mathrm{D}_{4}\right)$ of $483 \mu \mathrm{m}$ in Table 6-9 for Microtrac ${ }^{\circledR}$ Log-Normal distribution. Prior to execution of the runs, the total capacity of the resin, $\rho_{\mathrm{b}} \mathrm{C}_{\mathrm{T}}$, in $\mathrm{mmol} / \mathrm{ml}$ was adjusted to match the equilibrium cesium loading observed in the experiment. The AN-105 isotherm parameters $\left(C_{T}\right.$ and $\left.\beta\right)$ for the spherical Resorcinol-Formaldehyde resin are specified in Table 4-7.

Figure 7-1 shows a comparison of the transient aqueous cesium concentration for Experiment 2 to the VERSE-LC simulation for various tortuosity factors set to 1.0, 1.5, 2.0, 2.5 and 3.0. The VERSE-LC simulation represents the transient cesium concentration exiting the CSTR upstream of the differential column. The VERSE-LC simulation using a tortuosity factor of 1.5 provides excellent agreement with the data from Experiment 2. Therefore, particle kinetics and column breakthrough assessment will be made using the following average particle radius and tortuosity factor for spherical RF.

$$
<\mathrm{r}_{\mathrm{p}}>=241.5 \mu \mathrm{m} \text { and } \tau=1.5
$$

Figure 7-2 shows the transient cesium solid loading computed from the VERSE-LC simulation for Experiment 2 using the parameter settings from Eq. (7-3).

\subsection{SRNL Particle Kinetics Rig Assessment}

To evaluate the accuracy of the parameters, $<\mathrm{r}_{\mathrm{p}}>$ and $\tau$, predictions made by VERSE-LC were compared with additional data from the SRNL particle kinetics rig. Additional experiments 
included variations in bed flowrate, state and type of RF resin, and temperature effect on particle kinetics. These comparisons are shown in Figures 7-3 through 7-14.

VERSE-LC models were compared with SRNL particle kinetics rig data from Experiments 1 and 3 which used data from the SRNL particle kinetics rig, Table 4-6 (King et al., 2004). The purpose of these experiments was to assess the impact of "low" and "high" bed flowrates on particle kinetics. The bed flowrates were set to 90 and $0.5 \mathrm{ml} / \mathrm{min}$ for Experiments 1 and 3, respectively. Prior to execution of the runs, the total capacity of the resin, $\rho_{b} C_{T}$, in $\mathrm{mmol} / \mathrm{ml}$ was adjusted to match the equilibrium cesium loading observed in the experiment. Figures 7-3 and 7-4 show the transient aqueous cesium concentration and solid loading, respectively, for Experiment 1. The data point at 18 minutes appears to be an outlier. The VERSE-LC simulation has excellent agreement with the later data points. Figures 7-5 and 7-6 show the transient aqueous cesium concentration and solid loading, respectively, for Experiment 3. The VERSELC simulation shows poor agreement at intermediate times during the transient. The reasons for the discrepancy between the VERSE-LC simulation and the Experiment 3 data are:

- The SRNL particle kinetics rig has a single CSTR with a volume of $120 \mathrm{ml}$. The VERSE-LC model is restricted to two CSTRs with a volume of $60 \mathrm{ml}$ each. One CSTR upstream and the other downstream of the differential column.

- The SRNL particle kinetics rig contains approximately $2.5 \mathrm{ft}$ of tubing with an ID of 5/64 in. At a bed flowrate of $0.5 \mathrm{ml} / \mathrm{min}$, the transit time of simulant in the tubing is about 4.6 min. The VERSE-LC model does not include this lag time between the CSTRs and the differential column. This is not a problem at the higher bed flowrates (shorter transit times).

VERSE-LC models were compared with SRNL particle kinetics rig data from Experiments 4, 5 and 6 which used data from the SRNL particle kinetics rig, Table 4-4 (King et al., 2004). The purpose of these experiments was to assess the impact of used spherical, unused spherical and granular RF resin on particle kinetics. The bed flowrates were set to $30 \mathrm{ml} / \mathrm{min}$ at a temperature of $25^{\circ} \mathrm{C}$. Prior to execution of the runs, the total capacity of the resin, $\rho_{\mathrm{b}} \mathrm{C}_{\mathrm{T}}$, in $\mathrm{mmol} / \mathrm{ml}$ was adjusted to match the equilibrium cesium loading observed in the experiment. Figures 7-7 and 7-8 show the transient aqueous cesium concentration and solid loading, respectively, for Experiment 4. Experiment 4 utilized used spherical RF and is a repeat of Experiment 2 with a lower initial aqueous cesium concentration. The VERSE-LC simulation shows faster particle kinetics than the experimental data early in the transient. Figures 7-9 and 7-10 show the transient aqueous cesium concentration and solid loading, respectively, for Experiment 5. Experiment 5 utilized unused spherical RF resin that had not been subjected to compressibility testing at PNNL. The results are very similar to those of Experiment 4; VERSE-LC predicting faster particle kinetics. Figures 7-11 and 7-12 show the transient aqueous cesium concentration and solid loading, respectively, for Experiment 6 . Experiment 6 consists of RF in the granular form, similar to SuperLig ${ }^{\circledR}$ 644. A spherically-equivalent volume mean diameter of $608 \mu \mathrm{m}$ was used based on wet sieve Rosin-Rammler in Table 6-8. The physical properties and AN-105 isotherm for spherical RF were utilized. The pore diffusivity of $\mathrm{Cs}^{+}$in granular $\mathrm{RF}$ was assumed to be same as that in spherical RF. The total capacity of the resin, $\rho_{b} C_{T}$, in $\mathrm{mmol} / \mathrm{ml}$ was increased to match the equilibrium cesium loading observed in the experiment. After all these 
assumptions and adjustments, there is excellent agreement between the VERSE-LC simulation and the experimental data.

A VERSE-LC model was compared with SRNL particle kinetics rig data from Experiment 7 which used data from the SRNL particle kinetics rig, Table 4-2 (King et al., 2004). The purpose of this experiment was to assess the impact of temperature on particle kinetics. Experiment 7 is a repeat of Experiment 4 at a higher temperature of $45^{\circ} \mathrm{C}$. Figures $7-13$ and 7-14 show the transient aqueous cesium concentration and solid loading, respectively, for Experiment 7. Our current cesium isotherm model for RF was developed at a temperature of $25^{\circ} \mathrm{C}$ and therefore not applicable. The detailed thermodynamic isotherm model needs additional batch contact experiments at difference temperatures to fit the equilibrium constants in the mass-actions equations as functions of temperature. These figures emphasize the need for a comprehensive database of isotherm data and particle kinetics data at various temperatures.

Table 7-1. OLI diffusivities of Cs + in simulants and LAW IX feeds at $25^{\circ} \mathrm{C}$.

\begin{tabular}{|c|c|c|c|c|}
\hline Feed or Simulant & $\begin{array}{c}\text { Composition } \\
\text { Variability }\end{array}$ & $\begin{array}{c}\text { Diffusivity } \\
\left(\mathrm{m}^{2} / \mathrm{s}\right)\end{array}$ & $\begin{array}{l}\text { Diffusivity } \\
\left(\mathrm{cm}^{2} / \mathrm{min}\right)\end{array}$ & Ratio \\
\hline AN-105 Simulant & 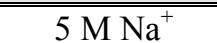 & $2.6328 \mathrm{E}-10$ & 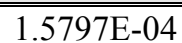 & 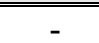 \\
\hline AZ-102 Simulant & $5 \mathrm{M} \mathrm{Na}^{+}$ & $1.8996 \mathrm{E}-10$ & $1.1398 \mathrm{E}-04$ & - \\
\hline Hot Commissioning Operation & Nominal & $5.6046 \mathrm{E}-10$ & $3.3628 \mathrm{E}-04$ & - \\
\hline Envelope B Operation & Nominal & $8.7046 \mathrm{E}-10$ & $5.2228 \mathrm{E}-04$ & - \\
\hline Subsequent Operation & Nominal & $6.4681 \mathrm{E}-10$ & $3.8809 \mathrm{E}-04$ & - \\
\hline Hot Commissioning Operation & {$\left[\mathrm{K}^{+}\right]+20 \%$} & $4.8857 \mathrm{E}-10$ & $2.9314 \mathrm{E}-04$ & 0.87 \\
\hline Hot Commissioning Operation & {$\left[\mathrm{K}^{+}\right]-20 \%$} & $6.2890 \mathrm{E}-10$ & $3.7734 \mathrm{E}-04$ & 1.12 \\
\hline Hot Commissioning Operation & {$\left[\mathrm{Na}^{+}\right]+20 \%$} & $2.6241 \mathrm{E}-11$ & $1.5745 \mathrm{E}-05$ & 0.05 \\
\hline Hot Commissioning Operation & {$\left[\mathrm{Na}^{+}\right]-20 \%$} & $1.0540 \mathrm{E}-09$ & $6.3240 \mathrm{E}-04$ & 1.88 \\
\hline Hot Commissioning Operation & {$\left[\mathrm{OH}^{-}\right]+20 \%$} & $6.1161 \mathrm{E}-10$ & $3.6697 \mathrm{E}-04$ & 1.09 \\
\hline Hot Commissioning Operation & {$\left[\mathrm{OH}^{-}\right]-20 \%$} & $5.1332 \mathrm{E}-10$ & $3.0799 \mathrm{E}-04$ & 0.92 \\
\hline
\end{tabular}




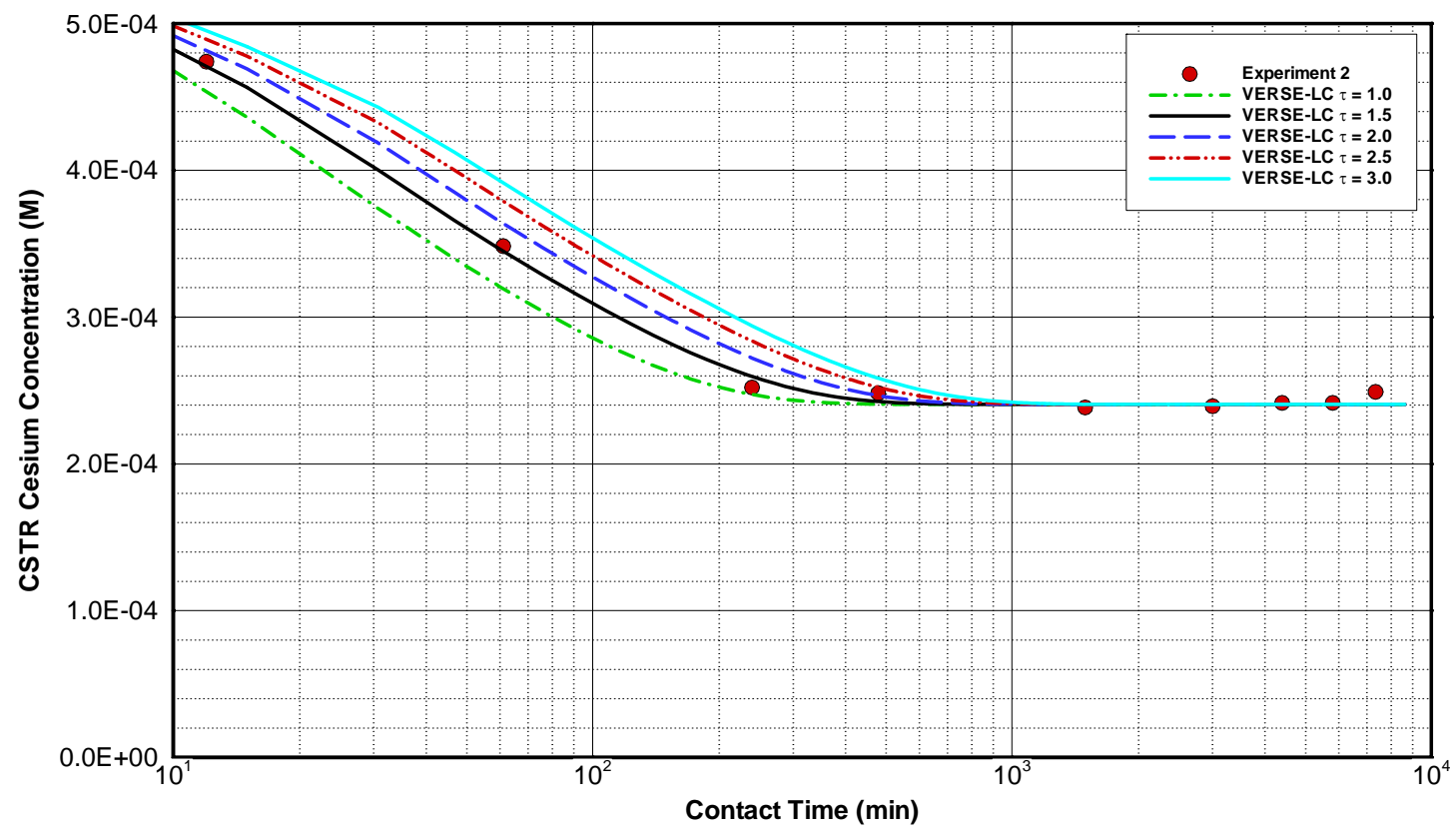

Figure 7-1. Transient aqueous cesium concentration during SRNL Experiment 2 with used spherical Resorcinol-Formaldehyde resin in AN-105 simulant at $25^{\circ} \mathrm{C}$. Tortuosity factor varied from 1 to 3 . Bed flowrate set to $30 \mathrm{ml} / \mathrm{min}$.

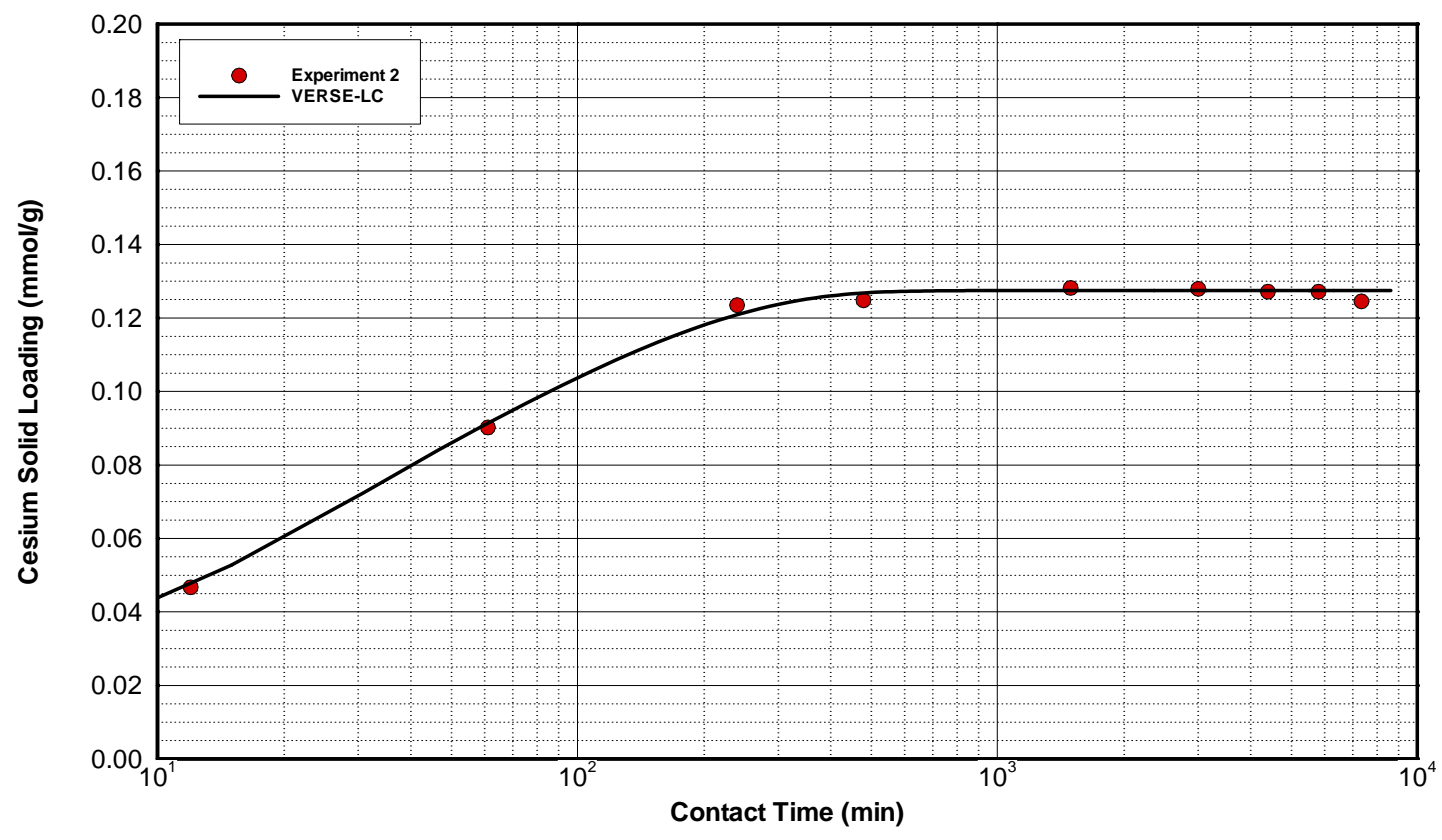

Figure 7-2. Transient cesium solid loading during SRNL Experiment 2 with used spherical Resorcinol-Formaldehyde resin in AN-105 simulant at $25^{\circ} \mathrm{C}$. Tortuosity factor set to 1.5 . Bed flowrate set to $30 \mathrm{ml} / \mathrm{min}$. 


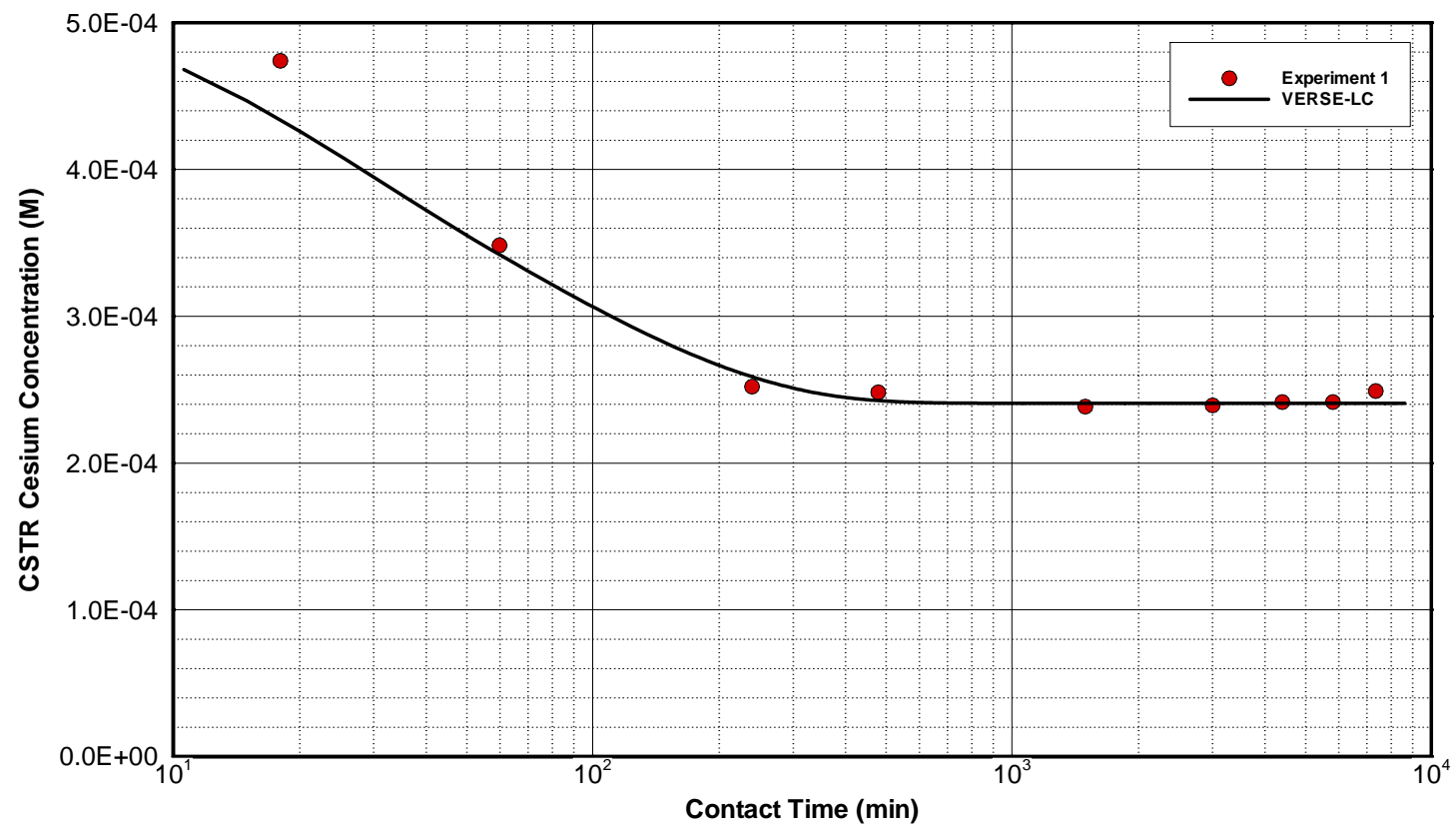

Figure 7-3. Transient aqueous cesium concentration during SRNL Experiment 1 with used spherical Resorcinol-Formaldehyde resin in AN-105 simulant at $25^{\circ} \mathrm{C}$. Bed flowrate set to $90 \mathrm{ml} / \mathrm{min}$.

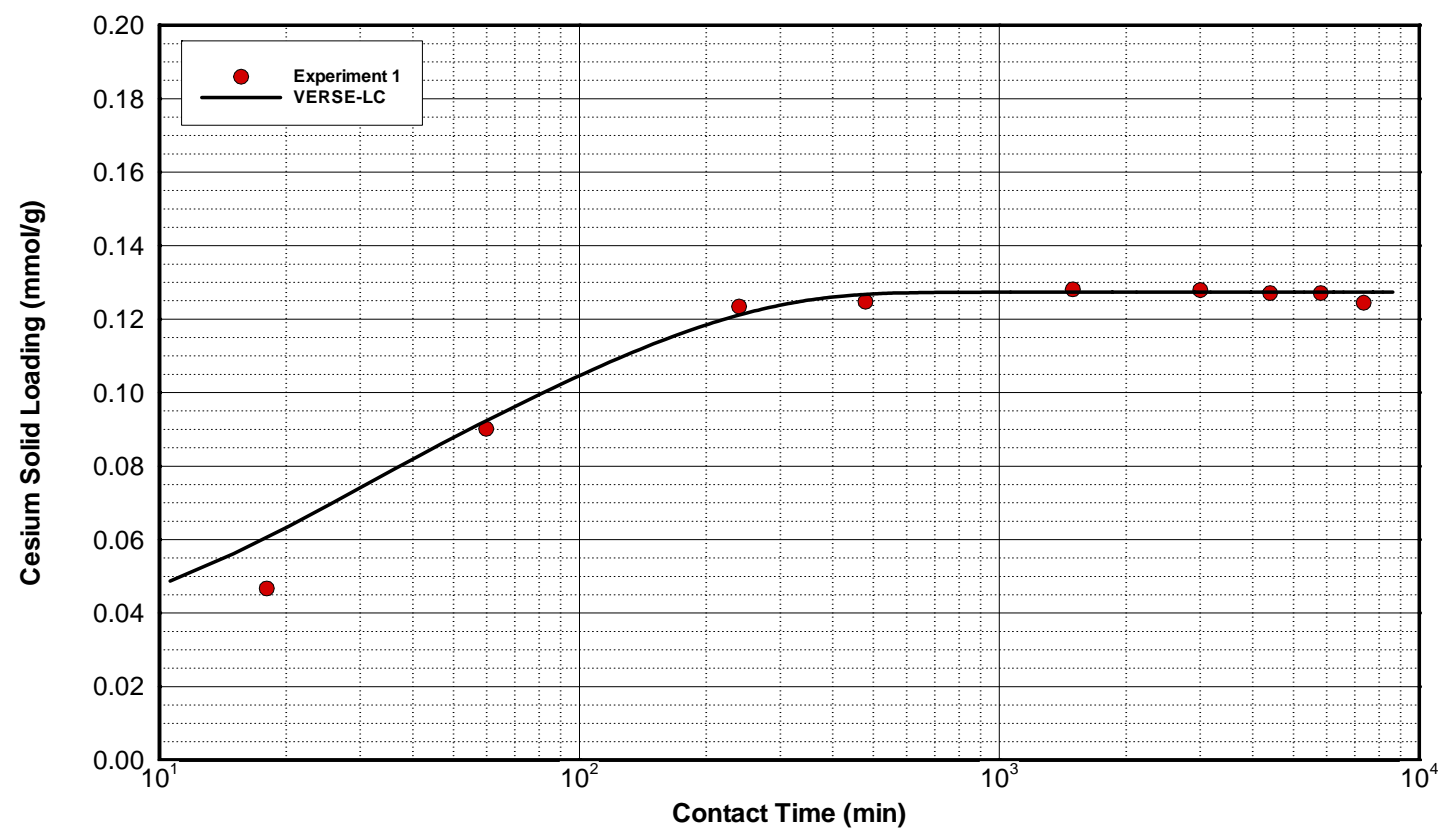

Figure 7-4. Transient cesium solid loading during SRNL Experiment 2 with used spherical Resorcinol-Formaldehyde resin in AN-105 simulant at $25^{\circ} \mathrm{C}$. Bed flowrate set to $90 \mathrm{ml} / \mathrm{min}$. 


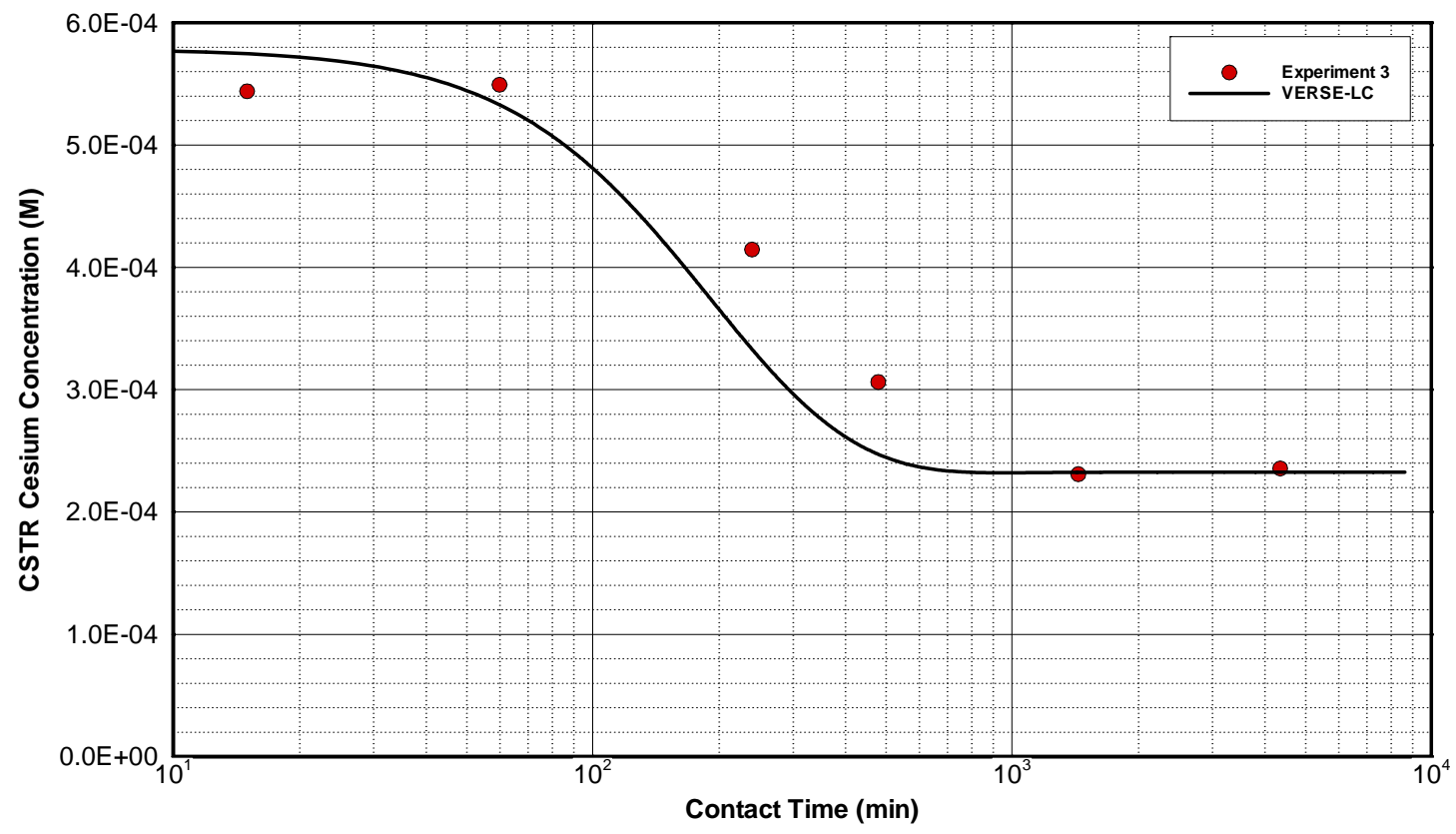

Figure 7-5. Transient aqueous cesium concentration during SRNL Experiment 3 with used spherical Resorcinol-Formaldehyde resin in AN-105 simulant at $25^{\circ} \mathrm{C}$. Bed flowrate set to $0.5 \mathrm{ml} / \mathrm{min}$.

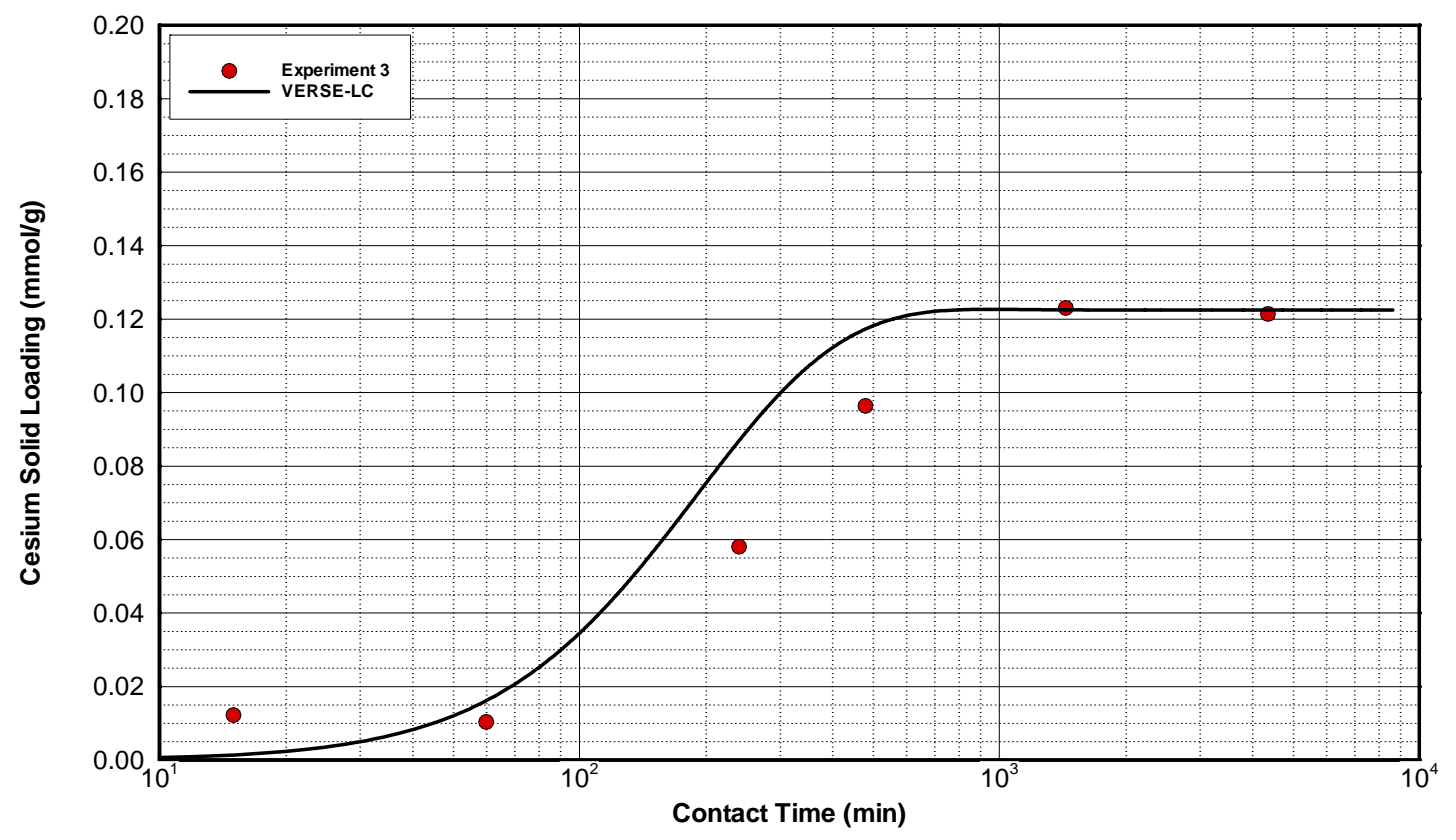

Figure 7-6. Transient cesium solid loading during SRNL Experiment 3 with used spherical Resorcinol-Formaldehyde resin in AN-105 simulant at $25^{\circ} \mathrm{C}$. Bed flowrate set to $0.5 \mathrm{ml} / \mathrm{min}$. 


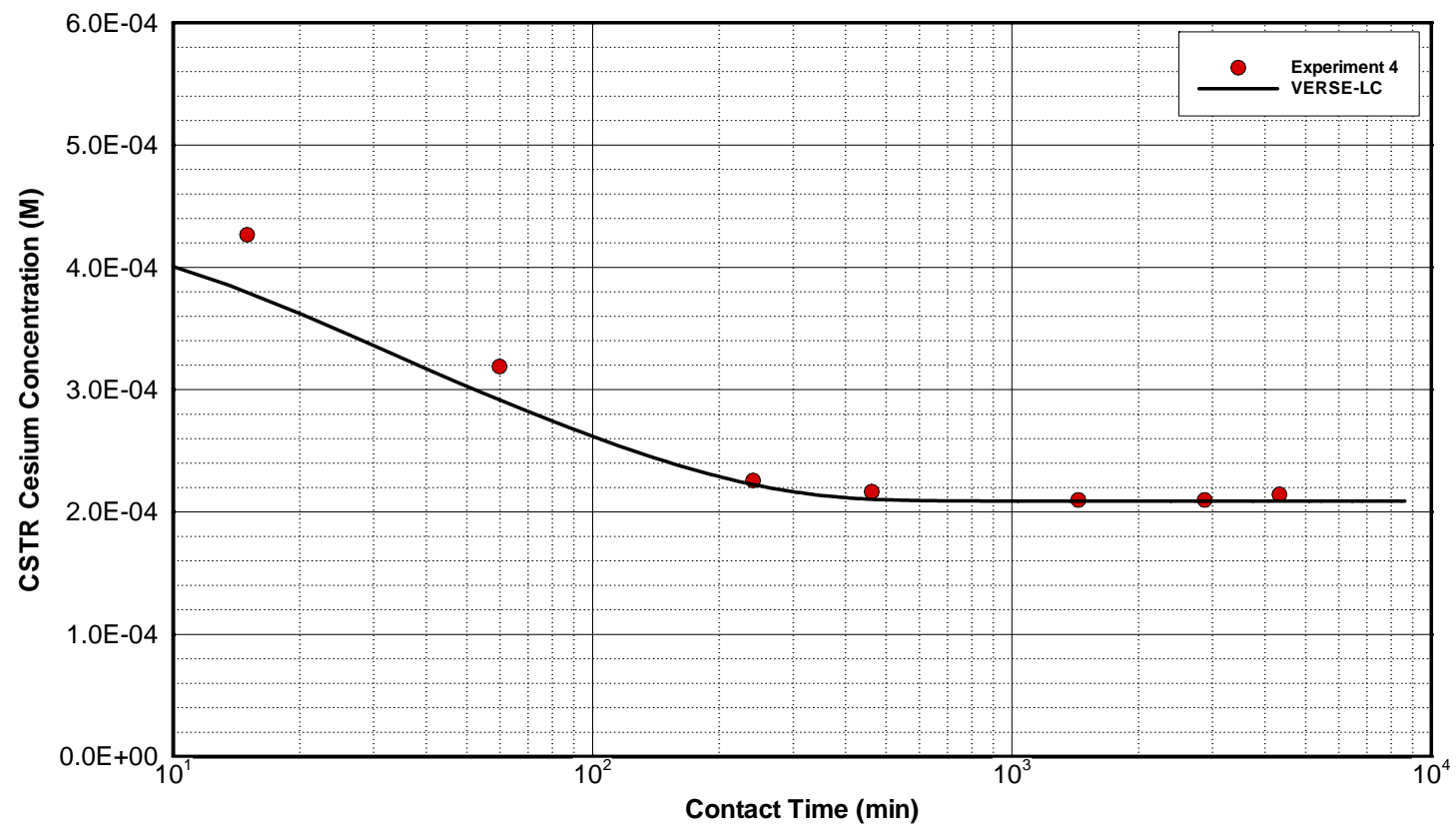

Figure 7-7. Transient aqueous cesium concentration during SRNL Experiment 4 with used spherical Resorcinol-Formaldehyde resin in AN-105 simulant at $25^{\circ} \mathrm{C}$. Bed flowrate set to $30 \mathrm{ml} / \mathrm{min}$.

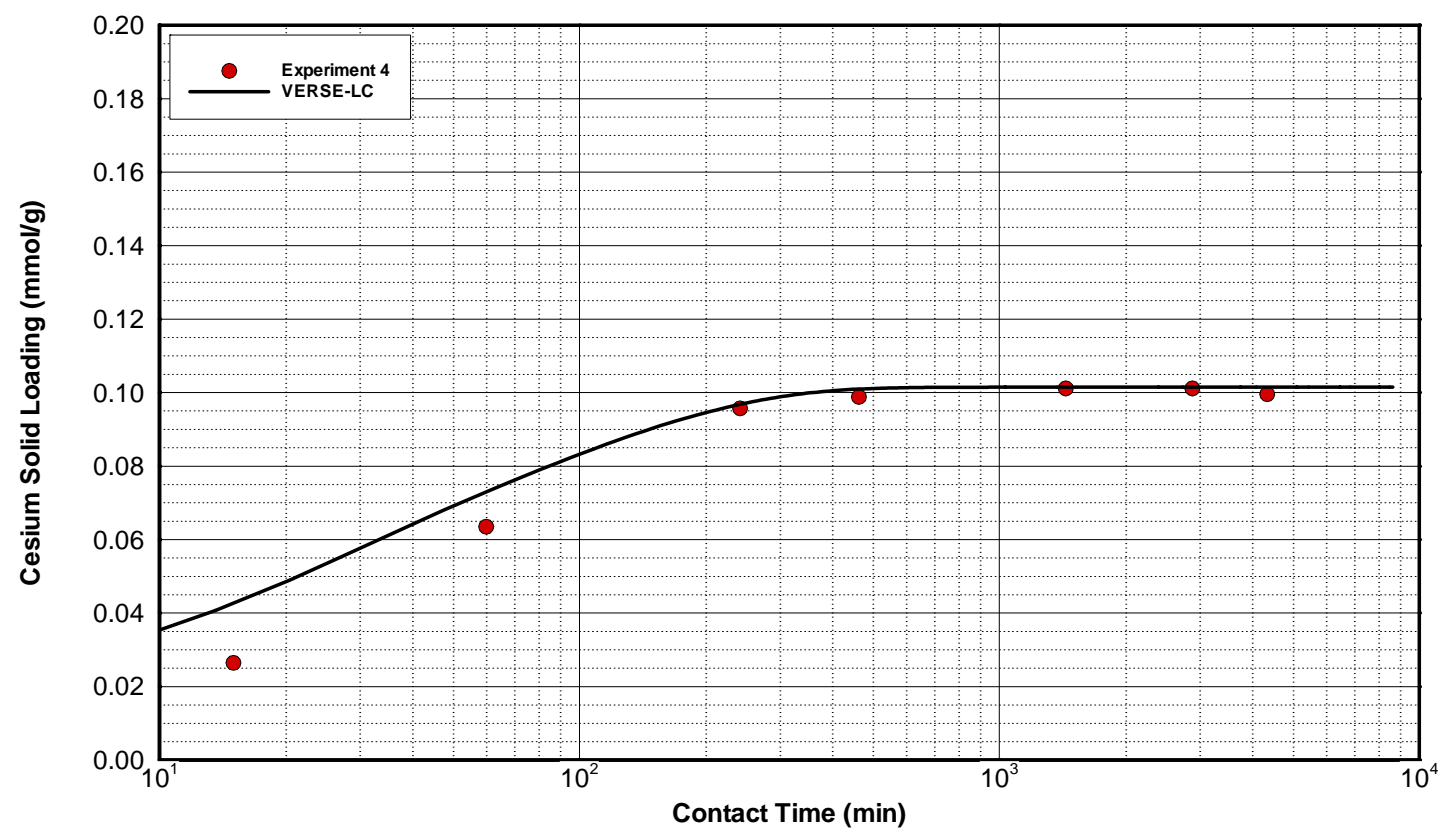

Figure 7-8. Transient cesium solid loading during SRNL Experiment 4 with used spherical Resorcinol-Formaldehyde resin in $\mathrm{AN}-105$ simulant at $25^{\circ} \mathrm{C}$. Bed flowrate set to $30 \mathrm{ml} / \mathrm{min}$. 


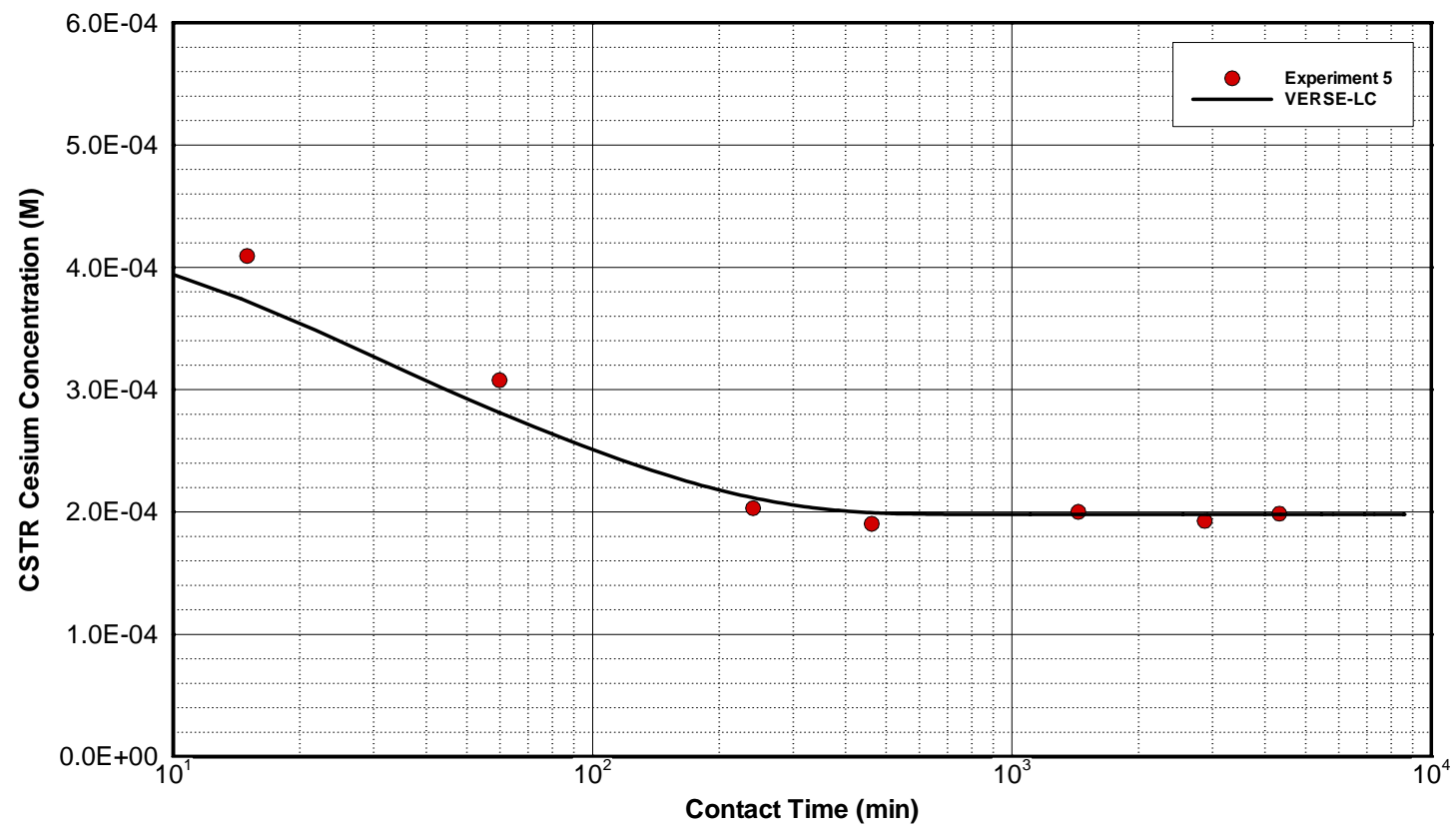

Figure 7-9. Transient aqueous cesium concentration during SRNL Experiment 5 with unused spherical Resorcinol-Formaldehyde resin in $\mathrm{AN}-105$ simulant at $25^{\circ} \mathrm{C}$. Bed flowrate set to $30 \mathrm{ml} / \mathrm{min}$.

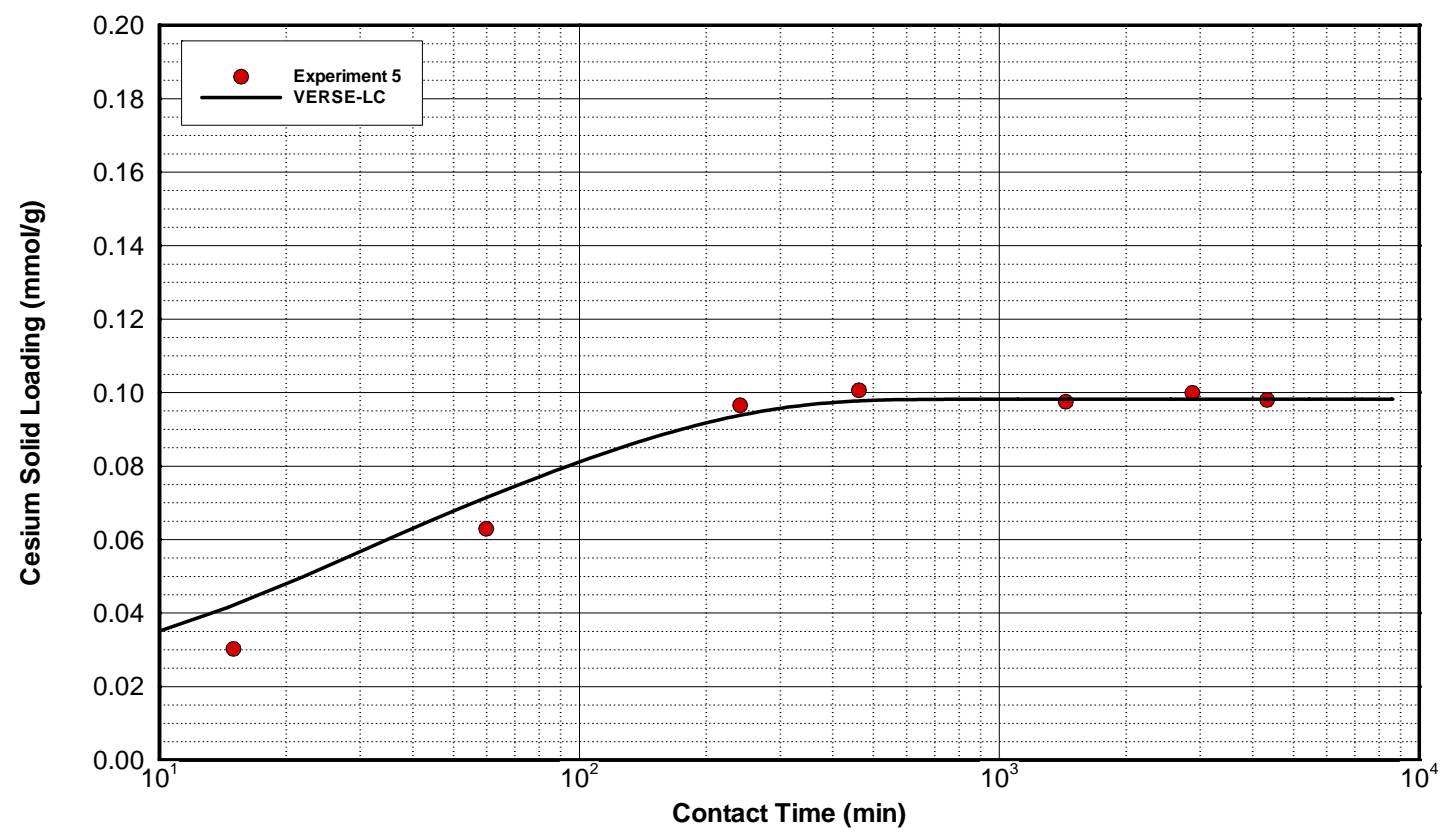

Figure 7-10. Transient cesium solid loading during SRNL Experiment 5 with unused spherical Resorcinol-Formaldehyde resin in AN-105 simulant at $25^{\circ} \mathrm{C}$. Bed flowrate set to $30 \mathrm{ml} / \mathrm{min}$. 
WSRC-TR-2004-00100, REVISION 0

SRT-RPP-2004-00019, REVISION 0

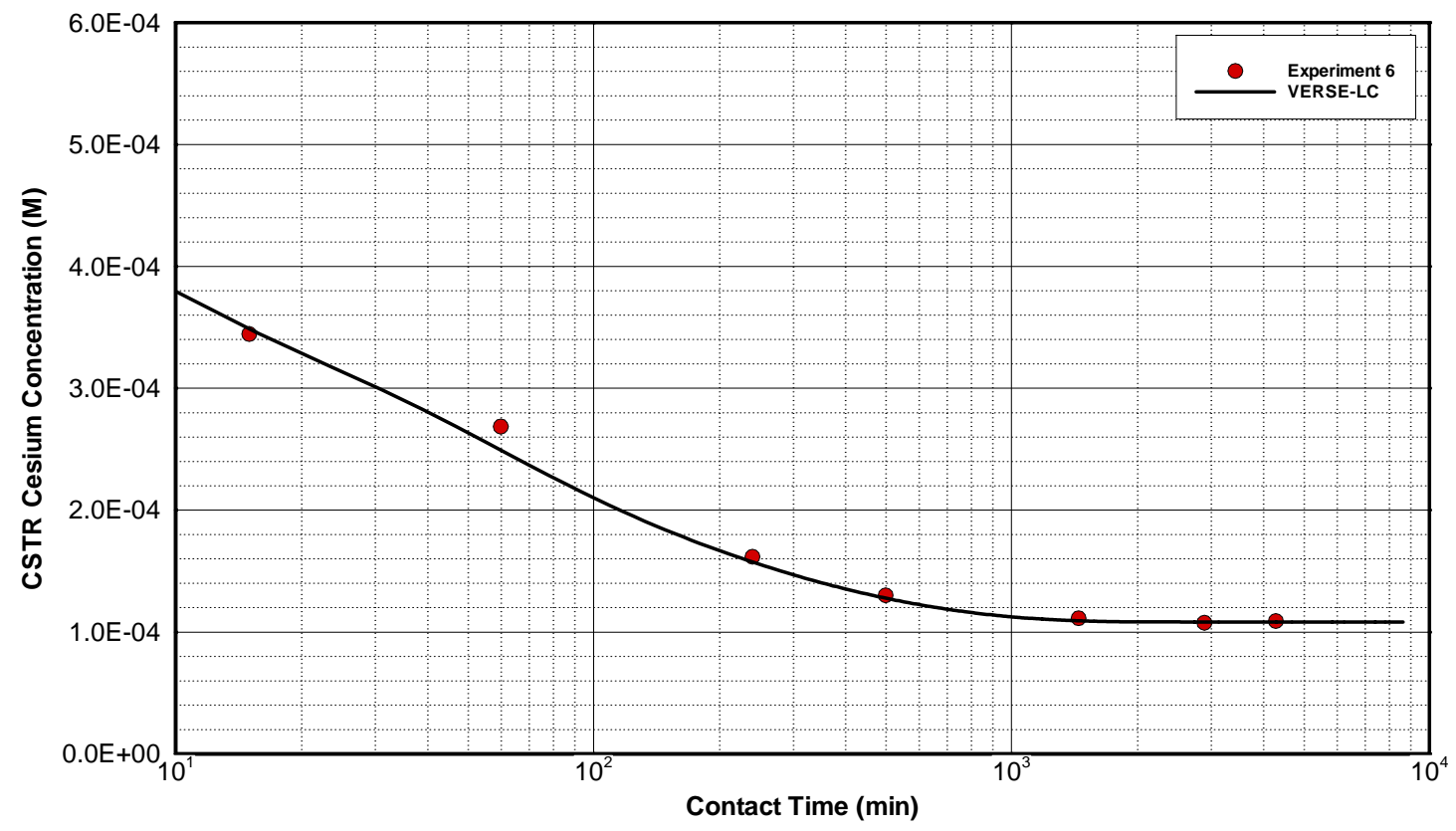

Figure 7-11. Transient aqueous cesium concentration during SRNL Experiment 6 with granular Resorcinol-Formaldehyde resin in AN-105 simulant at $25^{\circ} \mathrm{C}$. Bed flowrate set to $30 \mathrm{ml} / \mathrm{min}$.

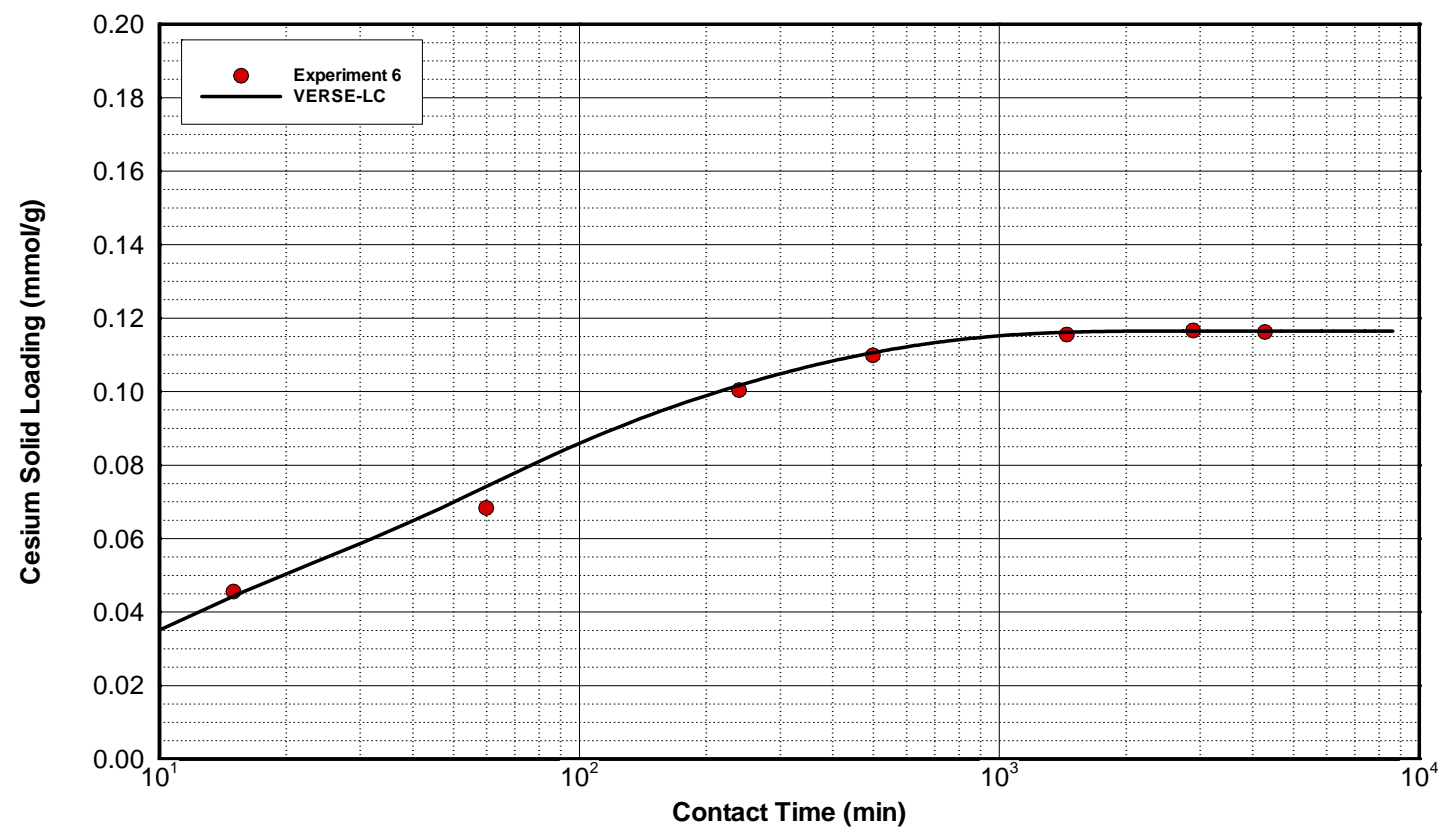

Figure 7-12. Transient cesium solid loading during SRNL Experiment 6 with granular Resorcinol-Formaldehyde resin in $\mathrm{AN}-105$ simulant at $25^{\circ} \mathrm{C}$. Bed flowrate set to $30 \mathrm{ml} / \mathrm{min}$. 


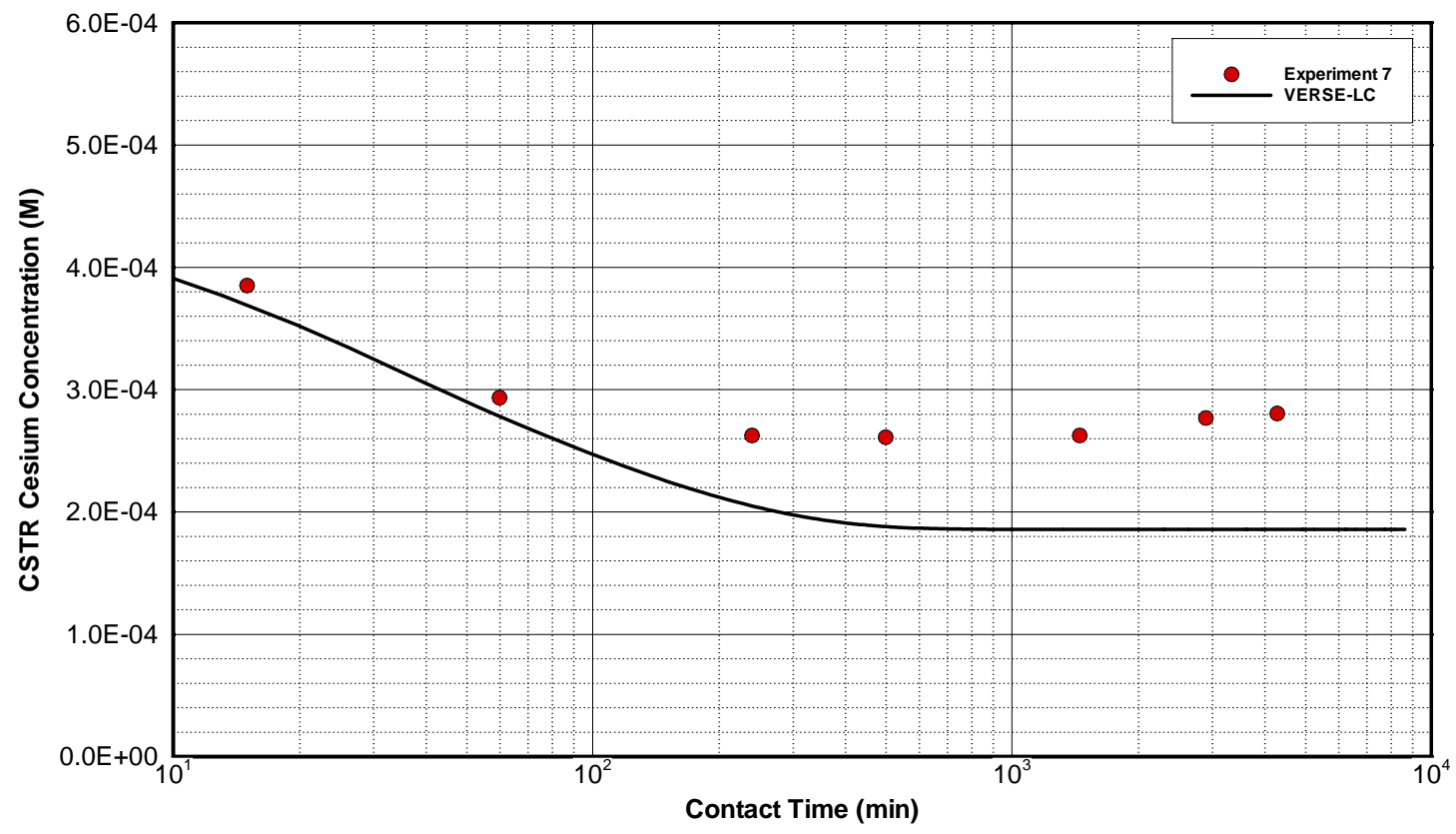

Figure 7-13. Transient aqueous cesium concentration during SRNL Experiment 7 with used spherical Resorcinol-Formaldehyde resin in AN-105 simulant at $45^{\circ} \mathrm{C}$. Bed flowrate set to $30 \mathrm{ml} / \mathrm{min}$.

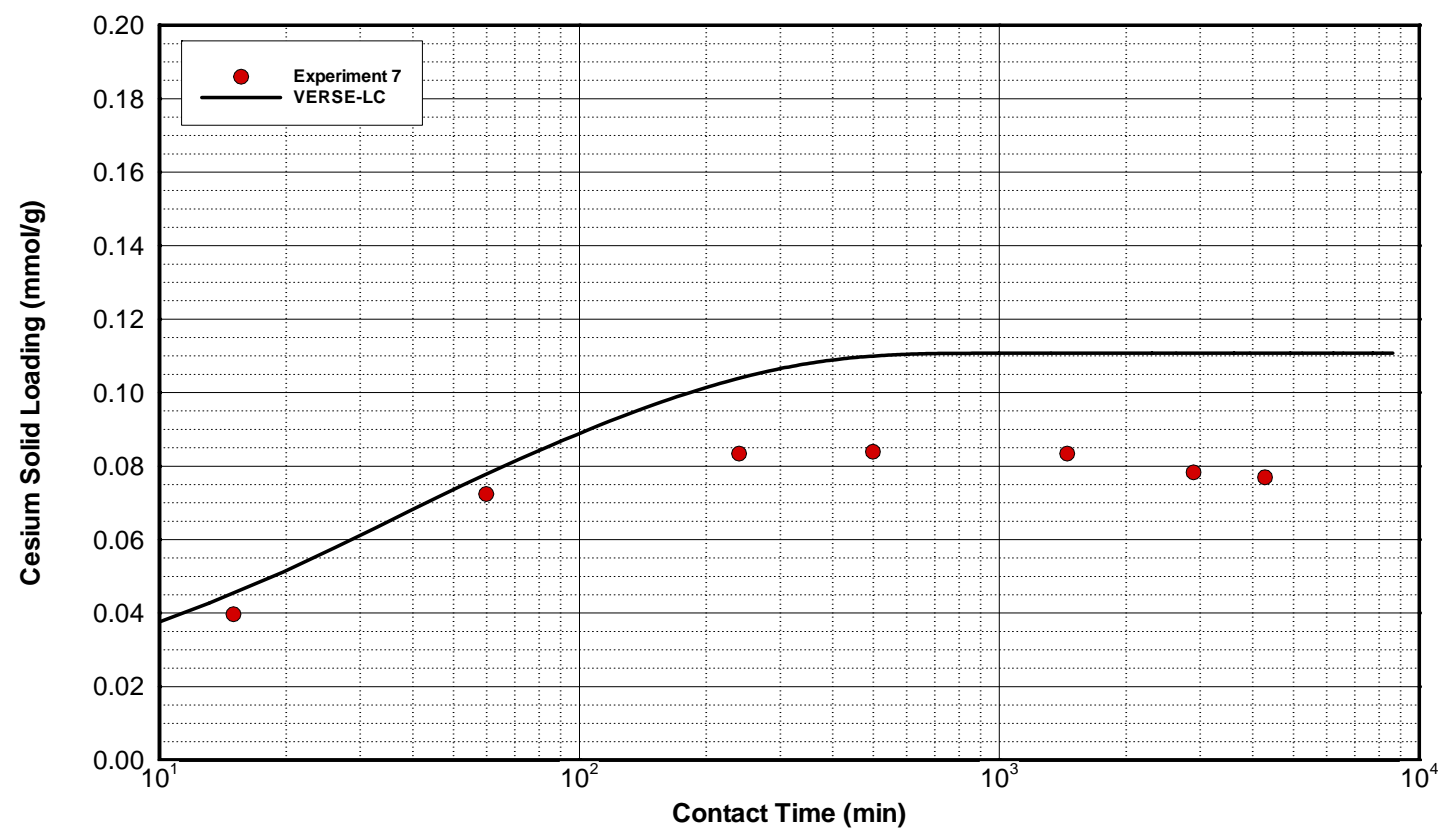

Figure 7-14. Transient cesium solid loading during SRNL Experiment 7 with used spherical Resorcinol-Formaldehyde resin in $\mathrm{AN}-105$ simulant at $44^{\circ} \mathrm{C}$. Bed flowrate set to $30 \mathrm{ml} / \mathrm{min}$. 


\subsection{Axial Dispersion and Film Diffusion}

For details on axial dispersion and film diffusion correlation values required to perform a VERSE-LC column performance analysis see Hamm et al. (2000b, preliminary Cs removal performance using SuperLig ${ }^{\circledR} 644$ report), Hamm et al. (2000c, preliminary Tc removal performance using SuperLig ${ }^{\circledR} 639$ report), and Hamm et al. (2002b, Cs removal performance using CST report).

In this section we present the correlations used to define: (1) axial dispersion along the bed length and (2) mass transfer across the liquid film separating the bed fluid from its neighboring particle pore fluid.

\subsection{Film Diffusion}

For the laboratory-scale column tests and proposed full-scale facility the Reynolds number range is approximately 0.1 to 1.0 . With respect to published literature this is a very low Reynolds number range. Numerous mass transfer correlations exist as discussed by Foo and Rice (1975, see their Figure 2). One of the correlations compared in Foo and Rice (1975) is one developed by Wilson and Geankoplis (1966) based on low Reynolds number data. Large variations between correlations can be seen; however, our sensitivity to the film coefficient is low as shown in the section discussing sensitivities. Since VERSE-LC has the Wilson and Geankoplis (1966) correlation as an option and this correlation falls somewhat within the spread of available low Reynolds number data we have chosen it for all the column simulations in this report. For each ion species considered, the Wilson and Geankoplis (1966) correlation is expressed as:

$$
\mathrm{J} \equiv\left[\frac{\mathrm{k}_{\mathrm{fi}}}{\mathrm{u} \varepsilon_{\mathrm{b}}}\right] \mathrm{Sc}_{\mathrm{i}}^{2 / 3}=\frac{1.09}{\varepsilon_{\mathrm{b}}} \operatorname{Re}^{-2 / 3},
$$

where the Reynolds number is defined as

$$
\operatorname{Re} \equiv \frac{2 \mathrm{R}_{\mathrm{p}} \rho_{\mathrm{w}} \mathrm{u} \varepsilon_{\mathrm{b}}}{\mu_{\mathrm{w}}},
$$

and the Schmidt number for each species is defined as

$$
\mathrm{Sc}_{\mathrm{i}} \equiv \frac{\mu_{\mathrm{w}}}{\rho_{\mathrm{w}} \mathrm{D}_{\mathrm{i}}^{\infty}} .
$$

A standard deviation of approximately $25 \%$ is reported for Eq. (8-1) by Wilson and Geankoplis (1966), while from comparison to the various correlations presented by Foo and Rice (1975) a standard deviation of $100 \%$ to $200 \%$ is observed.

\subsection{Axial Dispersion}

Axial dispersion in packed columns is the result of mechanical dispersion added onto molecular diffusion. For practical flowrates mechanical dispersion dominates. For well-packed columns of 
sufficient diameter such that wall effects (i.e., channeling) are minimal a variety of correlations exist for long column performance. A brief discussion of minimum column sizing is presented in Brooks (1994).

In the low Reynolds number range of interest the Chung and Wen (1968) correlation is applicable for sufficiently large columns (i.e., large diameter and length) and is expressed as:

$$
\mathrm{E}_{\mathrm{b}}=\frac{2 \mathrm{R}_{\mathrm{p}} \mathrm{u} \varepsilon_{\mathrm{b}}}{0.2+0.011 \mathrm{Re}^{0.48}},
$$

where the standard deviation of this correlation based on all available data points was reported to be $46 \%$. Equation (8-2) applies for only sufficiently large columns and correction factors must be considered for columns with small diameters and/or short active bed lengths.

\subsubsection{Radial Flow Maldistribution}

Flow maldistribution is caused by packing irregularities. As such the bed porosity varies over the cross-section of a column and increases as the outer wall is approached (even for wellpacked columns). "Channeling" near the wall becomes more serious for smaller column diameters and larger particle sizes. As a "rule of thumb" Helfferich (1962) states that this effect becomes significant when the bed diameter is less than thirty times the particle diameter.

The experimental and mathematical basis for this rule of thumb stems from the work of Schwartz and Smith (1953) and Morales et al. (1951). Their experimental efforts were for uniform packing of either spheres or cylinders using air-flowrates in the range of 145 to $547 \mathrm{~cm} / \mathrm{min}$. Over the range of their database they concluded that:

- The radial velocity profile (normalized) is independent of total flowrate and

- The divergence of the radial velocity profile from uniform behavior is less than $20 \%$ for column diameter to particle diameter ratios greater than 30 .

A measure of the degree of non-uniformity in the radial velocity profiles can be made by looking at the ratio of peak-to-average velocity. Based on the limited database of Schwartz and Smith (1953) this peak-to-average velocity ratio is plotted versus column-to-particle diameter ratio in Figure 8-1. As illustrated in Figure 8-1 velocity ratios greater than $100 \%$ can occur for columnto-particle diameter ratios less than 10 and beyond $\sim 50$ the impact is negligible. Also shown in Figure 8-1 is a least squares fit of the data in the power law form:

$$
\frac{\mathrm{u}_{\text {peak }}}{\mathrm{u}_{\mathrm{CL}}}=\left\{\begin{array}{cc}
4.3786\left(\frac{\mathrm{D}}{2<\mathrm{R}_{\mathrm{p}}>}\right)^{-0.372935} & \text { for } \frac{\mathrm{D}}{2<\mathrm{R}_{\mathrm{p}}>}<52.44 \\
1.0 & \text { for } \frac{\mathrm{D}}{2<\mathrm{R}_{\mathrm{p}}>} \geq 52.44
\end{array}\right. \text {. }
$$

Note that Eq. (8-3) is based on packed beds with uniformly shaped cylinders and air-flowrates in the range of 145 to $547 \mathrm{~cm} / \mathrm{min}$. This correlation may be suspect for conditions of non- 
uniformly shaped particles with liquid flows in the range of 0.5 to $12 \mathrm{~cm} / \mathrm{min}$ as applies to the various column tests considered in this report.

Dorweiler and Fahien (1959) performed similar experiments that agreed with Schwartz and Smith (1953) and went to flowrates as low as $30 \mathrm{~cm} / \mathrm{min}$. In a later study by Fahien and Smith (1955) significant radial effects were observed for column-to-particle diameters less than 20.

\subsubsection{Headspace and Short Column Impacts}

Liles and Geankoplis (1960) conducted experiments to ascertain the impact short column lengths and void headspaces have on axial dispersion in packed bed columns. When end effects were eliminated they concluded that no effects of length on axial dispersion were observed. However, in the presence of end effects such as void headspaces significant effects of length can result. A summary of their data is presented in Figure 8-2 illustrating that the impact can become significant for columns under $\sim 20 \mathrm{~cm}$. Also shown in Figure 8-2 is a least squares fit of the data in the power law form:

$$
\frac{\mathrm{E}_{\mathrm{b}}(\mathrm{L})}{\mathrm{E}_{\mathrm{b}}(\mathrm{L} \rightarrow \infty)}=1.0+61.4988 \mathrm{~L}^{-1.20799}
$$

where column length is in units of $\mathrm{cm}$.

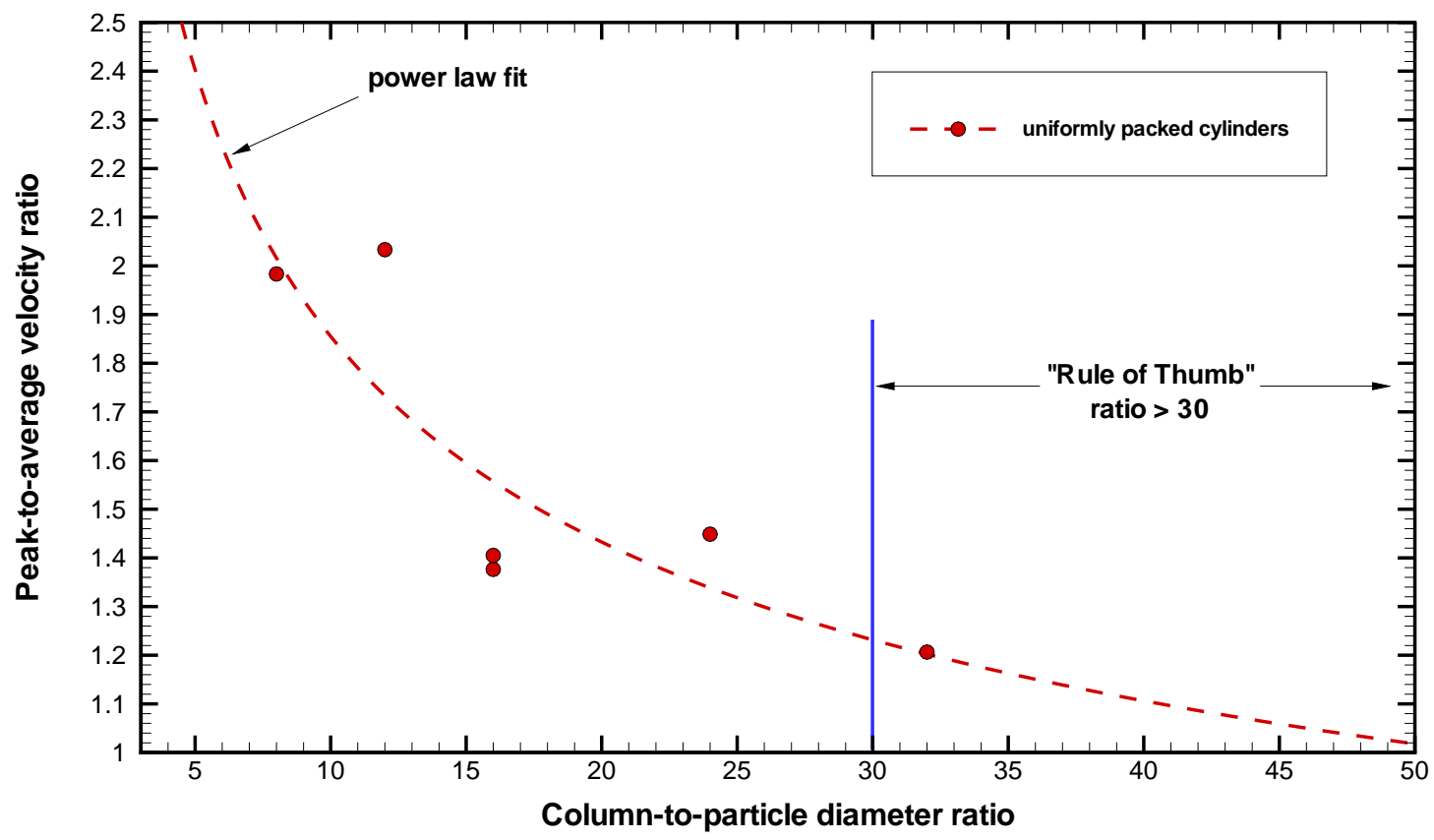

Figure 8-1. Estimated impact of column-to-particle diameter ratios on radial velocity profile based on the limited data by Schwartz and Smith (1953). 
WSRC-TR-2004-00100, REVISION 0

SRT-RPP-2004-00019, REVISION 0

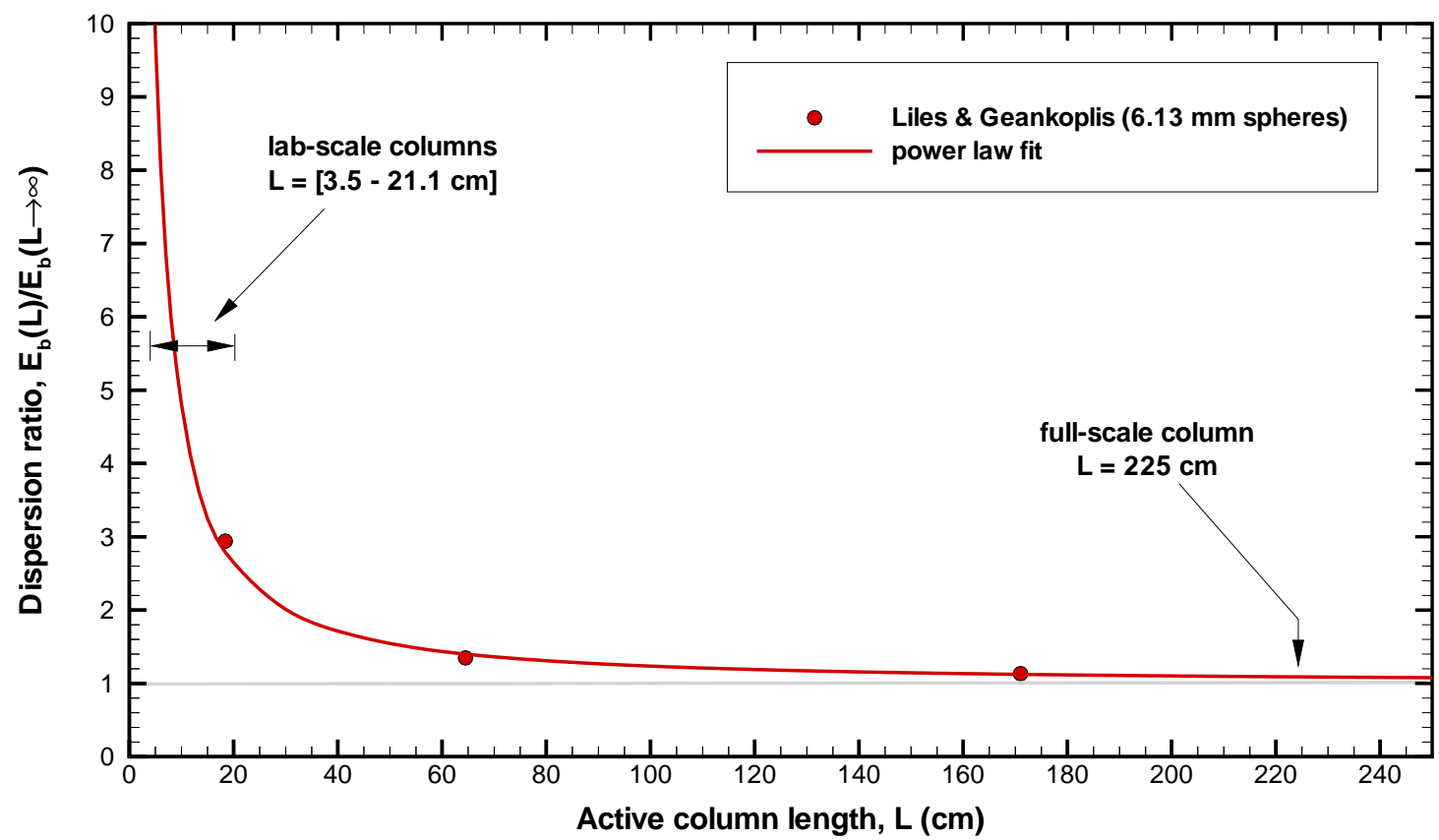

Figure 8-2. Estimation of the impact from end effects and short columns on axial dispersion based on the limited data by Liles and Geankoplis (1960). 


\subsection{Laboratory-Scale Column Assessments}

Several laboratory-scale column experiments have been performed to measure the cesium removal capability of the Resorcinol-Formaldehyde resin for feed conditions typical for a Hanford waste type (AZ-102).

VERSE-LC was used to model three column experiments where cesium breakthrough curves were experimentally measured by PNNL for granular and spherical Resorcinol-Formaldehyde in AZ-102 simulant (Fiskum et al., 2004). Figures 9-1 through 9-3 show comparisons of these model calculations to experimental data. The VERSE-LC input and output files for each of the simulations are listed in Appendix A.

\subsection{PNNL Column Data}

A series of VERSE-LC models were compared to PNNL column data as shown in Figures 9-1 through 9-3. The PNNL tests were designated as Column 6,7 and 8. A description of the tests is reported in Fiskum et al. (2004). The Column 6 test utilized granular ResorcinolFormaldehyde resin (Resin \#1) contacted with AZ-102 simulant. Column 7 and 8 tests utilized spherical Resorcinol-Formaldehyde resin (Resin \#3 and \#6, respectively) contacted with AZ-102 simulant.

Each ion exchange column was $10 \mathrm{~cm}$ tall with an inside diameter of $2.0 \mathrm{~cm}$. The fluid level above the resin bed was nominally maintained at a height of $9.5 \mathrm{ml}$. Depending on whether the resin was expanded or contracted, fluid volume above the resin bed nominally varied from $9 \mathrm{ml}$ to $17 \mathrm{ml}$. The dry mass of resin was computed using an $\mathrm{F}$-factor for damp resin in $\mathrm{H}$-form.

\subsubsection{Column 6 Data}

Column 6 tested granular Resorcinol-Formaldehyde resin (Resin \#1) with AZ-102 simulant. The mass of dry $\mathrm{H}$-form resin added to the column was 6.388 grams which expanded in AZ-102 simulant to a resin height of $6.6 \mathrm{~cm}$ and a resin volume of $20.7 \mathrm{ml}$. In the PNNL report, 20.4 $\mathrm{ml} / \mathrm{BV}$ was used to compute the $\mathrm{BVs}$, processed which corresponds to a resin height of $6.5 \mathrm{~cm}$. A column flowrate of AZ-102 simulant was established at an average value of $0.50 \mathrm{ml} / \mathrm{min}(1.45$ $\mathrm{BV} / \mathrm{hr}$ ) with an inlet cesium concentration of $48.7 \mu \mathrm{g} / \mathrm{ml}(3.66 \mathrm{E}-4 \mathrm{M})$. Cycle 1 cesium breakthrough did not occur until $20 \mathrm{BVs}, 50 \%$ breakthrough was at approximately $50 \mathrm{BVs}$.

The VERSE-LC model was compared with the PNNL Column 6, Cycle 1 load data from Table C.6 of Fiskum et al. (2004), which utilized granular Resorcinol-Formaldehyde resin (Resin \#1). In the model $<\mathrm{d}_{\mathrm{p}}>$ was assigned a mean particle size of $628 \mu \mathrm{m}$ from the data in Table 3.12 of Fiskum et al. (2004). Although the data were obtained for used spherical RF (Resin \#3), the model used the AZ-102 cesium isotherm parameters given in Table $4-7$ at $25^{\circ} \mathrm{C}$. The bulk diffusivity of $\mathrm{Cs}^{+}$in AZ-102 simulant is given in Table $7-1$ at $25^{\circ} \mathrm{C}$. The tortuosity factor of 1.5 , given in Section 7, was used to compute the pore diffusivity. Bed and particle porosity values were from Section 5 . The I-factor for converting from a dry H-form resin mass to a dry Na-form resin mass was 1.226, based on data from King et al. (2004). The bed density was estimated 
from the computed dry-Na resin mass of 7.832 grams and a bed volume of $20.7 \mathrm{ml}$. The total ionic capacity of the resin, $\mathrm{C}_{\mathrm{T}}$, in Table $7-1$, was decreased by $31 \%$ to match the $50 \%$ breakthrough point of the experimental data. From Figure 9-1 it can be seen that the model is in reasonable agreement with the data. The VERSE-LC cesium breakthrough curve is steeper beyond $50 \%$ breakthrough which translates to better particle kinetics in the model.

\subsubsection{Column 7 Data}

Column 7 tested spherical Resorcinol-Formaldehyde resin (Resin \#3) with AZ-102 simulant. The mass of dry H-form resin added to the column was 4.989 grams which expanded in AZ-102 simulant to a resin height of $5.7 \mathrm{~cm}$ and a resin volume of $17.9 \mathrm{ml}$. In the PNNL report, 18.5 $\mathrm{ml} / \mathrm{BV}$ (bed volume in $1 \mathrm{M} \mathrm{NaOH}$ ) was used to compute the BVs processed, which corresponds to a resin height of $5.9 \mathrm{~cm}$. A column flowrate of AZ-102 simulant was established at an average value of $0.483 \mathrm{ml} / \mathrm{min}(1.62 \mathrm{BV} / \mathrm{hr})$ with an inlet cesium concentration of $48.7 \mu \mathrm{g} / \mathrm{ml}$ (3.66E-4 M). Cycle 1 cesium breakthrough did not occur until $115 \mathrm{BVs}, 50 \%$ breakthrough was at approximately $150 \mathrm{BVs}$.

The VERSE-LC model was compared with the PNNL Column 7, Cycle 1 load data from Table C.7 of Fiskum et al. (2004), which utilized spherical Resorcinol-Formaldehyde resin (Resin \#3). In the model $\left\langle\mathrm{d}_{\mathrm{p}}>\right.$ was assigned a volume mean diameter of $483 \mu \mathrm{m}$ from Table 6-9 based on the Microtrac ${ }^{\circledR}$ Log-Normal distribution. The model used the AZ-102 cesium isotherm parameters given in Table $4-7$ at $25^{\circ} \mathrm{C}$. The bulk diffusivity of $\mathrm{Cs}^{+}$in AZ-102 simulant is given in Table $7-1$ at $25^{\circ} \mathrm{C}$. The tortuosity factor of 1.5 , given in Section 7 , was used to compute the pore diffusivity. Bed and particle porosity values were from Section 5. The I-factor for converting from a dry H-form resin mass to a dry Na-form resin mass was 1.226, based on data from King et al. (2004). The bed density was estimated from the computed dry-Na resin mass of 6.117 grams and a bed volume of $17.9 \mathrm{ml}$. The total ionic capacity of the resin, $\mathrm{C}_{\mathrm{T}}$, in Table 7-1, was increased by $4 \%$ to match the $50 \%$ breakthrough point of the experimental data. From Figure 9-2 it can be seen that the model using the pore diffusivity for AZ-102 exhibits slower particle kinetics than the data. The pore diffusivity of $\mathrm{Cs}^{+}$in AZ-102 was increased by a factor of 4.4 to provide better agreement with the experimental breakthrough data.

\subsubsection{Column 8 Data}

Column 8 tested spherical Resorcinol-Formaldehyde resin (Resin \#6) with AZ-102 simulant. The mass of dry H-form resin added to the column was 5.108 grams which expanded in AZ-102 simulant to a resin height of $5.79 \mathrm{~cm}$ and a resin volume of $18.2 \mathrm{ml}$. In the PNNL report, 19.2 $\mathrm{ml} / \mathrm{BV}$ (bed volume in $1 \mathrm{M} \mathrm{NaOH}$ ) was used to compute the BVs, processed which corresponds to a resin height of $6.1 \mathrm{~cm}$. A column flowrate of AZ-102 simulant was established at an average value of $0.51 \mathrm{ml} / \mathrm{min}(1.65 \mathrm{BV} / \mathrm{hr})$ with an inlet cesium concentration of $48.7 \mu \mathrm{g} / \mathrm{ml}$ (3.66E-4 M). Cycle 1 cesium breakthrough did not occur until $60 \mathrm{BVs}, 50 \%$ breakthrough was at approximately $90 \mathrm{BVs}$.

The VERSE-LC model was compared with the PNNL Column 8, Cycle 1 load data from Table C. 8 of Fiskum et al. (2004), which utilized spherical Resorcinol-Formaldehyde resin (Resin \#3). 
In the model $<d_{p}>$ was assigned a volume mean diameter of $483 \mu \mathrm{m}$ from Table 6-9 based on the Microtrac ${ }^{\circledR}$ Log-Normal distribution. The model used the AZ-102 cesium isotherm parameters given in Table $4-7$ at $25^{\circ} \mathrm{C}$. The bulk diffusivity of $\mathrm{Cs}^{+}$in AZ-102 simulant was given in Table $7-1$ at $25^{\circ} \mathrm{C}$. The tortuosity factor of 1.5 , given in Section 7 , was used to compute the pore diffusivity. Bed and particle porosity values were from Section 5. The I-factor for converting from a dry $\mathrm{H}$-form resin mass to a dry Na-form resin mass was 1.226, based on data from King et al. (2004). The bed density was estimated from the computed dry-Na resin mass of 6.117 grams and a bed volume of $17.9 \mathrm{ml}$. The total ionic capacity of the resin, $\mathrm{C}_{\mathrm{T}}$, in Table 7-1, was decreased by $61 \%$ to match the $50 \%$ breakthrough point of the experimental data. From Figure 9-3 it can be seen that the model using the pore diffusivity for AZ-102 exhibits slower particle kinetics than the data. The pore diffusivity of $\mathrm{Cs}^{+}$in AZ-102 was increased by a factor of 4.4 to provide better agreement with the experimental breakthrough data.

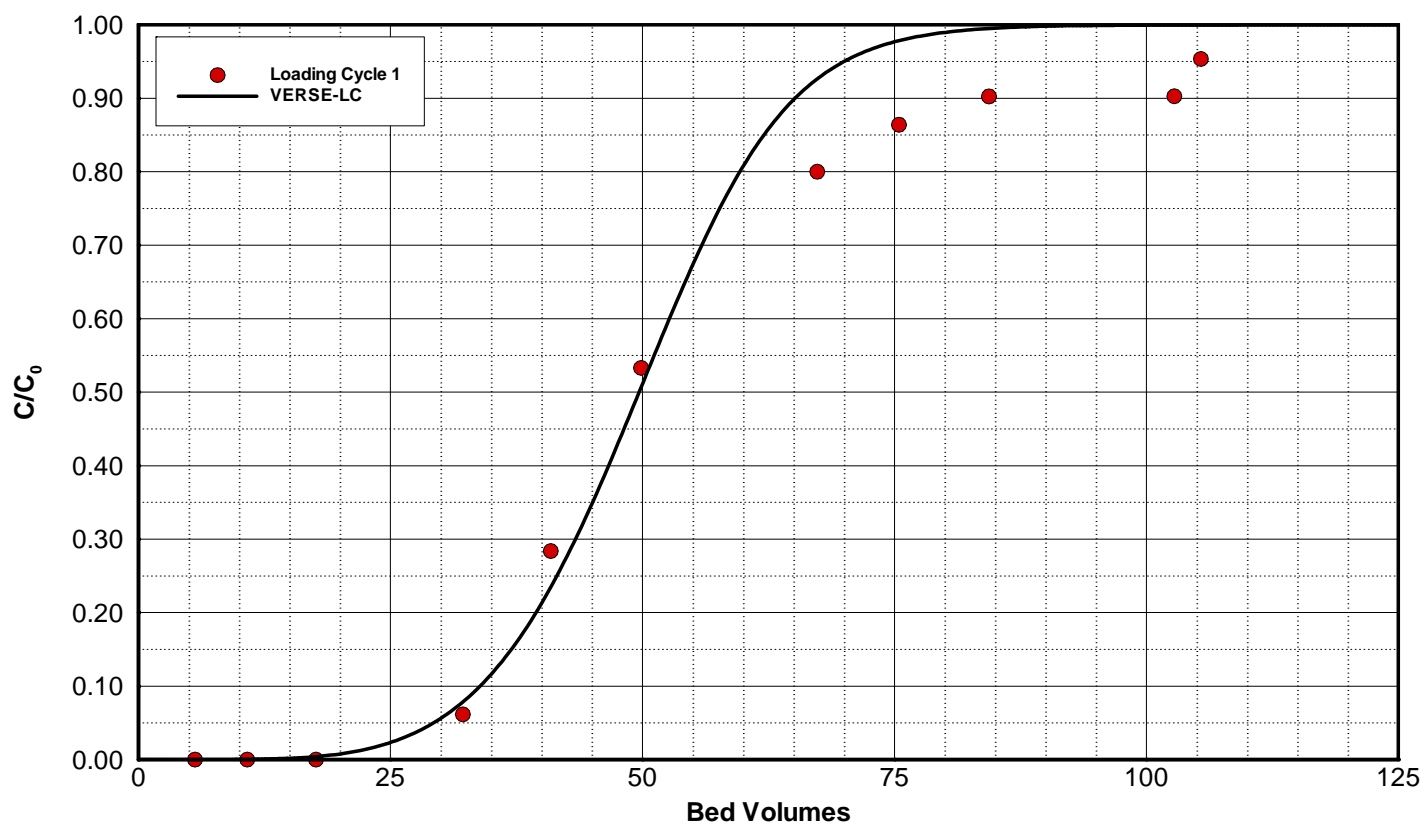

Figure 9-1. Comparison of VERSE-LC cesium breakthrough with data from the PNNL Column 6, Cycle 1 test. A sample of granular Resorcinol-Formaldehyde (Resin \#1) was tested with AZ-102 simulant. 


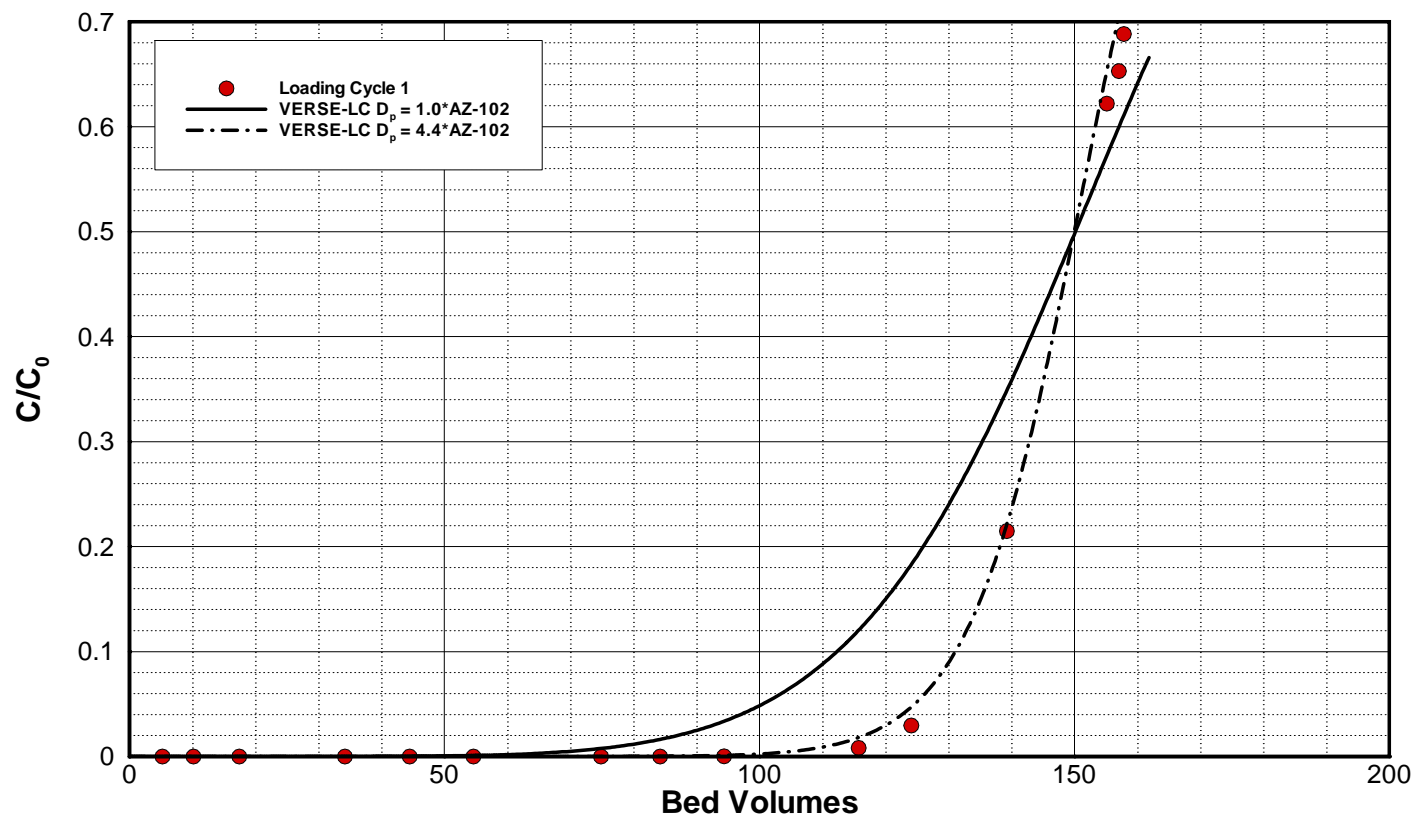

Figure 9-2. Comparison of VERSE-LC cesium breakthrough with data from the PNNL Column 7 Cycle 1 test. A sample of spherical Resorcinol-Formaldehyde (Resin \#3) was tested with AZ-102 simulant.

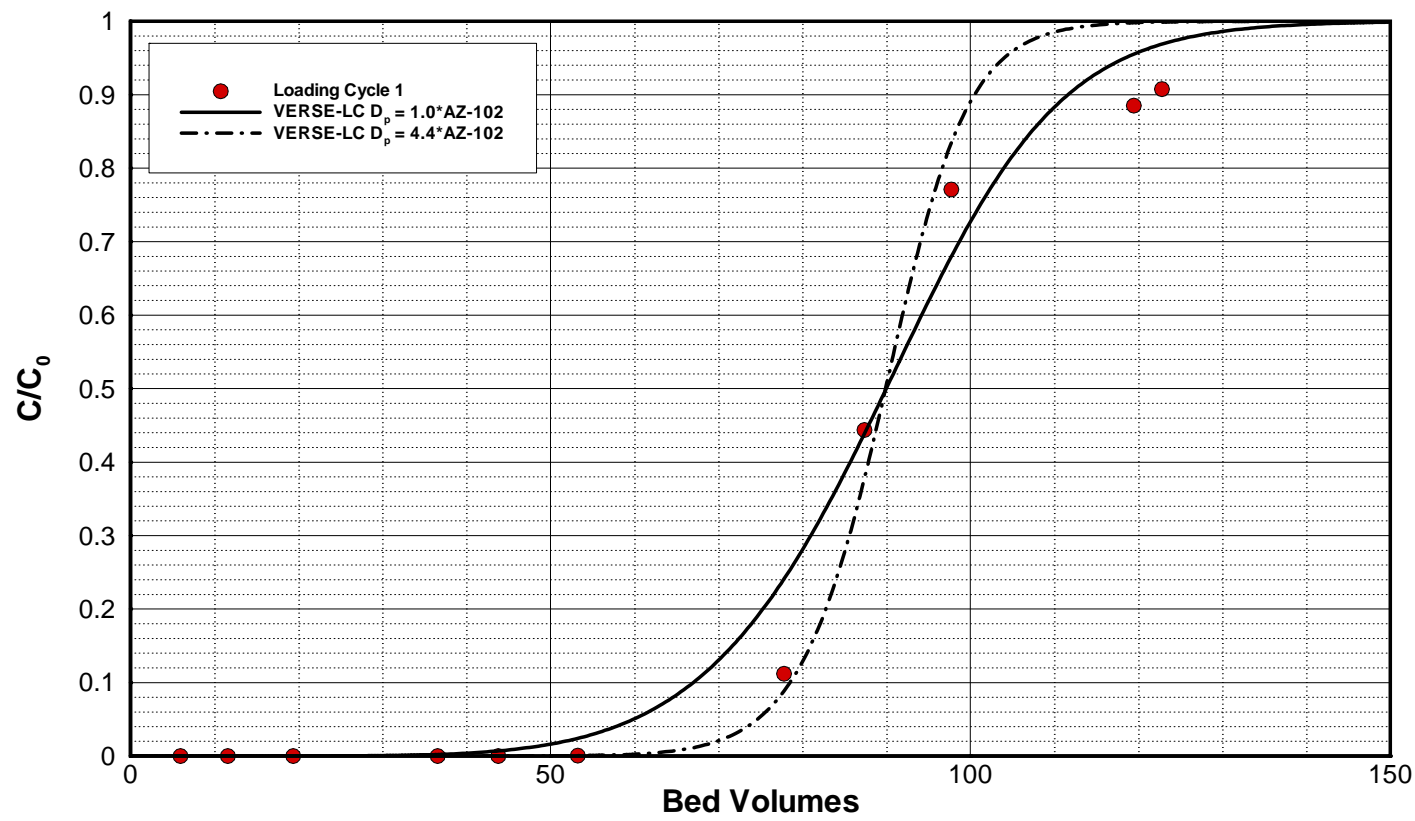

Figure 9-3. Comparison of VERSE-LC cesium breakthrough with data from the PNNL Column 8, Cycle 1 test. A sample of spherical Resorcinol-Formaldehyde (Resin \#6) was tested with AZ-102 simulant. 


\subsection{Full-Scale Column Predictions}

A series of VERSE-LC simulations were performed to predict the cesium removal performance of a full-scale facility consisting of a three-column carousel configuration. Each resin bed contained within a single column was 48 inches in diameter and 53 inches high. A total bed volume of 415 gallons of resin was assumed. The dimensions and operating parameters of the columns were specified by WTP. Nominal operations for "Nominal Hot Commissioning", "Envelope B Operations" and "Subsequent Operations" were investigated. In addition, sensitivity studies were made for the Nominal Hot Commissioning Operation feeds. The impact of degradation (due to resin usage; handled through reduction in the total Cs sorption capacity and referred to as a degradation factor) was examined for each of the three nominal feed cases. Facility carouseling operations were performed based on exit cesium product criteria as supplied by Toth (2003). For the carousel analyses no safety limit on the total amount of ${ }^{137}$ Cs inventory within a given column was imposed.

The computed number of bed volumes to reach cesium product criterion at the exit of the lag column is provided in Tables 10-1 through 10-3 for column operation under nominal parameter settings. Results for both fresh resin and estimated chemically degraded resin after 10 operating cycles are provided. Similar bed volume results are provided in Tables 10-4 and 10-5 for the various sensitivity simulations performed for the Hot Commissioning Operation feed where the nominal isotherm used represents the 10 cycle degraded resin bed. A basic star pattern approach to the sensitivity runs was employed. See Appendix D for the nominal input and output results for the three nominal feed stream case runs.

When a ${ }^{137} \mathrm{Cs}$ inventory limit is also imposed on the column loading, we find that the number of bed volumes to process the "Envelope B Operations" feed stream becomes limited prior to cycling of the carousel. A LAW feed loading limit of 75,000 Ci was provided by Toth (2003). Given this inventory limit VERSE predictions indicate that this limit is reached in 43 BVs for the Envelope B Operations feed stream. Table 10-6 summarizes the number of bed volumes required to reach the LAW loading limit (LLL), Limiting Condition for Operation (LCO)limit and Technical Safety Limit (TSL) of 75000, 125000 and $150000 \mathrm{Ci}$, respectively. Appendix E describes the method used to calculate total Cs inventories.

Figures 10-1 and 10-2 show the cesium breakthrough predictions for a full-scale 3 column carousel under Hot Commissioning Operations feed assuming fresh and chemically degraded resin, respectively.

Figures 10-3 and 10-4 show the cesium breakthrough predictions for a full-scale 3 column carousel under Envelope B Operations feed assuming fresh and chemically degraded resin, respectively.

Figures 10-5 and 10-6 show the cesium breakthrough predictions for a full-scale 3 column carousel under Subsequent Operations feed assuming fresh and chemically degraded resin, respectively. 
Figure 10-7 shows the cesium breakthrough prediction for the lead column under Hot Commissioning Operations feed. The impact on breakthrough with variation in potassium concentration is shown for the first cycle. The order of breakthrough is from high to low potassium concentration.

Figure 10-8 shows the cesium breakthrough prediction for the lead column under Hot Commissioning Operations feed. The impact on breakthrough with variation in sodium concentration is shown for the first cycle. The order of breakthrough is from high to low sodium concentration. The premature breakthrough at high sodium concentration is due to highly reduced cesium pore diffusivity. This impact has not been quantified experimentally. It is highly recommend that such testing be performed.

Figure 10-9 shows the cesium breakthrough prediction for the lead column under Hot Commissioning Operations feed. The impact on breakthrough with variation in hydroxide concentration is shown for the first cycle. The order of breakthrough is from low to high hydroxide concentration. The apparent cesium capacity is a function of $\mathrm{pH}$

Figure 10-10 shows the cesium breakthrough prediction for the lead column under Hot Commissioning Operations feed. The impact on breakthrough with variation in cesium concentration is shown for the first cycle. The order of breakthrough is from high to low cesium concentration.

Figure 10-11 shows the cesium breakthrough prediction for the lead column under Hot Commissioning Operations feed. The impact on breakthrough with variation in liquid flowrate is shown for the first cycle. The order of breakthrough is from high to low liquid flowrate.

Figure 10-12 shows the cesium breakthrough prediction for the lead column under Hot Commissioning Operations feed. The impact on breakthrough with variation in pore diffusivity is shown for the first cycle. The order of breakthrough is from low to high pore diffusivity.

Figure 10-13 shows the cesium breakthrough prediction for the lead column under Hot Commissioning Operations feed. The impact on breakthrough with variation in particle radius is shown for the first cycle. The order of breakthrough is from high to low particle radius.

Figure 10-14 shows the cesium breakthrough prediction for the lead column under Hot Commissioning Operations feed. The impact on breakthrough with variation in bed denity is shown for the first cycle. The order of breakthrough is from low to high bed density. Lower bed density implies less ion exchange sites which lead to earlier breakthrough.

Table 10-1. Number of bed volumes required to reach lag column Cs breakthrough during threecolumn carousel operation for Nominal Hot Commissioning Operations. Both degraded and fresh resin bed results are provided.

\begin{tabular}{|c|c|c|c|}
\hline $\begin{array}{c}\text { Percent } \\
\text { Degradation } \\
(\%)\end{array}$ & Cycle Number & $\begin{array}{c}\text { Lead Column Exit } \\
\text { Concentration } \\
\text { Ratio (\%) }\end{array}$ & $\begin{array}{c}\text { Number of bed volumes } \\
\text { required to reach lag } \\
\text { column exit criterion (BV) }\end{array}$ \\
\hline 0 & 1 & 96 & 171 \\
\hline 0 & 2 & 77 & 108 \\
\hline
\end{tabular}


WSRC-TR-2004-00100, REVISION 0

SRT-RPP-2004-00019, REVISION 0

\begin{tabular}{|c|c|c|c|}
\hline $\begin{array}{c}\text { Percent } \\
\text { Degradation } \\
\text { (\%) }\end{array}$ & Cycle Number & $\begin{array}{c}\text { Lead Column Exit } \\
\text { Concentration } \\
\text { Ratio (\%) }\end{array}$ & $\begin{array}{c}\text { Number of bed volumes } \\
\text { required to reach lag } \\
\text { column exit criterion (BV) }\end{array}$ \\
\hline 0 & 3 & 61 & 111 \\
\hline 0 & 4 & 51 & 114 \\
\hline 0 & 5 & 48 & 115 \\
\hline \hline 20 & 1 & 96 & 138 \\
\hline 20 & 2 & 76 & 87 \\
\hline 20 & 3 & 59 & 89 \\
\hline 20 & 4 & 52 & 91 \\
\hline 20 & 5 & 48 & 92 \\
\hline
\end{tabular}

Table 10-2. Number of bed volumes required to reach lag column Cs breakthrough during threecolumn carousel operation for Nominal Envelope B Operations. Both degraded and fresh resin bed results are provided.

\begin{tabular}{|c|c|c|c|}
\hline $\begin{array}{c}\text { Percent } \\
\text { Degradation } \\
(\%)\end{array}$ & Cycle Number & $\begin{array}{c}\text { Lead Column Exit } \\
\text { Concentration } \\
\text { Ratio (\%) }\end{array}$ & $\begin{array}{c}\text { Number of bed volumes } \\
\text { required to reach lag } \\
\text { column exit criterion (BV) }\end{array}$ \\
\hline 0 & 1 & 100 & 395 \\
\hline 0 & 2 & 100 & 210 \\
\hline 0 & 3 & 100 & 210 \\
\hline 0 & 4 & 100 & 210 \\
\hline 0 & 5 & 100 & 210 \\
\hline \hline 20 & 1 & 100 & 317 \\
\hline 20 & 2 & 100 & 168 \\
\hline 20 & 3 & 100 & 168 \\
\hline 20 & 4 & 100 & 168 \\
\hline 20 & 5 & 100 & 168 \\
\hline
\end{tabular}

Table 10-3. Number of bed volumes required to reach lag column Cs breakthrough during threecolumn carousel operation for Nominal Subsequent Operations. Both degraded and fresh resin bed results are provided.

\begin{tabular}{|c|c|c|c|}
\hline $\begin{array}{c}\text { Percent } \\
\text { Degradation } \\
(\%)\end{array}$ & Cycle Number & $\begin{array}{c}\text { Lead Column Exit } \\
\text { Concentration } \\
\text { Ratio (\%) }\end{array}$ & $\begin{array}{c}\text { Number of bed volumes } \\
\text { required to reach lag } \\
\text { column exit criterion (BV) }\end{array}$ \\
\hline 0 & 1 & 99 & 270 \\
\hline 0 & 2 & 91 & 170 \\
\hline 0 & 3 & 79 & 175 \\
\hline 0 & 4 & 70 & 179 \\
\hline 0 & 5 & 65 & 181 \\
\hline 20 & 1 & 99 & 216 \\
\hline 20 & 2 & 92 & 136 \\
\hline 20 & 3 & 78 & 141 \\
\hline 20 & 4 & 70 & 143 \\
\hline 20 & 5 & 63 & 145 \\
\hline
\end{tabular}


Table 10-4. Number of bed volumes required to reach lag column Cs breakthrough during threecolumn carousel operation for Nominal Hot Commissioning Operations 20\% degradation factor applied. Parameter sensitivity results provided for isotherm competitors.

\begin{tabular}{|c|c|c|c|c|c|c|c|c|c|}
\hline $\begin{array}{c}\text { Cycle } \\
\text { Number }\end{array}$ & $\begin{array}{c}\text { Nominal } \\
\mathbf{( 2 0 \%} \\
\text { degraded) }\end{array}$ & $\begin{array}{c}\mathbf{C s} \\
(\mathbf{+ 2 0 \% )}\end{array}$ & $\begin{array}{c}\mathbf{C s} \\
\mathbf{( - 2 0 \% )}\end{array}$ & $\begin{array}{c}\mathbf{N a} \\
\mathbf{( + 2 0 \% )}\end{array}$ & $\begin{array}{c}\mathbf{N a} \\
\mathbf{( - 2 0 \% )}\end{array}$ & $\begin{array}{c}\mathbf{K} \\
\mathbf{( + 2 0 \% )}\end{array}$ & $\begin{array}{c}\mathbf{K} \\
\mathbf{( - 2 0 \% )}\end{array}$ & $\begin{array}{c}\mathbf{O H} \\
\mathbf{( + 2 0 \% )}\end{array}$ & $\begin{array}{c}\mathbf{O H} \\
\mathbf{( - 2 0 \% )}\end{array}$ \\
\hline 1 & 138 & 137 & 149 & 26 & 171 & 117 & 164 & 147 & 129 \\
\hline 2 & 87 & 86 & 94 & 24 & 101 & 75 & 102 & 91 & 82 \\
\hline 3 & 89 & 89 & 96 & 24 & 104 & 78 & 105 & 94 & 85 \\
\hline 4 & 91 & 91 & 98 & 24 & 105 & 79 & 108 & 96 & 87 \\
\hline 5 & 92 & 92 & 100 & 24 & 106 & 80 & 109 & 98 & 87 \\
\hline 6 & 94 & 93 & 101 & 24 & 107 & 81 & 110 & 98 & 89 \\
\hline 7 & 94 & 94 & 101 & 24 & 108 & 81 & 111 & 99 & 89 \\
\hline
\end{tabular}

Table 10-5 Number of bed volumes required to reach lag column Cs breakthrough during threecolumn carousel operation for Nominal Hot Commissioning Operations 20\% degradation factor applied. Parameter sensitivity results provided for VERSE input variables.

\begin{tabular}{|c|c|c|c|c|c|c|c|c|c|}
\hline $\begin{array}{c}\text { Cycle } \\
\text { Number }\end{array}$ & $\begin{array}{c}\text { Nominal } \\
\mathbf{( 2 0 \%} \\
\text { degraded) }\end{array}$ & $\begin{array}{c}\text { Flow } \\
\mathbf{( 2 2} \\
\mathbf{g p m})\end{array}$ & $\begin{array}{c}\text { Flow } \\
\mathbf{( 5} \mathbf{g p m})\end{array}$ & $\begin{array}{c}\mathbf{D}_{\mathbf{p}} \\
\mathbf{( + 2 0 \% )}\end{array}$ & $\begin{array}{c}\mathbf{D}_{\mathbf{p}} \\
\mathbf{( - 2 0 \% )}\end{array}$ & $\begin{array}{c}\mathbf{R}_{\mathbf{p}} \\
\mathbf{( + 2 0 \% )}\end{array}$ & $\begin{array}{c}\mathbf{R}_{\mathbf{p}} \\
\mathbf{( - 2 0 \% )}\end{array}$ & $\begin{array}{c}\mathbf{\rho}_{\mathbf{b}} \\
\mathbf{( + 2 0 \% )}\end{array}$ & $\begin{array}{c}\mathbf{\rho}_{\mathbf{b}} \\
\mathbf{( - 2 0 \% )}\end{array}$ \\
\hline 1 & 138 & 126 & 163 & 143 & 131 & 126 & 150 & 165 & 111 \\
\hline 2 & 87 & 83 & 93 & 88 & 85 & 83 & 90 & 104 & 70 \\
\hline 3 & 89 & 87 & 96 & 91 & 88 & 87 & 93 & 107 & 72 \\
\hline 4 & 91 & 88 & 96 & 92 & 90 & 89 & 94 & 109 & 74 \\
\hline 5 & 92 & 90 & 97 & 94 & 91 & 90 & 95 & 111 & 74 \\
\hline 6 & 94 & 91 & 98 & 94 & 92 & 91 & 96 & 112 & 75 \\
\hline 7 & 94 & 91 & 98 & 95 & 93 & 91 & 96 & 113 & 76 \\
\hline
\end{tabular}

Table 10-6. Bed volumes required to reach ${ }^{137}$ Cs loading limits (Prior to Cycling).

\begin{tabular}{|c|c|c|c|c|}
\hline $\begin{array}{c}\text { LAW Feed } \\
\text { Operations }\end{array}$ & Isotherm & $\begin{array}{c}\text { LLL } \\
\mathbf{7 5 0 0 0} \mathbf{C i}\end{array}$ & $\begin{array}{c}\text { LCO } \\
\mathbf{1 2 5 0 0 0} \mathbf{C i}\end{array}$ & $\begin{array}{c}\text { TSL } \\
\mathbf{1 5 0 0 0 0} \mathbf{~ c I}\end{array}$ \\
\hline Hot Commissioning & Nominal & na & na & na \\
\hline Hot Commissioning & Degraded & na & na & na \\
\hline Envelope B & Nominal & 43 & 70 & 84 \\
\hline Envelope B & Degraded & 43 & 70 & 84 \\
\hline Subsequent & Nominal & na & na & na \\
\hline Subsequent & Degraded & na & na & na \\
\hline
\end{tabular}




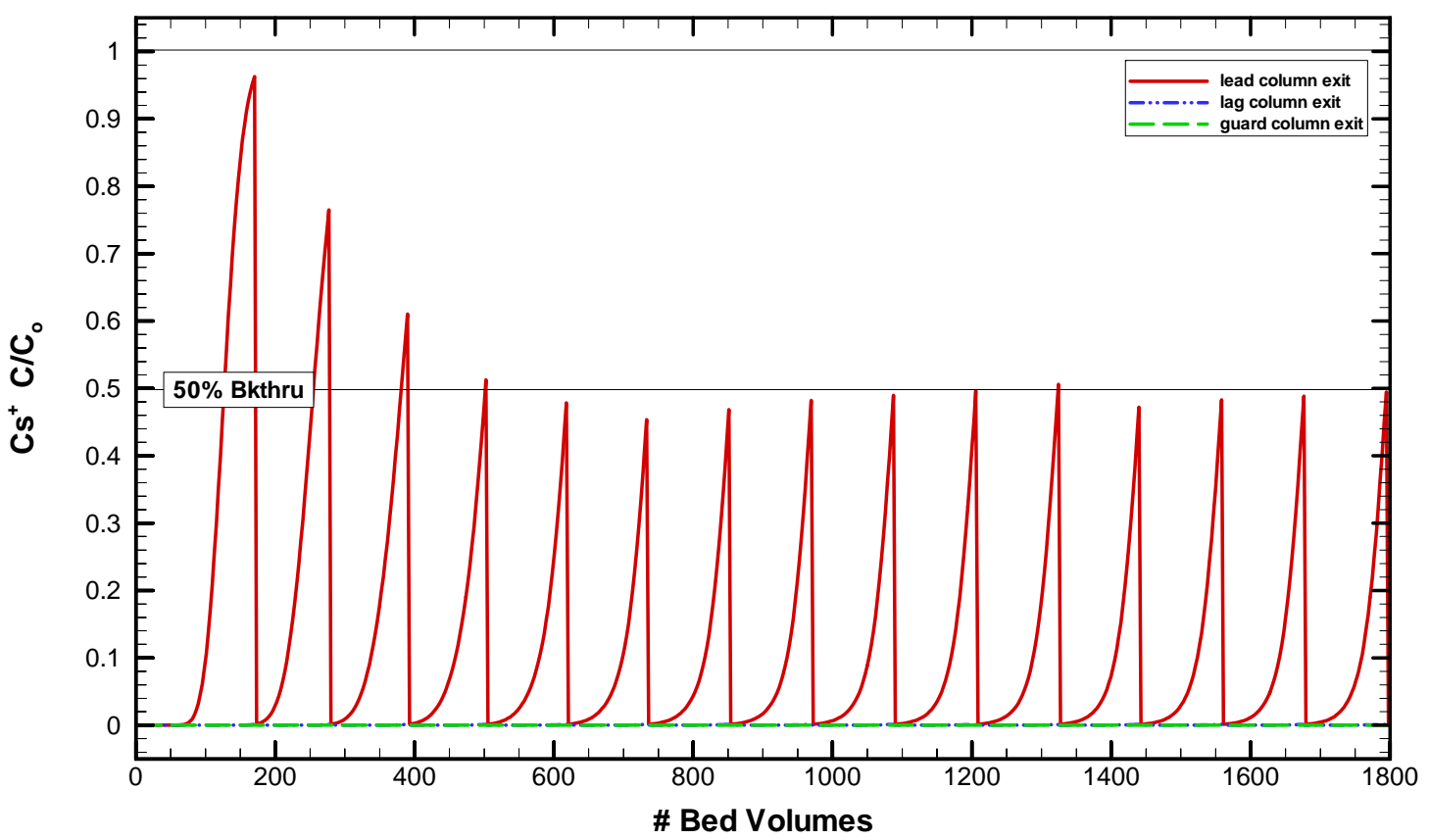

Figure 10-1. VERSE-LC cesium breakthrough predictions for a full-scale 3 column carousel under Hot Commissioning Operations feed. The calculations assume fresh Resorcinol-Formaldehyde resin.

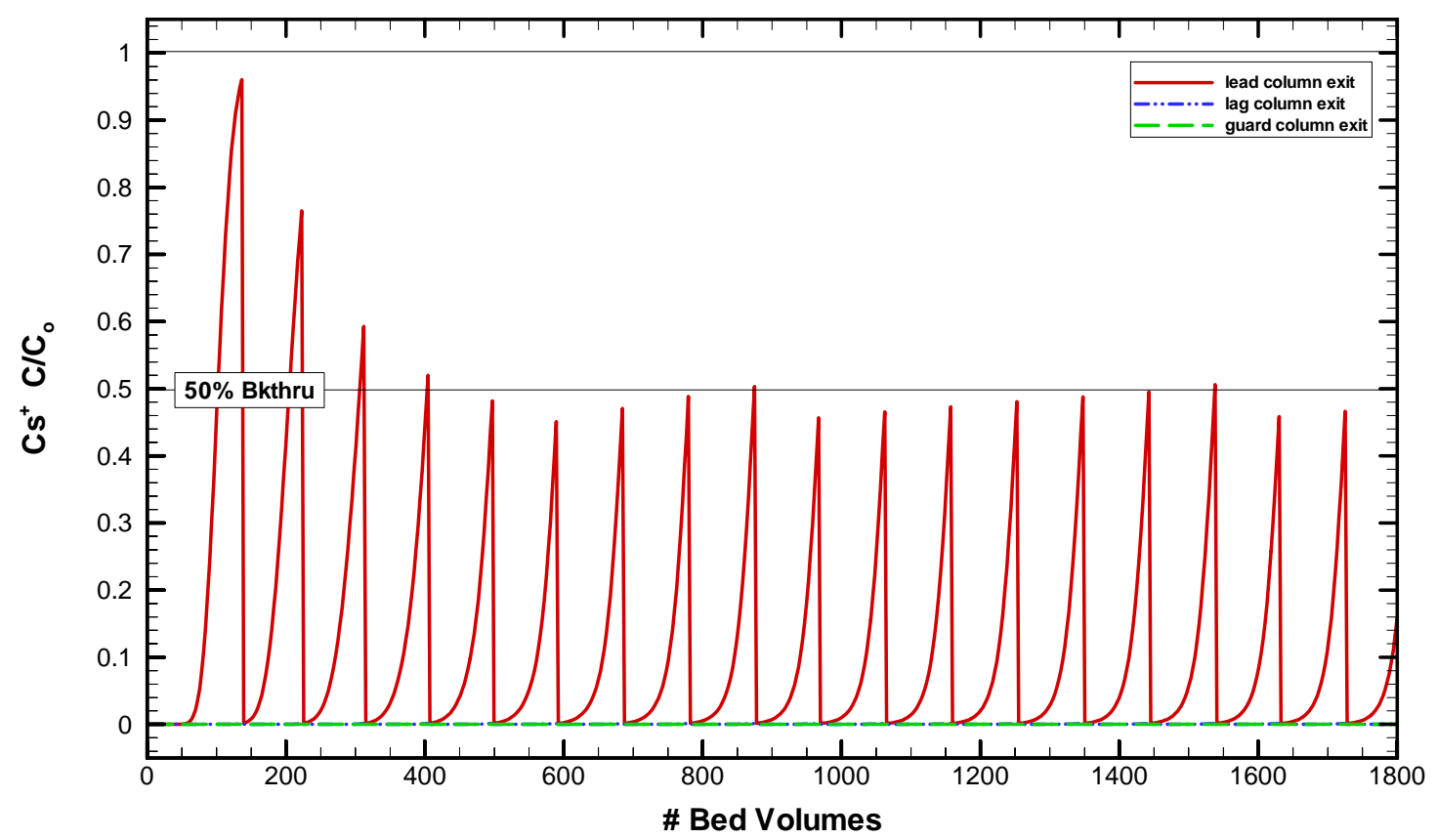

Figure 10-2. VERSE-LC cesium breakthrough predictions for a full-scale 3 column carousel under Hot Commissioning Operations feed. The calculations assume chemically degraded Resorcinol-Formaldehyde resin. 


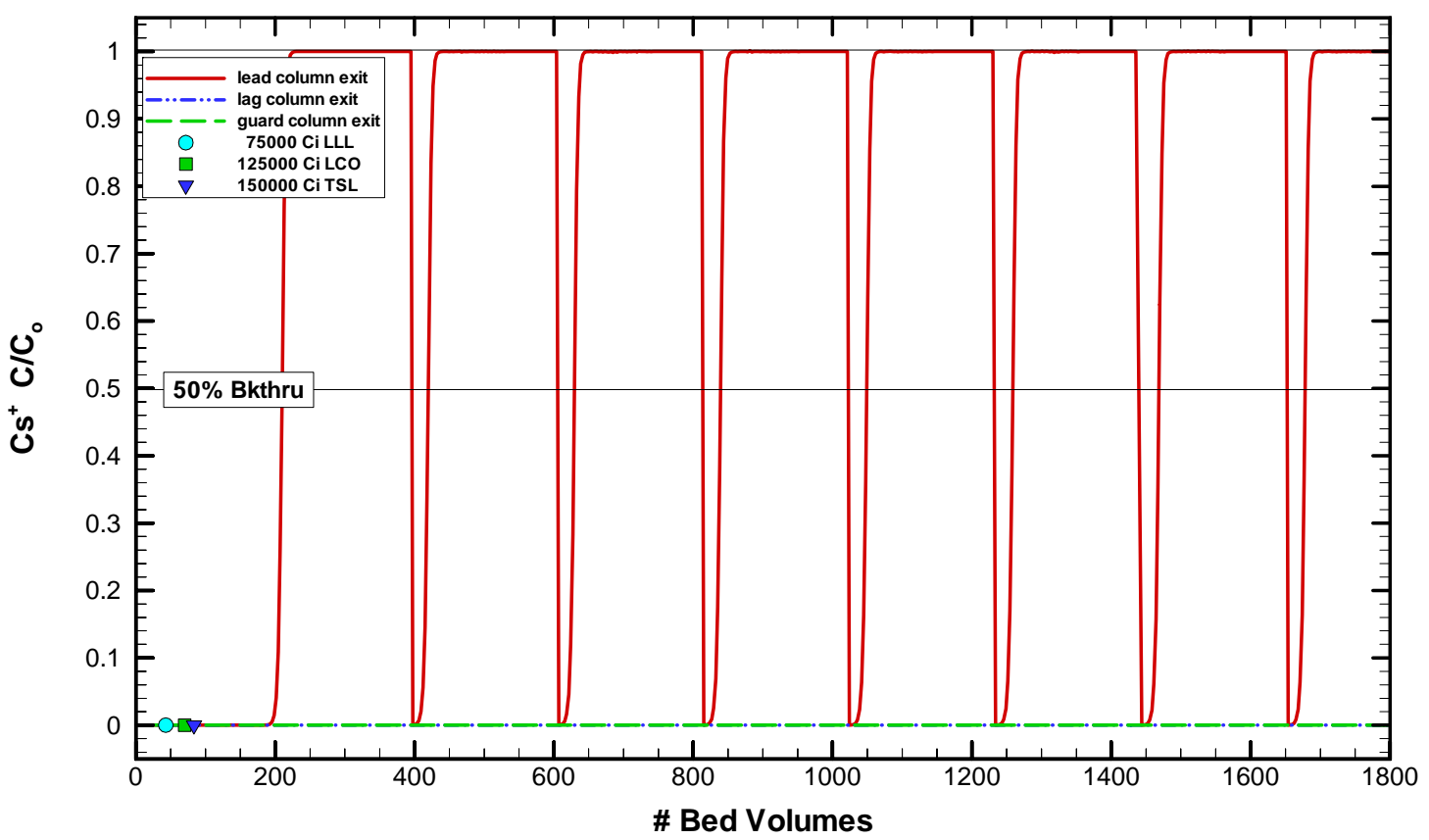

Figure 10-3. VERSE-LC cesium breakthrough predictions for a full-scale 3 column carousel under Envelope B Operations feed. The calculations assume fresh ResorcinolFormaldehyde resin.

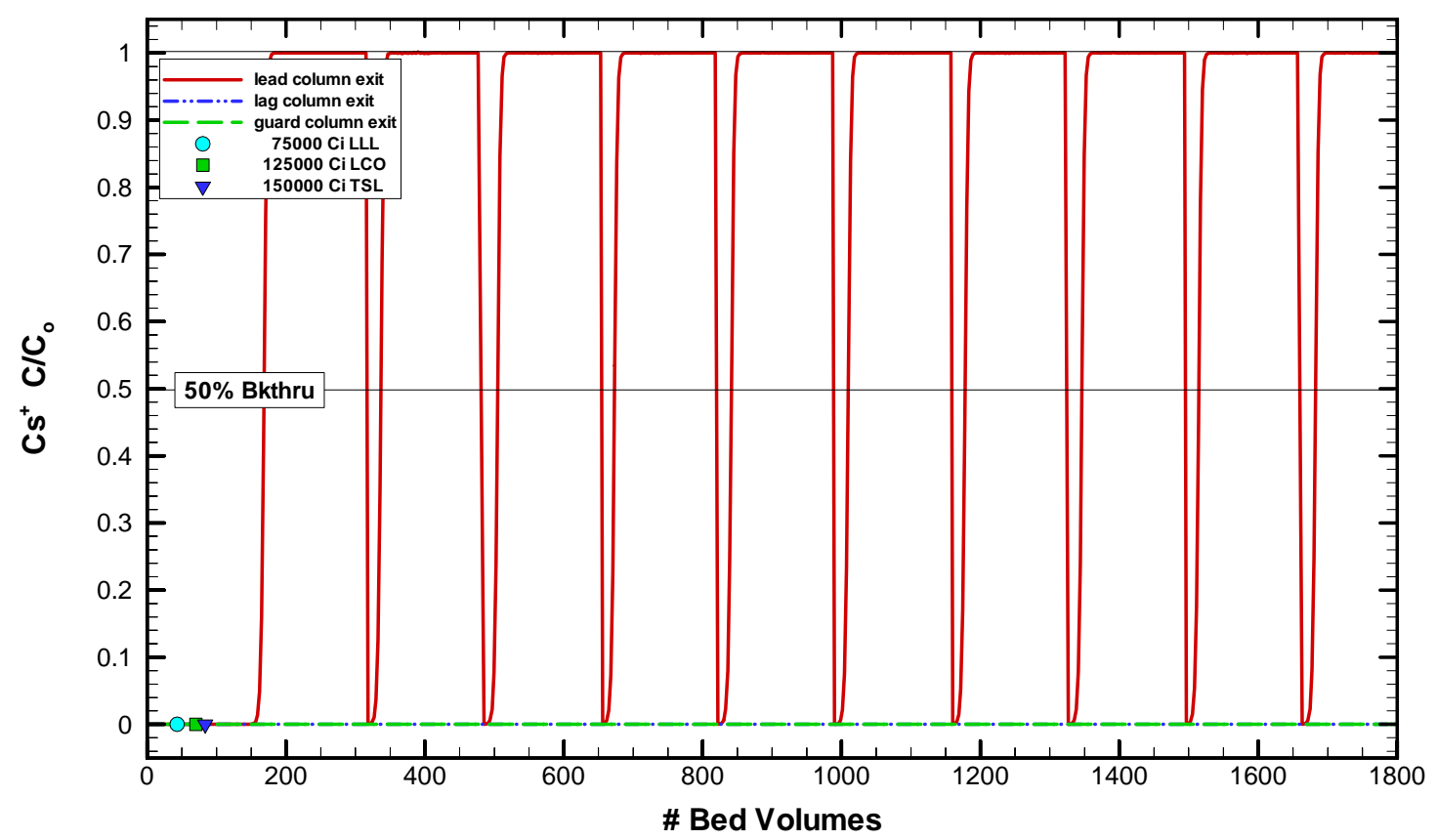

Figure 10-4. VERSE-LC cesium breakthrough predictions for a full-scale 3 column carousel under Envelope B Operations feed. The calculations assume chemically degraded Resorcinol-Formaldehyde resin. 


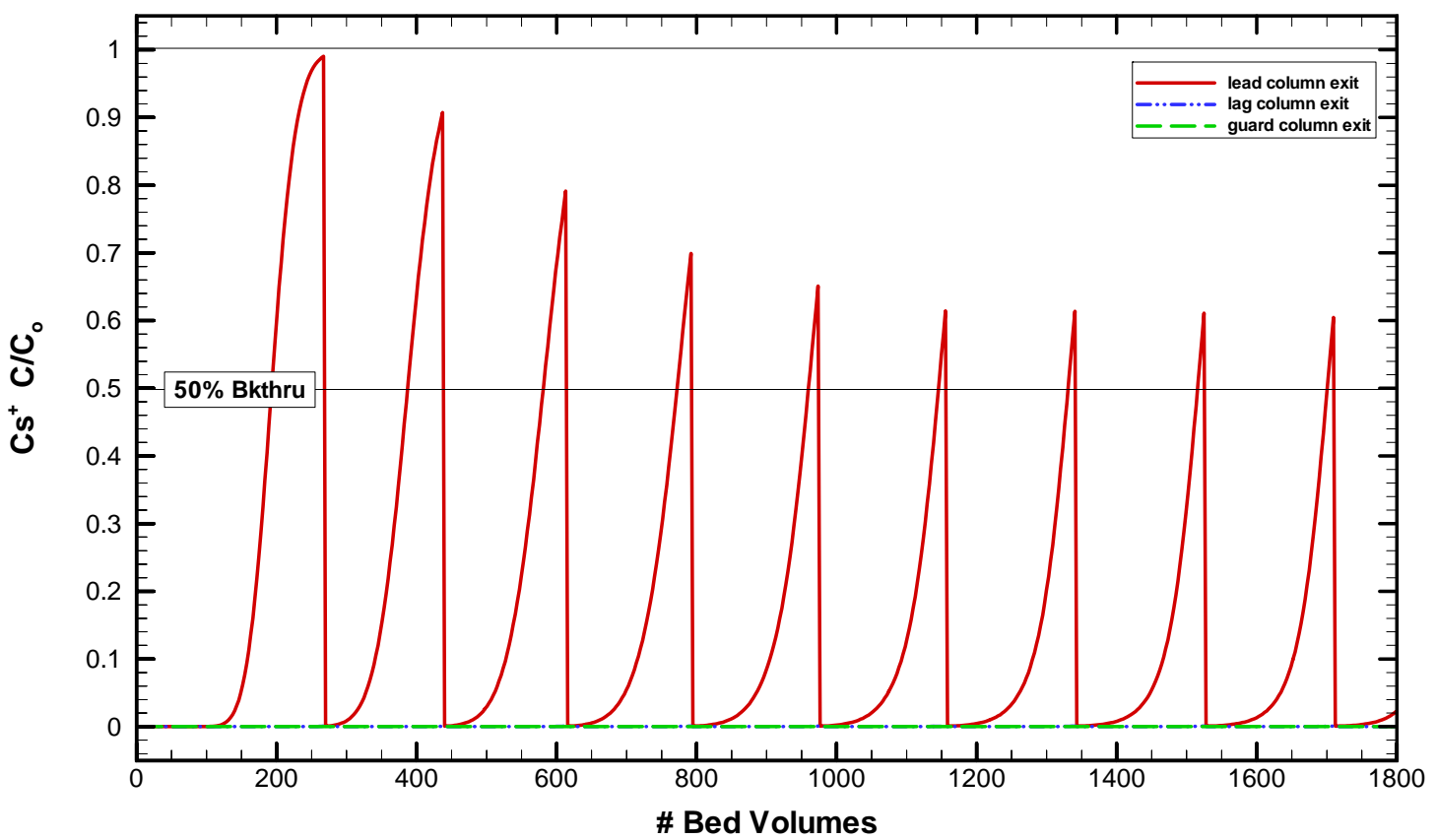

Figure 10-5. VERSE-LC cesium breakthrough predictions for a full-scale 3 column carousel under Subsequent Operations feed. The calculations assume fresh ResorcinolFormaldehyde resin.

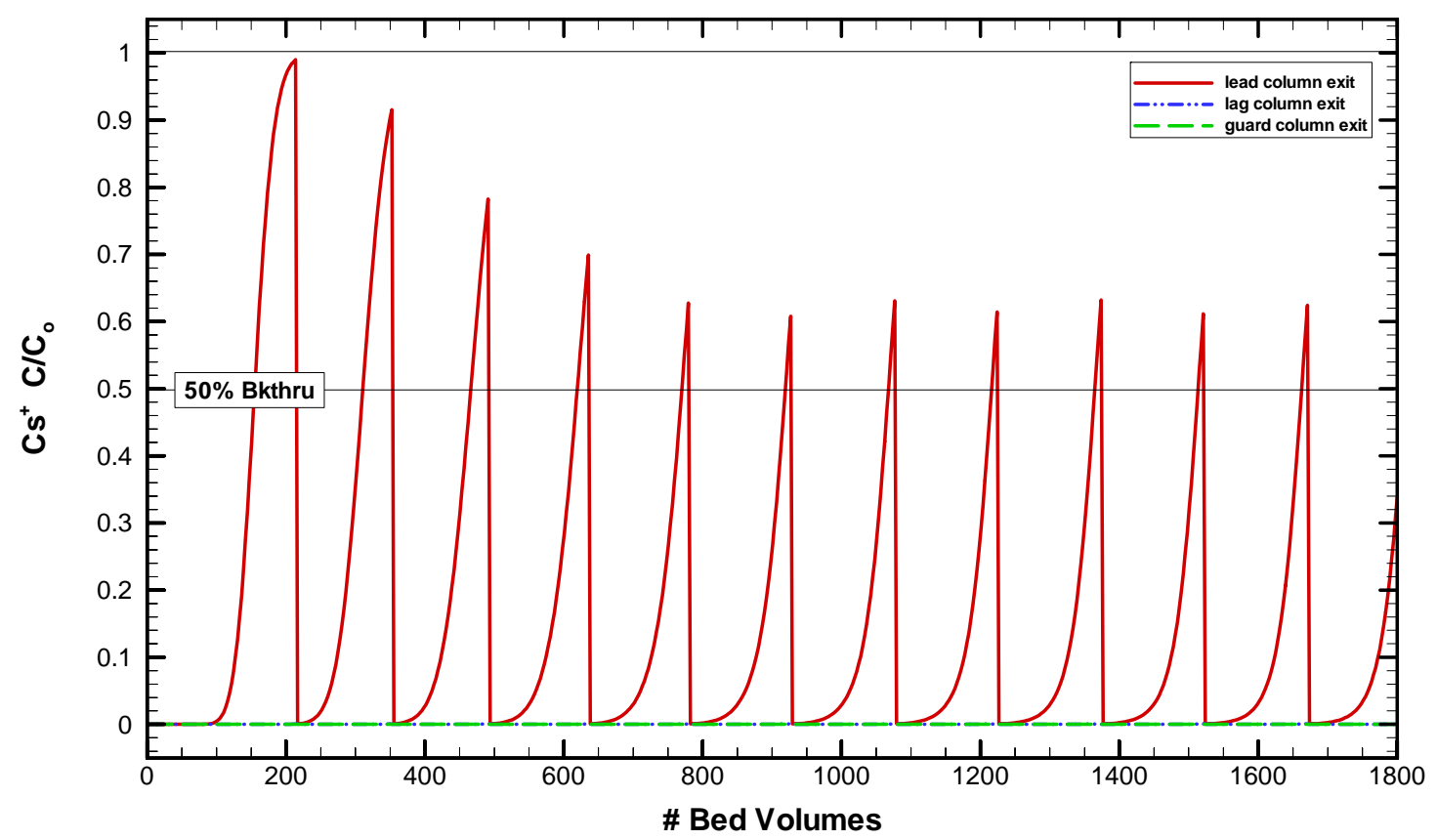

Figure 10-6. VERSE-LC cesium breakthrough predictions for a full-scale 3 column carousel under Subsequent Operations feed. The calculations assume chemically degraded Resorcinol-Formaldehyde resin. 


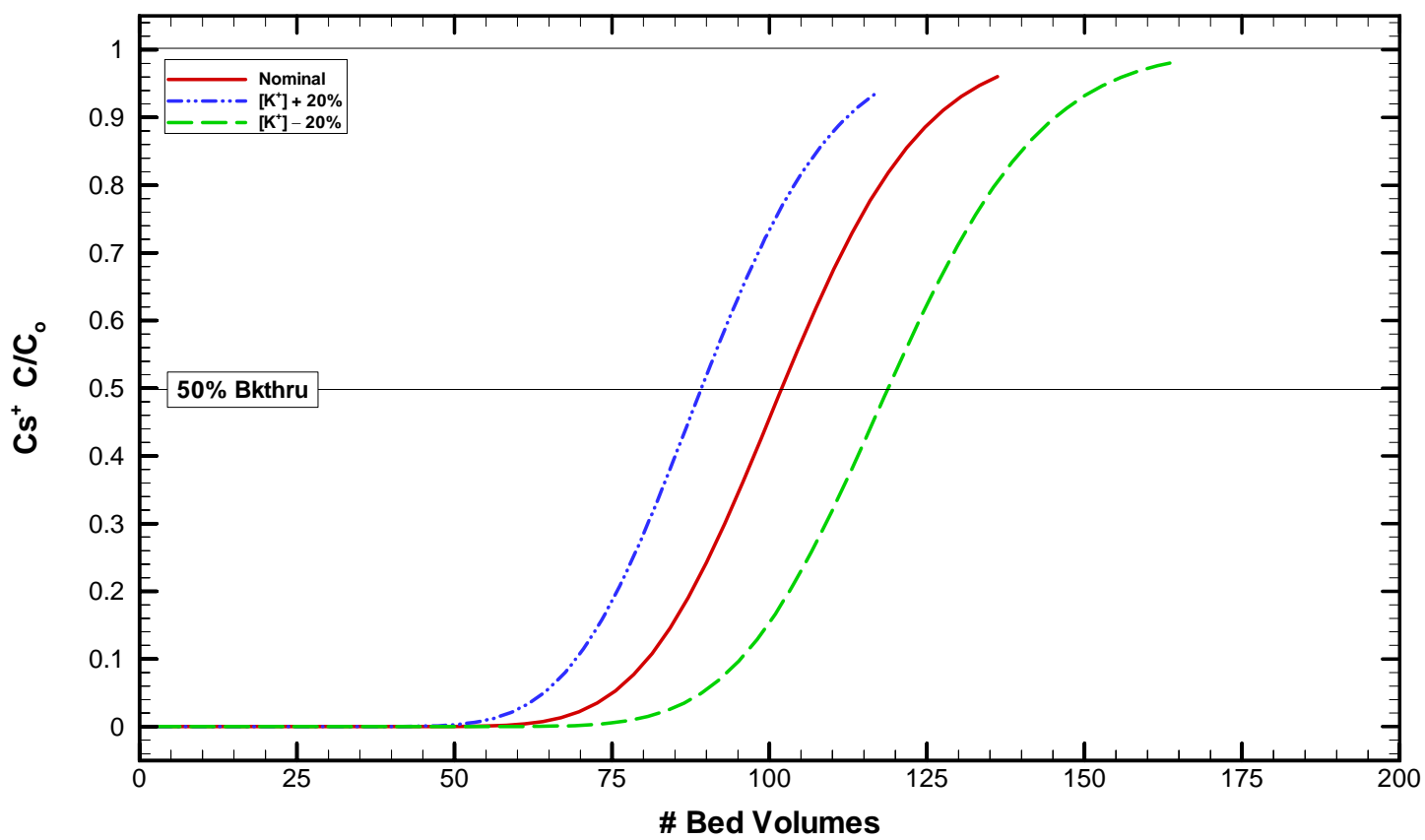

Figure 10-7. VERSE-LC cesium breakthrough prediction for the lead column under Hot Commissioning Operations feed. The impact on breakthrough with variation in potassium concentration is shown for the first cycle.

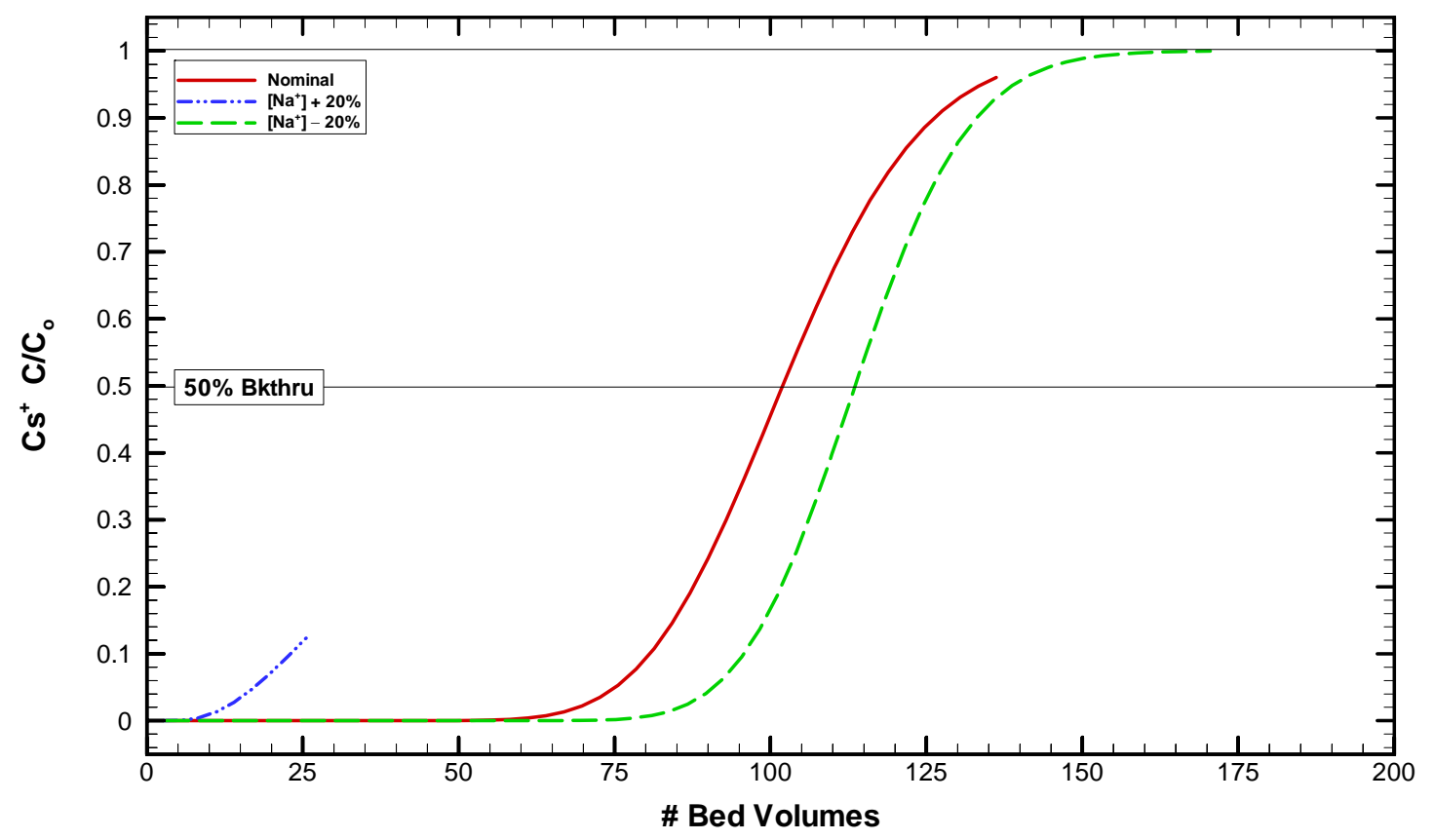

Figure 10-8. VERSE-LC cesium breakthrough prediction for the lead column under Hot Commissioning Operations feed. The impact on breakthrough with variation in sodium concentration is shown for the first cycle. 


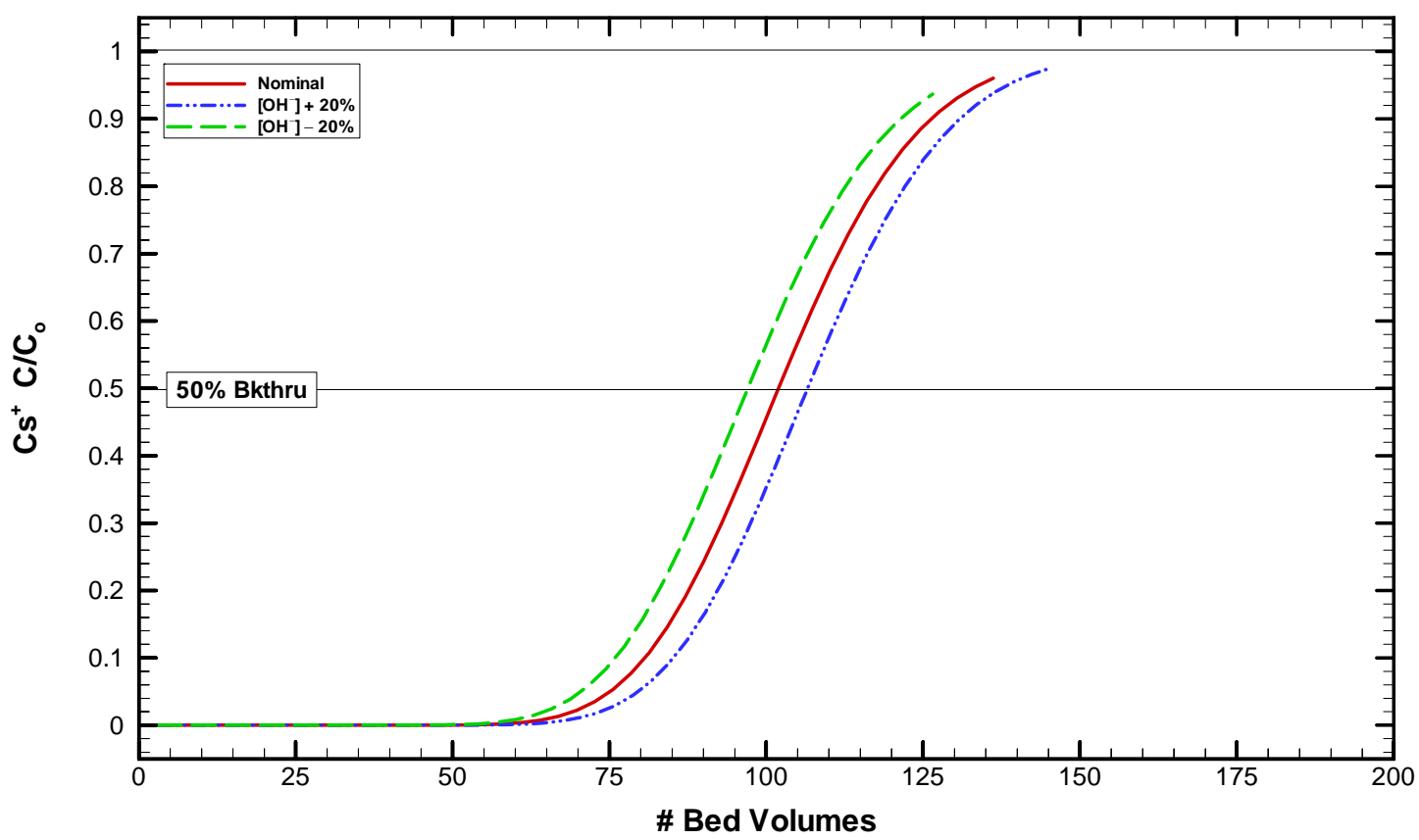

Figure 10-9. VERSE-LC cesium breakthrough prediction for the lead column under Hot Commissioning Operations feed. The impact on breakthrough with variation in hydroxide concentration is shown for the first cycle.

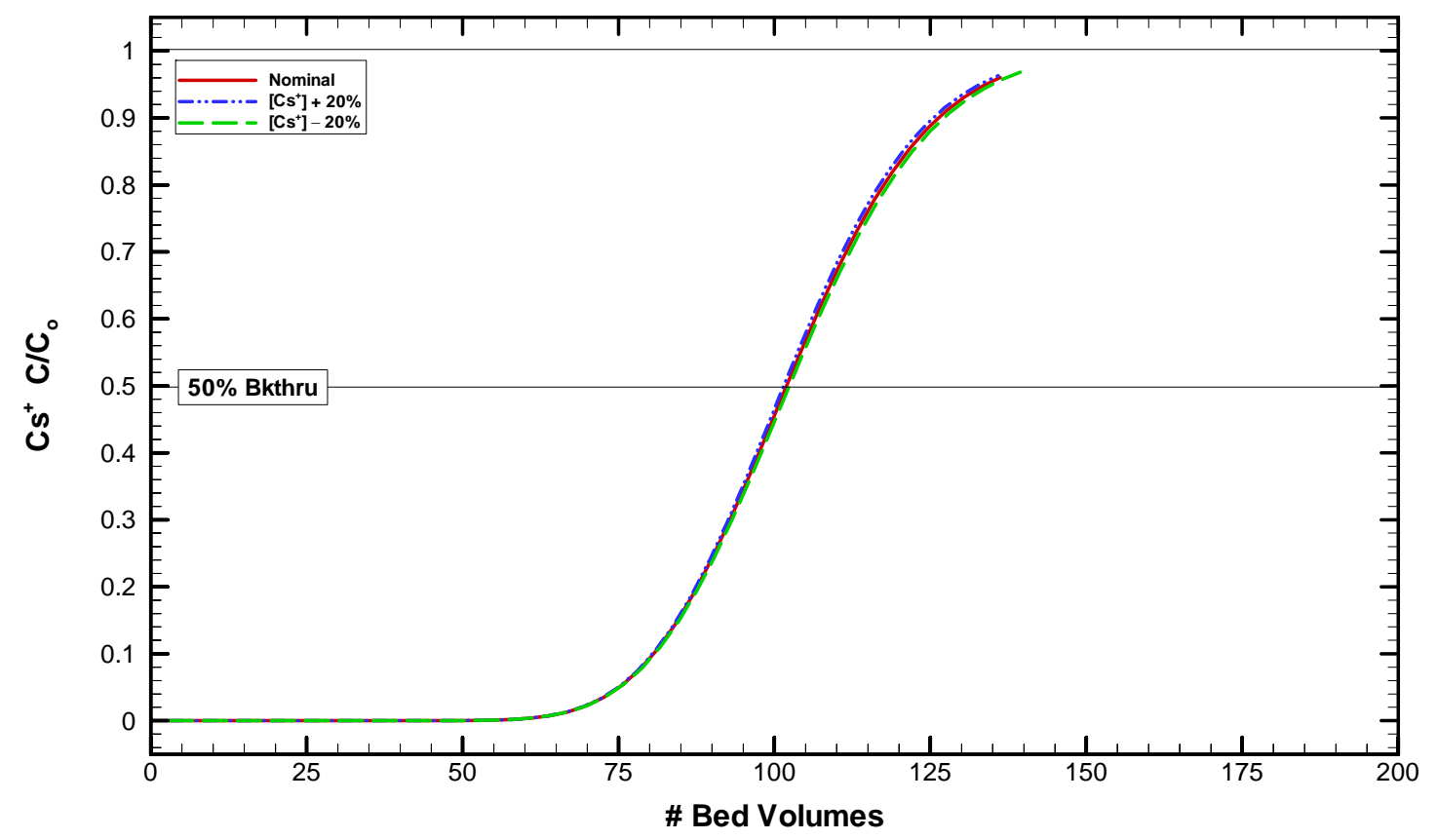

Figure 10-10. VERSE-LC cesium breakthrough prediction for the lead column under Hot Commissioning Operations feed. The impact on breakthrough with variation in cesium concentration is shown for the first cycle. 


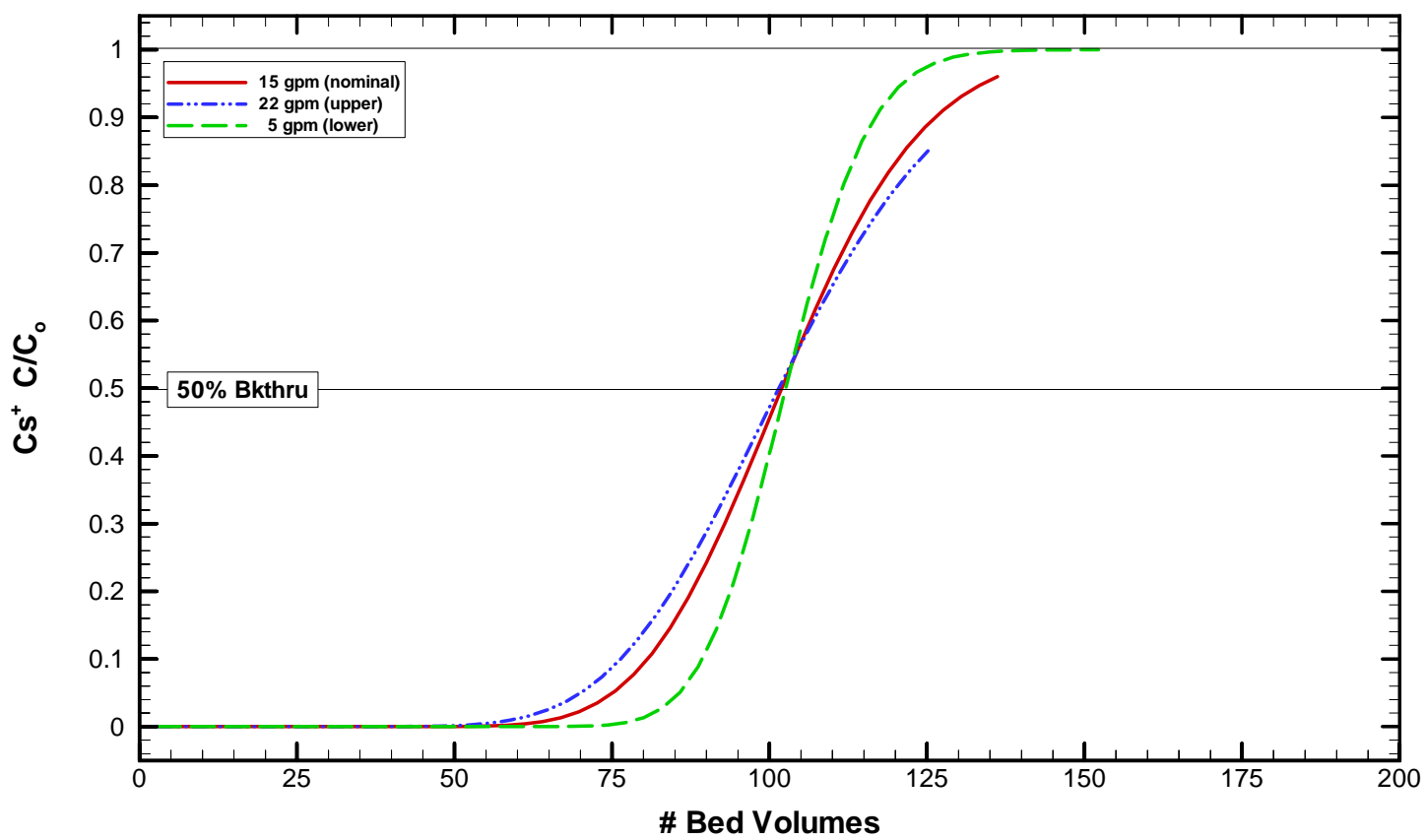

Figure 10-11. VERSE-LC cesium breakthrough prediction for the lead column under Hot Commissioning Operations feed. The impact on breakthrough with variation in liquid flowrate is shown for the first cycle.

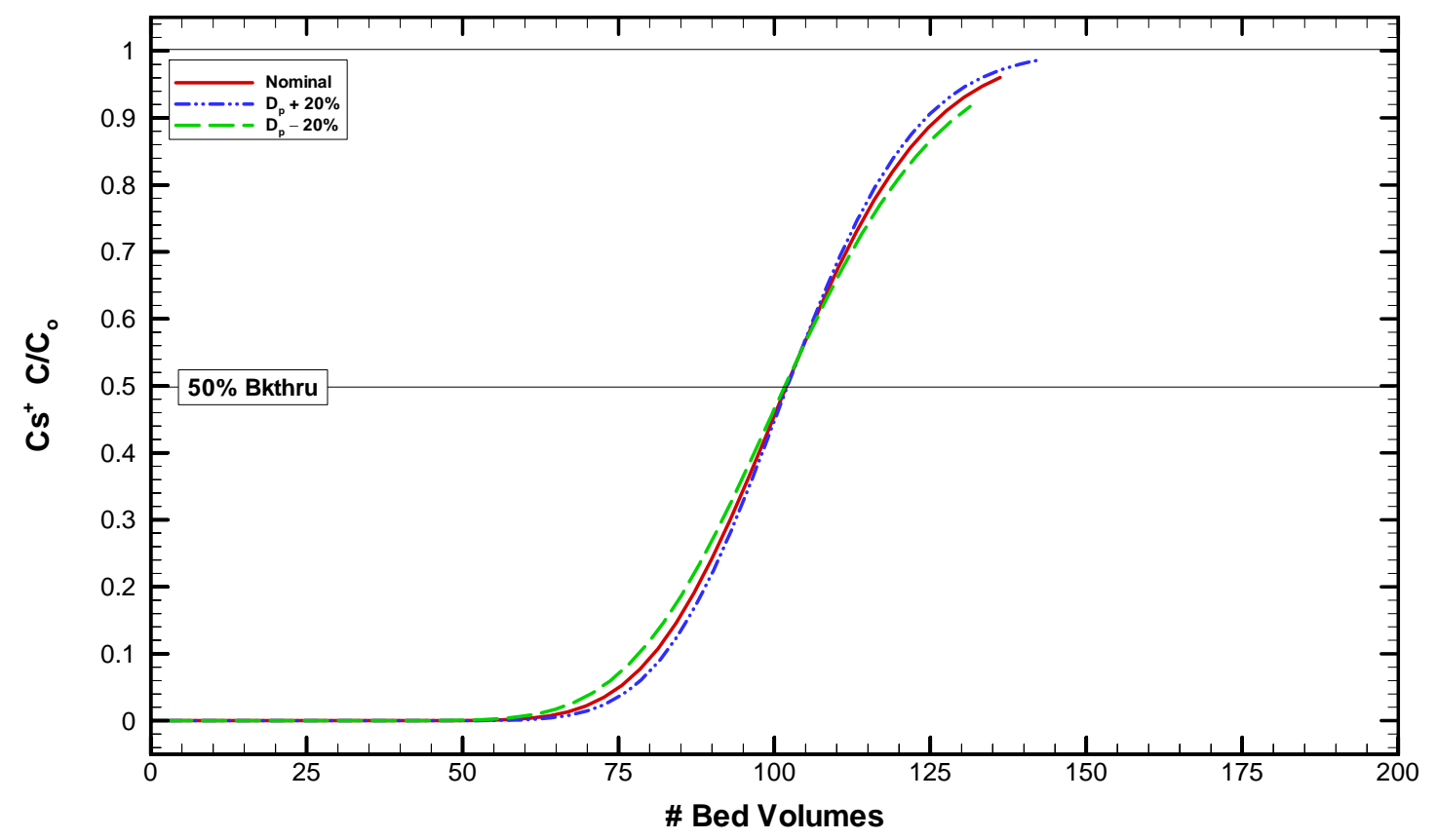

Figure 10-12. VERSE-LC cesium breakthrough prediction for the lead column under Hot Commissioning Operations feed. The impact on breakthrough with variation in pore diffusivity is shown for the first cycle. 


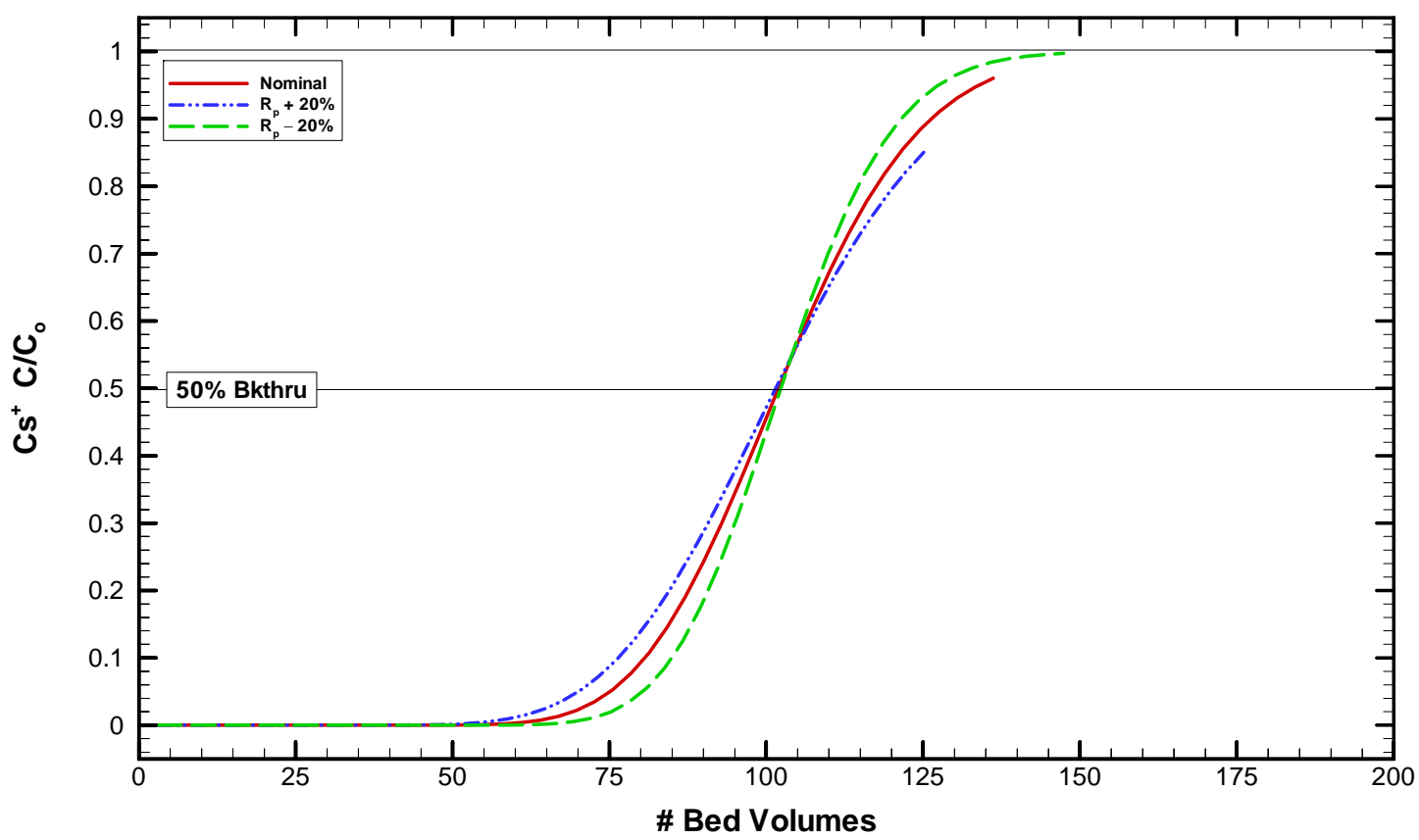

Figure 10-13. VERSE-LC cesium breakthrough prediction for the lead column under Hot Commissioning Operations feed. The impact on breakthrough with variation in particle radius is shown for the first cycle.

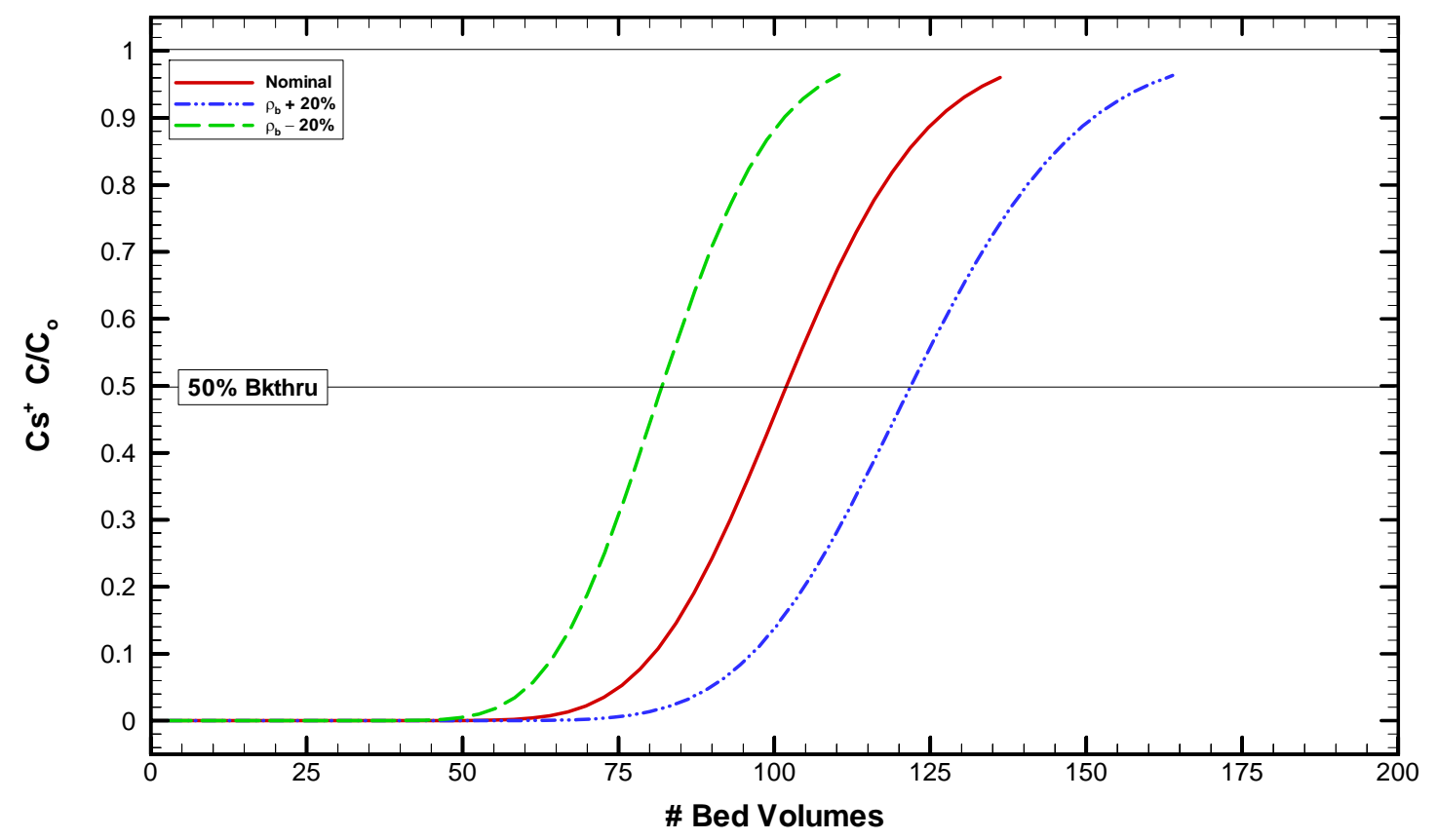

Figure 10-14. VERSE-LC cesium breakthrough prediction for the lead column under Hot Commissioning Operations feed. The impact on breakthrough with variation in bed density is shown for the first cycle. 
WSRC-TR-2004-00100, REVISION 0

SRT-RPP-2004-00019, REVISION 0

(This Page Intentionally Left Blank) 


\subsection{References}

Aleman, S. E., 1999. "Certification Package for FACT Version 2.0 (U)," Westinghouse Savannah River Co. document, WSRC-TR-99-00422, Rev. 0 (November).

Amtec Engineering, Inc., 2001. Tecplot ${ }^{\circledR}$ Version 9, Amtec Engineering, Inc., Bellevue, WA. (August 2001)

Aspen Technology, Inc. 2001. “Aspen Physical Property System, Physical Property Methods and Models 11.1," Cambridge, MA, September 2001.

ASTM D 2676, "Standard Practices for Sampling Ion Exchange Materials".

Berninger, J., R. D. Whitley, X. Zhang, and N.-H.L. Wang, 1991. "A Versatile Model for Simulation of Reaction and Nonequilibrium Dynamics in Multicomponent Fixed-Bed Adsorption Processes," Comput. Chem. Eng., 1991, 15(11), 749-768.

Bird, R. B., W. E. Stewart, and E. N. Lightfoot, 1960. Transport Phenomena, John Wiley and Sons, Inc., New York.Cornish, A. R. H., 1965. "Note on Minimum Possible Rate of Heat Transfer from a Sphere when other Spheres are Adjacent to it," Trans. Instn. Chem. Engrs., Vol. 43, pp. 332-333.

Bray, L. A., J. E. Amonette, G. N. Brown, T. M. Kafka, and S. F. Yates, 1995. "Efficient Separations and Processing Crosscutting Program: Develop and Test Sorbents," a FY 1995 Annual Progress Report, PNL-10750 (UC-2030), Battelle PNL, September.

Brooks, K. P., 1994. "Cesium Ion Exchange using Actual Waste: Column Size Considerations," TWRSPP-94-091, Battelle PNL, September.

Brown, G. N., S. R. Adami, L. A. Bray, S. A. Bryan, C. D. Carlson, K. J. Carson, J. R. DesChane, R. J. Elovich, S. J. Forbes, J. A. Franz, J. C. Linehan, W. J. Shaw, P. K. Tanaka, and M. R. Telander, 1995a. "Chemical and Radiation Stability of SuperLig ${ }^{\circledR}$ 644, Resorcinol-Formaldehyde, and CS-100 Cesium Ion Exchange Materials," PNL-10772 (UC2030), Battelle PNL, September.

Bruening, R. L., 2002. "Resin Acceptance Criteria Report to Bechtel National, Inc. on Quality Control Testrs and Data for the 250 Gallon Batch of SuperLig ${ }^{\circledR}$ 644," Report under purchase number \#24590-CM-POA-MWDO-00003 performed by IBC Advanced Technologies, Inc., December 16.

Chung, S. F. and C. Y. Wen, 1968. "Longitudinal Dispersion of Liquid Flowing Through Fixed and Fluidized Beds," AIChE J., Vol. 14, No. 6, pp. 857-866.

Dorweiler, V. P. and R. W. Fahien, 1959. "Mass Transfer at Low Flowrates in a Packed Column," AIChE Journal, Vol. 5, No. 2, pp. 139-144.

Duffey, C. E.; Hamm, L. L.; King, W. D., 2003. "Determination of Perrhenate $\left(\mathrm{ReO}_{4}{ }^{-}\right)$ Absorption Kinetics from Hanford Waste Simulants Using SuperLig ${ }^{\circledR} 639$ Resin”, WSRCTR-2002-00548, Rev. 0, SRT-RPP-2002-00272, Savannah River Site, Aiken SC 29808.

Eager, K. M. to J. Chiaramonte, 2001. "Sizing of Beds of Ion Exchange Contained within the Cesium Ion Exchange Columns," RPP-WTP CCN 023155, October 1.

Eibling, R.E., Nash, C.A., 2001. "Hanford Waste Simulants Created to Support the Research and Development on the River Protection Project - Waste Treatment Plant", WSRC-TR2000-00338, Rev. 0, SRT-RPP-2000-00017, Savannah River Site, Aiken SC 29808 (February).

Fahien, R. W. and J. M. Smith, 1955. "Mass Transfer in Packed Beds," AIChE Journal, Vol. 1, No. 1, pp. 28-37. 
Foo, S. C. and R. G. Rice, 1975. "On the Predication of Ultimate Separation in Parametric Pumps," AIChE Journal, Vol. 21, No. 6, pp. 1149-1158.

Fürst, Walter and Henri Renon, 1982. "Effect of the Various Parameters in the Application of Pitzer's Model to Solid-Liquid Equilibrium. Preliminary Study for Strong 1-1 Electrolytes," Ind. Eng. Chem. Process Des. Dev. 1982. 21, 396-400.

German, R. M., 1989. Particle Packing Characteristics, Metal Powder Industries Federation, Princeton, New Jersey.

Gotoh, Keishi, Hiroaki Masuda and Ko Higashitani, 1997. Powder Technology Handbook, $2^{\text {nd }}$ Revision Edition, ISBN: 0824700155, Marcel Dekker, Augusta 26, 1997.

Gunn, D. J. and J. F. C. De Souza, 1974. "Heat Transfer and Axial Dispersion in Packed Beds," Chem. Engr. Science, Vol. 29, pp. 1363-1371.

Hamm, L. L., F. G. Smith, and M. A. Shadday, 2000a. "QA Verification Package for VERSELC Version 7.80," Westinghouse Savannah River Co. document, WSRC-TR-99-00238, Rev. 0 (February).

Hamm, L. L., F. G. Smith, III, and D. J. McCabe, 2000b. "Preliminary Ion Exchange Modeling for Removal of Cesium from Hanford Waste Using SuperLig ${ }^{\circledR} 644$ Resin," BNF-003-980220, June 16.

Hamm, L. L., F. G. Smith, III, and D. J. McCabe, 2000c. "Preliminary Ion Exchange Modeling for Removal of Technetium from Hanford Waste Using SuperLig ${ }^{\mathbb{B}} 639$ Resin," WSRC-TR2000-00305 (SRT-RPP-2000-00011), August.

Hamm, L. L., B. J. Hardy and S. E. Aleman, 2002a. "Task Technical and Quality Assurance Plan for Ion Exchange Computer Model Upgrades (U)," Westinghouse Savannah River Co. document, WSRC-TR-2002-00041 (SRT-RPP-2002-00014), Rev. 0 (January 2002).

Hamm, L. L., T. Hang, D. J. McCabe, and W. D. King, 2002b. "Preliminary Ion Exchange Modeling for Removal of Cesium from Hanford Waste Using Crystalline Silicotitanate Material," WSRC-TR-2001-00400 (SRT-RPP-2001-00134), July.

Hamm, L. L., S. E. Aleman, B. J. Hardy, W. D. King, and C. E. Duffey, 2003b. "Ion Exchange Modeling for Removal of Cesium from Hanford Waste Using SuperLig ${ }^{\mathbb{R}} 644$ Resin," Westinghouse Savannah River Co. document, WSRC-TR-2003-00555 (SRT-RPP-200300242), Rev. 0 (February, 2004).

Hardy, B. J., Hamm, L. L., and S. E. Aleman, 2003. "Task Technical and Quality Assurance Plan for Computer Modeling of Ion Exchange with RF Resin - Stage 1 (U)," Westinghouse Savannah River Co. document, WSRC-TR-2003-00224 (SRT-RPP-2003-00101), Rev. 0 (June 19, 2003).

Hassan, N. M. and D. J. McCabe, 1997a. "Hanford Envelope A Tank Waste Ion Exchange Column Study (U)," SRNL-BNFL-019, Rev. 0, October 24.

Hassan, N. M. and D. J. McCabe, 1997b. "Hanford Envelope C Tank Waste Ion Exchange Column Study (U)," SRNL-BNFL-018, Rev. 0, October 24.

Hassan, N. M. and D. J. McCabe, 1997c. "Hanford Envelope A Tank Waste Ion Exchange Distribution Coefficient Study (U)," SRNL-BNFL-021, Rev. 0, November 13.

Hassan, N. M. and D. J. McCabe, 1997d. "Hanford Envelope B Tank Waste Ion Exchange Column Study (U),” SRNL-BNFL-017, Rev. 1, December 5.

Hassan, N. M. and D. J. McCabe, 1998. "Hanford Envelope C (hydroxide-adjusted) Tank Waste Batch Distribution Coefficient Study (U)," SRNL-BNFL-027, Rev. 0, January 19. 
Hassan, N. M., W. D. King, and D. J. McCabe, 1999a. "SuperLiq ${ }^{\circledR}$ Ion Exchange Resin Swelling and Buoyancy Study (U)," BNF-003-98-0051, March 25.

Hassan, N. M., D. J. McCabe, and W. D. King, 1999b. "Small-Scale Ion Exchange Removal of Cesium and Technetium from Hanford Tank 241-AN-103 (U)," BNF-003-98-00146, August 25.

Helfferich, 1962. Ion Exchange, McGraw-Hill series in advanced chemistry, McGraw-Hill Book Company, Inc., New York.

Helfferich, F. G. and P. W. Carr, 1993. The review paper "Non-linear Waves in Chromatography , I. Waves, Shocks, and Shapes,” Journal of Chromatography, Vol 627, pp. 97-122.

IBC Advanced Technologies, Inc., 1996. "Simulant Test Results for Cs, Sr, Tc, and TRU SuperLigands," Conducted for British Nuclear Fuels, Inc., October (report contains some IBC proprietary information).

Izatt, R. M., J. S. Bradshaw, R. L. Bruening, B. J. Tarbet, and K. E. Krakowiak, 1993. "Novel Metal Separations using SuperLig ${ }^{\circledR}$ Materials Involving Macrocyclic Chemistry," Published in The Minerals, Metals, \& Materials Society under Emerging Separation Technologies for Metals and Fuels.

King, W. D., D. J. McCabe, and N. M. Hassan, 2000. "Optimization of Cesium Removal from Hanford Envelope A Simulant with SuperLig ${ }^{\circledR} 644$ Ion Exchange Resin," BNF-003-9800169, Rev. 0, April 13.

King, W. D., 2003. "Hanford RPP-WTP SL-644 Program - Protocol P3: SuperLig ${ }^{\circledR} 644$ BenchScale Wet Sieving Protocol”, SRT-RPP-2003-0067, Rev. 0. Savannah River Site, Aiken SC 29808 (July).

King, W. D., C. E. Duffey, S. H. Malene, 2003. "Determination of Cesium $\left(\mathrm{Cs}^{+}\right)$Adsorption Kinetics and Equilibrium Isotherms from Hanford Waste Simulants using ResorcinolFormaldehyde Resins (U)," Westinghouse Savannah River Co. document, WSRC-TR-200300574 (SRT-RPP-2003-00252), Rev. 0 (March, 2004).

Kunii, D. and J. M. Smith, 1960. "Heat Transfer Characteristics of Porous Rocks," A.I.Ch.E. Journal, Vol. 6, No. 1, pp. 71-78.

Kunii, D. and J. M. Smith, 1961. "Heat Transfer Characteristics of Porous Rocks: II. Thermal Conductivities of Unconsolidated Particles with Flowing Fluids," A.I.Ch.E. Journal, Vol. 7, No. 1, pp. 29-34.

Kunii, D. and M. Suzuki, 1967. "Particle-to-Fluid Heat and Mass Transfer in Packed Beds of Fine Particles,” Int. J. Heat Mass Transfer, Vol. 10, No. 1, pp. 845-852.

Latham, John-Paul, Ante Munjiza and Yang Lu, 2002. "On the prediction of void porosity and packing of rock particulates," Powder Technology 125 (2002) 10-17.

Lee, S. Y., 2001. "Heat Transfer Calculations for Normal Operations of a Fixed CST Bed Column," WSRC-TR-2001-00255, May. Berninger, J., R. D. Whitley, X. Zhang, and N.H.L. Wang, 1991. "A Versatile Model for Simulation of Reaction and Nonequilibrium Dynamics in Multicomponent Fixed-Bed Adsorption Processes," Comput. Chem. Eng., 1991, 15(11), 749-768.

Liles, A. W. and C. J. Geankoplis, 1960. "Axial Diffusion of Liquids in Packed Beds and End Effects," AIChE Journal, Vol. 6, No. 4, pp. 591-595.

Ma, Z., R. D. Whitley, and N.-H.L. Wang, 1996. "Pore and Surface Diffusion in Multicomponent Adsorption and Liquid Chromatography Systems," AIChE J., 1996, Vol. 42(5), 1244-1262.

Malene, S. H. Private Communication. (2004). 
Morales, M., C. W. Spinn, and J. M. Smith, 1951. "Velocities and Effective Thermal Conductivities in Packed Beds," Industrial and Engr. Chemistry, Vol. 43, No. 1, pp. 225-232.

Olson, J.W. and M. L. Stewart, 2002a. "System Description for Cesium Removal Using Ion Exchange - System CXP," 24590-PTF-3YD-CXP-00001, Rev B, May 2002, Bechtel National Inc., Richland, Washington.

Olson, J.W. and M. L. Stewart, 2002b. "System Description for Technetium Removal Using Ion Exchange - System TXP," 24590-PTF-3YD-TXP-00001, Rev B, May 2002, Bechtel National Inc., Richland, Washington.

Pfeffer, R. and J. Happel, 1964. "An Analytical Study of Heat and Mass Transfer in Multiparticle Systems at Low Reynolds Numbers," A.I.Ch.E. Journal, Vol. 10, No. 5, pp. 605-611.

Pitzer, K.S., 1991. "Ion Interaction Approach: Theory and Data Correlation," in K. S. Pitzer, ed., "Activity Coefficients in Electrolyte Solutions," $2^{\text {nd }}$ Ed., CRC Press, Boca Raton, Florida (1991).

Rowe, P. N. and K. T. Claxton, 1965. "Heat and Mass Transfer from a Single Sphere to Fuild Flowing Through an Array,” Trans. Instn. Chem. Engrs., Vol. 43, pp. 321-331.

Ruthven, D. M. (Editor), 1997. Encyclopedia of Separation Technology (Volume 2), John Wiley and Sons, New York. (see Ion Exchange chapter by Charles Dickert)

Schwartz, C. E. and J. M. Smith, 1953. "Flow Distribution in Packed Beds," Industrial and Engr. Chemistry, Vol. 45, No. 6, pp. 1209-1218.

Serkiz, S. M. 2002. "Integrated Sr/TRU Precipitation and Cs Ion Exchange Process Validation Task Technical and QA plan (U)," Westinghouse Savannah River Co. document, WSRC-TR2002-00041 (SRT-RPP-2002-00029), Rev. 0 (March 2002).

Serkiz, S. M.; Pishko, A. L., 2004; Adu-wusu, K. "Measuring Physical and Chemical Property Variations of SuperLig ${ }^{\mathbb{B}} 644$ and SuperLig ${ }^{\mathbb{R}} 639$ Resin (U)", WSRC-TR-2003-00474, Rev. 0, SRT-RPP-2003-00226 Savannah River Site, Aiken SC 29808.

Smith, J. M., 1981. Chemical Engineering Kinetics, $3^{\text {rd }}$ ed., McGraw Hill, New York, pp. 331332.

Steimke, J. L., 2003a. "Hanford RPP-WTP SL-644 Program -Protocol P1: Resin Removal from Buckets, Resin Pretreatment and Resin Loading to Column", SRT-RPP-2003-0048, Rev. 0. Savannah River Site, Aiken SC 29808 (2003).

Steimke, J. L., 2003b. "Hanford RPP-WTP SL-644 Program -Protocol P4: Measurement of Column Resin Dry Mass Basis", SRT-RPP-2003-0049, Rev. 0. Savannah River Site, Aiken SC 29808.

Steimke, J. L., M. A. Norato, T. J. Steeper and D. J. McCabe, 2000. "Summary of Testing of SuperLig ${ }^{\circledR} 639$ at the TFL Ion Exchange Facility," Westinghouse Savannah River Co. document, WSRC-TR-2000-00302 (SRT-RPP-2000-00008), Rev. 0 (August 2000).

Steimke, J. L. and T. J. Steeper, 2002. "Status Report for Pilot Scale Testing of SuperLig ${ }^{\circledR} 644$ Ion Exchange Resin," Westinghouse Savannah River Co. document, WSRC-TR-2002-00340, Rev. 0 (July 2002).

Thorson, M., 2003. "Test Specification: Resorcinol Formaldehyde Ion Exchange Computer Model,” Bechtel Hanford document, 24590-PTF-TSP-RT-03-008, Rev. 0 (June 18, 2003).

Toth, J., 2002b. "Proposed Preliminary Cesium and Technetium Ion Exchange," (internal memorandum CCN 041301 to P. S. Sundar, September 2002), Bechtel National Inc., Richland, Washington. 
Toth, J., 2003. "Ion Exchange Feed Compositions and Minimum Required Cesium Removal from Low Activity Waste Solutions," Bechtel Hanford memorandum, CCN-075606, Rev. 0 (December 2).

Thorson, M., 2003. Personal communication sent 6/19/2003.

Visual Numerics, Inc. 1997. "IMSL ${ }^{\circledR}$ Fortran Subroutines for Mathematical Applications, Math/Library, Volume 1," Houston, TX.

Weber, C. F., 2001. “Thermodynamic Modeling of Savannah River Evaporators," ORNL/TM2001/102, Oak Ridge National Laboratory, August, 2001.

Whitley, R. D. and N.-H. Wang, 1998. "User's Manual VERSE (VErsatile Reaction Seperation) Simulation for Liquid Phase Adsorption and Chromatography Processes," School of Chemical Engineering, Purdue University, July, 1998.

Wilson, E. J.,Geankoplis, 1966. C. J. "Liquid Mass Transfer at Very Low Reynolds Numbers in Packed Beds", I \& EC Fundamentals, Vol 5, No 1 PP, 9-14.

Zemaitis, Joseph F., Diane M. Clark, Marshall Rafal and Noel C. Scrivner, 1986. "Handbook of Aqueous Electrolyte Thermodynamics," A publication of the Design Institute for Physical Property Data (DIPPR). 
WSRC-TR-2004-00100, REVISION 0

SRT-RPP-2004-00019, REVISION 0

(This page intentionally left blank.) 


\section{Appendix A (Particle Kinetics and Column Assessment Input and Output Files)}

VERSE-LC input and output files for the particle kinetics rig and laboratory-scale test columns are provided in this appendix. Ten simulations were run. The input and output files for each case are listed below. A datafile.yio file was required for each of the models for the SRNL particle kinetics experiments, but not for the PNNL column experiments. In this appendix, the datafile.yio files are listed after their corresponding datafile.

\section{A.1 SRNL Particle Kinetics Experiment 1}

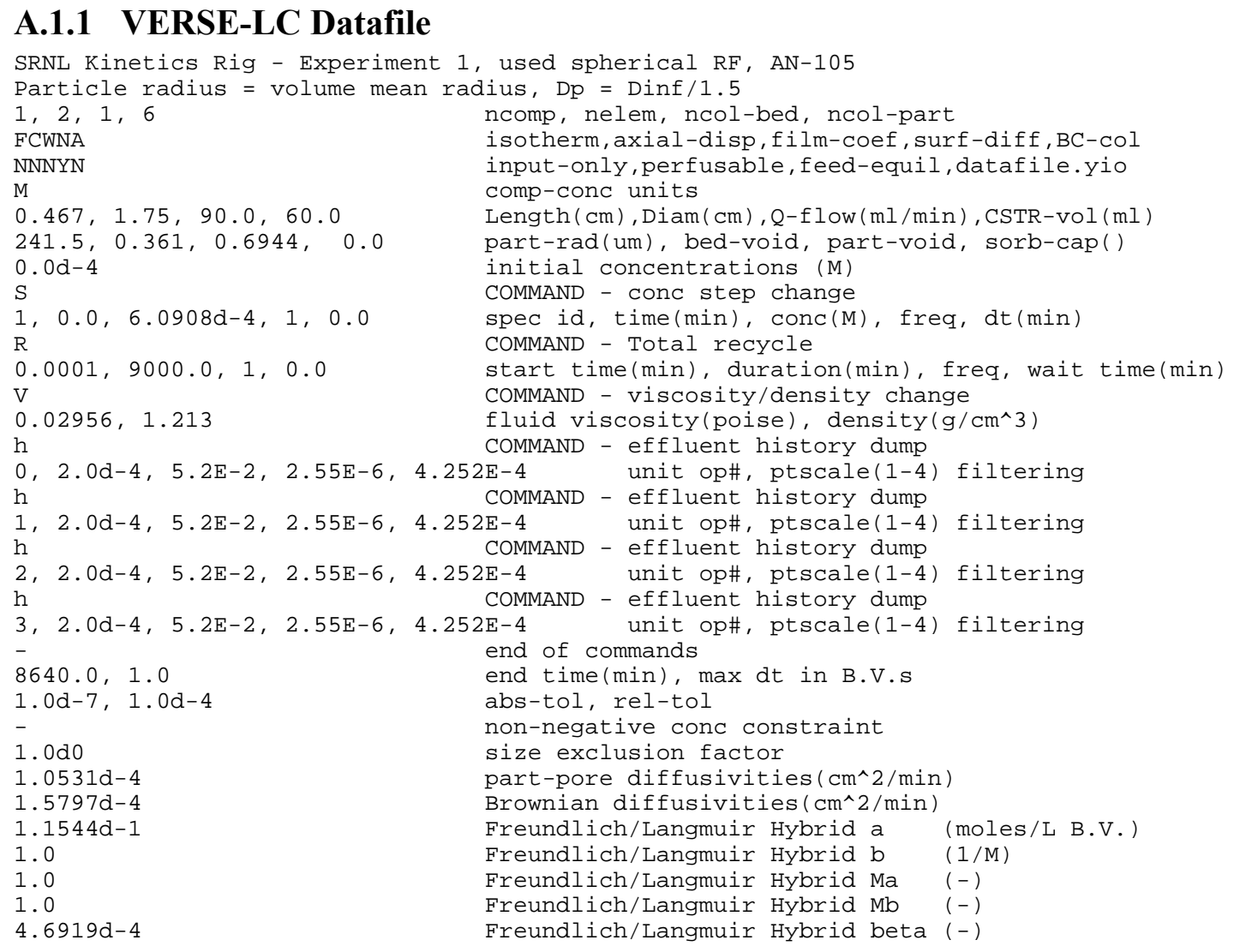

\section{A.1.2 VERSE-LC Datafile.yio}

\begin{tabular}{|c|c|}
\hline 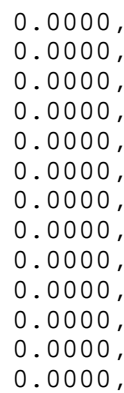 & 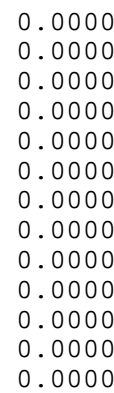 \\
\hline
\end{tabular}


WSRC-TR-2004-00100, REVISION 0

SRT-RPP-2004-00019, REVISION 0
$\odot .0000$,
$\odot .0000$
0.0000 ,
$\odot .0000$
0.0000 ,
0.0000
0.0000,
0.0000
$\odot .0000$,
$\odot .0000$
0.0000 ,
0.0000
$\odot .0 \odot \odot$, $^{-}$
$\odot .0000$
0.0000,
$\odot .0000$
0.0000
$0.0000, \quad 0.0000$
$0.0000, \quad 0.0000$
$0.0000, \quad 0.0000$
$0.0000, \quad 0.0000$
$0.0000, \quad 0.0000$
$0.0000, \quad 0.0000$
$0.0000, \quad 0.0000$
$0.0000, \quad 0.0000$
$0.0000, \quad 0.0000$
$0.0000, \quad 0.0000$
$0.0000, \quad 0.0000$
$0.0000, \quad 0.0000$
$0.0000, \quad 0.0000$
$0.0000, \quad 0.0000$
$0.0000, \quad 0.0000$
$0.0000, \quad 0.0000$
$0.0000, \quad 0.0000$
$6.0908 \mathrm{~d}-4, \quad 0.0000$
$6.0908 d-4,0.0000$

\section{A.1.3 VERSE-LC Datafile.run}

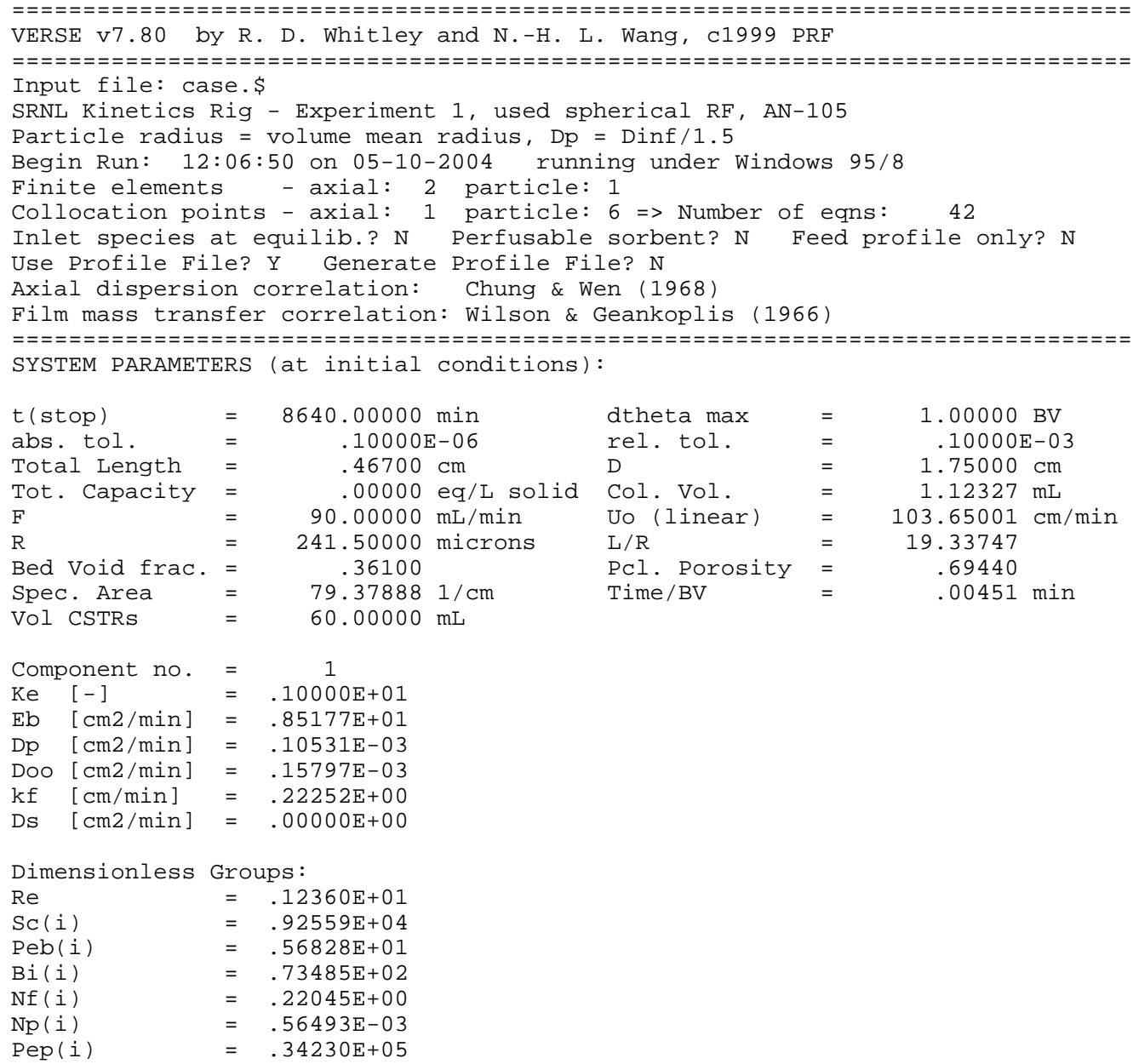


WSRC-TR-2004-00100, REVISION 0

SRT-RPP-2004-00019, REVISION 0

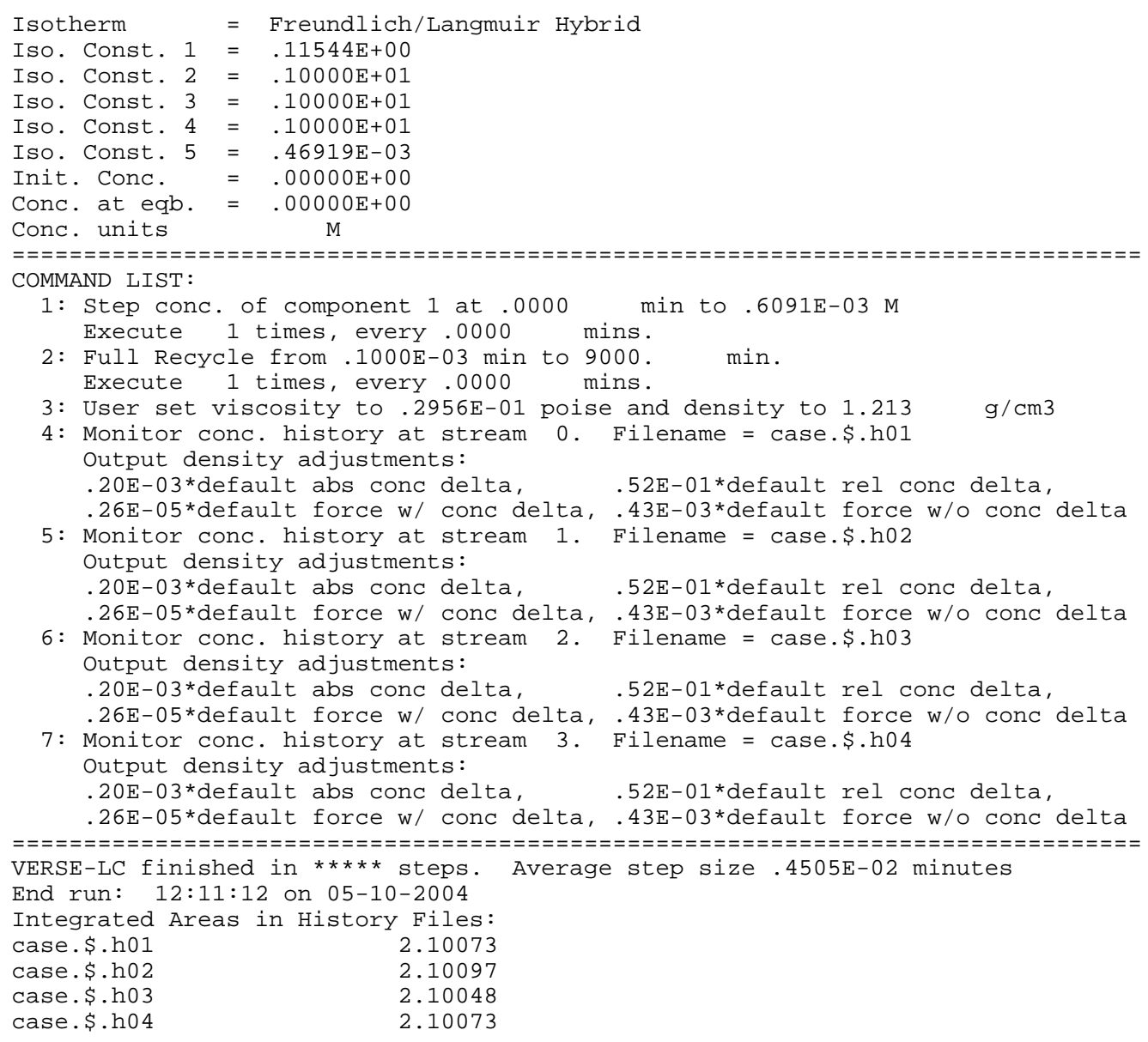

\section{A.2 SRNL Particle Kinetics Experiment 2}

\section{A.2.1 VERSE-LC Datafile}

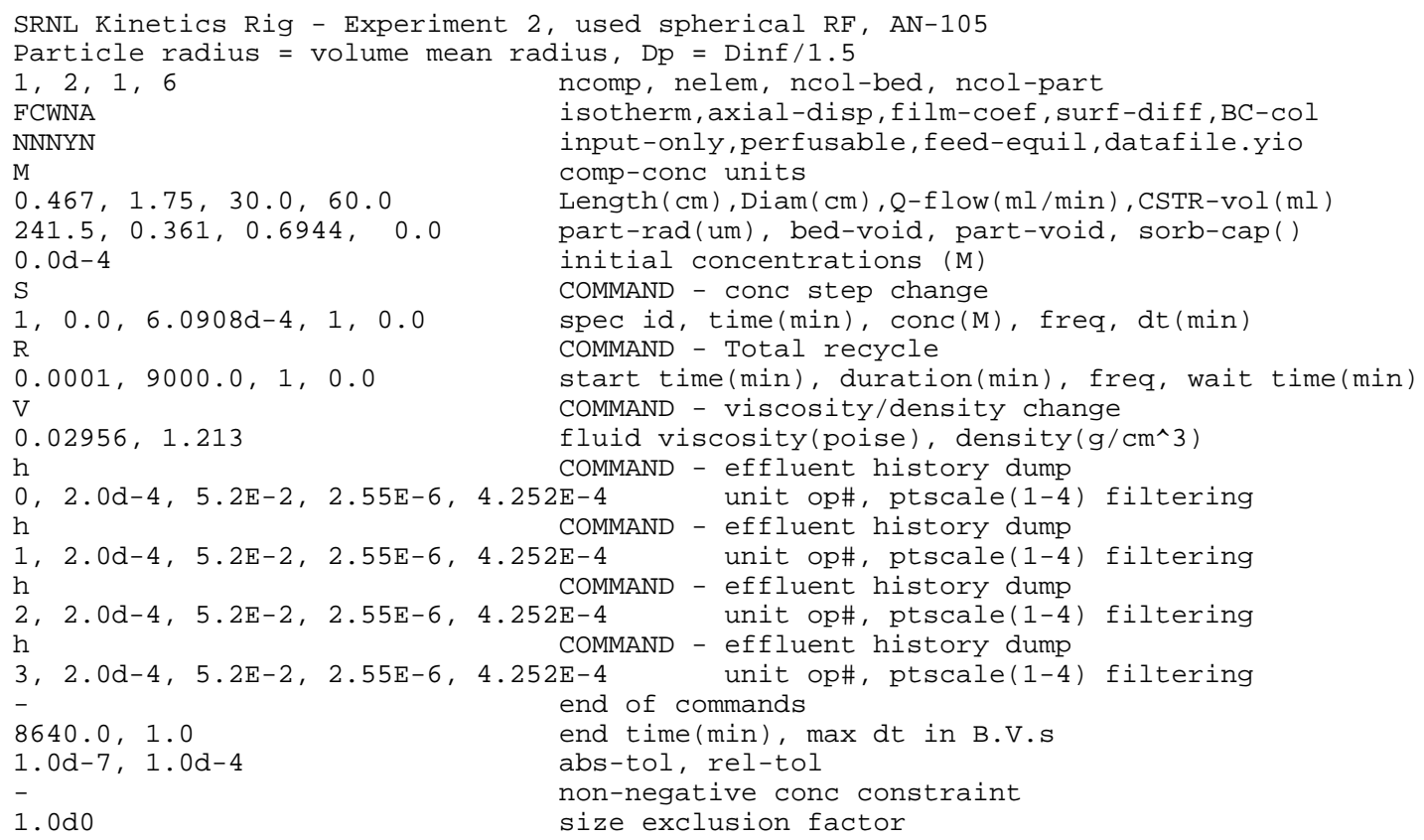


1. $0531 d-4$

$1.5797 \mathrm{~d}-4$

$1.1557 \mathrm{~d}-1$

1.0

1.0

1.0

4.6919d-4 part-pore diffusivities $\left(\mathrm{cm}^{\wedge} 2 / \mathrm{min}\right)$

Brownian diffusivities ( $\left.\mathrm{cm}^{\wedge} 2 / \mathrm{min}\right)$

Freundlich/Langmuir Hybrid a (moles/L B.V.)

Freundlich/Langmuir Hybrid b (1/M)

Freundlich/Langmuir Hybrid Ma (-)

Freundlich/Langmuir Hybrid Mb (-)

\section{A.2.2 VERSE-LC Datafile.yio}

\begin{tabular}{|c|c|}
\hline 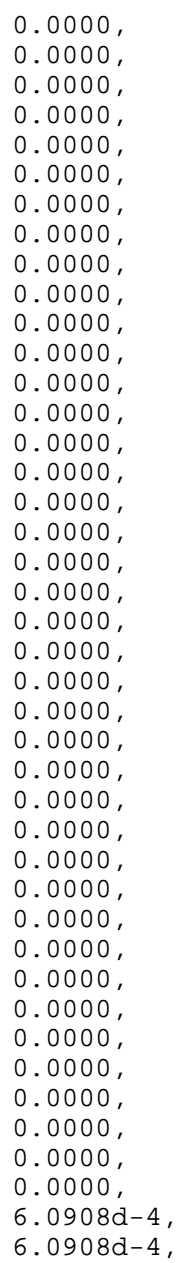 & 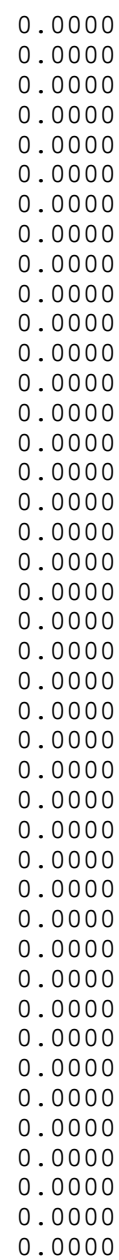 \\
\hline
\end{tabular}

\section{A.2.3 VERSE-LC Datafile.run}

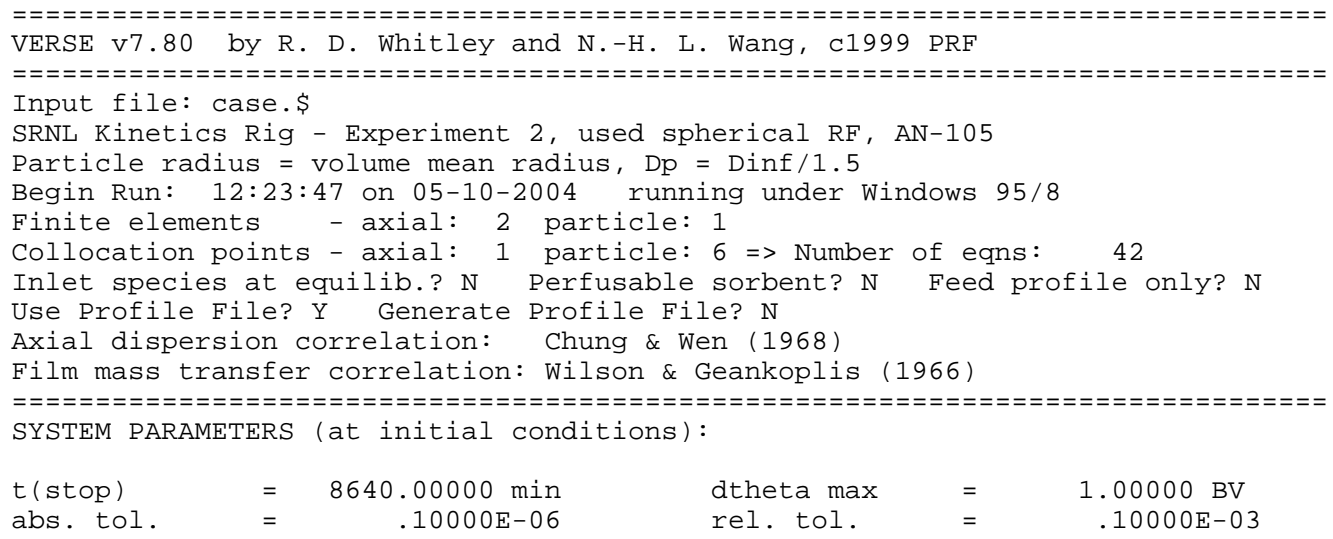


WSRC-TR-2004-00100, REVISION 0

SRT-RPP-2004-00019, REVISION 0

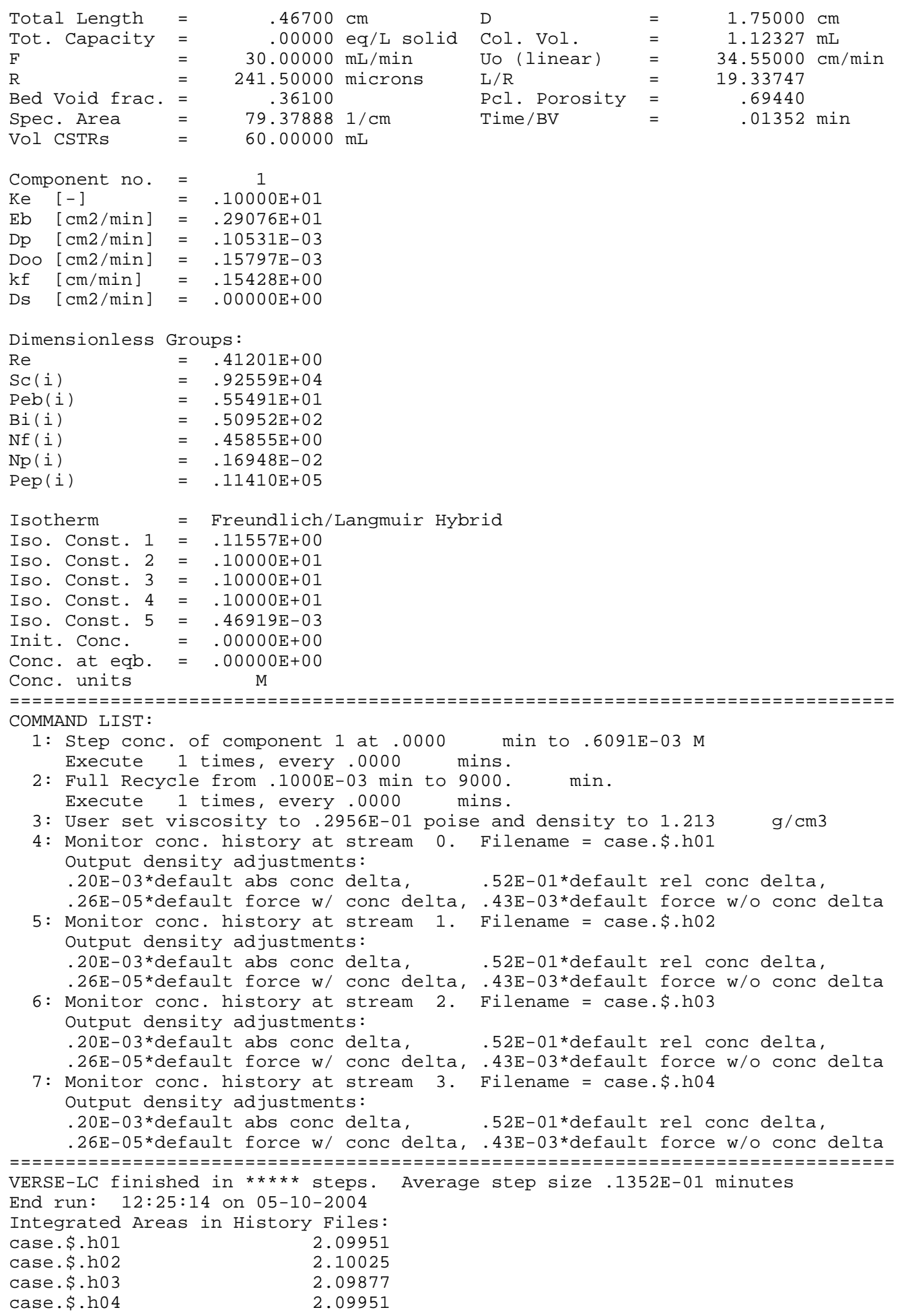

\section{A.3 SRNL Particle Kinetics Experiment 3}

\section{A.3.1 VERSE-LC Datafile}

SRNL Kinetics Rig - Experiment 3, used spherical RF, AN-105

Particle radius $=$ volume mean radius, $\mathrm{Dp}=\mathrm{Dinf} / 1.5$

$1,2,1,6$ ncomp, nelem, ncol-bed, ncol-part 
FCWNA

NNNYN

$\mathrm{M}$

$0.456,1.75,0.5,60.0$

$241.5, \quad 0.361, \quad 0.6944, \quad 0.0$

$\odot .0 \mathrm{~d}-4$

$\mathrm{S}$

$1,0.0,5.7861 d-4,1,0.0$

$0.0001,9000.0,1,0.0$

$\mathrm{V}$

$0.02956,1.213$

$0,1.0,1.0,0.25,0.1$

$1,1.0,1.0,0.25,0.1$

$\mathrm{h}$

$2,1.0,1.0,0.25,0.1$

$\mathrm{h}$

$3,1.0,1.0,0.25,0.1$

$8640.0,1.0$

$1.0 \mathrm{~d}-7,1.0 \mathrm{~d}-4$

1. $0 \mathrm{~d} \odot$

1. $0531 d-4$

1. $5797 d-4$

1. $1373 d-1$

1.0

1. 0

1.0

4. $6919 d-4$

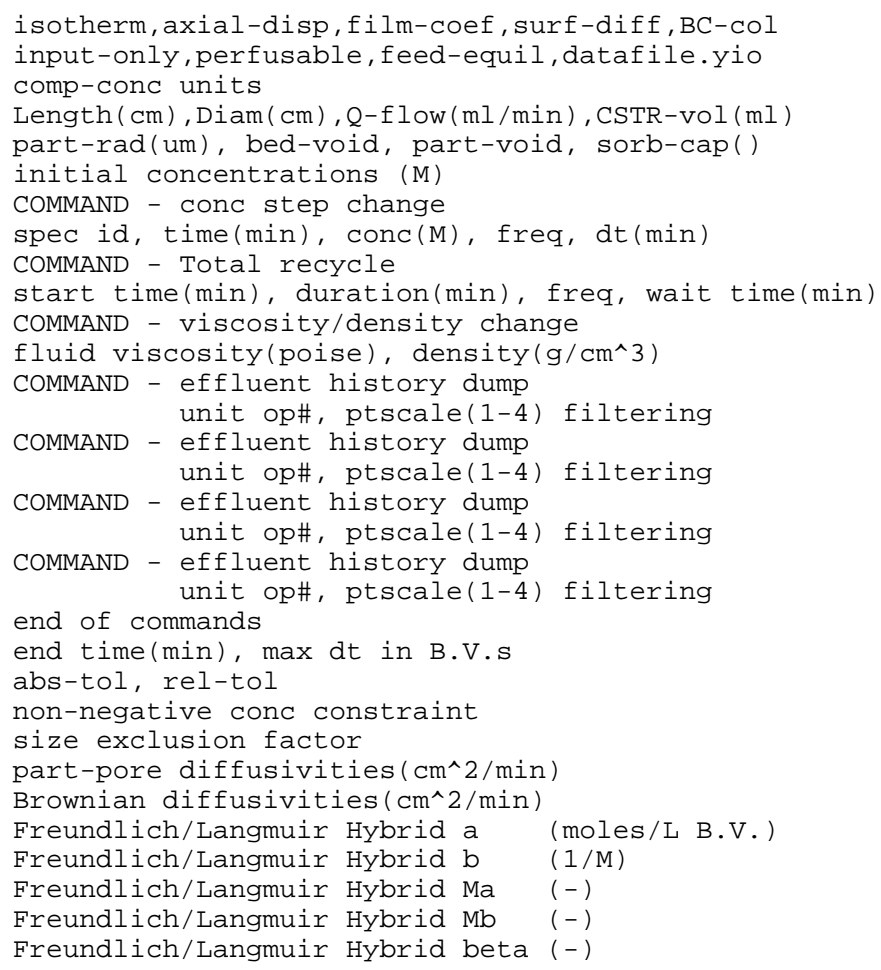

isotherm, axial-disp, film-coef, surf-diff, BC-col

comp-conc units

ength $(\mathrm{cm}), \operatorname{Diam}(\mathrm{cm}), \mathrm{Q}-f$

initial concentrations (M)

COMMAND - Total recycle

freq, wait time(min)

COMMAND - effluent history dump unit op\#, ptscale(1-4) filtering

effluent history dump

effluent history dump

end time(min), max dt in B.V.s

abs-tol, rel-tol

size exclusion factor

part-pore diffusivities $\left(\mathrm{cm}^{\wedge} 2 / \mathrm{min}\right)$

Freundlich/Langmuir Hybrid b (1/M)

Freundlich/Langmuir Hybrid $\mathrm{Mb}$ (-)

A.3.2 VERSE-LC Datafile.yio

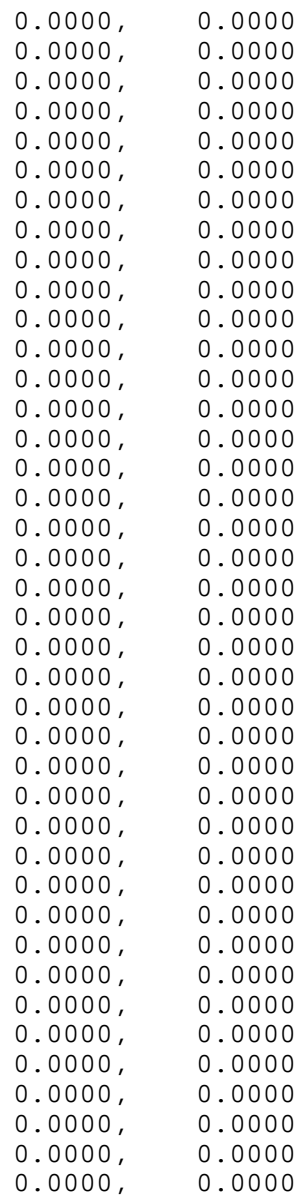




\section{A.3.3 VERSE-LC Datafile.run}

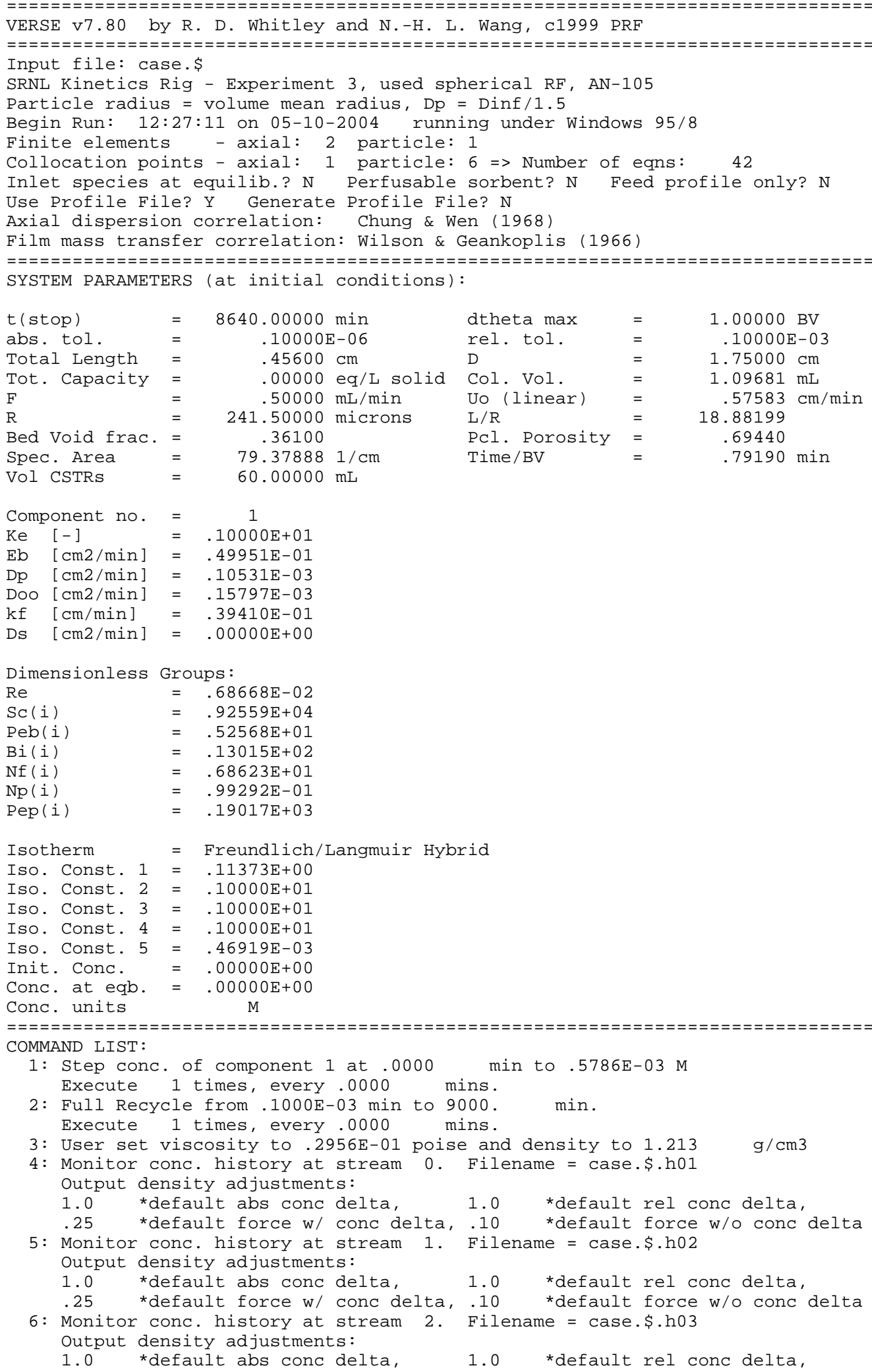




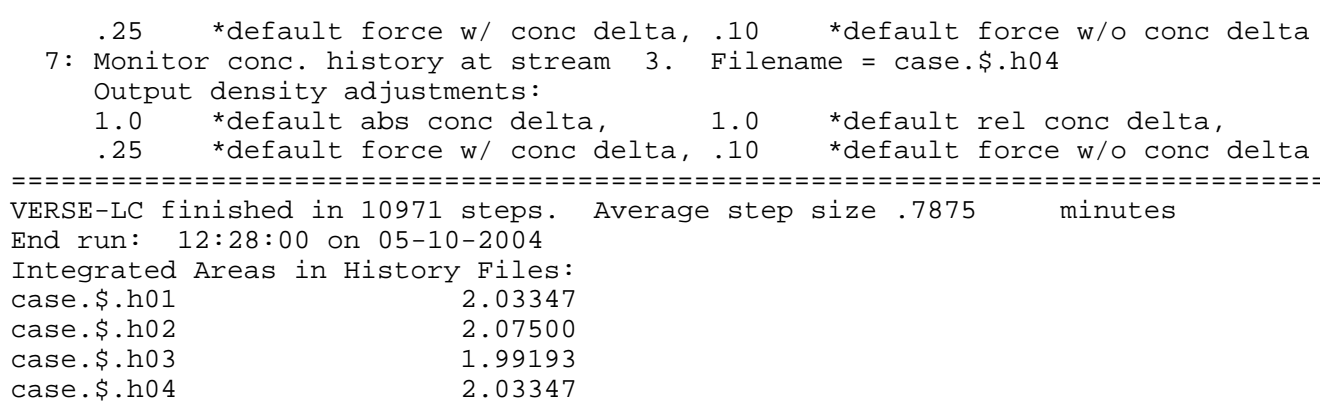

\section{A.4 SRNL Particle Kinetics Experiment 4}

\section{A.4.1 VERSE-LC Datafile}

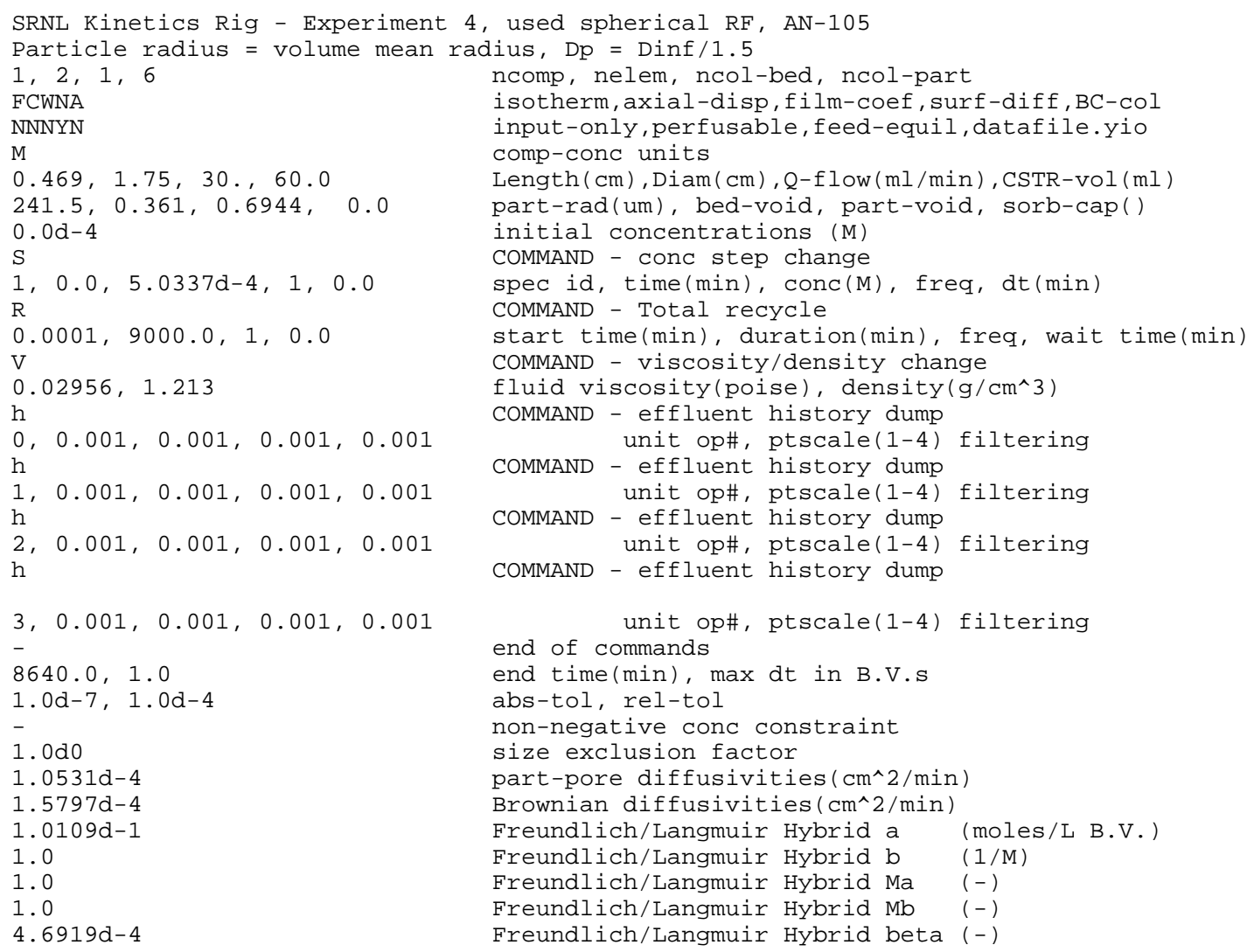

\section{A.4.2 VERSE-LC Datafile.yio}

\begin{tabular}{|c|c|}
\hline 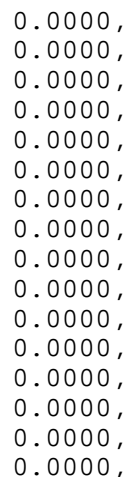 & $\begin{array}{l}0.000 \odot \\
0.000 \odot \\
0.000 \odot \\
0.000 \odot \\
0.000 \odot \\
0.000 \odot \\
0.000 \odot \\
0.000 \odot \\
0.000 \odot \\
0.000 \odot \\
0.000 \odot \\
0.000 \odot \\
0.000 \odot \\
0.000 \odot \\
0.000 \odot \\
0.000 \odot\end{array}$ \\
\hline
\end{tabular}


WSRC-TR-2004-00100, REVISION 0

SRT-RPP-2004-00019, REVISION 0

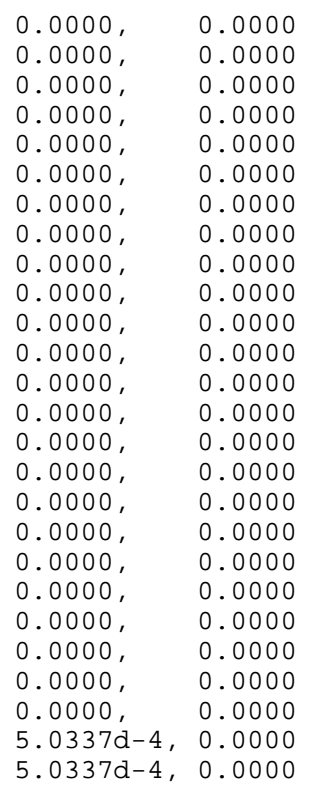

\section{A.4.3 VERSE-LC Datafile.run}

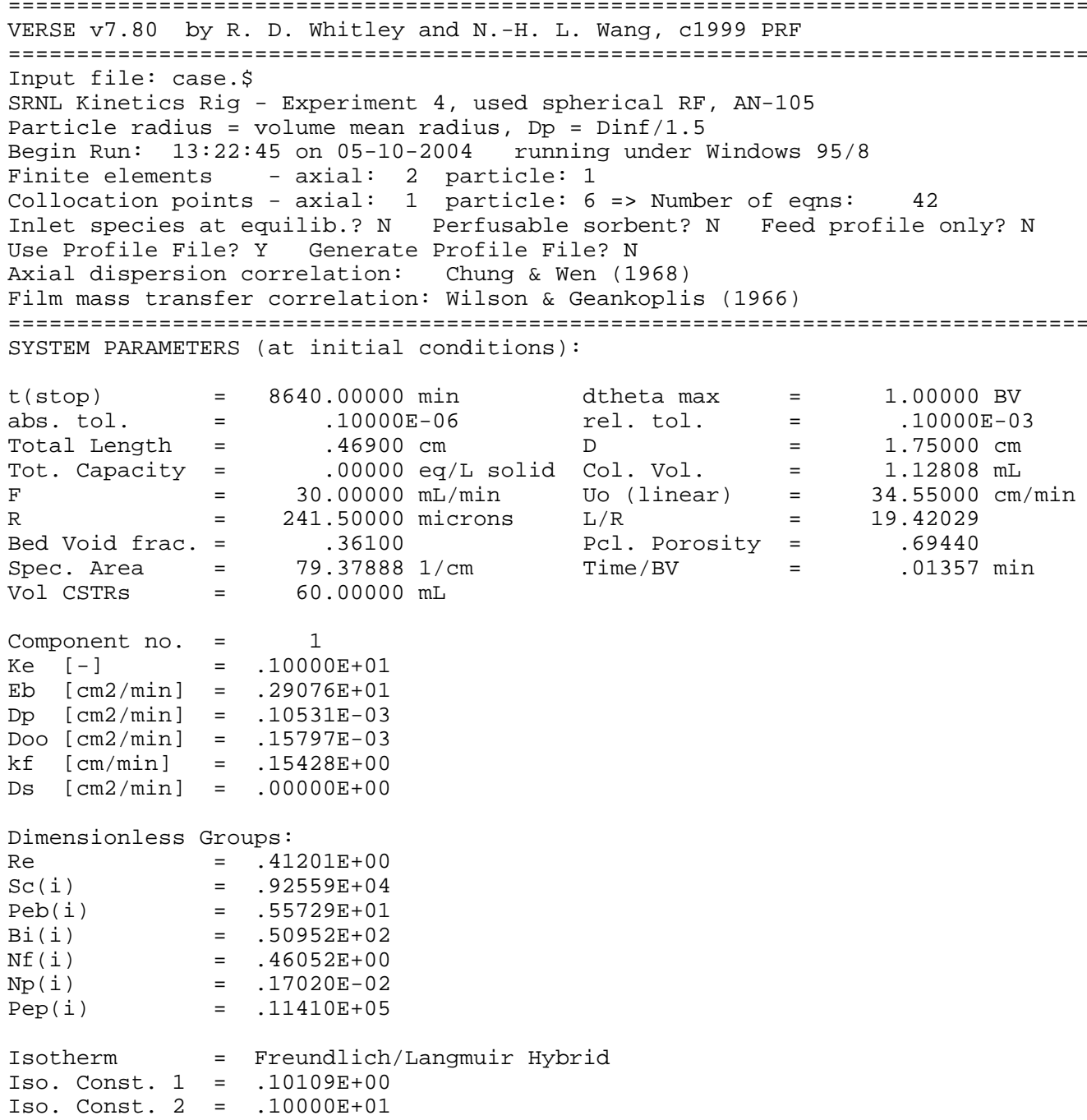




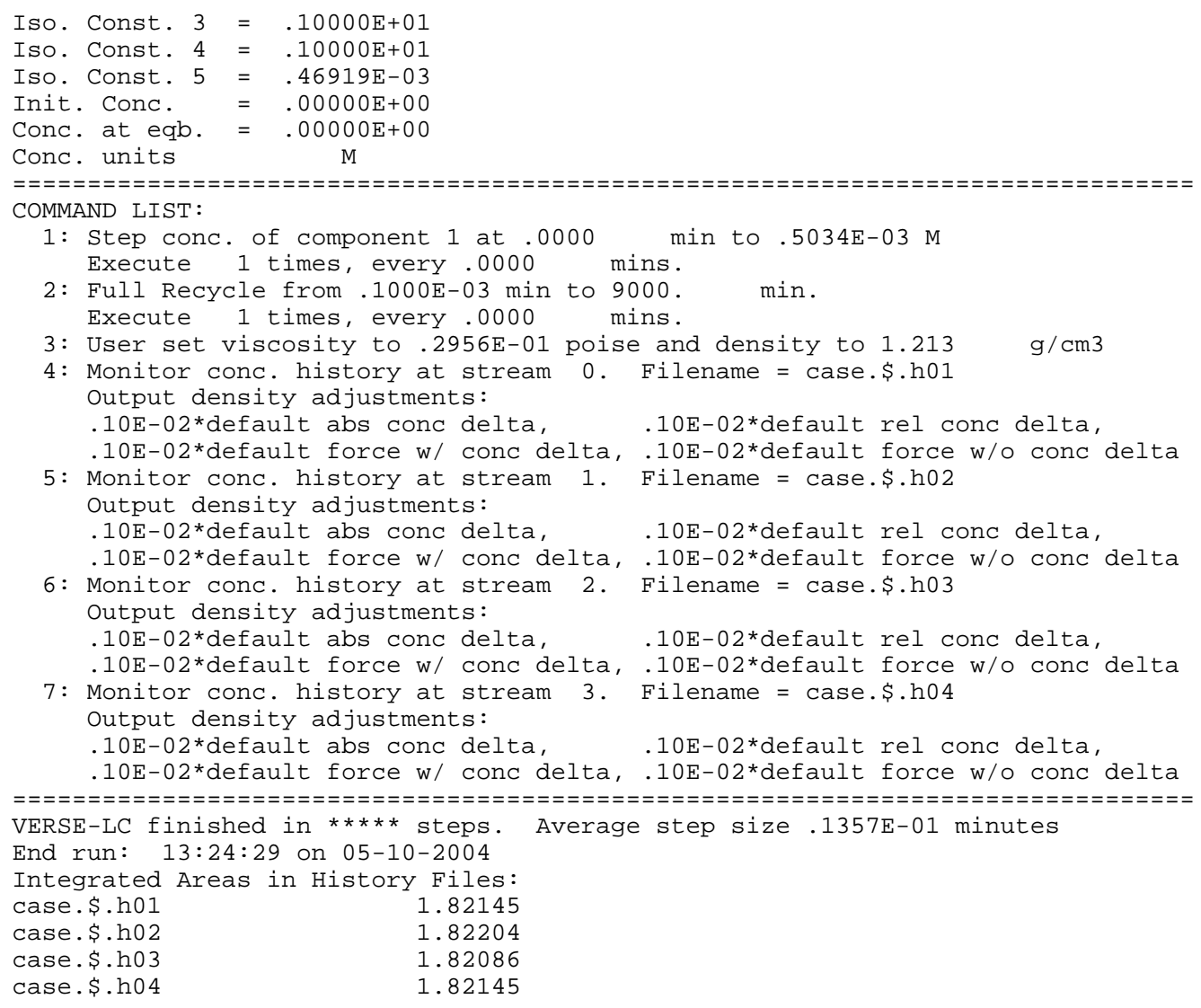

\section{A.5 SRNL Particle Kinetics Experiment 5}

\section{A.5.1 VERSE-LC Datafile}

SRNL Kinetics Rig - Experiment 5, unused spherical RF, AN-105

Particle radius $=$ volume mean radius, $\mathrm{Dp}=$ Dinf $/ 1.5$

$1,2,1,6$ ncomp, nelem, ncol-bed, ncol-part

FCWNA

isotherm, axial-disp, film-coef, surf-diff, BC-col

NNNYN

$M$

$0.5021 .75,30 ., 60.0$

input-only, perfusable, feed-equil, datafile.yio

comp-conc units

$241.5,0.361,0.6944,0.0$

$0.0 \mathrm{~d}-4$

Length $(\mathrm{cm})$, Diam $(\mathrm{cm}), \mathrm{Q}-\mathrm{flow}(\mathrm{ml} / \mathrm{min})$, CSTR-vol $(\mathrm{ml})$

$\mathrm{S}$

$1, \odot . \odot, 5.0337 d-4,1, \odot . \odot$

$\mathrm{R}$

$0.0001,9000.0,1,0.0$

$\mathrm{V}$

$0.02956,1.213$

$\mathrm{h}$

$0,0.001,0.001,0.001,0.001$

$\mathrm{h}$

$1,0.001,0.001,0.001,0.001$

$2,0.001,0.001,0.001,0.001$

$\mathrm{h}$

$3,0.001,0.001,0.001,0.001$

$8640.0,1.0$

$1.0 \mathrm{~d}-7,1.0 \mathrm{~d}-4$

$1.0 \mathrm{~d} \odot$

$1.0531 d-4$

$1.5797 d-4$

1. $0179 d-1$

part-rad(um), bed-void, part-void, sorb-cap( )

initial concentrations (M)

COMMAND - conc step change

spec id, time(min), conc(M), freq, dt(min)

COMMAND - Total recycle

start time(min), duration(min), freq, wait time(min)

COMMAND - viscosity/density change

fluid viscosity(poise), density $\left(\mathrm{g} / \mathrm{cm}^{\wedge} 3\right)$

COMMAND - effluent history dump unit op\#, ptscale(1-4) filtering

COMMAND - effluent history dump unit op\#, ptscale(1-4) filtering

COMMAND - effluent history dump unit op\#, ptscale(1-4) filtering

COMMAND - effluent history dump unit op\#, ptscale(1-4) filtering

end of commands

end time(min), $\max d t$ in B.V.s

abs-tol, rel-tol

non-negative conc constraint

size exclusion factor

part-pore diffusivities ( $\left.\mathrm{cm}^{\wedge} 2 / \mathrm{min}\right)$

Brownian diffusivities ( $\left.\mathrm{cm}^{\wedge} 2 / \mathrm{min}\right)$

Freundlich/Langmuir Hybrid a (moles/L B.V.) 
Freundlich/Langmuir Hybrid b (1/M)

1.0

Freundlich/Langmuir Hybrid Ma (-)

1.0
$4.6919 d-4$

Freundlich/Langmuir Hybrid Mb (-)

\section{A.5.2 VERSE-LC Datafile.yio}

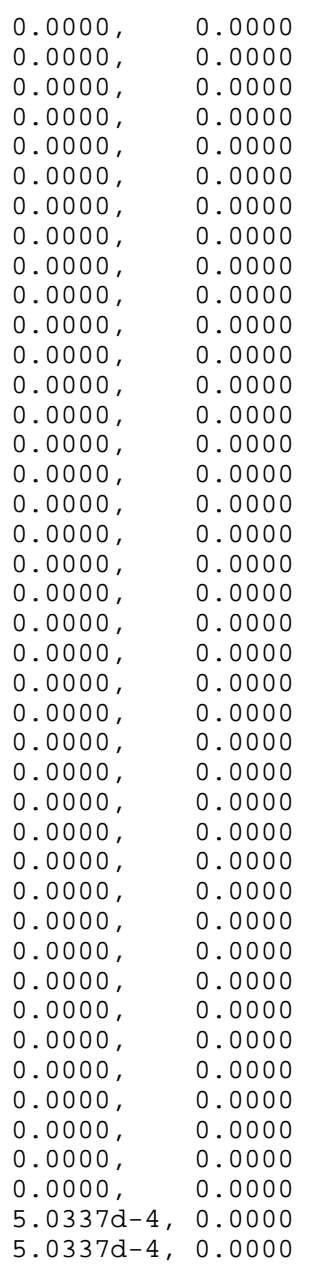

\section{A.5.3 VERSE-LC Datafile.run}

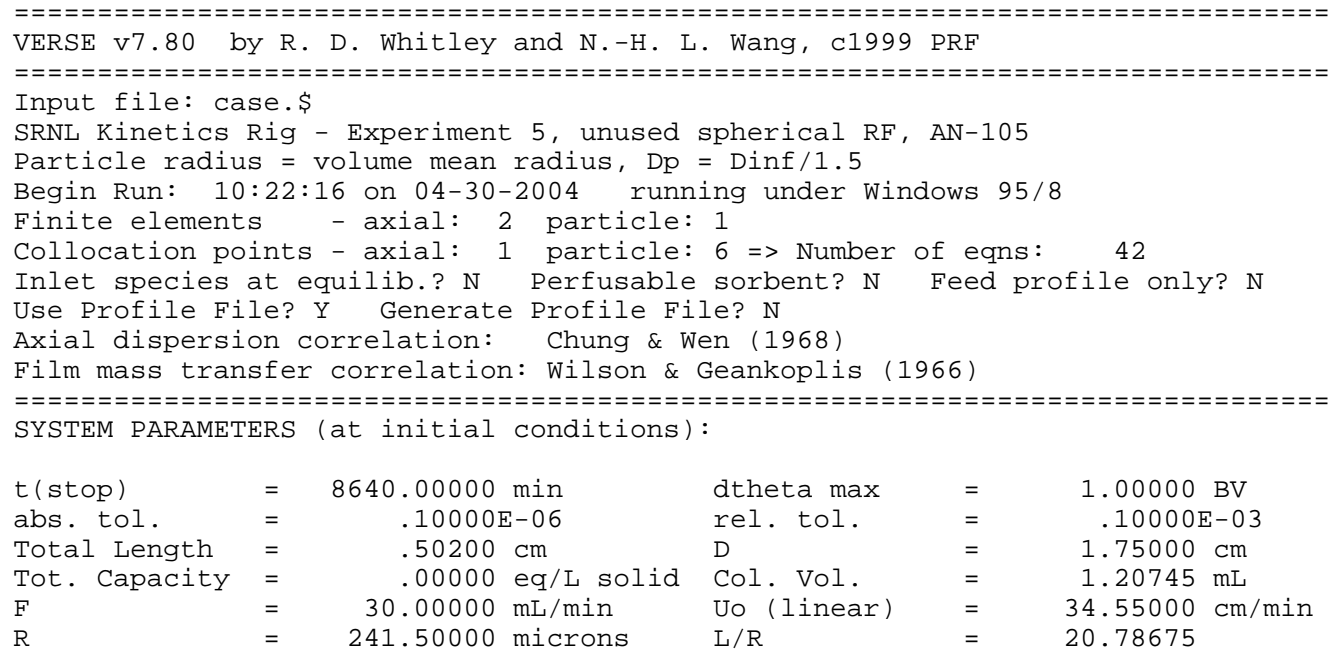


WSRC-TR-2004-00100, REVISION 0

SRT-RPP-2004-00019, REVISION 0

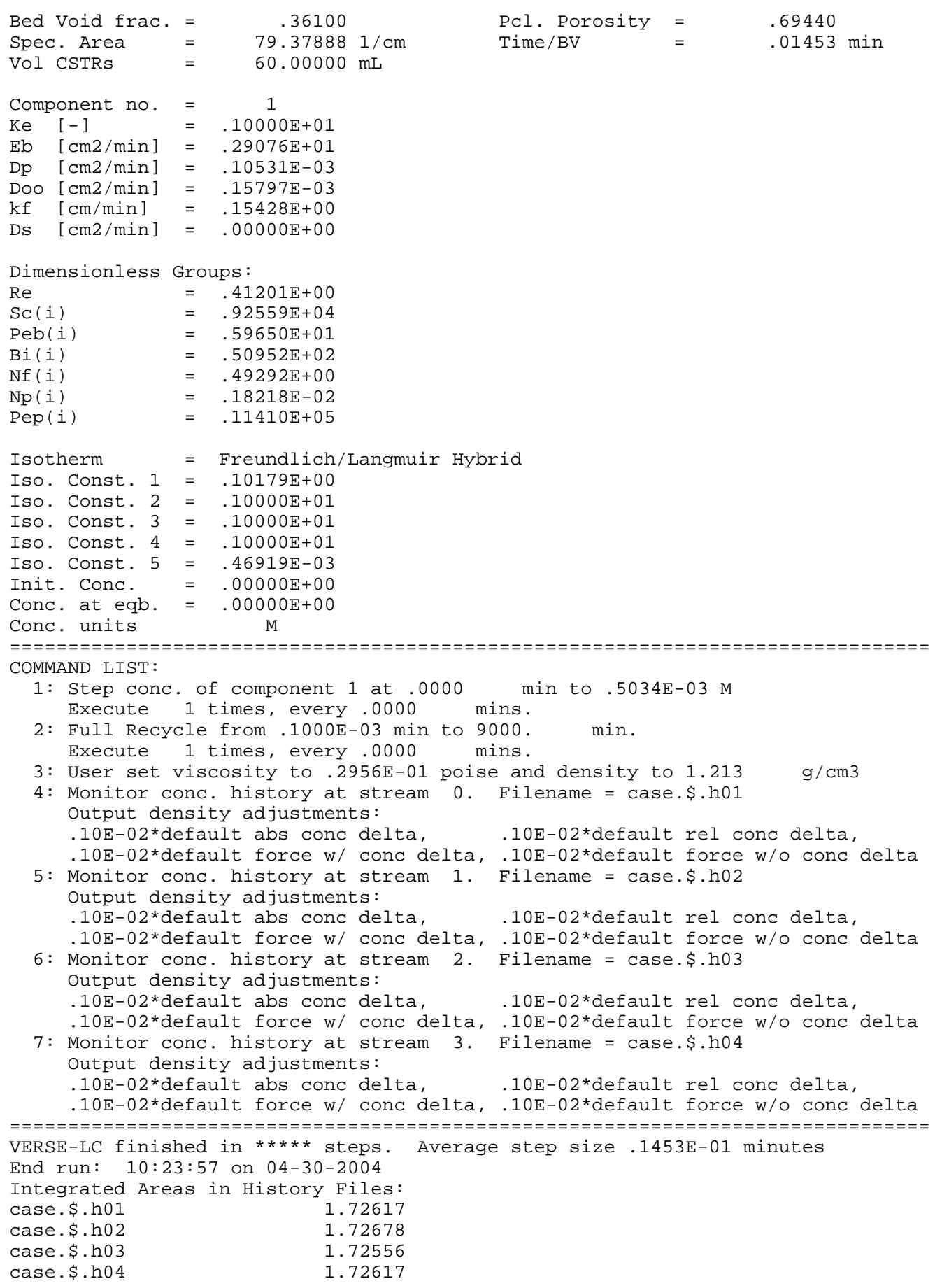

\section{A.6.1 SRNL Particle Kinetics Experiment 6}

\section{A.6.1 VERSE-LC Datafile}

SRNL Kinetics Rig - Experiment 6, granular RF, AN-105

Particle radius $=$ volume mean radius, $\mathrm{Dp}=\mathrm{Dinf} / 1.5$

$1,2,1,6 \quad$ ncomp, nelem, ncol-bed, ncol-part

FCWNA

isotherm, axial-disp, film-coef, surf-diff, BC-col

NNNYN

input-only, perfusable, feed-equil, datafile.yio

$M$

comp-conc units

$0.5381 .75,30 ., 60.0$

Length $(\mathrm{cm}), \operatorname{Diam}(\mathrm{cm}), \mathrm{Q}-\mathrm{flow}(\mathrm{ml} / \mathrm{min}), \operatorname{CSTR}-\operatorname{vol}(\mathrm{ml})$ 
$304.0, \quad 0.361, \quad 0.6944, \quad 0.0$ $\odot .0 \mathrm{~d}-4$

$\mathrm{S}$

$1,0.0,4.9660 \mathrm{~d}-4,1,0.0$

$\mathrm{R}$

๑. $0001,9000.0,1,0.0$

$0.02956,1.213$

$0,0.001,0.001,0.001,0.001$

h

1, $0.001,0.001,0.001,0.001$

$\mathrm{h}$

2, $0.001,0.001,0.001,0.001$

$3,0.001,0.001,0.001,0.001$

$8640.0,1.0$

$1.0 \mathrm{~d}-7,1.0 \mathrm{~d}-4$

$1.0 \mathrm{~d} \odot$

1. $0531 d-4$

$1.5797 d-4$

1. $9174 d-1$

1.0

1.0

1.0

4. $6919 d-4$

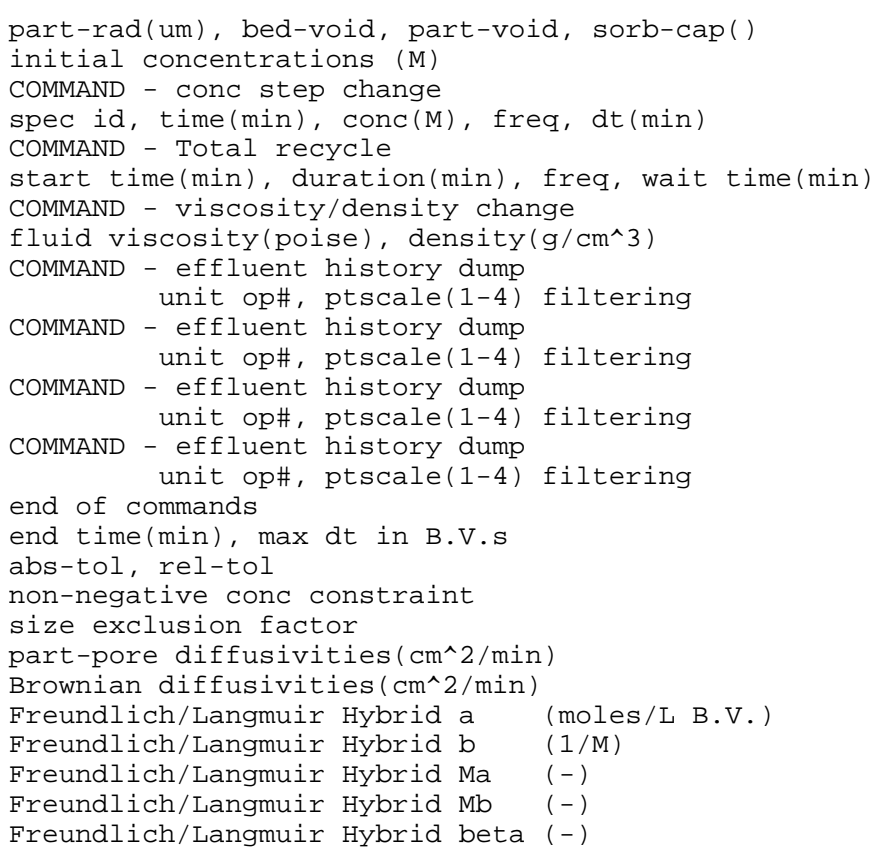

\section{A.6.2 VERSE-LC Datafile.yio}

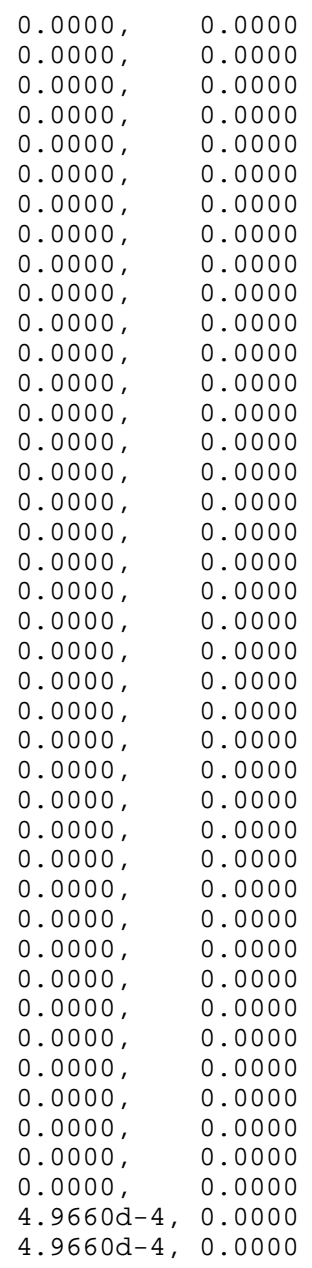




\section{A.6.3 VERSE-LC Datafile.run}

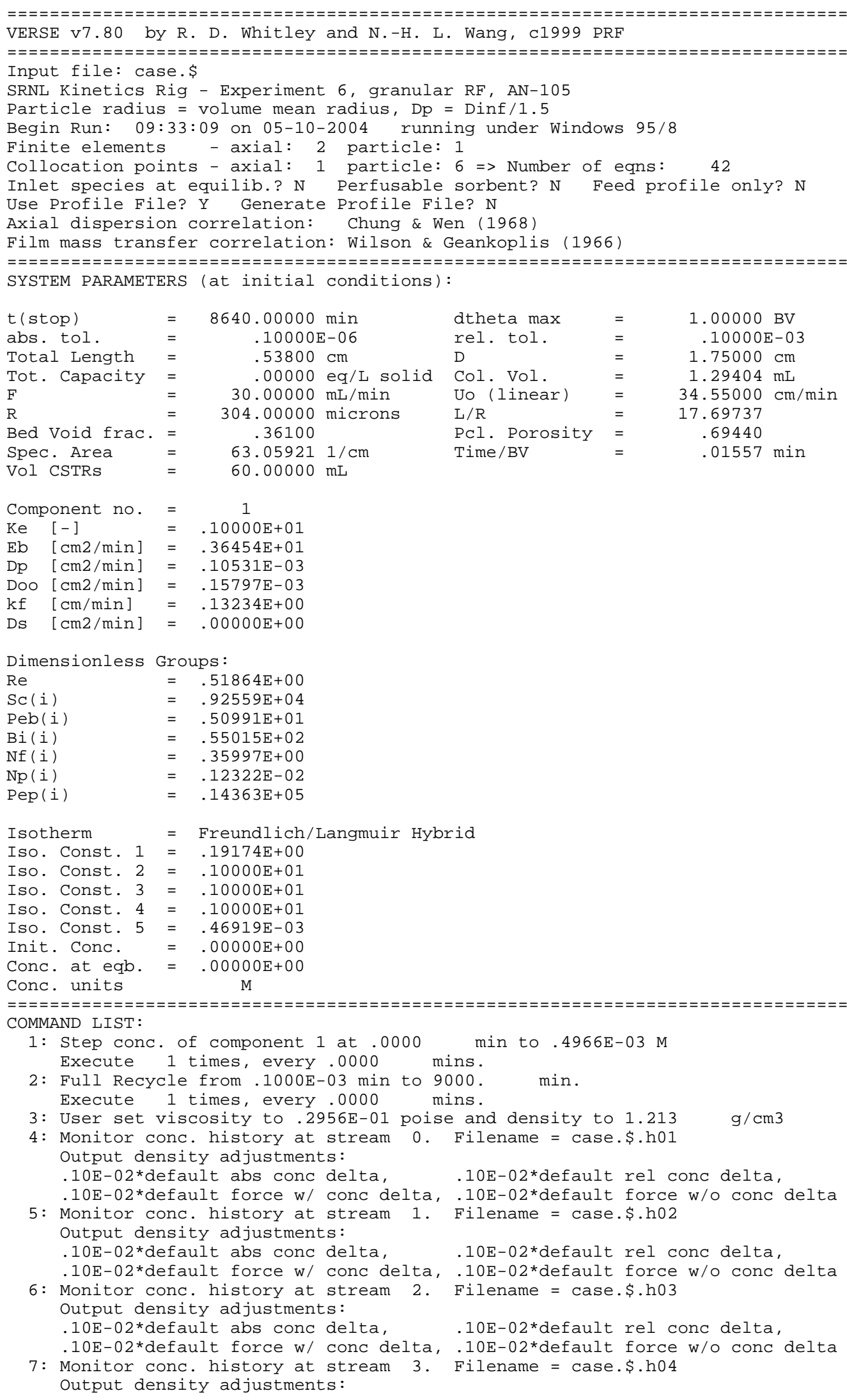




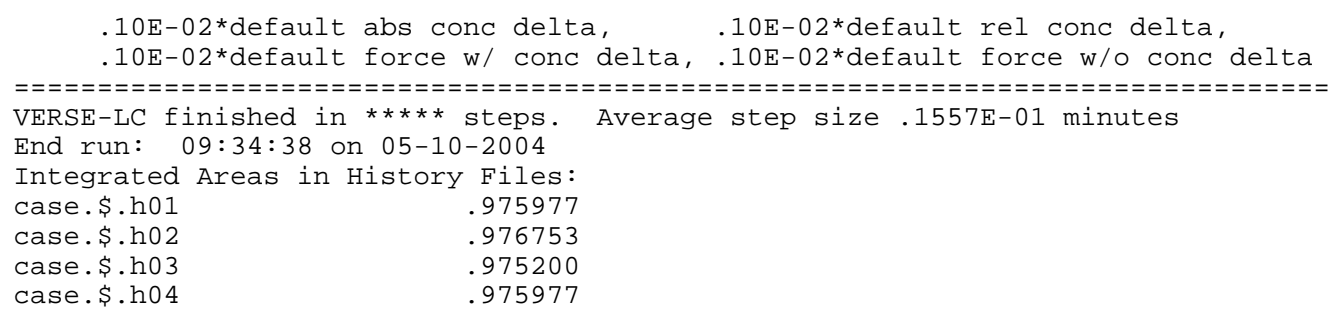

\section{A.7 SRNL Particle Kinetics Experiment 7}

\section{A.7.1 VERSE-LC Datafile}

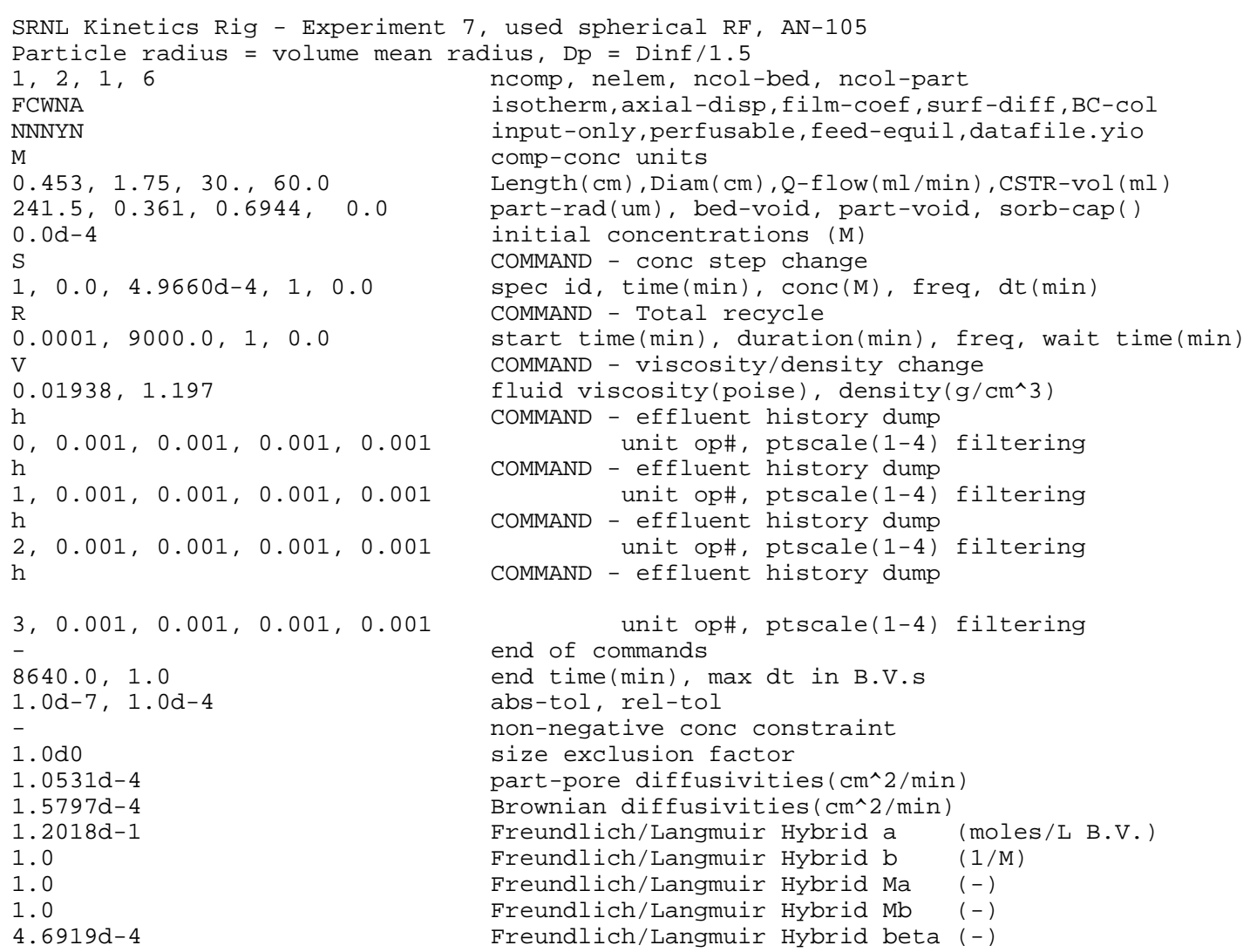

\section{A.7.2 VERSE-LC Datafile.yio}

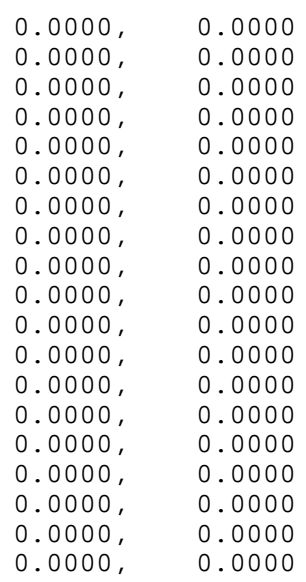


WSRC-TR-2004-00100, REVISION 0

SRT-RPP-2004-00019, REVISION 0

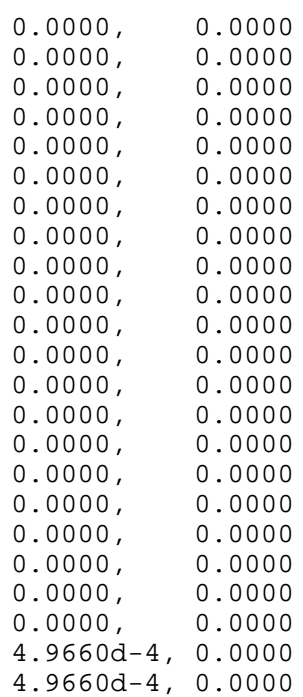

\section{A.7.3 VERSE-LC Datafile.run}

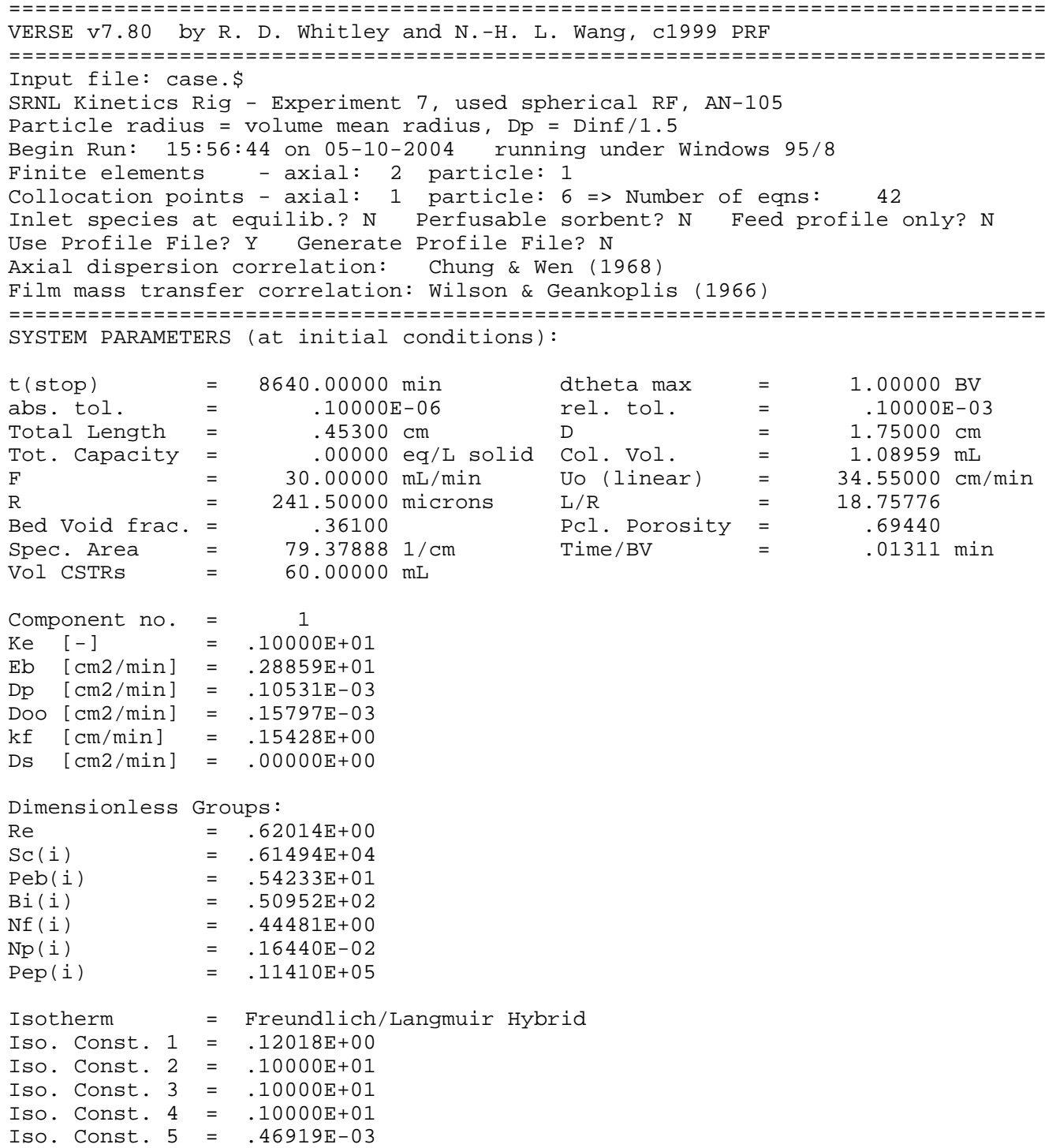




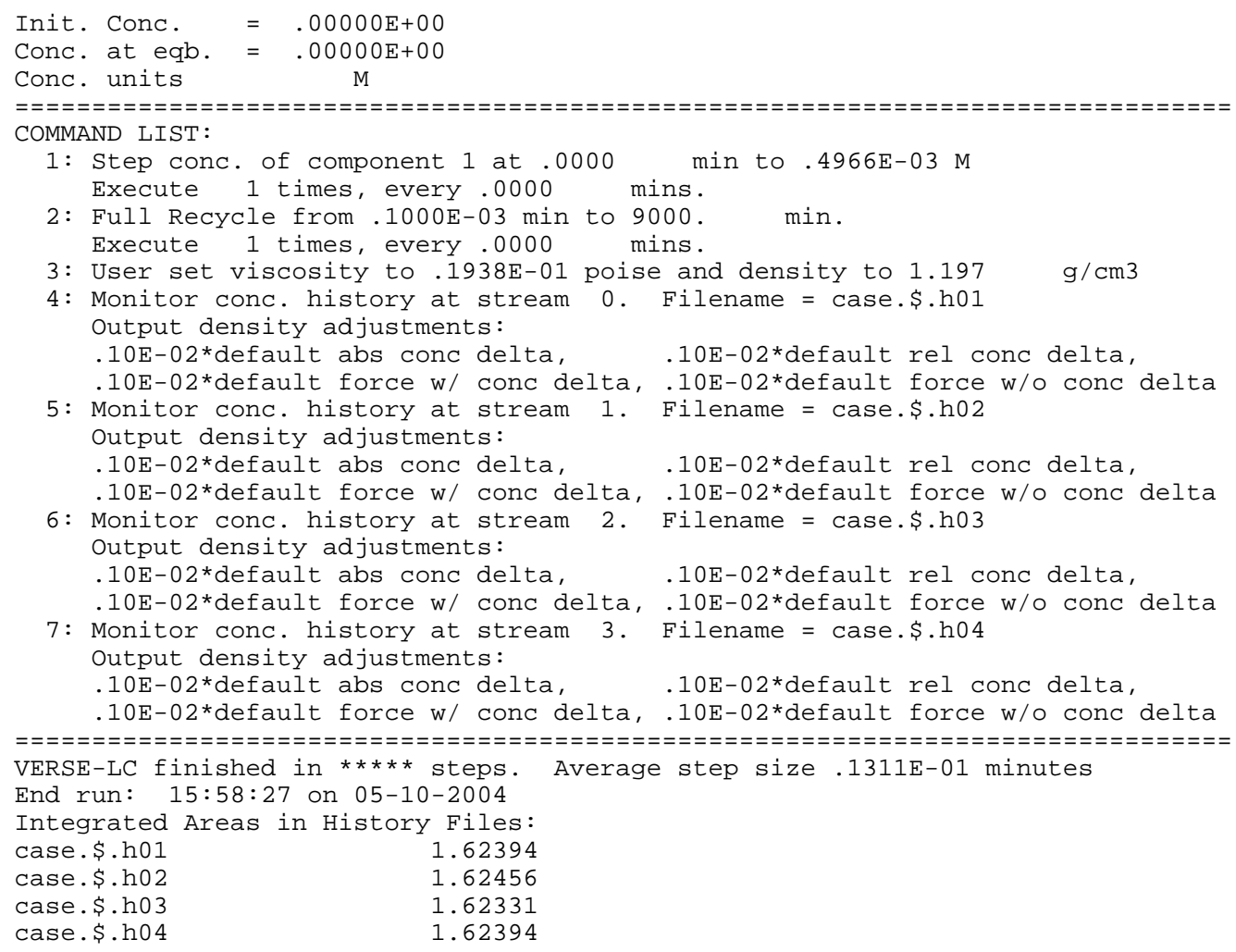

\section{A.8 PNNL Column 6}

\section{A.8.1 VERSE-LC Datafile}

PNNL Column 6: Resin \#1 with AZ-102 Simulant, Loading Cycle 1

Particle radius $=$ volume mean radius, $\mathrm{Dp}=\mathrm{Dinf} / 1.5$

$1,50,4,6 \quad$ ncomp, nelem, ncol-bed, ncol-part

FCWNA isotherm, axial-disp, film-coef, surf-diff, BC-col

NNNNN input-only, perfusable, feed-equil, datafile.yio

$\mathrm{M}$

$6.60,2.0,0.50,10.72$

$314.0,0.361,0.6944,0.0$

$\odot .0 \mathrm{~d}-4$

$\mathrm{S}$

$1,0.0,3.66 \mathrm{~d}-4,1,0.0$

$\mathrm{V}$

$0.028293,1.24$

$\mathrm{h}$

$0,1.0,1.0,0.25,1.0$

h

$1,1.0,1.0,0.25,1.0$

$2,1.0,1.0,0.25,1.0$

$\mathrm{h}$

$3,1.0,1.0,0.25,1.0$

$6000.0,1.0$

1. $0 \mathrm{~d}-7,1.0 \mathrm{~d}-4$

$1.0 \mathrm{~d} \odot$

7. 5984d-5

$1.1398 d-4$

4. $8223 d-2$

1.0

1.0

comp-conc units

Length $(\mathrm{cm}), \operatorname{Diam}(\mathrm{cm}), \mathrm{Q}-\mathrm{flow}(\mathrm{ml} / \mathrm{min}), \mathrm{CSTR}-\operatorname{vol}(\mathrm{ml})$

part-rad(um), bed-void, part-void, sorb-cap()

initial concentrations (M)

COMMAND - conc step change

spec id, time(min), conc(M), freq, dt(min)

COMMAND - viscosity/density change

fluid viscosity (poise), density $\left(\mathrm{g} / \mathrm{cm}^{\wedge} 3\right)$

COMMAND - effluent history dump

unit op\#, ptscale(1-4) filtering

COMMAND - effluent history dump

unit op\#, ptscale(1-4) filtering

COMMAND - effluent history dump

unit op\#, ptscale(1-4) filtering

COMMAND - effluent history dump

unit op\#, ptscale(1-4) filtering

end of commands

end time(min), max dt in B.V.s

abs-tol, rel-tol

non-negative conc constraint

size exclusion factor

part-pore diffusivities $\left(\mathrm{cm}^{\wedge} 2 / \mathrm{min}\right)$

Brownian diffusivities ( $\left.\mathrm{cm}^{\wedge} 2 / \mathrm{min}\right)$

Freundlich/Langmuir Hybrid a (moles/L B.V.)

Freundlich/Langmuir Hybrid b (1/M)

Freundlich/Langmuir Hybrid Ma (-)

Freundlich/Langmuir Hybrid Mb (-)

$1 \cdot 0$
$6.3132 d-4$

Freundlich/Langmuir Hybrid beta (-) 


\section{A.8.2 VERSE-LC Datafile.run}

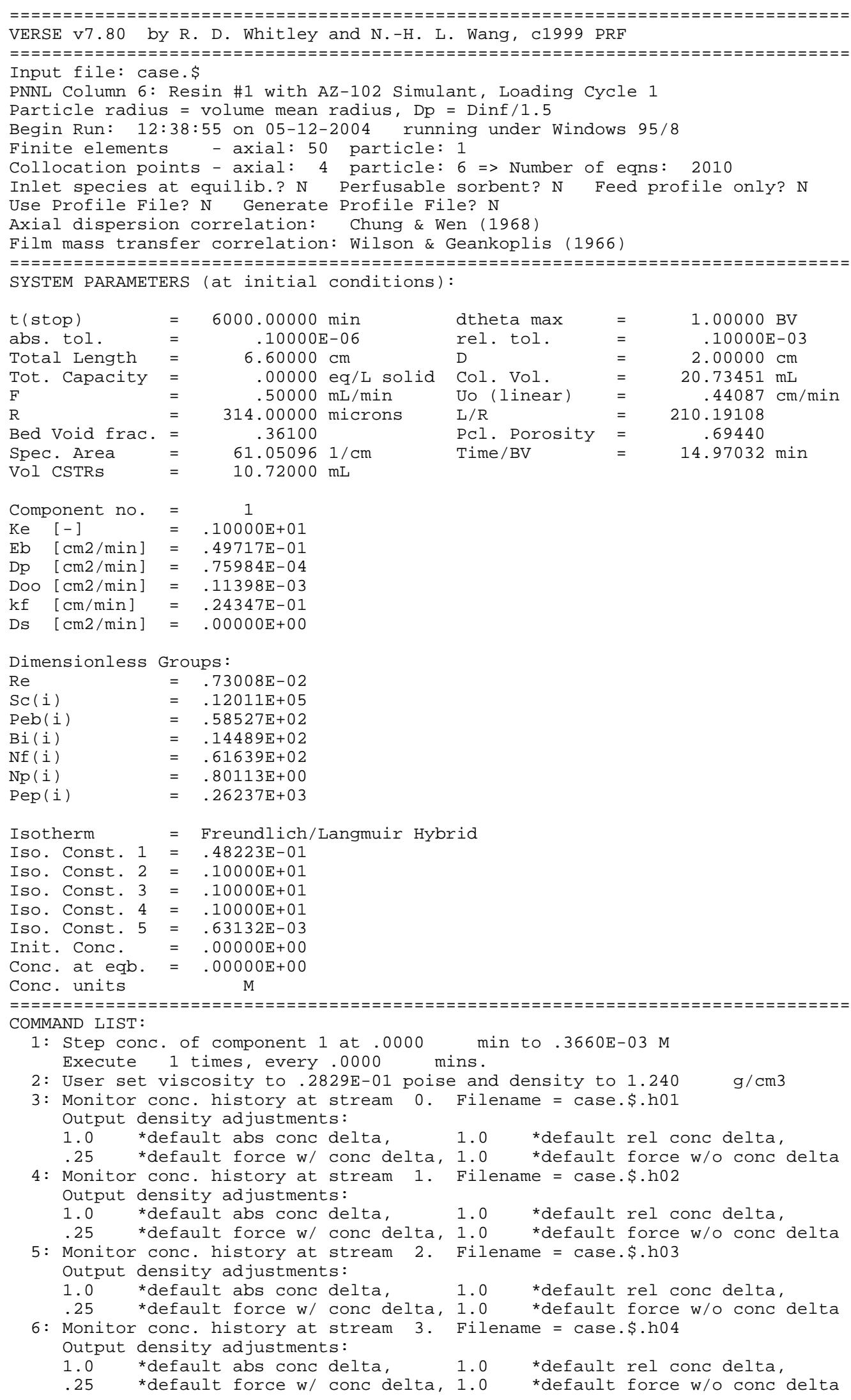


WSRC-TR-2004-00100, REVISION 0

SRT-RPP-2004-00019, REVISION 0

\begin{tabular}{|c|c|c|}
\hline \multicolumn{3}{|c|}{ VEPSF-IC finiched in } \\
\hline End run: & $12: 39: 120$ & $05-12-2004$ \\
\hline Integratec & d Areas in & Iistory Files: \\
\hline case.\$.h०1 & & 2.19598 \\
\hline case. $\$ . h \odot 2$ & & 2.18805 \\
\hline case. $\$ . h \odot 3$ & & 1.44206 \\
\hline case. $\$ . h \odot 4$ & & 1.43421 \\
\hline
\end{tabular}

\section{A.9 PNNL Column 7}

\section{A.9.1 VERSE-LC Datafile}

PNNL Column 7: Resin \#3 with AZ-102 Simulant, Loading Cycle 1

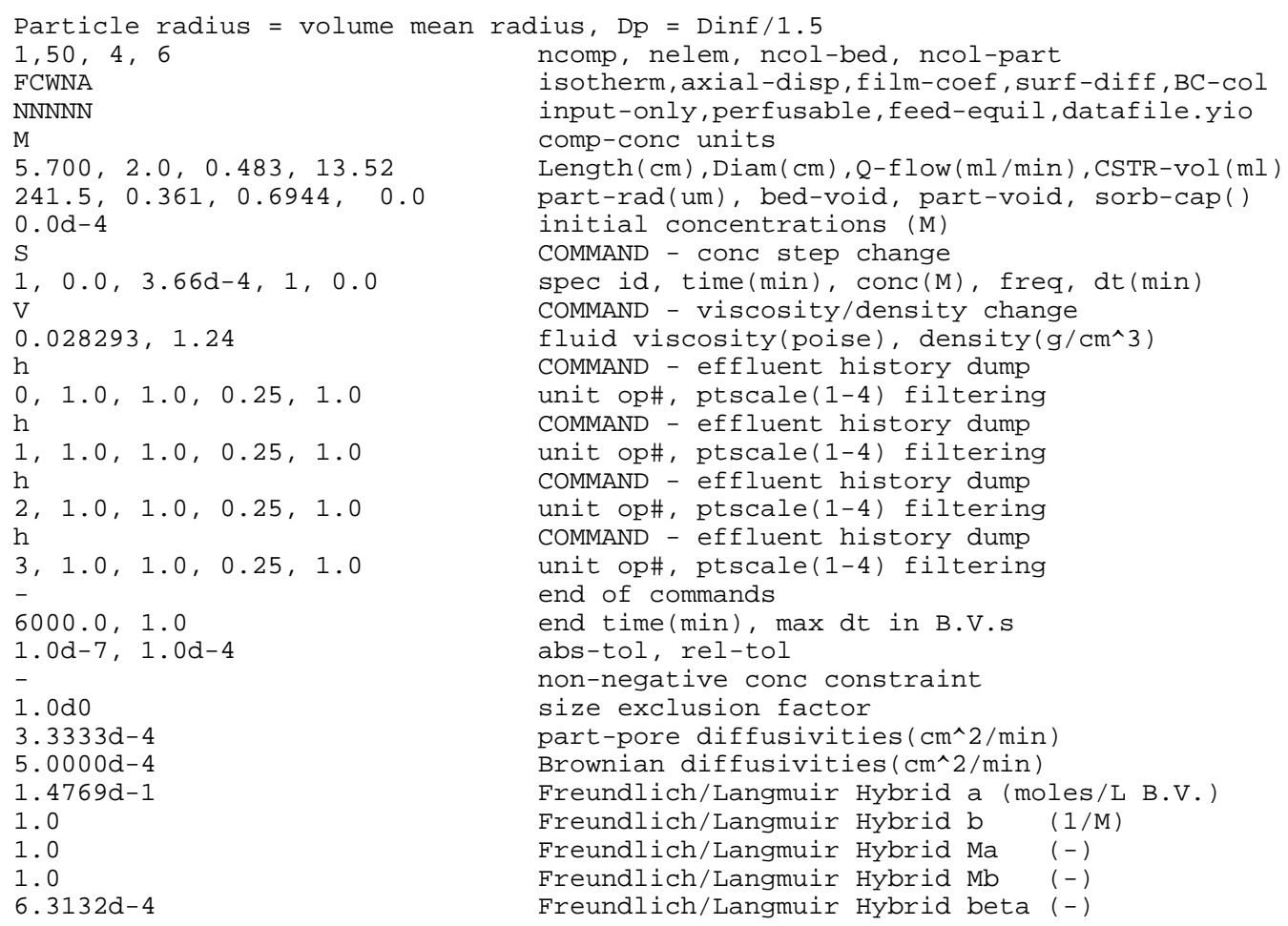

\section{A.9.2 VERSE-LC Datafile.run}

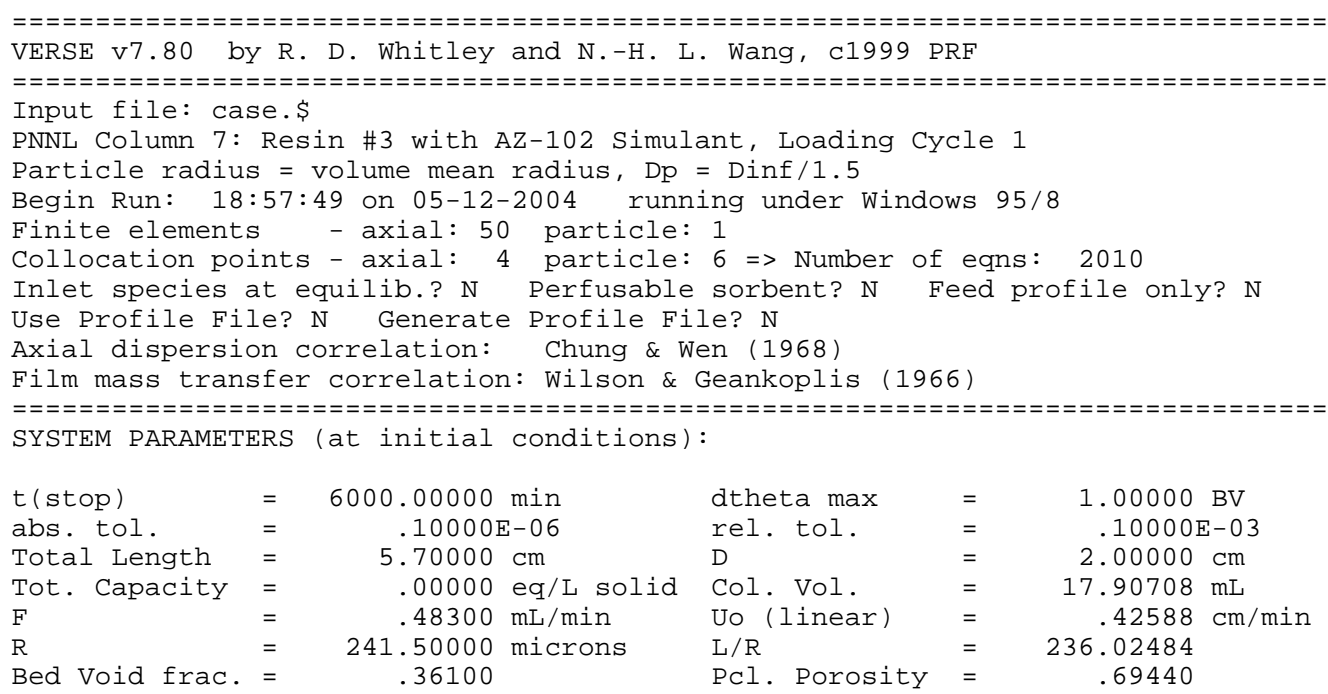


WSRC-TR-2004-00100, REVISION 0

SRT-RPP-2004-00019, REVISION 0

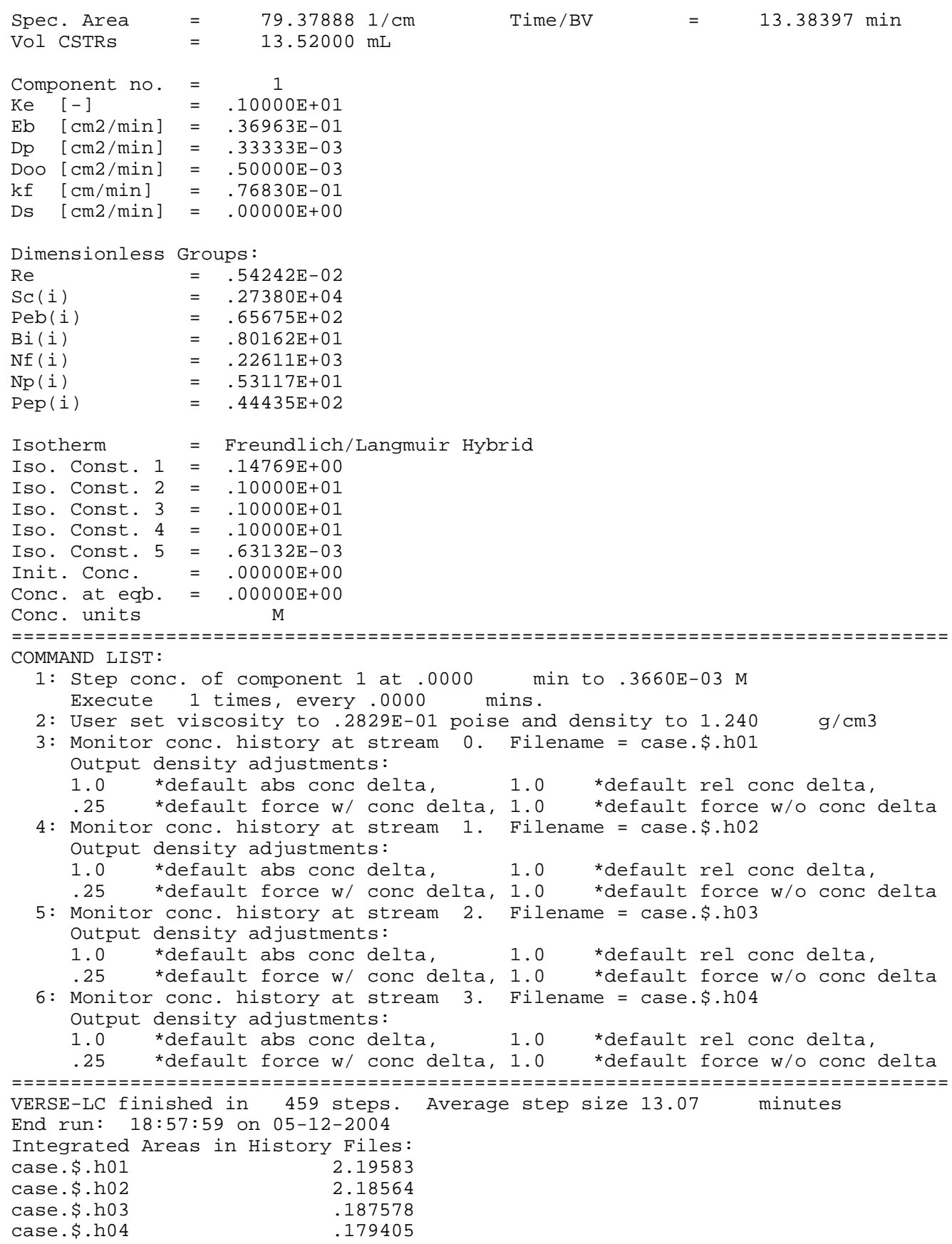

\section{A.10 PNNL Column 8}

\section{A.10.1 VERSE-LC Datafile}

PNNL Column 8: Resin \#6 with AZ-102 Simulant, Loading Cycle 1

Particle radius $=$ volume mean radius, $\mathrm{Dp}=\mathrm{Dinf} / 1.5$

$1,50,4,6$ ncomp, nelem, ncol-bed, ncol-part

FCWNA isotherm, axial-disp,film-coef, surf-diff, BC-col

NNNNN input-only, perfusable, feed-equil, datafile.yio

$\mathrm{M}$

comp-conc units

$5.790,2.0,0.51,13.52$

$241.5,0.361,0.6944,0.0$

$\odot .0 \mathrm{~d}-4$

Length $(\mathrm{cm}), \operatorname{Diam}(\mathrm{cm}), \mathrm{Q}-\mathrm{flow}(\mathrm{ml} / \mathrm{min}), \mathrm{CSTR}-\mathrm{vol}(\mathrm{ml})$

part-rad(um), bed-void, part-void, sorb-cap()

initial concentrations (M)

$\mathrm{S}$

COMMAND - conc step change 


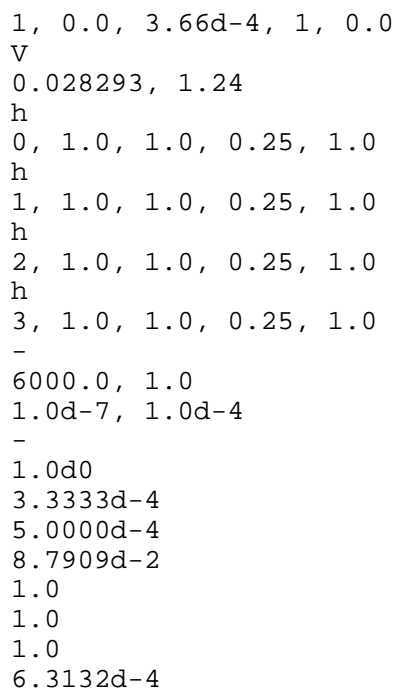

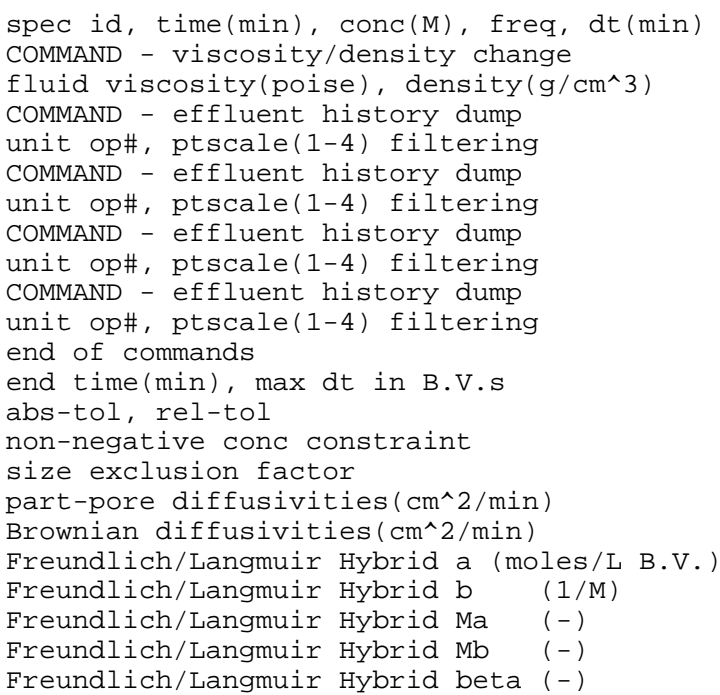

\section{A.10.2 VERSE-LC Datafile.run}

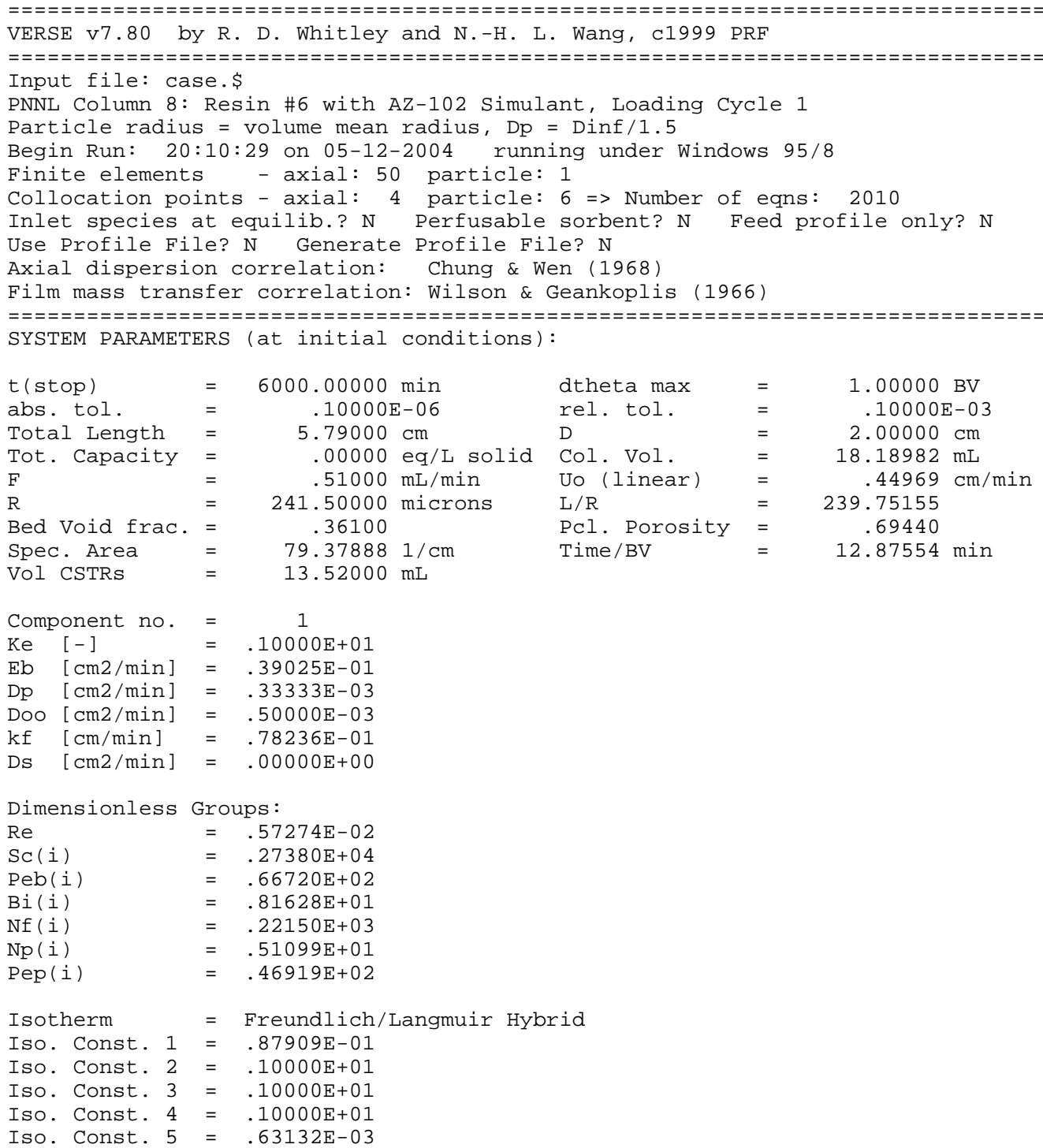


WSRC-TR-2004-00100, REVISION 0

SRT-RPP-2004-00019, REVISION 0

Init. Conc. $=.00000 \mathrm{E}+0 \odot$

Conc. at eqb. $=.00000 \mathrm{E}+00$

Conc. units $M$

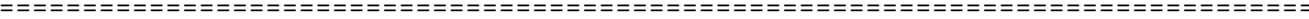

COMMAND LIST:

1: Step conc. of component 1 at .0000 min to .3660E-03 M

Execute 1 times, every .0000 mins.

2: User set viscosity to .2829E-01 poise and density to $1.240 \mathrm{~g} / \mathrm{cm} 3$

3: Monitor conc. history at stream $\odot$. Filename = case. $\$$. h $\Theta 1$

Output density adjustments:

1.0 *default abs conc delta, 1.0 *default rel conc delta,

.25 *default force $\mathrm{w} / \mathrm{conc}$ delta, 1.0 *default force w/o conc delta

4: Monitor conc. history at stream 1. Filename = case. $\mathbf{\$} . \mathrm{h} \odot 2$

Output density adjustments:

1.0 *default abs conc delta, 1.0 *default rel conc delta

$.25 *$ default force $\mathrm{w} / \mathrm{conc}$ delta, 1.0 *default force $\mathrm{w} / \mathrm{o}$ conc delta

5: Monitor conc. history at stream 2. Filename = case. $\$$. h०3

Output density adjustments:

1.0 *default abs conc delta, 1.0 *default rel conc delta,

.25 *default force $w /$ conc delta, $1 . \odot$ *default force $w / o$ conc delta

6: Monitor conc. history at stream 3. Filename = case. $\$$. ho4

Output density adjustments:

1.0 *default abs conc delta, 1.0 *default rel conc delta,

$.25 *$ default force $w /$ conc delta, 1.0 *default force w/o conc delta

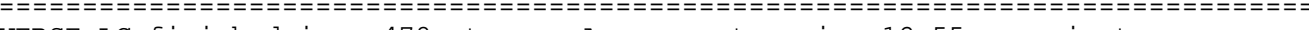

VERSE-LC finished in 478 steps. Average step size 12.55 minutes

End run: 20:10:40 on $05-12-2004$

Integrated Areas in History Files:

case. $\$$. h01 2.19583

case. $\$$.h०2 2.18626

case. $\$$. h03

case. $\$ . \mathrm{h} \odot 4$ 


\section{Appendix B (Full-Scale Facility Input and Output Files)}

VERSE-LC input and output files for the full-scale facility are provided in this appendix. Twenty-two simulations were run. The cases presented here correspond to the three nominal LAW feeds, three chemically degraded LAW feeds, and sixteen sensitivity runs for the chemically degraded Hot Commissioning Operations feed. The sensitivity runs include perturbations to cesium, potassium, sodium and hydroxide concentrations, liquid flowrate, bulk and pore diffusivities, particle radius and bed density.

\section{B.1 Hot Commissioning Operations (Nominal Isotherm)}

\section{B.1.1 VERSE-LC Datafile}

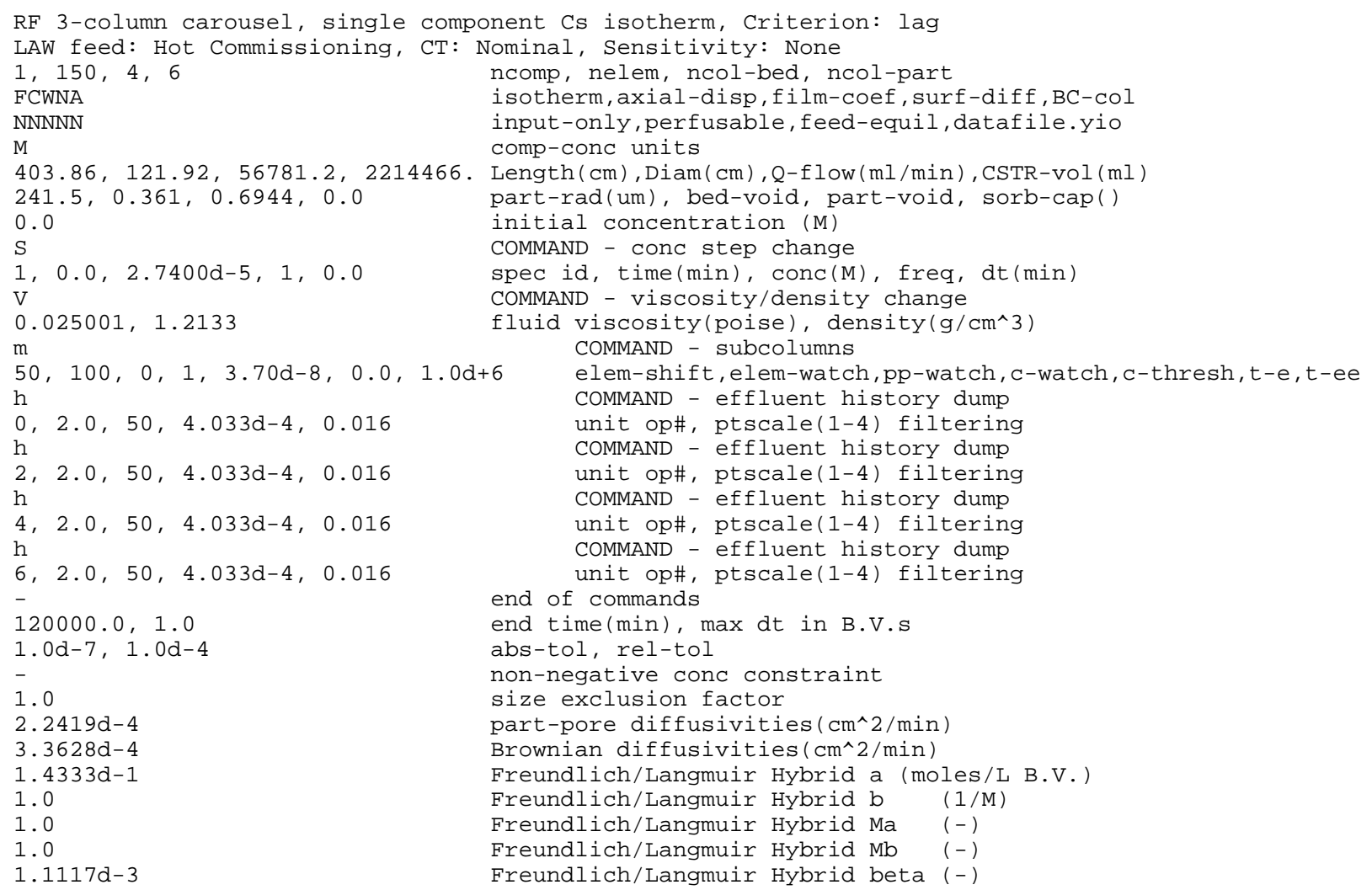

\section{B.1.2 VERSE-LC Datafile.run}

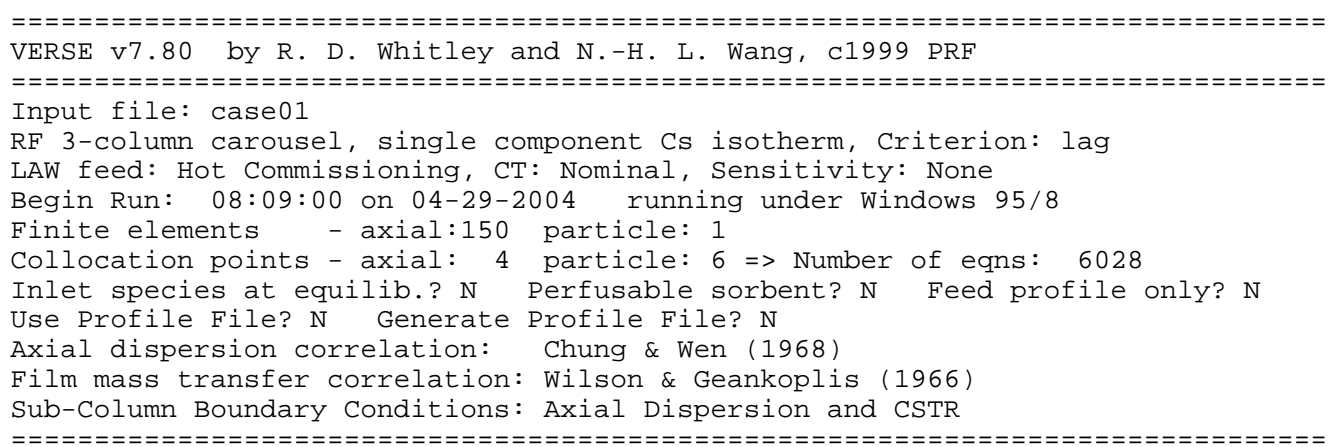


SYSTEM PARAMETERS (at initial conditions):

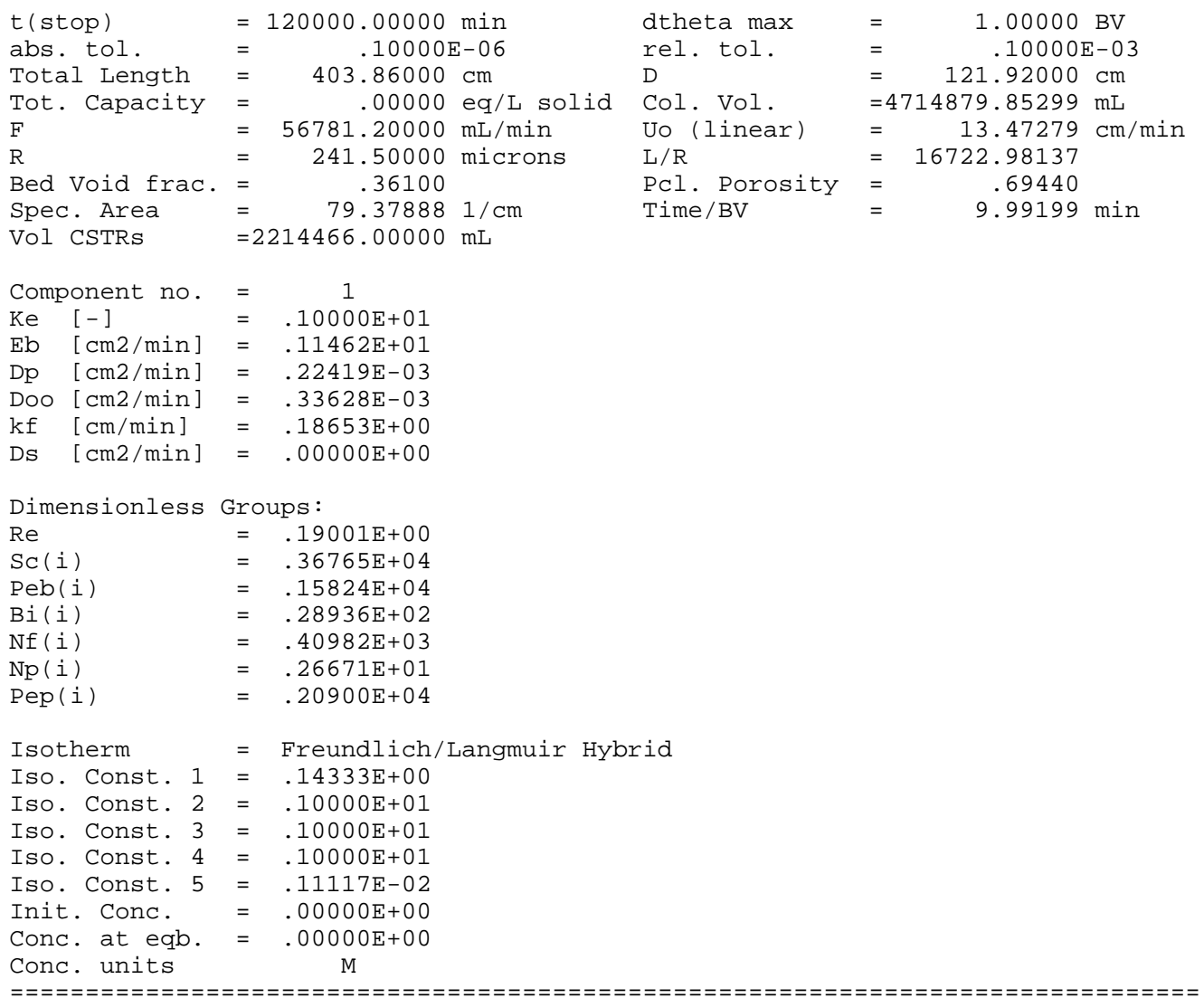

1: Step conc. of component 1 at .000९ min to .2740E-04 M Execute 1 times, every .0000 mins.

2: User set viscosity to .2500E-01 poise and density to $1.213 \mathrm{~g} / \mathrm{cm} 3$

3: Carousel (conc.). Active between $t=.0000$ and $.1000 \mathrm{E}+07 \mathrm{~min}$. When comp. 1 reaches .3700E-07 M at end of node 100, shift 50 axial elements out the feed end

4: Monitor conc. history at stream $\odot$. Filename $=$ case 01. h $\odot 1$ Output density adjustments: 2.0 *default abs conc delta, 50. *default rel conc delta, .40E-03*default force $\mathrm{w} /$ conc delta, .16E-01*default force w/o conc delta

5: Monitor conc. history at stream 2. Filename = case $01 . \mathrm{h} \odot 2$ Output density adjustments:

2.0 *default abs conc delta, 50. *default rel conc delta, .40E-03*default force $W /$ conc delta, .16E- $01^{*}$ default force $W / o$ conc delta

6: Monitor conc. history at stream 4. Filename $=$ case $01 . \mathrm{h} \odot 3$ Output density adjustments: 2.0 *default abs conc delta, 50. *default rel conc delta, . 40E-03*default force w/ conc delta, .16E-01*default force w/o conc delta

7: Monitor conc. history at stream 6. Filename = case 01. h 4 output density adjustments:

2.0 *default abs conc delta, 50. *default rel conc delta, $.40 \mathrm{E}-03^{*}$ default force $\mathrm{W} / \mathrm{conc}$ delta, .16E-01*default force $\mathrm{W} / \mathrm{o}$ conc delta

Conc. Carousel caused bed shift at $t=4746$. min

Conc. Carousel caused bed shift at $t=7724 . \quad \mathrm{min}$

Conc. Carousel caused bed shift at $t=.1080 \mathrm{E}+05 \mathrm{~min}$

Conc. Carousel caused bed shift at $t=.1395 \mathrm{E}+05 \mathrm{~min}$

Conc. Carousel caused bed shift at $t=.1714 \mathrm{E}+05 \mathrm{~min}$

Conc. Carousel caused bed shift at $t=.2036 \mathrm{E}+05 \mathrm{~min}$

Conc. Carousel caused bed shift at $t=.2360 \mathrm{E}+05 \mathrm{~min}$

Conc. Carousel caused bed shift at $t=.2686 \mathrm{E}+05 \mathrm{~min}$

Conc. Carousel caused bed shift at $t=.3012 \mathrm{E}+05 \mathrm{~min}$

Conc. Carousel caused bed shift at $t=.3339 \mathrm{E}+05 \mathrm{~min}$

Conc. Carousel caused bed shift at $t=.3665 \mathrm{E}+05 \mathrm{~min}$

Conc. Carousel caused bed shift at $t=.3991 \mathrm{E}+05 \mathrm{~min}$ 
WSRC-TR-2004-00100, REVISION 0

SRT-RPP-2004-00019, REVISION 0

Conc. Carousel caused bed shift at $t=.4317 \mathrm{E}+05 \mathrm{~min}$

Conc. Carousel caused bed shift at $t=.4643 \mathrm{E}+05 \mathrm{~min}$

Conc. Carousel caused bed shift at $t=.4969 \mathrm{E}+05 \mathrm{~min}$

Conc. Carousel caused bed shift at $t=.5296 \mathrm{E}+05 \mathrm{~min}$

Conc. Carousel caused bed shift at $t=.5622 \mathrm{E}+05 \mathrm{~min}$

Conc. Carousel caused bed shift at $\mathrm{t}=.5948 \mathrm{E}+05 \mathrm{~min}$

Conc. Carousel caused bed shift at $t=.6274 \mathrm{E}+05 \mathrm{~min}$

Conc. Carousel caused bed shift at $t=.6600 \mathrm{E}+05 \mathrm{~min}$

Conc. Carousel caused bed shift at $t=.6926 \mathrm{E}+05 \mathrm{~min}$

Conc. Carousel caused bed shift at $t=.7252 \mathrm{E}+05 \mathrm{~min}$

Conc. Carousel caused bed shift at $t=.7578 \mathrm{E}+05 \mathrm{~min}$

Conc. Carousel caused bed shift at $t=.7904 \mathrm{E}+05 \mathrm{~min}$

Conc. Carousel caused bed shift at $t=.8230 E+05 \mathrm{~min}$

Conc. Carousel caused bed shift at $t=.8557 \mathrm{E}+05 \mathrm{~min}$

Conc. Carousel caused bed shift at $\mathrm{t}=.8883 \mathrm{E}+05 \mathrm{~min}$

Conc. Carousel caused bed shift at $t=.9210 \mathrm{E}+05 \mathrm{~min}$

Conc. Carousel caused bed shift at $t=.9536 \mathrm{E}+05 \mathrm{~min}$

Conc. Carousel caused bed shift at $t=.9862 \mathrm{E}+05 \mathrm{~min}$

Conc. Carousel caused bed shift at $t=.1019 \mathrm{E}+06 \mathrm{~min}$

Conc. Carousel caused bed shift at $t=.1051 \mathrm{E}+06 \mathrm{~min}$

Conc. Carousel caused bed shift at $\mathrm{t}=.1084 \mathrm{E}+06 \mathrm{~min}$

Conc. Carousel caused bed shift at $t=.1117 \mathrm{E}+06 \mathrm{~min}$

Conc. Carousel caused bed shift at $t=.1149 \mathrm{E}+06 \mathrm{~min}$

Conc. Carousel caused bed shift at $\mathrm{t}=.1182 \mathrm{E}+06 \mathrm{~min}$

VERSE-LC finished in 13183 steps. Average step size 9.103 minutes

End run: 08:57:00 on 04-29-2004

Integrated Areas in History Files:

$\begin{array}{ll}\text { case } 01 . h 01 & 3.28800\end{array}$

case $01 . \mathrm{h} 02$.361835

case01.h03 .640587E- 03

case $01 . \mathrm{h} \odot 4 \quad .355849 \mathrm{E}-06$

\section{B.2 Envelope B Operations (Nominal Isotherm)}

\section{B.2.1 VERSE-LC Datafile}

RF 3-column carousel, single component Cs isotherm, Criterion: lag

LAW feed: Envelope B, CT: Nominal, Sensitivity: None

$1,150,4,6$

FCWNA

NNNNN

ncomp, nelem, ncol-bed, ncol-part

isotherm, axial-disp, film-coef, surf-diff, BC-col

input-only, perfusable, feed-equil, datafile.yio

$\mathrm{M}$ comp-conc units

403.86, 121.92, 28390.6, 2214466. Length $(\mathrm{cm}), \operatorname{Diam}(\mathrm{cm}), 0-f l o w(\mathrm{ml} / \mathrm{min}), \mathrm{CSTR}-\operatorname{vol}(\mathrm{ml})$

241.5, $0.361,0.6944,0 . \odot$ part-rad(um), bed-void, part-void, sorb-cap()

0.0

initial concentration (M)

COMMAND - conc step change

$1,0.0,2.8300 \mathrm{~d}-4,1,0.0 \quad$ spec id, time(min), conc(M), freq, dt(min)

$\mathrm{V}$

$0.020010,1.1793$

$\mathrm{m}$

COMMAND - viscosity/density change

fluid viscosity(poise), density $(\mathrm{g} / \mathrm{cm} \wedge 3)$

$5 \odot, 10 \odot, \odot, 1,3.40 \mathrm{~d}-8, \odot . \odot, 1.0 \mathrm{~d}+6$

COMMAND - subcolumns

elem-shift, elem-watch, pp-watch, c-watch, c-thresh, t-e,t-ee COMMAND - effluent history dump

$\odot, 2.0,50,4.033 d-4,0.016$

h

unit op\#, ptscale(1-4) filtering

COMMAND - effluent history dump

$2,2.0,50,4.033 d-4,0.016$

$\mathrm{h}$

$4,2.0,50,4.033 d-4,0.016$

$\mathrm{h}$

unit op\#, ptscale(1-4) filtering

COMMAND - effluent history dump

unit op\#, ptscale(1-4) filtering

COMMAND - effluent history dump

$6,2.0,50,4.033 d-4,0.016$

$120000.0,1.0$

1. $0 \mathrm{~d}-7,1.0 \mathrm{~d}-4$

1.0

3. $4819 \mathrm{~d}-4$

5. $2228 d-4$

1. $4179 d-1$

1.0

1.0

1.0

unit op\#, ptscale(1-4) filtering

end of commands

end time(min), $\max d t$ in B.V.S

abs-tol, rel-tol

non-negative conc constraint

size exclusion factor

part-pore diffusivities $\left(\mathrm{cm}^{\wedge} 2 / \mathrm{min}\right)$

Brownian diffusivities ( $\left.\mathrm{cm}^{\wedge} 2 / \mathrm{min}\right)$

Freundlich/Langmuir Hybrid a (moles/L B.V.)

Freundlich/Langmuir Hybrid b (1/M)

Freundlich/Langmuir Hybrid Ma (-)

4. $0009 d-4$

Freundlich/Langmuir Hybrid beta (-) 


\section{B.2.2 VERSE-LC Datafile.run}

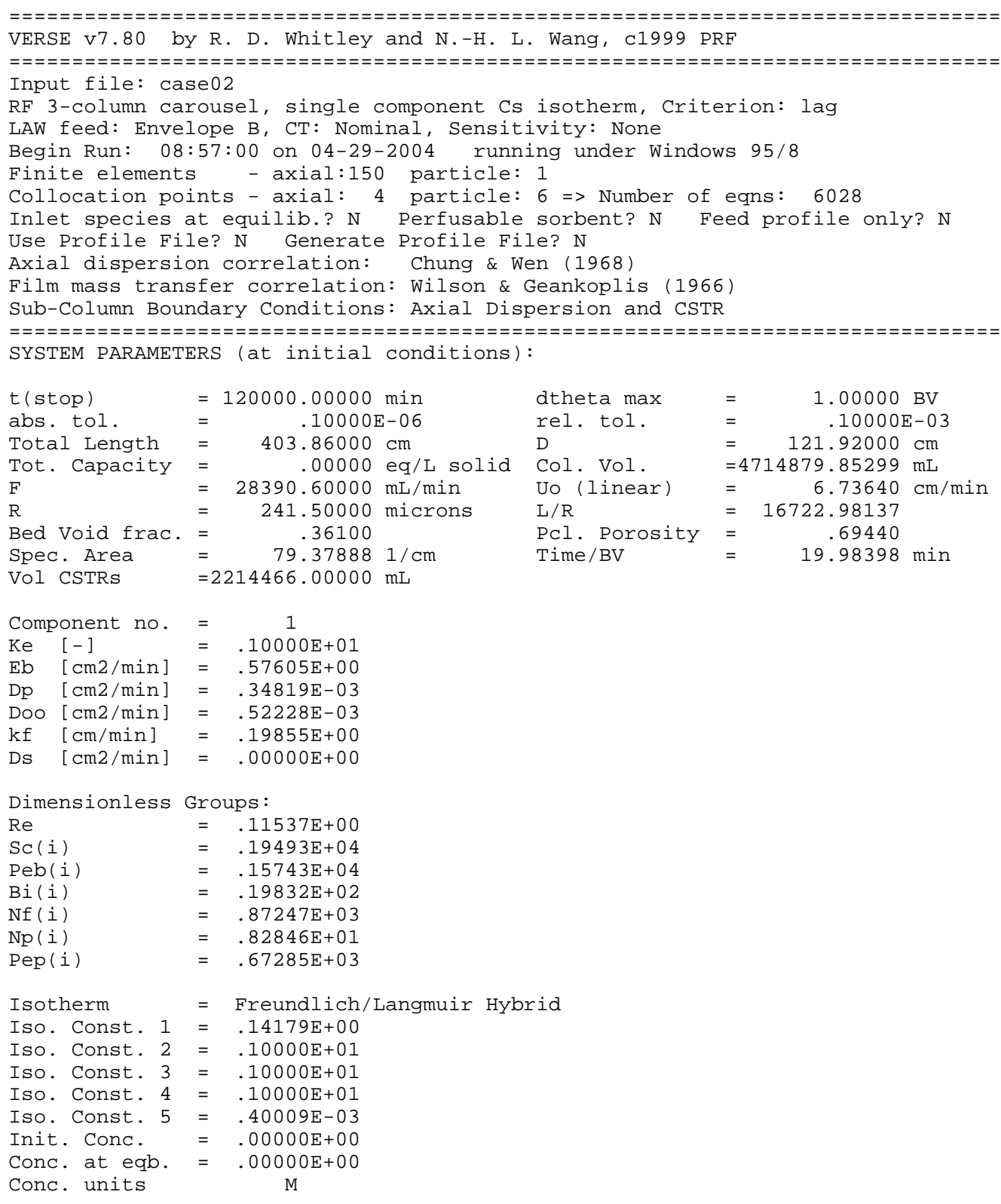

\section{=ニニニニニニニニニニニ=}

COMMAND LIST:

1: Step conc. of component 1 at . .๑०००

Execute 1 times, every .0000 mins. min to .2830E-03 M

2: User set viscosity to .2001E-01 poise and density to 1.179

3: Carousel (conc.). Active between $t=.0000$ and .1000E+07 min When comp. 1 reaches .3400E-07 M at end of node 100, shift 50 axial elements out the feed end

4: Monitor conc. history at stream $\odot$. Filename $=$ case $02 . \mathrm{h} \odot 1$ output density adjustments: 2.0 *default abs conc delta, 50. default rel conc delta, .40E-03*default force w/ conc delta, .16E-01*default force w/o conc delta

5: Monitor conc. history at stream 2. Filename = case $2 . \mathrm{h} \odot 2$ Output density adjustments: 2.0 *default abs conc delta, $50 . \quad$ default rel conc delta, .40E-03*default force w/ conc delta, .16E-01*default force w/o conc delta

6: Monitor conc. history at stream 4. Filename $=$ case 2. h०3 Output density adjustments:

2.0 *default abs conc delta, 50. *default rel conc delta, $.40 \mathrm{E}-03^{*}$ default force $\mathrm{w} / \mathrm{conc}$ delta, .16E-01*default force w/o conc delta 
7: Monitor conc. history at stream 6. Filename $=$ case $02 . \mathrm{h} \odot 4$

Output density adjustments:

2.0 *default abs conc delta, 50. *default rel conc delta, $.40 \mathrm{E}-03^{*}$ default force $\mathrm{W} / \mathrm{conc}$ delta, .16E- $01^{*}$ default force $\mathrm{W} / \mathrm{o}$ conc delta

Conc. Carousel caused bed shift at $t=.2186 \mathrm{E}+05 \mathrm{~min}$

Conc. Carousel caused bed shift at $t=.3349 E+05 \mathrm{~min}$

Conc. Carousel caused bed shift at $\mathrm{t}=.4510 \mathrm{E}+05 \mathrm{~min}$

Conc. Carousel caused bed shift at $t=.5670 \mathrm{E}+05 \mathrm{~min}$

Conc. Carousel caused bed shift at $t=.6832 \mathrm{E}+05 \mathrm{~min}$

Conc. Carousel caused bed shift at $t=.7992 \mathrm{E}+05 \mathrm{~min}$

Conc. Carousel caused bed shift at $t=.9154 \mathrm{E}+05 \mathrm{~min}$

Conc. Carousel caused bed shift at $t=.1032 \mathrm{E}+06 \mathrm{~min}$

Conc. Carousel caused bed shift at $\mathrm{t}=.1148 \mathrm{E}+06 \mathrm{~min}$

VERSE-LC finished in 6421 steps. Average step size 18.69 minutes

End run: $09: 14: 53$ on $04-29-2004$

Integrated Areas in History Files:

case 2 2. h01 33.9600

case $02 . \mathrm{h} \odot 2$

case $02 . \mathrm{h} 03 \quad .474594 \mathrm{E}-\odot 4$

case $02 . \mathrm{h} \odot 4-.672555 \mathrm{E}-21$

\section{B.3 Subsequent Operations (Nominal Isotherm)}

\section{B.3.1 VERSE-LC Datafile}

RF 3-column carousel, single component Cs isotherm, Criterion: lag LAW feed: Subsequent operation, CT: Nominal, Sensitivity: None $1,150,4,6$ FCWNA NNNNN ncomp, nelem, ncol-bed, ncol-part isotherm, axial-disp, film-coef, surf-diff, BC-col NNNNN input-only, perfusable, feed-equil, datafile.yio comp-conc units

403.86, 121.92, 56781.2, 2214466. Length(cm),Diam(cm), Q-flow(ml/min), CSTR-vol $(\mathrm{ml})$ $241.5,0.361,0.6944,0.0$ 0.0 part-rad(um), bed-void, part-void, sorb-cap() initial concentration (M)

$\mathrm{S}$ COMMAND - conc step change

$1, \odot . \odot, 5.0000 \mathrm{~d}-5,1, \odot . \odot$ spec id, time(min), conc(M), freq, dt(min) COMMAND - viscosity/density change

$0.019792,1.2093$

$\mathrm{m}$

fluid viscosity(poise), density $\left(\mathrm{g} / \mathrm{cm}^{\wedge} 3\right)$

100, $0,1,3.40 \mathrm{~d}-8,0.0,1.0 \mathrm{~d}+6$ elem-shift, elem-watch, pp-watch, c-watch, c-thresh, t-e,t-ee COMMAND - effluent history dump

$\odot, 2 . \odot, 5 \odot, 4.033 d-4,0.016$ $\mathrm{h}$

$2,2 . \odot, 50,4.033 d-4,0.016$

h

$4,2.0,50,4.033 d-4,0.016$

$\mathrm{h}$

$6,2.0,50,4.033 d-4,0.016$

$120000.0,1.0$

$1.0 \mathrm{~d}-7,1.0 \mathrm{~d}-4$

1.0

2. $5873 d-4$

3. $8809 \mathrm{~d}-4$

1. $3885 d-1$

1.0

1.0

1.0 unit op\#, ptscale(1-4) filtering

COMMAND - effluent history dump unit op\#, ptscale(1-4) filtering COMMAND - effluent history dump unit op\#, ptscale(1-4) filtering COMMAND - effluent history dump unit op\#, ptscale(1-4) filtering end of commands

end time(min), max $d t$ in B.V.s

abs-tol, rel-tol

non-negative conc constraint

size exclusion factor

part-pore diffusivities ( $\left.\mathrm{cm}^{\wedge} 2 / \mathrm{min}\right)$

Brownian diffusivities ( $\left.\mathrm{cm}^{\wedge} 2 / \mathrm{min}\right)$

Freundlich/Langmuir Hybrid a (moles/L B.V.)

Freundlich/Langmuir Hybrid b (1/M)

Freundlich/Langmuir Hybrid Ma (-)

Freundlich/Langmuir Hybrid Mb (-)

6. $7392 d-4$

Freundlich/Langmuir Hybrid beta (-)

\section{B.3.2 VERSE-LC Datafile.run}

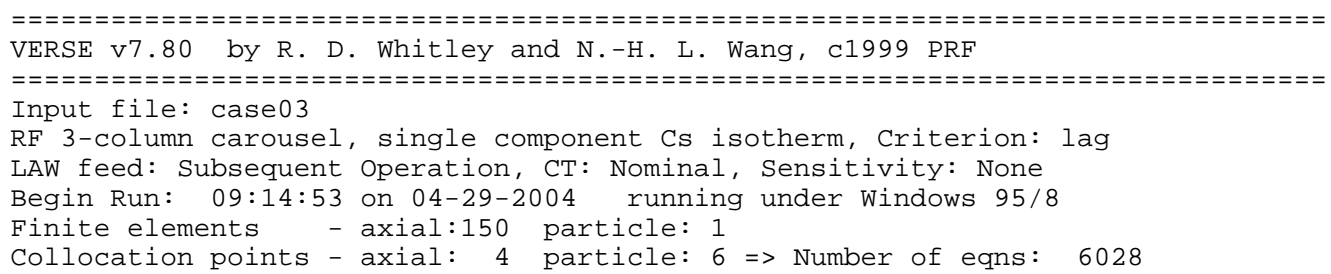


Inlet species at equilib.? N Perfusable sorbent? N Feed profile only? N Use Profile File? N Generate Profile File? N

Axial dispersion correlation: Chung \& Wen (1968)

Film mass transfer correlation: Wilson \& Geankoplis (1966)

Sub-Column Boundary Conditions: Axial Dispersion and CSTR

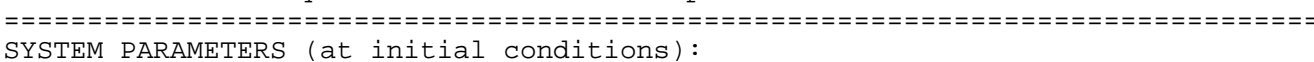

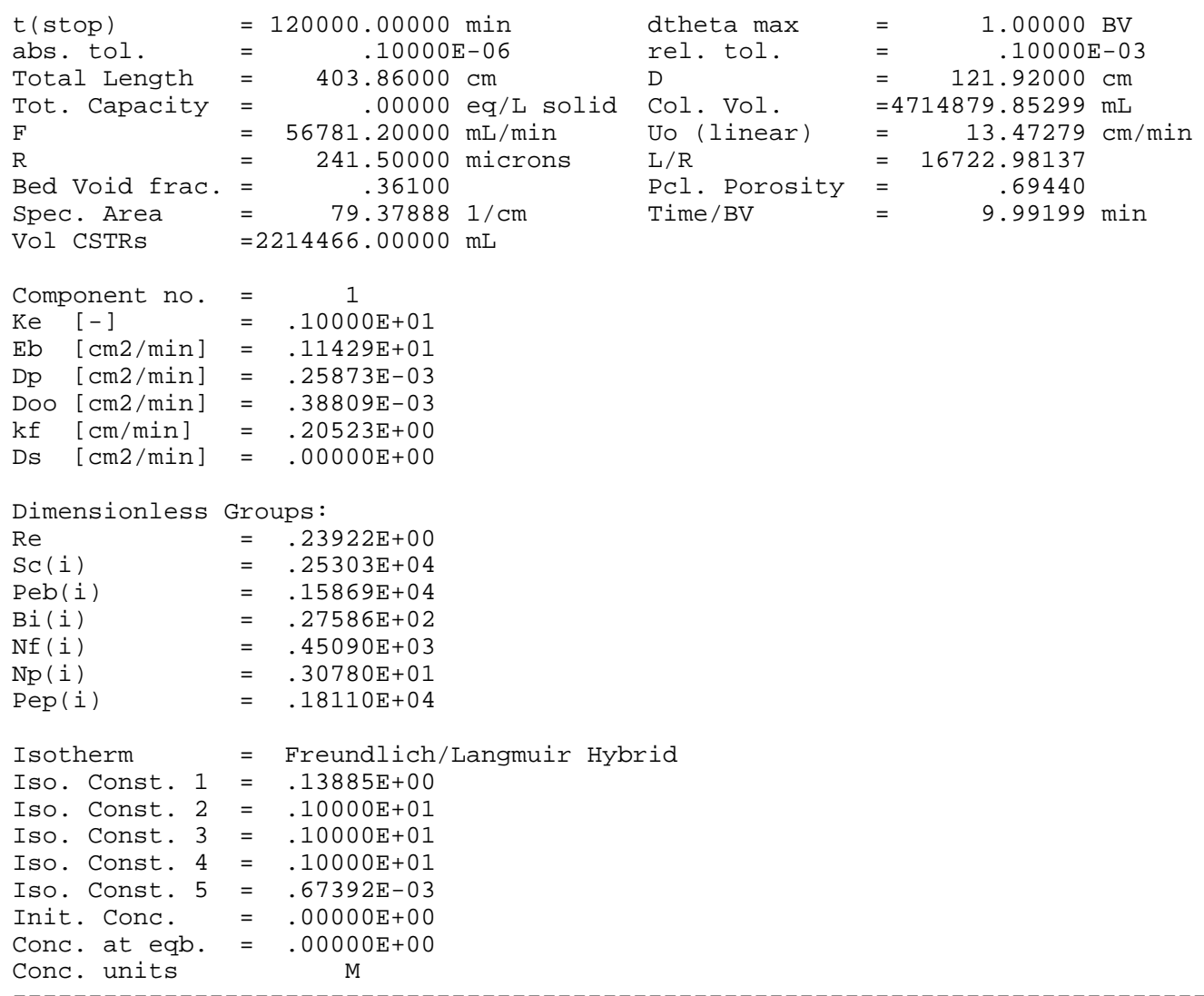

COMMAND LIST:

1: Step conc. of component 1 at .0000 min to .5000E-04 M

Execute 1 times, every .0000 mins.

2: User set viscosity to .1979E-01 poise and density to $1.209 \mathrm{~g} / \mathrm{cm} 3$

3: Carousel (conc.). Active between $t=.0000$ and $.1000 \mathrm{E}+07 \mathrm{~min}$. When comp. 1 reaches .3400E-07 M at end of node 100, shift 50 axial elements out the feed end

4: Monitor conc. history at stream 0 . Filename $=$ case $03 . \mathrm{h} 01$ Output density adjustments:

2.0 *default abs conc delta, 50. *default rel conc delta, .40E-03*default force $\mathrm{W} /$ conc delta, .16E-01*default force $\mathrm{W} / \mathrm{o}$ conc delta

5: Monitor conc. history at stream 2. Filename = case $03 . \mathrm{h} \odot 2$ Output density adjustments:

2.0 *default abs conc delta, 50. *default rel conc delta, . 40E- $03^{*}$ default force $W /$ conc delta, .16E- $01^{*}$ default force $w / 0$ conc delta

6: Monitor conc. history at stream 4. Filename $=$ case03.h03 Output density adjustments:

2.0 *default abs conc delta, 50. *default rel conc delta, .40E-03*default force $\mathrm{W} / \mathrm{conc}$ delta, .16E-01*default force $\mathrm{w} / \mathrm{o}$ conc delta

7: Monitor conc. history at stream 6. Filename = case 03. h०4 Output density adjustments:

2.0 *default abs conc delta, 50 . default rel conc delta, $.40 \mathrm{E}-03^{*}$ default force $\mathrm{W} / \mathrm{conc}$ delta, .16E-01*default force $\mathrm{w} / \mathrm{o}$ conc delta

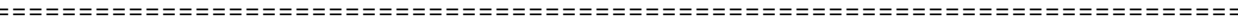

Conc. Carousel caused bed shift at $t=7467 . \quad$ min

Conc. Carousel caused bed shift at $t=.1216 \mathrm{E}+05 \mathrm{~min}$

Conc. Carousel caused bed shift at $\mathrm{t}=.1700 \mathrm{E}+05 \mathrm{~min}$

Conc. Carousel caused bed shift at $t=.2195 \mathrm{E}+05 \mathrm{~min}$

Conc. Carousel caused bed shift at $t=.2697 \mathrm{E}+05 \mathrm{~min}$

Conc. Carousel caused bed shift at $t=.3203 \mathrm{E}+05 \mathrm{~min}$ 
WSRC-TR-2004-00100, REVISION 0

SRT-RPP-2004-00019, REVISION 0

Conc. Carousel caused bed shift at $t=.3713 \mathrm{E}+05 \mathrm{~min}$

Conc. Carousel caused bed shift at $t=.4225 \mathrm{E}+05 \mathrm{~min}$

Conc. Carousel caused bed shift at $t=.4739 \mathrm{E}+05 \mathrm{~min}$

Conc. Carousel caused bed shift at $t=.5253 \mathrm{E}+05 \mathrm{~min}$

Conc. Carousel caused bed shift at $t=.5768 \mathrm{E}+05 \mathrm{~min}$

Conc. Carousel caused bed shift at $t=.6282 \mathrm{E}+05 \mathrm{~min}$

Conc. Carousel caused bed shift at $t=.6797 \mathrm{E}+05 \mathrm{~min}$

Conc. Carousel caused bed shift at $t=.7311 \mathrm{E}+05 \mathrm{~min}$

Conc. Carousel caused bed shift at $t=.7825 \mathrm{E}+05 \mathrm{~min}$

Conc. Carousel caused bed shift at $t=.8340 \mathrm{E}+05 \mathrm{~min}$

Conc. Carousel caused bed shift at $t=.8854 \mathrm{E}+05 \mathrm{~min}$

Conc. Carousel caused bed shift at $t=.9368 \mathrm{E}+05 \mathrm{~min}$

Conc. Carousel caused bed shift at $t=.9883 \mathrm{E}+05 \mathrm{~min}$

Conc. Carousel caused bed shift at $t=.1040 \mathrm{E}+06 \mathrm{~min}$

Conc. Carousel caused bed shift at $\mathrm{t}=.1091 \mathrm{E}+06 \mathrm{~min}$

Conc. Carousel caused bed shift at $t=.1142 \mathrm{E}+06 \mathrm{~min}$

Conc. Carousel caused bed shift at $t=.1194 \mathrm{E}+06 \mathrm{~min}$

VERSE-LC finished in 12959 steps. Average step size 9.260 minutes

End run: $09: 54: 15$ on $04-29-2004$

Integrated Areas in History Files:

case $03 . \mathrm{h} 01$

case03.h०2 $\quad .864147$

case03.h०3 .472597E-03

case $03 . \mathrm{h} \odot 4 \quad .670162 \mathrm{E}-07$

\title{
B.4 Hot Commissioning Operations (Degraded Isotherm)
}

\section{B.4.1 VERSE-LC Datafile}

RF 3-column carousel, single component Cs isotherm, Criterion: lag LAW feed: Hot Commissioning, CT: Degraded, Sensitivity: None $1,150,4,6$

FCWNA

NNNNN

$\mathrm{M}$ ncomp, nelem, ncol-bed, ncol-part isotherm, axial-disp, film-coef, surf-diff, BC-col input-only, perfusable, feed-equil, datafile.yio comp-conc units

403.86, 121.92, 56781.2, 2214466. Length(cm), Diam(cm),Q-flow(ml/min), CSTR-vol $(\mathrm{ml})$

$241.5,0.361,0.6944,0.0$

0.0

$\mathrm{S}$

$1, \odot . \odot, 2.7400 \mathrm{~d}-5,1, \odot . \odot$

part-rad(um), bed-void, part-void, sorb-cap()

initial concentration (M)

COMMAND - conc step change

spec id, time(min), conc(M), freq, dt(min)

COMMAND - viscosity/density change

$0.025001,1.2133$

$\mathrm{m}$

fluid viscosity (poise), density $\left(\mathrm{g} / \mathrm{cm}^{\wedge} 3\right)$

$50,100,0,1,3.70 \mathrm{~d}-8,0.0,1.0 \mathrm{~d}+6$

- subcolumns

elem-shift, elem-watch, pp-watch, c-watch, c-thresh, t-e,t-ee

$\odot, 2.0,50,4.033 d-4,0.016$

$\mathrm{h}$

$2,2.0,50,4.033 d-4,0.016$

$4,2.0,5 \odot, 4.033 d-4,0.016$

$\mathrm{h}$

$6,2.0,50,4.033 d-4,0.016$

$120000.0,1.0$

$1.0 \mathrm{~d}-7,1.0 \mathrm{~d}-4$

1.0

COMMAND - effluent history dump

unit op\#, ptscale(1-4) filtering

COMMAND - effluent history dump

unit op\#, ptscale(1-4) filtering

COMMAND - effluent history dump

unit op\#, ptscale(1-4) filtering

COMMAND - effluent history dump

end of commands

end time(min), $\max d t$ in B.V.S

abs-tol, rel-tol

non-negative conc constraint

size exclusion factor

part-pore diffusivities $\left(\mathrm{cm}^{\wedge} 2 / \mathrm{min}\right)$

Brownian diffusivities $\left(\mathrm{cm}^{\wedge} 2 / \mathrm{min}\right)$

Freundlich/Langmuir Hybrid a (moles/L B.V.)

$3.3628 d-4$

$1.1467 \mathrm{~d}-1$

1.0

1.0

Freundlich/Langmuir Hybrid b (1/M)

Freundlich/Langmuir Hybrid Ma (-)

1.0

Freundlich/Langmuir Hybrid Mb (-)

$1.1117 d-3$

Freundlich/Langmuir Hybrid beta (-)

\section{B.4.2 VERSE-LC Datafile.run}

\author{
(1) \\ VERSE V7.80 by R. D. Whitley and N.-H. L. Wang, c1999 PRF

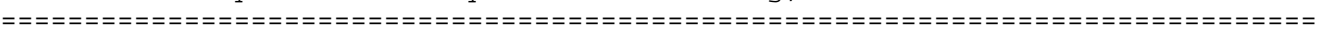 \\ Input file: caseo4 \\ RF 3-column carousel, single component Cs isotherm, Criterion: lag \\ LAW feed: Hot Commissioning, CT: Degraded, Sensitivity: None
}


Begin Run: $09: 54: 15$ on $04-29-2004$ running under Windows 95/8

Finite elements - axial:150 particle: 1

Collocation points - axial: 4 particle: $6 \Rightarrow$ Number of eqns: 6028

Inlet species at equilib.? $N$ Perfusable sorbent? $N$ Feed profile only? $N$

Use Profile File? N Generate Profile File? N

Axial dispersion correlation: Chung \& Wen (1968)

Film mass transfer correlation: Wilson \& Geankoplis (1966)

Sub-Column Boundary Conditions: Axial Dispersion and CSTR

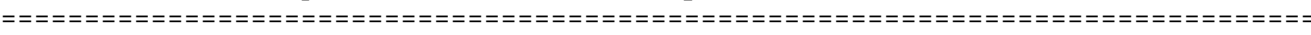

SYSTEM PARAMETERS (at initial conditions):

\begin{tabular}{|c|c|c|c|c|c|}
\hline $\mathrm{t}$ (stop) & $=120000.00000$ & $\min$ & dtheta $\max$ & $1 . \odot \odot \odot \odot \odot$ & BV \\
\hline abs. tol. & .10000 & E- 06 & rel. tol. & .10000 & E- $\odot 3$ \\
\hline Total Length & 403.86000 & $\mathrm{~cm}$ & D & 121.92000 & $\mathrm{~cm}$ \\
\hline Tot. Capacity & .00000 & eq/L solid & Col. Vol. & $=4714879.85299$ & $\mathrm{~mL}$ \\
\hline $\mathrm{F}$ & 56781.20000 & $\mathrm{~mL} / \mathrm{min}$ & Uo (linear) & 13.47279 & $\mathrm{~cm} / \mathrm{min}$ \\
\hline $\mathrm{R}$ & 241.50000 & microns & $\mathrm{L} / \mathrm{R}$ & 16722.98137 & \\
\hline Bed Void frac. & .36100 & & Pcl. Porosity & .69440 & \\
\hline Spec. Area & 79.37888 & $1 / \mathrm{cm}$ & Time/BV & 9.99199 & $\min$ \\
\hline Vol CSTRs & $=2214466.0000 \odot$ & $\mathrm{mL}$ & & & \\
\hline Component no. & $=$ & & & & \\
\hline $\mathrm{Ke} \quad[-]$ & $.10000 \mathrm{E}+01$ & & & & \\
\hline $\mathrm{Eb} \quad[\mathrm{cm} 2 / \mathrm{min}]$ & $.11462 \mathrm{E}+01$ & & & & \\
\hline $\mathrm{Dp} \quad[\mathrm{cm} 2 / \mathrm{min}]$ & $.22419 \mathrm{E}-03$ & & & & \\
\hline Doo $[\mathrm{cm} 2 / \mathrm{min}]$ & $.33628 \mathrm{E}-03$ & & & & \\
\hline $\mathrm{kf} \quad[\mathrm{cm} / \mathrm{min}]$ & $.18653 \mathrm{E}+\Theta \odot$ & & & & \\
\hline Ds $\quad[\mathrm{cm} 2 / \mathrm{min}]$ & $.000 \odot \odot E+\odot \odot$ & & & & \\
\hline \multicolumn{6}{|c|}{ Dimensionless Groups: } \\
\hline $\operatorname{Re}$ & $.19001 \mathrm{E}+0 \odot$ & & & & \\
\hline $\mathrm{Sc}(i)$ & $.36765 \mathrm{E}+\odot 4$ & & & & \\
\hline $\operatorname{Peb}(i)$ & $.15824 \mathrm{E}+04$ & & & & \\
\hline $\mathrm{Bi}(\mathrm{i})$ & $.28936 \mathrm{E}+02$ & & & & \\
\hline$N f(i)$ & $.40982 \mathrm{E}+03$ & & & & \\
\hline $\mathrm{Np}(\mathrm{i})$ & $.26671 \mathrm{E}+01$ & & & & \\
\hline Pep(i) & $=.2090 \odot E+\odot 4$ & & & & \\
\hline Isotherm & $=$ Freundlich $/$ & Langmuir Hyb & \multicolumn{3}{|c|}{ Hybrid } \\
\hline Iso. Const. 1 & $.11467 \mathrm{E}+0 \odot$ & & & & \\
\hline Iso. Const. 2 & $.10000 \mathrm{E}+01$ & & & & \\
\hline Iso. Const. 3 & $.10000 \mathrm{E}+01$ & & & & \\
\hline Iso. Const. 4 & $.10000 \mathrm{E}+01$ & & & & \\
\hline Iso. Const. 5 & $.11117 \mathrm{E}-02$ & & & & \\
\hline Init. Conc. & $=.0 \odot \odot \odot \odot E+\odot \odot$ & & & & \\
\hline Conc. at eqb. & $=. .0 \odot \odot \odot \odot E+\odot \odot$ & & & & \\
\hline $\begin{array}{l}\text { Conc. units } \\
===========\end{array}$ & 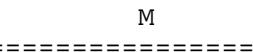 & & & & \\
\hline
\end{tabular}

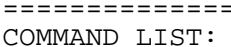

1: Step conc. of component 1 at .0000 min to .2740E-04 M

Execute 1 times, every .0000 mins.

2: User set viscosity to $.2500 \mathrm{E}-01$ poise and density to $1.213 \mathrm{~g} / \mathrm{cm} 3$

3: Carousel (conc.). Active between $t=.0000$ and $.1000 \mathrm{E}+07 \mathrm{~min}$. When comp. 1 reaches .3700E-07 M at end of node 100, shift 50 axial elements out the feed end

4: Monitor conc. history at stream $\odot$. Filename $=$ case $\odot 4 . h \odot 1$ Output density adjustments:

2.0 *default abs conc delta, 50. *default rel conc delta, .40E-03*default force W/ conc delta, .16E-01*default force W/o conc delta

5: Monitor conc. history at stream 2. Filename $=$ case $04 . \mathrm{h} \odot 2$ output density adjustments:

2.0 *default abs conc delta, 50. *default rel conc delta, $.40 \mathrm{E}-03^{*}$ default force $\mathrm{W} / \mathrm{conc}$ delta, $.16 \mathrm{E}-01^{*}$ default force $\mathrm{w} / \mathrm{o}$ conc delta

6: Monitor conc. history at stream 4. Filename $=$ case $04 . \mathrm{h} \odot 3$ Output density adjustments:

2. 0 *default abs conc delta, 50. *default rel conc delta, . 40E-03*default force $\mathrm{W} /$ conc delta, .16E-01*default force $\mathrm{W} / \mathrm{o}$ conc delta

7: Monitor conc. history at stream 6. Filename = case $64 . \mathrm{h} \odot 4$ Output density adjustments:

2.0 *default abs conc delta, 50. *default rel conc delta, $.40 \mathrm{E}-03^{*}$ default force $\mathrm{W} / \mathrm{conc}$ delta, .16E-01*default force $\mathrm{W} / \mathrm{o}$ conc delta

(a)

Conc. Carousel caused bed shift at $t=3810$. min

Conc. Carousel caused bed shift at $t=6215$. min

Conc. Carousel caused bed shift at $t=8692$. min 
WSRC-TR-2004-00100, REVISION 0

SRT-RPP-2004-00019, REVISION 0

Conc. Carousel caused bed shift at $t=.1122 \mathrm{E}+05 \mathrm{~min}$

Conc. Carousel caused bed shift at $t=.1378 \mathrm{E}+05 \mathrm{~min}$

Conc. Carousel caused bed shift at $t=.1637 \mathrm{E}+05 \mathrm{~min}$

Conc. Carousel caused bed shift at $t=.1897 \mathrm{E}+05 \mathrm{~min}$

Conc. Carousel caused bed shift at $t=.2159 \mathrm{E}+05 \mathrm{~min}$

Conc. Carousel caused bed shift at $t=.2421 \mathrm{E}+05 \mathrm{~min}$

Conc. Carousel caused bed shift at $t=.2683 \mathrm{E}+05 \mathrm{~min}$

Conc. Carousel caused bed shift at $t=.2946 \mathrm{E}+05 \mathrm{~min}$

Conc. Carousel caused bed shift at $t=.3208 \mathrm{E}+05 \mathrm{~min}$

Conc. Carousel caused bed shift at $t=.3470 \mathrm{E}+05 \mathrm{~min}$

Conc. Carousel caused bed shift at $t=.3733 \mathrm{E}+05 \mathrm{~min}$

Conc. Carousel caused bed shift at $t=.3994 \mathrm{E}+05 \mathrm{~min}$

Conc. Carousel caused bed shift at $t=.4256 \mathrm{E}+05 \mathrm{~min}$

Conc. Carousel caused bed shift at $t=.4519 \mathrm{E}+05 \mathrm{~min}$

Conc. Carousel caused bed shift at $t=.4781 \mathrm{E}+05 \mathrm{~min}$

Conc. Carousel caused bed shift at $t=.5043 \mathrm{E}+05 \mathrm{~min}$

Conc. Carousel caused bed shift at $t=.5305 \mathrm{E}+05 \mathrm{~min}$

Conc. Carousel caused bed shift at $t=.5567 \mathrm{E}+05 \mathrm{~min}$

Conc. Carousel caused bed shift at $t=.5830 \mathrm{E}+05 \mathrm{~min}$

Conc. Carousel caused bed shift at $t=.6092 \mathrm{E}+05 \mathrm{~min}$

Conc. Carousel caused bed shift at $t=.6354 \mathrm{E}+05 \mathrm{~min}$

Conc. Carousel caused bed shift at $t=.6616 \mathrm{E}+05 \mathrm{~min}$

Conc. Carousel caused bed shift at $t=.6878 \mathrm{E}+05 \mathrm{~min}$

Conc. Carousel caused bed shift at $t=.7140 \mathrm{E}+05 \mathrm{~min}$

Conc. Carousel caused bed shift at $t=.7403 \mathrm{E}+05 \mathrm{~min}$

Conc. Carousel caused bed shift at $t=.7665 \mathrm{E}+05 \mathrm{~min}$

Conc. Carousel caused bed shift at $t=.7927 \mathrm{E}+05 \mathrm{~min}$

Conc. Carousel caused bed shift at $t=.8189 \mathrm{E}+05 \mathrm{~min}$

Conc. Carousel caused bed shift at $t=.8451 \mathrm{E}+05 \mathrm{~min}$

Conc. Carousel caused bed shift at $t=.8713 \mathrm{E}+05 \mathrm{~min}$

Conc. Carousel caused bed shift at $t=.8976 \mathrm{E}+05 \mathrm{~min}$

Conc. Carousel caused bed shift at $t=.9238 \mathrm{E}+05 \mathrm{~min}$

Conc. Carousel caused bed shift at $t=.9499 \mathrm{E}+05 \mathrm{~min}$

Conc. Carousel caused bed shift at $\mathrm{t}=.9762 \mathrm{E}+05 \mathrm{~min}$

Conc. Carousel caused bed shift at $\mathrm{t}=.1002 \mathrm{E}+06 \mathrm{~min}$

Conc. Carousel caused bed shift at $t=.1029 \mathrm{E}+06 \mathrm{~min}$

Conc. Carousel caused bed shift at $t=.1055 \mathrm{E}+06 \mathrm{~min}$

Conc. Carousel caused bed shift at $t=.1081 \mathrm{E}+06 \mathrm{~min}$

Conc. Carousel caused bed shift at $t=.1107 \mathrm{E}+06 \mathrm{~min}$

Conc. Carousel caused bed shift at $t=.1133 \mathrm{E}+06 \mathrm{~min}$

Conc. Carousel caused bed shift at $t=.1160 \mathrm{E}+06 \mathrm{~min}$

Conc. Carousel caused bed shift at $t=.1186 \mathrm{E}+06 \mathrm{~min}$

VERSE-LC finished in 13237 steps. Average step size 9.065 minutes

End run: $10: 45: 41$ on $04-29-2004$

Integrated Areas in History Files:

\begin{tabular}{ll} 
case 4. h०1 3.28800 \\
\hline
\end{tabular}

case $04 . \mathrm{h} \odot 2$

case $04 . \mathrm{h} 03 \quad .656022 \mathrm{E}-03$

case $04 . \mathrm{h} \odot 4 \quad .390968 \mathrm{E}-06$

\section{B.5 Envelope B Operations (Degraded Isotherm)}

\section{B.5.1 VERSE-LC Datafile}

RF 3-column carousel, single component Cs isotherm, criterion: lag

LAW feed: Envelope B, CT: Degraded, Sensitivity: None

$1,150,4,6$

ncomp, nelem, ncol-bed, ncol-part

FCWNA

$\mathrm{M}$

isotherm, axial-disp, film-coef, surf-diff, BC-col

input-only, perfusable, feed-equil, datafile.yio

403.86, 121.92, 28390.6, 2214466. Length(cm),Diam(cm), Q-flow(ml/min), CSTR-vol(ml)

$241.5,0.361,0.6944,0.0$

0.0

part-rad(um), bed-void, part-void, sorb-cap()

initial concentration (M)

COMMAND - conc step change

$1,0.0,2.8300 \mathrm{~d}-4,1,0.0$

spec id, time(min), conc(M), freq, dt(min)

$\mathrm{V}$

$0.020010,1.1793$

$\mathrm{m}$

$50,100, \odot, 1,3.40 \mathrm{~d}-8,0 . \odot, 1.0 \mathrm{~d}+6$

COMMAND - viscosity/density change

fluid viscosity(poise), density $\left(\mathrm{g} / \mathrm{cm}^{\wedge} 3\right)$

$\mathrm{h}$

$\odot, 2.0,50,4.033 d-4,0.016$

$\mathrm{h}$ COMMAND - subcolumns

elem-shift, elem-watch, pp-watch, c-watch, c-thresh, t-e,t-ee COMMAND - effluent history dump

unit op\#, ptscale(1-4) filtering

COMMAND - effluent history dump

$2,2.0,50,4.033 d-4,0.016$

unit op\#, ptscale(1-4) filtering 
h

$4,2.0,50,4.033 d-4,0.016$

$\mathrm{h}$

$6,2.0,50,4.033 d-4,0.016$

$120000.0,1.0$

$1.0 \mathrm{~d}-7,1.0 \mathrm{~d}-4$

1. 0

3. $4819 \mathrm{~d}-4$

$5.2228 d-4$

1. $1343 d-1$

1.0

1.0

1.0

4. $0009 d-4$
COMMAND - effluent history dump

unit op\#, ptscale(1-4) filtering

COMMAND - effluent history dump

unit op\#, ptscale(1-4) filtering

end of commands

end time(min), max dt in B.V.s

abs-tol, rel-tol

non-negative conc constraint

size exclusion factor

part-pore diffusivities $\left(\mathrm{cm}^{\wedge} 2 / \mathrm{min}\right)$

Brownian diffusivities ( $\left.\mathrm{cm}^{\wedge} 2 / \mathrm{min}\right)$

Freundlich/Langmuir Hybrid a (moles/L B.V.)

Freundlich/Langmuir Hybrid b (1/M)

Freundlich/Langmuir Hybrid Ma (-)

Freundlich/Langmuir Hybrid Mb (-)
Freundlich/Langmuir Hybrid beta (-)

\section{B.5.2 VERSE-LC Datafile.run}

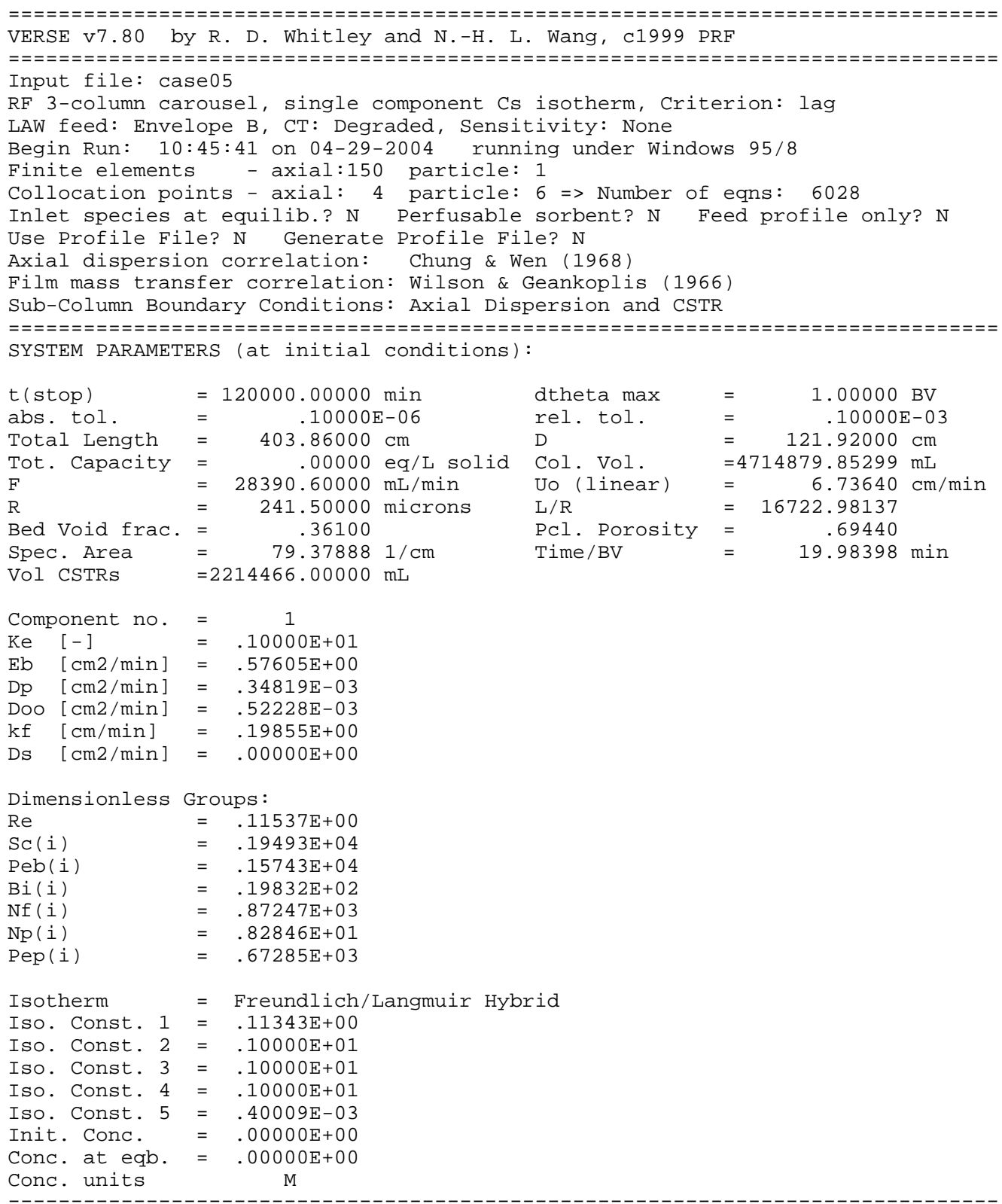

COMMAND LIST:

1: Step conc. of component 1 at . .0000

$\min$ to $.2830 \mathrm{E}-03 \mathrm{M}$ 
Execute 1 times, every .000๑ mins.

2: User set viscosity to .2001E-01 poise and density to $1.179 \mathrm{~g} / \mathrm{cm} 3$

3: Carousel (conc.). Active between $t=.0000$ and $.1000 \mathrm{E}+07 \mathrm{~min}$. When comp. 1 reaches .3400E-07 M at end of node 100, shift 50 axial elements out the feed end

4: Monitor conc. history at stream 0 . Filename $=$ case $05 . \mathrm{h} 01$ Output density adjustments: 2.0 *default abs conc delta, 50. *default rel conc delta, .40E-03*default force $\mathrm{W} /$ conc delta, .16E-01*default force $\mathrm{W} / \mathrm{o}$ conc delta

5: Monitor conc. history at stream 2. Filename $=$ case $05 . \mathrm{h} \odot 2$ Output density adjustments: 2.0 *default abs conc delta, 50. *default rel conc delta, .40E-03*default force $\mathrm{W} / \mathrm{conc}$ delta, .16E-01*default force w/o conc delta

6: Monitor conc. history at stream 4. Filename = case $05 . \mathrm{h} \odot 3$ Output density adjustments: 2.0 *default abs conc delta, $50 . \quad$ default rel conc delta, .40E-03*default force $W /$ conc delta, .16E-01*default force w/o conc delta

7: Monitor conc. history at stream 6. Filename = case $05 . \mathrm{h} 04$ Output density adjustments: 2.0 *default abs conc delta, 50. *default rel conc delta . 40E- $03^{*}$ default force $\mathrm{W} /$ conc delta, .16E- $01^{*}$ default force $\mathrm{W} / \mathrm{o}$ conc delta

Conc. Carousel caused bed shift at $\mathrm{t}=.1754 \mathrm{E}+05 \mathrm{~min}$

Conc. Carousel caused bed shift at $t=.2686 \mathrm{E}+05 \mathrm{~min}$

Conc. Carousel caused bed shift at $t=.3617 \mathrm{E}+05 \mathrm{~min}$

Conc. Carousel caused bed shift at $t=.4549 \mathrm{E}+05 \mathrm{~min}$

Conc. Carousel caused bed shift at $t=.5480 \mathrm{E}+05 \mathrm{~min}$

Conc. Carousel caused bed shift at $\mathrm{t}=.6411 \mathrm{E}+05 \mathrm{~min}$

Conc. Carousel caused bed shift at $t=.7343 \mathrm{E}+05 \mathrm{~min}$

Conc. Carousel caused bed shift at $t=.8274 \mathrm{E}+05 \mathrm{~min}$

Conc. Carousel caused bed shift at $t=.9207 \mathrm{E}+05 \mathrm{~min}$

Conc. Carousel caused bed shift at $t=.1014 \mathrm{E}+06 \mathrm{~min}$

Conc. Carousel caused bed shift at $t=.1107 \mathrm{E}+06 \mathrm{~min}$

Conc. Carousel caused bed shift at $t=.1200 \mathrm{E}+06 \mathrm{~min}$

VERSE-LC finished in 6404 steps. Average step size 18.74 minutes

End run: $11: 02: 35$ on $04-29-2004$

Integrated Areas in History Files:

case05.h01 33.9600

case $05 . \mathrm{h} 02$

case $05 . \mathrm{h} 03 \quad .514570 \mathrm{E}-04$

case05.h०4 - .398834E-20

\section{B.6 Subsequent Operations (Degraded Isotherm)}

\section{B.6.1 VERSE-LC Datafile}

RF 3-column carousel, single component Cs isotherm, Criterion: lag

LAW feed: Subsequent operation, CT: Degraded, Sensitivity: None

$1,150,4,6$

FCWNA

ncomp, nelem, ncol-bed, ncol-part

NNNNN

$\mathrm{M}$

isotherm, axial-disp, film-coef, surf-diff, BC-col

input-only, perfusable, feed-equil, datafile.yio comp-conc units

403.86, 121.92, 56781.2, 2214466. Length(cm), Diam(cm), Q-flow(ml/min), CSTR-vol $(\mathrm{ml})$

$241.5,0.361,0.6944,0.0 \quad$ part-rad(um), bed-void, part-void, sorb-cap ()

0.0

initial concentration (M)

COMMAND - conc step change

$1,0.0,5.0000 \mathrm{~d}-5,1,0.0$

spec id, time(min), conc(M), freq, dt(min)

$\mathrm{V}^{\prime}$

$0.019792,1.2093$

$50,100, \odot, 1,3.40 \mathrm{~d}-8,0 . \odot, 1.0 \mathrm{~d}+6$

COMMAND - viscosity/density change

fluid viscosity(poise), density $\left(\mathrm{g} / \mathrm{cm}^{\wedge} 3\right)$ COMMAND - subcolumns

$\odot, 2.0,50,4.033 d-4,0.016$

elem-shift, elem-watch,pp-watch, c-watch, c-thresh,t-e,t-ee COMMAND - effluent history dump

unit op\#, ptscale(1-4) filtering

COMMAND - effluent history dump

unit op\#, ptscale(1-4) filtering

$2,2 . \odot, 5 \odot, 4.033 d-4,0.016$

$\mathrm{h}$

$4,2.0,50,4.033 d-4,0.016$

$6,2.0,50,4.033 d-4,0.016$

$120000.0,1.0$

COMMAND - effluent history dump

unit op\#, ptscale(1-4) filtering

COMMAND - effluent history dump

end of commands

end time(min), $\max d t$ in B.V.s

$1.0 \mathrm{~d}-7,1.0 \mathrm{~d}-4$

abs-tol, rel-tol 
1.0

$2.5873 d-4$

3. $8809 d-4$

1. $1108 \mathrm{~d}-1$

1.0

1.0

1.0

$6.7392 d-4$ non-negative conc constraint

size exclusion factor

part-pore diffusivities $\left(\mathrm{cm}^{\wedge} 2 / \mathrm{min}\right)$

Brownian diffusivities $\left(\mathrm{cm}^{\wedge} 2 / \mathrm{min}\right)$

Freundlich/Langmuir Hybrid a (moles/L B.V.)

Freundlich/Langmuir Hybrid b (1/M)

Freundlich/Langmuir Hybrid Ma (-)

Freundlich/Langmuir Hybrid Mb (-)

Freundlich/Langmuir Hybrid beta (-)

\section{B.6.2 VERSE-LC Datafile.run}

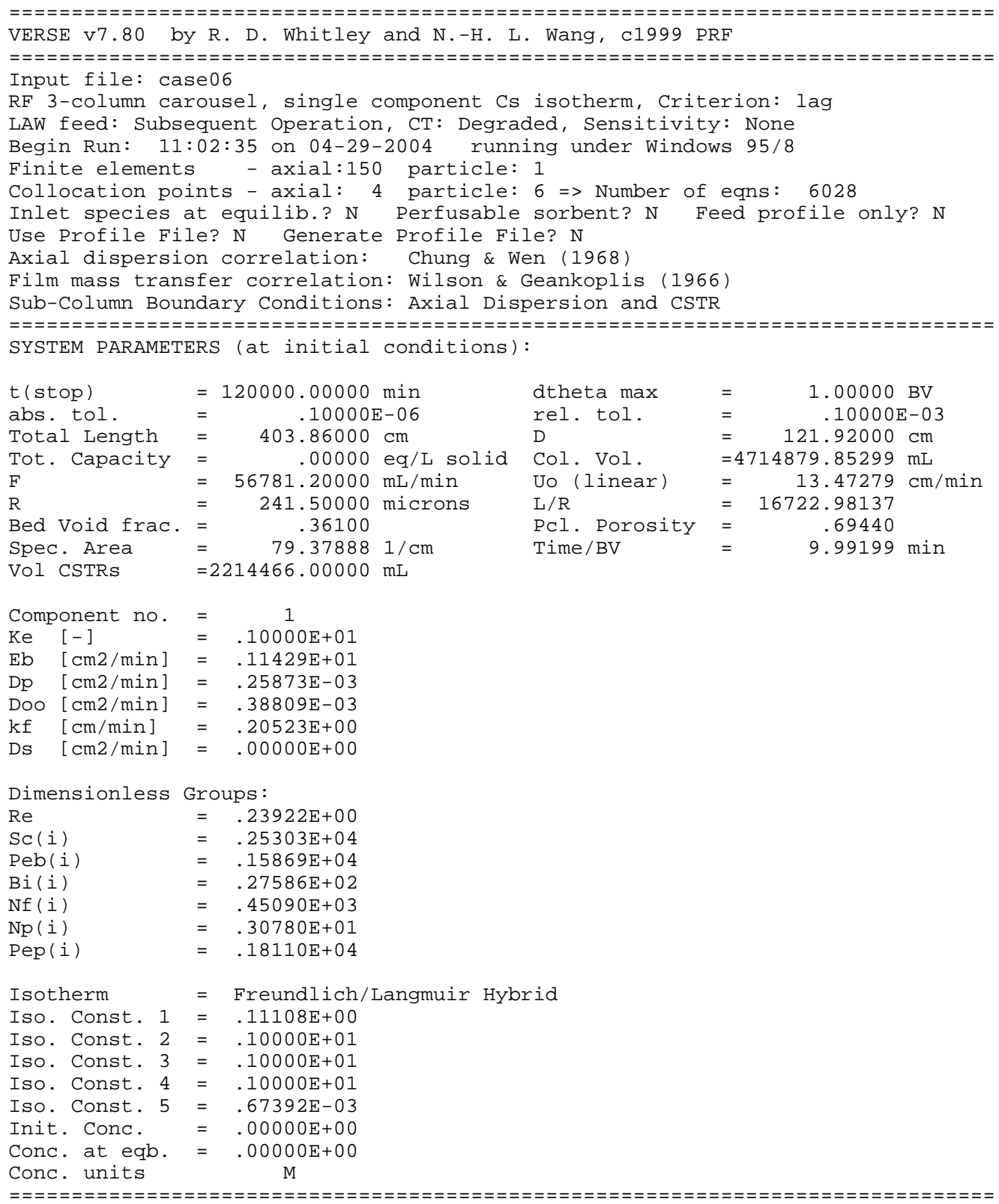

=ニニニニニニニニニニニ

1: Step conc. of component 1 at .0000 min to .5000E-04 M

Execute 1 times, every .0000 mins.

2: User set viscosity to .1979E-01 poise and density to $1.209 \mathrm{~g} / \mathrm{cm} 3$

3: Carousel (conc.). Active between $t=.0000$ and .1000E+07 min. When comp. 1 reaches .3400E-๑7 M at end of node 100 , shift 50 axial elements out the feed end

4: Monitor conc. history at stream $\odot$. Filename $=$ case $06 . \mathrm{h} \odot 1$ output density adjustments: 


\author{
2.0 *default abs conc delta, 50. *default rel conc delta, \\ . 40E-03*default force $\mathrm{W} / \mathrm{conc}$ delta, .16E-01*default force W/o conc delta \\ 5: Monitor conc. history at stream 2. Filename $=$ case $\odot 6 . h \odot 2$ \\ output density adjustments: \\ 2.0 *default abs conc delta, 50. *default rel conc delta, \\ $.40 \mathrm{E}-03^{*}$ default force $\mathrm{W} / \mathrm{conc}$ delta, .16E- $01^{*}$ default force $\mathrm{W} / \mathrm{o}$ conc delta \\ 6: Monitor conc. history at stream 4. Filename $=$ case06.h03 \\ Output density adjustments: \\ 2.0 *default abs conc delta, 50 . default rel conc delta, \\ .40E-03*default force w/ conc delta, .16E-01*default force w/o conc delta \\ 7: Monitor conc. history at stream 6. Filename $=$ case $66 . \mathrm{h} \odot 4$ \\ Output density adjustments: \\ 2.0 *default abs conc delta, 50. *default rel conc delta, \\ $.40 \mathrm{E}-03^{*}$ default force $\mathrm{W} / \mathrm{conc}$ delta, .16E- $01^{*}$ default force $\mathrm{W} / \mathrm{o}$ conc delta \\ Conc. Carousel caused bed shift at $t=5990 . \quad$ min \\ Conc. Carousel caused bed shift at $t=9757$ min \\ Conc. Carousel caused bed shift at $t=.1365 \mathrm{E}+05 \mathrm{~min}$ \\ Conc. Carousel caused bed shift at $t=.1762 \mathrm{E}+05 \mathrm{~min}$ \\ Conc. Carousel caused bed shift at $t=.2164 \mathrm{E}+05 \mathrm{~min}$ \\ Conc. Carousel caused bed shift at $t=.2570 \mathrm{E}+05 \mathrm{~min}$ \\ Conc. Carousel caused bed shift at $t=.2980 \mathrm{E}+05 \mathrm{~min}$ \\ Conc. Carousel caused bed shift at $t=.3390 \mathrm{E}+05 \mathrm{~min}$ \\ Conc. Carousel caused bed shift at $\mathrm{t}=.3802 \mathrm{E}+05 \mathrm{~min}$ \\ Conc. Carousel caused bed shift at $t=.4216 \mathrm{E}+05 \mathrm{~min}$ \\ Conc. Carousel caused bed shift at $t=.4628 \mathrm{E}+05 \mathrm{~min}$ \\ Conc. Carousel caused bed shift at $t=.5041 \mathrm{E}+05 \mathrm{~min}$ \\ Conc. Carousel caused bed shift at $t=.5454 \mathrm{E}+05 \mathrm{~min}$ \\ Conc. Carousel caused bed shift at $t=.5866 \mathrm{E}+05 \mathrm{~min}$ \\ Conc. Carousel caused bed shift at $t=.6280 \mathrm{E}+05 \mathrm{~min}$ \\ Conc. Carousel caused bed shift at $t=.6692 \mathrm{E}+05 \mathrm{~min}$ \\ Conc. Carousel caused bed shift at $\mathrm{t}=.7105 \mathrm{E}+05 \mathrm{~min}$ \\ Conc. Carousel caused bed shift at $t=.7517 \mathrm{E}+05 \mathrm{~min}$ \\ Conc. Carousel caused bed shift at $t=.7930 E+05 \mathrm{~min}$ \\ Conc. Carousel caused bed shift at $t=.8342 \mathrm{E}+05 \mathrm{~min}$ \\ Conc. Carousel caused bed shift at $t=.8756 \mathrm{E}+05 \mathrm{~min}$ \\ Conc. Carousel caused bed shift at $t=.9168 \mathrm{E}+05 \mathrm{~min}$ \\ Conc. Carousel caused bed shift at $t=.9581 \mathrm{E}+05 \mathrm{~min}$ \\ Conc. Carousel caused bed shift at $t=.9993 \mathrm{E}+05 \mathrm{~min}$ \\ Conc. Carousel caused bed shift at $\mathrm{t}=.1041 \mathrm{E}+06 \mathrm{~min}$ \\ Conc. Carousel caused bed shift at $t=.1082 \mathrm{E}+06 \mathrm{~min}$ \\ Conc. Carousel caused bed shift at $t=.1123 \mathrm{E}+06 \mathrm{~min}$ \\ Conc. Carousel caused bed shift at $t=.1164 \mathrm{E}+06 \mathrm{~min}$ \\ VERSE-LC finished in 13011 steps. Average step size 9.223 minutes \\ End run: $11: 43: 43$ on $04-29-2004$ \\ Integrated Areas in History Files: \\ 6.00000 \\ case $06 . \mathrm{h} 02$ \\ case-06.h०3 .479348E-03 \\ case $06 . \mathrm{h} \odot 4 \quad .762311 \mathrm{E}-07$
}

\title{
B.7 Hot Commissioning Operations $\left(\left[\mathrm{Cs}^{+}\right]+\mathbf{2 0 \%}\right)$
}

\section{B.7.1 VERSE-LC Datafile}

RF 3-column carousel, single component Cs isotherm, criterion: lag LAW feed: Hot Commissioning, CT: Degraded, Sensitivity: $1.2^{*}[\mathrm{Cs}+]$ $1,150,4,6 \quad$ ncomp, nelem, ncol-bed, ncol-part FCWNA NNNNN isotherm, axial-disp, film-coef, surf-diff, BC-col input-only, perfusable, feed-equil, datafile.yio $\mathrm{M}$ comp-conc units

403.86, 121.92, 56781.2, 2214466. Length (cm), Diam (cm),0-flow (ml/min), CSTR-vol $(\mathrm{ml})$

$241.5,0.361,0.6944,0.0$

0.0

part-rad(um), bed-void, part-void, sorb-cap() initial concentration (M)

S COMMAND - conc step change

$1,0 . \odot, 3.2880 \mathrm{~d}-5,1,0 . \odot$ spec id, time(min), conc(M), freq, dt(min)

$\mathrm{V}$

$0.025001,1.2133$

COMMAND - viscosity/density change

$\mathrm{m}$

fluid viscosity(poise), density $\left(\mathrm{g} / \mathrm{cm}^{\wedge} 3\right)$

$5 \odot, 10 \odot, 0,1,3.70 \mathrm{~d}-8,0.0,1.0 \mathrm{~d}+6$ COMMAND - subcolumns

$\odot, 2.0,50,4.033 d-4,0.016$ elem-shift, elem-watch,pp-watch, c-watch, c-thresh,t-e,t-ee COMMAND - effluent history dump unit op\#, ptscale(1-4) filtering

$\mathrm{h}$ COMMAND - effluent history dump 
$2,2.0,50,4.033 d-4,0.016$

$4,2 . \odot, 5 \odot, 4.033 d-4,0.016$

h

$6,2.0,50,4.033 d-4,0.016$

$120000.0,1.0$

$1.0 \mathrm{~d}-7,1.0 \mathrm{~d}-4$

1.0

2. $2419 d-4$

3. $3628 d-4$

$1.1467 d-1$

1.0

1.0

1.0

1. $1117 d-3$ unit op\#, ptscale(1-4) filtering

COMMAND - effluent history dump

unit op\#, ptscale(1-4) filtering

COMMAND - effluent history dump

unit op\#, ptscale(1-4) filtering

end of commands

end time(min), $\max d t$ in B.V.S

abs-tol, rel-tol

non-negative conc constraint

size exclusion factor

part-pore diffusivities $\left(\mathrm{cm}^{\wedge} 2 / \mathrm{min}\right)$

Brownian diffusivities ( $\left.\mathrm{cm}^{\wedge} 2 / \mathrm{min}\right)$

Freundlich/Langmuir Hybrid a (moles/L B.V.)

Freundlich/Langmuir Hybrid b (1/M)

Freundlich/Langmuir Hybrid Ma (-)

Freundlich/Langmuir Hybrid Mb (-)

Freundlich/Langmuir Hybrid beta (-)

\section{B.7.2 VERSE-LC Datafile.run}

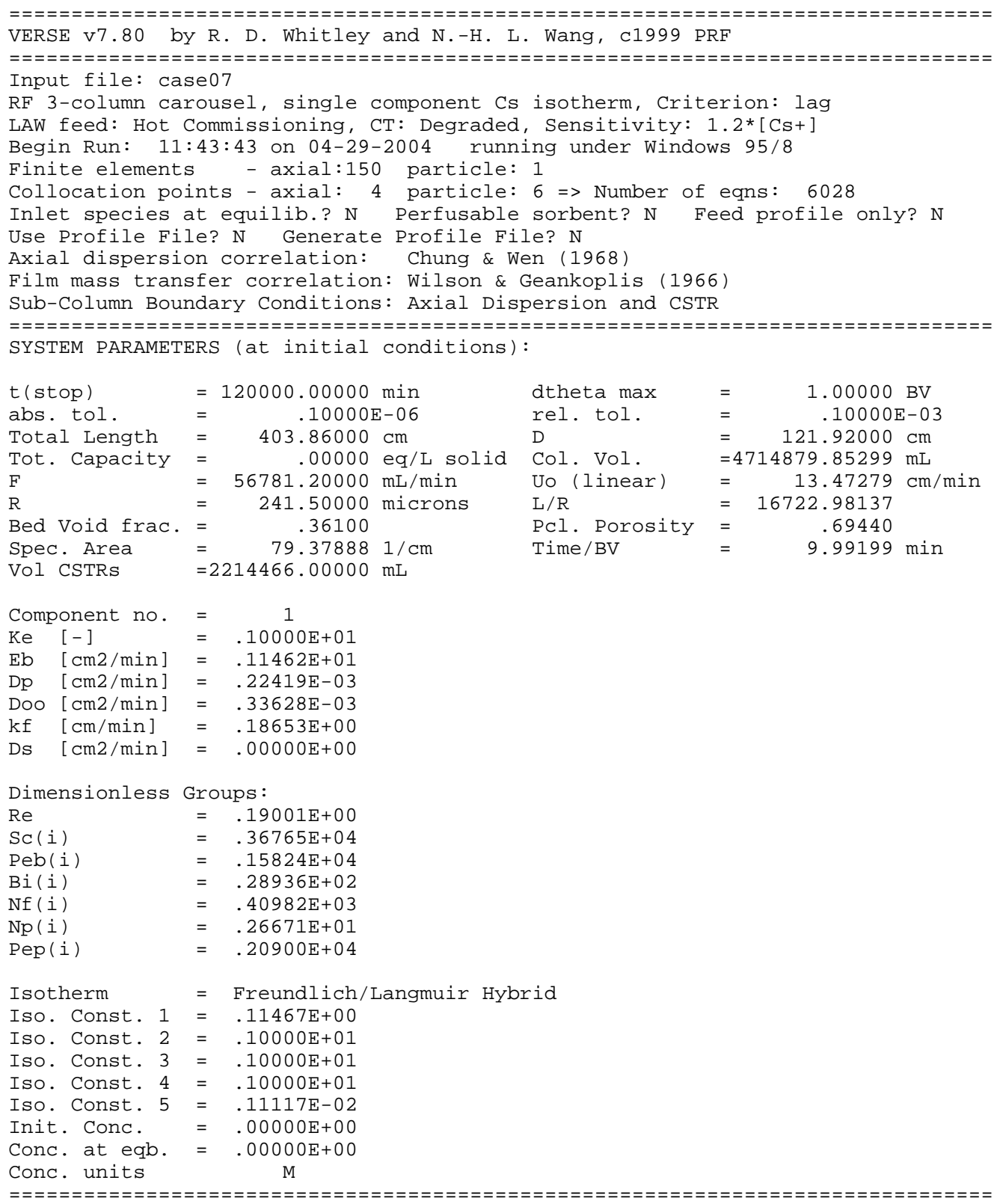

COMMAND LIST: 
1: Step conc. of component 1 at . . $.00 \odot$ Execute 1 times, every .0000

$\min$ to $.3288 \mathrm{E}-04 \mathrm{M}$

2: User set viscosity to .2500E-01 poise and density to $1.213 \mathrm{~g} / \mathrm{cm} 3$

3: Carousel (conc.). Active between $t=.0000$ and .1000E+07 min When comp. 1 reaches .3700E-07 M at end of node 100, shift 50 axial elements out the feed end

4: Monitor conc. history at stream $\odot$. Filename $=$ case 07. h०1 output density adjustments: 2.0 *default abs conc delta, $50 . \quad$ *default rel conc delta, .40E-03*default force w/ conc delta, .16E-01*default force w/o conc delta

5: Monitor conc. history at stream 2. Filename = case $07 . \mathrm{h} \odot 2$ output density adjustments:

$2.0 \quad$ *default abs conc delta

50. *default rel conc delta, .40E-03*default force W/ conc delta, .16E-01*default force w/o conc delta

6: Monitor conc. history at stream 4. Filename = case 07. h०3 output density adjustments: 2.0 *default abs conc delta, 50. *default rel conc delta, 40E-03*default force w/ conc delta, .16E-01*default force w/o conc delta

7: Monitor conc. history at stream 6. Filename = case $07 . \mathrm{h} \odot 4$ Output density adjustments:

2.0 *default abs conc delta, $50 . \quad{ }^{*}$ default rel conc delta . 40E-03*default force W/ conc delta, .16E-01*default force w/o conc delta

Conc. Carousel caused bed shift at $t=3780$. min

Conc. Carousel caused bed shift at $t=6166$. min

Conc. Carousel caused bed shift at $t=8639 . \quad \mathrm{min}$

Conc. Carousel caused bed shift at $t=.1115 \mathrm{E}+05 \mathrm{~min}$

Conc. Carousel caused bed shift at $t=.1371 \mathrm{E}+05 \mathrm{~min}$

Conc. Carousel caused bed shift at $t=.1629 \mathrm{E}+05 \mathrm{~min}$

Conc. Carousel caused bed shift at $t=.1889 \mathrm{E}+05 \mathrm{~min}$

Conc. Carousel caused bed shift at $\mathrm{t}=.2149 \mathrm{E}+05 \mathrm{~min}$

Conc. Carousel caused bed shift at $t=.2411 \mathrm{E}+05 \mathrm{~min}$

Conc. Carousel caused bed shift at $t=.2672 \mathrm{E}+05 \mathrm{~min}$

Conc. Carousel caused bed shift at $t=.2934 \mathrm{E}+05 \mathrm{~min}$

Conc. Carousel caused bed shift at $t=.3195 \mathrm{E}+05 \mathrm{~min}$

Conc. Carousel caused bed shift at $t=.3456 \mathrm{E}+05 \mathrm{~min}$

Conc. Carousel caused bed shift at $t=.3717 \mathrm{E}+05 \mathrm{~min}$

Conc. Carousel caused bed shift at $t=.3979 E+05 \mathrm{~min}$

Conc. Carousel caused bed shift at $t=.4240 E+05 \mathrm{~min}$

Conc. Carousel caused bed shift at $t=.4501 \mathrm{E}+05 \mathrm{~min}$

Conc. Carousel caused bed shift at $t=.4762 \mathrm{E}+05 \mathrm{~min}$

Conc. Carousel caused bed shift at $t=.5024 \mathrm{E}+05 \mathrm{~min}$

Conc. Carousel caused bed shift at $t=.5285 \mathrm{E}+05 \mathrm{~min}$

Conc. Carousel caused bed shift at $t=.5545 \mathrm{E}+05 \mathrm{~min}$

Conc. Carousel caused bed shift at $t=.5807 \mathrm{E}+05 \mathrm{~min}$

Conc. Carousel caused bed shift at $t=.6068 \mathrm{E}+05 \mathrm{~min}$

Conc. Carousel caused bed shift at $t=.6330 \mathrm{E}+05 \mathrm{~min}$

Conc. Carousel caused bed shift at $t=.6590 \mathrm{E}+05 \mathrm{~min}$

Conc. Carousel caused bed shift at $t=.6852 \mathrm{E}+05 \mathrm{~min}$

Conc. Carousel caused bed shift at $t=.7113 \mathrm{E}+05 \mathrm{~min}$

Conc. Carousel caused bed shift at $t=.7374 \mathrm{E}+05 \mathrm{~min}$

Conc. Carousel caused bed shift at $t=.7635 \mathrm{E}+05 \mathrm{~min}$

Conc. Carousel caused bed shift at $t=.7896 \mathrm{E}+05 \mathrm{~min}$

Conc. Carousel caused bed shift at $t=.8158 \mathrm{E}+05 \mathrm{~min}$

Conc. Carousel caused bed shift at $t=.8419 \mathrm{E}+05 \mathrm{~min}$

Conc. Carousel caused bed shift at $t=.8680 E+05 \mathrm{~min}$

Conc. Carousel caused bed shift at $t=.8941 \mathrm{E}+05 \mathrm{~min}$

Conc. Carousel caused bed shift at $t=.9203 \mathrm{E}+05 \mathrm{~min}$

Conc. Carousel caused bed shift at $t=.9464 \mathrm{E}+05 \mathrm{~min}$

Conc. Carousel caused bed shift at $t=.9725 \mathrm{E}+05 \mathrm{~min}$

Conc. Carousel caused bed shift at $t=.9986 \mathrm{E}+05 \mathrm{~min}$

Conc. Carousel caused bed shift at $t=.1025 E+06 \mathrm{~min}$

Conc. Carousel caused bed shift at $t=.1051 \mathrm{E}+06 \mathrm{~min}$

Conc. Carousel caused bed shift at $t=.1077 \mathrm{E}+06 \mathrm{~min}$

Conc. Carousel caused bed shift at $t=.1103 \mathrm{E}+06 \mathrm{~min}$

Conc. Carousel caused bed shift at $t=.1129 \mathrm{E}+06 \mathrm{~min}$

Conc. Carousel caused bed shift at $t=.1155 \mathrm{E}+06 \mathrm{~min}$

Conc. Carousel caused bed shift at $t=.1181 \mathrm{E}+06 \mathrm{~min}$

VERSE-LC finished in 13229 steps. Average step size 9.071 minutes

End run: 12:34:37 on 04-29-2004

Integrated Areas in History Files:

case07.h01 3.94560

case $07 . \mathrm{h} \odot 2 \quad .415767$

case $07 . \mathrm{h} 03 \quad .637349 \mathrm{E}-03$

case07.h०4 .322995E-06 


\section{B.8 Hot Commissioning Operations $\left(\left[\mathrm{Cs}^{+}\right]-20 \%\right)$}

\section{B.8.1 VERSE-LC Datafile}

RF 3-column carousel, single component Cs isotherm, criterion: lag LAW feed: Hot Commissioning, CT: Degraded, Sensitivity: $0.8^{*}[\mathrm{Cs}+]$ $1,150,4,6$ FCWNA NNNNN

$\mathrm{M}$ ncomp, nelem, ncol-bed, ncol-part isotherm, axial-disp, film-coef, surf-diff, BC-col input-only, perfusable, feed-equil, datafile.yio comp-conc units

403.86, 121.92, 56781.2, 2214466. Length $(\mathrm{cm}), \operatorname{Diam}(\mathrm{cm}), \mathrm{Q}-\mathrm{flow}(\mathrm{ml} / \mathrm{min}), \operatorname{cSTR}-\operatorname{vol}(\mathrm{ml})$

$241.5,0.361,0.6944,0.0$

0.0 part-rad(um), bed-void, part-void, sorb-cap() initial concentration (M) $\mathrm{S}$ $1, \odot . \odot, 2.1920 \mathrm{~d}-5,1, \odot . \odot$ COMMAND - conc step change spec id, time(min), conc(M), freq, dt(min) $0.025001,1.2133$

$5 \odot, 100, \odot, 1,3.70 \mathrm{~d}-8,0 . \odot, 1.0 \mathrm{~d}+6$ COMMAND - viscosity/density change

fluid viscosity (poise), density $\left(\mathrm{g} / \mathrm{cm}^{\wedge} 3\right)$ COMMAND - subcolumns

$0,2.0,50,4.033 d-4,0.016$

$\mathrm{h}$

$2,2.0,50,4.033 d-4,0.016$

$\mathrm{h}$

$4,2.0,50,4.033 d-4,0.016$

$\mathrm{h}$

$6,2.0,50,4.033 d-4,0.016$

$120000.0,1.0$

$1.0 \mathrm{~d}-7,1.0 \mathrm{~d}-4$

1.0

2. $2419 d-4$

$3.3628 d-4$

$1.1467 d-1$

1.0

1.0

elem-shift, elem-watch,pp-watch, c-watch, c-thresh, t-e,t-ee COMMAND - effluent history dump

unit op\#, ptscale(1-4) filtering

COMMAND - effluent history dump

unit op\#, ptscale(1-4) filtering

COMMAND - effluent history dump

unit op\#, ptscale(1-4) filtering

COMMAND - effluent history dump

end of commands

end time(min), $\max d t$ in B.V.S

abs-tol, rel-tol

non-negative conc constraint

size exclusion factor

part-pore diffusivities $\left(\mathrm{cm}^{\wedge} 2 / \mathrm{min}\right)$

Brownian diffusivities $\left(\mathrm{cm}^{\wedge} 2 / \mathrm{min}\right)$

Freundlich/Langmuir Hybrid a (moles/L B.V.)

Freundlich/Langmuir Hybrid b (1/M)

Freundlich/Langmuir Hybrid Ma (-)

1.0

Freundlich/Langmuir Hybrid Mb (-)

$1.1117 d-3$

Freundlich/Langmuir Hybrid beta (-)

\section{B.8.2 VERSE-LC Datafile.run}

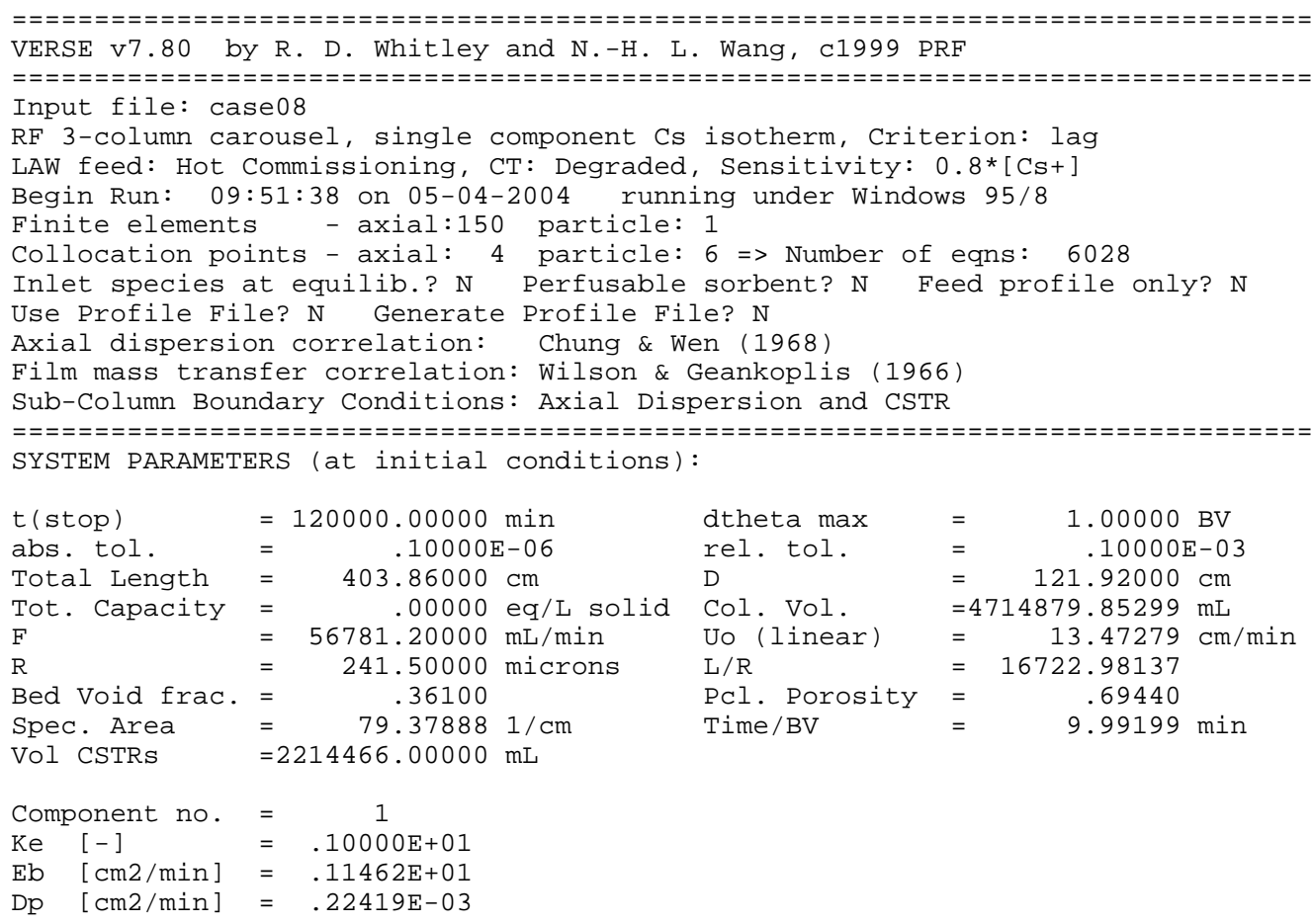




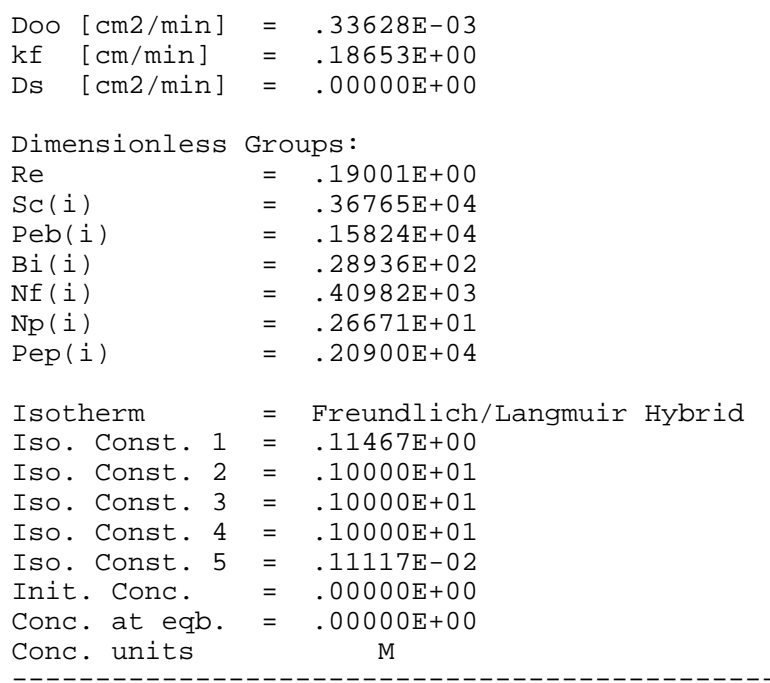


WSRC-TR-2004-00100, REVISION 0

SRT-RPP-2004-00019, REVISION 0

Conc. Carousel caused bed shift at $t=.7699 \mathrm{E}+05 \mathrm{~min}$

Conc. Carousel caused bed shift at $t=.7962 \mathrm{E}+05 \mathrm{~min}$

Conc. Carousel caused bed shift at $t=.8226 \mathrm{E}+05 \mathrm{~min}$

Conc. Carousel caused bed shift at $t=.8489 \mathrm{E}+05 \mathrm{~min}$

Conc. Carousel caused bed shift at $t=.8752 \mathrm{E}+05 \mathrm{~min}$

Conc. Carousel caused bed shift at $t=.9016 \mathrm{E}+05 \mathrm{~min}$

Conc. Carousel caused bed shift at $t=.9279 E+05 \mathrm{~min}$

Conc. Carousel caused bed shift at $t=.9542 \mathrm{E}+05 \mathrm{~min}$

Conc. Carousel caused bed shift at $t=.9806 \mathrm{E}+05 \mathrm{~min}$

Conc. Carousel caused bed shift at $t=.1007 \mathrm{E}+06 \mathrm{~min}$

Conc. Carousel caused bed shift at $t=.1033 \mathrm{E}+06 \mathrm{~min}$

Conc. Carousel caused bed shift at $t=.1060 \mathrm{E}+06 \mathrm{~min}$

Conc. Carousel caused bed shift at $t=.1086 \mathrm{E}+06 \mathrm{~min}$

Conc. Carousel caused bed shift at $t=.1112 \mathrm{E}+06 \mathrm{~min}$

Conc. Carousel caused bed shift at $t=.1138 \mathrm{E}+06 \mathrm{~min}$

Conc. Carousel caused bed shift at $\mathrm{t}=.1165 \mathrm{E}+06 \mathrm{~min}$

Conc. Carousel caused bed shift at $t=.1191 \mathrm{E}+06 \mathrm{~min}$

VERSE-LC finished in 13273 steps. Average step size 9.041 minutes

End run: 10:44:14 on $05-04-2004$

Integrated Areas in History Files:

case $08 . \mathrm{h} 01$

case08.h०2 $\quad .295353$

case $08 . \mathrm{h} 03$

case $08 . \mathrm{h} \odot 4 \quad .491497 \mathrm{E}-06$

\section{B.9 Hot Commissioning Operations $\left(\left[\mathrm{K}^{+}\right]+\mathbf{2 0 \%}\right)$}

\section{B.9.1 VERSE-LC Datafile}

RF 3-column carousel, single component Cs isotherm, criterion: lag

LAW feed: Hot Commissioning, CT: Degraded, Sensitivity: $1.2^{*}[\mathrm{~K}+]$

$1,150,4,6$

FCWNA

NNNNN

$\mathrm{M}$

ncomp, nelem, ncol-bed, ncol-part

isotherm, axial-disp, film-coef, surf-diff, BC-col

input-only, perfusable, feed-equil, datafile.yio

$403.86,121.92,50781.2,00 m$-conc units

$241.5,0.361,0.6944,0.0$

0.0

$\mathrm{S}$

$1, \odot . \odot, 2.7400 \mathrm{~d}-5,1, \odot . \odot$

Length $(\mathrm{cm}), \operatorname{Diam}(\mathrm{cm}), \mathrm{Q}-\mathrm{flow}(\mathrm{ml} / \mathrm{min}), \mathrm{CSTR}-\mathrm{vol}(\mathrm{ml})$

$\mathrm{V}$

$0.025207,1.2183$

$\mathrm{m}$

$50,10 \odot, \odot, 1,3.70 \mathrm{~d}-8,0 . \odot, 1 . \odot \mathrm{d}+6$

part-rad(um), bed-void, part-void, sorb-cap()

initial concentration (M)

COMMAND - conc step change

spec id, time(min), conc(M), freq, dt(min)

COMMAND - viscosity/density change

fluid viscosity (poise), density $\left(\mathrm{g} / \mathrm{cm}^{\wedge} 3\right)$

COMMAND - subcolumns

$\mathrm{h}$

$0,2.0,50,4.033 d-4,0.016$

$\mathrm{h}$

$2,2.0,50,4.033 d-4,0.016$

$4,2.0,50,4.033 d-4,0.016$

$\mathrm{h}$

$6,2.0,50,4.033 d-4,0.016$

$120000.0,1.0$

$1.0 \mathrm{~d}-7,1.0 \mathrm{~d}-4$

1.0

elem-shift, elem-watch, pp-watch, c-watch, c-thresh, t-e,t-ee

COMMAND - effluent history dump

unit op\#, ptscale(1-4) filtering

COMMAND - effluent history dump

unit op\#, ptscale(1-4) filtering

COMMAND - effluent history dump

unit op\#, ptscale(1-4) filtering

COMMAND - effluent history dump

end of commands

end time(min), max dt in B.V.S

abs-tol, rel-tol

non-negative conc constraint

size exclusion factor

part-pore diffusivities $\left(\mathrm{cm}^{\wedge} 2 / \mathrm{min}\right)$

Brownian diffusivities $\left(\mathrm{cm}^{\wedge} 2 / \mathrm{min}\right)$

Freundlich/Langmuir Hybrid a (moles/L B.V.)

$2.9314 d-4$

$1.1467 \mathrm{~d}-1$

1.0

1.0

Freundlich/Langmuir Hybrid b (1/M)

Freundlich/Langmuir Hybrid Ma (-)

1.0

Freundlich/Langmuir Hybrid Mb (-)

1. $2765 d-3$

Freundlich/Langmuir Hybrid beta (-)

\section{B.9.2 VERSE-LC Datafile.run}

ニニニニニニニニニニニニニニニニニニニニニニニニニニニニニニニニニニニニニニニニニニニニニニニニニニニニニニニニニニニニニニニニニニニニニニニニニニニニニニ

VERSE V7.80 by R. D. Whitley and N.-H. L. Wang, c1999 PRF

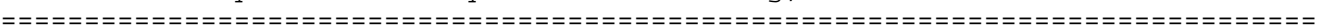

Input file: case $\odot 9$

RF 3-column carousel, single component Cs isotherm, Criterion: lag

LAW feed: Hot Commissioning, CT: Degraded, Sensitivity: $1.2^{*}[\mathrm{~K}+]$ 
Begin Run: 13:26:0๑ on $04-29-2004$ running under Windows 95/8

Finite elements - axial:150 particle: 1

Collocation points - axial: 4 particle: 6 => Number of eqns: 6028

Inlet species at equilib.? $N$ Perfusable sorbent? $N$ Feed profile only? $N$

Use Profile File? N Generate Profile File? N

Axial dispersion correlation: Chung \& Wen (1968)

Film mass transfer correlation: Wilson \& Geankoplis (1966)

Sub-Column Boundary Conditions: Axial Dispersion and CSTR

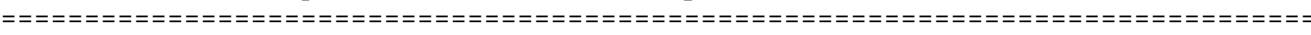

SYSTEM PARAMETERS (at initial conditions):

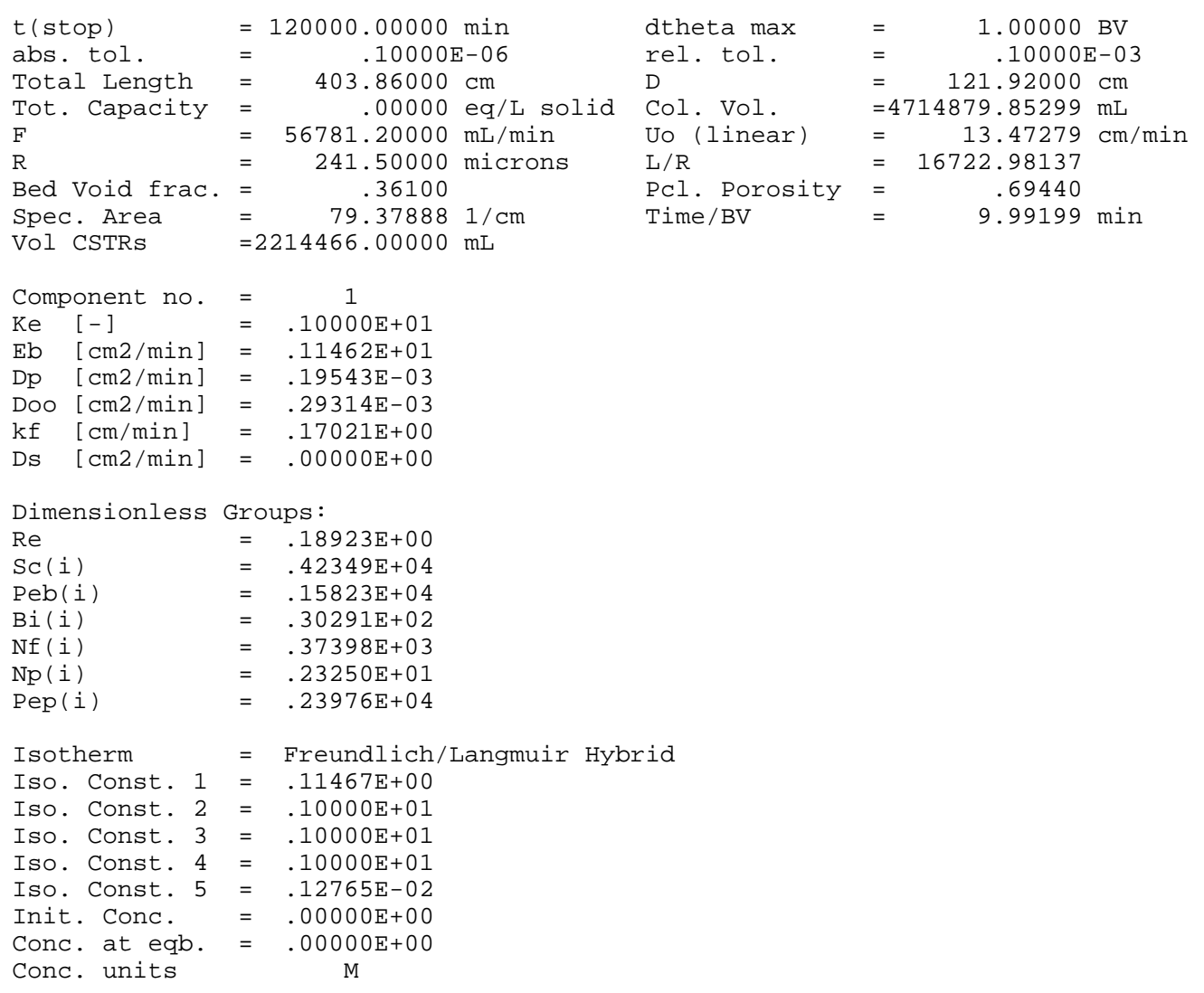

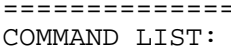

1: Step conc. of component 1 at .0000 min to .2740E-04 M

Execute 1 times, every .0000 mins.

2: User set viscosity to .2521E-01 poise and density to $1.218 \mathrm{~g} / \mathrm{cm} 3$

3: Carousel (conc.). Active between $t=.0000$ and $.1000 \mathrm{E}+07 \mathrm{~min}$. When comp. 1 reaches .3700E-07 M at end of node 100, shift 50 axial elements out the feed end

4: Monitor conc. history at stream $\odot$. Filename $=$ case $\odot 9$. h $\odot 1$ Output density adjustments:

2.0 *default abs conc delta, 50. *default rel conc delta, .40E-03*default force W/ conc delta, .16E-01*default force W/o conc delta

5: Monitor conc. history at stream 2. Filename = case@9.h@2 output density adjustments:

2.0 *default abs conc delta, 50. *default rel conc delta, . 40E- $03^{*}$ default force $\mathrm{W} / \mathrm{conc}$ delta, .16E- $01^{*}$ default force w/o conc delta

6: Monitor conc. history at stream 4. Filename $=$ case $09 . \mathrm{h} \odot 3$ Output density adjustments:

2. 0 *default abs conc delta, 50. *default rel conc delta, . 40E-03*default force $\mathrm{W} /$ conc delta, .16E-01*default force w/o conc delta

7: Monitor conc. history at stream 6. Filename = case $69 . \mathrm{h} \odot 4$ Output density adjustments:

2.0 *default abs conc delta, 50. *default rel conc delta, $.40 \mathrm{E}-03^{*}$ default force $\mathrm{W} / \mathrm{conc}$ delta, .16E-01*default force $\mathrm{W} / \mathrm{o}$ conc delta

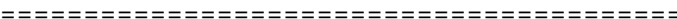

Conc. Carousel caused bed shift at $t=3240$. min

Conc. Carousel caused bed shift at $t=5304$. min

Conc. Carousel caused bed shift at $t=7450$. min 
WSRC-TR-2004-00100, REVISION 0

SRT-RPP-2004-00019, REVISION 0

Conc. Carousel caused bed shift at $t=9636$.

$\min$

Conc. Carousel caused bed shift at $t=.1186 \mathrm{E}+05 \mathrm{~min}$

Conc. Carousel caused bed shift at $t=.1410 \mathrm{E}+05 \mathrm{~min}$

Conc. Carousel caused bed shift at $t=.1635 \mathrm{E}+05 \mathrm{~min}$

Conc. Carousel caused bed shift at $t=.1862 \mathrm{E}+05 \mathrm{~min}$

Conc. Carousel caused bed shift at $t=.2088 \mathrm{E}+05 \mathrm{~min}$

Conc. Carousel caused bed shift at $t=.2315 \mathrm{E}+05 \mathrm{~min}$

Conc. Carousel caused bed shift at $t=.2541 \mathrm{E}+05 \mathrm{~min}$

Conc. Carousel caused bed shift at $t=.2767 \mathrm{E}+05 \mathrm{~min}$

Conc. Carousel caused bed shift at $t=.2993 \mathrm{E}+05 \mathrm{~min}$

Conc. Carousel caused bed shift at $t=.3220 \mathrm{E}+05 \mathrm{~min}$

Conc. Carousel caused bed shift at $t=.3446 \mathrm{E}+05 \mathrm{~min}$

Conc. Carousel caused bed shift at $t=.3672 \mathrm{E}+05 \mathrm{~min}$

Conc. Carousel caused bed shift at $t=.3898 \mathrm{E}+05 \mathrm{~min}$

Conc. Carousel caused bed shift at $t=.4124 \mathrm{E}+05 \mathrm{~min}$

Conc. Carousel caused bed shift at $\mathrm{t}=.4351 \mathrm{E}+05 \mathrm{~min}$

Conc. Carousel caused bed shift at $t=.4577 \mathrm{E}+05 \mathrm{~min}$

Conc. Carousel caused bed shift at $t=.4803 \mathrm{E}+05 \mathrm{~min}$

Conc. Carousel caused bed shift at $t=.5030 \mathrm{E}+05 \mathrm{~min}$

Conc. Carousel caused bed shift at $t=.5256 \mathrm{E}+05 \mathrm{~min}$

Conc. Carousel caused bed shift at $t=.5482 \mathrm{E}+05 \mathrm{~min}$

Conc. Carousel caused bed shift at $t=.5708 \mathrm{E}+05 \mathrm{~min}$

Conc. Carousel caused bed shift at $t=.5935 \mathrm{E}+05 \mathrm{~min}$

Conc. Carousel caused bed shift at $t=.6161 \mathrm{E}+05 \mathrm{~min}$

Conc. Carousel caused bed shift at $t=.6387 \mathrm{E}+05 \mathrm{~min}$

Conc. Carousel caused bed shift at $t=.6613 \mathrm{E}+05 \mathrm{~min}$

Conc. Carousel caused bed shift at $t=.6839 \mathrm{E}+05 \mathrm{~min}$

Conc. Carousel caused bed shift at $t=.7065 \mathrm{E}+05 \mathrm{~min}$

Conc. Carousel caused bed shift at $t=.7292 \mathrm{E}+05 \mathrm{~min}$

Conc. Carousel caused bed shift at $\mathrm{t}=.7517 \mathrm{E}+05 \mathrm{~min}$

Conc. Carousel caused bed shift at $t=.7744 \mathrm{E}+05 \mathrm{~min}$

Conc. Carousel caused bed shift at $t=.7970 \mathrm{E}+05 \mathrm{~min}$

Conc. Carousel caused bed shift at $t=.8197 \mathrm{E}+05 \mathrm{~min}$

Conc. Carousel caused bed shift at $t=.8422 \mathrm{E}+05 \mathrm{~min}$

Conc. Carousel caused bed shift at $t=.8648 \mathrm{E}+05 \mathrm{~min}$

Conc. Carousel caused bed shift at $t=.8875 \mathrm{E}+05 \mathrm{~min}$

Conc. Carousel caused bed shift at $t=.9101 \mathrm{E}+05 \mathrm{~min}$

Conc. Carousel caused bed shift at $t=.9327 \mathrm{E}+05 \mathrm{~min}$

Conc. Carousel caused bed shift at $t=.9554 \mathrm{E}+05 \mathrm{~min}$

Conc. Carousel caused bed shift at $t=.9780 \mathrm{E}+05 \mathrm{~min}$

Conc. Carousel caused bed shift at $t=.1001 \mathrm{E}+06 \mathrm{~min}$

Conc. Carousel caused bed shift at $t=.1023 \mathrm{E}+06 \mathrm{~min}$

Conc. Carousel caused bed shift at $t=.1046 \mathrm{E}+06 \mathrm{~min}$

Conc. Carousel caused bed shift at $t=.1069 \mathrm{E}+06 \mathrm{~min}$

Conc. Carousel caused bed shift at $\mathrm{t}=.1091 \mathrm{E}+06 \mathrm{~min}$

Conc. Carousel caused bed shift at $t=.1114 \mathrm{E}+06 \mathrm{~min}$

Conc. Carousel caused bed shift at $\mathrm{t}=.1136 \mathrm{E}+06 \mathrm{~min}$

Conc. Carousel caused bed shift at $t=.1159 \mathrm{E}+06 \mathrm{~min}$

Conc. Carousel caused bed shift at $t=.1182 \mathrm{E}+06 \mathrm{~min}$

VERSE-LC finished in 13346 steps. Average step size 8.991 minutes

End run: 14:21:56 on $04-29-2004$

Integrated Areas in History Files:

case 3.2880 . h01

case $09 . \mathrm{h} \odot 2 \quad .327276$

case $09 . \mathrm{h} 03 \quad .681295 \mathrm{E}-03$

case $09 . \mathrm{h} \odot 4 \quad .496229 \mathrm{E}-06$

\section{B.10 Hot Commissioning Operations $\left(\left[\mathrm{K}^{+}\right]-20 \%\right)$}

\section{B.10.1 VERSE-LC Datafile}

RF 3-column carousel, single component Cs isotherm, criterion: lag

LAW feed: Hot Commissioning, CT: Degraded, Sensitivity: $0.8^{*}[\mathrm{~K}+]$

$1,150,4,6$

FCWNA

NNNNN

$M$ ncomp, nelem, ncol-bed, ncol-part isotherm, axial-disp, film-coef, surf-diff, BC-col input-only, perfusable, feed-equil, datafile.yio comp-conc units

403.86, 121.92, 56781.2, 2214466. Length(cm), Diam(cm),Q-flow(ml/min), CSTR-vol $(\mathrm{ml})$

$241.5,0.361,0.6944,0.0$

0.0

$\mathrm{S}$

part-rad(um), bed-void, part-void, sorb-cap()

initial concentration (M)

COMMAND - conc step change

$1, \odot . \odot, 2.7400 \mathrm{~d}-5,1, \odot . \odot$

spec id, time(min), conc(M), freq, dt(min)

COMMAND - viscosity/density change 
$0.024799,1.2083$

$5 \odot, 100, \Theta, 1,3.70 \mathrm{~d}-8,0 . \odot, 1.0 \mathrm{~d}+6$

$\mathrm{h}$

$0,2.0,50,4.033 d-4,0.016$

$\mathrm{h}$

$2,2.0,50,4.033 d-4,0.016$

$\mathrm{h}$

$4,2.0,50,4.033 d-4,0.016$

$6,2.0,50,4.033 d-4,0.016$

$120000.0,1.0$

$1.0 \mathrm{~d}-7,1.0 \mathrm{~d}-4$

1.0

2. $5156 \mathrm{~d}-4$

3. $7734 d-4$

$1.1467 \mathrm{~d}-1$

1.0

1.0

1.0

9. $4800 \mathrm{~d}-4$ fluid viscosity(poise), density $\left(\mathrm{g} / \mathrm{cm}^{\wedge} 3\right)$ COMMAND - subcolumns elem-shift, elem-watch, pp-watch, c-watch, c-thresh, t-e,t-ee COMMAND - effluent history dump unit op\#, ptscale(1-4) filtering COMMAND - effluent history dump unit op\#, ptscale(1-4) filtering COMMAND - effluent history dump unit op\#, ptscale(1-4) filtering COMMAND - effluent history dump end of commands unit op\#, ptscale(1-4) filtering

end time(min), $\max d t$ in B.V.s

abs-tol, rel-tol

non-negative conc constraint

size exclusion factor

part-pore diffusivities $\left(\mathrm{cm}^{\wedge} 2 / \mathrm{min}\right)$

Brownian diffusivities $\left(\mathrm{cm}^{\wedge} 2 / \mathrm{min}\right)$

Freundlich/Langmuir Hybrid a (moles/L B.V.)

Freundlich/Langmuir Hybrid b (1/M)

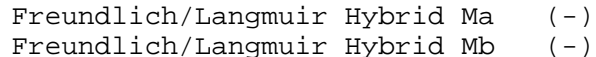

Freundlich/Langmuir Hybrid Mb (-)
Freundlich/Langmuir Hybrid beta (-)

\section{B.10.2 VERSE-LC Datafile.run}

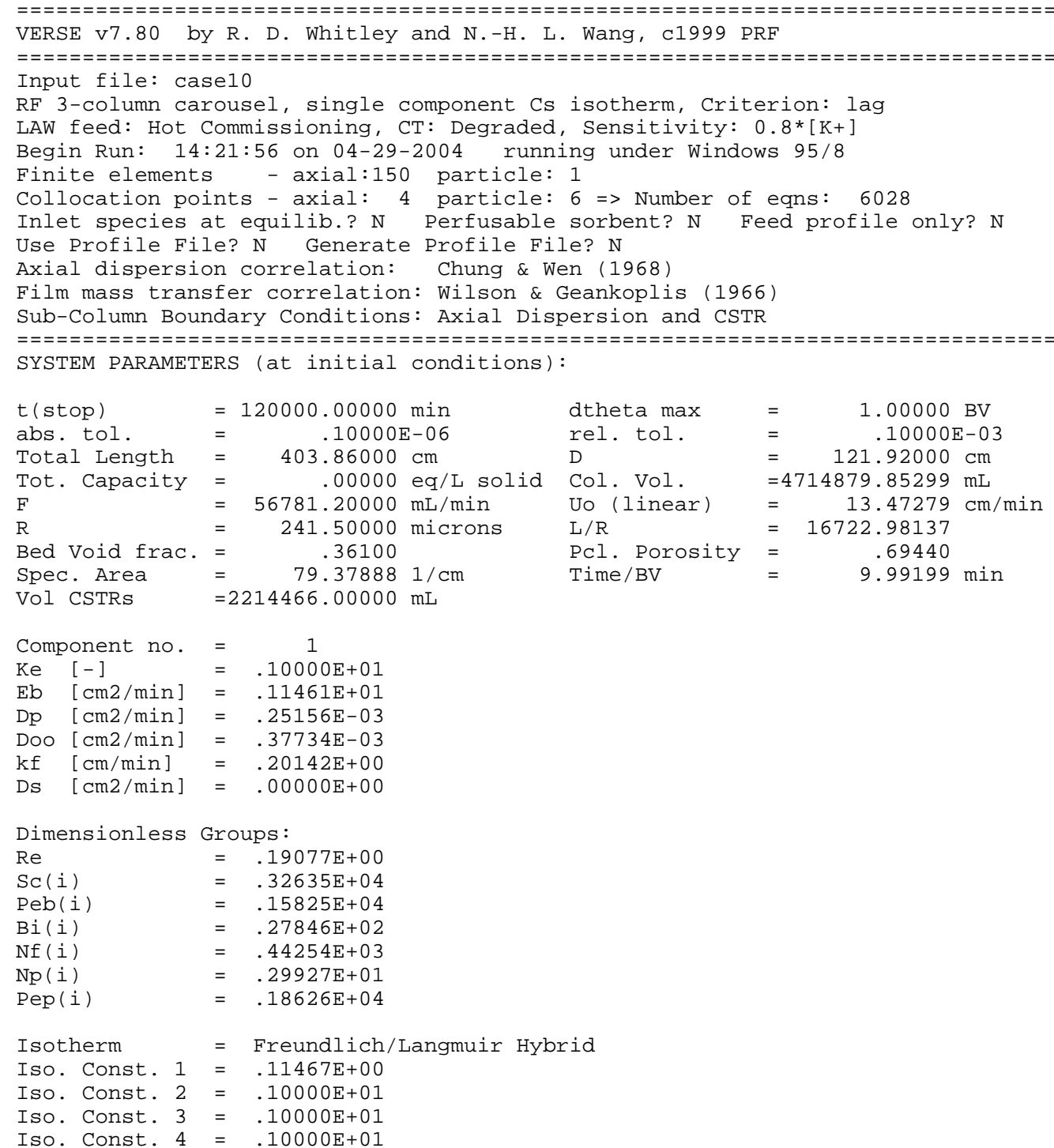


Iso. Const. $5=.94800 \mathrm{E}-03$

Init. Conc. $=.00000 \mathrm{E}+00$

Conc. at eqb. $=.00000 \mathrm{E}+\Theta \odot$

Conc. units $M$

COMMAND LIST:

1: Step conc. of component 1 at . 0000

Execute 1 times, every .0000 mins.

$\min$ to $.2740 \mathrm{E}-04 \mathrm{M}$

2: User set viscosity to .2480E-01 poise and density to 1.208

3: Carousel (conc.). Active between $t=.0000$ and $.1000 \mathrm{E}+07 \mathrm{~min}$. When comp. 1 reaches .3700E-07 M at end of node 100, shift 50 axial elements out the feed end

4: Monitor conc. history at stream $\odot$. Filename $=$ case10.h०1 Output density adjustments: 2.0 *default abs conc delta, 50. *default rel conc delta, $.40 \mathrm{E}-03^{*}$ default force $\mathrm{W} / \mathrm{conc}$ delta, .16E- $01 *$ default force $\mathrm{W} / \mathrm{o}$ conc delta

5: Monitor conc. history at stream 2. Filename = case10.h०2 Output density adjustments: 2.0 *default abs conc delta, 50. *default rel conc delta, .40E-03*default force $\mathrm{W} / \mathrm{conc}$ delta, .16E-01*default force $\mathrm{W} / \mathrm{o}$ conc delta

6: Monitor conc. history at stream 4. Filename $=$ case10.h03 Output density adjustments: 2. 0 *default abs conc delta, 50. *default rel conc delta, $.40 \mathrm{E}-03^{*}$ default force $\mathrm{W} / \mathrm{conc}$ delta, .16E- $01^{*}$ default force $\mathrm{W} / \mathrm{o}$ conc delta

7: Monitor conc. history at stream 6. Filename = case10.h@4 Output density adjustments:

2.0 *default abs conc delta, 50. *default rel conc delta, $.40 \mathrm{E}-03^{*}$ default force $\mathrm{W} / \mathrm{conc}$ delta, .16E- $01^{*}$ default force $\mathrm{W} / \mathrm{o}$ conc delta

Conc. Carousel caused bed shift at $\mathrm{t}=4551$. min

Conc. Carousel caused bed shift at $t=7384$. min

Conc. Carousel caused bed shift at $t=.1030 \mathrm{E}+05 \mathrm{~min}$

Conc. Carousel caused bed shift at $t=.1328 \mathrm{E}+05 \mathrm{~min}$

Conc. Carousel caused bed shift at $t=.1629 \mathrm{E}+05 \mathrm{~min}$

Conc. Carousel caused bed shift at $t=.1933 \mathrm{E}+05 \mathrm{~min}$

Conc. Carousel caused bed shift at $t=.2240 E+05 \mathrm{~min}$

Conc. Carousel caused bed shift at $t=.2548 \mathrm{E}+05 \mathrm{~min}$

Conc. Carousel caused bed shift at $t=.2857 \mathrm{E}+05 \mathrm{~min}$

Conc. Carousel caused bed shift at $t=.3166 \mathrm{E}+05 \mathrm{~min}$

Conc. Carousel caused bed shift at $t=.3475 \mathrm{E}+05 \mathrm{~min}$

Conc. Carousel caused bed shift at $t=.3785 \mathrm{E}+05 \mathrm{~min}$

Conc. Carousel caused bed shift at $t=.4094 \mathrm{E}+05 \mathrm{~min}$

Conc. Carousel caused bed shift at $t=.4404 \mathrm{E}+05 \mathrm{~min}$

Conc. Carousel caused bed shift at $t=.4713 \mathrm{E}+05 \mathrm{~min}$

Conc. Carousel caused bed shift at $t=.5022 \mathrm{E}+05 \mathrm{~min}$

Conc. Carousel caused bed shift at $t=.5330 \mathrm{E}+05 \mathrm{~min}$

Conc. Carousel caused bed shift at $t=.5640 \mathrm{E}+05 \mathrm{~min}$

Conc. Carousel caused bed shift at $t=.5949 \mathrm{E}+05 \mathrm{~min}$

Conc. Carousel caused bed shift at $t=.6258 \mathrm{E}+05 \mathrm{~min}$

Conc. Carousel caused bed shift at $t=.6568 \mathrm{E}+05 \mathrm{~min}$

Conc. Carousel caused bed shift at $t=.6877 \mathrm{E}+05 \mathrm{~min}$

Conc. Carousel caused bed shift at $t=.7186 \mathrm{E}+05 \mathrm{~min}$

Conc. Carousel caused bed shift at $t=.7495 \mathrm{E}+05 \mathrm{~min}$

Conc. Carousel caused bed shift at $t=.7805 \mathrm{E}+05 \mathrm{~min}$

Conc. Carousel caused bed shift at $t=.8114 \mathrm{E}+05 \mathrm{~min}$

Conc. Carousel caused bed shift at $t=.8423 \mathrm{E}+05 \mathrm{~min}$

Conc. Carousel caused bed shift at $t=.8732 \mathrm{E}+05 \mathrm{~min}$

Conc. Carousel caused bed shift at $t=.9042 \mathrm{E}+05 \mathrm{~min}$

Conc. Carousel caused bed shift at $t=.9351 \mathrm{E}+05 \mathrm{~min}$

Conc. Carousel caused bed shift at $t=.9660 \mathrm{E}+05 \mathrm{~min}$

Conc. Carousel caused bed shift at $t=.9970 \mathrm{E}+05 \mathrm{~min}$

Conc. Carousel caused bed shift at $t=.1028 \mathrm{E}+06 \mathrm{~min}$

Conc. Carousel caused bed shift at $t=.1059 \mathrm{E}+06 \mathrm{~min}$

Conc. Carousel caused bed shift at $t=.1090 \mathrm{E}+06 \mathrm{~min}$

Conc. Carousel caused bed shift at $\mathrm{t}=.1121 \mathrm{E}+06 \mathrm{~min}$

Conc. Carousel caused bed shift at $t=.1152 \mathrm{E}+06 \mathrm{~min}$

Conc. Carousel caused bed shift at $t=.1182 \mathrm{E}+06 \mathrm{~min}$

VERSE-LC finished in 13073 steps. Average step size 9.179 minutes

End run: 15:07:20 on $04-29-2004$

Integrated Areas in History Files:

case10.h01 3.28800

case10.h02 $\quad .388850$

case10.h03 $\quad .630252 \mathrm{E}-03$

case10.h०4 .300489E-06 


\section{B.11 Hot Commissioning Operations $\left(\left[\mathrm{Na}^{+}\right]+20 \%\right)$}

\section{B.11.1 VERSE-LC Datafile}

RF 3-column carousel, single component Cs isotherm, criterion: lag LAW feed: Hot Commissioning, CT: Degraded, Sensitivity: $1.2 *[\mathrm{Na}+]$ $1,150,4,6$

FCWNA ncomp, nelem, ncol-bed, ncol-part NNNNN

$M$ isotherm, axial-disp, film-coef, surf-diff, BC-col input-only, perfusable, feed-equil, datafile.yio comp-conc units

403.86, 121.92, 56781.2, 2214466. Length $(\mathrm{cm}), \operatorname{Diam}(\mathrm{cm}), \mathrm{Q}-\mathrm{flow}(\mathrm{ml} / \mathrm{min}), \operatorname{CSTR}-\operatorname{vol}(\mathrm{ml})$

$241.5,0.361,0.6944,0.0$

0.0 part-rad(um), bed-void, part-void, sorb-cap() initial concentration (M) COMMAND - conc step change spec id, time(min), conc(M), freq, dt(min)

$1, \odot . \odot, 2.7400 \mathrm{~d}-5,1, \odot . \odot$ COMMAND - viscosity/density change

$0.029577,1.2494$

$\mathrm{m}$

$50,100,0,1,3.70 \mathrm{~d}-8,0.0,1.0 \mathrm{~d}+6$

fluid viscosity (poise), density $\left(\mathrm{g} / \mathrm{cm}^{\wedge} 3\right)$

$\mathrm{h}$

$0,2.0,50,4.033 d-4,0.016$

$\mathrm{h}$

$2,2.0,50,4.033 d-4,0.016$

$\mathrm{h}$

$4,2.0,50,4.033 d-4,0.016$

h

$6,2.0,50,4.033 d-4,0.016$

$120000.0,1.0$

1. $0 d-7,1.0 d-4$

1.0

$1.0497 d-5$

$1.5745 d-5$

1. $1467 \mathrm{~d}-1$

1.0

1.0

1.0

1. $2732 d-3$ COMMAND - subcolumns

elem-shift, elem-watch, pp-watch, c-watch, c-thresh, t-e,t-ee COMMAND - effluent history dump

unit op\#, ptscale(1-4) filtering

COMMAND - effluent history dump

unit op\#, ptscale(1-4) filtering

COMMAND - effluent history dump

unit op\#, ptscale(1-4) filtering

COMMAND - effluent history dump

end of commands

end time(min), max dt in B.V.s

abs-tol, rel-tol

non-negative conc constraint

size exclusion factor

part-pore diffusivities $\left(\mathrm{cm}^{\wedge} 2 / \mathrm{min}\right)$

Brownian diffusivities ( $\left.\mathrm{cm}^{\wedge} 2 / \mathrm{min}\right)$

Freundlich/Langmuir Hybrid a (moles/L B.V.)

Freundlich/Langmuir Hybrid b (1/M)

Freundlich/Langmuir Hybrid Ma (-)

Freundlich/Langmuir Hybrid Mb (-)

Freundlich/Langmuir Hybrid beta (-)

\section{B.11.2 VERSE-LC Datafile.run}

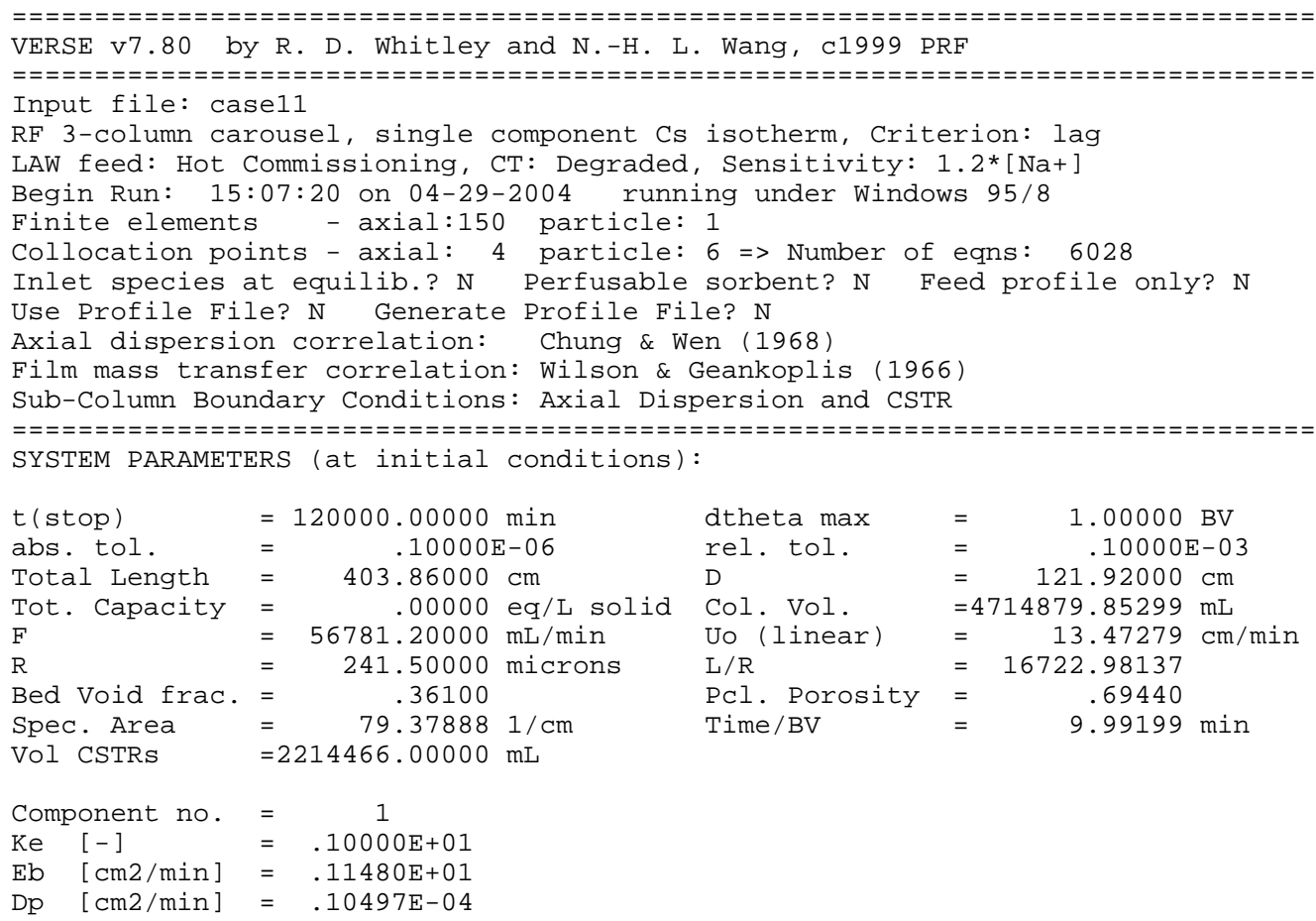




Doo $[\mathrm{cm} 2 / \mathrm{min}]=.15745 \mathrm{E}-\odot 4$
$\mathrm{kf}[\mathrm{cm} / \mathrm{min}]=.24231 \mathrm{E}-\odot 1$
$\operatorname{Ds}[\mathrm{cm} 2 / \mathrm{min}]=.0 \odot \odot \odot \odot \mathrm{E}+\odot \odot$

Dimensionless Groups:

Sc (i)

Peb(i)

$\mathrm{Bi}$ (i)

$\mathrm{Nf}$ (i)

$\mathrm{Np}$ (i)

$\operatorname{Pep}(i)$

$=\quad .16539 \mathrm{E}+\odot \odot$

$.90211 \mathrm{E}+05$

$.15799 \mathrm{E}+04$

$.80281 \mathrm{E}+02$

$53238 \mathrm{E}+02$

$.12488 E+0 \odot$

Isotherm = Freundlich/Langmuir Hybrid

Iso. Const. $1=.11467 \mathrm{E}+00$

Iso. Const. $2=.10000 \mathrm{E}+01$

Iso. Const. $3=.10000 \mathrm{E}+01$

Iso. Const. $4=.10000 \mathrm{E}+01$

Iso. Const. $5=.12732 \mathrm{E}-02$

Init. Conc. $=.00000 \mathrm{E}+0 \odot$

Conc. at eqb. $=.00000 \mathrm{E}+0 \odot$

Conc. units $M$

COMMAND LIST:

1: Step conc. of component 1 at . . $९ \odot \odot$ Execute 1 times, every .0000 mins.

2: User set viscosity to .2958E-01 poise and density to $1.249 \mathrm{~g} / \mathrm{cm} 3$

3: Carousel (conc.). Active between $t=.0000$ and .1000E+07 min. When comp. 1 reaches .3700E-07 M at end of node 100, shift 50 axial elements out the feed end

4: Monitor conc. history at stream $\odot$. Filename $=$ case 11. h $\odot 1$ Output density adjustments: 2.0 *default abs conc delta, $50 . \quad$ default rel conc delta, .40E-03* default force w/ conc delta, .16E-01*default force w/o conc delta

5: Monitor conc. history at stream 2. Filename $=$ case $11 . h \odot 2$ Output density adjustments:

2.0 *default abs conc delta, 50. default rel conc delta, .40E-03*default force w/ conc delta, .16E-01*default force w/o conc delta

6: Monitor conc. history at stream 4. Filename $=$ case $11 . h 03$ Output density adjustments: 2.0 *default abs conc delta, $50 . \quad$ default rel conc delta, 40E-03*default force w/ conc delta, .16E-01*default force w/o conc delta

7: Monitor conc. history at stream 6. Filename $=$ case 11. h $\odot 4$ output density adjustments:

2.0 *default abs conc delta, $50 . \quad$ default rel conc delta . 40E- $03^{*}$ default force w/ conc delta, .16E-01*default force w/o conc delta

Conc. Carousel caused bed shift at $t=726.9 \mathrm{~min}$

Conc. Carousel caused bed shift at $t=1403$. min

Conc. Carousel caused bed shift at $t=2081$. $\mathrm{min}$

Conc. Carousel caused bed shift at $t=2759$. min

Conc. Carousel caused bed shift at $t=3436$. min

Conc. Carousel caused bed shift at $t=4114$. $\mathrm{min}$

Conc. Carousel caused bed shift at $t=4792$. min

Conc. Carousel caused bed shift at $t=5470 . \quad \min$

Conc. Carousel caused bed shift at $t=6148$. min

Conc. Carousel caused bed shift at $t=6826 . \quad \mathrm{min}$

Conc. Carousel caused bed shift at $t=7504$. min

Conc. Carousel caused bed shift at $t=8181$. min

Conc. Carousel caused bed shift at $t=8859$. min

Conc. Carousel caused bed shift at $t=9537$. min

Conc. Carousel caused bed shift at $t=.1022 \mathrm{E}+05 \mathrm{~min}$

Conc. Carousel caused bed shift at $t=.1089 \mathrm{E}+05 \mathrm{~min}$

Conc. Carousel caused bed shift at $t=.1157 \mathrm{E}+05 \mathrm{~min}$

Conc. Carousel caused bed shift at $t=.1225 \mathrm{E}+05 \mathrm{~min}$

Conc. Carousel caused bed shift at $t=.1293 E+05 \mathrm{~min}$

Conc. Carousel caused bed shift at $t=.1360 E+05 \mathrm{~min}$

Conc. Carousel caused bed shift at $t=.1428 E+05 \mathrm{~min}$

Conc. Carousel caused bed shift at $t=.1496 \mathrm{E}+05 \mathrm{~min}$

Conc. Carousel caused bed shift at $t=.1564 \mathrm{E}+05 \mathrm{~min}$

Conc. Carousel caused bed shift at $t=.1632 \mathrm{E}+05 \mathrm{~min}$

Conc. Carousel caused bed shift at $t=.1699 \mathrm{E}+05 \mathrm{~min}$

Conc. Carousel caused bed shift at $t=.1767 \mathrm{E}+05 \mathrm{~min}$

Conc. Carousel caused bed shift at $t=.1835 \mathrm{E}+05 \mathrm{~min}$

Conc. Carousel caused bed shift at $t=.1903 E+05 \mathrm{~min}$ 
WSRC-TR-2004-00100, REVISION 0

SRT-RPP-2004-00019, REVISION 0

Conc. Carousel caused bed shift at $t=.1970 \mathrm{E}+05 \mathrm{~min}$

Conc. Carousel caused bed shift at $t=.2038 \mathrm{E}+05 \mathrm{~min}$

Conc. Carousel caused bed shift at $t=.2106 \mathrm{E}+05 \mathrm{~min}$

Conc. Carousel caused bed shift at $t=.2174 \mathrm{E}+05 \mathrm{~min}$

Conc. Carousel caused bed shift at $t=.2242 \mathrm{E}+05 \mathrm{~min}$

Conc. Carousel caused bed shift at $t=.2309 \mathrm{E}+05 \mathrm{~min}$

Conc. Carousel caused bed shift at $t=.2377 \mathrm{E}+05 \mathrm{~min}$

Conc. Carousel caused bed shift at $t=.2445 \mathrm{E}+05 \mathrm{~min}$

Conc. Carousel caused bed shift at $t=.2513 \mathrm{E}+05 \mathrm{~min}$

Conc. Carousel caused bed shift at $t=.2581 \mathrm{E}+05 \mathrm{~min}$

Conc. Carousel caused bed shift at $t=.2648 \mathrm{E}+05 \mathrm{~min}$

Conc. Carousel caused bed shift at $\mathrm{t}=.2716 \mathrm{E}+05 \mathrm{~min}$

Conc. Carousel caused bed shift at $t=.2784 \mathrm{E}+05 \mathrm{~min}$

Conc. Carousel caused bed shift at $t=.2852 \mathrm{E}+05 \mathrm{~min}$

Conc. Carousel caused bed shift at $t=.2919 \mathrm{E}+05 \mathrm{~min}$

Conc. Carousel caused bed shift at $t=.2987 \mathrm{E}+05 \mathrm{~min}$

Conc. Carousel caused bed shift at $t=.3055 \mathrm{E}+05 \mathrm{~min}$

Conc. Carousel caused bed shift at $t=.3123 \mathrm{E}+05 \mathrm{~min}$

Conc. Carousel caused bed shift at $t=.3191 \mathrm{E}+05 \mathrm{~min}$

Conc. Carousel caused bed shift at $t=.3258 \mathrm{E}+05 \mathrm{~min}$

Conc. Carousel caused bed shift at $t=.3326 \mathrm{E}+05 \mathrm{~min}$

Conc. Carousel caused bed shift at $t=.3394 \mathrm{E}+05 \mathrm{~min}$

Conc. Carousel caused bed shift at $t=.3462 \mathrm{E}+05 \mathrm{~min}$

Conc. Carousel caused bed shift at $t=.3530 \mathrm{E}+05 \mathrm{~min}$

Conc. Carousel caused bed shift at $t=.3597 \mathrm{E}+05 \mathrm{~min}$

Conc. Carousel caused bed shift at $t=.3665 \mathrm{E}+05 \mathrm{~min}$

Conc. Carousel caused bed shift at $t=.3733 \mathrm{E}+05 \mathrm{~min}$

Conc. Carousel caused bed shift at $t=.3801 E+05$ min

Conc. Carousel caused bed shift at $t=.3868 \mathrm{E}+05 \mathrm{~min}$

Conc. Carousel caused bed shift at $t=.3936 \mathrm{E}+05 \mathrm{~min}$

Conc. Carousel caused bed shift at $t=.4004 \mathrm{E}+05 \mathrm{~min}$

Conc. Carousel caused bed shift at $t=.4072 \mathrm{E}+05 \mathrm{~min}$

Conc. Carousel caused bed shift at $t=.4140 \mathrm{E}+05 \mathrm{~min}$

Conc. Carousel caused bed shift at $t=.4207 \mathrm{E}+05 \mathrm{~min}$

Conc. Carousel caused bed shift at $t=.4275 \mathrm{E}+05 \mathrm{~min}$

Conc. Carousel caused bed shift at $t=.4343 \mathrm{E}+05 \mathrm{~min}$

Conc. Carousel caused bed shift at $t=.4411 \mathrm{E}+05 \mathrm{~min}$

Conc. Carousel caused bed shift at $t=.4479 \mathrm{E}+05 \mathrm{~min}$

Conc. Carousel caused bed shift at $t=.4546 \mathrm{E}+05 \mathrm{~min}$

Conc. Carousel caused bed shift at $\mathrm{t}=.4614 \mathrm{E}+05 \mathrm{~min}$

Conc. Carousel caused bed shift at $t=.4682 \mathrm{E}+05 \mathrm{~min}$

Conc. Carousel caused bed shift at $t=.4750 E+05 \mathrm{~min}$

Conc. Carousel caused bed shift at $t=.4817 \mathrm{E}+05 \mathrm{~min}$

Conc. Carousel caused bed shift at $t=.4885 \mathrm{E}+05 \mathrm{~min}$

Conc. Carousel caused bed shift at $t=.4953 \mathrm{E}+05 \mathrm{~min}$

Conc. Carousel caused bed shift at $t=.5021 \mathrm{E}+05 \mathrm{~min}$

Conc. Carousel caused bed shift at $t=.5089 \mathrm{E}+05 \mathrm{~min}$

Conc. Carousel caused bed shift at $t=.5156 \mathrm{E}+05 \mathrm{~min}$

Conc. Carousel caused bed shift at $t=.5224 \mathrm{E}+05 \mathrm{~min}$

Conc. Carousel caused bed shift at $t=.5292 \mathrm{E}+05 \mathrm{~min}$

Conc. Carousel caused bed shift at $t=.5360 \mathrm{E}+05 \mathrm{~min}$

Conc. Carousel caused bed shift at $t=.5428 \mathrm{E}+05 \mathrm{~min}$

Conc. Carousel caused bed shift at $t=.5495 \mathrm{E}+05 \mathrm{~min}$

Conc. Carousel caused bed shift at $t=.5563 \mathrm{E}+05 \mathrm{~min}$

Conc. Carousel caused bed shift at $t=.5631 \mathrm{E}+05 \mathrm{~min}$

Conc. Carousel caused bed shift at $t=.5699 \mathrm{E}+05 \mathrm{~min}$

Conc. Carousel caused bed shift at $t=.5766 \mathrm{E}+05 \mathrm{~min}$

Conc. Carousel caused bed shift at $t=.5834 \mathrm{E}+05 \mathrm{~min}$

Conc. Carousel caused bed shift at $t=.5902 \mathrm{E}+05 \mathrm{~min}$

Conc. Carousel caused bed shift at $t=.5970 E+05 \mathrm{~min}$

Conc. Carousel caused bed shift at $t=.6038 \mathrm{E}+05 \mathrm{~min}$

Conc. Carousel caused bed shift at $t=.6105 \mathrm{E}+05 \mathrm{~min}$

Conc. Carousel caused bed shift at $t=.6173 \mathrm{E}+05 \mathrm{~min}$

Conc. Carousel caused bed shift at $t=.6241 \mathrm{E}+05 \mathrm{~min}$

Conc. Carousel caused bed shift at $t=.6309 \mathrm{E}+05 \mathrm{~min}$

Conc. Carousel caused bed shift at $t=.6377 \mathrm{E}+05 \mathrm{~min}$

Conc. Carousel caused bed shift at $t=.6444 \mathrm{E}+05 \mathrm{~min}$

Conc. Carousel caused bed shift at $t=.6512 \mathrm{E}+05 \mathrm{~min}$

Conc. Carousel caused bed shift at $t=.6580 \mathrm{E}+05 \mathrm{~min}$

Conc. Carousel caused bed shift at $t=.6648 \mathrm{E}+05 \mathrm{~min}$

Conc. Carousel caused bed shift at $t=.6715 \mathrm{E}+05 \mathrm{~min}$

Conc. Carousel caused bed shift at $t=.6783 \mathrm{E}+05 \mathrm{~min}$

Conc. Carousel caused bed shift at $t=.6851 \mathrm{E}+05 \mathrm{~min}$

Conc. Carousel caused bed shift at $t=.6919 E+05 \mathrm{~min}$

Conc. Carousel caused bed shift at $t=.6987 \mathrm{E}+05 \mathrm{~min}$ 
WSRC-TR-2004-00100, REVISION 0

SRT-RPP-2004-00019, REVISION 0

Conc. Carousel caused bed shift at $t=.7054 \mathrm{E}+05 \mathrm{~min}$

Conc. Carousel caused bed shift at $t=.7122 \mathrm{E}+05 \mathrm{~min}$

Conc. Carousel caused bed shift at $t=.7190 \mathrm{E}+05 \mathrm{~min}$

Conc. Carousel caused bed shift at $t=.7258 \mathrm{E}+05 \mathrm{~min}$

Conc. Carousel caused bed shift at $t=.7326 \mathrm{E}+05 \mathrm{~min}$

Conc. Carousel caused bed shift at $t=.7393 \mathrm{E}+05 \mathrm{~min}$

Conc. Carousel caused bed shift at $t=.7461 \mathrm{E}+05 \mathrm{~min}$

Conc. Carousel caused bed shift at $t=.7529 \mathrm{E}+05 \mathrm{~min}$

Conc. Carousel caused bed shift at $t=.7597 \mathrm{E}+05 \mathrm{~min}$

Conc. Carousel caused bed shift at $t=.7664 \mathrm{E}+05 \mathrm{~min}$

Conc. Carousel caused bed shift at $t=.7732 \mathrm{E}+05 \mathrm{~min}$

Conc. Carousel caused bed shift at $\mathrm{t}=.7800 \mathrm{E}+05 \mathrm{~min}$

Conc. Carousel caused bed shift at $t=.7868 \mathrm{E}+05 \mathrm{~min}$

Conc. Carousel caused bed shift at $t=.7936 \mathrm{E}+05 \mathrm{~min}$

Conc. Carousel caused bed shift at $t=.8003 \mathrm{E}+05 \mathrm{~min}$

Conc. Carousel caused bed shift at $\mathrm{t}=.8071 \mathrm{E}+05 \mathrm{~min}$

Conc. Carousel caused bed shift at $t=.8139 \mathrm{E}+05 \mathrm{~min}$

Conc. Carousel caused bed shift at $t=.8207 \mathrm{E}+05 \mathrm{~min}$

Conc. Carousel caused bed shift at $t=.8275 \mathrm{E}+05 \mathrm{~min}$

Conc. Carousel caused bed shift at $t=.8342 \mathrm{E}+05 \mathrm{~min}$

Conc. Carousel caused bed shift at $t=.8410 \mathrm{E}+05 \mathrm{~min}$

Conc. Carousel caused bed shift at $t=.8478 \mathrm{E}+05 \mathrm{~min}$

Conc. Carousel caused bed shift at $t=.8546 \mathrm{E}+05 \mathrm{~min}$

Conc. Carousel caused bed shift at $t=.8613 \mathrm{E}+05 \mathrm{~min}$

Conc. Carousel caused bed shift at $t=.8681 \mathrm{E}+05 \mathrm{~min}$

Conc. Carousel caused bed shift at $t=.8749 \mathrm{E}+05 \mathrm{~min}$

Conc. Carousel caused bed shift at $t=.8817 \mathrm{E}+05 \mathrm{~min}$

Conc. Carousel caused bed shift at $t=.8885 \mathrm{E}+05 \mathrm{~min}$

Conc. Carousel caused bed shift at $t=.8952 \mathrm{E}+05 \mathrm{~min}$

Conc. Carousel caused bed shift at $t=.9020 \mathrm{E}+05 \mathrm{~min}$

Conc. Carousel caused bed shift at $t=.9088 \mathrm{E}+05 \mathrm{~min}$

Conc. Carousel caused bed shift at $t=.9156 \mathrm{E}+05 \mathrm{~min}$

Conc. Carousel caused bed shift at $t=.9224 \mathrm{E}+05 \mathrm{~min}$

Conc. Carousel caused bed shift at $t=.9291 \mathrm{E}+05 \mathrm{~min}$

Conc. Carousel caused bed shift at $t=.9359 \mathrm{E}+05 \mathrm{~min}$

Conc. Carousel caused bed shift at $t=.9427 \mathrm{E}+05 \mathrm{~min}$

Conc. Carousel caused bed shift at $t=.9495 \mathrm{E}+05 \mathrm{~min}$

Conc. Carousel caused bed shift at $t=.9562 \mathrm{E}+05 \mathrm{~min}$

Conc. Carousel caused bed shift at $t=.9630 \mathrm{E}+05 \mathrm{~min}$

Conc. Carousel caused bed shift at $\mathrm{t}=.9698 \mathrm{E}+05 \mathrm{~min}$

Conc. Carousel caused bed shift at $t=.9766 \mathrm{E}+05 \mathrm{~min}$

Conc. Carousel caused bed shift at $t=.9834 \mathrm{E}+05 \mathrm{~min}$

Conc. Carousel caused bed shift at $t=.9901 \mathrm{E}+05 \mathrm{~min}$

Conc. Carousel caused bed shift at $t=.9969 \mathrm{E}+05 \mathrm{~min}$

Conc. Carousel caused bed shift at $\mathrm{t}=.1004 \mathrm{E}+06 \mathrm{~min}$

Conc. Carousel caused bed shift at $t=.1010 \mathrm{E}+06 \mathrm{~min}$

Conc. Carousel caused bed shift at $t=.1017 \mathrm{E}+06 \mathrm{~min}$

Conc. Carousel caused bed shift at $t=.1024 \mathrm{E}+06 \mathrm{~min}$

Conc. Carousel caused bed shift at $t=.1031 \mathrm{E}+06 \mathrm{~min}$

Conc. Carousel caused bed shift at $t=.1038 \mathrm{E}+06 \mathrm{~min}$

Conc. Carousel caused bed shift at $t=.1044 \mathrm{E}+06 \mathrm{~min}$

Conc. Carousel caused bed shift at $t=.1051 \mathrm{E}+06 \mathrm{~min}$

Conc. Carousel caused bed shift at $t=.1058 \mathrm{E}+06 \mathrm{~min}$

Conc. Carousel caused bed shift at $t=.1065 \mathrm{E}+06 \mathrm{~min}$

Conc. Carousel caused bed shift at $t=.1071 \mathrm{E}+06 \mathrm{~min}$

Conc. Carousel caused bed shift at $t=.1078 \mathrm{E}+06 \mathrm{~min}$

Conc. Carousel caused bed shift at $t=.1085 \mathrm{E}+06 \mathrm{~min}$

Conc. Carousel caused bed shift at $t=.1092 \mathrm{E}+06 \mathrm{~min}$

Conc. Carousel caused bed shift at $t=.1099 \mathrm{E}+06 \mathrm{~min}$

Conc. Carousel caused bed shift at $t=.1105 \mathrm{E}+06 \mathrm{~min}$

Conc. Carousel caused bed shift at $t=.1112 \mathrm{E}+06 \mathrm{~min}$

Conc. Carousel caused bed shift at $t=.1119 \mathrm{E}+06 \mathrm{~min}$

Conc. Carousel caused bed shift at $t=.1126 \mathrm{E}+06 \mathrm{~min}$

Conc. Carousel caused bed shift at $t=.1132 \mathrm{E}+06 \mathrm{~min}$

Conc. Carousel caused bed shift at $t=.1139 \mathrm{E}+06 \mathrm{~min}$

Conc. Carousel caused bed shift at $t=.1146 \mathrm{E}+06 \mathrm{~min}$

Conc. Carousel caused bed shift at $t=.1153 \mathrm{E}+06 \mathrm{~min}$

Conc. Carousel caused bed shift at $t=.1159 \mathrm{E}+06 \mathrm{~min}$

Conc. Carousel caused bed shift at $t=.1166 \mathrm{E}+06 \mathrm{~min}$

Conc. Carousel caused bed shift at $t=.1173 \mathrm{E}+06 \mathrm{~min}$

Conc. Carousel caused bed shift at $t=.1180 \mathrm{E}+06 \mathrm{~min}$

Conc. Carousel caused bed shift at $t=.1186 \mathrm{E}+06 \mathrm{~min}$

Conc. Carousel caused bed shift at $t=.1193 \mathrm{E}+06 \mathrm{~min}$

Conc. Carousel caused bed shift at $t=.1200 \mathrm{E}+06 \mathrm{~min}$

VERSE-LC finished in 47650 steps. Average step size 2.518 minutes 
WSRC-TR-2004-00100, REVISION 0

SRT-RPP-2004-00019, REVISION 0

End run: 11:05:59 on $04-30-2004$

Integrated Areas in History Files:

case11.h01 3.28800

case11.h०2 $\quad .127554$

case11.h03 .880390E-03

case11.h०4 .329653E-05

\section{B.12 Hot Commissioning Operations $\left(\left[\mathrm{Na}^{+}\right]-20 \%\right)$}

\section{B.12.1 VERSE-LC Datafile}

RF 3-column carousel, single component Cs isotherm, criterion: lag

LAW feed: Hot Commissioning, CT: Degraded, Sensitivity: $0.8^{*}[\mathrm{Na}+]$

$1,150,4,6$

FCWNA

NNNNN

$M$ ncomp, nelem, ncol-bed, ncol-part

isotherm, axial-disp, film-coef, surf-diff,BC-col

input-only, perfusable, feed-equil, datafile.yio comp-conc units

403.86, 121.92, 56781.2, 2214466. Length $(\mathrm{cm}), \operatorname{Diam}(\mathrm{cm}), \mathrm{Q}-\mathrm{flow}(\mathrm{ml} / \mathrm{min}), \mathrm{CSTR}-\operatorname{vol}(\mathrm{ml})$

241.5, $0.361,0.6944,0.0$ part-rad(um), bed-void, part-void, sorb-cap ()

0.0

initial concentration (M)

COMMAND - conc step change

S $, 0.0,2.7400 \mathrm{~d}-5,1,0.0$

spec id, time(min), conc(M), freq, dt(min)

$0.021256,1.1750$

$5 \odot, 100, \odot, 1,3.70 \mathrm{~d}-8,0 . \odot, 1.0 \mathrm{~d}+6$

COMMAND - viscosity/density change

fluid viscosity(poise), density $\left(\mathrm{g} / \mathrm{cm}^{\wedge} 3\right)$

$0,2.0,50,4.033 d-4,0.016$

$\mathrm{h}$

$2,2.0,50,4.033 d-4,0.016$

$\mathrm{h}$

$4,2.0,50,4.033 d-4,0.016$

$6,2.0,50,4.033 d-4,0.016$

$120000.0,1.0$

$1.0 \mathrm{~d}-7,1.0 \mathrm{~d}-4$ COMMAND - subcolumns

elem-shift, elem-watch, pp-watch, c-watch, c-thresh, t-e,t-ee COMMAND - effluent history dump

unit op\#, ptscale(1-4) filtering

COMMAND - effluent history dump

unit op\#, ptscale(1-4) filtering

COMMAND - effluent history dump

unit op\#, ptscale(1-4) filtering

COMMAND - effluent history dump

end of commands

unit op\#, ptscale(1-4) filtering

end time(min), max $d t$ in B.V.s

abs-tol, rel-tol

non-negative conc constraint

size exclusion factor

part-pore diffusivities $\left(\mathrm{cm}^{\wedge} 2 / \mathrm{min}\right)$

Brownian diffusivities $\left(\mathrm{cm}^{\wedge} 2 / \mathrm{min}\right)$

4. $2156 \mathrm{~d}-4$

$6.3234 d-4$

$1.1467 \mathrm{~d}-1$

1.0

Freundlich/Langmuir Hybrid a (moles/L B.V.)

1.0

1.0

Freundlich/Langmuir Hybrid b (1/M)

Freundlich/Langmuir Hybrid Ma (-)

Freundlich/Langmuir Hybrid Mb (-)

$9.9764 d-4$

Freundlich/Langmuir Hybrid beta (-)

\section{B.12.2 VERSE-LC Datafile.run}

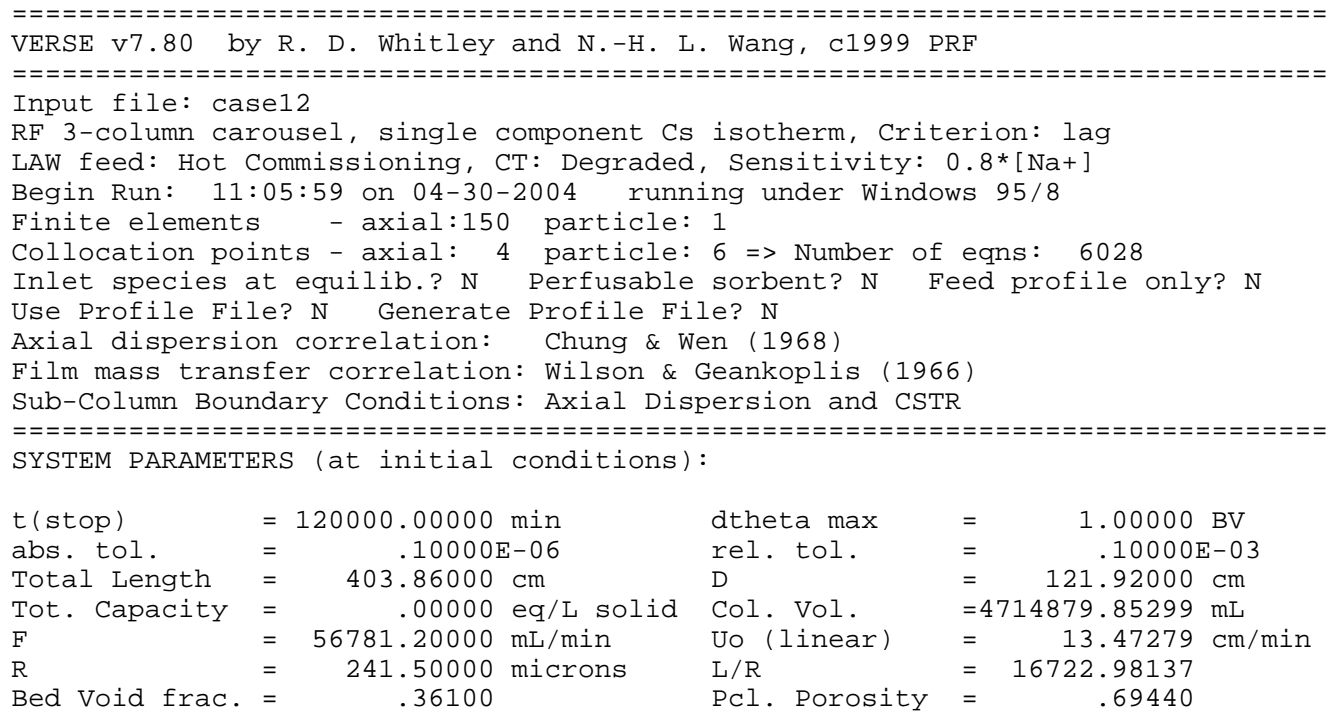


WSRC-TR-2004-00100, REVISION 0

SRT-RPP-2004-00019, REVISION 0

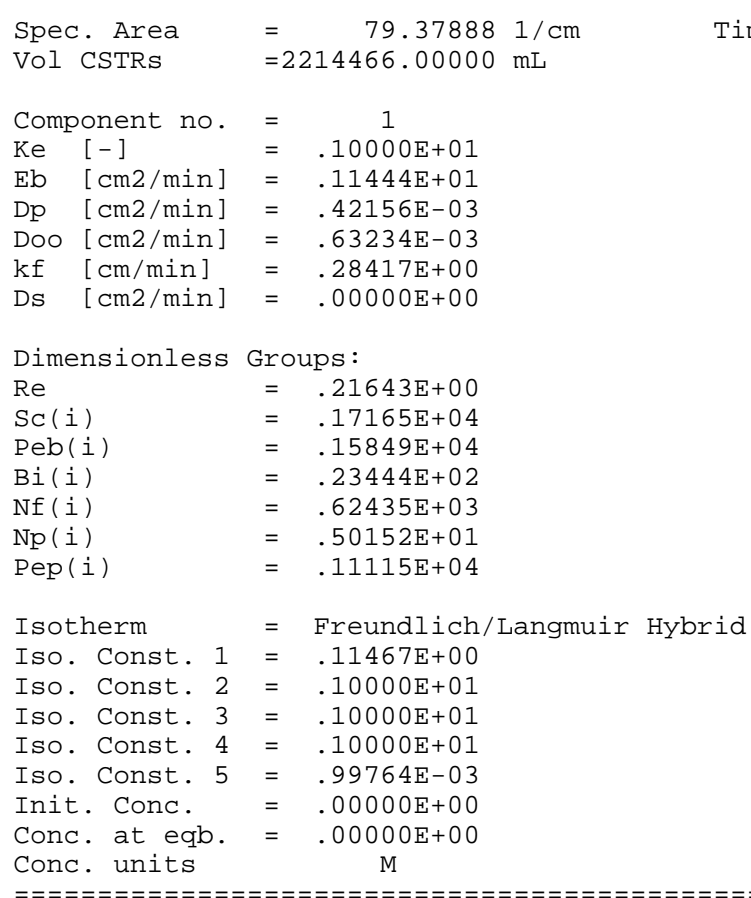

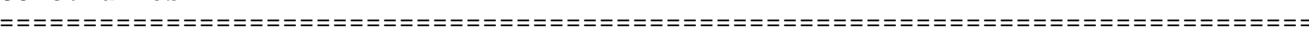

COMMAND LIST:

1: Step conc. of component 1 at . $000 \odot$ min to .2740E-๑4 M

Execute 1 times, every .0000 mins.

2: User set viscosity to .2126E-01 poise and density to $1.175 \mathrm{~g} / \mathrm{cm} 3$

3: Carousel (conc.). Active between $t=.0000$ and $.1000 \mathrm{E}+07 \mathrm{~min}$. When comp. 1 reaches .3700E-07 M at end of node 100, shift 50 axial elements out the feed end

4: Monitor conc. history at stream $\odot$. Filename $=$ case12.h 01 Output density adjustments:

$2.0{ }^{*}$ default abs conc delta, $50 .{ }^{*}$ default rel conc delta, .40E-03*default force $\mathrm{W} /$ conc delta, .16E-01*default force W/o conc delta

5: Monitor conc. history at stream 2. Filename $=$ case12.hO2 Output density adjustments: 2.0 *default abs conc delta, 50. *default rel conc delta, .40E-03*default force $\mathrm{W} / \mathrm{conc}$ delta, .16E-01*default force $\mathrm{W} / \mathrm{o}$ conc delta

6: Monitor conc. history at stream 4. Filename $=$ case12.h०3 Output density adjustments:

2.0 *default abs conc delta, $50 .{ }^{*}$ default rel conc delta, .40E-03*default force W/ conc delta, .16E-01*default force W/o conc delta

7: Monitor conc. history at stream 6. Filename $=$ case12.ho4 Output density adjustments: 2.0 *default abs conc delta, 50. *default rel conc delta, . 40E-03*default force $\mathrm{W} / \mathrm{conc}$ delta, .16E-01*default force w/o conc delta

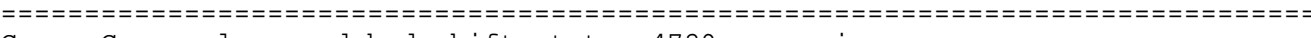

Conc. Carousel caused bed shift at $t=4729 . \quad \min$

Conc. Carousel caused bed shift at $t=7524$ min

Conc. Carousel caused bed shift at $t=.1040 \mathrm{E}+05 \mathrm{~min}$

Conc. Carousel caused bed shift at $t=.1331 \mathrm{E}+05 \mathrm{~min}$

Conc. Carousel caused bed shift at $t=.1625 \mathrm{E}+05 \mathrm{~min}$

Conc. Carousel caused bed shift at $t=.1921 \mathrm{E}+05 \mathrm{~min}$

Conc. Carousel caused bed shift at $t=.2219 \mathrm{E}+05 \mathrm{~min}$

Conc. Carousel caused bed shift at $t=.2518 \mathrm{E}+05 \mathrm{~min}$

Conc. Carousel caused bed shift at $t=.2820 \mathrm{E}+05 \mathrm{~min}$

Conc. Carousel caused bed shift at $t=.3122 \mathrm{E}+05 \mathrm{~min}$

Conc. Carousel caused bed shift at $t=.3424 \mathrm{E}+05 \mathrm{~min}$

Conc. Carousel caused bed shift at $t=.3727 \mathrm{E}+05 \mathrm{~min}$

Conc. Carousel caused bed shift at $t=.4031 \mathrm{E}+05 \mathrm{~min}$

Conc. Carousel caused bed shift at $t=.4334 \mathrm{E}+05 \mathrm{~min}$

Conc. Carousel caused bed shift at $t=.4638 \mathrm{E}+05 \mathrm{~min}$

Conc. Carousel caused bed shift at $t=.4944 \mathrm{E}+05 \mathrm{~min}$

Conc. Carousel caused bed shift at $t=.5248 \mathrm{E}+05 \mathrm{~min}$

Conc. Carousel caused bed shift at $t=.5552 \mathrm{E}+05 \mathrm{~min}$

Conc. Carousel caused bed shift at $t=.5856 \mathrm{E}+05 \mathrm{~min}$

Conc. Carousel caused bed shift at $t=.6160 \mathrm{E}+05 \mathrm{~min}$

Conc. Carousel caused bed shift at $t=.6464 \mathrm{E}+05 \mathrm{~min}$ 
WSRC-TR-2004-00100, REVISION 0

SRT-RPP-2004-00019, REVISION 0

Conc. Carousel caused bed shift at $t=.6768 \mathrm{E}+05 \mathrm{~min}$

Conc. Carousel caused bed shift at $t=.7072 \mathrm{E}+05 \mathrm{~min}$

Conc. Carousel caused bed shift at $t=.7377 \mathrm{E}+05 \mathrm{~min}$

Conc. Carousel caused bed shift at $\mathrm{t}=.7681 \mathrm{E}+05 \mathrm{~min}$

Conc. Carousel caused bed shift at $t=.7985 \mathrm{E}+05 \mathrm{~min}$

Conc. Carousel caused bed shift at $t=.8289 \mathrm{E}+05 \mathrm{~min}$

Conc. Carousel caused bed shift at $t=.8593 \mathrm{E}+05 \mathrm{~min}$

Conc. Carousel caused bed shift at $\mathrm{t}=.8897 \mathrm{E}+05 \mathrm{~min}$

Conc. Carousel caused bed shift at $t=.9201 \mathrm{E}+05 \mathrm{~min}$

Conc. Carousel caused bed shift at $t=.9505 \mathrm{E}+05 \mathrm{~min}$

Conc. Carousel caused bed shift at $t=.9810 \mathrm{E}+05 \mathrm{~min}$

Conc. Carousel caused bed shift at $t=.1011 \mathrm{E}+06 \mathrm{~min}$

Conc. Carousel caused bed shift at $t=.1042 \mathrm{E}+06 \mathrm{~min}$

Conc. Carousel caused bed shift at $t=.1072 \mathrm{E}+06 \mathrm{~min}$

Conc. Carousel caused bed shift at $\mathrm{t}=.1103 \mathrm{E}+06 \mathrm{~min}$

Conc. Carousel caused bed shift at $t=.1133 \mathrm{E}+06 \mathrm{~min}$

Conc. Carousel caused bed shift at $t=.1163 \mathrm{E}+06 \mathrm{~min}$

Conc. Carousel caused bed shift at $\mathrm{t}=.1194 \mathrm{E}+06 \mathrm{~min}$

VERSE-LC finished in 12672 steps. Average step size 9.470 minutes

End run: $11: 38: 15$ on $04-30-2004$

Integrated Areas in History Files:

$\begin{array}{ll}\text { case } 12 . h 01 & 3.28800\end{array}$

case12.h०2 $\quad .504014$

case12.h03 .578420E- 03

case12.h०4 .134116E-06

\section{B.13 Hot Commissioning Operations $\left(\left[\mathrm{OH}^{-}\right]+20 \%\right)$}

\section{B.13.1 VERSE-LC Datafile}

RF 3-column carousel, single component Cs isotherm, criterion: lag

LAW feed: Hot Commissioning, CT: Degraded, Sensitivity: $1.2^{*}[\mathrm{OH}-]$

$1,150,4,6$

FCWNA

NNNNN

ncomp, nelem, ncol-bed, ncol-part

isotherm, axial-disp, film-coef, surf-diff, BC-col

input-only, perfusable, feed-equil, datafile.yio

comp-conc units

403.86, 121.92, 56781.2, 2214466. Length $(\mathrm{cm}), \operatorname{Diam}(\mathrm{cm}), \mathrm{Q}-\mathrm{flow}(\mathrm{ml} / \mathrm{min}), \mathrm{cSTR}-\operatorname{vol}(\mathrm{ml})$

$241.5,0.361,0.6944,0.0 \quad$ part-rad(um), bed-void, part-void, sorb-cap()

$\odot . \odot$

initial concentration (M)

COMMAND - conc step change

$1,0.0,2.7400 \mathrm{~d}-5,1,0.0$

spec id, time(min), conc(M), freq, dt(min)

$\mathrm{V}$

$\odot .025991,1.2090$

$5 \odot, 10 \odot, \odot, 1,3.70 \mathrm{~d}-8,0 . \odot, 1.0 \mathrm{~d}+6$

COMMAND - viscosity/density change

fluid viscosity(poise), density $\left(\mathrm{g} / \mathrm{cm}^{\wedge} 3\right)$ COMMAND - subcolumns

$\mathrm{h}$

$\odot, 2.0,50,4.033 d-4,0.016$

$\mathrm{h}$

$2,2.0,50,4.033 d-4,0.016$

$\mathrm{h}$

$4,2.0,50,4.033 d-4,0.016$

$\mathrm{h}$

$6,2.0,50,4.033 d-4,0.016$

$120000.0,1.0$

$1.0 \mathrm{~d}-7,1.0 \mathrm{~d}-4$

elem-shift, elem-watch, pp-watch, c-watch, c-thresh, t-e,t-ee COMMAND - effluent history dump

unit op\#, ptscale(1-4) filtering

COMMAND - effluent history dump

unit op\#, ptscale(1-4) filtering

COMMAND - effluent history dump

unit op\#, ptscale(1-4) filtering

COMMAND - effluent history dump

end of commands

end time(min), $\max d t$ in B.V.s

abs-tol, rel-tol

non-negative conc constraint

1.0

2. $4465 d-4$

3. $6697 d-4$

1. $1513 d-1$

1.0

1.0

1.0

size exclusion factor

part-pore diffusivities $(\mathrm{cm} \wedge 2 / \mathrm{min})$

Brownian diffusivities ( $\left.\mathrm{cm}^{\wedge} 2 / \mathrm{min}\right)$

Freundlich/Langmuir Hybrid a (moles/L B.V.)

Freundlich/Langmuir Hybrid b (1/M)

Freundlich/Langmuir Hybrid Ma (-)

Freundlich/Langmuir Hybrid Mb (-)

$1.0664 d-3$

Freundlich/Langmuir Hybrid beta (-)

\section{B.13.2 VERSE-LC Datafile.run}

VERSE V7.80 by R. D. Whitley and N.-H. L. Wang, c1999 PRF

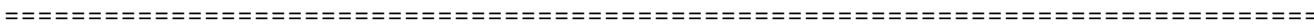

Input file: case13

RF 3-column carousel, single component Cs isotherm, criterion: lag 
LAW feed: Hot Commissioning, CT: Degraded, Sensitivity: $1.2 *[0 \mathrm{OH}-]$

Begin Run: 11:38:15 on 04-30-2004 running under Windows 95/8

Finite elements - axial:150 particle: 1

Collocation points - axial: 4 particle: $6=>$ Number of eqns: 6028

Inlet species at equilib.? $\mathrm{N}$ Perfusable sorbent? $\mathrm{N}$ Feed profile only? $\mathrm{N}$

Use Profile File? N Generate Profile File? N

Axial dispersion correlation: Chung \& Wen (1968)

Film mass transfer correlation: Wilson \& Geankoplis (1966)

Sub-Column Boundary Conditions: Axial Dispersion and CSTR

SYSTEM PARAMETERS (at initial conditions):

$\begin{array}{llr}\mathrm{t}(\mathrm{stop}) & = & \\ \text { abs. tol. } & = & .1000000 \\ \text { Total Length } & = & 403.86000 \\ \text { Tot. Capacity } & = & .00000 \\ \mathrm{~F} & = & 56781.20000 \\ \mathrm{R} & & 241.50000 \\ \text { Bed Void frac. } & = & .36100 \\ \text { Spec. Area } & = & 79.37888 \\ \text { Vol CSTRs } & =2214466.00000 \\ & & \\ \text { Component no. } & = & 1 \\ \mathrm{Ke}[-] & = & .10000 \mathrm{E}+01 \\ \mathrm{~Eb}[\mathrm{~cm} / \mathrm{min}] & = & .11467 \mathrm{E}+01 \\ \mathrm{Dp}[\mathrm{cm} 2 / \mathrm{min}] & = & .24465 \mathrm{E}-03 \\ \mathrm{Doo}[\mathrm{cm} 2 / \mathrm{min}] & = & .36697 \mathrm{E}-03 \\ \mathrm{kf}[\mathrm{cm} / \mathrm{min}] & = & .19771 \mathrm{E}+00 \\ \mathrm{DS}[\mathrm{cm} 2 / \mathrm{min}] & = & .00000 \mathrm{E}+00\end{array}$

Dimensionless Groups:

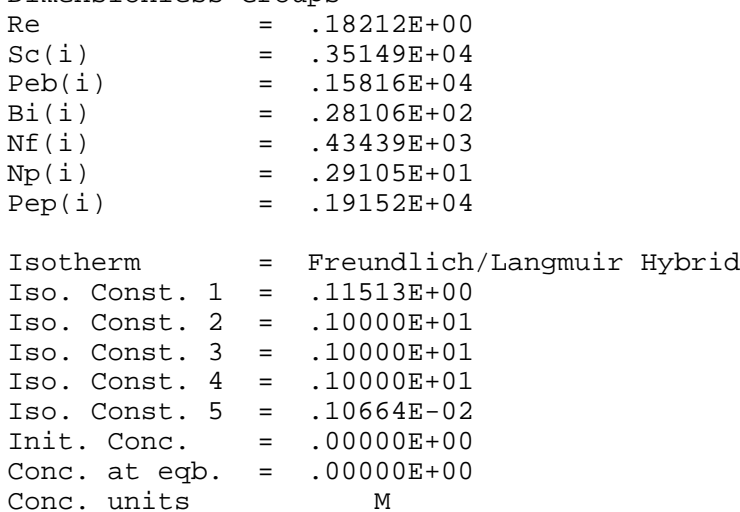

eqb. $=$.00000E+00

Conc. units $M$

COMMAND LIST:

1: Step conc. of component 1 at . $.0 \odot \odot$

Execute 1 times, every .000๑ mins.

2: User set viscosity to .2599E-01 poise and density to $1.209 \mathrm{~g} / \mathrm{cm} 3$

3: Carousel (conc.). Active between $t=.0000$ and $.1000 \mathrm{E}+07 \mathrm{~min}$. When comp. 1 reaches .3700E-07 M at end of node 100, shift 50 axial elements out the feed end

4: Monitor conc. history at stream $\odot$. Filename $=$ case13.h01 Output density adjustments:

2.0 *default abs conc delta, 50. *default rel conc delta, .40E- $03^{*}$ default force $W /$ conc delta, .16E- $01^{*}$ default force $W / o$ conc delta

5: Monitor conc. history at stream 2. Filename $=$ case13.hO2 Output density adjustments:

2. 0 *default abs conc delta, 50. *default rel conc delta, $.40 \mathrm{E}-03^{*}$ default force $\mathrm{W} / \mathrm{conc}$ delta, $.16 \mathrm{E}-01^{*}$ default force $\mathrm{w} / \mathrm{o}$ conc delta

6: Monitor conc. history at stream 4. Filename = case13.h@3 Output density adjustments:

2.0 *default abs conc delta, 50. *default rel conc delta, .40E- $03^{*}$ default force $W /$ conc delta, .16E- 01 *default force $w / 0$ conc delta

7: Monitor conc. history at stream 6. Filename $=$ case13.h०4 Output density adjustments:

2. 0 *default abs conc delta, 50. *default rel conc delta . 40E-03*default force $\mathrm{W} /$ conc delta, .16E-01*default force w/o conc delta

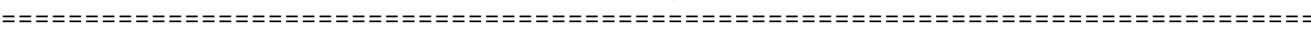

Conc. Carousel caused bed shift at $t=4059 . \quad \min$

Conc. Carousel caused bed shift at $t=6582$ min 
WSRC-TR-2004-00100, REVISION 0

SRT-RPP-2004-00019, REVISION 0

Conc. Carousel caused bed shift at $\mathrm{t}=9188$.

$\min$

Conc. Carousel caused bed shift at $t=.1184 \mathrm{E}+05 \mathrm{~min}$

Conc. Carousel caused bed shift at $t=.1454 \mathrm{E}+05 \mathrm{~min}$

Conc. Carousel caused bed shift at $t=.1726 \mathrm{E}+05 \mathrm{~min}$

Conc. Carousel caused bed shift at $t=.2000 \mathrm{E}+05 \mathrm{~min}$

Conc. Carousel caused bed shift at $\mathrm{t}=.2275 \mathrm{E}+05 \mathrm{~min}$

Conc. Carousel caused bed shift at $t=.2551 \mathrm{E}+05 \mathrm{~min}$

Conc. Carousel caused bed shift at $t=.2828 \mathrm{E}+05 \mathrm{~min}$

Conc. Carousel caused bed shift at $\mathrm{t}=.3104 \mathrm{E}+05 \mathrm{~min}$

Conc. Carousel caused bed shift at $t=.3380 \mathrm{E}+05 \mathrm{~min}$

Conc. Carousel caused bed shift at $t=.3656 \mathrm{E}+05 \mathrm{~min}$

Conc. Carousel caused bed shift at $t=.3932 \mathrm{E}+05 \mathrm{~min}$

Conc. Carousel caused bed shift at $t=.4209 \mathrm{E}+05 \mathrm{~min}$

Conc. Carousel caused bed shift at $t=.4485 \mathrm{E}+05 \mathrm{~min}$

Conc. Carousel caused bed shift at $t=.4761 \mathrm{E}+05 \mathrm{~min}$

Conc. Carousel caused bed shift at $t=.5037 \mathrm{E}+05 \mathrm{~min}$

Conc. Carousel caused bed shift at $t=.5313 \mathrm{E}+05 \mathrm{~min}$

Conc. Carousel caused bed shift at $t=.5589 \mathrm{E}+05 \mathrm{~min}$

Conc. Carousel caused bed shift at $t=.5865 \mathrm{E}+05 \mathrm{~min}$

Conc. Carousel caused bed shift at $t=.6142 \mathrm{E}+05 \mathrm{~min}$

Conc. Carousel caused bed shift at $t=.6418 \mathrm{E}+05 \mathrm{~min}$

Conc. Carousel caused bed shift at $t=.6694 \mathrm{E}+05 \mathrm{~min}$

Conc. Carousel caused bed shift at $t=.6970 \mathrm{E}+05 \mathrm{~min}$

Conc. Carousel caused bed shift at $t=.7246 \mathrm{E}+05 \mathrm{~min}$

Conc. Carousel caused bed shift at $t=.7522 \mathrm{E}+05 \mathrm{~min}$

Conc. Carousel caused bed shift at $t=.7798 \mathrm{E}+05 \mathrm{~min}$

Conc. Carousel caused bed shift at $t=.8075 \mathrm{E}+05 \mathrm{~min}$

Conc. Carousel caused bed shift at $t=.8351 \mathrm{E}+05 \mathrm{~min}$

Conc. Carousel caused bed shift at $t=.8627 \mathrm{E}+05 \mathrm{~min}$

Conc. Carousel caused bed shift at $t=.8903 \mathrm{E}+05 \mathrm{~min}$

Conc. Carousel caused bed shift at $t=.9179 \mathrm{E}+05 \mathrm{~min}$

Conc. Carousel caused bed shift at $t=.9455 \mathrm{E}+05 \mathrm{~min}$

Conc. Carousel caused bed shift at $t=.9732 \mathrm{E}+05 \mathrm{~min}$

Conc. Carousel caused bed shift at $t=.1001 \mathrm{E}+06 \mathrm{~min}$

Conc. Carousel caused bed shift at $\mathrm{t}=.1028 \mathrm{E}+06 \mathrm{~min}$

Conc. Carousel caused bed shift at $\mathrm{t}=.1056 \mathrm{E}+06 \mathrm{~min}$

Conc. Carousel caused bed shift at $\mathrm{t}=.1084 \mathrm{E}+06 \mathrm{~min}$

Conc. Carousel caused bed shift at $t=.1111 \mathrm{E}+06 \mathrm{~min}$

Conc. Carousel caused bed shift at $t=.1139 \mathrm{E}+06 \mathrm{~min}$

Conc. Carousel caused bed shift at $\mathrm{t}=.1166 \mathrm{E}+06 \mathrm{~min}$

Conc. Carousel caused bed shift at $t=.1194 \mathrm{E}+06 \mathrm{~min}$

VERSE-LC finished in 13112 steps. Average step size 9.152 minutes

End run: 12:25:14 on $04-30-2004$

Integrated Areas in History Files:

case13. h01 3.28800

case13.h०2 $\quad .375063$

case13.h०3 .648682E-03

case13. h०4 .343217E- 06

\section{B.14 Hot Commissioning Operations $\left(\left[\mathrm{OH}^{-}\right]-20 \%\right)$}

\section{B.14.1 VERSE-LC Datafile}

RF 3-column carousel, single component Cs isotherm, criterion: lag

LAW feed: Hot Commissioning, CT: Degraded, Sensitivity: $\odot .8^{*}[\mathrm{OH}-]$

$1,150,4,6$

FCWNA

NNNNN

$\mathrm{M}$ ncomp, nelem, ncol-bed, ncol-part isotherm, axial-disp, film-coef, surf-diff,BC-col input-only, perfusable, feed-equil, datafile.yio comp-conc units

403.86, 121.92, 56781.2, 2214466. Length(cm),Diam(cm),Q-flow(ml/min), CSTR-vol $(\mathrm{ml})$

$241.5,0.361,0.6944,0.0$

0.0

$\mathrm{S}$

$1, \odot . \odot, 2.7400 \mathrm{~d}-5,1, \odot . \odot$

part-rad(um), bed-void, part-void, sorb-cap()

initial concentration (M)

COMMAND - conc step change

spec id, time(min), conc(M), freq, dt(min)

COMMAND - viscosity/density change

$0.023995,1.2176$

$\mathrm{m}$

fluid viscosity (poise), density $\left(\mathrm{g} / \mathrm{cm}^{\wedge} 3\right)$

$50,100,0,1,3.70 \mathrm{~d}-8,0.0,1.0 \mathrm{~d}+6$

COMMAND - subcolumns

$\mathrm{h}$

$0,2.0,50,4.033 d-4,0.016$

$\mathrm{h}$

$2,2.0,50,4.033 d-4,0.016$

elem-shift, elem-watch, pp-watch, c-watch, c-thresh, t-e,t-ee COMMAND - effluent history dump

unit op\#, ptscale(1-4) filtering

COMMAND - effluent history dump

unit op\#, ptscale(1-4) filtering

$\mathrm{h}$

COMMAND - effluent history dump 
$4,2.0,5 \odot, 4.033 d-4,0.016$

$6,2 . \odot, 5 \odot, 4.033 d-4,0.016$

$120000.0,1.0$

$1.0 \mathrm{~d}-7,1.0 \mathrm{~d}-4$

1.0

2. $0533 d-4$

3. $0799 d-4$

$1.1397 d-1$

1.0

1.0

1.0

1. $1618 d-3$ unit op\#, ptscale(1-4) filtering

COMMAND - effluent history dump

end of commands

unit op\#, ptscale(1-4) filtering

end time(min), $\max d t$ in B.V.s

abs-tol, rel-tol

non-negative conc constraint

size exclusion factor

part-pore diffusivities ( $\left.\mathrm{cm}^{\wedge} 2 / \mathrm{min}\right)$

Brownian diffusivities ( $\left.\mathrm{cm}^{\wedge} 2 / \mathrm{min}\right)$

Freundlich/Langmuir Hybrid a (moles/L B.V.)

Freundlich/Langmuir Hybrid b (1/M)

Freundlich/Langmuir Hybrid Ma (-)

Freundlich/Langmuir Hybrid Mb (-)

Freundlich/Langmuir Hybrid beta (-)

\section{B.14.2 VERSE-LC Datafile.run}

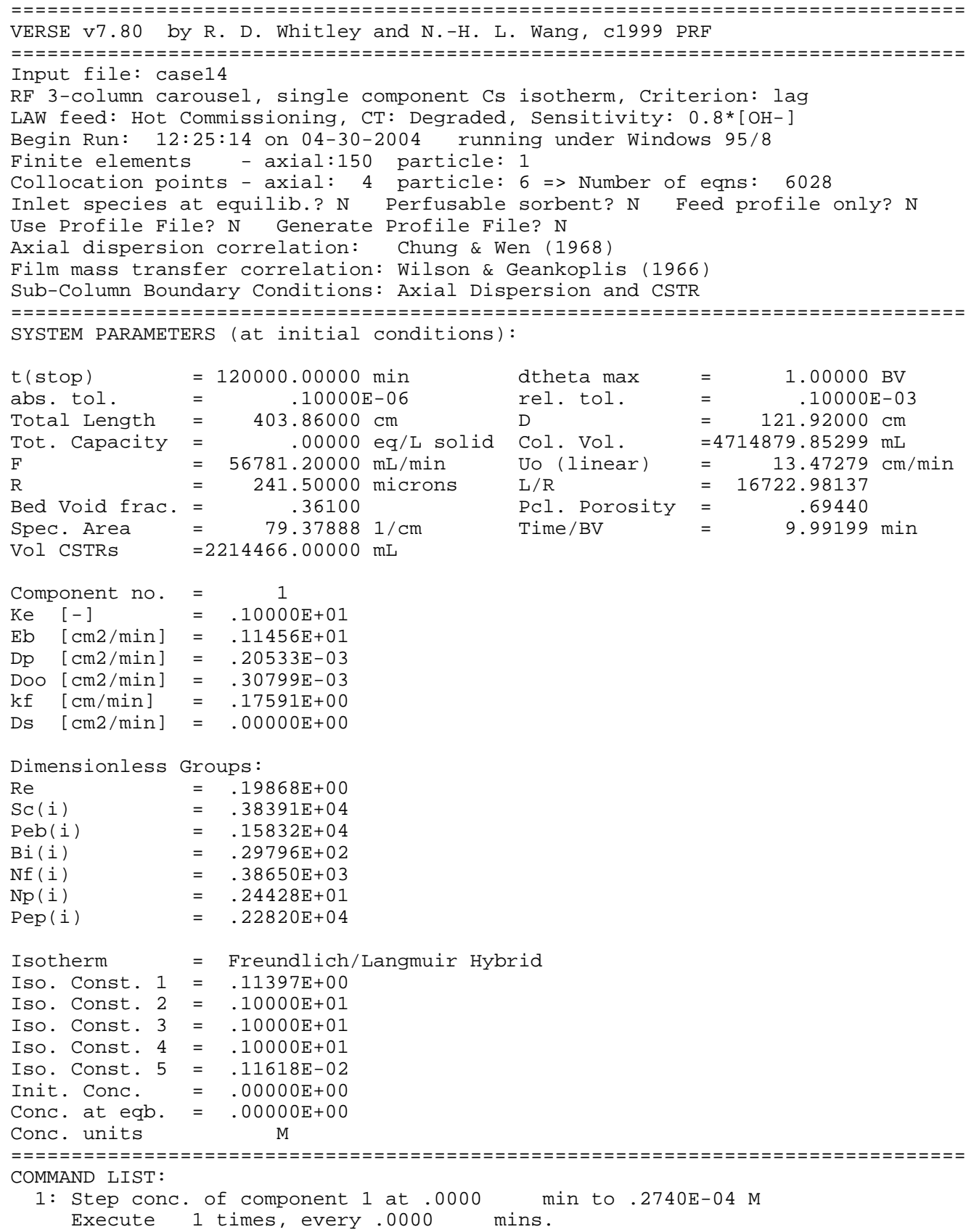


2: User set viscosity to .2399E-01 poise and density to 1.218 $\mathrm{g} / \mathrm{cm} 3$

3: Carousel (conc.). Active between $t=.0000$ and $.1000 \mathrm{E}+07 \mathrm{~min}$. When comp. 1 reaches .3700E-07 M at end of node 100, shift 50 axial elements out the feed end

4: Monitor conc. history at stream $\odot$. Filename $=$ case14.h01 Output density adjustments: 2.0 *default abs conc delta, 50. *default rel conc delta, . 40E- $03^{*}$ default force $\mathrm{W} / \mathrm{conc}$ delta, .16E-01*default force $\mathrm{W} / \mathrm{o}$ conc delta

5: Monitor conc. history at stream 2. Filename = case14.h०2 Output density adjustments: 2.0 *default abs conc delta, 50. *default rel conc delta, $.40 \mathrm{E}-03^{*}$ default force $\mathrm{W} / \mathrm{conc}$ delta, $.16 \mathrm{E}-01^{*}$ default force $\mathrm{W} / \mathrm{o}$ conc delta

6: Monitor conc. history at stream 4. Filename $=$ case14.h03 Output density adjustments: 2.0 *default abs conc delta, 50. *default rel conc delta, . 40E-03*default force $\mathrm{W} /$ conc delta, .16E- $01^{*}$ default force $\mathrm{w} / \mathrm{o}$ conc delta

7: Monitor conc. history at stream 6. Filename = case14.h०4 Output density adjustments:

2.0 *default abs conc delta, 50. *default rel conc delta, .40E- $03^{*}$ default force $\mathrm{W} / \mathrm{conc}$ delta, .16E-01*default force $\mathrm{W} / \mathrm{o}$ conc delta

Conc. Carousel caused bed shift at $\mathrm{t}=3571$. min

Conc. Carousel caused bed shift at $t=5828$ min

Conc. Carousel caused bed shift at $t=8170$. min

Conc. Carousel caused bed shift at $t=.1057 \mathrm{E}+05 \mathrm{~min}$

Conc. Carousel caused bed shift at $t=.1299 \mathrm{E}+05 \mathrm{~min}$

Conc. Carousel caused bed shift at $t=.1545 \mathrm{E}+05 \mathrm{~min}$

Conc. Carousel caused bed shift at $t=.1791 \mathrm{E}+05 \mathrm{~min}$

Conc. Carousel caused bed shift at $t=.2038 \mathrm{E}+05 \mathrm{~min}$

Conc. Carousel caused bed shift at $t=.2287 \mathrm{E}+05 \mathrm{~min}$

Conc. Carousel caused bed shift at $t=.2534 \mathrm{E}+05 \mathrm{~min}$

Conc. Carousel caused bed shift at $t=.2781 \mathrm{E}+05 \mathrm{~min}$

Conc. Carousel caused bed shift at $t=.3030 \mathrm{E}+05 \mathrm{~min}$

Conc. Carousel caused bed shift at $t=.3277 \mathrm{E}+05 \mathrm{~min}$

Conc. Carousel caused bed shift at $t=.3524 \mathrm{E}+05 \mathrm{~min}$

Conc. Carousel caused bed shift at $t=.3772 \mathrm{E}+05 \mathrm{~min}$

Conc. Carousel caused bed shift at $t=.4020 \mathrm{E}+05 \mathrm{~min}$

Conc. Carousel caused bed shift at $t=.4267 \mathrm{E}+05 \mathrm{~min}$

Conc. Carousel caused bed shift at $t=.4515 \mathrm{E}+05 \mathrm{~min}$

Conc. Carousel caused bed shift at $t=.4762 \mathrm{E}+05 \mathrm{~min}$

Conc. Carousel caused bed shift at $t=.5011 \mathrm{E}+05 \mathrm{~min}$

Conc. Carousel caused bed shift at $t=.5258 \mathrm{E}+05 \mathrm{~min}$

Conc. Carousel caused bed shift at $t=.5505 \mathrm{E}+05 \mathrm{~min}$

Conc. Carousel caused bed shift at $t=.5753 \mathrm{E}+05 \mathrm{~min}$

Conc. Carousel caused bed shift at $t=.6001 \mathrm{E}+05 \mathrm{~min}$

Conc. Carousel caused bed shift at $t=.6248 \mathrm{E}+05 \mathrm{~min}$

Conc. Carousel caused bed shift at $t=.6496 \mathrm{E}+05 \mathrm{~min}$

Conc. Carousel caused bed shift at $t=.6743 \mathrm{E}+05 \mathrm{~min}$

Conc. Carousel caused bed shift at $t=.6991 \mathrm{E}+05 \mathrm{~min}$

Conc. Carousel caused bed shift at $\mathrm{t}=.7239 \mathrm{E}+05 \mathrm{~min}$

Conc. Carousel caused bed shift at $t=.7486 \mathrm{E}+05 \mathrm{~min}$

Conc. Carousel caused bed shift at $t=.7734 \mathrm{E}+05 \mathrm{~min}$

Conc. Carousel caused bed shift at $t=.7982 \mathrm{E}+05 \mathrm{~min}$

Conc. Carousel caused bed shift at $t=.8229 \mathrm{E}+05 \mathrm{~min}$

Conc. Carousel caused bed shift at $t=.8477 \mathrm{E}+05 \mathrm{~min}$

Conc. Carousel caused bed shift at $t=.8724 \mathrm{E}+05 \mathrm{~min}$

Conc. Carousel caused bed shift at $t=.8972 \mathrm{E}+05 \mathrm{~min}$

Conc. Carousel caused bed shift at $t=.9220 E+05 \mathrm{~min}$

Conc. Carousel caused bed shift at $t=.9467 \mathrm{E}+05 \mathrm{~min}$

Conc. Carousel caused bed shift at $t=.9714 \mathrm{E}+05 \mathrm{~min}$

Conc. Carousel caused bed shift at $t=.9963 \mathrm{E}+05 \mathrm{~min}$

Conc. Carousel caused bed shift at $t=.1021 \mathrm{E}+06 \mathrm{~min}$

Conc. Carousel caused bed shift at $t=.1046 \mathrm{E}+06 \mathrm{~min}$

Conc. Carousel caused bed shift at $t=.1070 \mathrm{E}+06 \mathrm{~min}$

Conc. Carousel caused bed shift at $t=.1095 \mathrm{E}+06 \mathrm{~min}$

Conc. Carousel caused bed shift at $t=.1120 \mathrm{E}+06 \mathrm{~min}$

Conc. Carousel caused bed shift at $t=.1145 \mathrm{E}+06 \mathrm{~min}$

Conc. Carousel caused bed shift at $t=.1170 \mathrm{E}+06 \mathrm{~min}$

Conc. Carousel caused bed shift at $\mathrm{t}=.1194 \mathrm{E}+06 \mathrm{~min}$

VERSE-LC finished in 13333 steps. Average step size 9.000 minutes

End run: 13:20:15 on $04-30-2004$

Integrated Areas in History Files:

case14.h01 3.28800
2.340567

case14.h०2 $\quad .340567$

case14.h०3 .673294E- 03 
WSRC-TR-2004-00100, REVISION 0

SRT-RPP-2004-00019, REVISION 0

\section{B.15 Hot Commissioning Operations ( $Q=22$ GPM)}

\section{B.15.1 VERSE-LC Datafile}

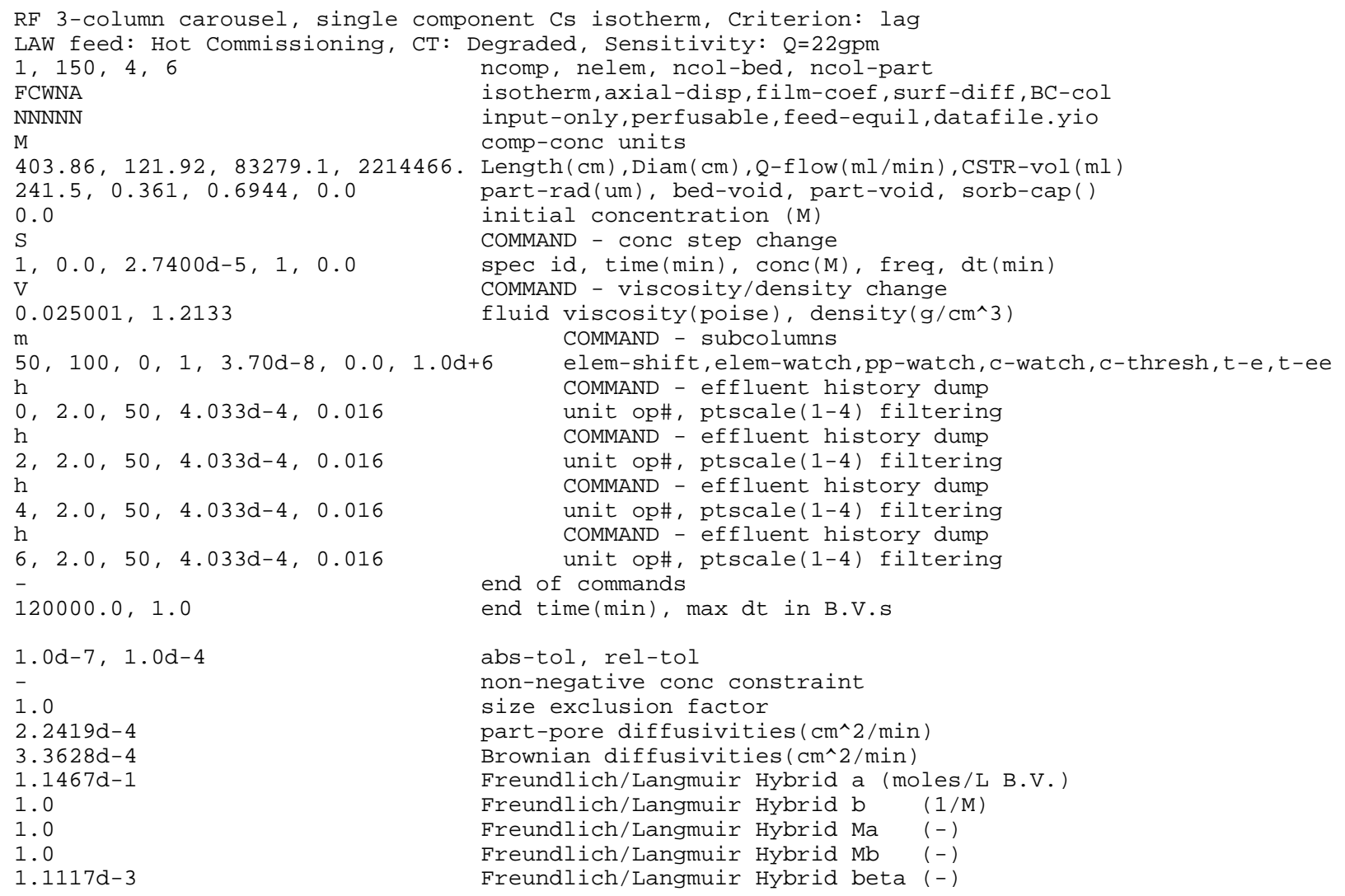

\section{B.15.2 VERSE-LC Datafile.run}

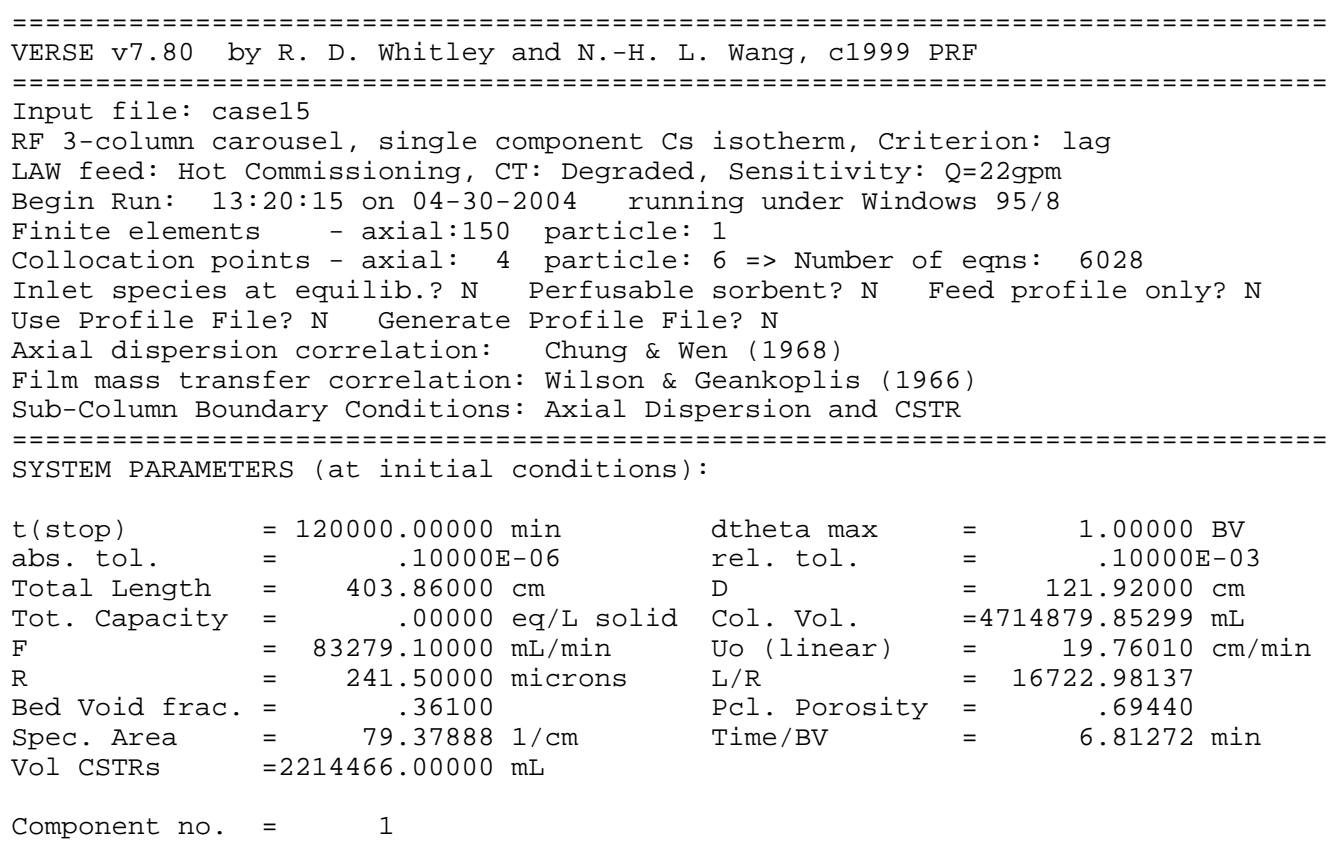


WSRC-TR-2004-00100, REVISION 0

SRT-RPP-2004-00019, REVISION 0

\begin{tabular}{|c|c|c|c|}
\hline $\mathrm{Ke}$ & {$[-]$} & $=$ & $.10000 \mathrm{E}+01$ \\
\hline $\mathrm{Eb}$ & {$[\mathrm{cm} 2 / \mathrm{min}]$} & $=$ & $.16729 \mathrm{E}+01$ \\
\hline & {$[\mathrm{cm} 2 / \mathrm{min}]$} & - & $.22419 E-\odot 3$ \\
\hline Doo & {$[\mathrm{cm} 2 / \mathrm{min}]$} & $=$ & $.33628 \mathrm{E}-\odot 3$ \\
\hline & {$[\mathrm{cm} / \mathrm{min}]$} & $=$ & $.21193 \mathrm{E}+\odot \mathrm{C}$ \\
\hline & $\mathrm{cm} 2 / \mathrm{min}]$ & & $.00000 \mathrm{E}+\mathrm{C}$ \\
\hline
\end{tabular}

Dimensionless Groups:

$\operatorname{Sc}(i)$

$=.27868 \mathrm{E}+\odot \odot$

$\operatorname{Peb}(i)$

$\mathrm{Bi}(\mathrm{i})$

$\mathrm{Nf}(\mathrm{i})$

$\operatorname{Np}(i)$

$.36765 \mathrm{E}+04$

$.15901 \mathrm{E}+04$

$.32876 \mathrm{E}+02$

$.31747 \mathrm{E}+03$

$=\cdot 18185 \mathrm{E}+01$

Isotherm = Freundlich/Langmuir Hybrid

Iso. Const. $1=.11467 \mathrm{E}+00$

Iso. Const. $2=.10000 \mathrm{E}+01$

Iso. Const. $3=.10000 \mathrm{E}+01$

Iso. Const. $4=.10000 \mathrm{E}+01$

Iso. Const. $5=.11117 \mathrm{E}-02$

Init. Conc. $=.00000 \mathrm{E}+00$

Conc. at eqb. $=.00000 \mathrm{E}+\odot \odot$

Conc. units $M$

COMMAND LIST:

1: Step conc. of component 1 at . .0000 min to .2740E-04 M Execute 1 times, every .0000 mins.

2: User set viscosity to .2500E-01 poise and density to $1.213 \mathrm{~g} / \mathrm{cm} 3$

3: Carousel (conc.). Active between $t=.0000$ and $.1000 \mathrm{E}+07 \mathrm{~min}$. When comp. 1 reaches .3700E- $07 \mathrm{M}$ at end of node 100, shift 50 axial elements out the feed end

4: Monitor conc. history at stream $\odot$. Filename $=$ case15.h01 Output density adjustments: 2. 0 *default abs conc delta, 50. *default rel conc delta, $.40 \mathrm{E}-03^{*}$ default force $\mathrm{W} / \mathrm{conc}$ delta, .16E-01*default force $\mathrm{W} / \mathrm{o}$ conc delta

5: Monitor conc. history at stream 2. Filename $=$ case15.h०2 Output density adjustments:

2.0 *default abs conc delta, 50 . default rel conc delta, .40E-03*default force $\mathrm{W} / \mathrm{conc}$ delta, .16E-01*default force $\mathrm{W} / \mathrm{o}$ conc delta

6: Monitor conc. history at stream 4. Filename $=$ case15.h03 Output density adjustments: 2.0 *default abs conc delta, 50. *default rel conc delta, .40E-03*default force $\mathrm{W} / \mathrm{conc}$ delta, .16E-01*default force $\mathrm{w} / \mathrm{o}$ conc delta

7: Monitor conc. history at stream 6. Filename $=$ case15.h $\mathrm{h} 4$ Output density adjustments:

2.0 *default abs conc delta, 50. *default rel conc delta, . $40 \mathrm{E}-03^{*}$ default force $\mathrm{W} / \mathrm{conc}$ delta, .16E- $01^{*}$ default force $\mathrm{W} / \mathrm{o}$ conc delta

Conc. Carousel caused bed shift at $\mathrm{t}=2380$. min

Conc. Carousel caused bed shift at $t=3952$. min

Conc. Carousel caused bed shift at $t=5585$. min

Conc. Carousel caused bed shift at $t=7253$. min

Conc. Carousel caused bed shift at $t=8956$ min

Conc. Carousel caused bed shift at $\mathrm{t}=.1067 \mathrm{E}+05 \mathrm{~min}$

Conc. Carousel caused bed shift at $t=.1238 \mathrm{E}+05 \mathrm{~min}$

Conc. Carousel caused bed shift at $t=.1410 \mathrm{E}+05 \mathrm{~min}$

Conc. Carousel caused bed shift at $t=.1581 \mathrm{E}+05 \mathrm{~min}$

Conc. Carousel caused bed shift at $t=.1752 \mathrm{E}+05 \mathrm{~min}$

Conc. Carousel caused bed shift at $t=.1924 \mathrm{E}+05 \mathrm{~min}$

Conc. Carousel caused bed shift at $t=.2096 \mathrm{E}+05 \mathrm{~min}$

Conc. Carousel caused bed shift at $t=.2267 \mathrm{E}+05 \mathrm{~min}$

Conc. Carousel caused bed shift at $t=.2438 \mathrm{E}+05 \mathrm{~min}$

Conc. Carousel caused bed shift at $t=.2610 \mathrm{E}+05 \mathrm{~min}$

Conc. Carousel caused bed shift at $t=.2782 \mathrm{E}+05 \mathrm{~min}$

Conc. Carousel caused bed shift at $t=.2952 \mathrm{E}+05 \mathrm{~min}$

Conc. Carousel caused bed shift at $t=.3124 \mathrm{E}+05 \mathrm{~min}$

Conc. Carousel caused bed shift at $t=.3296 \mathrm{E}+05 \mathrm{~min}$

Conc. Carousel caused bed shift at $t=.3467 \mathrm{E}+05 \mathrm{~min}$

Conc. Carousel caused bed shift at $t=.3638 \mathrm{E}+05 \mathrm{~min}$

Conc. Carousel caused bed shift at $t=.3810 \mathrm{E}+05 \mathrm{~min}$

Conc. Carousel caused bed shift at $t=.3982 E+05 \mathrm{~min}$

Conc. Carousel caused bed shift at $t=.4153 \mathrm{E}+05 \mathrm{~min}$

Conc. Carousel caused bed shift at $t=.4324 \mathrm{E}+05 \mathrm{~min}$ 
WSRC-TR-2004-00100, REVISION 0

SRT-RPP-2004-00019, REVISION 0

Conc. Carousel caused bed shift at $t=.4496 \mathrm{E}+05 \mathrm{~min}$

Conc. Carousel caused bed shift at $t=.4667 \mathrm{E}+05 \mathrm{~min}$

Conc. Carousel caused bed shift at $t=.4839 \mathrm{E}+05 \mathrm{~min}$

Conc. Carousel caused bed shift at $t=.5010 \mathrm{E}+05 \mathrm{~min}$

Conc. Carousel caused bed shift at $t=.5182 \mathrm{E}+05 \mathrm{~min}$

Conc. Carousel caused bed shift at $t=.5353 \mathrm{E}+05 \mathrm{~min}$

Conc. Carousel caused bed shift at $t=.5524 \mathrm{E}+05 \mathrm{~min}$

Conc. Carousel caused bed shift at $t=.5696 \mathrm{E}+05 \mathrm{~min}$

Conc. Carousel caused bed shift at $t=.5868 \mathrm{E}+05 \mathrm{~min}$

Conc. Carousel caused bed shift at $t=.6039 \mathrm{E}+05 \mathrm{~min}$

Conc. Carousel caused bed shift at $t=.6210 \mathrm{E}+05 \mathrm{~min}$

Conc. Carousel caused bed shift at $t=.6382 \mathrm{E}+05 \mathrm{~min}$

Conc. Carousel caused bed shift at $t=.6553 \mathrm{E}+05 \mathrm{~min}$

Conc. Carousel caused bed shift at $t=.6725 \mathrm{E}+05 \mathrm{~min}$

Conc. Carousel caused bed shift at $t=.6896 \mathrm{E}+05 \mathrm{~min}$

Conc. Carousel caused bed shift at $t=.7068 \mathrm{E}+05 \mathrm{~min}$

Conc. Carousel caused bed shift at $t=.7239 \mathrm{E}+05 \mathrm{~min}$

Conc. Carousel caused bed shift at $t=.7410 \mathrm{E}+05 \mathrm{~min}$

Conc. Carousel caused bed shift at $t=.7582 \mathrm{E}+05 \mathrm{~min}$

Conc. Carousel caused bed shift at $t=.7754 \mathrm{E}+05 \mathrm{~min}$

Conc. Carousel caused bed shift at $t=.7925 \mathrm{E}+05 \mathrm{~min}$

Conc. Carousel caused bed shift at $t=.8096 \mathrm{E}+05 \mathrm{~min}$

Conc. Carousel caused bed shift at $t=.8268 \mathrm{E}+05 \mathrm{~min}$

Conc. Carousel caused bed shift at $t=.8439 \mathrm{E}+05 \mathrm{~min}$

Conc. Carousel caused bed shift at $t=.8611 \mathrm{E}+05 \mathrm{~min}$

Conc. Carousel caused bed shift at $t=.8782 \mathrm{E}+05 \mathrm{~min}$

Conc. Carousel caused bed shift at $t=.8954 \mathrm{E}+05 \mathrm{~min}$

Conc. Carousel caused bed shift at $t=.9125 \mathrm{E}+05 \mathrm{~min}$

Conc. Carousel caused bed shift at $t=.9297 \mathrm{E}+05 \mathrm{~min}$

Conc. Carousel caused bed shift at $t=.9468 \mathrm{E}+05 \mathrm{~min}$

Conc. Carousel caused bed shift at $t=.9639 E+05 \mathrm{~min}$

Conc. Carousel caused bed shift at $t=.9811 \mathrm{E}+05 \mathrm{~min}$

Conc. Carousel caused bed shift at $t=.9982 \mathrm{E}+05 \mathrm{~min}$

Conc. Carousel caused bed shift at $t=.1015 \mathrm{E}+06 \mathrm{~min}$

Conc. Carousel caused bed shift at $t=.1033 \mathrm{E}+06 \mathrm{~min}$

Conc. Carousel caused bed shift at $t=.1050 \mathrm{E}+06 \mathrm{~min}$

Conc. Carousel caused bed shift at $\mathrm{t}=.1067 \mathrm{E}+06 \mathrm{~min}$

Conc. Carousel caused bed shift at $t=.1084 \mathrm{E}+06 \mathrm{~min}$

Conc. Carousel caused bed shift at $t=.1101 \mathrm{E}+06 \mathrm{~min}$

Conc. Carousel caused bed shift at $t=.1118 \mathrm{E}+06 \mathrm{~min}$

Conc. Carousel caused bed shift at $t=.1135 \mathrm{E}+06 \mathrm{~min}$

Conc. Carousel caused bed shift at $t=.1153 \mathrm{E}+06 \mathrm{~min}$

Conc. Carousel caused bed shift at $t=.1170 \mathrm{E}+06 \mathrm{~min}$

Conc. Carousel caused bed shift at $t=.1187 \mathrm{E}+06 \mathrm{~min}$

VERSE-LC finished in 20020 steps. Average step size 5.994 minutes

End run: 14:55:43 on $04-30-2004$

Integrated Areas in History Files:

case15.h01 3.28800

case15.h०2 $\quad .295669$

case15.h03 $\quad .702828 \mathrm{E}-03$

case15.h०4 .652831E- 06

\section{B.16 Hot Commissioning Operations ( $Q=5$ GPM)}

\section{B.16.1 VERSE-LC Datafile}

RF 3-column carousel, single component Cs isotherm, criterion: lag

LAW feed: Hot Commissioning, CT: Degraded, Sensitivity: Q=5gpm

$1,150,4,6$

FCWNA

NNNNN

$\mathrm{M}$

ncomp, nelem, ncol-bed, ncol-part

isotherm, axial-disp, film-coef, surf-diff, BC-col

403.86, 121.92, 18927.1, 2214466. Length $(\mathrm{cm}), \operatorname{Diam}(\mathrm{cm}), \mathrm{Q}-\mathrm{flow}(\mathrm{ml} / \mathrm{min}), \operatorname{csTR}-\operatorname{vol}(\mathrm{ml})$

$241.5,0.361,0.6944,0.0$

0.0

$\mathrm{S}$

$1, \odot . \odot, 2.7400 \mathrm{~d}-5,1, \odot . \odot$

$\mathrm{V}$

$0.025001,1.2133$

$\mathrm{m}$

$50,100,0,1,3.70 \mathrm{~d}-8,0.0,1.0 \mathrm{~d}+6$

part-rad(um), bed-void, part-void, sorb-cap()

initial concentration (M)

COMMAND - conc step change

spec id, time(min), conc(M), freq, dt(min)

COMMAND - viscosity/density change

fluid viscosity(poise), density $\left(\mathrm{g} / \mathrm{cm}^{\wedge} 3\right)$

$\mathrm{h}$ COMMAND - subcolumns

elem-shift, elem-watch, pp-watch, c-watch, c-thresh, t-e,t-ee

COMMAND - effluent history dump

$0,2.0,50,4.033 d-4,0.016$

unit op\#, ptscale(1-4) filtering 
$\mathrm{h}$

$2,2.0,50,4.033 d-4,0.016$

$\mathrm{h}$

$4,2.0,50,4.033 d-4,0.016$

$\mathrm{h}$

$6,2 . \odot, 50,4.033 d-4,0.016$

$120000.0,1.0$

$1.0 \mathrm{~d}-7,1.0 \mathrm{~d}-4$

1.0

2. $2419 d-4$

3. $3628 d-4$

1. $1467 \mathrm{~d}-1$

1.0

1.0

1.0

$1.1117 d-3$
COMMAND - effluent history dump

unit op\#, ptscale(1-4) filtering

COMMAND - effluent history dump

unit op\#, ptscale(1-4) filtering

COMMAND - effluent history dump

unit op\#, ptscale(1-4) filtering

end of commands

end time(min), $\max d t$ in B.V.S

abs-tol, rel-tol

non-negative conc constraint

size exclusion factor

part-pore diffusivities $\left(\mathrm{cm}^{\wedge} 2 / \mathrm{min}\right)$

Brownian diffusivities ( $\mathrm{cm}^{\wedge} 2 / \mathrm{min}$ )

Freundlich/Langmuir Hybrid a (moles/L B.V.)

Freundlich/Langmuir Hybrid b (1/M)

Freundlich/Langmuir Hybrid $\mathrm{Ma}(-)$
Freundlich/Langmuir Hybrid $\mathrm{Mb}(-)$

Freundlich/Langmuir Hybrid beta (-)

\section{B.16.2 VERSE-LC Datafile.run}

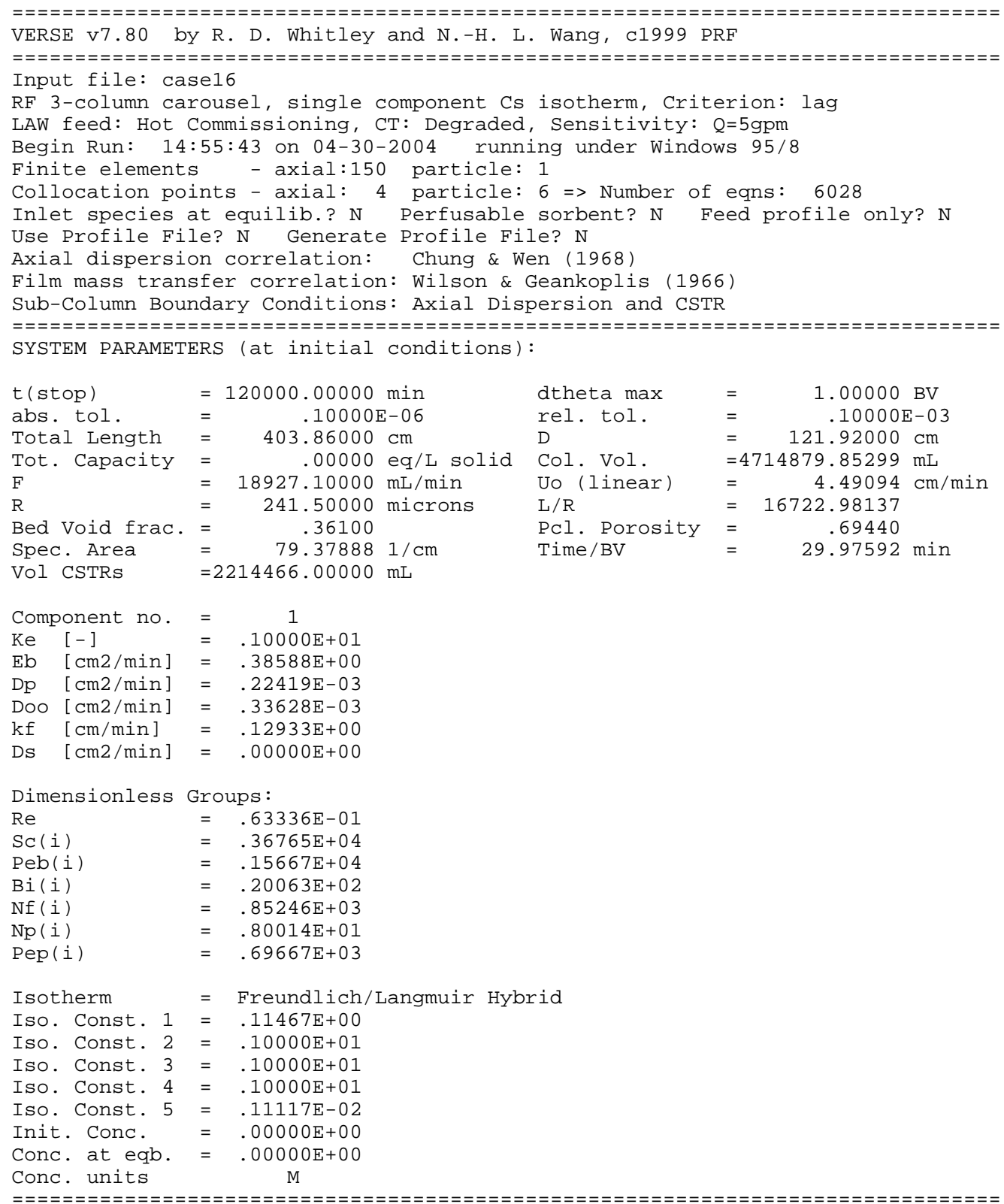




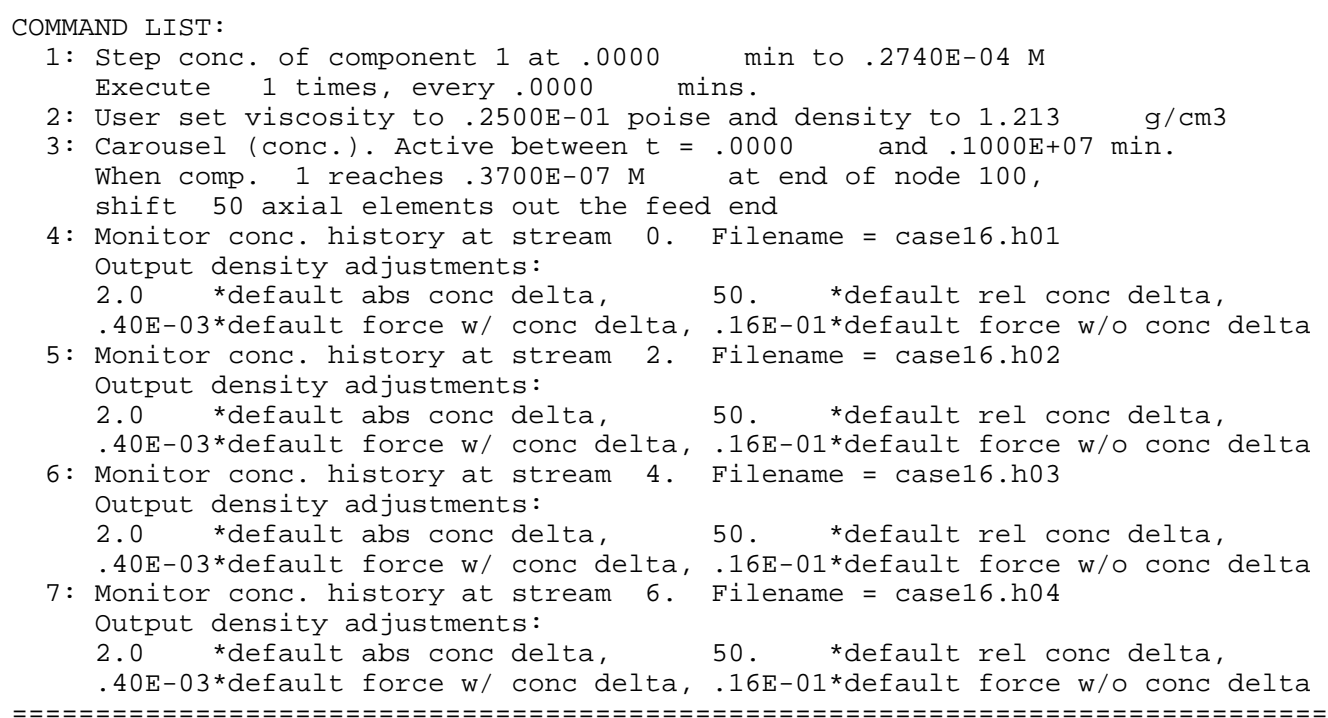

Conc. Carousel caused bed shift at $t=.1354 \mathrm{E}+05 \mathrm{~min}$

Conc. Carousel caused bed shift at $t=.2129 \mathrm{E}+05 \mathrm{~min}$

Conc. Carousel caused bed shift at $t=.2923 \mathrm{E}+05 \mathrm{~min}$

Conc. Carousel caused bed shift at $t=.3724 \mathrm{E}+05 \mathrm{~min}$

Conc. Carousel caused bed shift at $t=.4531 \mathrm{E}+05 \mathrm{~min}$

Conc. Carousel caused bed shift at $t=.5343 \mathrm{E}+05 \mathrm{~min}$

Conc. Carousel caused bed shift at $t=.6159 \mathrm{E}+05 \mathrm{~min}$

Conc. Carousel caused bed shift at $\mathrm{t}=.6981 \mathrm{E}+05 \mathrm{~min}$

Conc. Carousel caused bed shift at $t=.7803 \mathrm{E}+05 \mathrm{~min}$

Conc. Carousel caused bed shift at $\mathrm{t}=.8628 \mathrm{E}+05 \mathrm{~min}$

Conc. Carousel caused bed shift at $t=.9453 \mathrm{E}+05 \mathrm{~min}$

Conc. Carousel caused bed shift at $t=.1028 \mathrm{E}+06 \mathrm{~min}$

Conc. Carousel caused bed shift at $\mathrm{t}=.1111 \mathrm{E}+06 \mathrm{~min}$

Conc. Carousel caused bed shift at $t=.1194 \mathrm{E}+06 \mathrm{~min}$

VERSE-LC finished in 4191 steps. Average step size 28.63 minutes

End run: 15:04:57 on $04-30-2004$

Integrated Areas in History Files:

case16. h01 3.28800

case16.h०2 . 914001

case16.h०3 .362583E-03

case16.h०4 .113278E- -08

\section{B.17 Hot Commissioning Operations $\left(\mathrm{D}_{\mathrm{p}}+\mathbf{2 0} \%\right)$}

\section{B.17.1 VERSE-LC Datafile}

RF 3-column carousel, single component Cs isotherm, Criterion: lag LAW feed: Hot Commissioning, CT: Degraded, Sensitivity: 1.2*Dp

$1,150,4,6$ FCWNA

NNNNN

$M$ ncomp, nelem, ncol-bed, ncol-part isotherm, axial-disp, film-coef, surf-diff, BC-col input-only, perfusable, feed-equil, datafile.yio comp-conc units

403.86, 121.92, 56781.2, 2214466. Length $(\mathrm{cm}), \operatorname{Diam}(\mathrm{cm}), \mathrm{Q}-\mathrm{flow}(\mathrm{ml} / \mathrm{min}), \mathrm{CSTR}-\mathrm{vol}(\mathrm{ml})$

241.5, $0.361,0.6944,0.0$ part-rad(um), bed-void, part-void, sorb-cap()

0.0

initial concentration (M)

$\mathrm{S}$

$1, \odot . \odot, 2.7400 \mathrm{~d}-5,1,0 . \odot$

COMMAND - conc step change

V. $025001,1.2133$

spec id, time(min), conc(M), freq, dt(min)

COMMAND - viscosity/density change

$\odot .025001,1.2133$ fluid viscosity(poise), density $\left(\mathrm{g} / \mathrm{cm}^{\wedge} 3\right)$

$\mathrm{m}$ COMMAND - subcolumns

$50,100, \odot, 1,3.70 \mathrm{~d}-8,0 . \odot, 1.0 \mathrm{~d}+6$

elem-shift, elem-watch, pp-watch, c-watch, c-thresh, t-e,t-ee

$\odot, 2.0,50,4.033 d-4,0.016$ COMMAND - effluent history dump

unit op\#, ptscale(1-4) filtering

h

$2,2.0,50,4.033 d-4,0.016$

h

$4,2.0,50,4.033 d-4,0.016$

$\mathrm{h}$ unit op\#, ptscale(1-4) filtering COMMAND - effluent history dump

unit op\#, ptscale(1-4) filtering

COMMAND - effluent history dump

$6,2.0,50,4.033 d-4,0.016$

unit op\#, ptscale(1-4) filtering 
$120000.0,1.0$

$1.0 \mathrm{~d}-7,1.0 \mathrm{~d}-4$

1.0

$2.6902 d-4$

4. $0354 d-4$

$1.1467 d-1$

1.0

1.0

1.0

1. $1117 d-3$ end of commands

end time(min), $\max d t$ in B.V.s

abs-tol, rel-tol

non-negative conc constraint

size exclusion factor

part-pore diffusivities $\left(\mathrm{cm}^{\wedge} 2 / \mathrm{min}\right)$

Brownian diffusivities ( $\left.\mathrm{cm}^{\wedge} 2 / \mathrm{min}\right)$

Freundlich/Langmuir Hybrid a (moles/L B.V.)

Freundlich/Langmuir Hybrid b (1/M)

Freundlich/Langmuir Hybrid Ma (-)

Freundlich/Langmuir Hybrid Mb (-)

Freundlich/Langmuir Hybrid beta (-)

\section{B.17.2 VERSE-LC Datafile.run}

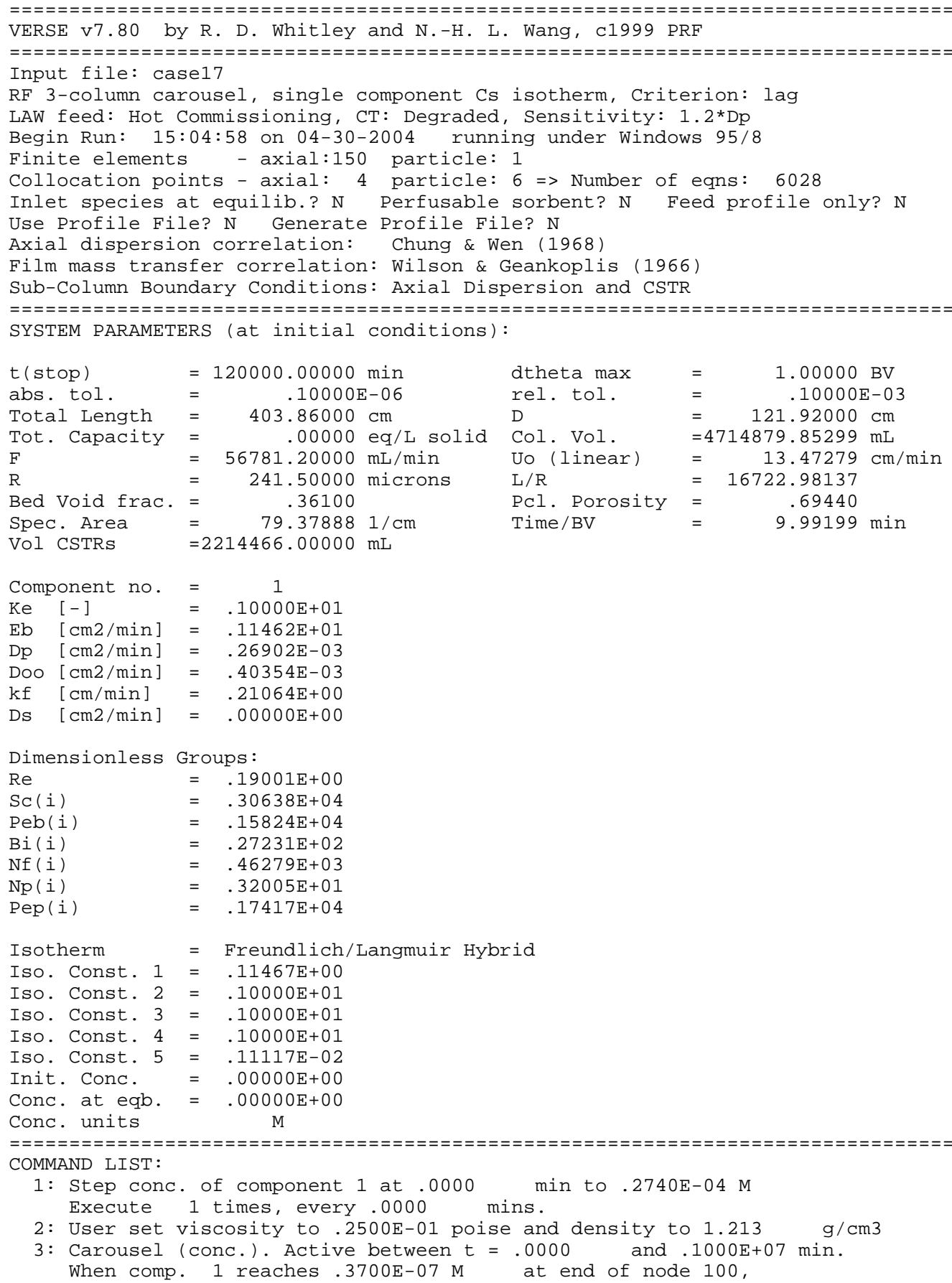


shift 50 axial elements out the feed end

4: Monitor conc. history at stream 0 . Filename $=$ case17.h01 Output density adjustments: 2.0 *default abs conc delta, 50. *default rel conc delta, . 40E- $03^{*}$ default force $\mathrm{W} / \mathrm{conc}$ delta, .16E-01*default force $\mathrm{W} / \mathrm{o}$ conc delta

5: Monitor conc. history at stream 2. Filename $=$ case17.h०2 output density adjustments: 2.0 *default abs conc delta, 50. *default rel conc delta, .40E-03*default force $\mathrm{W} /$ conc delta, .16E-01*default force $\mathrm{W} / \mathrm{o}$ conc delta

6: Monitor conc. history at stream 4. Filename $=$ case17.h03 Output density adjustments: 2.0 *default abs conc delta, 50. *default rel conc delta, .40E-03*default force $\mathrm{W} / \mathrm{conc}$ delta, .16E-01*default force w/o conc delta

7: Monitor conc. history at stream 6. Filename $=$ case17.h $\mathrm{h} 4$ Output density adjustments:

2.0 *default abs conc delta, 50. *default rel conc delta, .40E-03*default force $\mathrm{W} /$ conc delta, .16E-01*default force w/o conc delta

Conc. Carousel caused bed shift at $t=3956 . \quad$ min

Conc. Carousel caused bed shift at $t=6387 . \quad \min$

Conc. Carousel caused bed shift at $t=8902 . \quad \min$

Conc. Carousel caused bed shift at $t=.1146 \mathrm{E}+05 \mathrm{~min}$

Conc. Carousel caused bed shift at $t=.1405 \mathrm{E}+05 \mathrm{~min}$

Conc. Carousel caused bed shift at $t=.1666 \mathrm{E}+05 \mathrm{~min}$

Conc. Carousel caused bed shift at $t=.1930 \mathrm{E}+05 \mathrm{~min}$

Conc. Carousel caused bed shift at $t=.2194 \mathrm{E}+05 \mathrm{~min}$

Conc. Carousel caused bed shift at $t=.2460 \mathrm{E}+05 \mathrm{~min}$

Conc. Carousel caused bed shift at $t=.2726 \mathrm{E}+05 \mathrm{~min}$

Conc. Carousel caused bed shift at $t=.2992 \mathrm{E}+05 \mathrm{~min}$

Conc. Carousel caused bed shift at $t=.3258 \mathrm{E}+05 \mathrm{~min}$

Conc. Carousel caused bed shift at $t=.3525 \mathrm{E}+05 \mathrm{~min}$

Conc. Carousel caused bed shift at $t=.3792 \mathrm{E}+05 \mathrm{~min}$

Conc. Carousel caused bed shift at $t=.4057 \mathrm{E}+05 \mathrm{~min}$

Conc. Carousel caused bed shift at $t=.4324 \mathrm{E}+05 \mathrm{~min}$

Conc. Carousel caused bed shift at $t=.4589 \mathrm{E}+05 \mathrm{~min}$

Conc. Carousel caused bed shift at $t=.4856 \mathrm{E}+05 \mathrm{~min}$

Conc. Carousel caused bed shift at $t=.5122 \mathrm{E}+05 \mathrm{~min}$

Conc. Carousel caused bed shift at $t=.5389 \mathrm{E}+05 \mathrm{~min}$

Conc. Carousel caused bed shift at $t=.5654 \mathrm{E}+05 \mathrm{~min}$

Conc. Carousel caused bed shift at $t=.5920 \mathrm{E}+05 \mathrm{~min}$

Conc. Carousel caused bed shift at $t=.6187 \mathrm{E}+05 \mathrm{~min}$

Conc. Carousel caused bed shift at $t=.6452 \mathrm{E}+05 \mathrm{~min}$

Conc. Carousel caused bed shift at $t=.6719 \mathrm{E}+05 \mathrm{~min}$

Conc. Carousel caused bed shift at $t=.6985 \mathrm{E}+05 \mathrm{~min}$

Conc. Carousel caused bed shift at $t=.7252 \mathrm{E}+05 \mathrm{~min}$

Conc. Carousel caused bed shift at $t=.7517 \mathrm{E}+05 \mathrm{~min}$

Conc. Carousel caused bed shift at $t=.7784 \mathrm{E}+05 \mathrm{~min}$

Conc. Carousel caused bed shift at $t=.8050 \mathrm{E}+05 \mathrm{~min}$

Conc. Carousel caused bed shift at $\mathrm{t}=.8315 \mathrm{E}+05 \mathrm{~min}$

Conc. Carousel caused bed shift at $\mathrm{t}=.8582 \mathrm{E}+05 \mathrm{~min}$

Conc. Carousel caused bed shift at $t=.8848 \mathrm{E}+05 \mathrm{~min}$

Conc. Carousel caused bed shift at $t=.9115 \mathrm{E}+05 \mathrm{~min}$

Conc. Carousel caused bed shift at $t=.9380 \mathrm{E}+05 \mathrm{~min}$

Conc. Carousel caused bed shift at $t=.9647 \mathrm{E}+05 \mathrm{~min}$

Conc. Carousel caused bed shift at $t=.9913 \mathrm{E}+05 \mathrm{~min}$

Conc. Carousel caused bed shift at $t=.1018 \mathrm{E}+06 \mathrm{~min}$

Conc. Carousel caused bed shift at $t=.1045 \mathrm{E}+06 \mathrm{~min}$

Conc. Carousel caused bed shift at $t=.1071 \mathrm{E}+06 \mathrm{~min}$

Conc. Carousel caused bed shift at $t=.1098 \mathrm{E}+06 \mathrm{~min}$

Conc. Carousel caused bed shift at $t=.1124 \mathrm{E}+06 \mathrm{~min}$

Conc. Carousel caused bed shift at $\mathrm{t}=.1151 \mathrm{E}+06 \mathrm{~min}$

Conc. Carousel caused bed shift at $t=.1178 \mathrm{E}+06 \mathrm{~min}$

VERSE-LC finished in 13053 steps. Average step size 9.193 minutes

End run: 15:50:17 on $04-30-2004$

Integrated Areas in History Files:

case17. h01 3.28800

case17.h०2 $\quad .386561$

case17.h03 .639639E- -03

case17.h๑4 .305828E- 06 


\section{B.18 Hot Commissioning Operations ( $\left.D_{p}-20 \%\right)$}

\section{B.18.1 VERSE-LC Datafile}

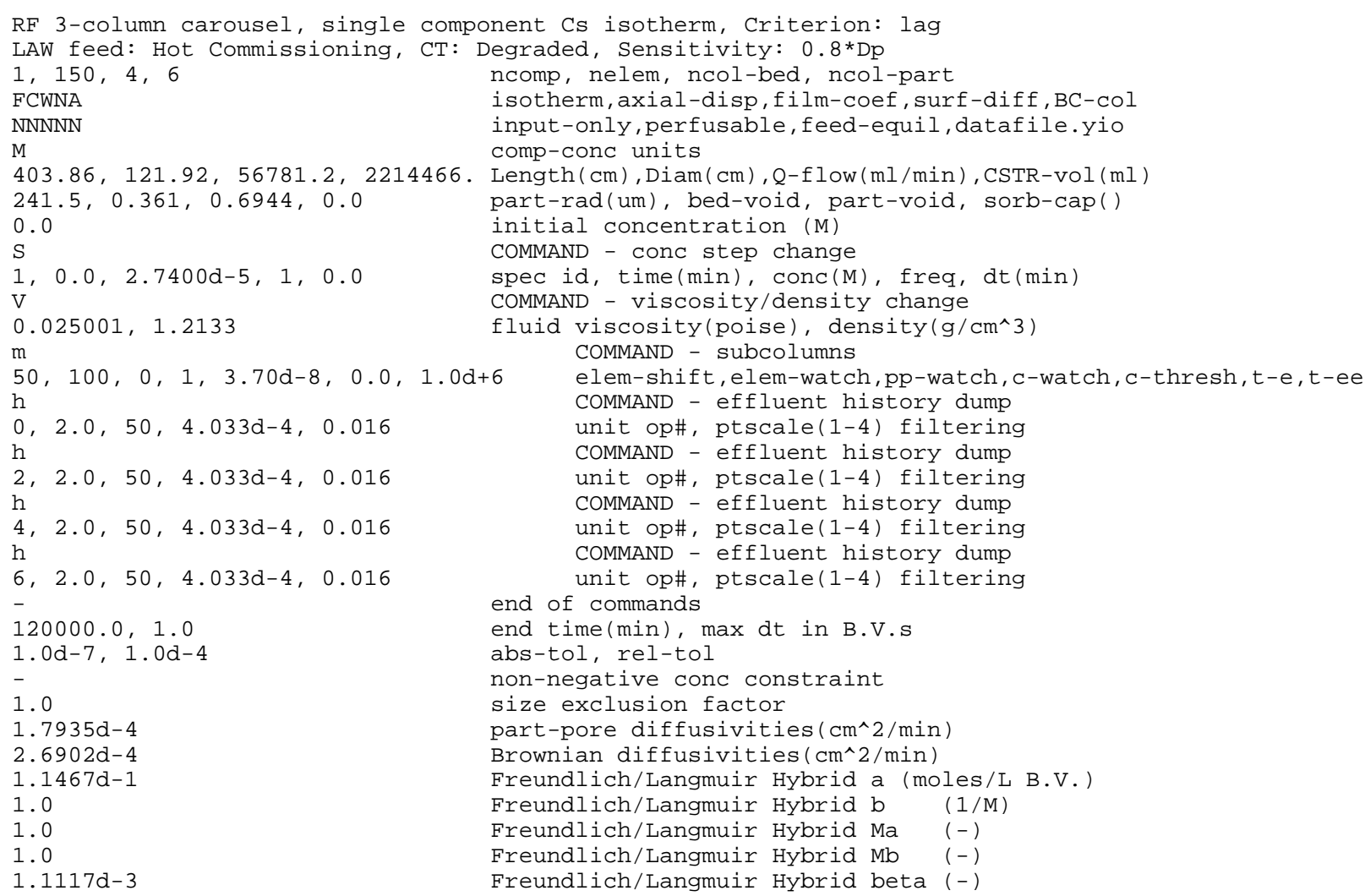

\section{B.18.2 VERSE-LC Datafile.run}

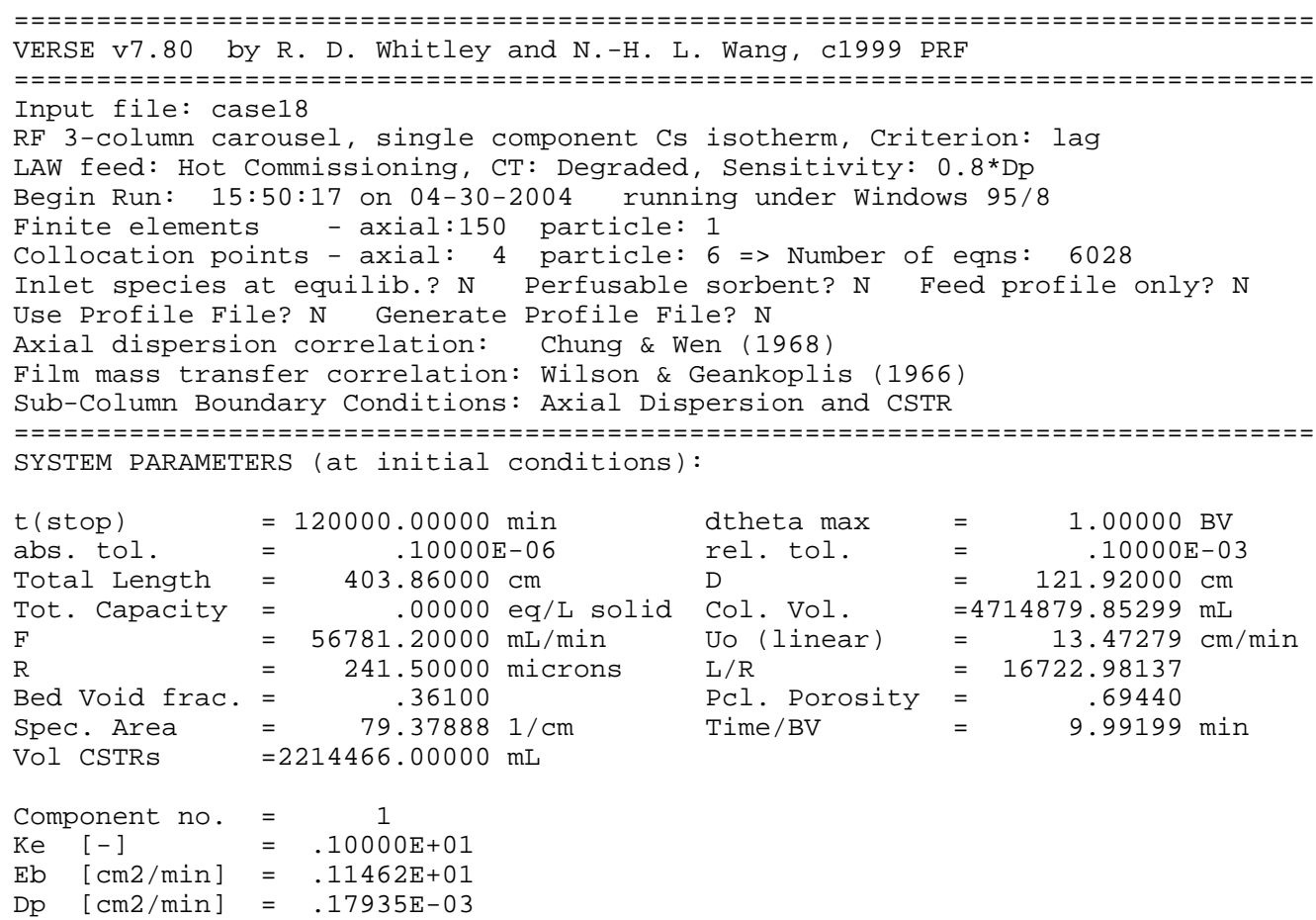




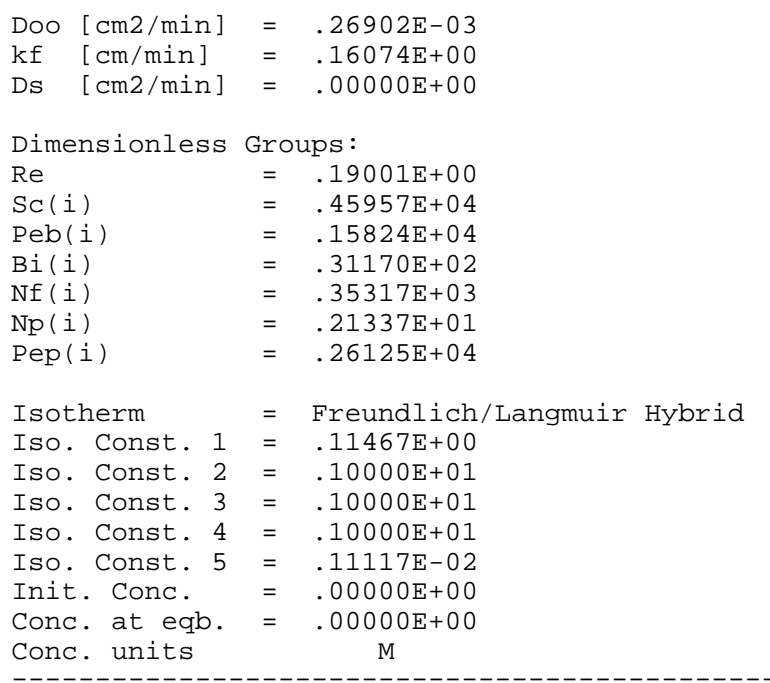


WSRC-TR-2004-00100, REVISION 0

SRT-RPP-2004-00019, REVISION 0

Conc. Carousel caused bed shift at $t=.7492 \mathrm{E}+05 \mathrm{~min}$

Conc. Carousel caused bed shift at $t=.7749 \mathrm{E}+05 \mathrm{~min}$

Conc. Carousel caused bed shift at $t=.8005 \mathrm{E}+05 \mathrm{~min}$

Conc. Carousel caused bed shift at $t=.8261 \mathrm{E}+05 \mathrm{~min}$

Conc. Carousel caused bed shift at $t=.8518 \mathrm{E}+05 \mathrm{~min}$

Conc. Carousel caused bed shift at $t=.8774 \mathrm{E}+05 \mathrm{~min}$

Conc. Carousel caused bed shift at $t=.9030 \mathrm{E}+05 \mathrm{~min}$

Conc. Carousel caused bed shift at $\mathrm{t}=.9287 \mathrm{E}+05 \mathrm{~min}$

Conc. Carousel caused bed shift at $t=.9543 \mathrm{E}+05 \mathrm{~min}$

Conc. Carousel caused bed shift at $t=.9799 \mathrm{E}+05 \mathrm{~min}$

Conc. Carousel caused bed shift at $t=.1006 \mathrm{E}+06 \mathrm{~min}$

Conc. Carousel caused bed shift at $t=.1031 \mathrm{E}+06 \mathrm{~min}$

Conc. Carousel caused bed shift at $t=.1057 \mathrm{E}+06 \mathrm{~min}$

Conc. Carousel caused bed shift at $t=.1082 \mathrm{E}+06 \mathrm{~min}$

Conc. Carousel caused bed shift at $\mathrm{t}=.1108 \mathrm{E}+06 \mathrm{~min}$

Conc. Carousel caused bed shift at $t=.1134 \mathrm{E}+06 \mathrm{~min}$

Conc. Carousel caused bed shift at $\mathrm{t}=.1159 \mathrm{E}+06 \mathrm{~min}$

Conc. Carousel caused bed shift at $t=.1185 \mathrm{E}+06 \mathrm{~min}$

VERSE-LC finished in 13482 steps. Average step size 8.901 minutes

End run: $16: 49: 20$ on $04-30-2004$

Integrated Areas in History Files:

case18.h01 3.28800

case18.h०2 .321871

case18.h03 .676271E- 03

case18.h०4 .512608E-06

\section{B.19 Hot Commissioning Operations $\left(R_{p}+20 \%\right)$}

\section{B.19.1 VERSE-LC Datafile}

RF 3-column carousel, single component Cs isotherm, criterion: lag

LAW feed: Hot Commissioning, CT: Degraded, Sensitivity: $1.2{ }^{*} \mathrm{R}$

$1,150,4,6$

FCWNA

NNNNN

$\mathrm{M}$

ncomp, nelem, ncol-bed, ncol-part

isotherm, axial-disp, film-coef, surf-diff, BC-col

input-only, perfusable, feed-equil, datafile.yio

403.86, 121.92, 56781.2, 2214466. Length $(\mathrm{cm}), \operatorname{Diam}(\mathrm{cm}), \mathrm{Q}-\mathrm{flow}(\mathrm{ml} / \mathrm{min}), \mathrm{CSTR}-\operatorname{vol}(\mathrm{ml})$

$289.8,0.361,0.6944,0 . \odot$

0.0

$\mathrm{S}$

$1, \odot . \odot, 2.7400 \mathrm{~d}-5,1, \odot . \odot$

$\mathrm{V}$

$0.025001,1.2133$

$m$

$50,100, \odot, 1,3.70 \mathrm{~d}-8,0.0,1.0 \mathrm{~d}+6$

Length(cm), Diam(cm), Q-flow(ml/min), CSTR-Vol(m
part-rad(um), bed-void, part-void, sorb-cap( $)$

initial concentration (M)

COMMAND - conc step change

spec id, time(min), conc(M), freq, dt(min)

COMMAND - viscosity/density change

fluid viscosity(poise), density $\left(\mathrm{g} / \mathrm{cm}^{\wedge} 3\right)$ COMMAND - subcolumns

$\mathrm{h}$

$0,2.0,50,4.033 d-4,0.016$

$\mathrm{h}$

$2,2.0,50,4.033 d-4,0.016$

$\mathrm{h}$

$4,2.0,50,4.033 d-4,0.016$

$\mathrm{h}$

$6,2.0,50,4.033 d-4,0.016$

$120000.0,1.0$

$1.0 \mathrm{~d}-7,1.0 \mathrm{~d}-4$

1.0

elem-shift, elem-watch, pp-watch, c-watch, c-thresh, t-e,t-ee

COMMAND - effluent history dump

unit op\#, ptscale(1-4) filtering

COMMAND - effluent history dump

unit op\#, ptscale(1-4) filtering

COMMAND - effluent history dump

unit op\#, ptscale(1-4) filtering

COMMAND - effluent history dump

end of commands

unit op\#, ptscale(1-4) filtering

end time(min), max dt in B.V.s

abs-tol, rel-tol

non-negative conc constraint

size exclusion factor

part-pore diffusivities $\left(\mathrm{cm}^{\wedge} 2 / \mathrm{min}\right)$

Brownian diffusivities $(\mathrm{cm} \wedge 2 / \mathrm{min})$

Freundlich/Langmuir Hybrid a (moles/L B.V.)

$3.3628 d-4$

$1.1467 d-1$

1.0

1.0

Freundlich/Langmuir Hybrid b

$(1 / \mathrm{M})$

1.0

$1.1117 d-3$

Freundlich/Langmuir Hybrid Mb (-)

Freundlich/Langmuir Hybrid beta (-)

\section{B.19.2 VERSE-LC Datafile.run}

VERSE V7.80 by R. D. Whitley and N.-H. L. Wang, c1999 PRF

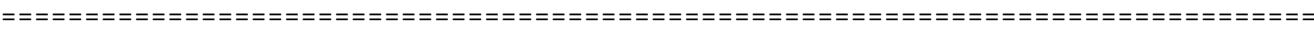

Input file: case19 
RF 3-column carousel, single component Cs isotherm, criterion: lag

LAW feed: Hot Commissioning, CT: Degraded, Sensitivity: $1.2{ }^{\star} \mathrm{R}$

Begin Run: 16:49:20 on 04-30-2004 running under Windows 95/8

Finite elements - axial:150 particle: 1

Collocation points - axial: 4 particle: $6 \Rightarrow$ Number of eqns: 6028

Inlet species at equilib.? N Perfusable sorbent? $N$ Feed profile only? $N$

Use Profile File? N Generate Profile File? N

Axial dispersion correlation: Chung \& Wen (1968)

Film mass transfer correlation: Wilson \& Geankoplis (1966)

Sub-Column Boundary Conditions: Axial Dispersion and CSTR

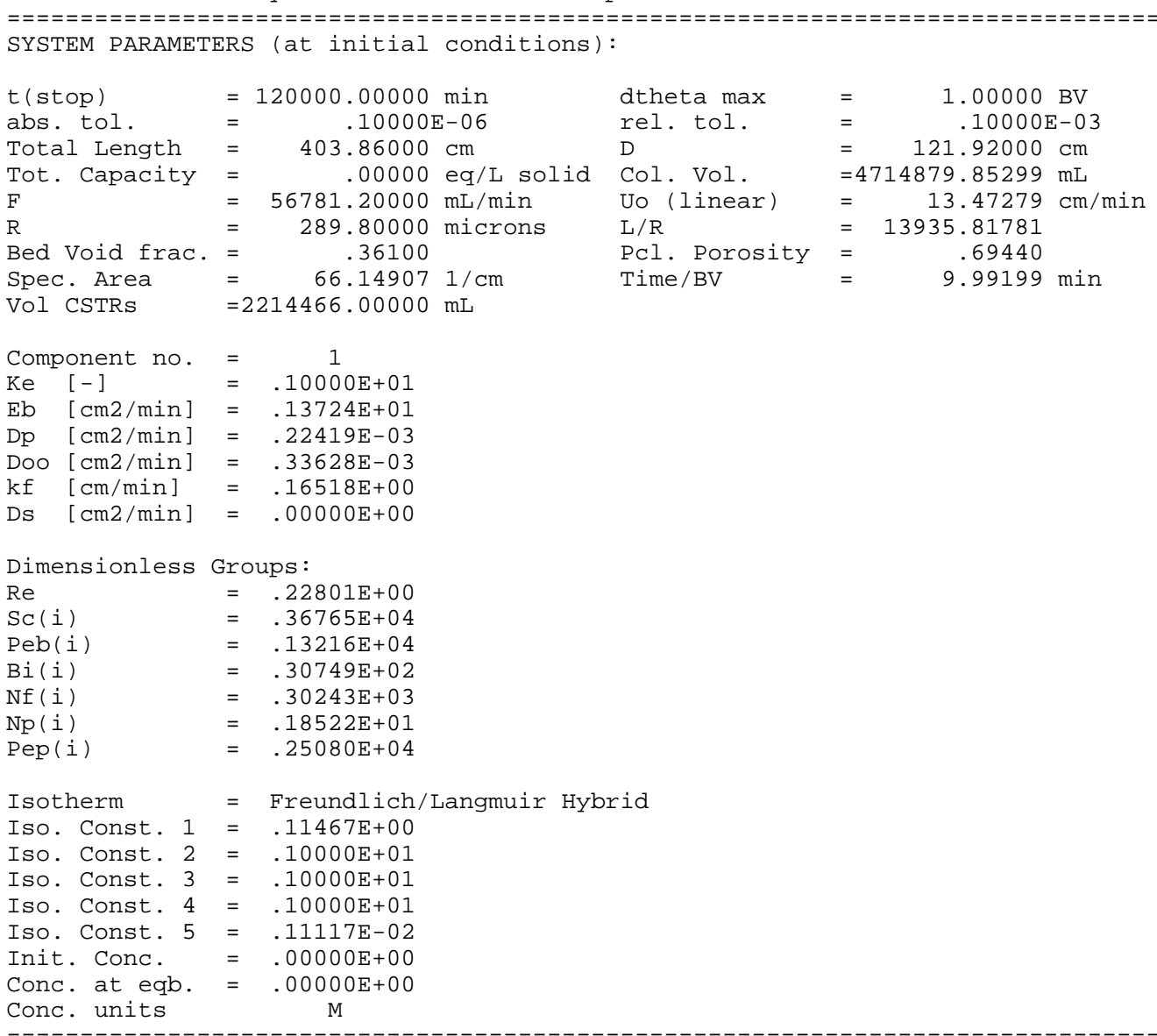

COMMAND LIST:

1: Step conc. of component 1 at . 0000 min to .2740E- $04 \mathrm{M}$ Execute 1 times, every .0000 mins.

2: User set viscosity to .2500E-01 poise and density to $1.213 \mathrm{~g} / \mathrm{cm} 3$

3: Carousel (conc.). Active between $t=.0000$ and $.1000 \mathrm{E}+07 \mathrm{~min}$. When comp. 1 reaches $.3700 \mathrm{E}-07 \mathrm{M}$ at end of node 100, shift 50 axial elements out the feed end

4: Monitor conc. history at stream $\odot$. Filename $=$ case19.h 01 Output density adjustments: $2.0{ }^{*}$ default abs conc delta, 50. *default rel conc delta, .40E-03*default force $\mathrm{W} / \mathrm{conc}$ delta, .16E-01*default force w/o conc delta

5: Monitor conc. history at stream 2. Filename $=$ case19.h๑2 Output density adjustments:

2.0 *default abs conc delta, 50. *default rel conc delta, .40E-03*default force $\mathrm{W} /$ conc delta, .16E-01*default force w/o conc delta

6: Monitor conc. history at stream 4. Filename $=$ case19.h०3 Output density adjustments: $2.0{ }^{*}$ default abs conc delta, 50. *default rel conc delta, . 40E-03*default force $\mathrm{W} / \mathrm{conc}$ delta, .16E-01*default force $\mathrm{w} / \mathrm{o}$ conc delta

7: Monitor conc. history at stream 6. Filename = case19.h॰4 Output density adjustments:

2.0 *default abs conc delta, 50. *default rel conc delta, .40E-03*default force $\mathrm{W} / \mathrm{conc}$ delta, .16E-01*default force $\mathrm{W} / \mathrm{o}$ conc delta

Conc. Carousel caused bed shift at $t=3500$ min 
WSRC-TR-2004-00100, REVISION 0

SRT-RPP-2004-00019, REVISION 0

Conc. Carousel caused bed shift at $t=5792$. min

Conc. Carousel caused bed shift at $t=8196$. min

Conc. Carousel caused bed shift at $t=.1065 \mathrm{E}+05 \mathrm{~min}$

Conc. Carousel caused bed shift at $t=.1313 \mathrm{E}+05 \mathrm{~min}$

Conc. Carousel caused bed shift at $t=.1565 \mathrm{E}+05 \mathrm{~min}$

Conc. Carousel caused bed shift at $t=.1817 \mathrm{E}+05 \mathrm{~min}$

Conc. Carousel caused bed shift at $t=.2069 \mathrm{E}+05 \mathrm{~min}$

Conc. Carousel caused bed shift at $t=.2319 \mathrm{E}+05 \mathrm{~min}$

Conc. Carousel caused bed shift at $t=.2571 \mathrm{E}+05 \mathrm{~min}$

Conc. Carousel caused bed shift at $t=.2823 \mathrm{E}+05 \mathrm{~min}$

Conc. Carousel caused bed shift at $t=.3075 \mathrm{E}+05 \mathrm{~min}$

Conc. Carousel caused bed shift at $t=.3326 \mathrm{E}+05 \mathrm{~min}$

Conc. Carousel caused bed shift at $t=.3578 \mathrm{E}+05 \mathrm{~min}$

Conc. Carousel caused bed shift at $t=.3829 \mathrm{E}+05 \mathrm{~min}$

Conc. Carousel caused bed shift at $t=.4080 E+05 \mathrm{~min}$

Conc. Carousel caused bed shift at $t=.4332 \mathrm{E}+05 \mathrm{~min}$

Conc. Carousel caused bed shift at $t=.4584 \mathrm{E}+05 \mathrm{~min}$

Conc. Carousel caused bed shift at $t=.4836 \mathrm{E}+05 \mathrm{~min}$

Conc. Carousel caused bed shift at $t=.5087 \mathrm{E}+05 \mathrm{~min}$

Conc. Carousel caused bed shift at $t=.5338 \mathrm{E}+05 \mathrm{~min}$

Conc. Carousel caused bed shift at $t=.5590 \mathrm{E}+05 \mathrm{~min}$

Conc. Carousel caused bed shift at $t=.5842 \mathrm{E}+05 \mathrm{~min}$

Conc. Carousel caused bed shift at $t=.6093 \mathrm{E}+05 \mathrm{~min}$

Conc. Carousel caused bed shift at $t=.6345 \mathrm{E}+05 \mathrm{~min}$

Conc. Carousel caused bed shift at $t=.6596 \mathrm{E}+05 \mathrm{~min}$

Conc. Carousel caused bed shift at $t=.6848 \mathrm{E}+05 \mathrm{~min}$

Conc. Carousel caused bed shift at $t=.7099 \mathrm{E}+05 \mathrm{~min}$

Conc. Carousel caused bed shift at $t=.7351 \mathrm{E}+05 \mathrm{~min}$

Conc. Carousel caused bed shift at $t=.7603 \mathrm{E}+05 \mathrm{~min}$

Conc. Carousel caused bed shift at $t=.7854 \mathrm{E}+05 \mathrm{~min}$

Conc. Carousel caused bed shift at $t=.8105 \mathrm{E}+05 \mathrm{~min}$

Conc. Carousel caused bed shift at $t=.8357 \mathrm{E}+05 \mathrm{~min}$

Conc. Carousel caused bed shift at $t=.8609 \mathrm{E}+05 \mathrm{~min}$

Conc. Carousel caused bed shift at $\mathrm{t}=.8860 \mathrm{E}+05 \mathrm{~min}$

Conc. Carousel caused bed shift at $t=.9112 \mathrm{E}+05 \mathrm{~min}$

Conc. Carousel caused bed shift at $t=.9363 \mathrm{E}+05 \mathrm{~min}$

Conc. Carousel caused bed shift at $t=.9615 \mathrm{E}+05 \mathrm{~min}$

Conc. Carousel caused bed shift at $t=.9866 \mathrm{E}+05 \mathrm{~min}$

Conc. Carousel caused bed shift at $t=.1012 \mathrm{E}+06 \mathrm{~min}$

Conc. Carousel caused bed shift at $t=.1037 \mathrm{E}+06 \mathrm{~min}$

Conc. Carousel caused bed shift at $t=.1062 \mathrm{E}+06 \mathrm{~min}$

Conc. Carousel caused bed shift at $t=.1087 \mathrm{E}+06 \mathrm{~min}$

Conc. Carousel caused bed shift at $t=.1112 \mathrm{E}+06 \mathrm{~min}$

Conc. Carousel caused bed shift at $t=.1138 \mathrm{E}+06 \mathrm{~min}$

Conc. Carousel caused bed shift at $t=.1163 \mathrm{E}+06 \mathrm{~min}$

Conc. Carousel caused bed shift at $t=.1188 \mathrm{E}+06 \mathrm{~min}$

VERSE-LC finished in 13688 steps. Average step size 8.767 minutes

End run: 17:55:15 on $04-30-2004$

Integrated Areas in History Files:

case19. h01 3.28800

case19.h०2 .300861

case19.h03 .690190E-03

case19. h०4 .613905E-06

\section{B.20 Hot Commissioning Operations $\left(R_{p}-20 \%\right)$}

\section{B.20.1 VERSE-LC Datafile}

RF 3-column carousel, single component Cs isotherm, Criterion: lag

LAW feed: Hot Commissioning, CT: Degraded, Sensitivity: $0.8^{*} \mathrm{R}$

$1,150,4,6$

FCWNA

NNNNN

$\mathrm{M}$ ncomp, nelem, ncol-bed, ncol-part isotherm, axial-disp, film-coef, surf-diff, BC-col input-only, perfusable, feed-equil, datafile.yio comp-conc units

403.86, 121.92, 56781.2, 2214466. Length $(\mathrm{cm}), \operatorname{Diam}(\mathrm{cm}), \mathrm{Q}-\mathrm{flow}(\mathrm{ml} / \mathrm{min}), \mathrm{CSTR}-\operatorname{vol}(\mathrm{ml})$

193.2, $0.361,0.6944,0 . \odot \quad$ part-rad(um), bed-void, part-void, sorb-cap()

0.0

initial concentration (M)

COMMAND - conc step change

$1, \odot . \odot, 2.7400 \mathrm{~d}-5,1, \odot . \odot \quad$ spec id, time(min), conc(M), freq, dt(min)

$\mathrm{V}$

COMMAND - viscosity/density change

$0.025001,1.2133$ fluid viscosity(poise), density $(\mathrm{g} / \mathrm{cm} \wedge 3)$

$\mathrm{m}$ COMMAND - subcolumns

$50,10 \odot, 0,1,3.70 \mathrm{~d}-8,0 . \odot, 1 . \odot \mathrm{d}+6 \quad$ elem-shift, elem-watch,pp-watch, c-watch, c-thresh,t-e,t-ee 
$\mathrm{h}$

$0,2.0,50,4.033 d-4,0.016$

$\mathrm{h}$

$2,2.0,50,4.033 d-4,0.016$

$\mathrm{h}$

$4,2.0,50,4.033 d-4,0.016$

$6,2.0,50,4.033 d-4,0.016$

$120000.0,1.0$

$1.0 \mathrm{~d}-7,1.0 \mathrm{~d}-4$

1.0

2. $2419 d-4$

3. $3628 d-4$

1. $1467 d-1$

1.0

1.0

1.0

$1.1117 d-3$
COMMAND - effluent history dump

unit op\#, ptscale(1-4) filtering

COMMAND - effluent history dump

unit op\#, ptscale(1-4) filtering

COMMAND - effluent history dump

unit op\#, ptscale(1-4) filtering

COMMAND - effluent history dump

end of commands

end time(min), $\max d t$ in B.V.S

abs-tol, rel-tol

non-negative conc constraint

size exclusion factor

part-pore diffusivities $\left(\mathrm{cm}^{\wedge} 2 / \mathrm{min}\right)$

Brownian diffusivities ( $\left.\mathrm{cm}^{\wedge} 2 / \mathrm{min}\right)$

Freundlich/Langmuir Hybrid a (moles/L B.V.)

Freundlich/Langmuir Hybrid b (1/M)

Freundlich/Langmuir Hybrid Ma (-)

Freundlich/Langmuir Hybrid Mb (-)

Freundlich/Langmuir Hybrid beta (-)

\section{B.20.2 VERSE-LC Datafile.run}

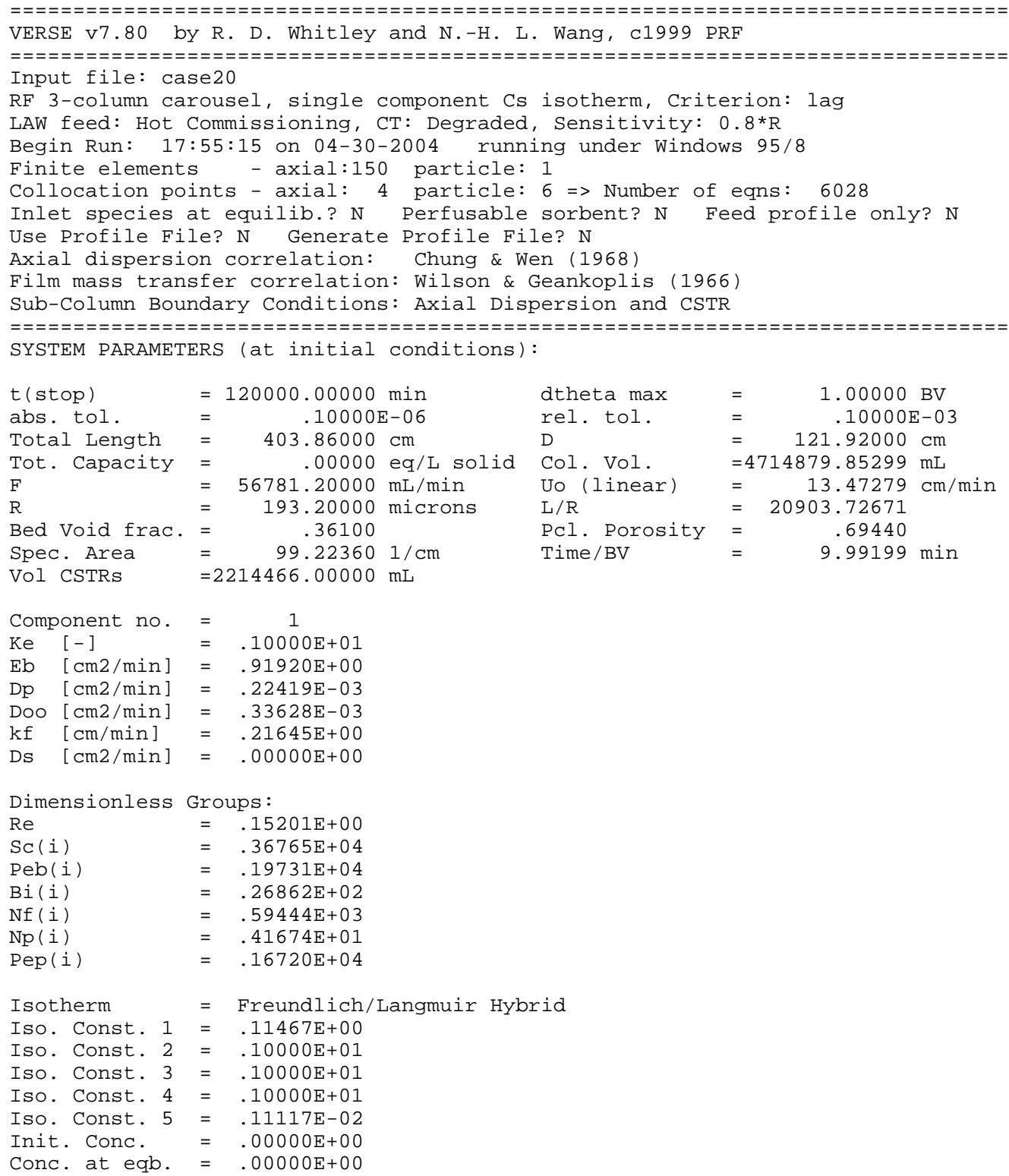


1: Step conc. of component 1 at . . 0000 Execute 1 times, every .0000 mins.

2: User set viscosity to .2500E-01 poise and density to 1.213

3: Carousel (conc.). Active between $t=.0000$ When comp. 1 reaches $.3700 \mathrm{E}-07 \mathrm{M}$ shift 50 axial elements out the feed end

4: Monitor conc. history at stream $\odot$. Filename $=$ case $20 . \mathrm{h} 01$ Output density adjustments: 2.0 *default abs conc delta, 50. *default rel conc delta, $.40 \mathrm{E}-03 *$ default force $\mathrm{W} / \mathrm{conc}$ delta, .16E-01*default force $\mathrm{W} / \mathrm{o}$ conc delta

5: Monitor conc. history at stream 2. Filename = case $2 \odot . \mathrm{h} \odot 2$ Output density adjustments: 2.0 *default abs conc delta, $50 .{ }^{*}$ default rel conc delta, .40E- $03^{*}$ default force $\mathrm{W} /$ conc delta, .16E- $01^{*}$ default force $\mathrm{W} / \mathrm{o}$ conc delta

6: Monitor conc. history at stream 4. Filename $=$ case20.h03 Output density adjustments: 2.0 *default abs conc delta, 50. *default rel conc delta, .40E-03*default force $\mathrm{W} /$ conc delta, .16E- $01^{*}$ default force $\mathrm{w} / \mathrm{o}$ conc delta

7: Monitor conc. history at stream 6. Filename = case20.h०4 Output density adjustments: 2.0 *default abs conc delta, 50. *default rel conc delta, .40E- $03^{*}$ default force $\mathrm{W} / \mathrm{conc}$ delta, .16E- $01^{*}$ default force $\mathrm{W} / \mathrm{o}$ conc delta

Conc. Carousel caused bed shift at $t=4149$. min

Conc. Carousel caused bed shift at $t=6644$ min

Conc. Carousel caused bed shift at $t=9210 . \quad \mathrm{min}$

Conc. Carousel caused bed shift at $t=.1180 \mathrm{E}+05 \mathrm{~min}$

Conc. Carousel caused bed shift at $t=.1443 \mathrm{E}+05 \mathrm{~min}$

Conc. Carousel caused bed shift at $t=.1708 \mathrm{E}+05 \mathrm{~min}$

Conc. Carousel caused bed shift at $t=.1975 \mathrm{E}+05 \mathrm{~min}$

Conc. Carousel caused bed shift at $\mathrm{t}=.2243 \mathrm{E}+05 \mathrm{~min}$

Conc. Carousel caused bed shift at $t=.2512 \mathrm{E}+05 \mathrm{~min}$

Conc. Carousel caused bed shift at $t=.2783 \mathrm{E}+05 \mathrm{~min}$

Conc. Carousel caused bed shift at $t=.3053 \mathrm{E}+05 \mathrm{~min}$

Conc. Carousel caused bed shift at $t=.3324 \mathrm{E}+05 \mathrm{~min}$

Conc. Carousel caused bed shift at $t=.3596 \mathrm{E}+05 \mathrm{~min}$

Conc. Carousel caused bed shift at $t=.3867 \mathrm{E}+05 \mathrm{~min}$

Conc. Carousel caused bed shift at $t=.4138 \mathrm{E}+05 \mathrm{~min}$

Conc. Carousel caused bed shift at $t=.4410 E+05 \mathrm{~min}$

Conc. Carousel caused bed shift at $t=.4681 \mathrm{E}+05 \mathrm{~min}$

Conc. Carousel caused bed shift at $t=.4952 \mathrm{E}+05 \mathrm{~min}$

Conc. Carousel caused bed shift at $t=.5224 \mathrm{E}+05 \mathrm{~min}$

Conc. Carousel caused bed shift at $t=.5495 \mathrm{E}+05 \mathrm{~min}$

Conc. Carousel caused bed shift at $t=.5766 \mathrm{E}+05 \mathrm{~min}$

Conc. Carousel caused bed shift at $t=.6039 \mathrm{E}+05 \mathrm{~min}$

Conc. Carousel caused bed shift at $t=.6310 \mathrm{E}+05 \mathrm{~min}$

Conc. Carousel caused bed shift at $t=.6581 \mathrm{E}+05 \mathrm{~min}$

Conc. Carousel caused bed shift at $t=.6852 \mathrm{E}+05 \mathrm{~min}$

Conc. Carousel caused bed shift at $t=.7124 \mathrm{E}+05 \mathrm{~min}$

Conc. Carousel caused bed shift at $t=.7395 \mathrm{E}+05 \mathrm{~min}$

Conc. Carousel caused bed shift at $t=.7666 \mathrm{E}+05 \mathrm{~min}$

Conc. Carousel caused bed shift at $t=.7937 \mathrm{E}+05 \mathrm{~min}$

Conc. Carousel caused bed shift at $t=.8209 \mathrm{E}+05 \mathrm{~min}$

Conc. Carousel caused bed shift at $t=.8480 E+05 \mathrm{~min}$

Conc. Carousel caused bed shift at $t=.8751 \mathrm{E}+05 \mathrm{~min}$

Conc. Carousel caused bed shift at $t=.9024 \mathrm{E}+05 \mathrm{~min}$

Conc. Carousel caused bed shift at $t=.9295 E+05$ min

Conc. Carousel caused bed shift at $t=.9566 \mathrm{E}+05 \mathrm{~min}$

Conc. Carousel caused bed shift at $t=.9837 \mathrm{E}+05 \mathrm{~min}$

Conc. Carousel caused bed shift at $t=.1011 \mathrm{E}+06 \mathrm{~min}$

Conc. Carousel caused bed shift at $t=.1038 \mathrm{E}+06 \mathrm{~min}$

Conc. Carousel caused bed shift at $t=.1065 \mathrm{E}+06 \mathrm{~min}$

Conc. Carousel caused bed shift at $t=.1092 \mathrm{E}+06 \mathrm{~min}$

Conc. Carousel caused bed shift at $t=.1119 \mathrm{E}+06 \mathrm{~min}$

Conc. Carousel caused bed shift at $t=.1147 \mathrm{E}+06 \mathrm{~min}$

Conc. Carousel caused bed shift at $\mathrm{t}=.1174 \mathrm{E}+06 \mathrm{~min}$

VERSE-LC finished in 12758 steps. Average step size 9.406 minutes

End run: 18:30:55 on $04-30-2004$

Integrated Areas in History Files:

case20.h01 3.28800

case20.h०2 .447001

case20.h०3 .613647E-๑3 
WSRC-TR-2004-00100, REVISION 0

SRT-RPP-2004-00019, REVISION 0

\section{B.21 Hot Commissioning Operations $\left(\rho_{b}+20 \%\right)$}

\section{B.21.1 VERSE-LC Datafile}

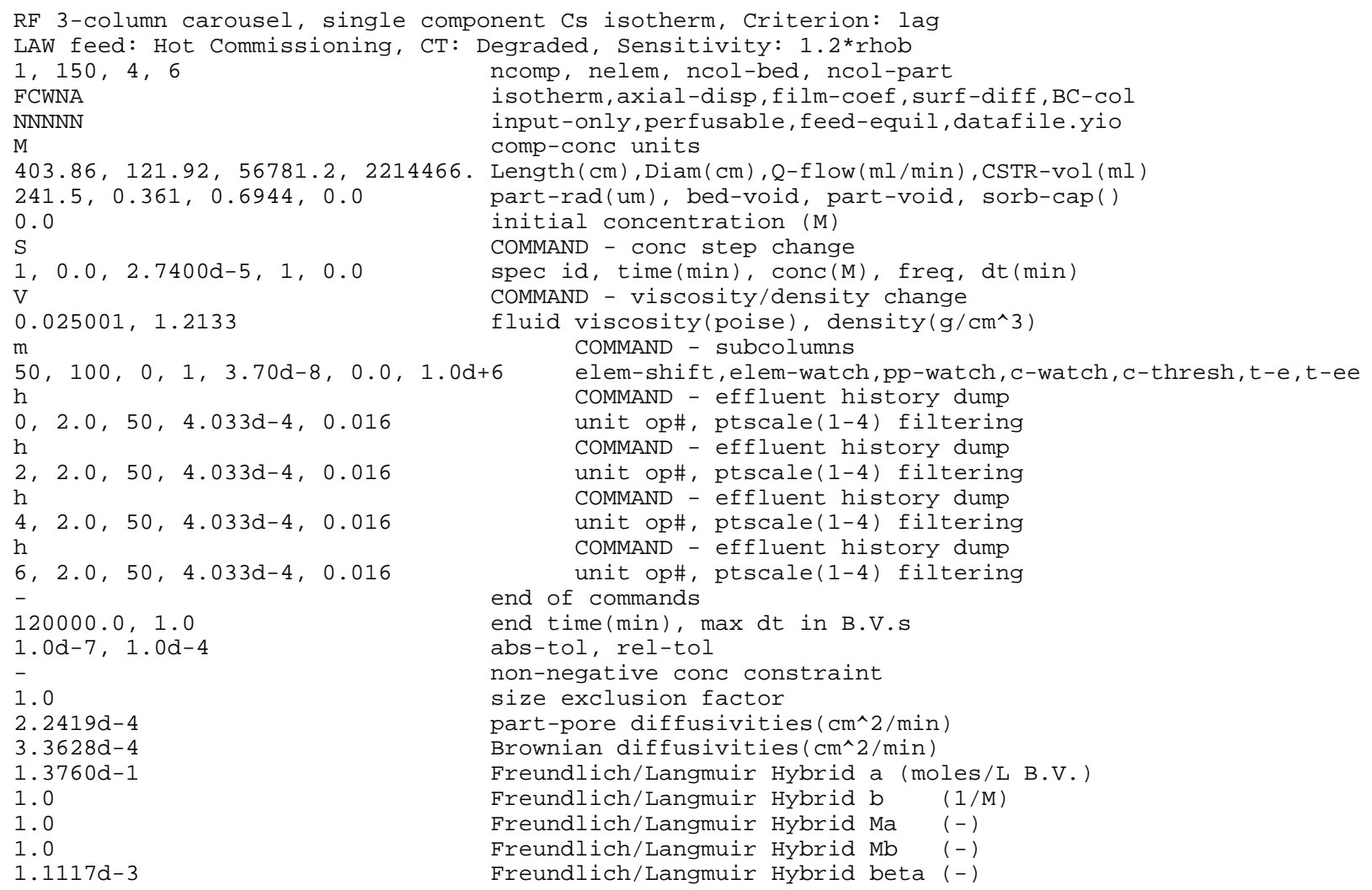

\section{B.21.2 VERSE-LC Datafile.run}

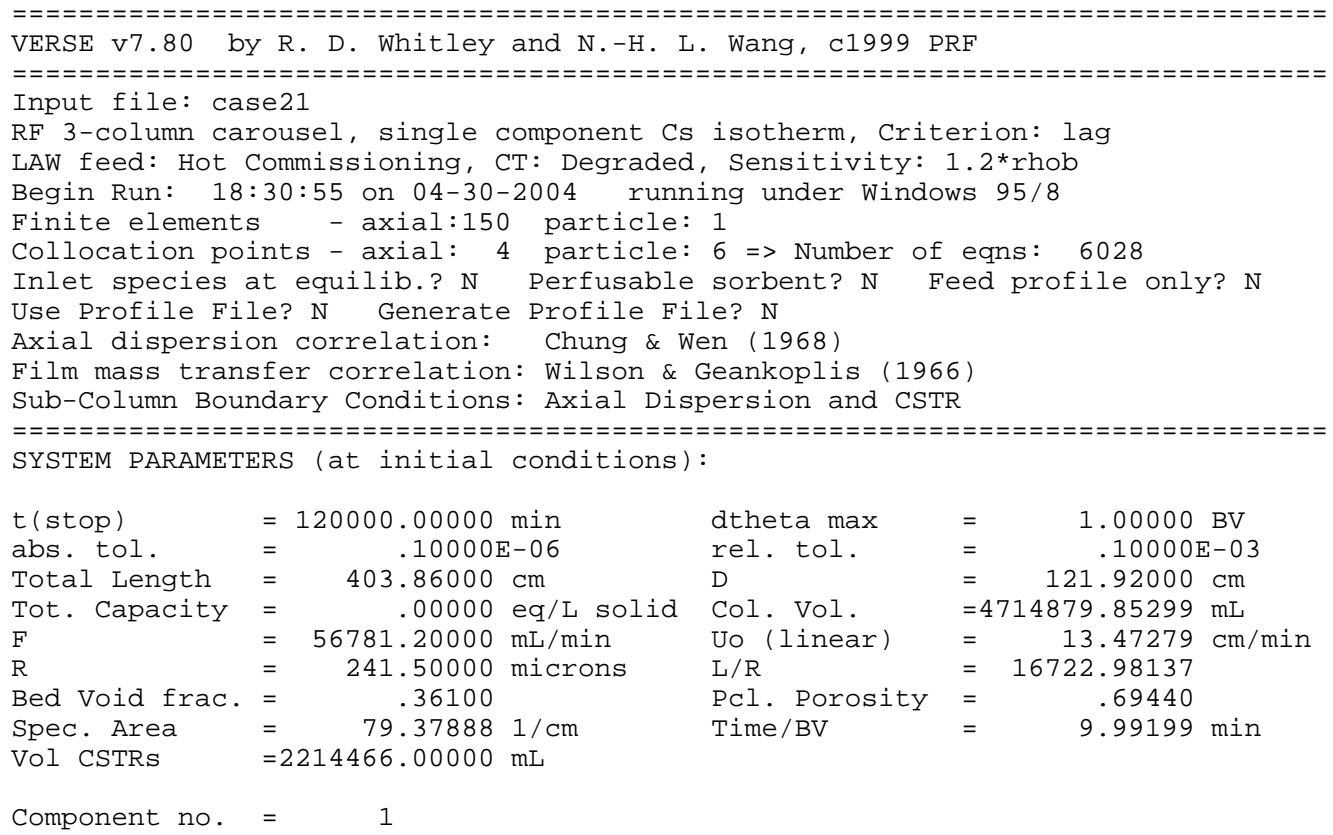


WSRC-TR-2004-00100, REVISION 0

SRT-RPP-2004-00019, REVISION 0

\begin{tabular}{|c|c|c|c|}
\hline $\mathrm{Ke}$ & {$[-]$} & $=$ & $.10000 \mathrm{E}+01$ \\
\hline $\mathrm{Eb}$ & {$[\mathrm{cm} 2 / \mathrm{min}]$} & $=$ & $.11462 \mathrm{E}+01$ \\
\hline & {$[\mathrm{cm} 2 / \mathrm{min}]$} & $=$ & $.22419 E-\odot 3$ \\
\hline Doo & {$[\mathrm{cm} 2 / \mathrm{min}]$} & $=$ & $.33628 \mathrm{E}-\odot 3$ \\
\hline & {$[\mathrm{cm} / \mathrm{min}]$} & $=$ & $.18653 \mathrm{E}+\odot$ \\
\hline & $\mathrm{cm} 2 / \mathrm{min}]$ & & $.00000 \mathrm{E}+\mathrm{C}$ \\
\hline
\end{tabular}

Dimensionless Groups:

$\operatorname{Sc}(i)$

$=.19001 \mathrm{E}+00$

$\operatorname{Peb}(i)$

$\mathrm{Bi}(\mathrm{i})$

$\mathrm{Nf}(\mathrm{i})$

$\operatorname{Np}(i)$

$.36765 \mathrm{E}+04$

$.15824 \mathrm{E}+04$

$.28936 \mathrm{E}+02$

$.40982 \mathrm{E}+03$

$.26671 \mathrm{E}+01$

$\operatorname{Pep}(i)=.20900 \mathrm{E}+04$

Isotherm = Freundlich/Langmuir Hybrid

Iso. Const. $1=.13760 \mathrm{E}+00$

Iso. Const. $2=.10000 \mathrm{E}+01$

Iso. Const. $3=.10000 \mathrm{E}+01$

Iso. Const. $4=.10000 \mathrm{E}+01$

Iso. Const. $5=.11117 \mathrm{E}-02$

Init. Conc. $=.00000 \mathrm{E}+00$

Conc. at eqb. $=.00000 \mathrm{E}+\odot \odot$

Conc. units $M$

COMMAND LIST:

1: Step conc. of component 1 at . .0000 min to .2740E-04 M Execute 1 times, every .0000 mins.

2: User set viscosity to .2500E-01 poise and density to $1.213 \mathrm{~g} / \mathrm{cm} 3$

3: Carousel (conc.). Active between $t=.0000$ and $.1000 \mathrm{E}+07 \mathrm{~min}$. When comp. 1 reaches .3700E- $07 \mathrm{M}$ at end of node 100, shift 50 axial elements out the feed end

4: Monitor conc. history at stream $\odot$. Filename $=$ case $21 . \mathrm{h} \odot 1$ Output density adjustments: 2. 0 *default abs conc delta, 50. *default rel conc delta, $.40 \mathrm{E}-03 *$ default force $\mathrm{W} / \mathrm{conc}$ delta, .16E-01*default force $\mathrm{W} / \mathrm{o}$ conc delta

5: Monitor conc. history at stream 2. Filename $=$ case21.h०2 Output density adjustments:

2.0 *default abs conc delta, 50 . default rel conc delta, .40E-03*default force W/ conc delta, .16E-01*default force w/o conc delta

6: Monitor conc. history at stream 4. Filename $=$ case21.h03 Output density adjustments: 2.0 *default abs conc delta, 50. *default rel conc delta, .40E-03*default force $\mathrm{W} / \mathrm{conc}$ delta, .16E-01*default force $\mathrm{w} / \mathrm{o}$ conc delta

7: Monitor conc. history at stream 6. Filename $=$ case $21 . h \odot 4$ Output density adjustments:

2.0 *default abs conc delta, 50. *default rel conc delta, . $40 \mathrm{E}-03^{*}$ default force $\mathrm{W} / \mathrm{conc}$ delta, .16E- $01^{*}$ default force $\mathrm{W} / \mathrm{o}$ conc delta

Conc. Carousel caused bed shift at $t=4555$. min

Conc. Carousel caused bed shift at $t=7423$. min

Conc. Carousel caused bed shift at $t=.1039 \mathrm{E}+05 \mathrm{~min}$

Conc. Carousel caused bed shift at $t=.1341 \mathrm{E}+05 \mathrm{~min}$

Conc. Carousel caused bed shift at $\mathrm{t}=.1647 \mathrm{E}+05 \mathrm{~min}$

Conc. Carousel caused bed shift at $\mathrm{t}=.1956 \mathrm{E}+05 \mathrm{~min}$

Conc. Carousel caused bed shift at $t=.2268 \mathrm{E}+05 \mathrm{~min}$

Conc. Carousel caused bed shift at $t=.2580 \mathrm{E}+05 \mathrm{~min}$

Conc. Carousel caused bed shift at $t=.2894 \mathrm{E}+05 \mathrm{~min}$

Conc. Carousel caused bed shift at $t=.3207 \mathrm{E}+05 \mathrm{~min}$

Conc. Carousel caused bed shift at $t=.3521 \mathrm{E}+05 \mathrm{~min}$

Conc. Carousel caused bed shift at $t=.3835 \mathrm{E}+05 \mathrm{~min}$

Conc. Carousel caused bed shift at $t=.4148 \mathrm{E}+05 \mathrm{~min}$

Conc. Carousel caused bed shift at $\mathrm{t}=.4461 \mathrm{E}+05 \mathrm{~min}$

Conc. Carousel caused bed shift at $t=.4775 \mathrm{E}+05 \mathrm{~min}$

Conc. Carousel caused bed shift at $t=.5088 \mathrm{E}+05 \mathrm{~min}$

Conc. Carousel caused bed shift at $t=.5401 \mathrm{E}+05 \mathrm{~min}$

Conc. Carousel caused bed shift at $t=.5715 \mathrm{E}+05 \mathrm{~min}$

Conc. Carousel caused bed shift at $t=.6028 \mathrm{E}+05 \mathrm{~min}$

Conc. Carousel caused bed shift at $t=.6341 \mathrm{E}+05 \mathrm{~min}$

Conc. Carousel caused bed shift at $\mathrm{t}=.6654 \mathrm{E}+05 \mathrm{~min}$

Conc. Carousel caused bed shift at $\mathrm{t}=.6968 \mathrm{E}+05 \mathrm{~min}$

Conc. Carousel caused bed shift at $t=.7281 \mathrm{E}+05 \mathrm{~min}$

Conc. Carousel caused bed shift at $t=.7594 \mathrm{E}+05 \mathrm{~min}$

Conc. Carousel caused bed shift at $t=.7908 \mathrm{E}+05 \mathrm{~min}$ 
WSRC-TR-2004-00100, REVISION 0

SRT-RPP-2004-00019, REVISION 0

Conc. Carousel caused bed shift at $t=.8222 \mathrm{E}+05 \mathrm{~min}$

Conc. Carousel caused bed shift at $t=.8535 \mathrm{E}+05 \mathrm{~min}$

Conc. Carousel caused bed shift at $t=.8849 \mathrm{E}+05 \mathrm{~min}$

Conc. Carousel caused bed shift at $t=.9162 \mathrm{E}+05 \mathrm{~min}$

Conc. Carousel caused bed shift at $t=.9475 \mathrm{E}+05 \mathrm{~min}$

Conc. Carousel caused bed shift at $t=.9789 \mathrm{E}+05 \mathrm{~min}$

Conc. Carousel caused bed shift at $t=.1010 \mathrm{E}+06 \mathrm{~min}$

Conc. Carousel caused bed shift at $t=.1042 \mathrm{E}+06 \mathrm{~min}$

Conc. Carousel caused bed shift at $t=.1073 \mathrm{E}+06 \mathrm{~min}$

Conc. Carousel caused bed shift at $\mathrm{t}=.1104 \mathrm{E}+06 \mathrm{~min}$

Conc. Carousel caused bed shift at $t=.1136 \mathrm{E}+06 \mathrm{~min}$

Conc. Carousel caused bed shift at $t=.1167 \mathrm{E}+06 \mathrm{~min}$

Conc. Carousel caused bed shift at $t=.1198 \mathrm{E}+06 \mathrm{~min}$

VERSE-LC finished in 13225 steps. Average step size 9.074 minutes

End run: 19:20:35 on $04-30-2004$

Integrated Areas in History Files:

case21. h01 3.28800

case21.h०2 $\quad .364190$

case21.h०3 .652628E- -03

case21. h०4 .370119E- -06

\title{
B.22 Hot Commissioning Operations $\left(\rho_{\mathbf{b}}-20 \%\right)$
}

\section{B.22.1 VERSE-LC Datafile}

RF 3-column carousel, single component Cs isotherm, Criterion: lag

LAW feed: Hot Commissioning, CT: Degraded, Sensitivity: $0.8^{*}$ rhob

$1,150,4,6 \quad$ ncomp, nelem, ncol-bed, ncol-part

FCWNA isotherm, axial-disp, film-coef, surf-diff, BC-col

NNNNN input-only, perfusable, feed-equil, datafile.yio

$M \quad$ comp-conc units

403.86, 121.92, 56781.2, 2214466. Length(cm),Diam(cm),Q-flow(ml/min), CSTR-vol $(\mathrm{ml})$

241.5, $0.361,0.6944,0.0$ part-rad(um), bed-void, part-void, sorb-cap()

0.0

$\mathrm{S}$

$1,0 . \odot, 2.7400 \mathrm{~d}-5,1,0 . \odot$

initial concentration (M)

COMMAND - conc step change

spec id, time(min), conc(M), freq, dt(min)

$\mathrm{V}$

$0.025001,1.2133$

$5 \odot, 10 \odot, \odot, 1,3.70 \mathrm{~d}-8,0 . \odot, 1.0 \mathrm{~d}+6$

COMMAND - viscosity/density change

fluid viscosity (poise), density $\left(\mathrm{g} / \mathrm{cm}^{\wedge} 3\right)$

COMMAND - subcolumns

elem-shift, elem-watch, pp-watch, c-watch, c-thresh, t-e,t-ee COMMAND - effluent history dump

$0,2.0,50,4.033 d-4,0.016$

h

$2,2.0,50,4.033 d-4,0.016$

$\mathrm{h}$

$4,2.0,50,4.033 d-4,0.016$

$\mathrm{h}$

$6,2 . \odot, 5 \odot, 4.033 d-4, \odot .016$

$120000.0,1.0$

1. $0 d-7,1.0 d-4$

1.0

2. $2419 d-4$

3. $3628 d-4$

9. $1732 d-2$

1.0

1.0

1.0

unit op\#, ptscale(1-4) filtering

COMMAND - effluent history dump

unit op\#, ptscale(1-4) filtering

COMMAND - effluent history dump

unit op\#, ptscale(1-4) filtering

COMMAND - effluent history dump

end of commands

end time(min), $\max d t$ in B.V.S

abs-tol, rel-tol

non-negative conc constraint

size exclusion factor

part-pore diffusivities $\left(\mathrm{cm}^{\wedge} 2 / \mathrm{min}\right)$

Brownian diffusivities ( $\mathrm{cm}^{\wedge} 2 / \mathrm{min}$ )

Freundlich/Langmuir Hybrid a (moles/L B.V.)

Freundlich/Langmuir Hybrid b (1/M)

Freundlich/Langmuir Hybrid Ma (-)

Freundlich/Langmuir Hybrid Mb (-)

$1.1117 d-3$

Freundlich/Langmuir Hybrid beta (-)

\section{B.22.2 VERSE-LC Datafile.run}

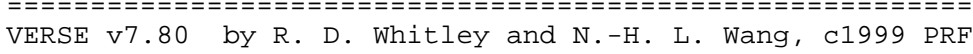 \\ =ニニニニニニニニニニニニニニニニニニニニニニニニニニニニニニニニニニニニニニニニニニニニニニニニニニニニニニニニニニニニニニニニニニニニニニニニニニニニ \\ Input file: case22 \\ RF 3-column carousel, single component Cs isotherm, criterion: lag \\ LAW feed: Hot Commissioning, CT: Degraded, Sensitivity: $0.8 *$ rhob \\ Begin Run: 19:20:35 on $04-30-20 \odot 4$ running under Windows 95/8 \\ Finite elements - axial:150 particle: 1
}


Collocation points - axial: 4 particle: 6 => Number of eqns: 6028

Inlet species at equilib.? N Perfusable sorbent? $\mathrm{N}$ Feed profile only? $\mathrm{N}$

Use Profile File? N Generate Profile File? N

Axial dispersion correlation: Chung \& Wen (1968)

Film mass transfer correlation: Wilson \& Geankoplis (1966)

Sub-Column Boundary Conditions: Axial Dispersion and CSTR

SYSTEM PARAMETERS (at initial conditions):

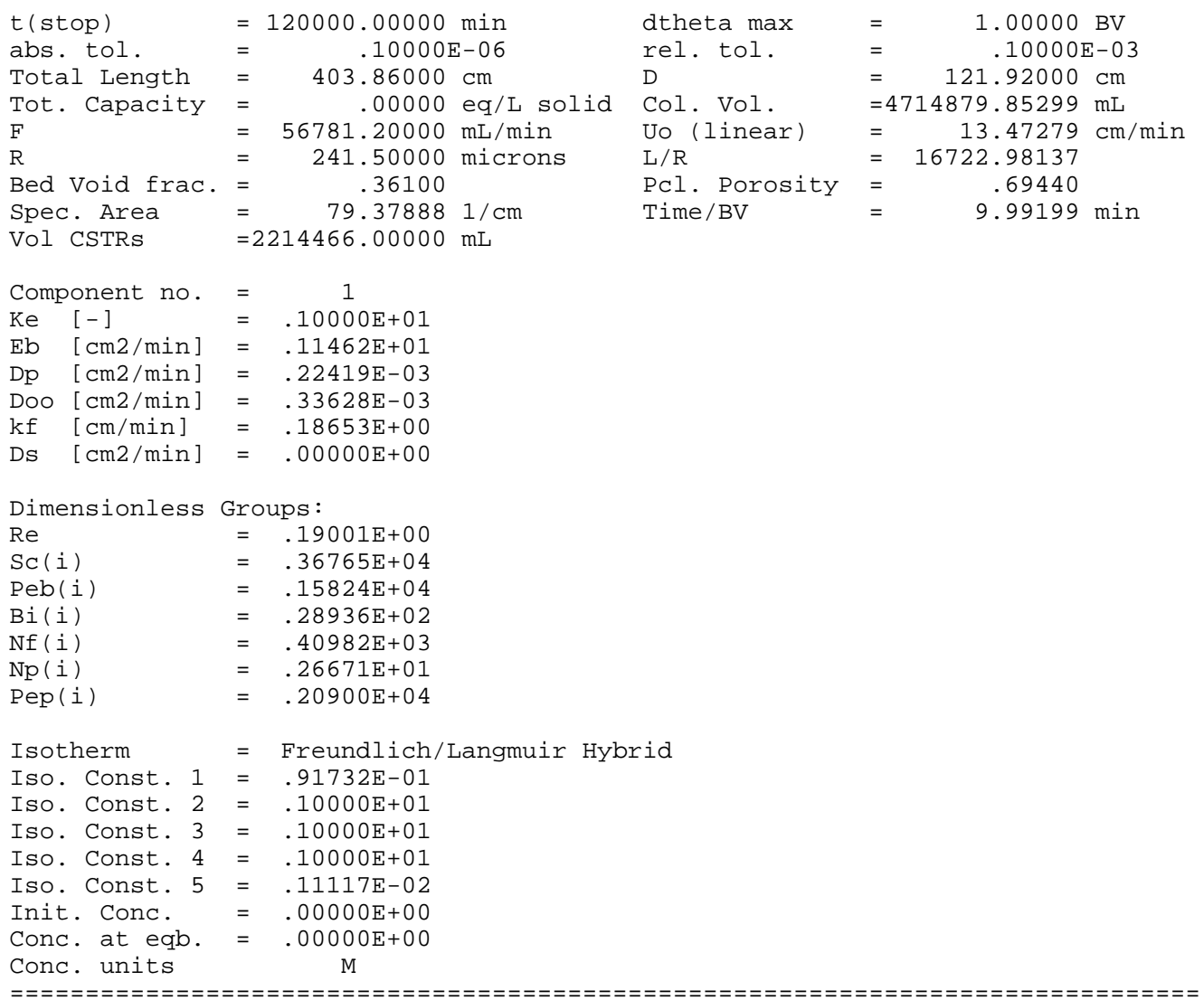

Conc. units

COMMAND LIST:

1: Step conc. of component 1 at .0000 min to .2740E-04 M

Execute 1 times, every .000๑ mins.

2: User set viscosity to .2500E-01 poise and density to $1.213 \mathrm{~g} / \mathrm{cm} 3$

3: Carousel (conc.). Active between $t=.0000$ and $.1000 \mathrm{E}+07 \mathrm{~min}$. When comp. 1 reaches .3700E-07 M at end of node 100, shift 50 axial elements out the feed end

4: Monitor conc. history at stream $\odot$. Filename $=$ case22.h 01 Output density adjustments:

2.0 *default abs conc delta, 50. ${ }^{*}$ default rel conc delta, .40E-03*default force $\mathrm{W} /$ conc delta, .16E-01*default force $\mathrm{W} / \mathrm{o}$ conc delta

5: Monitor conc. history at stream 2. Filename $=$ case22.h०2 Output density adjustments: $2.0{ }^{*}$ default abs conc delta, 50. *default rel conc delta, .40E-03*default force $\mathrm{W} / \mathrm{conc}$ delta, .16E-01*default force w/o conc delta

6: Monitor conc. history at stream 4. Filename $=$ case $22 . \mathrm{h} \odot 3$ Output density adjustments:

2.0 *default abs conc delta, 50. *default rel conc delta, .40E-03*default force $W /$ conc delta, .16E-01*default force w/o conc delta

7: Monitor conc. history at stream 6. Filename $=$ case22.h๑4 Output density adjustments:

$2.0{ }^{*}$ default abs conc delta, 50. *default rel conc delta, . 40E-03*default force $\mathrm{W} / \mathrm{conc}$ delta, .16E- $01^{*}$ default force $\mathrm{W} / \mathrm{o}$ conc delta

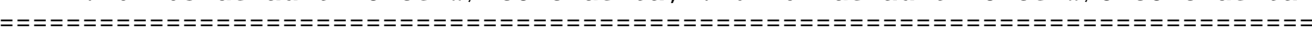

Conc. Carousel caused bed shift at $t=3075$. min

Conc. Carousel caused bed shift at $t=5002$. min

Conc. Carousel caused bed shift at $t=6992$. min

Conc. Carousel caused bed shift at $t=9028$. min

Conc. Carousel caused bed shift at $t=.1109 \mathrm{E}+05 \mathrm{~min}$ 
WSRC-TR-2004-00100, REVISION 0

SRT-RPP-2004-00019, REVISION 0

Conc. Carousel caused bed shift at $t=.1317 \mathrm{E}+05 \mathrm{~min}$

Conc. Carousel caused bed shift at $t=.1526 \mathrm{E}+05 \mathrm{~min}$

Conc. Carousel caused bed shift at $t=.1737 \mathrm{E}+05 \mathrm{~min}$

Conc. Carousel caused bed shift at $t=.1948 \mathrm{E}+05 \mathrm{~min}$

Conc. Carousel caused bed shift at $t=.2159 E+05 \mathrm{~min}$

Conc. Carousel caused bed shift at $\mathrm{t}=.2370 \mathrm{E}+05 \mathrm{~min}$

Conc. Carousel caused bed shift at $t=.2581 \mathrm{E}+05 \mathrm{~min}$

Conc. Carousel caused bed shift at $t=.2792 \mathrm{E}+05 \mathrm{~min}$

Conc. Carousel caused bed shift at $t=.3002 \mathrm{E}+05 \mathrm{~min}$

Conc. Carousel caused bed shift at $t=.3214 \mathrm{E}+05 \mathrm{~min}$

Conc. Carousel caused bed shift at $t=.3425 \mathrm{E}+05 \mathrm{~min}$

Conc. Carousel caused bed shift at $\mathrm{t}=.3636 \mathrm{E}+05 \mathrm{~min}$

Conc. Carousel caused bed shift at $t=.3846 \mathrm{E}+05 \mathrm{~min}$

Conc. Carousel caused bed shift at $t=.4058 \mathrm{E}+05 \mathrm{~min}$

Conc. Carousel caused bed shift at $t=.4268 \mathrm{E}+05 \mathrm{~min}$

Conc. Carousel caused bed shift at $\mathrm{t}=.4479 \mathrm{E}+05 \mathrm{~min}$

Conc. Carousel caused bed shift at $t=.4690 \mathrm{E}+05 \mathrm{~min}$

Conc. Carousel caused bed shift at $t=.4901 \mathrm{E}+05 \mathrm{~min}$

Conc. Carousel caused bed shift at $t=.5112 \mathrm{E}+05 \mathrm{~min}$

Conc. Carousel caused bed shift at $t=.5323 \mathrm{E}+05 \mathrm{~min}$

Conc. Carousel caused bed shift at $t=.5533 \mathrm{E}+05 \mathrm{~min}$

Conc. Carousel caused bed shift at $t=.5744 \mathrm{E}+05 \mathrm{~min}$

Conc. Carousel caused bed shift at $t=.5955 \mathrm{E}+05 \mathrm{~min}$

Conc. Carousel caused bed shift at $t=.6166 \mathrm{E}+05 \mathrm{~min}$

Conc. Carousel caused bed shift at $t=.6378 \mathrm{E}+05 \mathrm{~min}$

Conc. Carousel caused bed shift at $t=.6588 \mathrm{E}+05 \mathrm{~min}$

Conc. Carousel caused bed shift at $t=.6799 \mathrm{E}+05 \mathrm{~min}$

Conc. Carousel caused bed shift at $t=.7010 \mathrm{E}+05 \mathrm{~min}$

Conc. Carousel caused bed shift at $t=.7221 \mathrm{E}+05 \mathrm{~min}$

Conc. Carousel caused bed shift at $t=.7432 \mathrm{E}+05 \mathrm{~min}$

Conc. Carousel caused bed shift at $t=.7642 \mathrm{E}+05 \mathrm{~min}$

Conc. Carousel caused bed shift at $t=.7854 \mathrm{E}+05 \mathrm{~min}$

Conc. Carousel caused bed shift at $t=.8064 \mathrm{E}+05 \mathrm{~min}$

Conc. Carousel caused bed shift at $t=.8275 \mathrm{E}+05 \mathrm{~min}$

Conc. Carousel caused bed shift at $t=.8486 \mathrm{E}+05 \mathrm{~min}$

Conc. Carousel caused bed shift at $t=.8697 \mathrm{E}+05 \mathrm{~min}$

Conc. Carousel caused bed shift at $t=.8908 \mathrm{E}+05 \mathrm{~min}$

Conc. Carousel caused bed shift at $t=.9119 \mathrm{E}+05 \mathrm{~min}$

Conc. Carousel caused bed shift at $t=.9330 E+05 \mathrm{~min}$

Conc. Carousel caused bed shift at $\mathrm{t}=.9541 \mathrm{E}+05 \mathrm{~min}$

Conc. Carousel caused bed shift at $t=.9752 \mathrm{E}+05 \mathrm{~min}$

Conc. Carousel caused bed shift at $t=.9963 \mathrm{E}+05 \mathrm{~min}$

Conc. Carousel caused bed shift at $t=.1017 \mathrm{E}+06 \mathrm{~min}$

Conc. Carousel caused bed shift at $t=.1038 \mathrm{E}+06 \mathrm{~min}$

Conc. Carousel caused bed shift at $t=.1060 \mathrm{E}+06 \mathrm{~min}$

Conc. Carousel caused bed shift at $t=.1081 \mathrm{E}+06 \mathrm{~min}$

Conc. Carousel caused bed shift at $t=.1102 \mathrm{E}+06 \mathrm{~min}$

Conc. Carousel caused bed shift at $t=.1123 \mathrm{E}+06 \mathrm{~min}$

Conc. Carousel caused bed shift at $t=.1144 \mathrm{E}+06 \mathrm{~min}$

Conc. Carousel caused bed shift at $\mathrm{t}=.1165 \mathrm{E}+06 \mathrm{~min}$

Conc. Carousel caused bed shift at $t=.1186 \mathrm{E}+06 \mathrm{~min}$

VERSE-LC finished in 13168 steps. Average step size 9.113 minutes

End run: 20:10:51 on $04-30-2004$

Integrated Areas in History Files:

case22. h01 3.28800

case22.h०2 .349571

case22.h03 $.667997 \mathrm{E}-03$

case22. h०4 .420141E- 06 